\title{
CIRCULATING MOVING BED \\ COMBUSTION PROOF OF CONCEPT
}

FINAL REPORT

SUBMITTED BY

ALSTOM POWER INC.

POWER PLANT LABORATORIES

2000 DAY HILL ROAD

WINDSOR, CT 06095

Glen D. Jukkola

\author{
PREPARED FOR \\ U.S. DEPARTMENT OF ENERGY \\ NATIONAL ENERGY TECHNOLOGY LABORATORY \\ P.O. BOX 880, 3610 COLLINS FERRY ROAD \\ MORGANTOWN, WV 26507-0880 \\ (COOPERATIVE AGREEMENT NO. DE-FC26-01NT41223)
}

APRIL 2003

PROJECT PERFORMANCE PERIOD: July 1, 2001 - March 31, 2003 


\section{DISCLAIMER}

This report was prepared as an account of work sponsored by an agency of the United States Government. Neither the United States Government nor any agency thereof, nor any of their employees, makes any warranty, express or implied, or assumes any legal liability or responsibility for the accuracy, completeness, or usefulness of any information, apparatus, product, or process disclosed, or represent that its use would not infringe privately owned rights. Reference herein to any specific commercial product, process, or service by trade name, trademark, manufacturer, or otherwise does not necessarily constitute or imply its endorsement, recommendation, or favoring by the United States Government or any agency thereof. The views and opinions of authors expressed herein do not necessarily state or reflect those of the United States Government or any agency thereof. 


\section{ACKNOWLEDGEMENTS}

Financial support of the CMB Proof of Concept project was provided by the U.S. Department of Energy's National Energy Technology Laboratory (Cooperative Agreement No. DEFC26-01NT41223) and ALSTOM Power Inc.

The contributions of the key project team members also need to be recognized. The project task leaders who planned, coordinated, and lead the execution of the major project tasks included:

- Paul Thibeault - Process Analysis

- Bard Teigen - Component Development

- Armand Levasseur - MTF Modifications and Test Program

- Dave Turek - Data Analysis

The contributions of the project team members and MTF test crews who executed the project work are also greatly appreciated.

Finally, we recognize the contributions of our consultants, who provided ongoing guidance and advice throughout the project. They included the following three individuals:

- Janos M. Beér - Massachusetts Institute of Technology

- Leon Glicksman - Massachusetts Institute of Technology

- Jon G. McGowan - University of Massachusetts 


\begin{abstract}
Circulating Moving Bed (CMB) combustion technology has its roots in traditional circulating fluidized bed technology and involves a novel method of solid fuel combustion and heat transfer. $\mathrm{CMB}$ technology represents a step change in improved performance and cost relative to conventional PC and FBC boilers. The $\mathrm{CMB}$ heat exchanger will preheat the energy cycle working fluid, steam or air, to the high temperature levels required in systems for advanced power generation. Unique features of the CMB are the reduction of the heat transfer surfaces by about $60 \%$ as a result of the enhanced heat transfer rates, flexibility of operation, and about $30 \%$ lower cost over existing technology.

The objective of this project is to continue development of the CMB technology with a series of proof of concept tests. The tests will be conducted at a scale that will provide the design data for scale up to a demonstration plant. These objectives will be met by conducting a series of experiments in ALSTOM Power's Multi-use Test Facility (MTF). The MTF will be modified to operate under $\mathrm{CMB}$ conditions of commercial interest. The experiments will cover the technical issues discussed above and will also show the integration of all of the subsystems operating at commercially significant temperatures. The range of temperatures to be tested will demonstrate the operation of the falling solids heat transfer and bed operation needed for the demonstration plant. The tests will not attempt to show the operation of the integrated $\mathrm{CMB}$ with falling solids and gas over the entire expected temperature range at one time. Modifying the MTF for this would not be cost effective. However, at the end of this project all technical concepts used in the CMB will have been investigated and planning will start for the demonstration plant.
\end{abstract}




\section{TABLE OF CONTENTS}

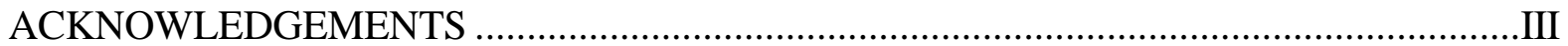

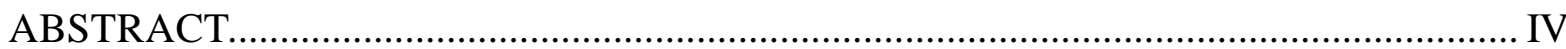

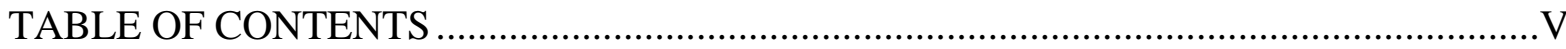

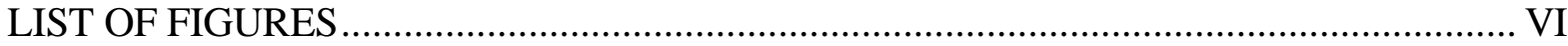

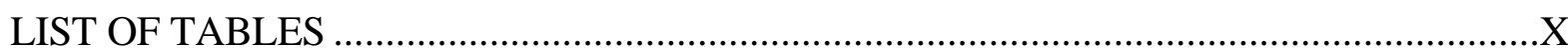

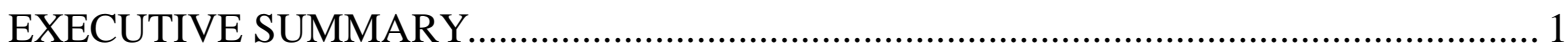

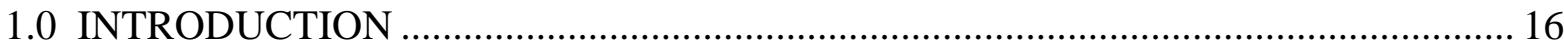

1.1 Circulating Moving Bed Technology Description....................................................... 16

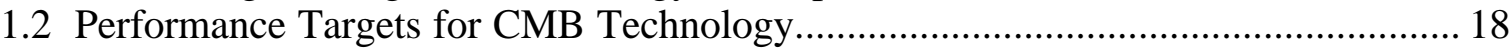

1.3 Improvements Over Existing Technologies ……………............................................ 19

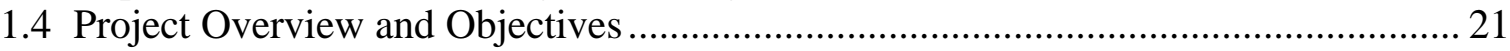

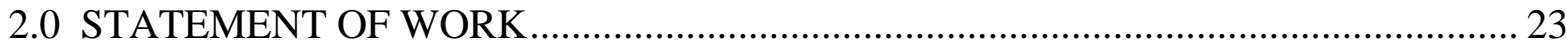

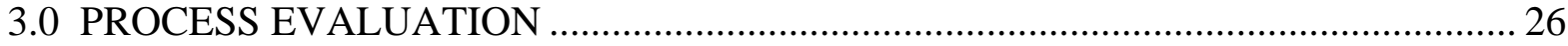

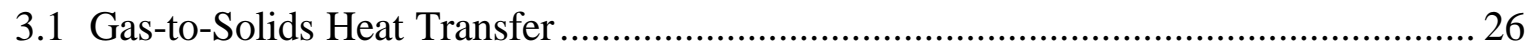

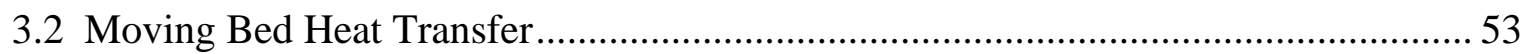

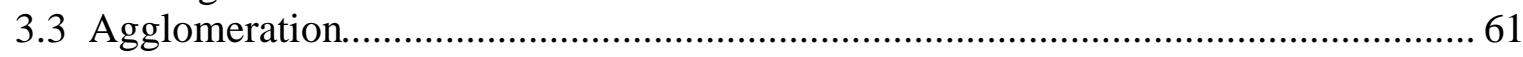

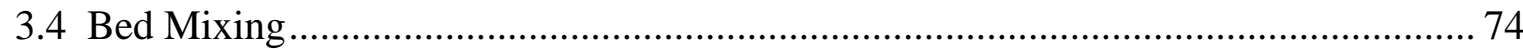

3.5 In-Furnace and FDA Sulfur Capture …………………......................................... 76

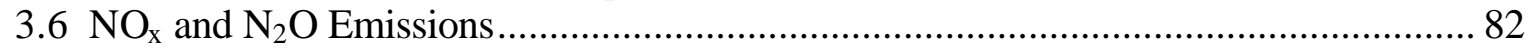

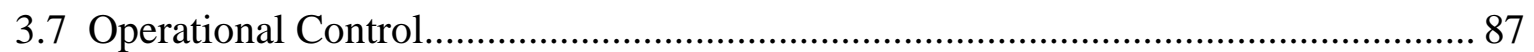

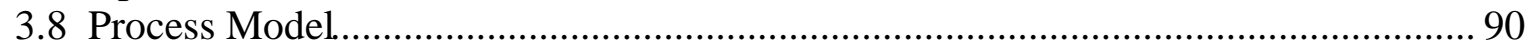

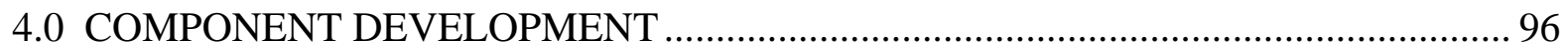

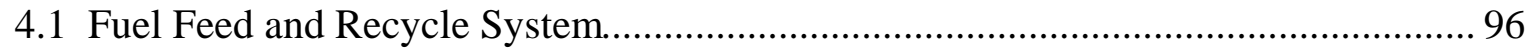

4.2 Solids Inlet Distributor System.......................................................................... 106

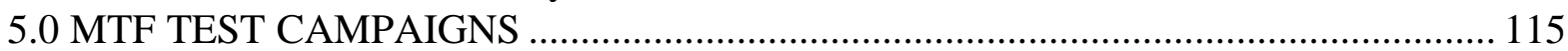

5.1 Description of ALSTOM Power Inc's. Multi-Use Combustion Test Facility........... 115

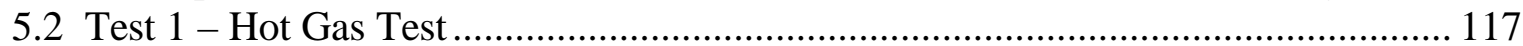

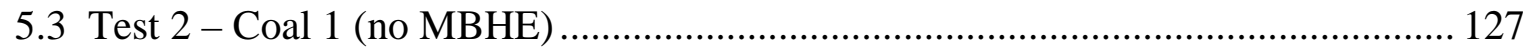

5.4 Test 3 - Coal 1 \& 2 (with MBHE) ...................................................................... 135

5.5 CMB Heat Exchanger Materials Test Probe …………......................................... 149

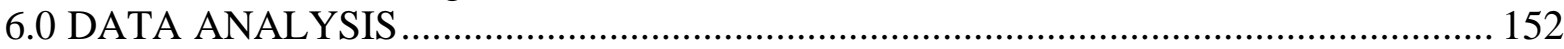

6.1 Gas-to-Solids Heat Transfer ................................................................................ 152

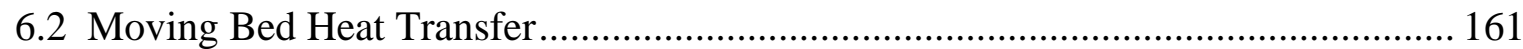

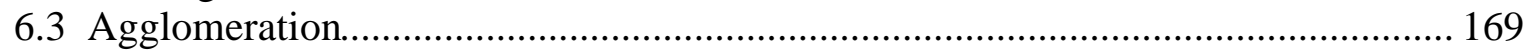

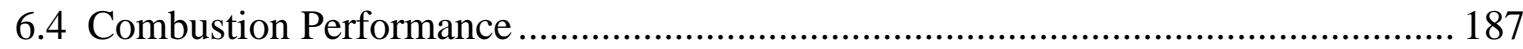

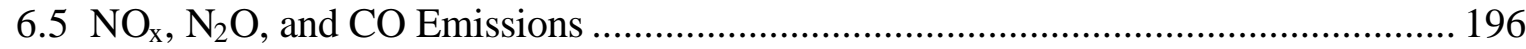

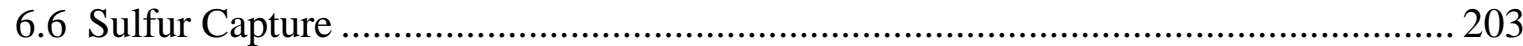

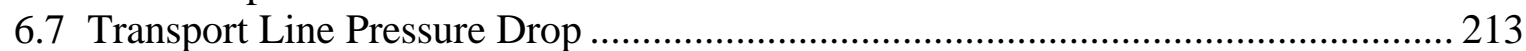

6.8 Transient Response - Loss of Coolant ……………............................................ 216

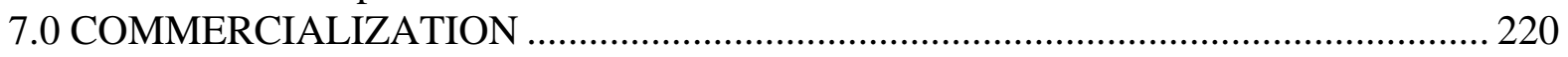

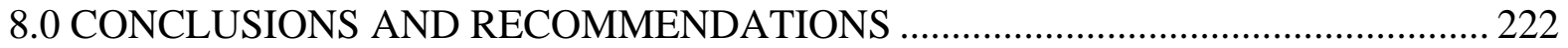

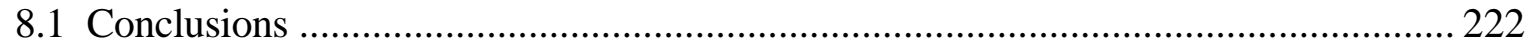

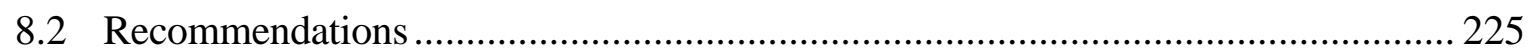

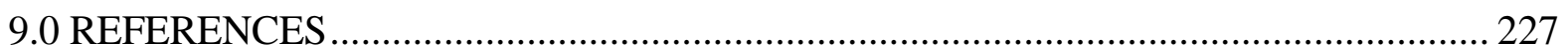

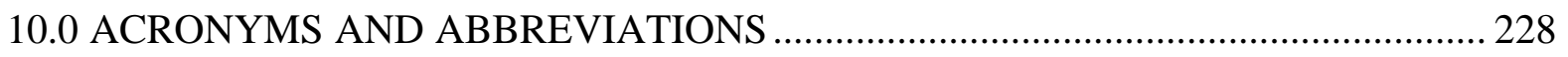




\section{LIST OF FIGURES}

Figure E-1: $\mathrm{CMB}^{\mathrm{TM}}$ Combustion System Schematic ........................................................ 2

Figure E-2: MTF Modifications and MBHE Assembly..................................................... 6

Figure E-3: Combustor Temperature Profiles During Natural Gas-Fired Tests ....................... 7

Figure E-4: Carbon Heat Loss with West Virginia Coal..................................................... 8

Figure E-5: MTF Temperature History with Pittsburgh \#8 Coal.......................................... 10

Figure E-6: Coating Growth Rate for Pittsburgh \#8 Coal................................................... 11

Figure 1.1-1: $\mathrm{CMB}^{\mathrm{TM}}$ Combustion System Schematic........................................................ 17

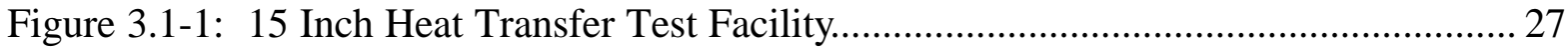

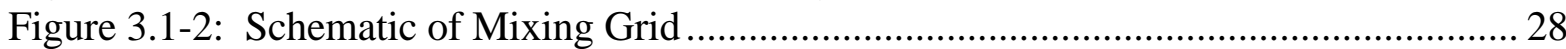

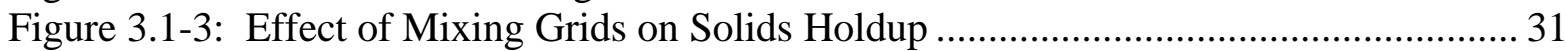

Figure 3.1-4: Effect of Mixing Grids and Gas Rise Velocity on $\mathrm{UA}_{\mathrm{p}}$................................. 32

Figure 3.1-5: Effect of Mixing Grids and Gas Rise Velocity on U....................................... 33

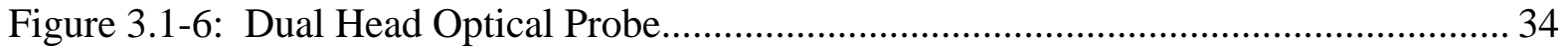

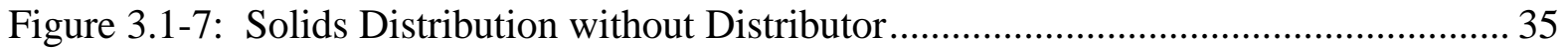

Figure 3.1-8: Optic Probe Frequency Test Results ............................................................... 36

Figure 3.1-9: Optic Probe Frequency vs Probe Location....................................................... 36

Figure 3.1-10: Optic Probe Particle Frequency................................................................ 37

Figure 3.1-11: Optic Probe Particle Frequency.................................................................... 37

Figure 3.1-12: Solids Temperature Probe ……………................................................... 38

Figure 3.1-13: Dual Laser Beam Level Indicator ………................................................... 40

Figure 3.1-14: CFD Prediction of Solids Distribution in 15 Inch Test Loop ......................... 41

Figure 3.1-15: Prediction of MTF Solids Concentration....................................................... 42

Figure 3.1-16: Path Lines of Solids Flow in the MTF with Tangential Overfire Air ............ 43

Figure 3.1-17: CFD Contours of Particle Concentration (lbm/ft3) ..................................... 45

Figure 3.1-18: Aerodynamic Effects at Solids/Gas Ratio of 1............................................. 47

Figure 3.1-19: Aerodynamic Effects at Solids/Gas Ratio of 2.............................................. 47

Figure 3.1-20: MTF Data vs. CFD Predictions of Temperature ............................................ 48

Figure 3.1-21: CFD Predictions of Solids Distribution in a 300Mw CMB .......................... 49

Figure 3.1-22: CFD Model of a 4:1 Scale-Up Using Similitude Criteria ................................ 52

Figure 3.2-1: Solids Flow Pattern Around a Tube ................................................................. 53

Figure 3.2-2: Laboratory Test Loop for Moving Bed Heat Transfer..................................... 54

Figure 3.2-3: FEA Spiral Fin Tube Temperature Model...................................................... 55

Figure 3.2-4: MTF MBHE...……………………………………………………...... 55

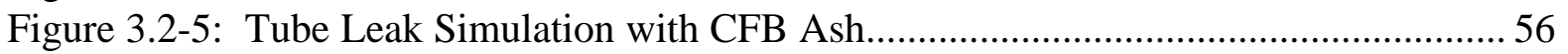

Figure 3.2-6: Tube Leak Simulation with CMB Ash........................................................ 57

Figure 3.2-7: Pressure Drop Comparison in Vertical Run.................................................... 59

Figure 3.2-8: Pressure Drop Comparison in Horizontal Run.................................................. 59

Figure 3.2-9: Pressure Drop Comparison in Impact Elbow..................................................... 60

Figure 3.3-1: Effect of Bed Temperature on Defluidization Velocity.................................... 63

Figure 3.3-2: Effect of Bed Temperature on Defluidization..................................................... 64

Figure 3.3-3: Bauxite Coating and Bonding During 4 Inch FBC Test .................................... 67

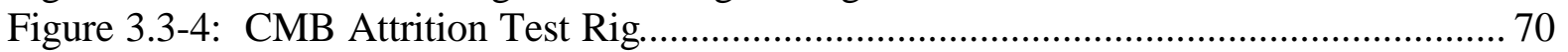

Figure 3.3-5: Filter Weight Gain from Attrition................................................................ 72

Figure 3.3-6: Effect of Attrition on Bauxite Coating ............................................................ 73

Figure 3.4-1: Impact of Bed Fluidizing Velocity on Solids Lateral Mixing........................... 75 
Figure 3.5-1: Effect of In-Furnace Sulfur Capture on Boiler Efficiency............................. 77

Figure 3.5-2: Effect of Particle Size and Combustor Temperature on Calcination............... 78

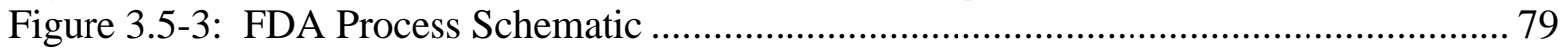

Figure 3.5-4: Effect of Ash Composition and $\mathrm{SO}_{2}$ Concentration on FDA Performance ..... 80

Figure 3.6-1: Effect of temperature on $\mathrm{NO}_{\mathrm{x}}$ and $\mathrm{N}_{2} \mathrm{O}$ Emissions ................................... 82

Figure 3.6-2: CMB Temperature Profiles in MTF Suitable for SNCR .............................. 85

Figure 3.7.1: CMB Heat Exchanger Surface Arrangement ............................................ 87

Figure 3.7-2: MBHE Solids Temperature Variation with Load......................................... 88

Figure 3.7-3: MBHE Solids Flow Rate with Load.......................................................... 89

Figure 3.8-1: Process Model Temperature Predictions for 300Mw CMB ......................... 90

Figure 3.8-2: Freeboard Slice Model Inputs, Assumptions and Outputs ............................. 91

Figure 3.8-3: Freeboard Slice Model Calculational Procedure........................................... 92

Figure 3.8-4: Gas Temperature Profile Predictions for the MTF and 300Mw CMB .......... 93

Figure 3.8-5: Effect of Solids Reflux on Gas Temperature Profile .................................... 94

Figure 4.1-1: Effect of Cyclone Recycle Rate on Bed Temperature .................................. 96

Figure 4.1-2: Trajectory of 0.25 Inch Coal Particles....................................................... 99

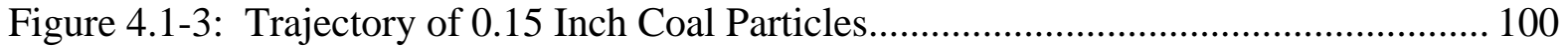

Figure 4.1-4: Trajectory of 0.05 Inch Coal Particles...................................................... 100

Figure 4.1-5: Pneumatic Air Swept Spreader............................................................... 102

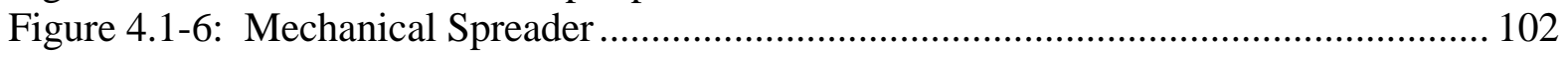

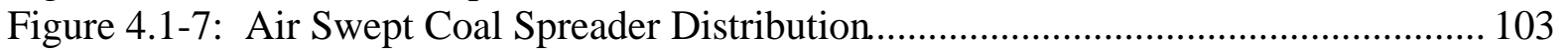

Figure 4.1-8: Mechanical Coal Spreader Distribution.................................................... 104

Figure 4.1-9: Coal Feed Distribution for 300 Mw CMB Boiler ...................................... 105

Figure 4.2-1: CMB Bauxite Inlet Distribution Slice Model Facility ................................ 107

Figure 4.2-2: Bauxite Slice Model Inlet \& Measurement Detail ....................................... 108

Figure 4.2-3: Effect of Straight Inlet Pipe on Solids Distribution.................................... 109

Figure 4.2-4: Effect of Diverter Cup on Solids Distribution............................................ 110

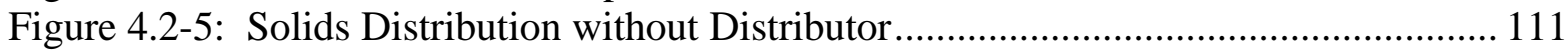

Figure 4.2-6: Solids Distribution at $16 \mathrm{ft}$ Elevation...................................................... 111

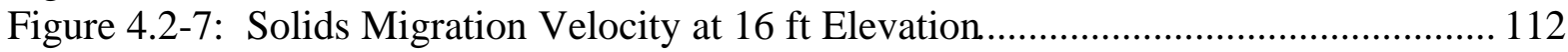

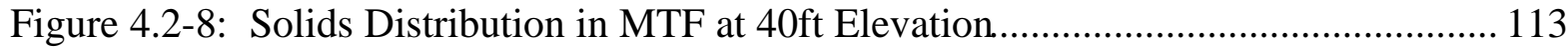

Figure 4.2-9: Solids Migration Velocity in MTF at $40 \mathrm{ft}$ Elevation................................. 113

Figure 4.2-10: Bauxite Solids Distribution in 300 Mw CMB with 7 Distributors .............. 114

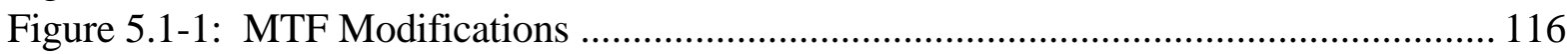

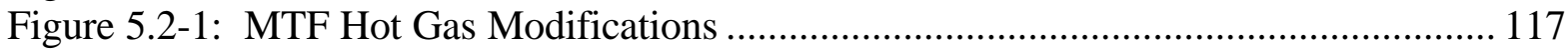

Figure 5.2-2: Bauxite Separator Being Mounted To Roof................................................. 118

Figure 5.2-3: Bauxite Distributor Being Mounted To Roof............................................ 118

Figure 5.2-4: Downcomer Screen .............................................................................. 119

Figure 5.2-5: Loop Seal Below The MTF................................................................... 119

Figure 5.2-6: Water-Cooled Transport Line Installation ............................................... 120

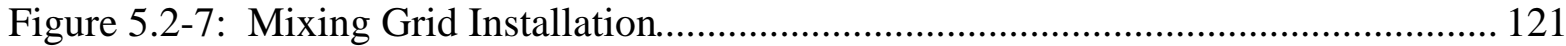

Figure 5.2-8: Refractory Accumulation In Solids Distributor .................................... 125

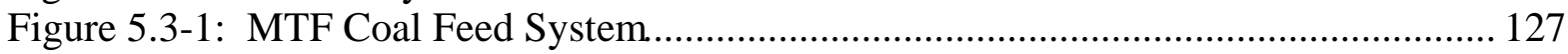

Figure 5.3-2: Laser Level Installation and Video Output ............................................. 129

Figure 5.3-3: MTF FDA Baghouse Conversion.............................................................. 129

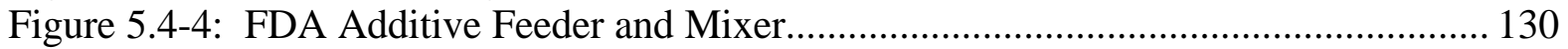

Figure 5.4-1: Overall View of the MBHE.................................................................... 136

Figure 5.4-2: MBHE Cross-Sectional View ................................................................. 137 
Figure 5.4-3: MBHE Flow Distribution Baffle............................................................ 138

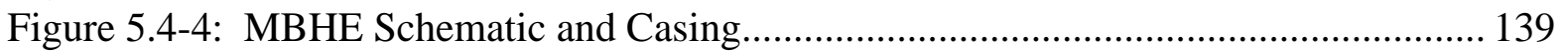

Figure 5.4-5: Wax Mold Endcaps Installed on Tube Bundles ............................................ 140

Figure 5.4-6: MBHE Cyclone and Transition Section..................................................... 140

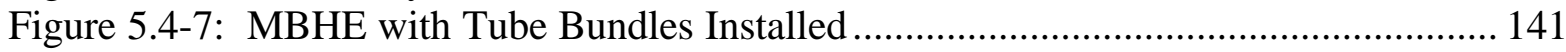

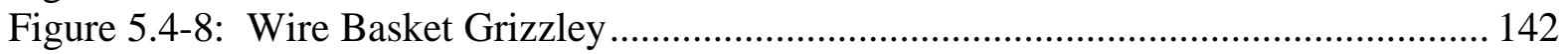

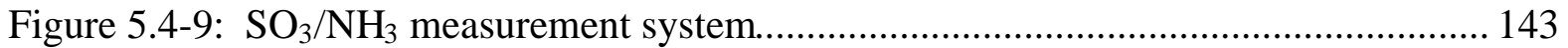

Figure 5.4-10: Modified Grizzly ............................................................................. 145

Figure 5.4-11: Perforated Grizzly Design....................................................................... 146

Figure 5.5-1: Assembled Materials Test Probe................................................................ 149

Figure 5.5-2: Material Selection and Location.................................................................. 149

Figure 5.5-3: Materials Probe Temperature Exposure History............................................ 150

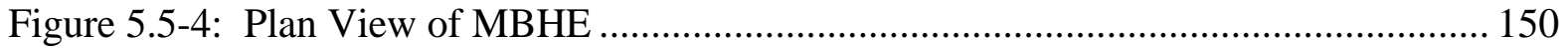

Figure 5.5-5: MBHE Solids Inlet Temperature History...................................................... 151

Figure 6.1-1: Combustor Temperature Profiles During Natural Gas-Fired Tests................ 152

Figure 6.1-2: Combustor Radial Temperature Profile ...................................................... 153

Figure 6.1-3: Combustor Axial Temperature Profile ......................................................... 154

Figure 6.1-4: Combustor Temperature Profile in February 2003 Test................................ 155

Figure 6.1-5: Heat Flow vs. Gas Velocity.................................................................... 156

Figure 6.1-6: Combustor Temperature Profile With Increasing Recycle Solids Rate......... 156

Figure 6.1-7: Cyclone Ash Recycle Flow Rate During September Test ............................. 157

Figure 6.1-8: Nusselt Number vs. Reynolds Number ....................................................... 159

Figure 6.2-1: MBHE Solids Temperatures for Typical Test Condition................................ 161

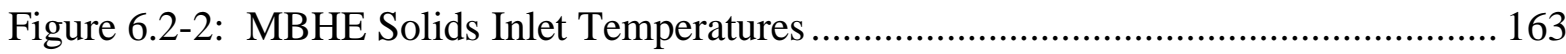

Figure 6.2-3: MBHE Solids Outlet Temperatures .............................................................. 163

Figure 6.2-4: MBHE Cooling Water Outlet Temperatures.................................................... 164

Figure 6.2-5: MBHE Measured vs Predicted Heat Flow................................................ 165

Figure 6.2-6: MBHE Bare Tube Heat Transfer Coefficient - Top Bundle............................ 166

Figure 6.2-7: Effect of Solids Flow on Heat Transfer Coefficients..................................... 167

Figure 6.3-1: MTF Temperature History with Pittsburgh \#8 coal........................................ 169

Figure 6.3-2: Bauxite Coating Thickness with West Virginia Coal................................... 170

Figure 6.3-3: Bauxite Coating Thickness vs Exposure Time (West Virginia Coal)............ 172

Figure 6.3-4: Coating Growth Rate vs Exposure Time (West Virginia Coal) ……….......... 172

Figure 6.3-5: SEM Photos after 42 Hrs Exposure (West Virginia Coal) .............................. 173

Figure 6.3-6: EDS Elemental Mapping of Bauxite Particle after 42 Hrs Exposure.............. 174

Figure 6.3-7: X-Ray Mapping of Bauxite Coating after 42 Hrs Exposure ........................... 175

Figure 6.3-8: Bauxite Coating Thickness with Pittsburgh \#8 Coal..................................... 176

Figure 6.3-9: Bauxite Coating Thickness vs Exposure Time (Pittsburgh \#8 Coal) ............. 177

Figure 6.3-10: Coating Growth Rate vs Exposure Time (Pittsburgh \#8 Coal).................... 178

Figure 6.3-11: Coating Growth Rate for West Virginia \& Pittsburgh \#8 Coal.................... 179

Figure 6.3-12: Coating Growth on Bauxite Particles with Pittsburgh \#8 Coal.................... 180

Figure 6.3-13: SEM Photos after 93 Hrs Exposure (Pittsburgh \#8 Coal) ............................. 181

Figure 6.3-14: EDS Elemental Mapping of Bauxite Particle after 93 Hrs Exposure............ 182

Figure 6.3-15: X-Ray Mapping of Bauxite Coating after 93 Hrs Exposure ......................... 183

Figure 6.3-16: Minimum Fluidization and Terminal Velocities for Bauxite........................ 184

Figure 6.3-17: Exposure Time Required for Final Particle Size.......................................... 185

Figure 6.4-1: Carbon Heat Loss With West Virginia Coal................................................... 189

Figure 6.4-2: Effect of Oxygen on Carbon Heat Loss - West Virginia Coal....................... 189 
Figure 6.4-3: Effect of Mixing Grids on Carbon Heat Loss ........................................... 190

Figure 6.4-4: Carbon Loss vs Bed Temperature - West Virginia Coal.............................. 190

Figure 6.4-5: Combustion Performance With Pittsburgh \#8 Coal..................................... 192

Figure 6.4-6: Effect of Bed Temperature on Carbon Loss - Pittsburgh \#8 Coal................ 193

Figure 6.5-1: Emissions With West Virginia Coal......................................................... 196

Figure 6.5-2: Combustor Temperature Profile During Recycle Location Variations.......... 198

Figure 6.6-1: Limestone Size Distributions ...................................................................... 204

Figure 6.6-2: CaO Fraction Carried Over to FDA - West Virginia Coal........................... 205

Figure 6.6-3: CaO Fraction Carried Over to FDA - Pittsburgh \#8 Coal............................. 206

Figure 6.6-4: Effect of Humidity on FDA Sulfur Capture............................................... 209

Figure 6.7-1: Effect of Solids to Gas Ratio on Pressure Drop .......................................... 214

Figure 6.7-2: Total Pressure Drop Comparison.......................................................... 215

Figure 6.8-1: Bed Temperature Excursion After Loss of Coolant ..................................... 216

Figure 6.8-2: Bed Temperature Response During Loss of Coolant Test........................... 217

Figure 6.8-3: Oxygen Concentration During Loss of Coolant Test.................................. 218

Figure 6.8-4: Effect of Temperature on Bed Carbon Concentration.................................. 219

Figure 7.1-1: CMB Commercialization Roadmap ................................................... 221 


\section{LIST OF TABLES}

Table 1.3-1: Potential CMB Cost Savings ................................................................ 21

Table 1.3-2: CMB Features From An Owner/Operator Point of View................................ 21

Table 3.1-1: CFD Aerodynamic Effects Summary...................................................... 45

Table 3.1-2: \% Heat Transfer Improvement due to Aerodynamic Effects ......................... 46

Table 3.1-3: Example of Simplified Scaling Relationship.............................................. 50

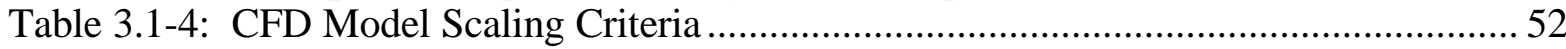

Table 3.2-1: Test Range for Pressure Drop Tests .............................................................. 58

Table 3.2-2: Transport Pressure Drop Predictions for MTF CMB Test ............................. 60

Table 3.3-1: Pneumatic Transport Attrition Results ............................................... 72

Table 3.3-2: Attrited Ash Chemical Composition............................................................. 73

Table 4.1-1: Effect of Particle Impact on Coal Trajectory.............................................. 99

Table 4.1-2: Interaction of coal from spreader stoker with falling bauxite........................ 101

Table 5.2-1: Test Matrix for the first MTF Campaign.................................................... 122

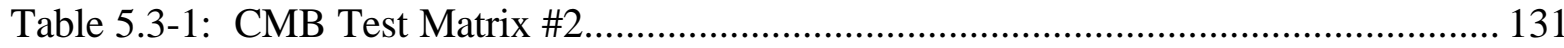

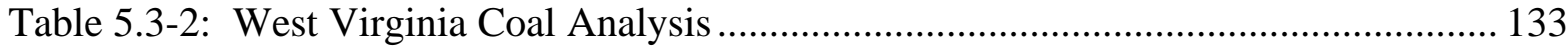

Table 5.3-3: West Virginia Coal Ash Analysis.............................................................. 133

Table 5.3-4: ASTM Ash Fusibility for West Virginia Coal........................................... 133

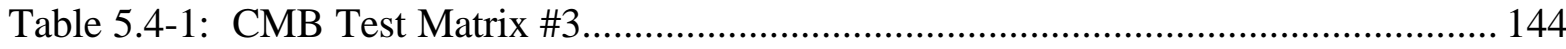

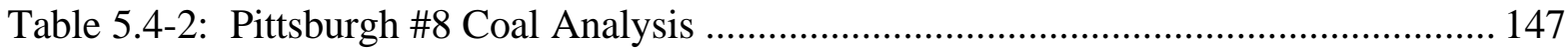

Table 5.4-3: Pittsburgh \#8 Coal Ash Analysis................................................................. 147

Table 5.4-4: ASTM Ash Fusibility for Pittsburgh \#8 Coal............................................. 148

Table 6.2-1: Identification of MBHE Thermocouples................................................. 162

Table 6.3-1: EDS Analysis of Bauxite Particles ............................................................ 171

Table 6.4-1: Combustion Performance with West Virginia Bituminous Coal................... 188

Table 6.4-2: Combustion Performance with Pittsburgh \#8 Bituminous Coal..................... 191

Table 6.4-3: Pittsburgh \#8 Coal Analysis During CMB and CFB Test Campaigns ............ 195

Table 6.5-1: Emissions with West Virginia Coal............................................................ 196

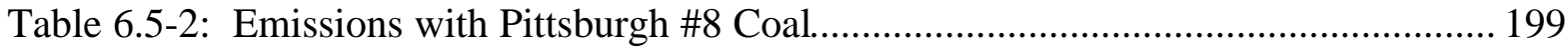

Table 6.5-3: CFB Emissions with West Virginia Coal................................................. 201

Table 6.5-4: CFB Emissions with Pittsburgh \#8 Coal................................................. 202

Table 6.6-1: CMB Combustor and FDA Sulfur Capture ................................................. 208 


\section{EXECUTIVE SUMMARY}

\section{Background}

ALSTOM Power Inc. is in the process of developing a novel Circulating Moving Bed ${ }^{\mathrm{TM}}$ (CMB) combustion system. The $\mathrm{CMB}$ is expected to provide significant advantages in advanced power cycles and enable the achievement of improved efficiency, environmental, and cost goals, as targeted for new energy plants. Specific plant systems have been conceived which would utilize the CMB technology for near-term repowering applications as well as the basis for achieving future advanced plant performance.

The U.S. Department of Energy (DOE) and ALSTOM jointly funded the CMB Proof of Concept project to evaluate and develop Circulating Moving Bed ${ }^{\mathrm{TM}}$ combustion system technology. The objective of this project was to demonstrate the "proof of concept" for $\mathrm{CMB}^{\mathrm{TM}}$ combustion system technology, enabling it to be used as a key building block of new energy plants. The total project cost was $\$ 2,797,468$ with the DOE's National Energy Technology Laboratory (NETL) providing $60 \%$ of the funding under Cooperative Agreement No. DE-FC26-01NT41223.

Circulating Moving Bed technology (illustrated in Figure E-1) is a new method for solid fuel combustion and heat transfer, which has roots in the traditional circulating fluidized bed (CFB) technology. The CMB technology completely separates the combustion process from the heat transfer surfaces. Fuel, including coal and a wide range of alternate fuels, is burned in the bubbling bed region of the combustor to produce combustion temperatures approaching $2000^{\circ} \mathrm{F}$. The heat from the products of combustion (upward flow) is exchanged (recuperated) with a flow of high-density solid particles falling downward through the upper region of the combustor. The solids have recuperated the heat of combustion upon reaching the bottom of the combustor and are then fluidized and transferred to a moving bed heat exchanger (MBHE) through standpipes.

Heat from moving particles is captured in a series of tubular moving bed heat exchangers that heat a working fluid, such as steam or compressed air, to the required process temperatures. From the bottom of the moving bed heat exchanger, the cooled solids are transported back to the top of the combustor to restart the lower recycle loop. Sintered bauxite particles can be used as the heat transfer solids media because they have a high density, have good bulk flow properties, are chemically inert, and are readily available. Figure E-1 also shows an enlarged photo of a group of bauxite particles.

The flyash entrained in the flue gas flows upward and is captured by a cyclone. A portion of the solids is returned to the bubbling bed with the balance going to a cooler and disposal. This flyash is used to reduce carbon loss and to give additional control of the resultant bed temperature. The $\mathrm{SO}_{2}$ emissions will be controlled primarily by a backend cleanup system such as ALSTOM's Flash Dry Absorber (FDA). Limestone is calcined in the combustor for use in the backend desulfurization system. Additional sulfur capture is achieved in the combustor. 


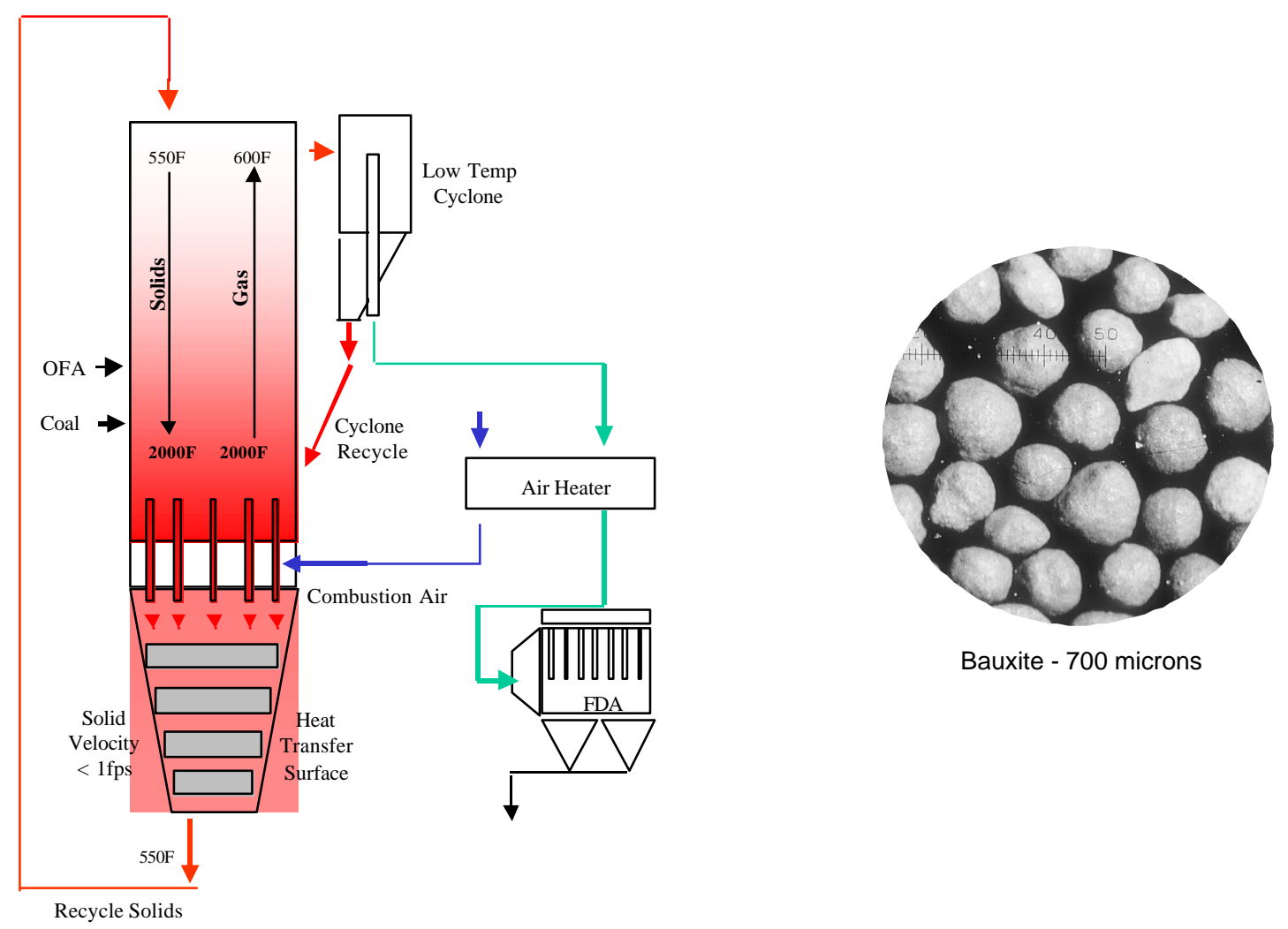

Figure E-1: $\mathrm{CMB}^{\mathrm{TM}}$ Combustion System Schematic

The high CMB combustion temperature makes it possible to achieve working fluid temperatures as high as $1750^{\circ} \mathrm{F}$. In addition to enabling high-temperature, high-efficiency power plant cycles, the combustion temperature offers better carbon burnout, virtual elimination of $\mathrm{N}_{2} \mathrm{O}$ emission, and low carbon monoxide emissions.

\section{Project Objectives and Workscope}

The objective of the CMB Proof of Concept project was to identify the technical, design, and performance challenges that need to be met to commercialize the CMB system. Many of these challenges were addressed and solved in the course of completing the proof of concept tests. These solutions and the results of conceptual design economics and performance comparisons will help potential power plant developers to assess the advantages of the CMB system, thus increasing the likelihood of further development of the technology. The specific project objectives were set by ALSTOM Power, in concert with the U.S. DOE, and are summarized below:

- Modify the Multi-Use Test Facility to operate under CMB conditions of commercial interest

- Evaluate gas-to-solids heat transfer and mixing in the upper furnace

- Evaluate factors to control ash agglomeration in the bubbling bed

- Evaluate solids-to-tube heat transfer and solids distribution in the moving bed heat exchanger 
- Evaluate $\mathrm{CMB}$ process performance, including carbon burnout, sulfur capture both in-furnace and in the backend FDA system, and other gaseous emissions, including $\mathrm{CO}, \mathrm{NO}_{\mathrm{x}}$, and $\mathrm{N}_{2} \mathrm{O}$

- Develop a preliminary conceptual design for a demonstration plant

The project objectives were achieved through a series of experiments that were conducted at a scale that provides the design data for scale up to a demonstration plant. The proof of concept tests were conducted in ALSTOM Power's $3 \mathrm{MW}_{\text {th }}$ Multi-use Test Facility (MTF). The MTF was modified to operate with all CMB subsystems fully integrated and operating at commercially significant temperatures. The CMB Proof of Concept workscope also included process evaluation and component development tasks in support of pilot plant testing.

\section{Process Evaluation and Component Development Results}

The objective of these tasks was to evaluate CMB processes and components in support of MTF testing and commercial design concepts. The emphasis of the process evaluation task was on evaluating factors that affect heat transfer, bed operating conditions, emissions, and overall performance. The focus of the component development task focus was on fuel feed systems and solids distributors. The results from these tasks formed the basis for the MTF test campaigns and are summarized below:

\section{Gas-to-Solids Heat Transfer}

The cold flow heat transfer tests showed that the solids holdup in the test column increased as both the gas velocity increased and as the number of mixing grids increased. The effect of the mixing grids was most pronounced as the gas velocity approached the particle terminal velocity. The results also show that the total heat transfer from the gas to the solids increased with the gas velocity. This increase was largely attributed to the increase in available heat transfer surface area as the solids holdup increased. There was a reduction in the gas-tosolids heat transfer coefficient as the gas velocity increased.

Several instruments were developed for evaluating for gas-to-solids heat transfer. A dual head optical probe was developed for measuring the passing frequency and velocity of the particles falling through the column, which indicated the presence, location, and motion of clusters of falling particles. A solids temperature probe was developed to measure the solids temperature rise as they fell through the combustion chanber. The probe also measured the gas temperature and velocity. These devices were used for both cold flow model tests and also for MTF tests during warm air operation A high temperature level indicator was also developed to measure the solids level in the solids separation hoppers above the MBHE and at the top of the combustor.

Computational Fluid Dynamics (CFD) models were used to predict the effect of aerodynamics on the solids distribution in the MTF combustor. The models were initially developed and calibrated against the cold flow test facilities and did a good job of predicting the measured temperatures of the solids for most of the test data. The models were then modified for the MTF geometry and predicted that the MTF heat transfer performan*ce and solids distribution would be quite good along the length of the combustor. These predictions 
generally agreed with the MTF results. However, the CFD models did not work as well when they were applied to larger scale geometries.

A disperse-phase and an Eulerian-Eulerian CFD model were used to predict the performance of a commercial sized plant. This effort pointed out some of the problems in using CFD for scaleup, since these CFD models do not handle particle-particle interactions well. Using computational variables that predict the MTF performance, the commercial model gave a wide range of predictions on gas and solids flow distributions and heat transfer performance. The CFD models require a better representation of the physical phenomena occurring in the combustor, particularly the particle-to-particle interactions. Grid dynamics also need to be better understood. CFD models can be used as a reliable tool for scale up predictions once these issues are addressed.

\section{Moving Bed Heat Transfer}

A simulation was run to assess the ability to clean extended surface tubes in the MBHE in the event of a tube leak. The finned tube was cleaned easily after the simulated leak and the solids surrounding the tube were very free flowing.

Pneumatic transport pressure drop tests were conducted to confirm that the MTF bauxite transport system siphon seal would provide sufficient sealing during CMB operation. The calculated pressure drops from these tests were lower than the measured pressure drops for both the ALSTOM model and the other correlations. Since the transport line pressure drop was less than the seal pressure for all test conditions, the solids transport system for the CMB MTF was predicted to work.

\section{Agglomeration}

Attrition testing was conducted on coated bauxite samples from a prior ALSTOM test program. The tests showed that an appreciable amount of attrition occurs in the pneumatic transport lines. This attrition may be sufficient to control the coating growth observed in the high temperature MTF tests. The amount of attrition that takes place may be different at higher transport temperatures.

\section{Bed Mixing}

A bed mixing model was developed and used to predict that good bed mixing and correspondingly uniform bed temperatures can be achieved if the fuel feed points are no more than 12 to 21 feet apart. This type of fuel distribution can be easily met with an overbed spreader type of feeder.

\section{Sulfur Capture}

A limestone calcination model predicted that 30-micron particles will calcine in the combustor on the first pass, provided that they are injected low enough in the furnace to have sufficient residence time and have adequate mixing.

Little sulfur capture is expected to take place until the gas cools down towards the optimum temperature window of $1550^{\circ} \mathrm{F}$ to $1650^{\circ} \mathrm{F}$. Furthermore, it is likely that any $\mathrm{CaSO}_{4}$ exposed to the high temperature bubbling bed may release $\mathrm{SO}_{2}$ and form $\mathrm{CaO}$. One consequence of 
this is that any cyclone recycle ash containing $\mathrm{CaSO}_{4}$ should not be recycled directly back to the bubbling bed or it will re-release any $\mathrm{SO}_{2}$ that was captured by the sorbent in its prior pass through the combustor. Instead, the recycle should be injected above the bed in more oxidizing conditions and at a more moderate temperature to avoid $\mathrm{CaSO}_{4}$ decomposition.

$\mathrm{NO}_{X} / \mathrm{N}_{2} \mathrm{O}$

Thermal $\mathrm{NO}_{\mathrm{x}}$ is only significant at temperatures over $2700^{\circ} \mathrm{F}$. Fuel $\mathrm{NO}_{\mathrm{x}}$ can be controlled by introducing the fuel into a fuel rich region and staging the air to minimize $\mathrm{NO}_{\mathrm{x}}$ formation. $\mathrm{N}_{2} \mathrm{O}$ formation should be extremely low because of the high combustor temperatures

\section{Operational Control}

A load following study for a conceptual 300MW CMB plant showed that using bauxite inlet temperature as a principle control and bypassing of steam around the low temperature reheat section for a trim is a viable approach.

Recycle System

The process model predicted that changes in recycle rate has little effect on bed temperature, but significantly changes the combustor gas outlet temperature. Recycle distribution can still have an impact on local bed temperatures.

\section{Fuel Feed System}

A conceptual fuel feed system was developed for a nominal 300Mw CMB boiler. The design requires 10 pneumatic air-swept spreaders arranged around the perimeter of the combustor. Air swept spreaders were selected because of their large capacity and simplicity.

\section{Solids Inlet Distributor}

A solids distributor developed in the ALSTOM 15-inch cold flow model was scaled up and successfully used in the MTF to distribute solids. This design was then scaled up and used in the conceptual $300 \mathrm{MW}$ plant design. This design uses 7 distributors, each covering a 20-ft diameter area.

\section{MTF Modifications}

The MTF was modified to allow evaluation of process and equipment performance under CMB conditions. The modifications proceeded in three stages. The first modification was adding a water-cooled bauxite transport line for transporting and cooling the bauxite. This focused the testing on gas-to-solids heat transfer and process performance without having to deal with the complexity of shaking down additional components associated with the MBHE.

The MTF baghouse was next converted into a FDA system, which is an integral component in the CMB design. This modification allowed evaluation of CMB sulfur capture in both the combustor and in the FDA system.

The final modification was the installation of a MBHE adjacent to the MTF combustor. The MBHE not only provided an opportunity to characterize solids-to-tube heat transfer, but the larger heat extraction in the MBHE allowed the MTF to be operated at higher loads. This 
permitted greater flexibility in running the combustor under staged conditions. Figure E-2 shows a side elevation of the two combustor modifications, along with the nearly assembled MBHE with tube bundle installed.

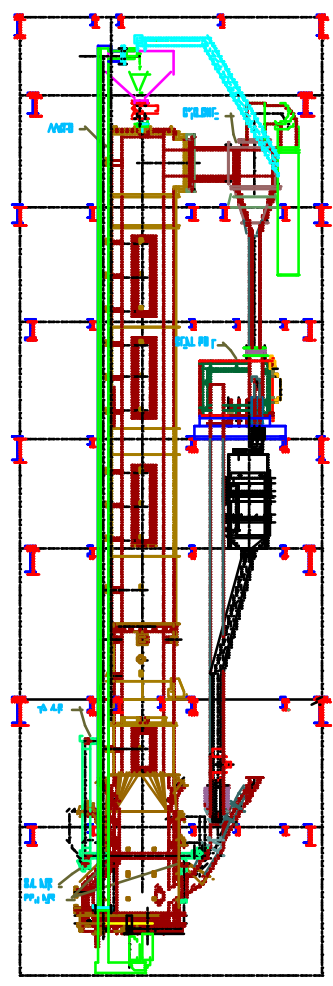

MTF w/o MBHE

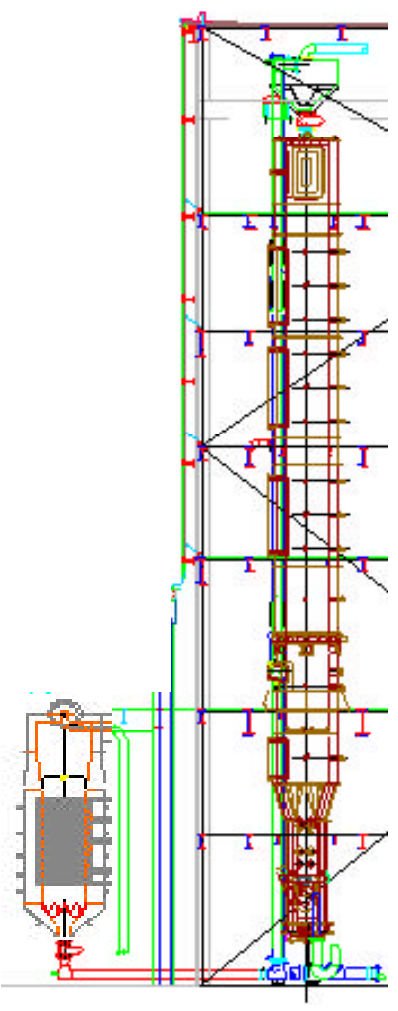

MTF w MBHE

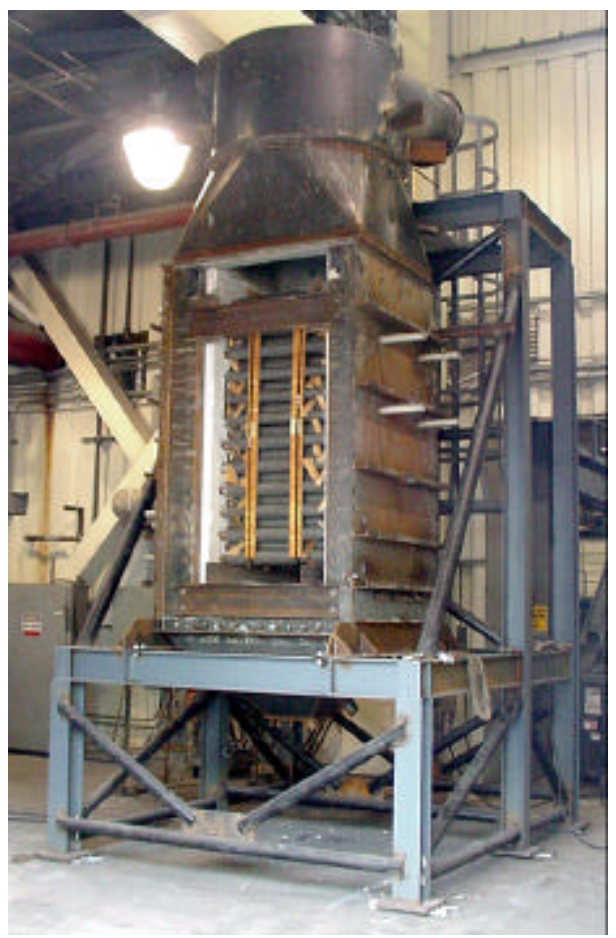
.

.

Figure E-2: MTF Modifications and MBHE Assembly

\section{Test Campaign Results}

Three test campaigns were conducted of approximately 2 weeks duration each. The first campaign focused on gas-to-solids heat transfer during warm air, natural gas, and coal firing operation. The second campaign evaluated CMB process performance while firing a West Virginia bituminous coal. The water-cooled bauxite transport line was used for cooling duty instead of a MBHE for the first two campaigns. A MBHE was added for the final test campaign. This test series addressed solids-to-tube heat transfer in the MBHE and overall process performance with Pittsburgh \#8 coal. It also allowed evaluation of temperature limitations on the bubbling bed with a coal that had a very low ASTM ash fusion temperature.

\section{Test Campaign \#1}

The objective of this test campaign was to evaluate gas-to-solids heat transfer under high temperature conditions and on a larger scale than in the cold flow heat transfer facility. Over 20 tests were conducted with warm air, natural gas firing, and coal firing. Parametric 
variations were made in airflow rate, bauxite flow rate, bauxite particle size, and number of combustion chamber mixing grids. The test results confirmed that combustion gases could be effectively cooled in the combustor solely by heat transfer to a stream of falling particles. The heat transfer performance was as good or better than expected based on earlier heat transfer tests in ALSTOM's two cold flow models. The measured gas-to-solids heat transfer coefficients fit a heat transfer correlation for falling particles at all Reynolds Numbers.

Figure E-3 shows some heat transfer data that was collected during the natural gas-fired portion of this program. The top six trend lines show the gas temperatures decreasing as the gases rose up the combustor and were cooled by the falling particles. The bottom trend line shows the solids inlet temperature as they were introduced into the top of the combustor. This figure clearly shows that the gas can be effectively cooled solely by the falling particles. It also shows the effect of varying the gas-to-solids ratio on the gas temperature profile.

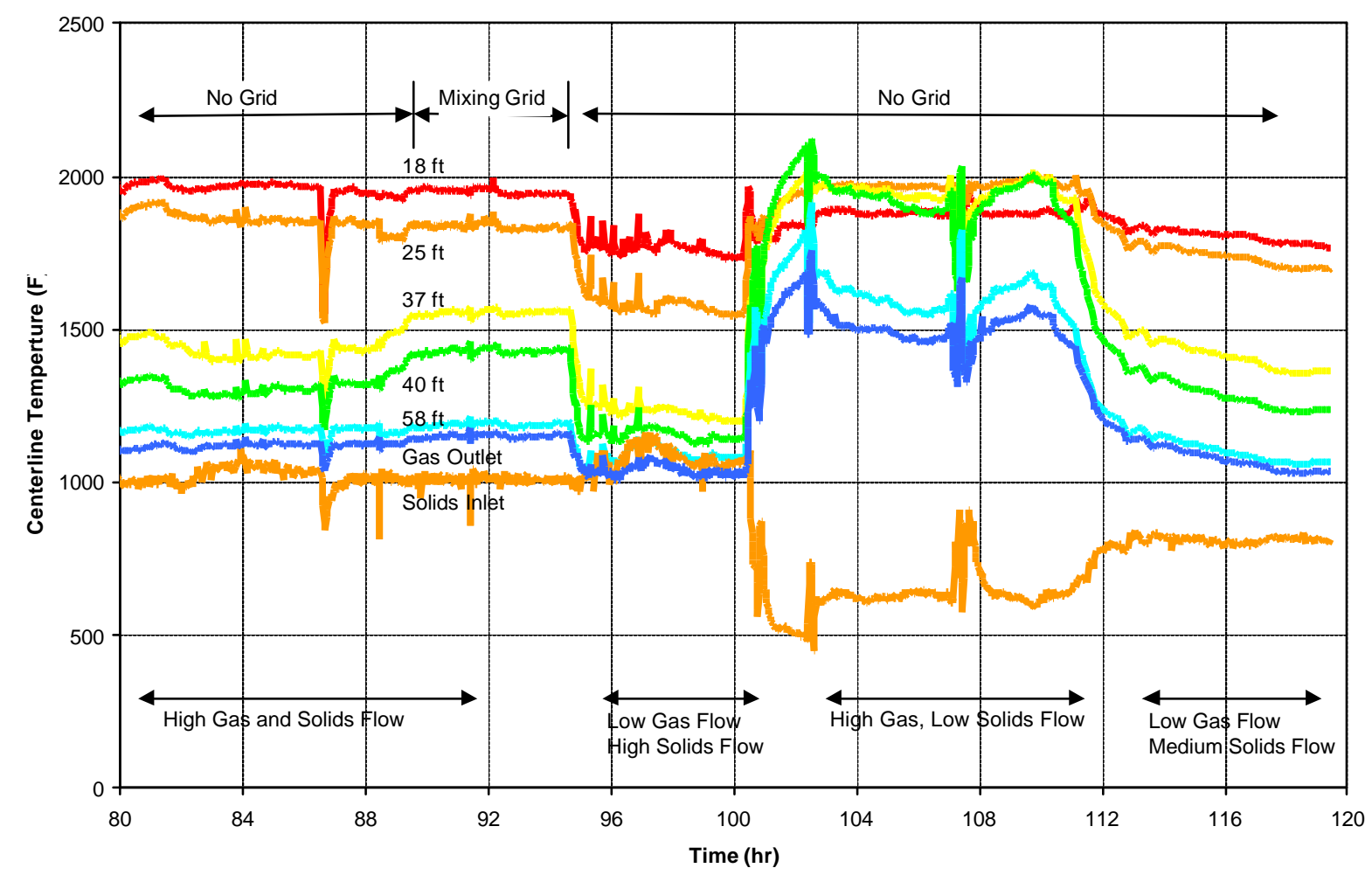

Figure E-3: Combustor Temperature Profiles During Natural Gas-Fired Tests

Overall, the results were very encouraging with respect to both operability and thermal performance. The following list summarizes some major achievements during this test campaign.

- Demonstrated reliable transport, circulation, distribution, and control of bauxite solids.

- Demonstrated that bauxite could be distributed into the combustor gas stream and get very good heat transfer between the gas and solids. Solids distribution was very uniform.

- Demonstrated that the pilot plant could be operated in full CMB mode with coal firing.

- Demonstrated that the combustor gas outlet temperatures could be controlled solely by the bauxite recirculation loop. 


\section{Test Campaign \#2}

The objective of this test campaign was to continue evaluation of CMB process performance under coal-fired conditions. Tests were conducted with a West Virginia bituminous coal and with three different limestones of various size distributions. Over 20 test conditions were completed over a two week test duration.

Some of the key findings from this test campaign are summarized below.

- The MTF could be operated very smoothly in CMB mode with lower combustor temperatures at and exceeding $2000^{\circ} \mathrm{F}$. The combustion gases were cooled to $1000^{\circ}-$ $1400^{\circ} \mathrm{F}$ solely by gas-to-solids heat transfer from the falling bauxite particles.

- The bauxite solids circulation system worked very reliably. The solids circulation rate responded immediately to changes in the bauxite feed rotary valve speed and provided excellent control of combustor temperatures. The dual beam laser level indicator on the bauxite supply hopper was trouble-free and was a reliable indicator of bauxite supply hopper inventory.

- The gas-to-solids heat transfer performance was similar to or slightly better than previously observed.

- Combustion performance was very good. The combustion efficiency ranged from $98.5-$ 99.6\%. The CO emissions for most of the testing were also low and were typically about $50 \mathrm{ppm}$ at $3 \% \mathrm{O}_{2}$. Figure E-4 compares the CMB carbon heat loss with recent CFB test results in the MTF with the same fuel. The CMB carbon heat loss was at least as good or better than the CFB results.

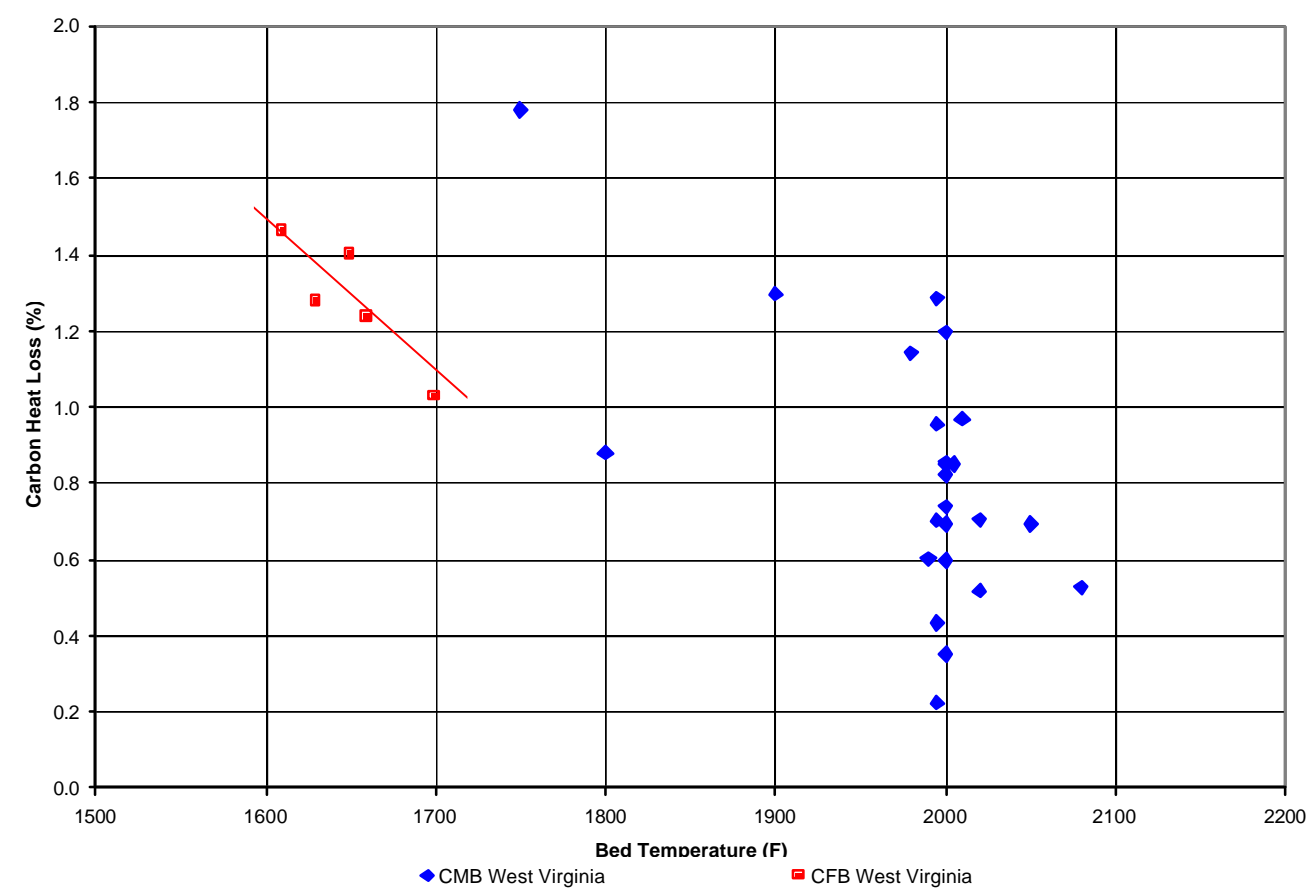

Figure E-4: Carbon Heat Loss with West Virginia Coal

- Excellent sulfur capture was demonstrated for the overall CMB system, including the combustor and the backend FDA system while using fine limestone size distributions. The $\mathrm{CMB}$ was able to achieve virtually $100 \%$ sulfur removal with the pulverized 
Chemstone limestone at a $\mathrm{Ca} / \mathrm{S}$ mole ratio of $2: 1$. A $4 \%$ sulfur coal was also simulated by feeding elemental sulfur with the coal. In this case, over $99 \%$ sulfur capture was achieved at a $\mathrm{Ca} / \mathrm{S}$ mole ratio of $2: 1$.

- The coarse sorbents (typical CFB size distributions) had low in-furnace sulfur capture and modest sulfur removal in the FDA. Only a fraction of the unreacted calcium passed through the cyclone and reached the FDA. Increasing the calcium feed to the FDA by adding FBHE bed drain (unsized or pulverized) caused an increase in the FDA sulfur capture.

- Nitrogen oxide emissions were higher than typical CFB levels for this fuel, although similar to emissions from pulverized coal firing with low $\mathrm{NO}_{\mathrm{x}}$ burners. $\mathrm{NO}_{\mathrm{x}}$ emissions were clearly reduced through air staging. However, the degree of air staging was limited during these tests because of the limited cooling duty from the water-cooled transport line. $\mathrm{N}_{2} \mathrm{O}$ emissions were practically eliminated for both low load and high load CMB operation.

- A transient loss-of-coolant test showed that the bed temperature would quickly decrease following a loss of coolant if the fuel feed system trips with the coolant loss. The bed carbon concentration was estimated to be well less than $0.1 \%$ carbon.

\section{Test Campaign \#3}

The objective of the third test campaign was to expand the evaluation of CMB process performance to include MBHE performance and a second fuel. The MBHE not only provided an opportunity to characterize solids-to-tube heat transfer, but the larger heat extraction in the MBHE allowed the MTF to be operated at higher loads. Tests were conducted with two different coals and three different limestones with a range of size distributions.

The MTF with MBHE installed required two independent transport systems to convey the solids. Once the system was shaken down, the bauxite transport system was very reliable. In fact, there was not a single instance of interruptions in solids transport during the last test period in either the transport to or from the MBHE. All other subsystems also worked reliably during the final test period. Some of the key findings from this test campaign are summarized below.

- The MBHE test results confirmed that high solids-to-tube heat transfer rates are attainable in the MBHE. The heat transfer rate was $60 \%$ higher than predicted from earlier ALSTOM test results with an inline tube design. The improvement was attributed to the staggered tube bundle arrangement.

- The MBHE heat transfer rate deteriorated when the solids flow distribution was disrupted in the MBHE. This illustrated the importance of maintaining a uniform solids flow distribution throughout the MBHE.

- All mechanical systems, including both solids transport systems and the FDA system, worked without any problems or pluggages after the system was shaken down.

- The combustion performance was very good with both coals. The combustion efficiency ranged from $98.4 \%$ to $99 \%$ for the Pittsburgh \#8 coal, which is again as good or better than results with this fuel during CFB operation in the MTF.

- $\mathrm{NO}_{\mathrm{x}}$ emissions were reduced to $88 \mathrm{ppm}$ through air staging. $\mathrm{NO}_{\mathrm{x}}$ reductions of up to $40 \%$ were achieved when aqueous ammonia was injected. The reduction level was affected by 
the injection location, the local temperatures, and oxidizing conditions. No ammonia slip was detected during this testing.

- The sulfur capture was $96 \%$ at a $\mathrm{Ca} / \mathrm{S}$ mole ratio of 2:1 while using a fine commercial grind of Marblewhite limestone.

- The results showed that the flyash generated in the CMB combustor is well-suited for high humidities in the FDA. High internal ash recirculation rates in the FDA improves the performance at high humidity

- The combustor ran for 110 hours at $2000^{\circ} \mathrm{F}$ and 6 hours at higher temperatures up to $2160^{\circ} \mathrm{F}$ with Pittsburgh $\# 8$ coal with no signs of agglomeration. The results confirmed that the $\mathrm{CMB}$ can operate over an extended temperature range without agglomeration. Figure E-5 shows the bed temperature history for the duration of this test campaign. The occasional temperature drops were caused by momentary fuel disruptions due to wet coal hanging up in the feeder. For comparison, the light blue band in this figure indicates the normal operating temperature range in a conventional CFB boiler.

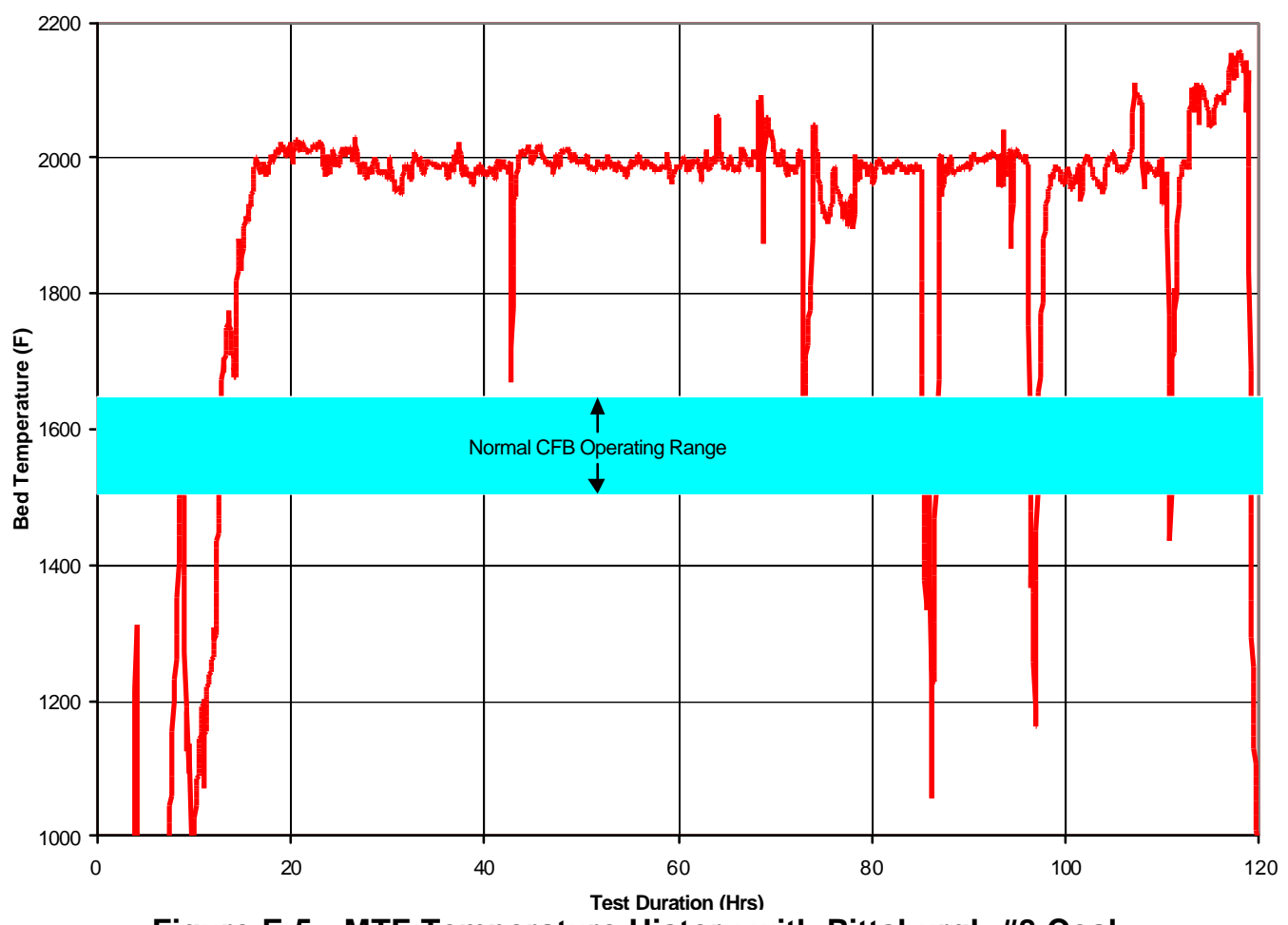

Figure E-5: MTF Temperature History with Pittsburgh \#8 Coal

- An ash buildup was observed on the particle surface during tests with both coals. The ash coating was primarily a mixture of calcium, aluminum, silica, and iron oxides in varying proportions. Figure E-6 shows the ash coating growth rate with the Pittsburgh \#8 coal, with the duration normalized to actual high temperature exposure time. This figure also includes data from a previous high temperature test with this fuel that did not include a solids recirculation system. Results show that the growth rate during this campaign was considerably less than observed in the prior tests. These results confirm that attrition in the solids recirculation loop removed some of the coating and slowed the buildup of ash on the particle surface. Although the growth rate was slowing, the MTF was not run long enough to conclude if the particle ash coating would eventually reach a steady state level, 
where any further growth was offset by attrition. There is some evidence from prior work that portions of the coating spalled off when the coating becomes thick.

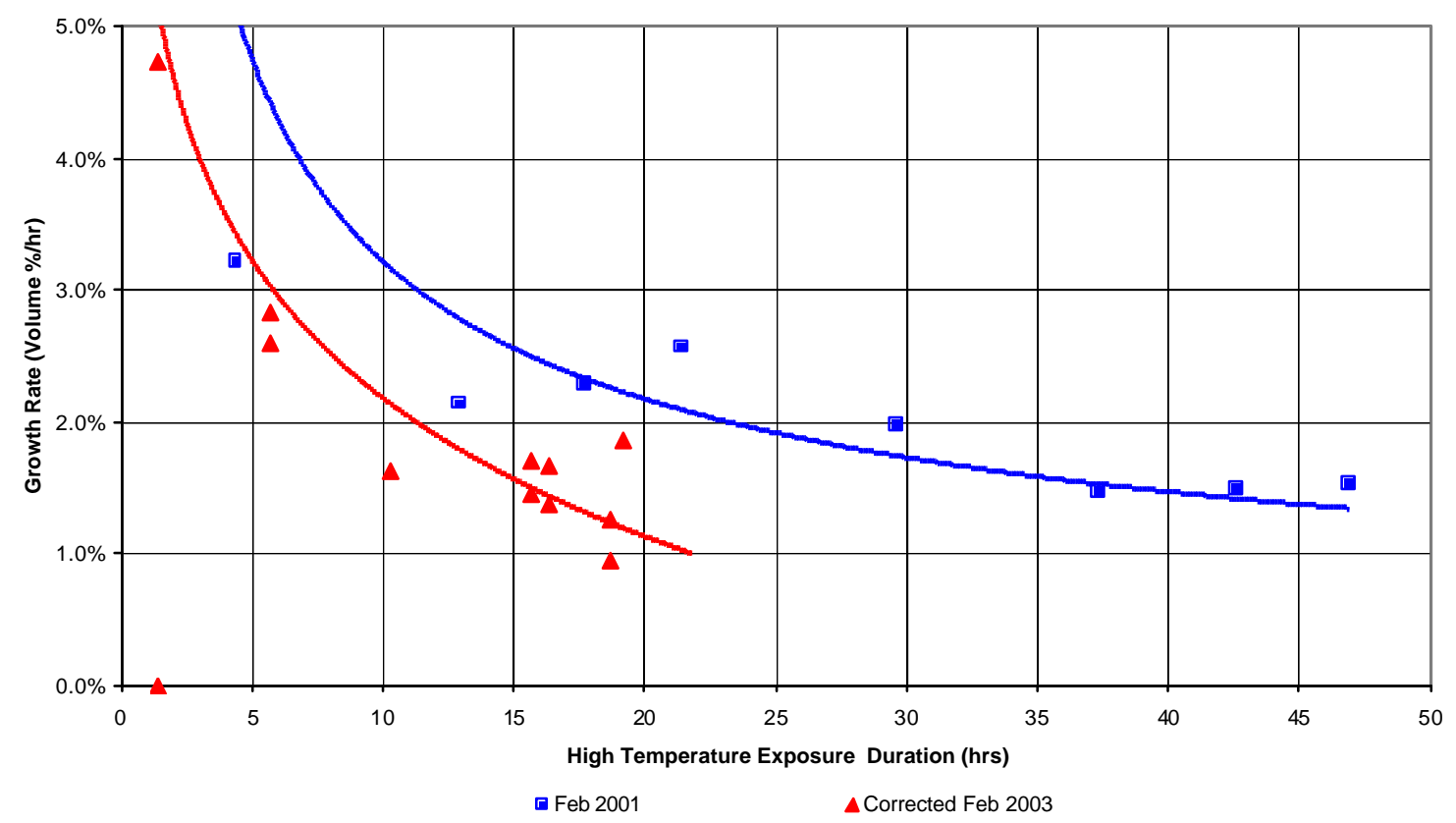

Figure E-6: Coating Growth Rate for Pittsburgh \#8 Coal

\section{Conclusions}

The objective of the CMB Proof of Concept project was to identify the technical, design, and performance challenges that need to be met to make a commercial CMB system. The project objectives were achieved through a series of experiments that were conducted in ALSTOM Power's Multi-use Test Facility. Overall project results confirmed high heat transfer rates in the combustor and MBHE. Combustion performance was very good and bed ash agglomeration was controllable. Emissions were close to state-of-the art levels and can be further optimized to meet the DOE's Advanced Combustion Systems targets. Mechanical systems worked well and no technical obstacles were identified to impede continued CMB development. The following section summarizes the progress that was made against the specific project objectives that were set by ALSTOM Power, in concert with the U.S. DOE, for the CMB Proof of Concept project.

\section{MTF Modification and Operation for CMB Process and Equipment Performance Evaluation}

The MTF was modified in several phases. A water-cooled transport system was initially installed to allow gas-to-solids heat transfer tests to be conducted in the MTF combustion chamber. The baghouse was then converted into a FDA system to enable sulfur capture evaluation in the furnace and in the backend FDA system. Finally, a moving bed heat exchanger was installed to enable solids-to-tube heat transfer evaluation. All of the subsystems worked well after shakedown. The MTF was then able to operate as a fully integrated $\mathrm{CMB}$ system. Three test campaigns were completed in the MTF with three different fuels, including natural gas and two bituminous coals, providing a wealth of performance data. All mechanical systems, including both solids transport systems and the FDA system, were operated without problems or pluggages in the last test sequence. 


\section{Gas-To-Solids Heat Transfer and Mixing in the Upper Furnace}

Results confirm that combustion gases can be effectively cooled in the combustor solely by heat transfer to a stream of falling particles. Over 20 gas-to-solids heat transfer tests were conducted in the first test campaign with warm air, natural gas firing, and coal firing. Parametric variations were made in airflow rate, bauxite flow rate, bauxite particle size, and number of combustion chamber mixing grids. The results showed that the gas and solids flow distribution was relatively uniform throughout the combustor and that mixing grids were not necessary at the MTF scale.

As expected, the Nusselt Number was generally lower than predicted for single particles due to increased particle-to-particle interactions. Particles in close proximity had a tendency to follow in each other's wake due to a drag reduction phenomena. Particles following a lead particle were exposed to gas cooled by that particle, and therefore did not have the full gasparticle temperature difference available to the lead particle. This accounted for the reduction in the Nusselt Number at high gas velocities or at low migration Reynolds Number. A multiparticle model developed from earlier warm air tests gave a good fit to the whole range of MTF data.

\section{Control Ash Agglomeration in the Bubbling Bed}

Results indicate that bed ash agglomeration is controllable over the range of commercial temperatures. Two bituminous coals were fired for over 270 hours of operation at $2000^{\circ} \mathrm{F}$ or above. The Pittsburgh \#8 coal, which had a very low ASTM ash fusion temperature, was fired for an additional 6 hours at elevated temperatures as high as $2160^{\circ} \mathrm{F}$. No agglomerates were formed in the bed and the bed remained well fluidized throughout the operation. These results indicate that the $\mathrm{CMB}$ fluidized bed is quite robust and can tolerate temporary temperature excursions or temperature maldistributions.

The bauxite particles did develop an ash coating on its surface that slowly accumulated during operation. The ash coating was primarily a mixture of calcium, aluminum, silica, and iron oxides in varying proportions. The coating rate was retarded by the mechanical abrasion and attrition as the particles passed through the transport system. Although the growth rate was slowing, test duration was not long enough to conclude if the particle ash coating would eventually reach a steady state level, where any further growth was offset by attrition. There was some evidence from our prior work that portions of the coating would spall off when the coating became thick.

If not controlled, the ash buildup on the particle surface can have a significant impact on gasto-solids heat transfer and bed pressure drop. The larger particle size will increase the combustor gas outlet temperature due to the reduced particle surface area at a given solids circulation rate. Furthermore, bed inventory will need to be controlled to maintain a constant bed pressure drop as the ash coating increases. The bauxite particle size will thus need to be managed to some maximum size level to maintain proper boiler performance. Particle size 
can be controlled through several techniques, including attrition, modifying local bed conditions to reduce the coating growth rate, and solids replenishment.

\section{MBHE Heat Transfer and Solids Distribution}

Results confirm that high solids-to-tube heat transfer rates are attainable in the MBHE. The heat transfer was $60 \%$ higher than predicted from earlier ALSTOM test results with an inline tube design. This improvement was attributed to the use of a staggered pitch tube bundle design. The results also showed the importance of maintaining uniform solids flow through the heat exchanger. Blockages in the lower MBHE caused non-uniform solids flow patterns that significantly reduced the heat transfer rate.

The heat transfer rate for the upper tube bundle was always as good or better than predicted from the inline bundle even with the non-uniform solids distribution. The top tube bundle also had higher heat transfer performance than the lower bundles. This was attributed to the maldistribution of the solids flowing through the distributing grid at the bottom of the heat exchanger. The heat transfer coefficient tended to increase with solids flow rate through the MBHE. The tube bundle fins were also largely unplugged, with only a few instances of rocks lodged in the fins.

\section{CMB Combustion and Environmental Performance}

Results indicate good combustion performance and gaseous emissions that could be controlled to current state-of-the-art CFB levels and can be further optimized to meet the DOE Advanced Combustion System targets. Tests were conducted with two different coals, four different sorbents with six different size distributions, and with ammonia injection.

The combustion performance was as good as or better than CFB performance with the same coals. The combustion efficiency for the two coals ranged from 98.4 to $99.6 \%$. One test condition was run at reduced load without any ash recycle from the cyclone. The combustion performance during this test was slightly better than the performance at full load with ash recycle. Further work needs to be done to assess this condition as operation without a cyclone represents a considerable cost savings for a commercial CMB boiler.

$\mathrm{NO}_{\mathrm{x}}$ emissions were reduced to below $100 \mathrm{ppm}$ without the addition of ammonia by low excess air and deeper staging. $\mathrm{NO}_{\mathrm{x}}$ emissions with Pittsburgh \#8 coal were comparable to MTF performance during CFB operation. $\mathrm{NO}_{\mathrm{x}}$ levels were as low as $88 \mathrm{ppm}$ or $0.11 \mathrm{lb}$ $\mathrm{NO}_{\mathrm{x}} / \mathrm{MBtu}$ without ammonia injection. $\mathrm{NO}_{\mathrm{x}}$ emissions were higher with the West Virginia coal than during CFB operation. However, the air staging was limited during these tests because of limitations with the water-cooled transport line during this test campaign. $\mathrm{NO}_{\mathrm{x}}$ reductions of up to $40 \%$ were achieved when aqueous ammonia was injected. The reduction level was affected by the injection location and the local temperature and oxidizing conditions. No ammonia slip was detected during this testing. Further $\mathrm{NO}_{\mathrm{x}}$ reduction can be achieved through a combination of approaches:

- Deeper staging

- Optimizing SNCR injection 
- Lower excess air

- Fine limestone injection overbed

$\mathrm{N}_{2} \mathrm{O}$ emissions were extremely low during all tests because of the high temperatures in the lower furnace. Emissions were always less than $5 \mathrm{ppm}$, which is considerably less than during CFB operation.

CO emissions were generally higher than observed during CFB operation. CO is apparently generated in the upper furnace where the gas temperatures are low. Emissions tended to increase as the temperature in the upper furnace decreased. $\mathrm{CO}$ emissions typically ranged from 150 to 300 ppm during these tests.

Overall CMB/FDA sulfur capture of $98 \%$ or greater was achieved with the West Virginia bituminous coal at a $\mathrm{Ca} / \mathrm{S}$ mole ratio of $2: 1$ and using pulverized limestone. This corresponds to about $0.04 \mathrm{lb} \mathrm{SO} / \mathrm{MBtu}$ and meets both the DOE and CURC advanced plant targets. Additional tests with Pittsburgh \#8 coal using pulverized sorbents with coarser size distributions yielded up to $96 \%$ sulfur capture at the same $\mathrm{Ca} / \mathrm{S}$ mole ratio of $2: 1$. This corresponds to $0.18 \mathrm{lb} \mathrm{SO}_{2} / \mathrm{Mbtu}$. An overall sulfur capture of $98 \%$ is needed to satisfy both the DOE and CURC targets with this fuel.

The coarse sorbents (typical CFB size distributions) had low in-furnace sulfur capture and modest sulfur removal in the FDA. The FDA performance was affected by the limited amount of unreacted calcium that reached the FDA. The fine sorbents gave higher in-furnace sulfur capture, especially at higher humidities. The in-furnace capture improved to $40 \%$ while the FDA and the overall sulfur capture increased up to $100 \%$ at a $\mathrm{Ca} / \mathrm{S}$ mole ratio of $2: 1$. The project goal of $98 \%$ sulfur capture over a combined CMB/FDA system is clearly attainable with fine sorbent sizes.

The flyash generated in the CMB combustor is well-suited for high humidities in the FDA. The ash was able to retain a very high moisture content and still have good handling properties in the FDA. A high internal ash recirculation rate in the FDA will improve the performance at high humidity.

The sulfur capture can be further improved through a combination of approaches:

- Limestone size distribution optimization

- Limestone injection above the bed - but with sufficient time for calcination

- FDA optimization

\section{Preliminary Conceptual Design for a Demonstration Plant}

This task was deferred to a follow-on CMB development program. However, many key inputs for a demonstration plant design were developed during the course of this program. Design correlations were developed for predicting gas-to-solids heat transfer, solids-to-tube heat transfer, and pressure drop in the solids transport systems. Concepts were developed for the fuel feed system and the solids inlet distributor. Process design criteria, including combustion and environmental performance, were assessed for two bituminous coals. 


\section{Recommendations}

The following recommendations are made for further CMB development:

1. Gas-to-solids heat transfer testing showed that the solids distribution and heat transfer performance are quite good at the MTF scale. However, CFD models require a better representation of the physical phenomena occurring in the combustor, particularly the particle-to-particle interactions, before they can be used as a reliable tool for scale up predictions. Grid dynamics need to be better understood also. A larger scale test loop is needed to properly calibrate the CFD model so it can be used for scale up. The test loop should be large enough to model a full scale solids distributor and several other critical components at significant scale.

2. The MBHE demonstrated that very good solids-to-tube heat transfer can be achieved with a properly designed bundle. It is clear that future work must focus on improving the solids flow distribution through the MBHE. The results demonstrated that maldistribution of the solids flow through the tube bundle has a significant influence on performance. An improved design needs to be developed to replace the distribution baffle at the bottom of the MBHE to ensure uniform solids flow.

3. Additional work is needed on the extended surface tube design in the MBHE. A design review is needed to keep material stresses to acceptable levels, thus enabling its use in the high temperature tube bundle of an ultra-supercritical boiler.

4. Additional process optimization is required to meet the performance targets for the DOE's and CURC's advanced plants. Additional work is needed to reduce $\mathrm{NO}_{\mathrm{x}}$ emissions, including more aggressive air staging and SNCR injection. $\mathrm{CO}$ emissions need to be better understood and a strategy developed for reducing $\mathrm{CO}$ as furnace outlet temperatures are lowered. The CMB sulfur capture performance will be able to meet the emissions targets. The impact of sorbent feed design on calcination, recarbonation, and deactivation of the sorbent needs to be further investigated. 


\subsection{INTRODUCTION}

ALSTOM Power Inc. is in the process of developing a novel Circulating Moving Bed ${ }^{\mathrm{TM}}$ (CMB) combustion system. The CMB is expected to provide significant advantages in advanced power cycles and enable the achievement of improved efficiency, environmental, and cost goals, as targeted for new energy plants. The technology is seen as the successor to Circulating Fluidized Bed (CFB) technology. Specific plant systems have been conceived which would utilize the $\mathrm{CMB}$ technology for near-term repowering applications as well as for the basis for achieving future advanced plant performance.

The U.S. Department of Energy (DOE) and ALSTOM jointly funded the CMB Proof of Concept program to evaluate and develop Circulating Moving Bed ${ }^{\mathrm{TM}}$ combustion system technology. The objective of this program was to demonstrate the "proof of concept" for $\mathrm{CMB}^{\mathrm{TM}}$ combustion system technology, enabling it to be used as a key building block of new energy plants. The total program cost was $\$ 2,797,468$ with the DOE's National Energy Technology Laboratory (NETL) providing $60 \%$ of the funding under Cooperative Agreement No. DE-FC26-01NT41223. Participants included the U.S. DOE, ALSTOM, the University of Massachusetts, and the Massachusetts Institute of Technology. The project was initiated in July 2001 and completed in March 2003. This report documents the results from the $\mathrm{CMB}^{\mathrm{TM}}$ combustion system Proof of Concept program.

\subsection{Circulating Moving Bed Technology Description}

Circulating Moving Bed technology (illustrated in Figure 1.1-1) is a new method for solid fuel combustion and heat transfer, which has roots in the traditional circulating fluidized bed (CFB) technology. The CMB technology completely separates the combustion process from the heat transfer surfaces. Fuel is burned in the lower region of the combustor using bubbling fluid bed technology. The combustor burns coal or alternative fuels, such as petroleum coke, anthracite, sludge, and a variety of wood waste and biomass products to produce combustion temperatures approaching $1095^{\circ} \mathrm{C}\left(2000^{\circ} \mathrm{F}\right)$. These temperatures are higher than the combustion temperatures of 845 to $900^{\circ} \mathrm{C}\left(1550\right.$ to $\left.1650^{\circ} \mathrm{F}\right)$ generated in traditional CFB boiler designs. The upper zone of the combustor is a relatively long residence time reactor that exchanges (recuperates) the heat from the products of combustion (upward flow) to a flow of high-density solid particles flowing downward. The solids have recuperated the heat of combustion upon reaching the bottom of the combustor and are then fluidized and transferred to a lower chamber by means of standpipes. The lower chamber contains a counterflow, direct contact "moving bed" heat exchanger. Heat from moving solid particles is captured in a series of tubular heat exchangers that preheat a working fluid such as steam or compressed air to the required process temperatures.

The moving bed heat exchanger uses a simple mass flow of solids that move downward at very low velocity. Sintered bauxite particles can be used as the heat transfer solids media because they have a high density, have good bulk flow properties, are chemically inert, and are readily available. Figure 1.1-1 also shows an enlarged photo of a group of bauxite particles. The solids flow over tube circuits that contain the working fluid(s) of the cycle. The heat exchange is 100\% counter-flow and, because the solids velocity is constant, there is no need to vary tube spaces. 
The solids in the fluidized bed are primarily bauxite and contain a minimum amount of ash due to the high bauxite feed rates to the bed and because the fluidized bed acts as an effective classifier. The mass flow of bauxite into the fluidized bed is greater than the ash input. Furthermore, the ash and sorbent particles are considerably finer than the bauxite particles and are mostly entrained upward by the high bed fluidizing velocity. The larger and denser bauxite particles are retained in the bed and are then passed into the moving bed heat exchanger. At the bottom of the moving bed heat exchanger, the cooled solids are transported back to the top of the combustor to restart the "lower recycle loop".

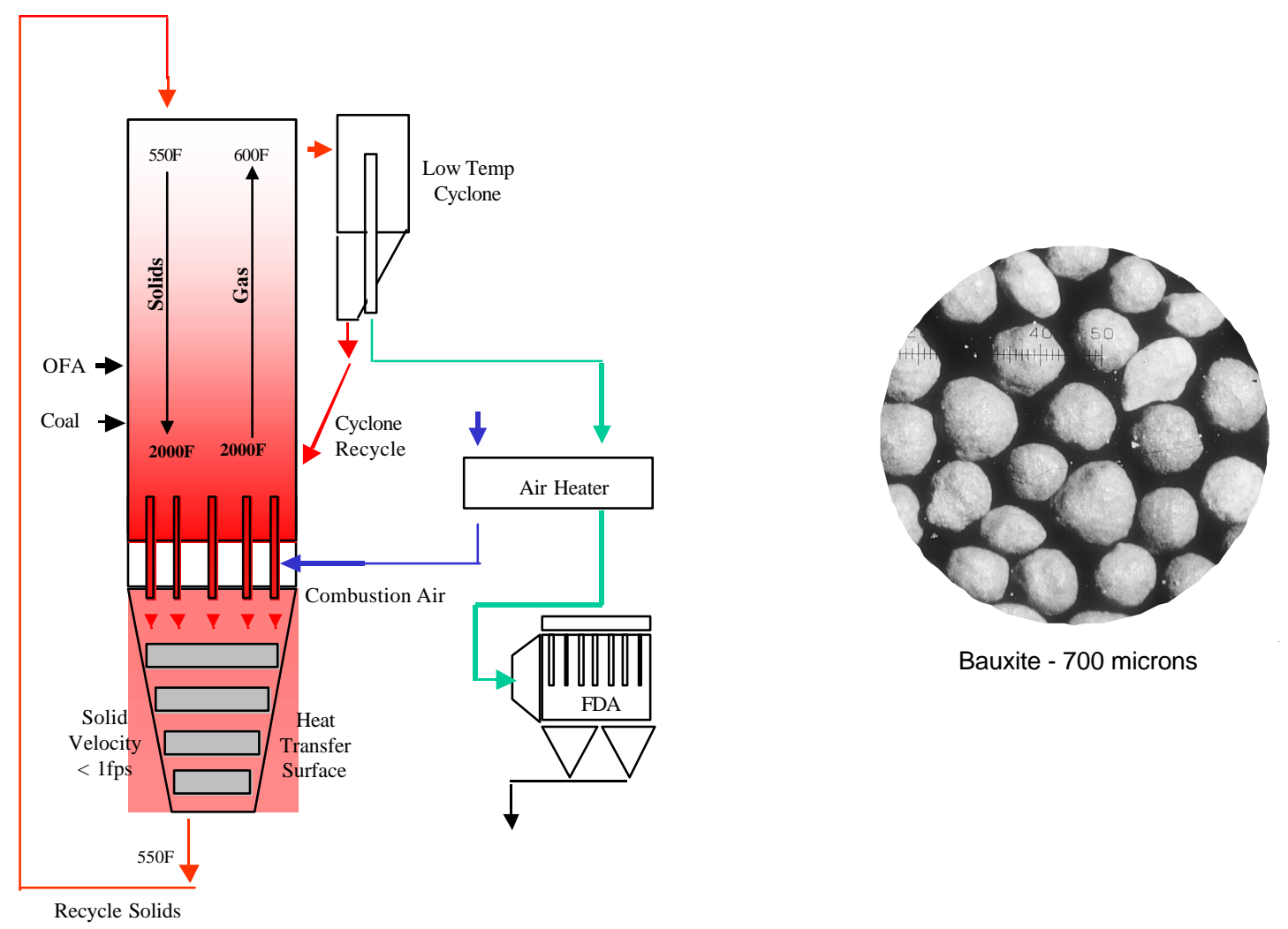

Figure 1.1-1: CMB ${ }^{1 \mathrm{M}}$ Combustion System Schematic

The flyash entrained in the flue gas flows upward and is captured by a cold cyclone. Portions of the solids are returned to the bubbling bed with the balance of the solids going to a cooler and disposal (not shown). This flyash recycle is used to reduce carbon loss and to give additional control of the resultant bed temperature. The $\mathrm{SO}_{2}$ emissions will be controlled primarily by a backend cleanup system such as ALSTOM's Flash Dry Absorber (FDA). Limestone is calcined in the combustor for use in the backend desulfurization system and additional sulfur capture can be achieved in the combustor also.

The CMB combustion temperature makes it possible to develop a design in which the working fluid can reach temperatures as high as $955^{\circ} \mathrm{C}\left(1750^{\circ} \mathrm{F}\right)$. In addition to enabling high temperature, high efficiency power plant cycles, the combustion temperature offers better carbon burnout, virtual elimination of $\mathrm{N}_{2} \mathrm{O}$ emission, low carbon monoxide emissions, and hence, increased combustion efficiency with reduced pollutant emission. 


\subsection{Performance Targets for CMB Technology}

The CMB combustion system is designed to meet or exceed the DOE's performance targets for advanced combustion systems. These goals for advanced FBC plants are emissions less than $0.1 \mathrm{lb} /$ million Btu for $\mathrm{SO}_{2}$, less than $0.15 \mathrm{lb} /$ million Btu for $\mathrm{NO}_{\mathrm{x}}$, less than 0.01 $\mathrm{lb} /$ million Btu for particulate, and $80-99 \% \mathrm{CO}_{2}$ production (compared to conventional plants). ALSTOM is also working towards meeting the Coal Utilization Research Council's (CURC) 2010 performance targets for advanced coal fired plants. These targets include boiler cost less than $\$ 900 / \mathrm{kw}$, thermal efficiency at least $45 \%, \mathrm{NO}_{\mathrm{x}}$ emissions less than 0.05 $\mathrm{lb} / \mathrm{MBtu}$, sulfur removal greater than $98 \%$, and over $90 \%$ mercury removal. The following discussion shows ALSTOM's approach towards meeting these targets.

\section{Reduced Capital and Operating Costs}

A cost comparison between a CMB boiler and a traditional CFB unit both designed for conventional steam turbine conditions showed potential cost reductions of up to $30 \%$ of the material for the CMB boiler. Major savings were realized in the areas of pressure parts, structural steel, and refractory. The use of a relatively cold cyclone further reduced the size and cost. The high efficiency heat exchanger reduced the overall surface and costs of the heat exchangers. All of the pressure parts were on the lowest elevation of the plant, reducing structural steel costs. This also resulted in shorter main steam lines to the steam turbine, which is a major cost reduction to an overall steam power plant.

CMB auxiliary power consumption can be less than conventional CFB because the CMB transports less total solids than a standard CFB. CMB reliability will be comparable to or better than existing technologies, because most $\mathrm{CMB}$ components are already proven. In fact, many of the corrosion/erosion problems experienced with conventional coal-fired boilers will be avoided, since the CMB heat exchanger tubes are untouched by combustion gases. The major difference is in the arrangement of the new heat exchangers and they are being developed as part of this program.

\section{High Thermal Efficiency}

High combustor temperatures in the CMB module will enable higher cycle working fluid temperatures. Higher temperatures permit the use of advanced plants capable of dramatic improvement in power plant cycle efficiency. A majority of current coal fired subcritical plants operate at relatively modest steam conditions of $165 \mathrm{bar} / 538^{\circ} \mathrm{C} / 538^{\circ} \mathrm{C}$ $\left(2400 \mathrm{psig} / 1000^{\circ} / 1000^{\circ} \mathrm{F}\right)$. These power stations have thermal efficiencies in the range of 33$38 \%$ (HHV). Upgrading steam pressures and temperatures to supercritical conditions improves efficiency to the $39-42 \%$ range. Higher thermal efficiencies are possible, but will require steam turbine conditions similar to the Thermie project of $375 \mathrm{bar} / 720^{\circ} \mathrm{C}\left(5440 \mathrm{psig} / 1330^{\circ} \mathrm{F}\right)$ and above.

The CMB moving bed heat exchanger is the most practical and cost effective way to achieve these elevated steam temperatures. This is because it is very effective in heat transfer resulting in significant heat transfer surface reduction. The high temperature heat exchanger is placed inside the moving bed, which is outside of the corrosive environment of the combustor. For higher temperature steam plants or applications for other working fluids, heat 
transfer surfaces will be made of very expensive materials. In these cases, Circulating Moving Bed technology will have even more significant economic benefit.

CMB technology can be utilized for a new boiler and also for repowering by replacing an existing boiler. In this case, the steam turbine would be retained and a new high temperature topping steam turbine would be added to increase the original plant output and net efficiency. The high temperature topping steam turbine would be installed close to the CMB module. This would minimize the need for expensive, high temperature piping and expand the steam to the existing steam turbine conditions, which could be in the range of $310-379$ bar $/ 593-704^{\circ} \mathrm{C}$ (4500-5500 psig/1100-1300 $\left.{ }^{\circ} \mathrm{F}\right)$. These steam conditions would generate power at efficiencies in the mid-40\% range. These values compare favorably with current efficiencies of 33\%-38\%, resulting in reduced fuel use and considerably lower emissions, including $\mathrm{CO}_{2}$. Since the total US installed generation capacities of coal-fired plants over 20 and 30 years old are 171,236 MW and 185,552 MW, respectively, the market potential for coal fired repowering is enormous for the right technology that can meet both financial and environmental concerns.

The CMB technology is also envisioned as the platform for other advanced plant concepts. The solids recirculation loop or thermal looping process within the $\mathrm{CMB}^{\mathrm{TM}}$ combustion system can be utilized as a building block for advanced chemical looping combustion and gasification processes. Chemical looping is a technique to selectively capture gases by reacting it with a solid. The solid is then separated from the rest of the gases in the system and transferred to another reactor. The gas/solid reaction is then reversed through changes in temperature or pressure. Advanced chemical looping systems can be developed that utilize one or more chemical looping processes and a thermal looping process to transfer energy between reactors. These systems can significantly improve thermal efficiencies beyond the limits of Rankine cycles and ultimately lead up to the production of syngas, hydrogen, or hydrogen with $\mathrm{CO}_{2}$ sequestration. ${ }^{1}$

\section{NO $_{\mathbf{x}}$ Emissions}

$\mathrm{NO}_{\mathrm{x}}$ emissions would be controlled primarily through in-furnace air staging. A more aggressive strategy for in-furnace $\mathrm{NO}_{x}$ control using SNCR may be utilized. $\mathrm{N}_{2} \mathrm{O}$ emissions, a problem in conventional fluidized bed systems, are virtually eliminated as a result of the higher combustion temperature in the CMB.

\section{Sulfur Capture, Particulate, and Mercury}

The $\mathrm{SO}_{2}$ and particulate goals will be met by a backend cleanup system such as ALSTOM Power's Flash Dry Absorber. This allows the design of the combustor to be separated from the need to remove sulfur and optimizes the combustion process. On the other hand, limestone can be easily calcined in the combustor for use in the backend installed desulfurization system. As an added benefit, the FDA system is expected to capture most of the mercury.

\subsection{Improvements Over Existing Technologies}

The unique design of $\mathrm{CMB}$ technology provides it with a number of advantages relative to conventional combustion technologies. Heat contained in a mass of free-flowing solids 
separated from the combustion gases makes possible many design solutions that are not available with other combustion systems. Some of these advantages are summarized below.

- There is a minimum corrosion, erosion, or pluggage potential regardless of the fuel characteristics. Therefore, high temperature heat exchangers made of less expensive alloy tubes can be installed.

- Tubes can be finned regardless of fuel properties. A finned tube can load 5 times the surface per linear foot of tube compared with conventional boiler tubing. This enables a very compact design with less weight.

- Since the tubes can be finned, there is a major advantage to the CMB module in terms of the weight of heat transfer surface used and an overwhelming advantage in terms of $\mathrm{W} / \mathrm{m}^{2}$ of wetted inside tube surface. The reduced heat transfer surface also results in lower steam side pressure drop.

- The CMB heat exchanger peak heat transfer rate is close to the mean due to the uniform temperature of the recycle solids. Therefore, the use of less expensive materials is possible.

- All tubes are heated uniformly about the axis of the tube. This results in a more uniform stress distribution and minimizes the potential for stress induced damage.

- Heat transfer surface utilization is superior in a moving bed environment as compared to in a flue gas stream. This favorable condition stems from a significantly higher heat transfer coefficient produced by the moving solid particles and the ability to use heat transfer assemblies constructed of finned tubes. Smaller heat exchangers require less steel structure and casing producing additional cost savings.

- Reduced high temperature surfaces of up to $50 \%$ for non-finned surfaces and greater than $50 \%$ for finned surfaces. Nickel based alloys are inevitable for high temperature cycles, but the $\mathrm{CMB}$ module should use much less of these expensive alloys than other combustion technologies.

- Reduced pressure drops on the working fluid side of the cycle. For example, the path length of the feedwater/steam-finned circuit in the heat exchangers could be $20 \%$ shorter than that of a typical pulverized coal (PC) or CFB design. This could be translated into a combination of reduced pressure drop and higher velocities of fluid in the tubes to reduce film resistance, and thus, metal temperature rise. Reduced pressure drops also improve efficiency.

- High temperature finishing heat transfer section outlets are at the same elevation as a gas turbine, oxygen transport membranes, or other high temperature downstream components. This enables a shorter path length for costly high temperature piping and, therefore, a lower cost.

The success of the CMB market introduction depends upon realizing significant capital and operating cost savings over conventional product lines. Table 1.3-1 summarizes some of the CMB cost saving opportunities that have already been identified. Initial analysis for conventional steam condition cycles has shown that the weight of the CMB boiler pressure parts may be almost $60 \%$ less than the comparable weight and surfaces in a CFB. This, along with other design features, translates into significantly lower costs in many areas, such as structural steel, fuel handling equipment, building volume and footprint, and erection. 
Table 1.3-1: Potential CMB Cost Savings

\begin{tabular}{|l|l|l|}
\hline LOWER CAPITAL COSTS & LOWER OPERATING COSTS & LOWER ENVIRONMENTAL COSTS \\
\hline Reduced Pressure Parts & Low Gas Side Pressure Drop & No Pressure Parts in SNCR \\
No Hi-Temp Cyclone & Low Steam Side Pressure Drop & Temperature Windows \\
Reduced Structural Steel & Reduced Auxiliary Power & \\
Smaller Footprint/Building & Low Cost Fuels & \\
Standard Pressure Parts & Reduced Fuel Consumption & \\
Shorter Links, No RH Sprays & & \\
No Sootblowers & & \\
No Pulverizers & & \\
\hline
\end{tabular}

Table 1.3-2 summarizes some of the many CMB features from an Owner or Operator point of view, relative to conventional $\mathrm{PC}$ or $\mathrm{CFB}$ technologies. $\mathrm{CMB}$ technology compares favorably against both technologies from a capital cost, cycle time, and availability standpoint. It is expected to have better fuel efficiency than CFBs and better thermal efficiency than both PCs and CFBs, when combined with a topping cycle. It also retains the fuel flexibility of a CFB, although it actually will be truly fuel independent and lends itself to a true standard combustor design. The one drawback from the customer's point of view is that $\mathrm{CMB}$ is an unproven technology and will require some demonstration to achieve acceptance. The CMB Proof of Concept project is providing much of the design information required for a demonstration plant.

Table 1.3-2: CMB Features From An Owner/Operator Point of View

\begin{tabular}{|c|c|c|c|}
\hline 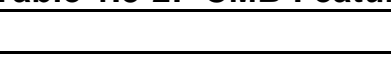 & PC & CFB & CMB \\
\hline First Cost with Scrubber & Base & Same as PC & Lower first cost \\
\hline Environmental & Base & Lower $\mathrm{NO}_{\mathrm{x}}$ & $\begin{array}{l}\text { Lower } \mathrm{NO}_{\mathrm{x}} \text {, Higher } \\
\text { Efficiency, } \mathrm{NO}_{\mathrm{x}} \text { Reduction } \\
\text { with SNCR }\end{array}$ \\
\hline Cycle Time & Base & Same as PC & $\begin{array}{l}\text { Lower, High reuse potential } \\
\text { of pressure part designs }\end{array}$ \\
\hline Unit Availability & Base & Same as PC & $\begin{array}{l}\text { Higher, No erosion or } \\
\text { corrosion }\end{array}$ \\
\hline Fuel Efficiency & Base & $\begin{array}{l}\text { Slighlty lower, } \\
\text { High Fan HP }\end{array}$ & $\begin{array}{l}\text { Same as PC, } \\
\text { Moderate Fan HP }\end{array}$ \\
\hline Fuel Flexibility & Not flexible & Very Flexible & Very Flexible \\
\hline
\end{tabular}

\subsection{Project Overview and Objectives}

The objective of the CMB Proof of Concept project was to identify the technical, design, and performance challenges that need to be solved in order for the CMB combustion system to continue progress along its commercialization path. Many of these challenges were addressed and solved in the course of completing the CMB Proof of Concept tests. These solutions and the results of conceptual design economics and performance comparisons will help potential 
power plant developers to assess the advantages of the CMB system, thus increasing the likelihood of further development of the technology.

The project objectives were achieved through a series of experiments that were conducted at a scale that provides the design data for scale up to a demonstration plant. The CMB Proof of Concept tests were conducted in ALSTOM Power's Multi-use Test Facility (MTF). The MTF was modified to operate with all CMB subsystems fully integrated and operating at commercially significant temperatures. Towards that end, the following specific project objectives were set by ALSTOM Power, in concert with the U.S. DOE, for work to be performed in response to the above goal:

- Modify the Multi-Use Test Facility to operate under CMB conditions

- Evaluate gas-to-solids heat transfer and mixing in the upper furnace

- Evaluate factors to control or mitigate agglomeration in the bubbling bed

- Evaluate solids-to-tube heat transfer and solids distribution in the moving bed heat exchanger

- Evaluate $\mathrm{CMB}$ process performance, including carbon burnout, sulfur capture both in-furnace and in the backend FDA system, and other gaseous emissions, including $\mathrm{CO}, \mathrm{NO}_{\mathrm{x}}$, and $\mathrm{N}_{2} \mathrm{O}$

- Develop a preliminary conceptual design for a demonstration plant 


\subsection{STATEMENT OF WORK}

The following outline is adapted from the Statement of Work that was accepted by the DOE for Cooperative Agreement DE-FC26-01NT41223. The outline, along with the major task objectives, provides an overview of how the project was structured and executed.

The work included in this project included tasks for process evaluation and component development. These tasks were a continuation of ALSTOM Power's CMB development program and included items that needed to be done in parallel with the MTF test program as data was developed.

Three test campaigns were conducted of approximately 2 weeks duration each. The testing addressed each of the technical issues identified in Section 1.4 in a systematic manner and optimized the associated systems. Gas-to-solids heat transfer was studied in the first test campaign with warm air and natural gas firing instead of coal firing. The solids transport and distribution systems were shaken down. Coal was then fired and the feed and ash recycle systems were developed.

The first coal combustion tests were completed in the second test campaign with a low sulfur, high ash fusibility coal. Next, a moving bed heat exchanger was added and modifications were made to the lower combustor to simulate the CMB Module. Performance testing was done in the final test campaign with all systems operating and fully integrated. A high sulfur, low ash fusibility coal was tested to generate data across a broader range of coal properties. A conceptual design for a demonstration plant was initially planned as part of this program. This task was then deferred to a follow-on program that includes some additional mechanical design and plant arrangement tasks that will also influence a demonstration plant design. The following list summarizes the Work Breakdown Structure for the CMB Proof of Concept project.

\subsection{Process Evaluation}

The objective of this task was to evaluate the process parameters that have a major impact on $\mathrm{CMB}$ process performance. The results from this task supported the design of the pilot plant test experiments and the analysis of the experimental data associated with pilot scale combustion tests.

1.1 Gas Solid Heat Transfer

1.2 Moving Bed Heat Transfer

1.3 Agglomeration

1.4 Bed Mixing

1.5 FDA Performance Assessment

$1.6 \mathrm{NO}_{\mathrm{x}}$ and $\mathrm{N}_{2} \mathrm{O}$ 


\subsection{Operational Control}

\subsection{Process Model}

\subsection{Component Development}

The objective of this task was to evaluate the process parameters that have a major impact on CMB process performance. The results from this task supported the design of the pilot plant test experiments and the analysis of the experimental data associated with pilot scale combustion tests.

2.1 Fuel and Recycle Feed System

2.2 Solids Inlet Distributor System

3.0 MTF Facility (Design and Modifications)

This task included the modifications needed to conduct the CMB Proof of Concept tests in the MTF.

3.1 Test Plan Development

3.2 Pilot Plant Performance Predictions

3.3 Specialized Instrumentation

3.4 Data Acquisition and Reduction Software

\subsection{MTF Modifications}

\subsection{MTF Test Program}

This task further demonstrated the CMB Proof of Concept for the CMB module. Design information was recorded and data analysis was completed.

\subsection{Test Campaign \#1, Hot Solids Test on Gas Only}

\subsection{Test Campaign \#2, Coal \#1}

4.3 Test Campaign \#3, Coal \#1 (in series with Task 4.2)

4.4 Test Campaign \#4, Performance Test

4.5 Test Campaign \#5, Coal \#2 (in series with Task 4.4)

4.6 MTF Corrosion Test 
4.7 Data Analysis

4.8 Demonstration Plant Prestudy

Task 5.0 Program Management

This task provided program management and reports for this project.

5.1 Program Management

5.2 Project Planning

5.3 Project Reporting 


\subsection{PROCESS EVALUATION}

The objective of these tasks was to evaluate CMB processes in support of MTF testing and commercial design concepts. The focus was on evaluating factors that effect heat transfer (gas-to-solids and solids-to-tube), bed operating conditions (agglomeration and mixing), emissions $\left(\mathrm{NO}_{\mathrm{x}}, \mathrm{N}_{2} \mathrm{O}\right.$, and $\left.\mathrm{SO}_{2}\right)$, and overall performance (load following and process modeling). The results from these tasks formed the basis for the MTF test campaigns that were developed to prove the CMB concept.

\subsection{Gas-to-Solids Heat Transfer}

The objective of this task was to evaluate gas-to-solids heat transfer issues in support of the first MTF test campaign that would focus on heat transfer. Mixing grids were installed in the MTF at a much wider spacing than previously tested in the ALSTOM cold flow heat transfer test facility. Additional cold flow tests were therefore conducted to evaluate the effect of mixing grid spacing on solids holdup and on gas-to-solids heat transfer. The test facility was also used to develop specialized instrumentation that could be used for detailed heat transfer measurements in the MTF. Computational fluid dynamics (CFD) modeling techniques were evaluated for their ability to accurately simulate solids distribution and heat transfer. Successful modeling could then be used to evaluate test results and for scaling results up to commercial size units. Scaling methodologies were also evaluated and tested using CFD models.

\section{Cold Flow Modeling}

Overview

ALSTOM Power had previously built and operated a 4-inch x 9-inch heat transfer column and a 15-inch octagonal heat transfer test facility for gas-to-solids heat transfer studies prior to the CMB Proof of Concept program. The 15-inch test facility was used for additional heat transfer testing as part of this program in support of MTF heat transfer tests. The objective of these tests was to evaluate the effect of the mixing grid spacing on heat transfer performance. Tests were planned in the MTF with 2 mixing grids, but at a wider spacing than previously tested in the cold flow model. A series of tests was therefore performed in the column with 2 mixing grids installed and an identical series was performed in the column without mixing grids. Preliminary cold flow tests were performed to determine the column pressure drop as a function of the gas and solids mass flow rates. Various specialized instrumentation was also developed in the heat transfer test facility for use in the MTF.

\section{Facility Description}

The heat transfer tests were conducted in the 15 inch column and operated at temperatures between ambient and about $250^{\circ} \mathrm{F}$. The column was octagonal in plan area with an inside dimension of 15 inches wall to wall and 30 feet high. It was made of transparent lexan for observation of the particles during the tests. Two-inch test ports were installed every 4 feet of elevation so traverses could be made of air temperature, air rise velocity, and solids particle density or frequency. Shielded thermocouples were installed at 4 foot elevation intervals to measure the centerline gas temperature. Pressure taps were installed to measure the column pressure drop at the lower, middle, and top quarter points. Air was introduced around the 
perimeter of the bottom of the test column and exited at the top of the column through peripheral slits. Figure 3.1-1 shows a schematic of this facility.

The column was originally setup with 4 mixing grids, but was reconfigured for these tests

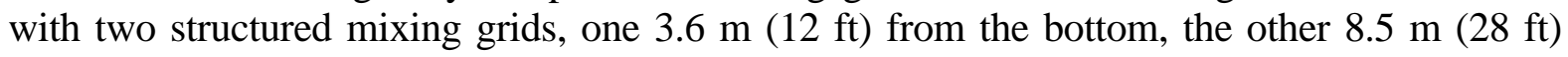
from the bottom. Then, the remaining grids were removed for a repeat of an empty column configuration. Three pressure drop cells were added to increase the measurement accuracy of the overall solids density, to increase the measurement accuracy of the solids density at the top quarter height where solids are introduced, and finally to increase measurement accuracy of the traversing pitot tube.

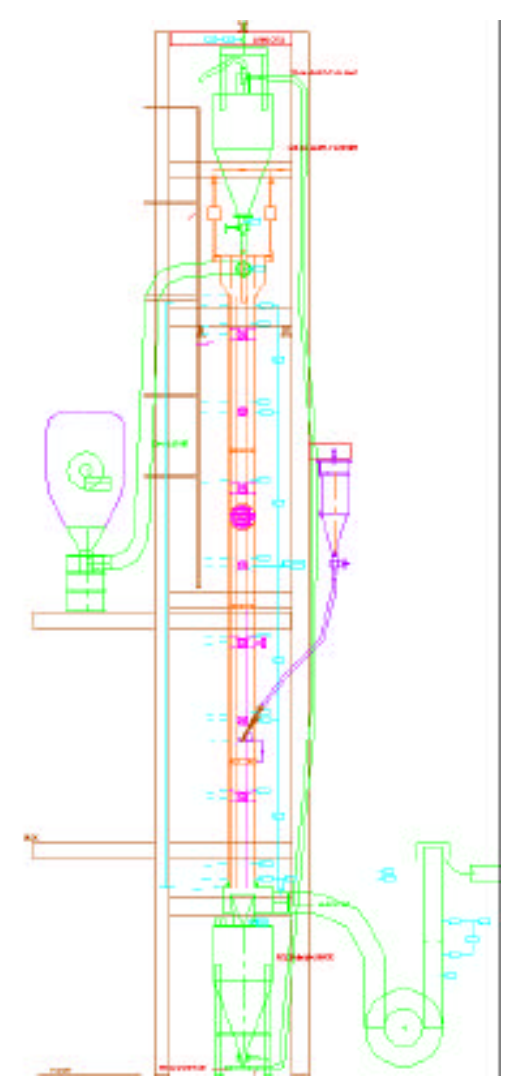

Figure 3.1-1: 15 Inch Heat Transfer Test Facility

The grid insert shown in Figure 3.1-2 was a rectangular array of bars. The grid consisted of 1 inch wide bars on 3.25 inch spacing. There were two grids rotated $45^{\circ}$ at each elevation. The grid pairs were installed at elevations of $4 \mathrm{ft}, 12 \mathrm{ft}, 20 \mathrm{ft}$, and $28 \mathrm{ft}$ with the grid pair +/- 5 inches at each elevation. The bars had a catenary vertical profile to allow for thermal expansion differences between the grid and wall, the grid being primarily in tension and drooping more as the thermal expansion difference increased. The catenary was approximated for this application with a 2 inch droop for a 15 inch span.

The solids distributor arrangement consisted of a section of 2-inch ID pipe that extended 5 inches into the top of the octagonal column. A slotted basket, formed by 4 bands of sheet metal, was attached to the end of the pipe to distribute the solids as they passed from the 
pipe. A 6-inch diameter shroud was placed around the basket in order to prevent solids from being cast against the walls of the column.

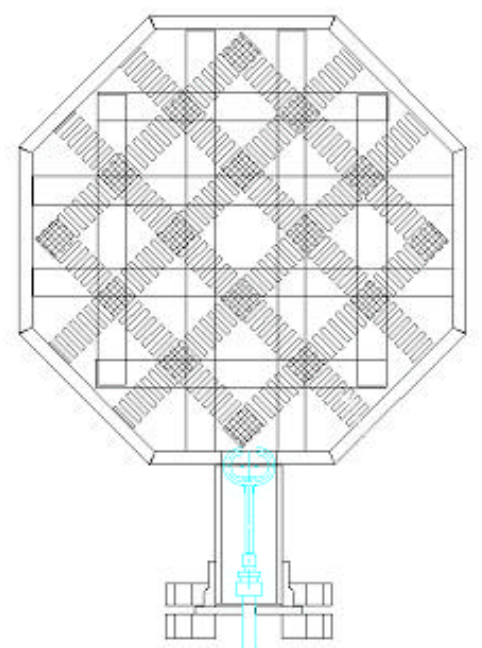

Figure 3.1-2: Schematic of Mixing Grid

\section{Test Methodology}

Bauxite or sand particles were admitted to the top of the column from a supply hopper mounted on load cells. The flow rate from the hopper was calculated from the hopper weight change with time during a test. The particulate flow rate was controlled by a knifegate valve on the bottom of the hopper. The temperature of the particles entering the column was measured by a thermocouple installed in the bottom of the supply hopper. A series of inlet pipe nozzles were installed at the top of the column to determine the effect of the nozzle on the solids distribution over the cross-sectional area of the column.

Particles exited the bottom of the column to a collecting hopper. Two solids monitoring impact thermocouples mounted at the top of the collecting hopper provided instantaneous solids outlet temperatures. A pneumatic transport system moved particles from the collection hopper to a cyclone at the top of the supply hopper after the test.

Hot air was used to simulate the gas in a combustor. An electric heater, flow metering orifice, and centrifugal blower supplied hot air to the bottom of the column. The inlet damper on the blower was used to set the air rise velocity to a desired value. An air inlet plenum was installed at the bottom of the column and admitted air around the periphery of the column through a 4 inch high opening. The air inlet temperature was measured by a thermocouple at the inlet plenum.

Air exited the top of the column through a 4-inch high circumferential opening to a discharge plenum and then through transport hoses to two bag filters. The exit air temperature was measured at the outlet nozzle of the discharge plenum.

Operating test conditions were measured by a Fluke 2208 data acquisition system connected to a portable PC controlled by a Labview operating system. Data was recorded every 3 seconds to the hard drive of the computer. This data was entered into a spreadsheet for 
subsequent analysis and calculation of an average value of selected test variables. The average values for each test were then copied to a summary spreadsheet for final data analysis.

A traversing probe was used to measure temperature, velocity, and particle concentrations for each probe position during a test. The probe was traversed across the test section at a selected elevation at 10 radial positions during a test to determine profiles of the solids frequency, air temperature, and air velocity.

Air properties were calculated from the average air inlet and outlet temperatures to provide specific heat, viscosity, density, and thermal conductivity. The test section airflow rates, temperatures, and pressure were converted to a superficial air velocity. The inlet and outlet air temperatures, flow rate, and specific heat was used to calculate the airside heat transfer. The airside heat transfer included heat loss from the walls of the test section to ambient air. This heat loss was determined by calculating heat loss coefficients for selected tests at steady state condition before particles were admitted to the test section. The heat loss was calculated as a function of the difference between the average inlet and outlet air temperature minus the ambient temperature to determine a corrected air side heat flow.

The particle temperatures were measured at the outlet of the supply hopper and by two impact thermocouples mounted below the air inlet at the bottom of the test section. The average solids temperature was used to calculate a particulate specific heat. The solids flow rate, specific heat, and inlet-outlet temperature difference were then used to calculate the solids heat pickup. The ratio between the solids heat flow and corrected air heat flow was compared to indicate accuracy of the heat transfer.

Measurement of the heat transfer to the solids from the gas was verified by performing an energy balance on the gas and solids mixture in the column. It was assumed that the solids only exchanged heat with the gas, while the gas could exchange heat with the solids and the column walls. The decrease in energy of the gas from the inlet to the outlet was equal to the heat pickup by the solids and heat loss to the wall.

Heat transfer coefficients of the individual particles were calculated from the airside heat transfer, air properties, and particle surface area. The particle surface area was calculated from the overall pressure drop, particle density, particle diameter, and particle flow rate. It was assumed that the frictional and momentum pressure drop of the test section was negligible compared to the hydrostatic pressure drop. This assumed that the pressure drop of the test section was only a function of the hydrostatic pressure drop caused by the particles present between the pressure taps. Adding the grid to the vortex breakers and the grid to the test section increased the air only pressure drop, so a modification was made to account for the air only pressure drop.

\section{Test Results}

Pressure Drop Tests

Preliminary cold flow tests were performed to determine the column pressure drop as a function of the gas and solids mass flow rates. Tests were performed at 5 different gas flow rates ranging from 0 to $0.8 \mathrm{~kg} / \mathrm{s}$ ( 0 to $6500 \mathrm{lb} / \mathrm{hr}$ ) and the solids mass flow rate of bauxite was varied from 0 to $1.5 \mathrm{~kg} / \mathrm{s}$ (0 to $12,000 \mathrm{lb} / \mathrm{hr}$ ) for each test. The tests showed that the pressure 
drop appears to be linearly dependent on solids flow rate over a wide range. However, the intercept of this line does not coincide with the pressure loss of the empty column at the given gas velocity. This offset is believed to be due to solids altering the gas flow in the area around the mixing grids. It would be expected that the pressure loss due to the mass of particles would go to zero for a column without mixing grids.

Pressure drop fluctuations were noticed at increasing gas and solids flow rates. These fluctuations appear to be qualitatively correlated to the appearance of unsteady particle clusters, observed as shadows when backlit through the translucent column.

\section{Effect of Mixing Grids on Solids Holdup Surface Area}

The primary objective of this test program was to evaluate the effect of mixing grids on the heat transfer performance of the heat transfer column. Tests were initially performed with two double sets of catenary mixing grids, using both 700-micron bauxite and then 530micron bauxite. The mixing grids were next removed and the tests were repeated with each bauxite size.

The distributor was removed for the next test sequence. One test was performed with the solids dropped directly into the top of the plenum. Two tests were then performed with a 6 inch length of 2 inch ID pipe to center the solids flow, and 2 additional tests were performed with the slotted basket of the original distributor attached to the 6 inch length of inlet pipe. Finally, the column was returned to the original condition for additional tests using 700-micron bauxite.

The effect of mixing grids on apparent holdup surface area is shown in Figure 3.1-3 for tests using 700 micron bauxite, identical distributor arrangements and 4 mixing grids (from earlier heat transfer tests), 2 mixing grids, and no mixing grids. The heat transfer surface area $A$ is equal to the total surface area of the spherical particles within the column. This is normalized on a per pound basis by dividing the surface area by the feed rate $\mathrm{W}_{\mathrm{s}}$ of solids into the column. It should be noted that there may be some amount of error in these measurements, as they assume no particle acceleration in the column. This is particularly problematic in the case of tests with the mixing grids, as the acceleration due to particle impact with the mixing grids is expected to be large.

This figure shows that the solids holdup $\left(\mathrm{A} / \mathrm{W}_{\mathrm{s}}\right)$ in the column increases as both the gas rise velocity increases and as the number of mixing grids increases. The solids migration velocity down the column is defined as the particle terminal velocity minus the gas rise velocity. The migration velocity decreases as the gas rise velocity increases, thus increasing solids residence time in the column and solids holdup. The mixing grids work in a similar manner. The gas velocity through the grid openings is significantly higher than the gas rise velocity. Solids tend to accumulate above the grids and locally redistribute. Eventually, they cluster together and pass through the grid openings. The effect of the mixing grids was most pronounced as the gas rise velocity approached the particle terminal velocity. 


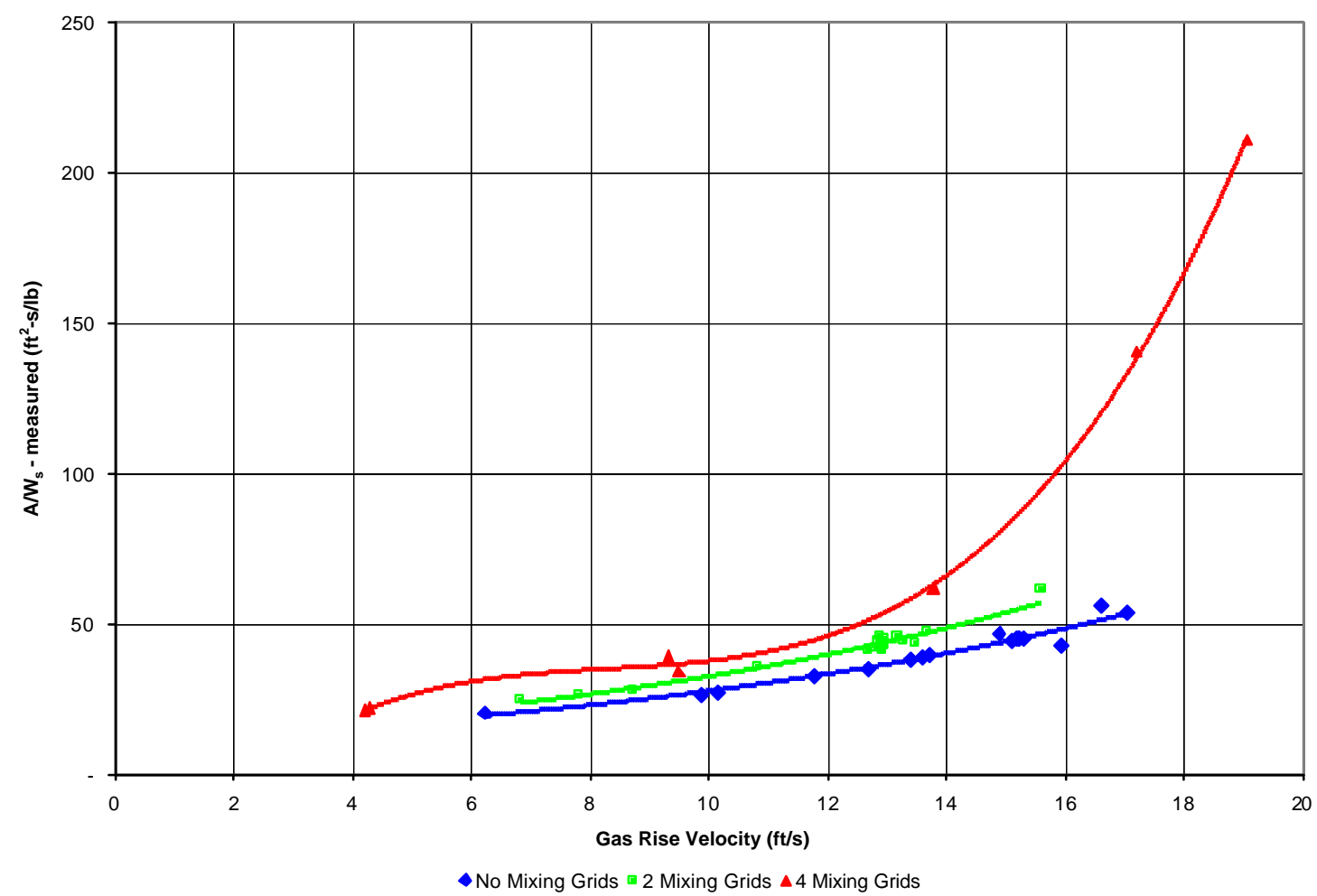

Figure 3.1-3: Effect of Mixing Grids on Solids Holdup

Figure 3.1-4 shows the effect of mixing grids and gas rise velocity on the product of the heat transfer coefficient and total surface area $\left(U \times A_{p}\right)$. This product was determined from the equation:

$$
\mathrm{UA}_{\mathrm{p}}=\mathrm{Q} / \mathrm{LMTD}
$$

where:

$\mathrm{U}=$ gas-to-solid heat transfer coefficient

$A_{p}=$ particle surface area

$\mathrm{Q}=$ heat transfer from gas to particles

$\mathrm{LMTD}=\log$ mean temperature difference (based on bulk gas temperatures) 


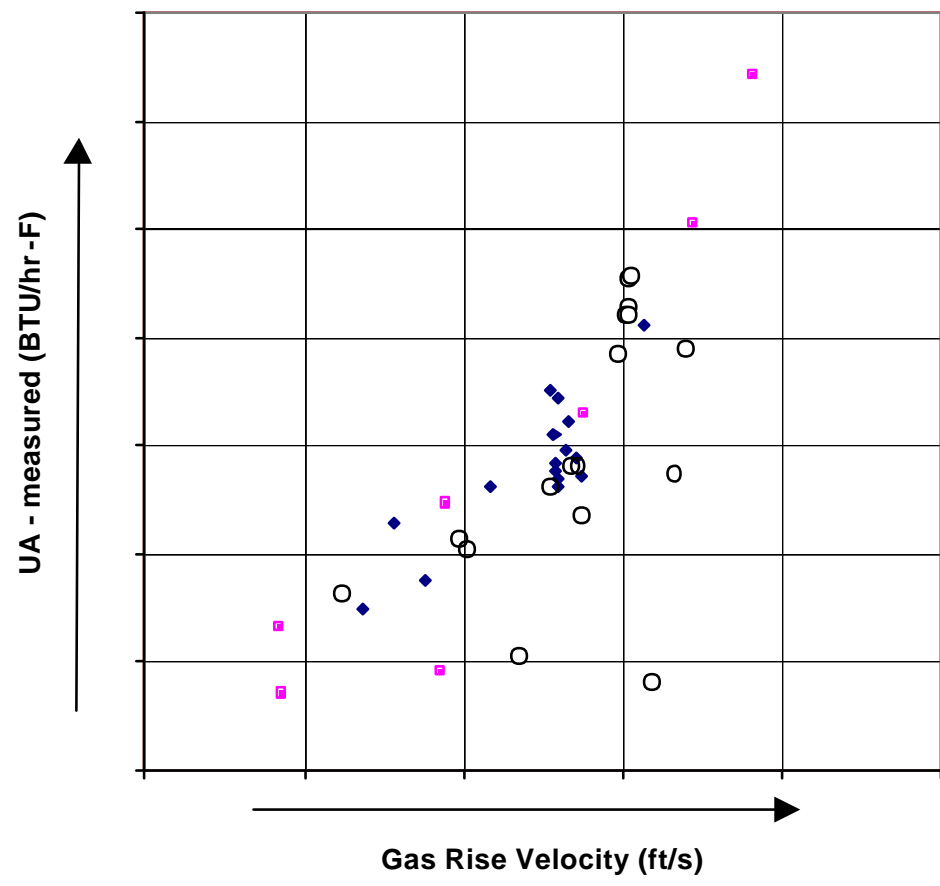

- 700 micron bauxite, 2 mixing grids

0700 micron, no mixing grids

- 700 micron bauxite, 4 mixing grids

Figure 3.1-4: Effect of Mixing Grids and Gas Rise Velocity on $U_{\mathrm{p}}$

This figure clearly shows that $\mathrm{UA}_{\mathrm{p}}$ increases significantly with the gas rise velocity. A very similar trend is seen with the total heat transfer $Q$ from the gas to the particles, which the term $\mathrm{UA}_{\mathrm{p}}$ is derived from. This increase is largely attributed to the increase in available heat transfer surface area $A_{p}$, as the solids holdup increases as the gas velocity increase. This figure also shows an increase in UA as solids distribution is improved by adding mixing grids. However, there is not a significant difference in performance between two or four mixing grids.

Figure 3.1-5 shows the effect of mixing grids and gas rise velocity on the gas to solid heat transfer coefficient $U$. The results do not show much effect of the mixing grids on the heat transfer coefficient. However, there is a sharp reduction in $U$ as the gas rise velocity increases.

The theoretical heat transfer coefficient for a single particle falling through a gas stream assumes that the particles fall freely in the gas with a relative velocity between the gas and particle equal to the particle terminal velocity. Changes in gas velocity should not affect the relative velocity or the heat transfer coefficient.

However, the particle density and heat transfer surface area increases because of reduced particle velocity as the gas velocity increases. This density increase causes more interactions between particles. Particles in close proximity have a tendency to follow in each other's wake due to drag reduction phenomena. Particles following a lead particle are exposed to gas cooled by the lead particle and therefore do not have the full gas-particle temperature difference available to the lead particle. This would account for the reduction in the heat transfer coefficient at high gas velocities. 


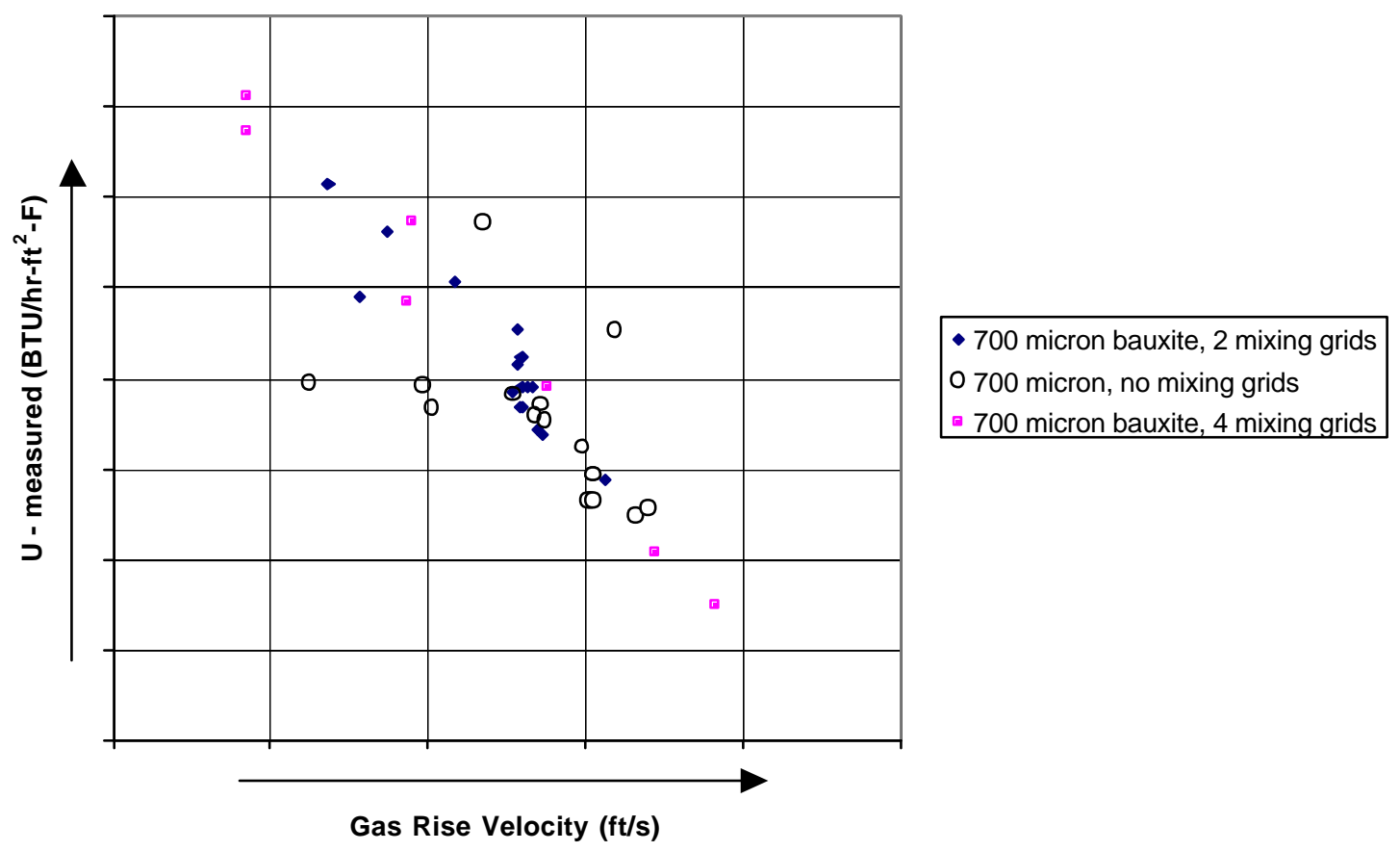

Figure 3.1-5: Effect of Mixing Grids and Gas Rise Velocity on U

\section{Optic Probe Measurements}

The particle passing frequency and velocity were measured using a dual head optical probe. Two versions of this probe were built and used during the course of testing. The first was a variation of an optic probe system used in previous test programs. It was based on a single head design using an LED and a photodetector to measure particle frequency passing the beam.

A later version of this probe was built to enhance the velocity resolution of the system. This probe used fiber optics to focus the light into beams and to decrease the distance between the two light beams, increasing the resolution of the probe into regimes of higher particle loading. Analysis of the two signal streams allowed the temporal and spatial measurement of the passing frequency and velocity of the particles falling through the column, which indicated the presence, location, and motion of clusters of falling particles. The refined probe was also used for low temperature tests using warm air in the MTF test campaign.

The dual head, optical particle counter probe shown in Figure 3.1-6 consisted of two heads displaced vertically $0.8 \mathrm{~cm}(5 / 16$ in) apart. Each head generated a light beam that passed to an opposing photodetector. As particles passed through each beam, a voltage signal was generated by the photodetector and recorded on analog tape and a digital data acquisition system. 


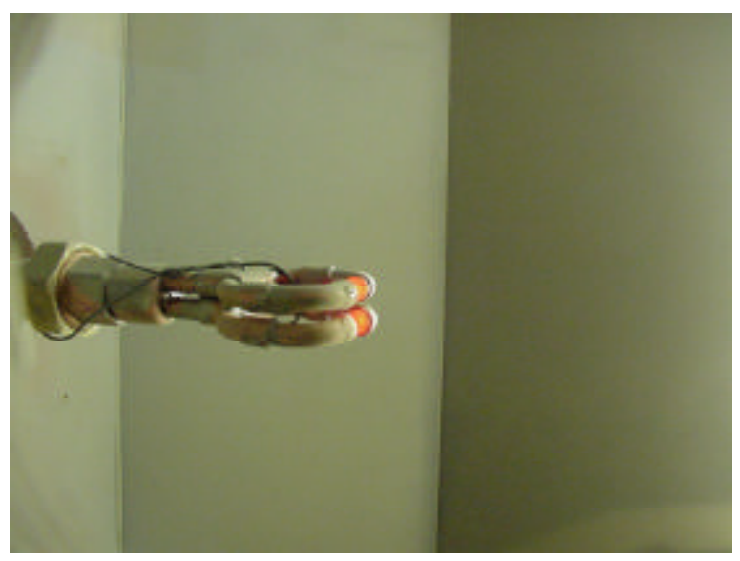

Dual optical particle counter probe installed in the test column

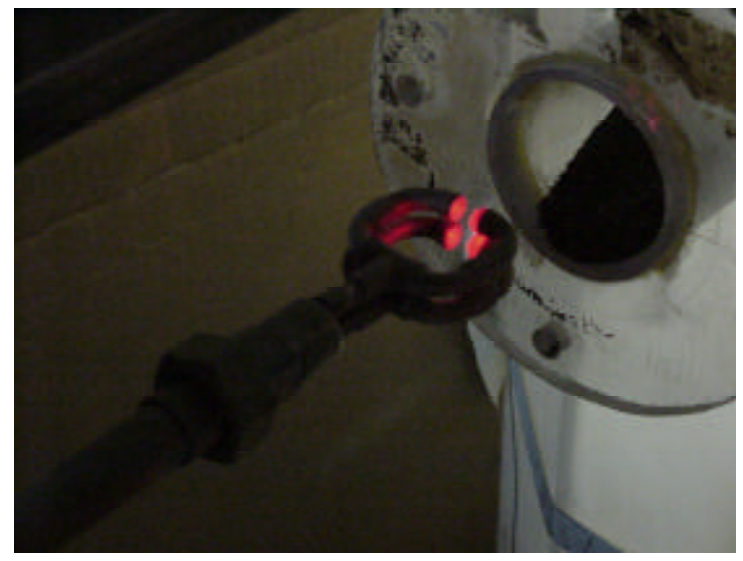

Dual optical particle counter probe removed from the column with the light sources illuminated

Figure 3.1-6: Dual Head Optical Probe

The probe was traversed across the diameter of the column during each heat transfer test at a location $4.9 \mathrm{~m}(16 \mathrm{ft})$ from the bottom of the column. The probe was stopped at 13 different positions across the diameter. At each point, a stream of data was recorded with the digital data acquisition system sampling at $30 \mathrm{kHz}$ per channel. An analog DAT tape recording was made over the duration of the entire test for later analysis.

The output of the optic probe was a data file containing 2 columns of voltage output from the upper and lower photodetectors. A third column was included to provide position information from a string potentiometer. These columns of data were then plotted against time.

One of the photodetector output signals provided information about the passing frequency of particles. The data was read into MATLAB, then a peak-finding algorithm was used to count particle passages. The number of peaks, divided by the absolute duration of the sample, determined the average passing frequency of particles for that period of time.

To measure particle velocity, the signal from the upper beam needed to be correlated to the lower beam signal. A common method to determine the velocity distribution in a sample is to determine the degree of correlation between the two sets of data, where the upper probe data is offset by a time $\operatorname{lag} \tau$. This process is repeated for a range of $\tau$. If the distance between beams is $\ell$, the velocity of a particle requiring a time $\tau$ to cross both beams can be determined by $\ell / \tau$. The resulting plot of correlation coefficient vs. velocity provides the velocity distribution over the sample period.

Several difficulties existed with this technique. If the interparticle distance was less than the distance $\ell$ between the beams, then particle signals were correlated against signals created by other particles, which gave erroneous high velocity values. For this reason, a discrete particle-by-particle approach was used. In this method, a peak on the upper probe signal at some time $t$ would be isolated. Then a plausible window of particle passing time would be examined on the lower probe signal. If a single peak was found on that interval, it was 
assumed that that was the correlating signal and a velocity value would be determined by determining the lag between the two peaks.

The vertical displacement of the two heads on the current probe was on the same order of magnitude of the estimated average interparticle spacing within the column. In addition, it was observed that the fraction of particles breaking both beams was small. These issues hindered attempts to measure the particle velocity by cross-correlating the signals. For this reason, the probe head was modified, utilizing aligned fiber optic light beams with a vertical displacement of less than $0.2 \mathrm{~cm}(5 / 64 \mathrm{in})$. This dimension was less than the estimated interparticle distance, which permitted a useful cross-correlation analysis to be performed. In addition, the reduced spacing increased the probability that a particle would break both beams, further strengthening the cross-correlation.

Optic Probe Results

A special series of tests with the optic probed was conducted to determine whether clustering had a significant effect on heat transfer rates. In most tests, dense structures of solids were not observed and the solids distribution appeared to be essentially uniform and dilute across the column diameter. In only one instance was an appreciable concentration structure recorded with the probe, which occurred during a test with 700-micron bauxite, no mixing grids, no solids distributor, and with an average gas velocity of $14.3 \mathrm{ft} / \mathrm{s}$. These results are shown in Figure 3.1-7. These results are qualitative, as it is not known if the probe passed directly through the center of the solids stream.

Due to the probe's limited range of motion, it was likely that the optic probe did not detect many details of the solids concentration distribution in the column. This was confirmed during one test condition with the solids distributor removed, where a well-defined column of solids was visually observed passing next to the optic probe head.

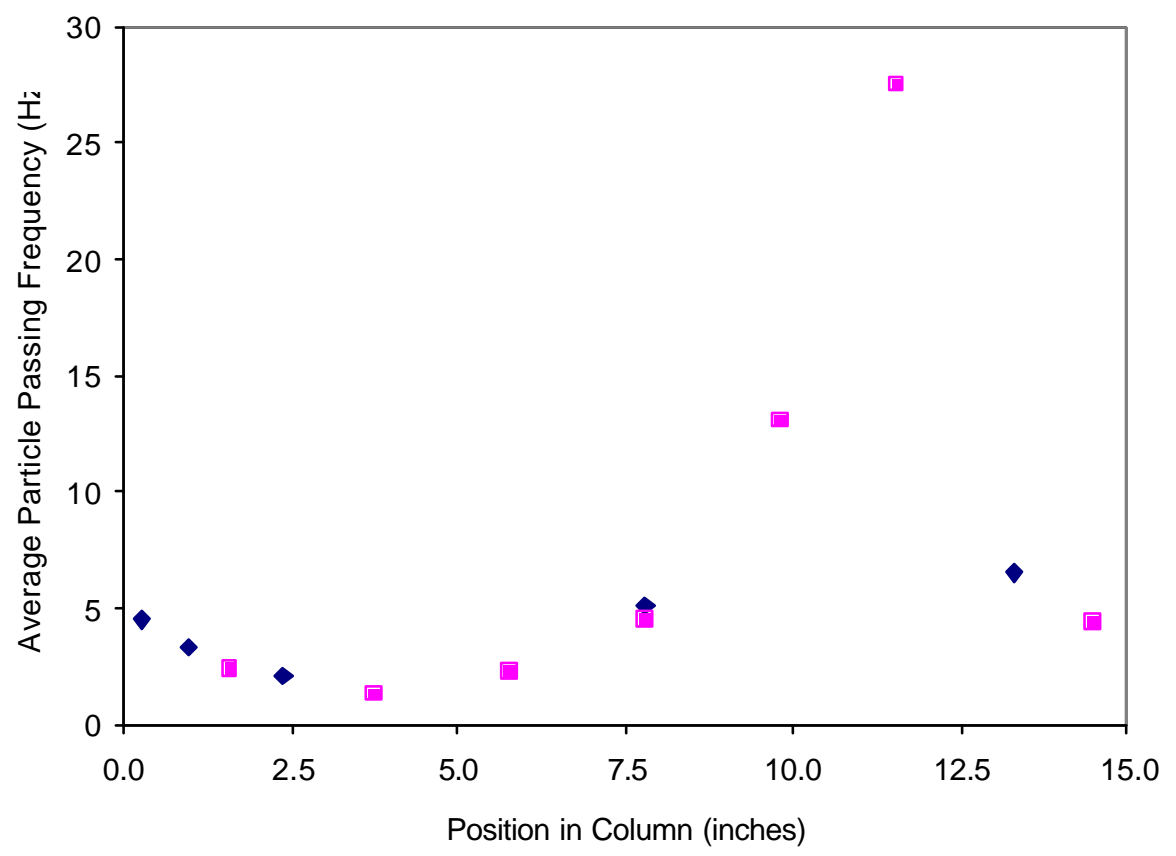

Figure 3.1-7: Solids Distribution without Distributor 
Figure 3.1-8 shows the particle frequency during one test condition for a 4 second span at each probe position. The frequency peaks near both walls and decreases towards the center.

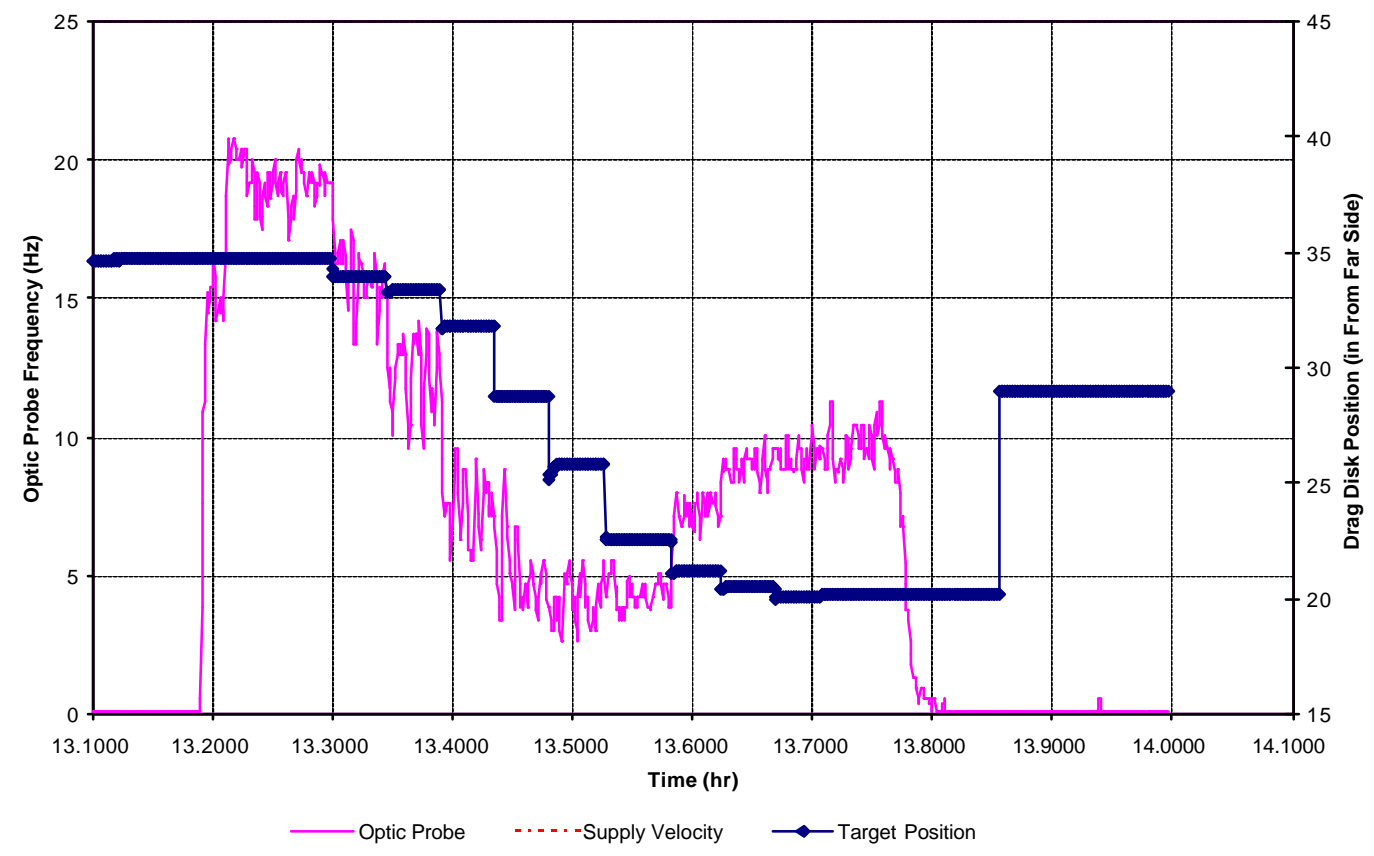

Figure 3.1-8: Optic Probe Frequency Test Results

The frequency results for this test are replotted in Figure 3.1-9 against the probe location. This figure more clearly shows the peak solids distribution near each wall. Also shown is the average gas velocity in the test section.

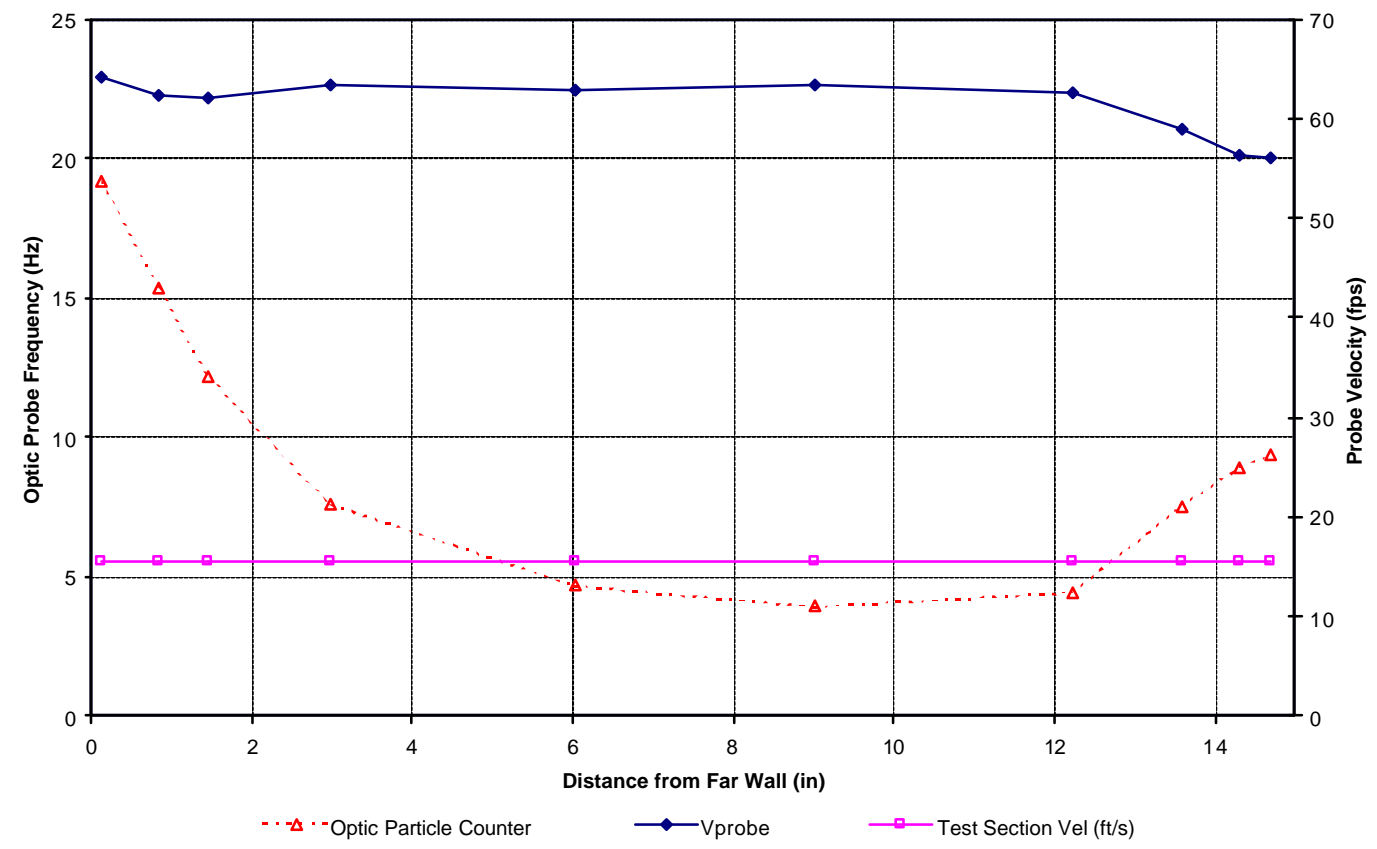

Figure 3.1-9: Optic Probe Frequency vs Probe Location 
The average time span between a particle passing through the probe beam and the root mean square (RMS) between particle passes through the probe was then calculated. These were converted to frequencies by the inverse of the time spans. Clustering would be indicated by significant differences in the root mean frequencies. Figures 3.1-10 and 3.1-11 show two examples of this data.

The plots of particle frequency indicate that some clustering may occur in the dilute regions of the traverse. However, the RMS frequency was generally the same as the average. No significant deviation between the ratio of mean and RMS frequencies was evident. These results indicate that clustering of the particles was not significant during these test conditions.

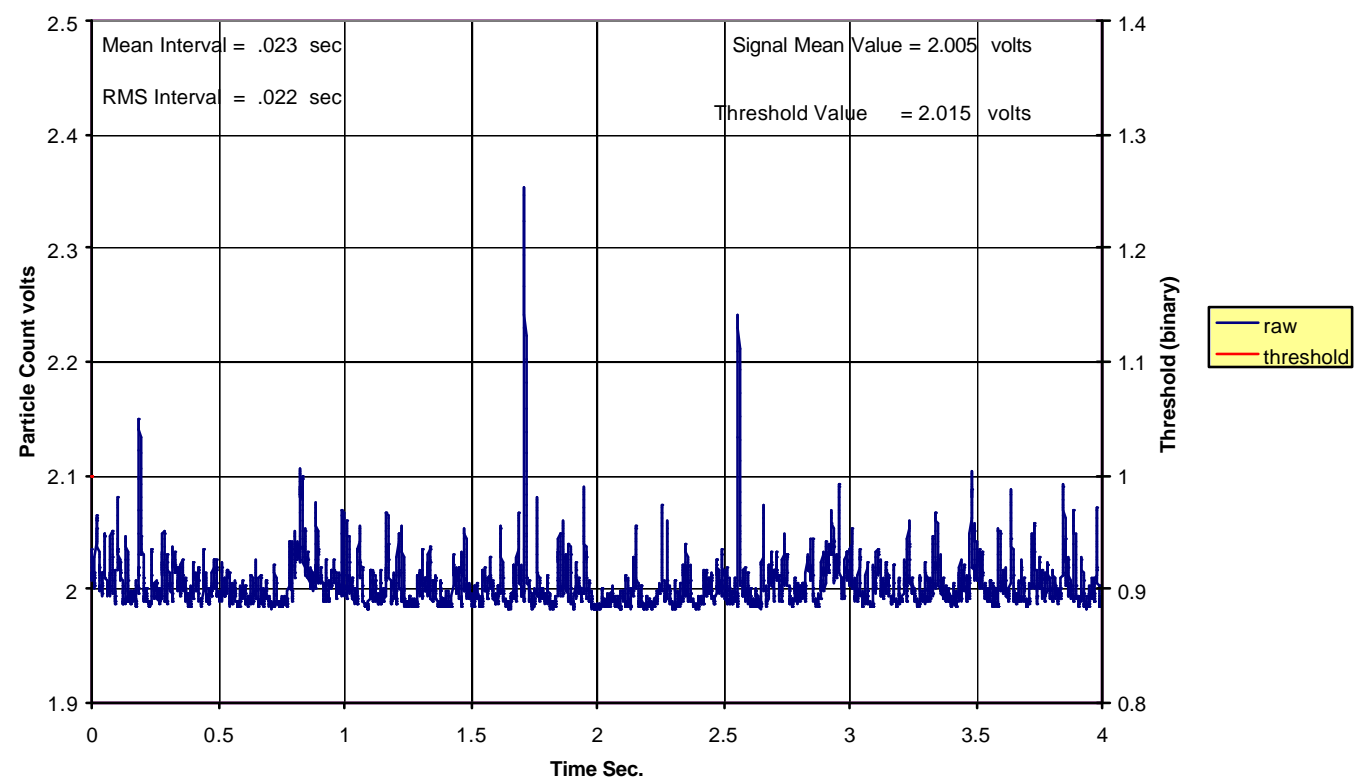

Figure 3.1-10: Optic Probe Particle Frequency

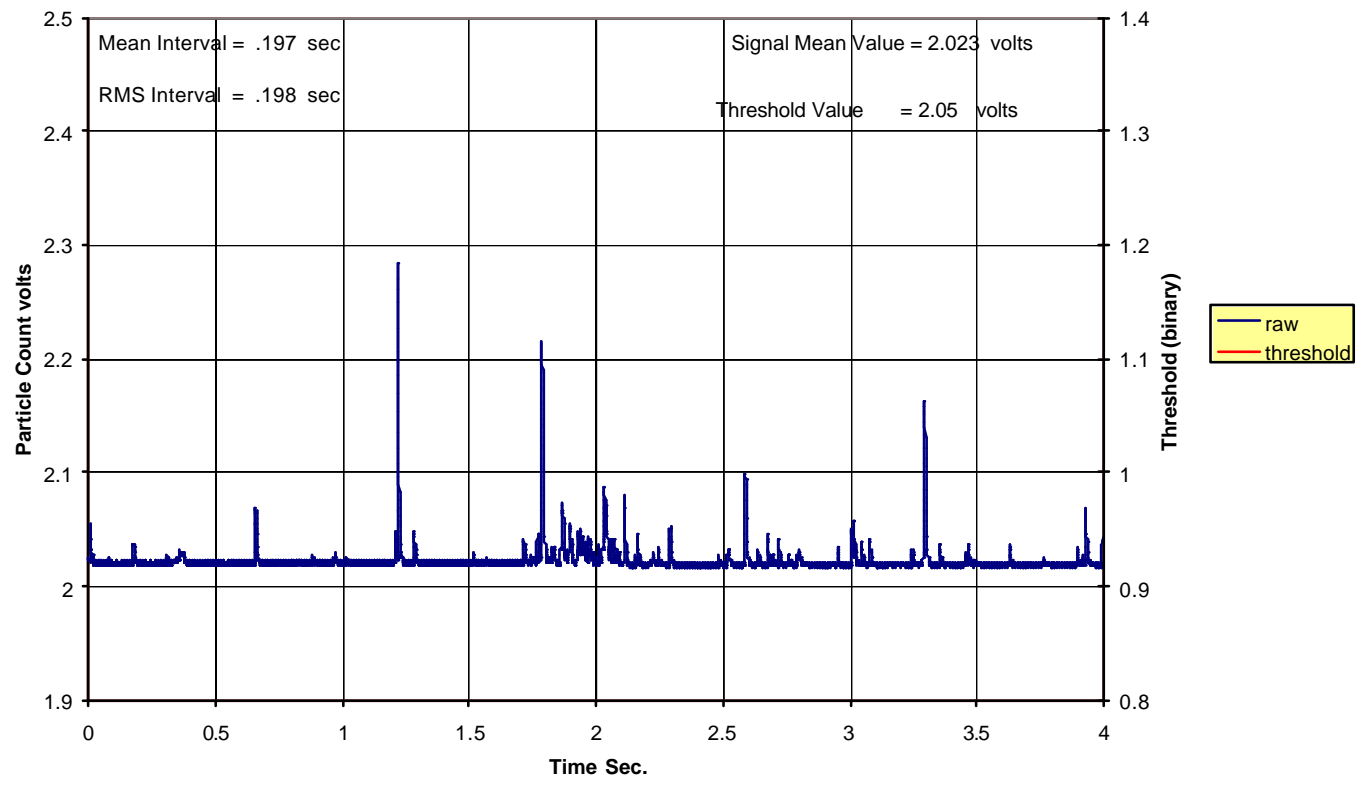

Figure 3.1-11: Optic Probe Particle Frequency 


\section{Solids Temperature Probe}

One of the objectives of the CMB MTF tests was to determine the heat transfer from the combustion gases to the bauxite cloud falling through the combustion chamber. The approach to determining the heat transfer was to measure the temperature drop of the combustion gases, gas mass flow rate, bauxite temperature, bauxite flow rate, combustion chamber pressure profile, and bauxite concentration. These measurements along with the gas specific heat gave the heat flow from the gas, the log mean temperature difference between gas and bauxite, and the surface area of the bauxite present in the combustor. This method was successfully used in the 15-inch heat transfer test facility. A series of thermocouple rakes were therefore installed in the MTF combustor to measure the average gas temperature in order to determine the heat transfer at different elevations of the combustor.

The combustion of natural gas and coal in the MTF occurs not only in the fluidized bed at the bottom of the combustor, but also in the combustion chamber above the bed. Overfire air introduced above the bed also promotes burnout of $\mathrm{CO}$ present in the gases flowing up the combustion chamber. Use of the gas temperature differences, specific heat, and gas flow alone does not permit the determination of heat flow from the gas to the bauxite. Either gas composition measurements are needed to determine the true heat flow from the gas or solids temperature differences are needed to determine the heat flow from the gas to the bauxite.

PPL therefore developed a solids temperature measurement probe to measure the solids temperature rise as they fall down the combustion chamber, based on the methodology developed by Hruby et.al. ${ }^{1}$ This device used a collecting cup with an orifice in the bottom. Solids were collected in the cup and flowed through the orifice. A thermocouple was installed in the cup to measure the temperature of the solids flowing through the orifice.

Figure 3.1-12 shows two photographs of the sample probe used for measuring solids temperature and gas temperature and velocity. The left photo identifies the various components in the probe. The picture on the right shows the probe inserted into the cold flow model and shows a stream of solids draining out of the measuring cup after having been collected from the falling curtain of solids.
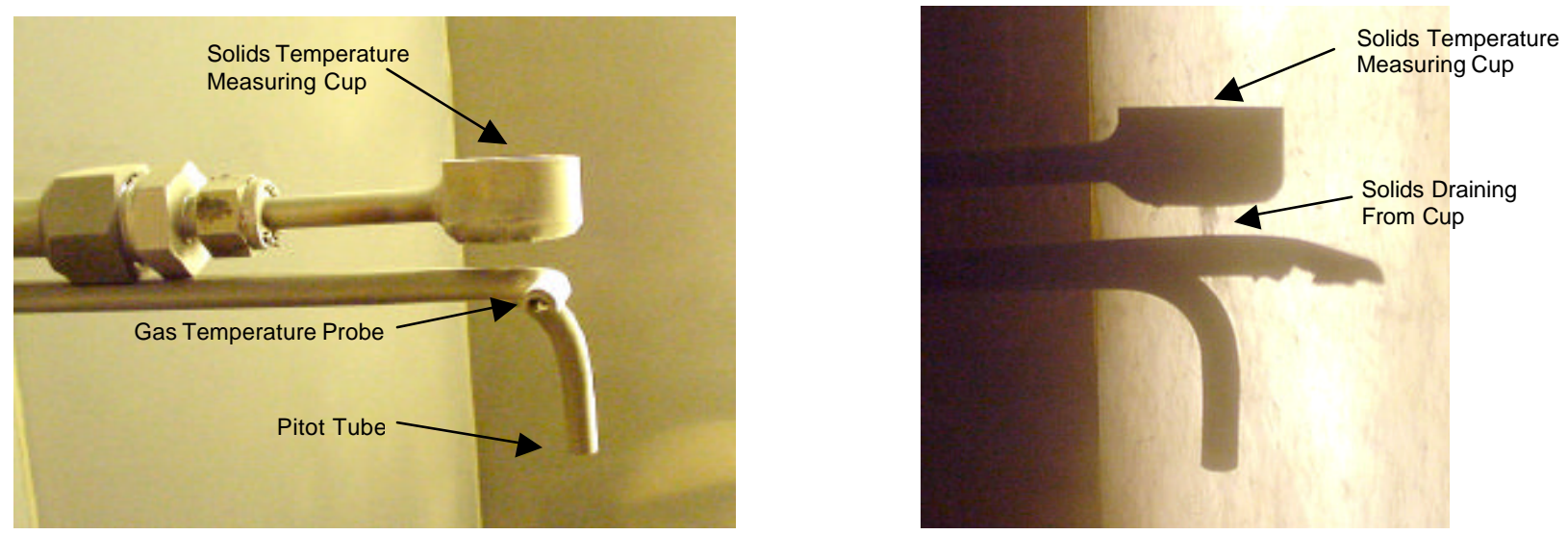

Figure 3.1-12: Solids Temperature Probe

This probe was subsequently used to traverse the MTF at selected elevations. The temperature profile of the solids was compared with that expected from the gas side 
temperature profile and was used to correct or interpret the heat transfer calculation procedure based on gas flow conditions. The test matrix developed for the CMB MTF test program included several tests with solids temperature probe traverses. Solids temperature profiles were determined at selected elevations for these tests.

\section{High Temperature Hopper Level Indicator}

The CMB test campaign in the MTF required a method of measuring the solids level in the solids separation hoppers above the MBHE and at the top of the combustor. The solids temperatures in each hopper ranged from $1600-2000^{\circ} \mathrm{F}$ in the MBHE hopper and 1000$1200^{\circ} \mathrm{F}$ in the hopper above the combustor. Three different commercial devices were evaluated before a decision was made to develop a specific level indicator.

The first device considered was a commercial laser range finder. This device was particularly attractive because the output could be supplied directly to the MTF Advant/Labview data acquisition system. The device was installed in the supply hopper of the PPL heat transfer test facility so that the laser range finder output could be compared with hopper load cell output. Bauxite was fed to the hopper by a pneumatic transport system and was then drained from the hopper into the facility. Dust from the transport system confused the laser range finder, giving random readings from the top of the hopper to the bauxite level. The range finder worked well when solids were drained from the hopper without solids also being transported into the hopper. However, this was not a realistic situation. Furthermore, the MTF solids separation hoppers have even more dust than the test supply hopper. The laser range finder was therefore determined to be not acceptable.

A commercial sonic level detector was also evaluated in the heat transfer test facility. Dust loading was determined not to be a problem for the detector. The sonic feedback signal was influenced by the length of the standpipe attached to the top of the hopper. A water-cooled standpipe was therefore necessary to protect the low temperature sonic pickup from the high temperatures in the MTF hoppers. The water-cooled standoff was required to protect the detector and rendered the detector ineffective. The vendor thought a high temperature device could be developed but not in time for the MTF CMB tests.

The third commercial device considered was a capacitance probe. This device has been successfully used in high temperature commercial applications. However, the vendor conducted tests with our bauxite and determined that the probe output signal was highly dependent upon the solids inlet temperature. This would have required a complex calibration procedure that had never been done before by the vendor.

Based on these evaluations, it was decided that it was necessary to develop a more reliable high temperature level measuring device. The approach taken was to use a dual laser beam level indicator for measuring the bauxite level in the hot solids separator hopper on top of the MTF and at the top of the MBHE. The indicator consisted of two laser beams projected downward from the top of a hopper. The beams were angled to intersect at the bottom of the hopper. A solids level above the intersection point gave two distinct intersections with the top of the solids. The two intersection points move further apart as the solids level rises. A video camera observing the beams through a cooled transparent window at the top of the hopper displayed the two intersection points on a monitor in the control room. A beam 
displacement scale on the monitor translated this signal into a solids level in the hopper. Figure 3.1-13 shows two pictures of the dual laser beam level indicator. The left figure shows a schematic of the MTF level indicator installation. The right figure shows the experimental test rig where the laser beam level indicator was tested. The device worked correctly and was subsequently installed on top of the high temperature supply hoppers on top of the MBHE and the combustor.
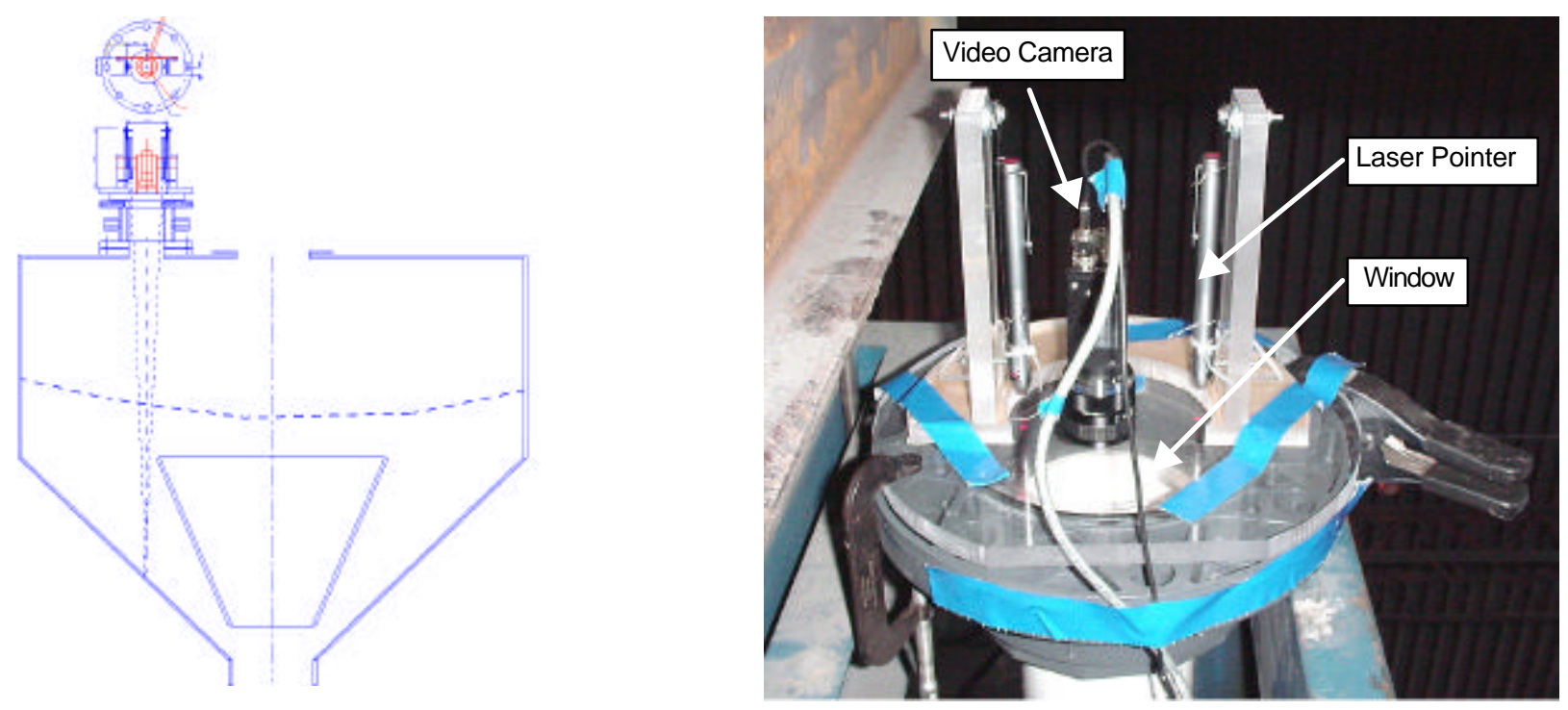

Figure 3.1-13: Dual Laser Beam Level Indicator

\section{CFD Modeling}

The original process evaluation for the $\mathrm{CMB}$ concept used a simple one-dimensional model to simulate gas-to-solids heat transfer in the combustor. The model used heat transfer coefficients derived from a heat transfer correlation for single particles. It also assumed that the horizontal cross-sectional area of the furnace had uniform velocities and temperatures. When the first heat transfer test column showed that the heat transfer was less than predicted by the correlation, the assumption of a uniform gas and solids distribution was questioned.

A more sophisticated method for predicting heat transfer in the falling solids region is to use a Computational Fluid Dynamics (CFD) model to predict the effect of aerodynamics on the solids distribution. The solids distribution affects the contact between the gas and solids streams and determines the heat transfer coefficients. The accuracy of the model's predictions depends on an accurate description of the underlying physics and on sufficient grid resolution to capture the gas-particle interactions. Of particular concern is the importance of particle-to-particle interactions, as this is not handled well by disperse-phase computational codes (e.g. - Fluent) at this time. 
The first heat transfer tests conducted were in a 4 inch $\mathrm{x} 9$ inch test column at temperatures between ambient and about $250^{\circ} \mathrm{F}$. A second test column with a 15 inch diameter crosssection was built and operated at the same temperatures. Results from these test columns were analyzed with CFD models. The initial models were run with relatively coarse grids to keep computational times reasonable. One model prediction for the 15-inch test column is shown in Figure 3.1-14. The chart is broken into three parts for clarity. The model predicted that the solids distribution was reasonably good.

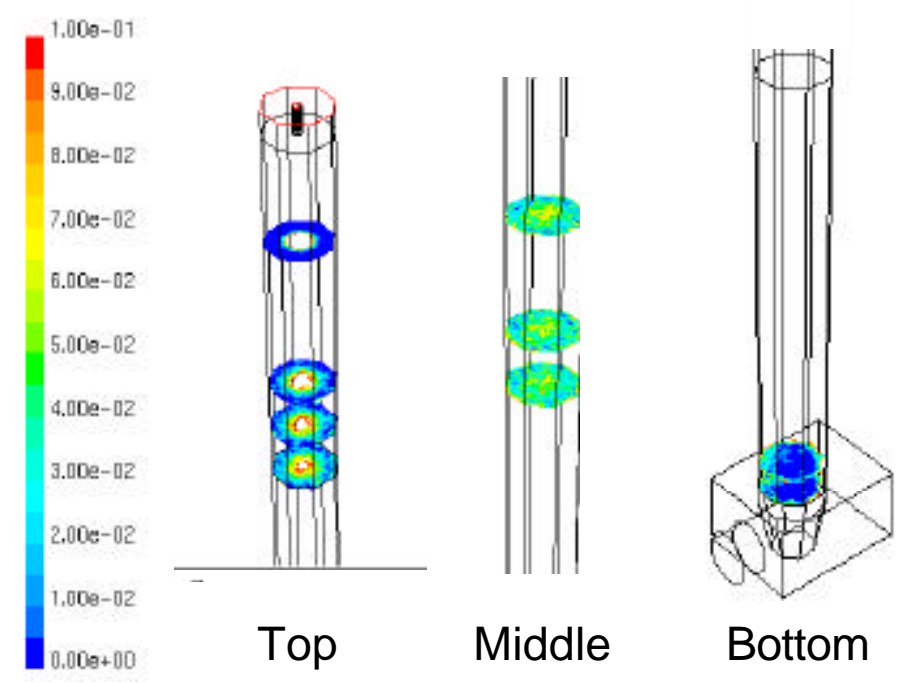

Figure 3.1-14: CFD Prediction of Solids Distribution in 15 Inch Test Loop

The models were calibrated by adjusting the heat loss from the walls, the drag of the bauxite particles, and other calculation variables until selected measurable test data were matched. These results were then checked against other measured test data to determine if the model was predicting correctly. The models were not intended to predict every component of the process. The primary prediction needed was the outlet temperatures of the solids. The CFD models did a good job at predicting the measured temperature of the solids for most of the test data.

\section{CFD Modeling of MTF}

The objective of the first MTF test campaign was to evaluate gas-to-solids heat transfer at a larger scale than the previous models and at temperatures representative of commercial CMB plants. The CFD model was again used to predict gas-to-solids heat transfer performance in the MTF tests as part of the test planning. Figure 3.1-15 shows one model prediction of the MTF solids concentration along the height of the combustor. The model predicted that the MTF would operate in a flow regime where there would be optimum conditions for good solids distribution using a scaled up version of the solids distributor used in the cold flow test facility. The model also predicted that there would be good gas-to-solids heat transfer performance. The predicted solids distribution was quite good along the length of the combustor. 

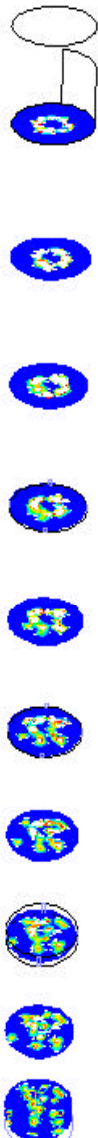

Figure 3.1-15: Prediction of MTF Solids Concentration

A CFD model was then created of the MTF firing natural gas for the hot solids heat transfer tests. The intent of this model was to predict the performance of the heat transfer test, and also to evaluate if any of several proposed heat transfer enhancement methods should be tested.

The model simulated a $102 \mathrm{~cm}$ (40 inch) diameter cylinder approximately $13.7 \mathrm{~m}$ (45 feet) from the base to the bottom of the cyclone outlet duct. The cylinder extended to about $0.6 \mathrm{~m}$ ( 2 feet) above the cyclone duct entrance. The bottom portion of the MTF, which is rectangular, and the transition piece were not modeled. It was assumed that hot gases from the combustion of natural gas enter the base of the cylinder at $1095^{\circ} \mathrm{C}\left(2000^{\circ} \mathrm{F}\right)$. Solids were injected near the top of the cylinder just at the bottom of the cyclone duct. The solids inlet temperature was $650^{\circ} \mathrm{C}\left(1200^{\circ} \mathrm{F}\right)$. Several cases were calculated. They included all gas flow from the base, $40 \%$ radial overfire air, $40 \%$ tangential overfire air, and high velocity solids injection. Heat transfer was evaluated by calculating the gas temperature at the outlet duct, after the falling solids had cooled it.

Previous cold physical models and the associated CFD models showed that the gases and solids tended to segregate and lower the overall heat transfer. Several heat transfer enhancement methods were proposed after observing those models. This model predicted that the heat transfer would be very good in the MTF with the solids falling in a fairly 
uniform cone pattern for the case with all of the air from the base. These results implied that the proposed heat transfer enhancement methods may not be effective in the MTF because the solids distribution was already very uniform. Several factors contributed to these results. First, the hot gases are less dense than the cold flow tests. Second, the height of the MTF is too short at these conditions and the residence time is too short to allow the flow to segregate. Finally, the aspect ratio of the MTF doesn't allow the flow at these conditions to establish a lateral component.

Figure 3.1-16 illustrates the model results for the case with tangential overfire air. The figure is tilted forward to show the path lines of the falling solids. Solids were injected in a circular pattern at eight points near the bottom of the cyclone duct. The solids dropped fairly uniformly until they reached the overfire air level, where they started to move towards the outside of the furnace. In the case without overfire air, the solids continued falling through the lower furnace in a straight fall.

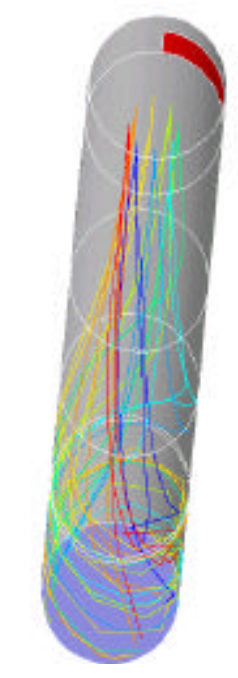

Figure 3.1-16: Path Lines of Solids Flow in the MTF with Tangential Overfire Air

These results indicated that the MTF would show good heat transfer performance and that certain heat transfer enhancement methods would not be effective in the MTF. Based on previous cold flow test results, it is still prudent to consider these heat transfer enhancement techniques when scaling CMB technology up to commercial sizes.

\section{Aerodynamic Effects on Heat Transfer}

The CFD model was also used to evaluate the effects of aerodynamics on gas to particle heat transfer in the combustor. Heat transfer is affected by the behavior of the falling solids in the hot gas flow field. Different gas flow patterns will therefore change the heat transfer and change the particle temperature approaching the bed.

Since this effect is minimized in a small unit, a model of a theoretical $300 \mathrm{Mw}$ unit was

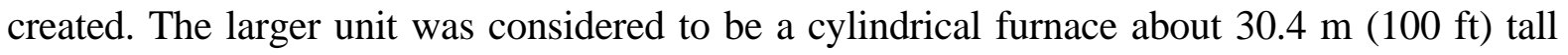
and $15.8 \mathrm{~m}(52 \mathrm{ft})$ in diameter. 
Hot gas entered the model at $1073^{\circ} \mathrm{C}\left(2000^{\circ} \mathrm{F}\right)$. About half of the gas came in the bottom to simulate the bed combustion products. The rest came in at the $1.8 \mathrm{~m}(6 \mathrm{ft})$ level from the side in eight equally spaced nozzles to simulate the overfire air. Bauxite particles were injected at the roof level in six injectors, each with eight streams forming a cone pattern. The particles were injected at about $3 \mathrm{~m} / \mathrm{s}(10 \mathrm{ft} / \mathrm{s})$. One case was run at particle injection velocities that were $30.4 \mathrm{~m} / \mathrm{s}(100 \mathrm{ft} / \mathrm{s})$ to improve the solids to gas velocity. The solids to gas mass ratio was about 2 to 1 . This model did not consider the effects of combustion. The primary concern of this model was to compare the relative performance of different aerodynamic conditions.

Four cases were considered:

1. Particles injected at $3 \mathrm{~m} / \mathrm{s}(10 \mathrm{ft} / \mathrm{s})$ and overfire air injected radially

2. Particles injected at $3 \mathrm{~m} / \mathrm{s}(10 \mathrm{ft} / \mathrm{s})$ and overfire air injected tangentially at an angle of 60 degrees. This angle was selected from previous CFD modeling.

3. Particles injected at $30.4 \mathrm{~m} / \mathrm{s}(100 \mathrm{ft} / \mathrm{s})$ and overfire air injected tangentially at an angle of 60 degrees.

4. Case 2 with half the particle flow

The CFD cases were each run for over 5000 iterations. Results showed that using tangential overfire air improved heat transfer by 18 to $21 \%$. Adding a higher particle velocity improved this by another $7 \%$. These results clearly showed the impact of unit scale on the effectiveness of these heat transfer enhancement methods. Using tangential overfire air did not appear to improve heat transfer at the smaller MTF scale.

The fourth case showed significantly poorer results than case 2 . The only difference between these two cases was the amount of particles injected. The results showed that the solids were affected more by the gas flow than in case 2 . The difference in heat transfer was clearly not only the result of different gas to solids temperature differences. The flow pattern of the solids was significantly different between case 2 and case 4 .

The results from this CFD study indicated that there are significant aerodynamic effects that need to be considered in scaleup. The results also showed that some of the heat transfer enhancement techniques might be used more successfully in larger units versus smaller units like the MTF. The models showed that increasing the solids injection velocity improves heat transfer and that injecting overfire air at an angle also improves heat transfer. However, reducing the solids to gas ratio reduced the heat transfer. The results from this study are summarized in Table 3.1-1. 
Table 3.1-1: CFD Aerodynamic Effects Summary

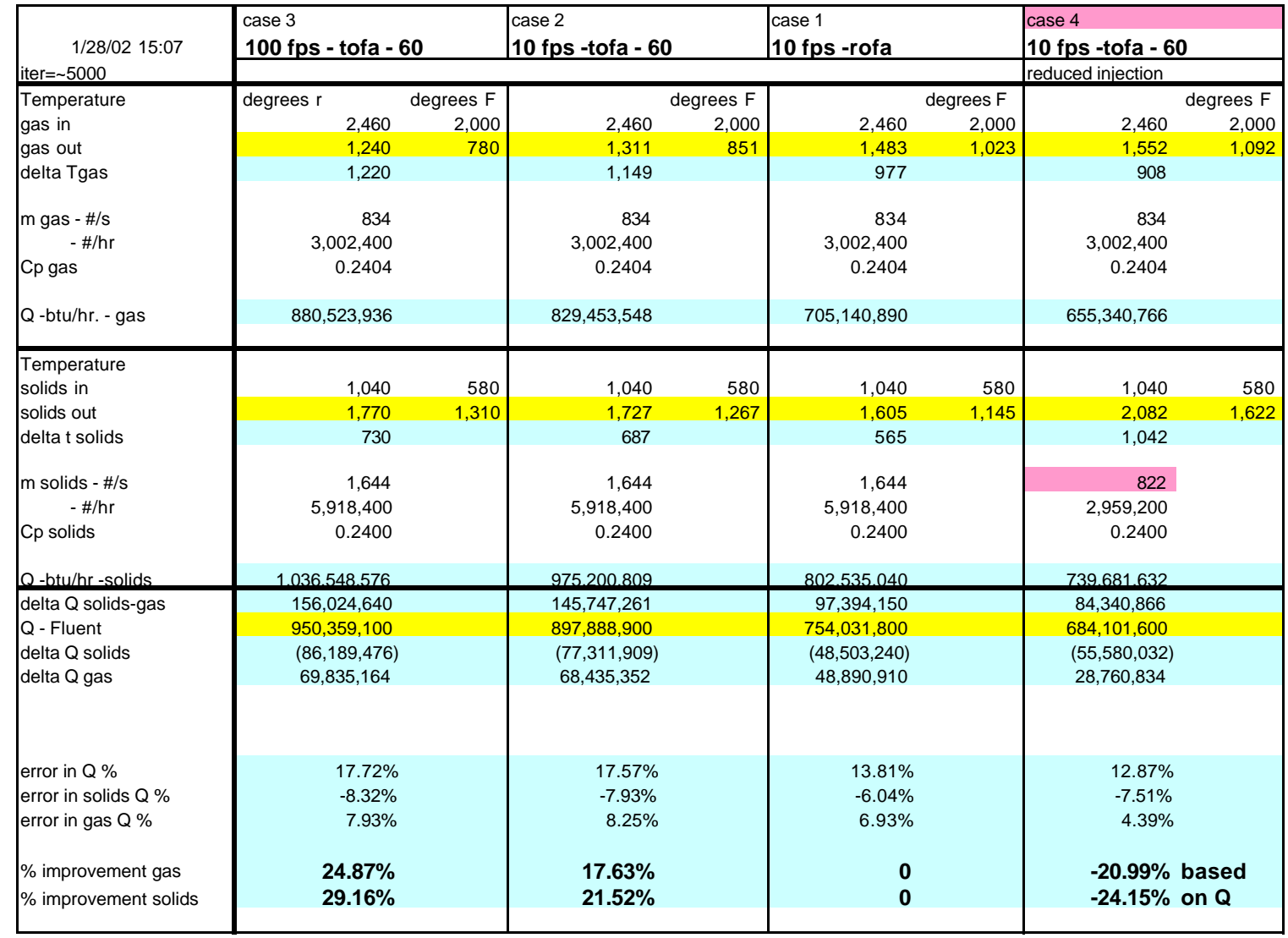

Figure 3.1-17 shows the predicted particle concentrations at several levels in the furnace for all four cases:

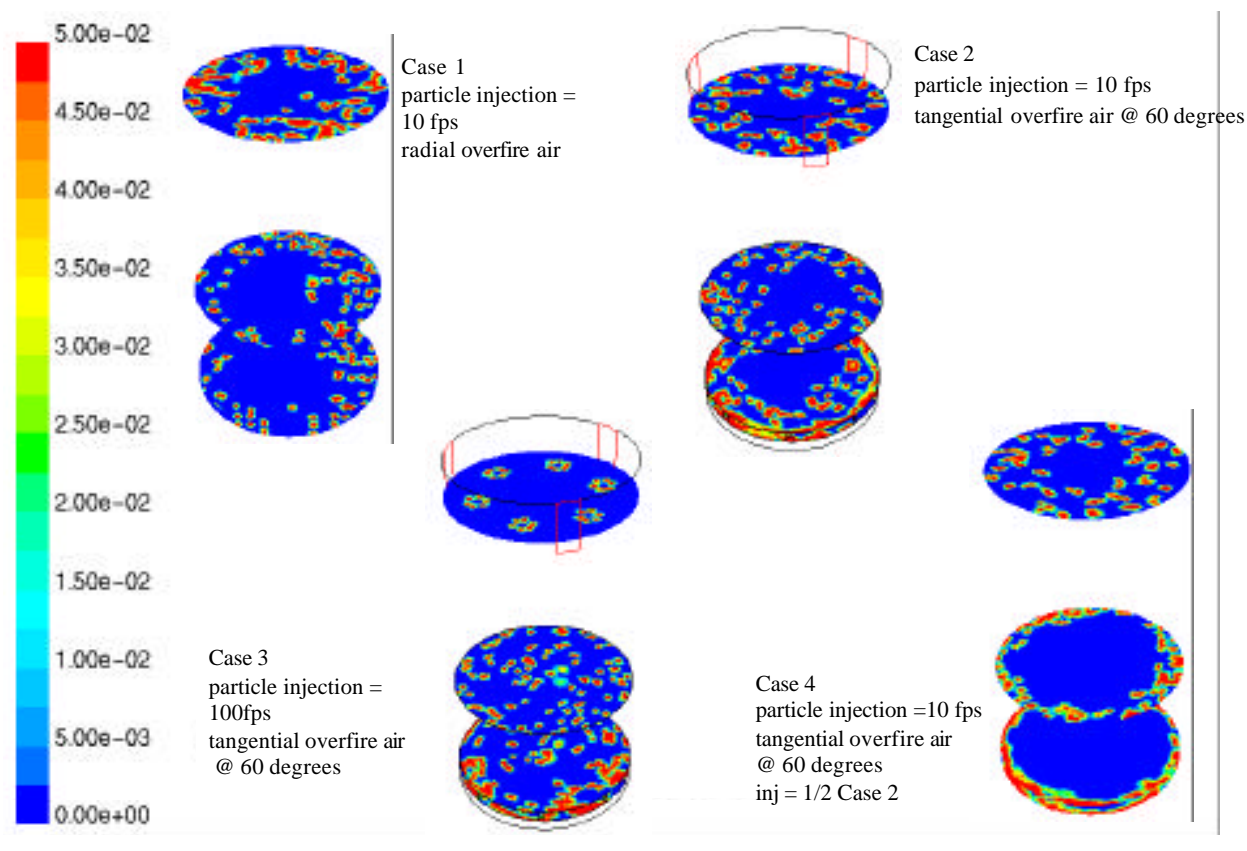

Figure 3.1-17: CFD Contours of Particle Concentration (Ibm/ft3) 
As previously discussed the CFD model predicted that the lower solids-to-gas ratio case caused a significant change in the solids flow pattern. With tangential overfire air, the solids were thrown to the walls of the furnace much more noticeably than with the higher solids to gas cases. Three additional cases were therefore run to understand the effect of solids to gas ratio. The previous low solids-to-gas ratio case was similar to case 2 below but without the upward tilt. The three new cases were:

1. Solids-to-gas ratio of 1:1 with radial overfire air.

2. Solids-to-gas ratio of 1:1 with tangential overfire air at $60^{\circ}$ from the radial with a $45^{\circ}$ upward tilt.

3. Solids-to-gas ratio of 1:1 with tangential overfire air at $75^{\circ}$ from the radial with upward tilt.

The results from these cases showed that the solids-to-gas ratio can have a significant effect on heat transfer. The solids were much more likely to be thrown outward by the tangential overfire air with a lower solids to gas ratio. There was still an improvement in heat transfer from the radial overfire air case, but the radial case with a solids to gas ratio of 1:1 had about $28 \%$ less heat transfer than the radial case with a solids to gas ratio of 2:1.

The CFD simulations suggest that there were competing effects with the tangential overfire air. The tangential air caused the solids to travel toward the wall, which reduced heat transfer by causing more solids segregation. The tangential air also introduced a horizontal component to the relative velocity between gas and solids, which increased the heat transfer. The net effect was an increase in heat transfer for the cases considered when the air was introduced tangentially. There also seemed to be a limit on the potential improvement, since the case with $75^{\circ}$ tangential air and the case with uptilted air had very small effects over the $60^{\circ}$ cases. Also the solids to gas ratio had as big an effect as the tangential overfire air.

The model results are summarized in Table 3.1-2. Figures 3.1-18 and 3.1-19 illustrate the effects of the solids to gas ratios. The figures show the predicted solids concentrations at the bed level. The segregation of the solids with increasing tangential overfire air can be seen. The figures also show the prediction of the falling solids flow pattern, illustrating how the overfire air changes the solids trajectories.

Table 3.1-2: \% Heat Transfer Improvement due to Aerodynamic Effects

\begin{tabular}{|l|c|c|}
\hline Condition: & Solids-to-gas $=1: 1$ & Solids-to-gas $=2: 1$ \\
\hline Radial OFA & base & +28.4 \\
\hline Tangential OFA @ $60^{\circ}$ & +25.8 & +52.9 \\
\hline $\begin{array}{l}\text { Tangential OFA @ 60 } \\
\text { with 45 up tilt }\end{array}$ & +28.4 & \\
\hline $\begin{array}{l}\text { Tangential OFA @ 60 } \\
+61.8\end{array}$ & na & +61.8 \\
injection vel = 100fps & & na \\
\hline Tangential OFA @ $75^{\circ}$ & +28.5 & \\
\hline
\end{tabular}




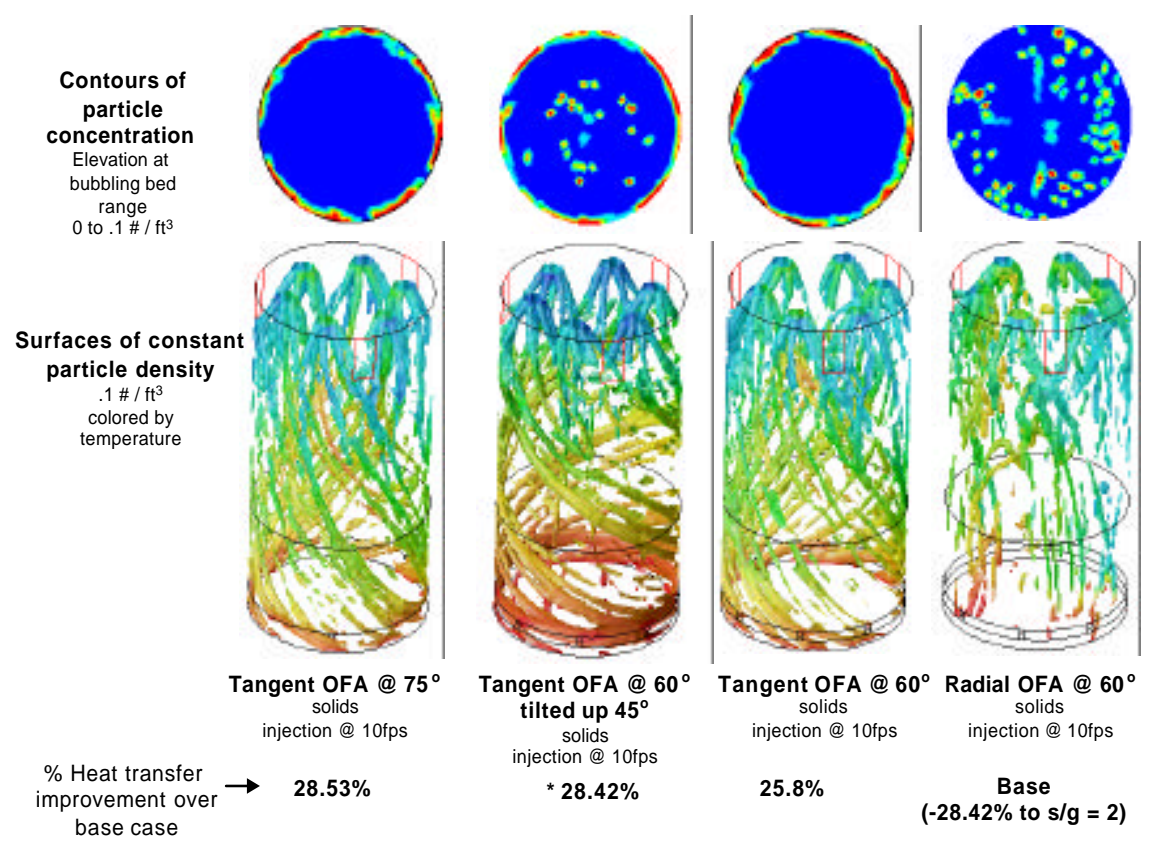

Figure 3.1-18: Aerodynamic Effects at Solids/Gas Ratio of 1
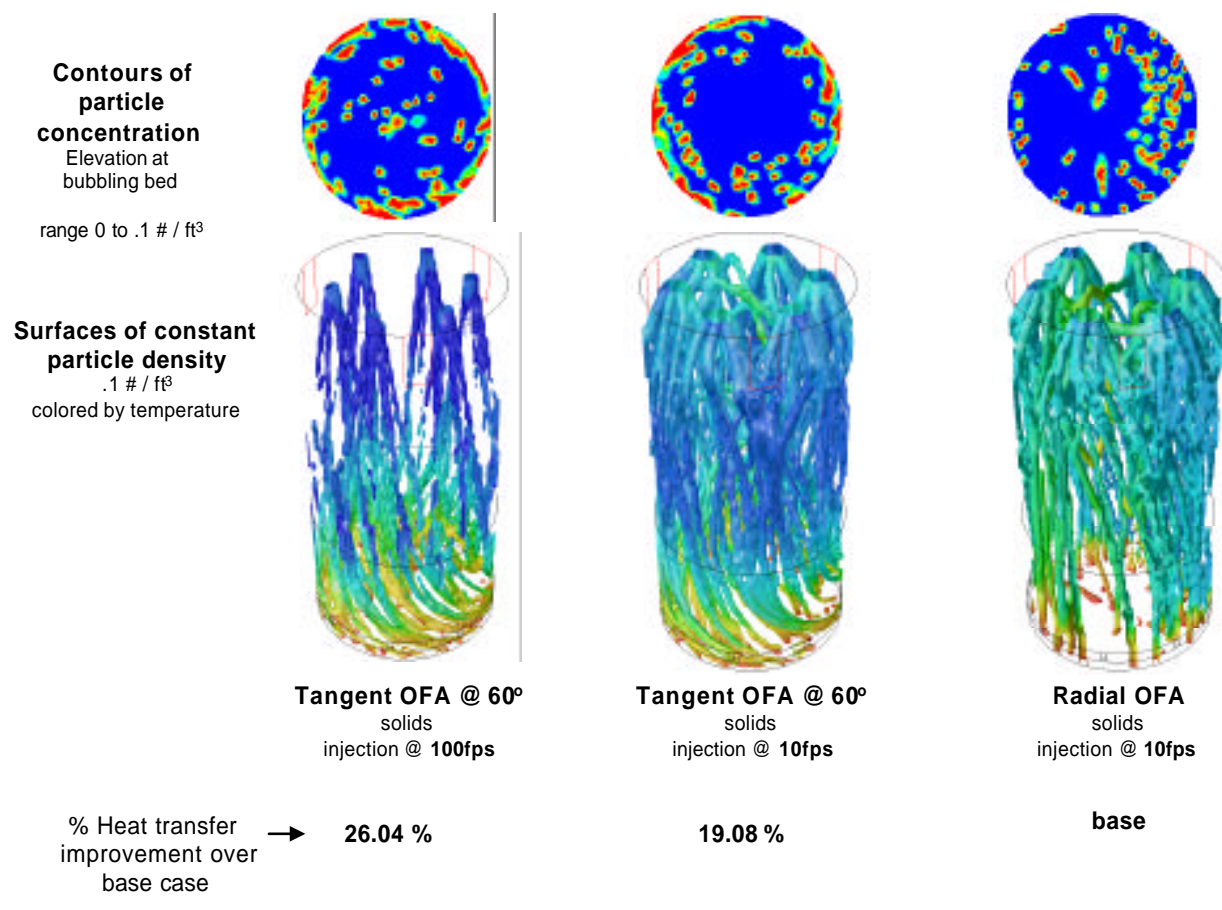

Tangent OFA@60

Radial OFA solids injection@10fps injection@10fps

base

Figure 3.1-19: Aerodynamic Effects at Solids/Gas Ratio of 2 


\section{MTF Comparison with Results}

The MTF tests showed that the CFD model trends were correct but details of the predictions needed improvement. The CFD model under-predicted the actual heat transfer by 5 to $20 \%$. Figure 3.1-20 shows one CFD model prediction vs. MTF test results. This simulation implies that the method for modeling was generally correct but that the grid resolution and calibration needs refinement.

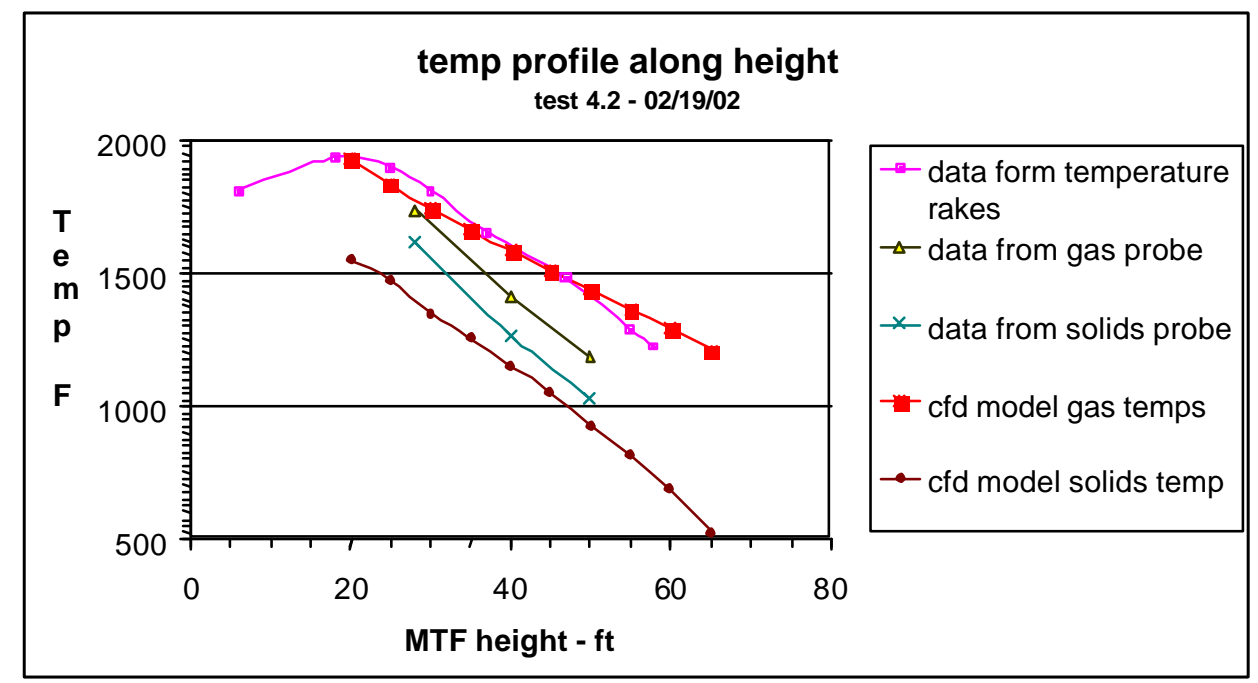

Figure 3.1-20: MTF Data vs. CFD Predictions of Temperature

\section{Modeling Larger Units}

The disperse-phase CFD model was also used to predict the performance of a commercial sized plant. This effort was made to determine if there were significant fluid dynamics scaleup issues with a commercial CMB process design. Using data from the existing test campaigns, the CFD model was calibrated and run to predict commercial scale performance.

The results of the commercial scale modeling point out some of the problems in using CFD for scaleup. Using computational variables that predict the MTF performance, the commercial model gave a wide range of predictions on gas and solid flow distributions and heat transfer performance. The predictions shown in Figure 3.1-21 illustrate the varying results as the grid resolution and the number of particle injections was changed. The predicted solids distributions range from all of the solids falling to one side of the combustor, to solids falling to the combustor outside perimeter, or to solids with a very good distribution throughout the combustor. Heat transfer predictions accordingly varied from bad to good among these flow conditions. 

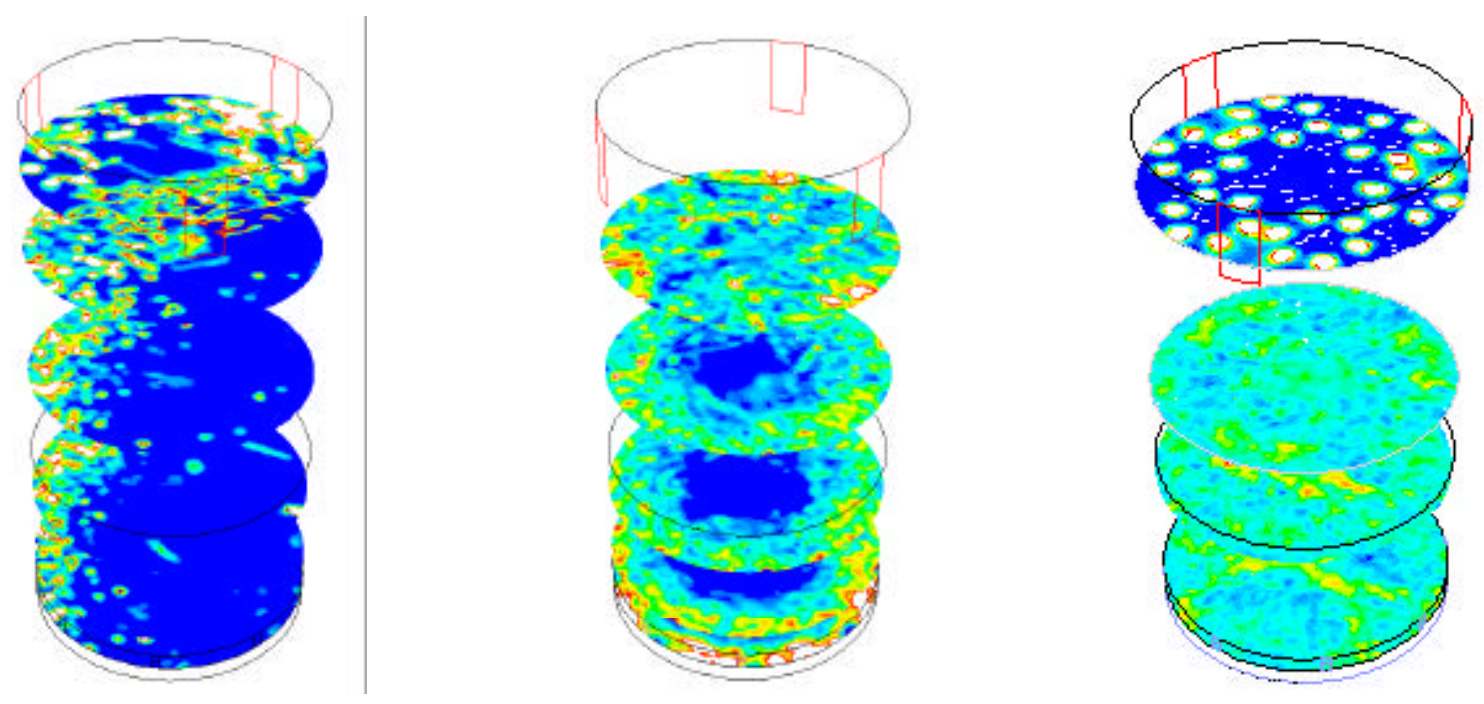

Figure 3.1-21: CFD Predictions of Solids Distribution in a 300Mw CMB

Since disperse-phase CFD models do not handle particle-particle interactions well, the CMB was also modeled with an Eulerian-Eulerian Fluent model. This model simulation did not provide any reasonable results. Clearly, the results with both disperse-phase and EulerianEulerian CFD models require a better representation of the physical phenomena occurring in the combustor, particularly the particle-to-particle interactions. The grid dynamics needs to be better understood also. The grid resolution must be fine enough that predictions will not change as grid sizes are further reduced. However, large grids and a high number of particle injections result in excessive computational run times. It is anticipated that CFD models can be used as a reliable tool for scale up predictions once the proper selection for grid size and the number of solids injections has been addressed.

ALSTOM Power plans to continue working with FLUENT and Dr. Leon Glicksman of MIT in this area, who is an expert in heat transfer and scaling. The CFD models can then be calibrated and used for scaling up to larger combustor sizes with more confidence. A larger scale test loop is also needed to properly calibrate the CFD model so it can be used for scale up. The test loop should be large enough to model a full-scale solids distributor. An advantage of this size is that several critical components can also be tested at significant scale.

\section{Scaling Criteria}

Professor Glicksman evaluated procedures for scaling results of the MTF pilot plant to a commercial sized unit. He concluded that no proper scaling was possible at a temperature of $1094^{\circ} \mathrm{C}\left(2000^{\circ} \mathrm{F}\right)$ while using the proper sized bauxite particles. If the MTF is run at CMB operating temperatures and proper sized bauxite particles are used, then the full set of scaling relationships indicate that the scale model must be the same size as the commercial model, i.e. no linear scaling can be accomplished. For this situation it can be shown that the linear dimension scales with the kinematic viscosity of the gas raised to the $3 / 2$ power. For the full set of scaling variables, the MTF bed must be operated at a lower temperature so that the kinematic viscosity will be reduced. In this situation, the cold MTF will then simulate a larger hot riser. This would also require the use of solid particles that are denser than the bauxite. 
An alternative procedure is the use of a simplified set of scaling relationships developed by Glicksman et. al. ${ }^{2}$ The full set of scaling parameters can be relaxed for most cases. The simplified set requires that the following parameters be matched between the test and the larger units:

$$
\frac{U_{0}{ }^{2}}{g L}, \frac{\rho_{s}}{\rho_{g}}, \frac{U_{0}}{U_{T}}, \frac{L_{1}}{L_{2}}, \frac{G_{S}}{\rho_{S} U_{0}}, \varphi, \text { particlesizedistribution }
$$

The terms in this relationship are the Froude number based on the bed dimensions, the solids to gas density ratio, the ratio of gas superficial velocity to particle terminal velocity, the ratio of linear bed dimensions, the dimensionless solids flow rate, the particle sphericity, and the dimensionless particle size distribution, respectively. In the original derivation, the third term was the ratio of gas velocity to the minimum fluidization velocity. For the counterflow riser, the terminal velocity is the more physically meaningful velocity. This allows the dimensionless drag coefficient on a single particle to be matched.

To use this relationship, first choose the linear scaling ratio between the test model and the commercial bed. From the Froude number, calculate the test superficial velocity $U_{b}$ so that the test and the commercial bed have the same value of the Froude number. Then calculate the terminal velocity from the third term so the velocity ratio is the same for the test and commercial bed. The mean particle diameter for the test bed is found from the terminal velocity.

Table 3.1-3 shows an example of using this simplified scaling relationship for a linear dimension scaling of $4: 1$, with both beds at $2000^{\circ} \mathrm{F}$ and using appropriately sized bauxite particles.

Table 3.1-3: Example of Simplified Scaling Relationship

\begin{tabular}{|l|l|l|}
\hline Parameter & MTF $($ test $)$ & Commercial \\
\hline Diameter & 40 inches & $13.3 \mathrm{feet}$ \\
\hline Height & $25 \mathrm{ft}$ & $100 \mathrm{ft}$ \\
\hline Uo & $10 \mathrm{ft} / \mathrm{s}$ & $20 \mathrm{ft} / \mathrm{s}$ \\
\hline Particle diameter & $0.48 \mathrm{~mm}$ & $0.9 \mathrm{~mm}$ \\
\hline Terminal velocity $\mathrm{U}_{\mathrm{T}}$ & $5.25 \mathrm{~m} / \mathrm{s}$ & $10.5 \mathrm{~m} / \mathrm{s}$ \\
\hline Minimum Fluidization velocity Umf & $0.305 \mathrm{~m} / \mathrm{s}$ & $1 \mathrm{~m} / \mathrm{s}$ \\
\hline $\mathrm{U}_{\mathrm{T}} / \mathrm{Uo}$ & 1.72 & 1.72 \\
\hline $\mathrm{U}_{\mathrm{T}} / \mathrm{Umf}$ & 17.2 & 10.5 \\
\hline Cluster diameter (assumed) & $2.5 \mathrm{~mm}$ & $10 \mathrm{~mm}$ \\
\hline $\mathrm{U}_{\mathrm{T}}($ cluster) / Uo & 8.5 & 10 \\
\hline
\end{tabular}

Note that the MTF must be modified so that the height of particle travel is only 25 feet to obtain the correct scaling. The terminal velocity scales by a factor of 2 . For a $0.9 \mathrm{~mm}$ particle in the commercial bed, the test bed must have a particle size of $0.48 \mathrm{~mm}$. The minimum fluidization velocity does not scale properly. It has a 3.2:1 ratio rather than a 2:1 ratio. However, in the riser the proper scaling of the forces for a bed of dense packed particles does 
not appear to be relevant. Assume that the cluster sizes scale with the bed linear dimensions. If the commercial bed has spherical clusters of $10 \mathrm{~mm}$ diameter and the MTF clusters of 2.5 $\mathrm{mm}$ diameter, then the terminal velocity of the clusters in the commercial bed and the MTF test bed scale reasonably closely with the terminal velocity of individual particles.

Carrying out the same calculations assuming that the particles in the commercial bed are 0.7 $\mathrm{mm}$ in diameter gives similar results. Again using a 4:1 linear scaling ratio, the scaled particles in the MTF must be $0.395 \mathrm{~mm}$ to yield a 2:1 scaling of the terminal velocity. The particle diameter ratio of the two beds is $0.56 / 1$ whereas using $0.9 \mathrm{~mm}$ particles the particle diameter ratio is $0.53 / 1$. This indicates that close scaling will be obtained for all particle terminal velocities by scaling all particle diameters by the ratio of $0.53 / 1$.

Another consideration is the scaling of the heat transfer results. The transit time of the solids from the top to bottom of the riser must be compared to the their thermal time constant. In this case the thermal time constant of single particles will be considered. The transit time for the MTF is given as:

$$
\tau_{\text {transittest })}=\frac{U_{T}-U_{0}}{L} \sim \frac{\sqrt{L}}{L} \sim \frac{1}{2} \tau_{\text {transit(commercial) }}
$$

For heat transfer to a single spherical particle, the thermal time constant is,

$$
\tau_{\text {thermal(test })}=\frac{\rho_{S} c_{S} \pi d_{p}^{3} / 6}{\pi d_{p}{ }^{2} h}=\frac{\rho_{S} c_{S} d_{p}}{6 h} \sim \frac{d_{p}{ }^{2}}{N u}
$$

Using a correlation for the Nusselt number for a sphere of $0.9 \mathrm{~mm}$ diameter from Rohsenow and Choi, the Nusselt number is 5.88 for the commercial bed and 3.51 for the MTF. The ratio of the thermal time constants between the MTF test bed and the commercial bed is 0.48 , almost exactly the same as that for the transit time constants when the effective MTF height is reduced to 25 feet. This suggests that if the heat transfer is primarily from the gas to dilute particles, the MTF will accurately simulate the heat transfer as well as the bed dynamics.

This analysis opens up the possibility of using the MTF to model a small demonstration plant, but some physical considerations need to be reviewed first. Another possibility is to use a cold flow model to scale a commercial unit, although this technique adds the complexity of finding particles denser than bauxite.

\section{CFD Modeling of Scaling Criteria}

A CFD model was constructed to visualize the scaling method described by Professor Glicksman. In his example a 4:1 scale factor was used. For the CFD model, the existing MTF model grid was used. The particles were injected at the $7.6 \mathrm{~m}(25 \mathrm{ft})$ high level. For the larger case, the MTF model was scaled up by a factor of 4 and the particles were injected at the $30.5 \mathrm{~m}(100 \mathrm{ft})$ level. This gave both models the same geometry to avoid any different exit effects. Table 3.1-4 summaries the CFD model scaling criteria for each model. 
Table 3.1-4: CFD Model Scaling Criteria

\begin{tabular}{|l|c|c|}
\hline Parameter & MTF & 4x Scale \\
\hline Diameter $(\mathrm{m})$ & 1.0 & 4.1 \\
\hline Height $(\mathrm{m})$ & 7.6 & 30.5 \\
\hline Gas Velocity $(\mathrm{m} / \mathrm{s})$ & 3.0 & 6.1 \\
\hline Particle Diameter $(\mathrm{mm})$ & 0.5 & 0.9 \\
\hline Temperature $\left({ }^{\circ} \mathrm{C}\right)$ & 1094 & 1094 \\
\hline
\end{tabular}

The particle tracks predicted by this CFD model showed essentially the same patterns for both cases, as shown in Figure 3.1-22. Particle concentrations and normalized velocity patterns also showed the same patterns for the two cases. These results indicated that the CFD model was capturing the effects of the variables used in the simplified scaling criteria. They also implied that a scale model of a moderately sized demonstration plant $(<20 \mathrm{Mw})$ could be modeled in the MTF and analyzed with a CFD model.
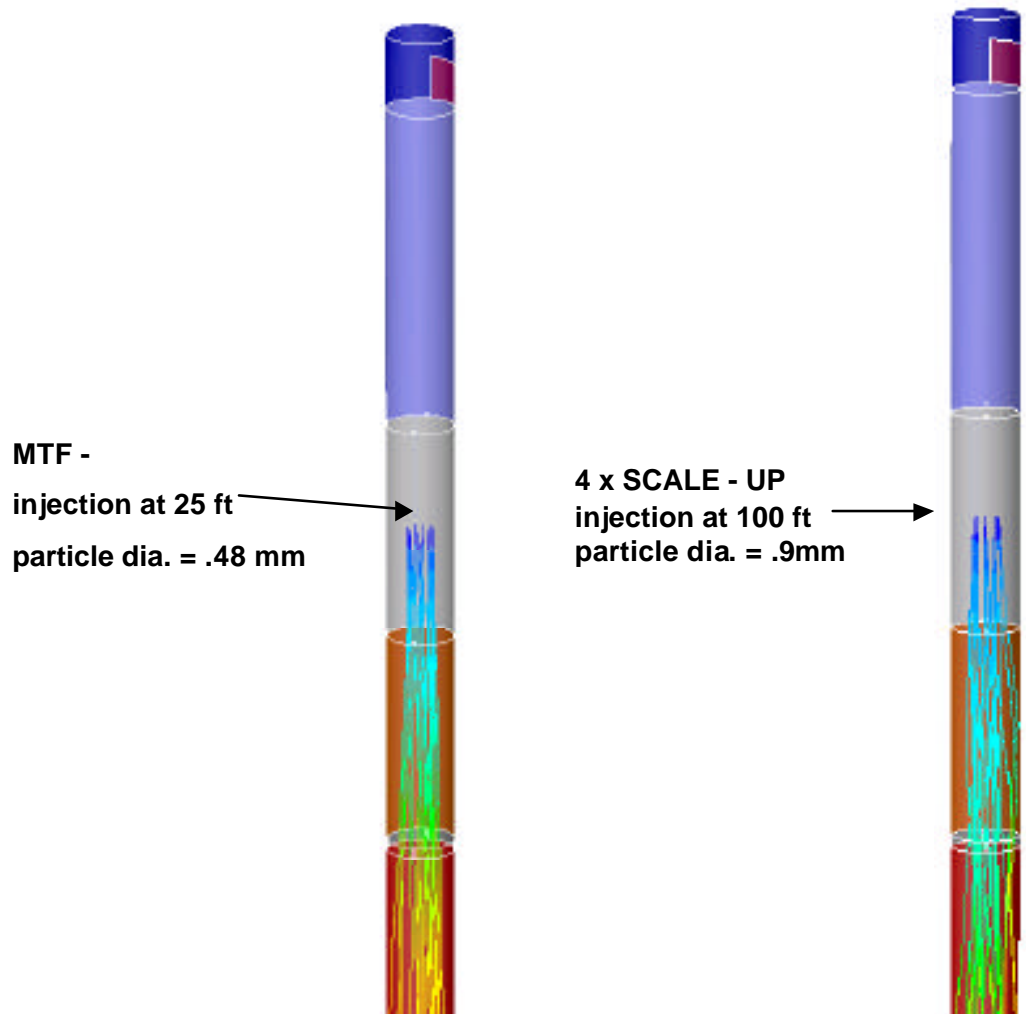

Figure 3.1-22: CFD Model of a 4:1 Scale-Up Using Similitude Criteria 


\subsection{Moving Bed Heat Transfer}

The objective of this task was to review moving bed heat transfer results from past ALSTOM work and to evaluate any potential development issues related to MTF operation or commercial design. This section briefly reviews ALSTOM's initial MBHE development work. It then discusses a MBHE tube leak simulation and an evaluation of the pressure seal capability of the siphon seal located between the MTF combustor and the transport line to the MBHE.

\section{Background on Prior Work}

Work on the moving bed heat exchanger concept began with a literature review for relevant work. Research by Jörg Niegsch ${ }^{1}$ showed that heat transfer effectiveness in a moving bed was strongly dependent on the tube bundle design and solids flow characteristics. His dissertation showed that a stagnant region of solids (see Figure 3.2-1) tended to build up on the tube crown, while a small voidage occurred at the bottom of the tube. The local heat transfer to the tube was significantly reduced in both of these areas. Niegsch further showed that the heat transfer for an individual tube was less than observed in a fluidized bed and then further decreased as the solids moved down through the tube bundle.

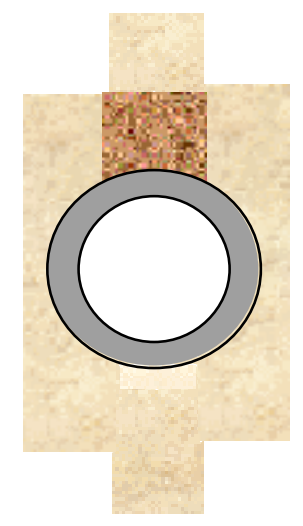

Figure 3.2-1: Solids Flow Pattern Around a Tube

Moving bed heat transfer tests were then conducted by Power Plant Laboratories at both laboratory and pilot plant scale to understand the magnitude and characteristics of heat transfer from moving solids to tubes. To better understand these fundamentals, a small heat transfer test loop was built to investigate moving bed heat transfer. The model was run under low temperature conditions and thus only gave information on the convective heat transfer coefficient. The model, shown in Figure $3.2-2$, was a $10 \mathrm{~cm} \times 10 \mathrm{~cm}$ (4in x 4in) column that was $2.5 \mathrm{~m}(8 \mathrm{ft})$ tall. A single $5 \mathrm{~cm}$ (2in) boiler tube with an embedded $1 \mathrm{~kW}$ heating element was located at the bottom portion of the moving bed. Thirteen chordal thermocouples were added around the tube circumference and along any extended surfaces. The tube was tested with both axial and spiral fins, and as a bare tube. The moving bed itself used either fluid bed ash, sized sand, or sintered bauxite as the heat transfer media. 
The test results showed that the heat transfer was uniformly distributed around the circumference of the bare tube configuration. The best heat transfer was observed with the bauxite, although there wasn't a large difference with various solids media. The overall heat transfer was weakly dependent upon the solids velocity. The largest effect was the tube configuration itself, with extended surfaces providing significant improvements in heat transfer. The tube with the spiral fin had significantly more heat transfer than the bare tube for the same tube length. Although the finned tube weighs more than a conventional boiler tube, the convective heat transfer for the spiral finned tube was still several times greater than the bare tube when normalized on a unit weight basis.

\section{4'x4" Moving}

Bed Test Column

Sand, Bauxite, or FBC Ash as Heat Transfer Media

2" Boiler Tube With 1 Kw Heating Element

\section{Solids Flow Control Valve and Collection Drum}

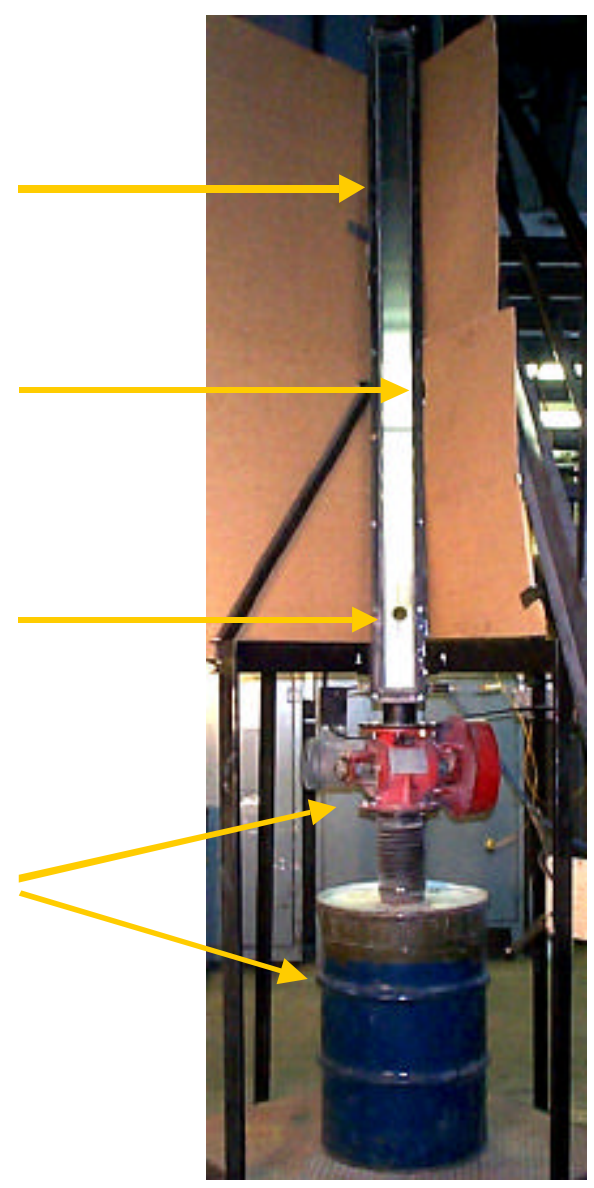

Figure 3.2-2: Laboratory Test Loop for Moving Bed Heat Transfer

A finite element analysis (FEA) model was then developed for the spiral fin tube arrangement. This model was used to predict the maximum temperature differential across the fin without exceeding the allowable material stress. It was also used to assess the impact of solids flow patterns on tube bundle heat transfer. Figure 3.2-3 shows an example of a FEA model of the temperature across a spiral fin tube. The FEA analyses indicated that all of the CMB heat transfer surfaces could be finned with conventional boiler materials for subcritical steam conditions, except for the finishing superheat and reheat sections. The FEA model also showed that the fins were very effective in transferring heat to the tube, even in regions 
where the local heat transfer coefficient might be low due to stagnant solids. Applying extended surfaces to the high temperature region tube bundle of an ultra-supercritical boiler is desirable but the fins must be designed properly to keep stresses to acceptable levels.

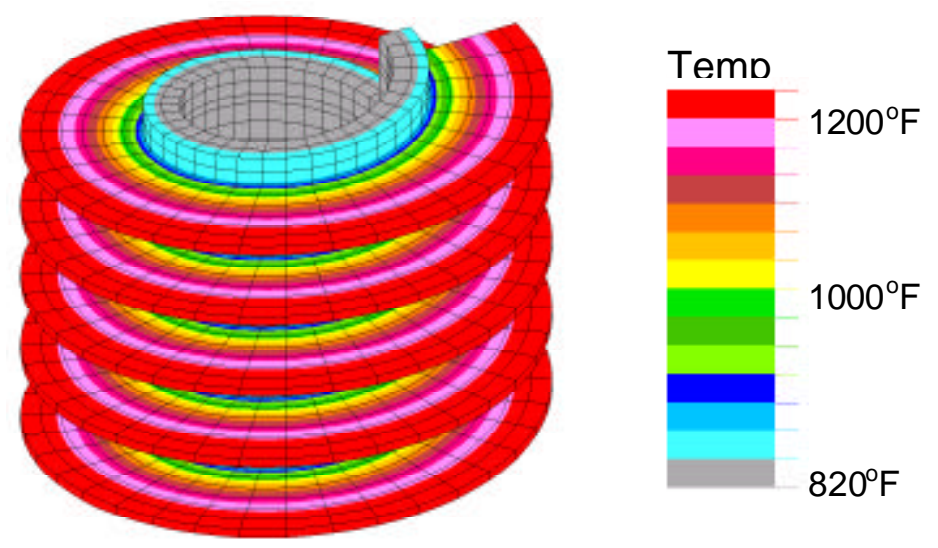

Figure 3.2-3: FEA Spiral Fin Tube Temperature Model

A $0.3 \mathrm{MW}_{\text {th }}$ moving bed heat exchanger with in-line spiral fin tubes (Figure 3.2-4) was then tested in the MTF pilot plant. It replaced an existing fluid bed heat exchanger and was used to cool CFB recirculated ash. Although not an exact model of the CMB heat exchanger, it provided detailed heat transfer data at a much larger scale and confirmed the heat transfer models developed from our earlier tests. A significant uncertainty remained about the magnitude of radiation heat transfer, as these MBHE tests were limited to maximum temperatures well below a commercial CMB heat exchanger.

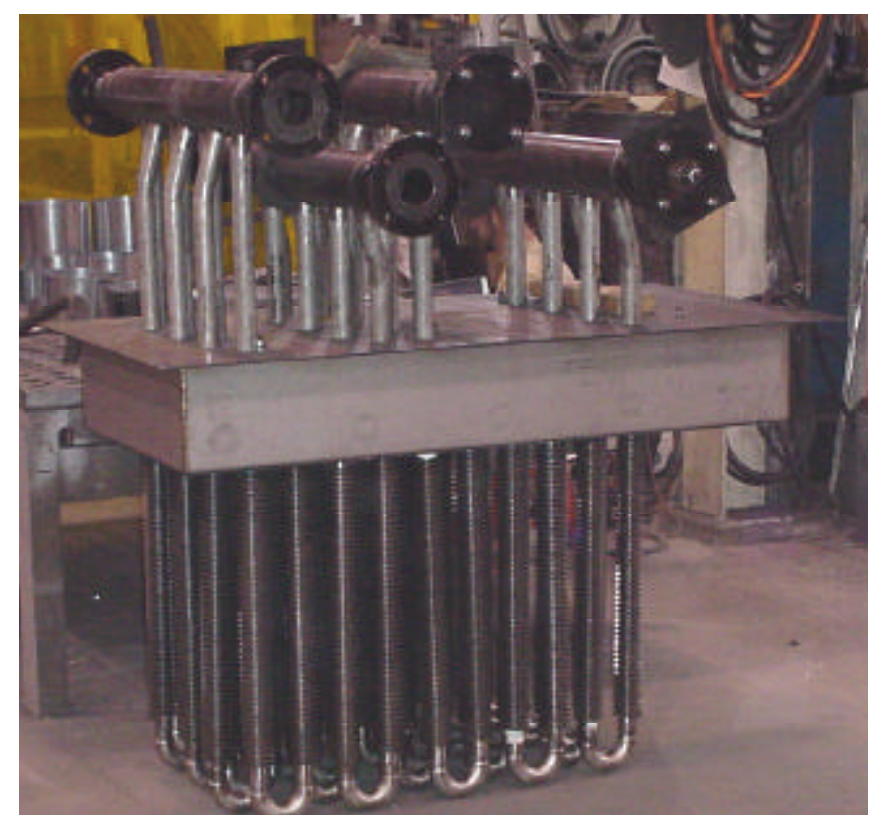

Figure 3.2-4: MTF MBHE 


\section{MBHE Tube Leak Simulation}

The CMB conceptual design was reviewed for potential operational issues. One concern from this review was about the cleaning of the moving bed heat exchanger in the event of a tube leak. Some tube leak experiments were then conducted prior to this program to assess this potential issue, using CFB bed ash and combinations of bed ash and fresh bauxite.

This test was repeated under the CMB Proof of Concept program using bed material from our high temperature MTF test (discussed further in Section 3.3). The objective of the revised test was to determine if the wetted bauxite behaved differently if it had a coating of bed ash around the individual particles.

A $7.6 \mathrm{~cm}$ (3 inch) length of spiral fin tubing was embedded in about $4 \mathrm{~kg}(9 \mathrm{lbs})$ of used bauxite from the $\mathrm{CMB}$ agglomeration test. The sample was preheated to about $93^{\circ} \mathrm{C}\left(200^{\circ} \mathrm{F}\right)$ before water was added to it. It was then soaked with hot water until it couldn't take any more liquid. The tube sample was finally placed in an oven at $49^{\circ} \mathrm{C}\left(120^{\circ} \mathrm{F}\right)$ for a week to dry out.

The sample was then removed for evaluation. The collection of photos in Figure 3.2-5 shows the results from the earlier test using CFB bed ash. The first picture shows water being added to the sample. The second photo (top right) shows the tube sample as it was pulled out of the can. The third photo (bottom left) is a close-up of the tube sample after rapping it lightly with a hammer. The last photo (bottom right) was taken after scraping a screwdriver across the top of the sample for additional cleaning.
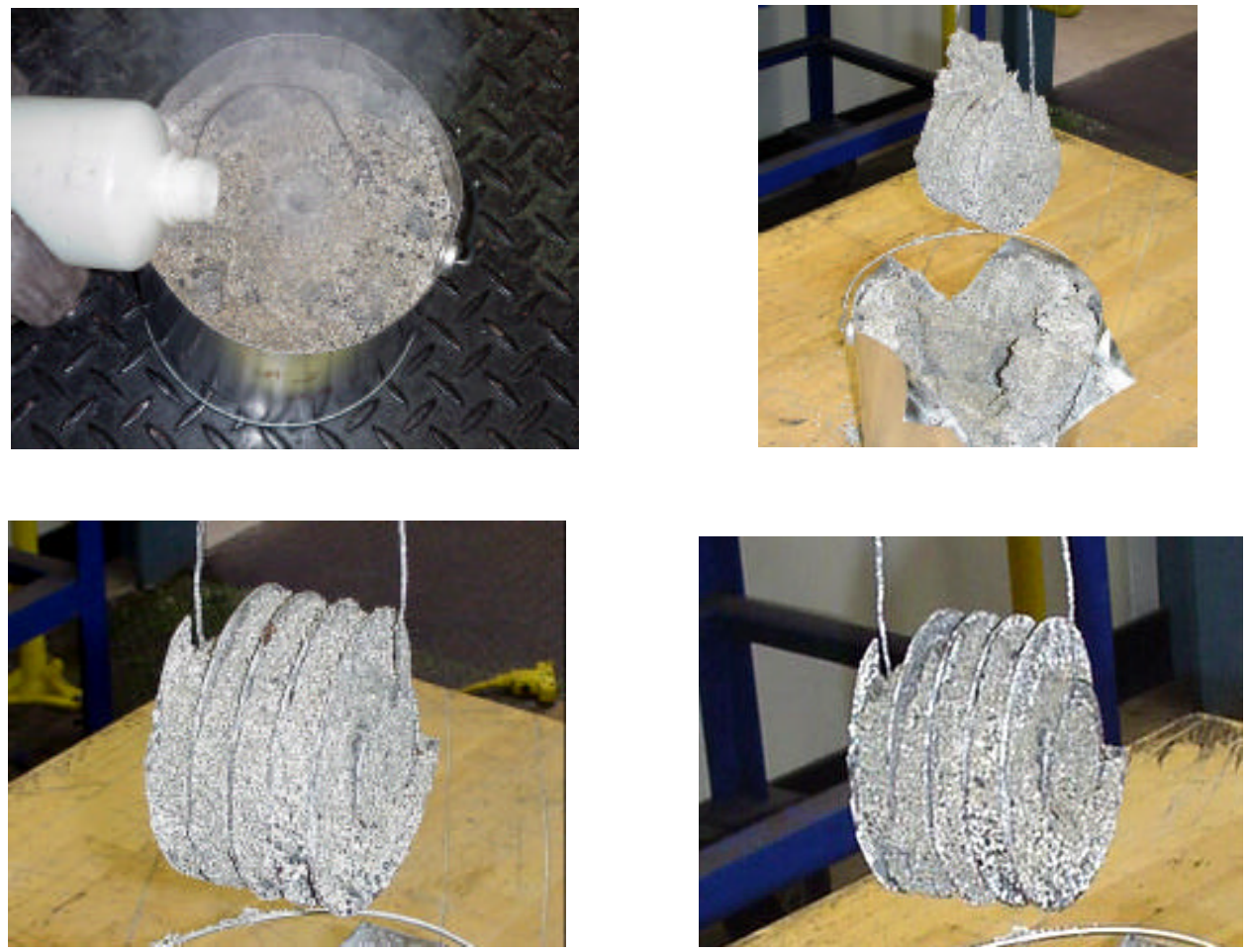

Figure 3.2-5: Tube Leak Simulation with CFB Ash

This CFB bed material sample was firmly embedded in the can. The bed material was quite hard and difficult to push a screwdriver through. Tin snips had to be used to cut the can open 
in order to free the tube sample. The tube came out with a large mass of bed material clinging to it. After rapping it ten times, the tube fins were still clogged with hard bed solids. Even using a screwdriver, it was difficult to clean the deposits down to the tube surface. The remaining solids in the can were large clumps of bed material. Clearly, it would be a major task to clean up extended surface tubes after a tube leak if the heat exchanger was full of bed material only and if the solids were not evacuated quickly.

The test results with the coated bauxite particles were dramatically better. A batch of bed material from the high temperature MTF test was air classified to remove rocks and fines. The remaining coated bauxite particles were used for the test, using the procedure described above. The four photos in Figure 3.2-6 show the test results again. After the test was completed, the tube sample was removed very easily (upper right photo) from the can. The tube had some particles clinging to it, but was generally clean. Many of the remaining particles fell off the tube when it was gently rapped with a screwdriver (lower left photo). The solids in the can itself were very free flowing. The fourth photo (lower right) compares the tube sample from the CFB bed material test (on the left) with the sample from this test with the used bauxite bed material.
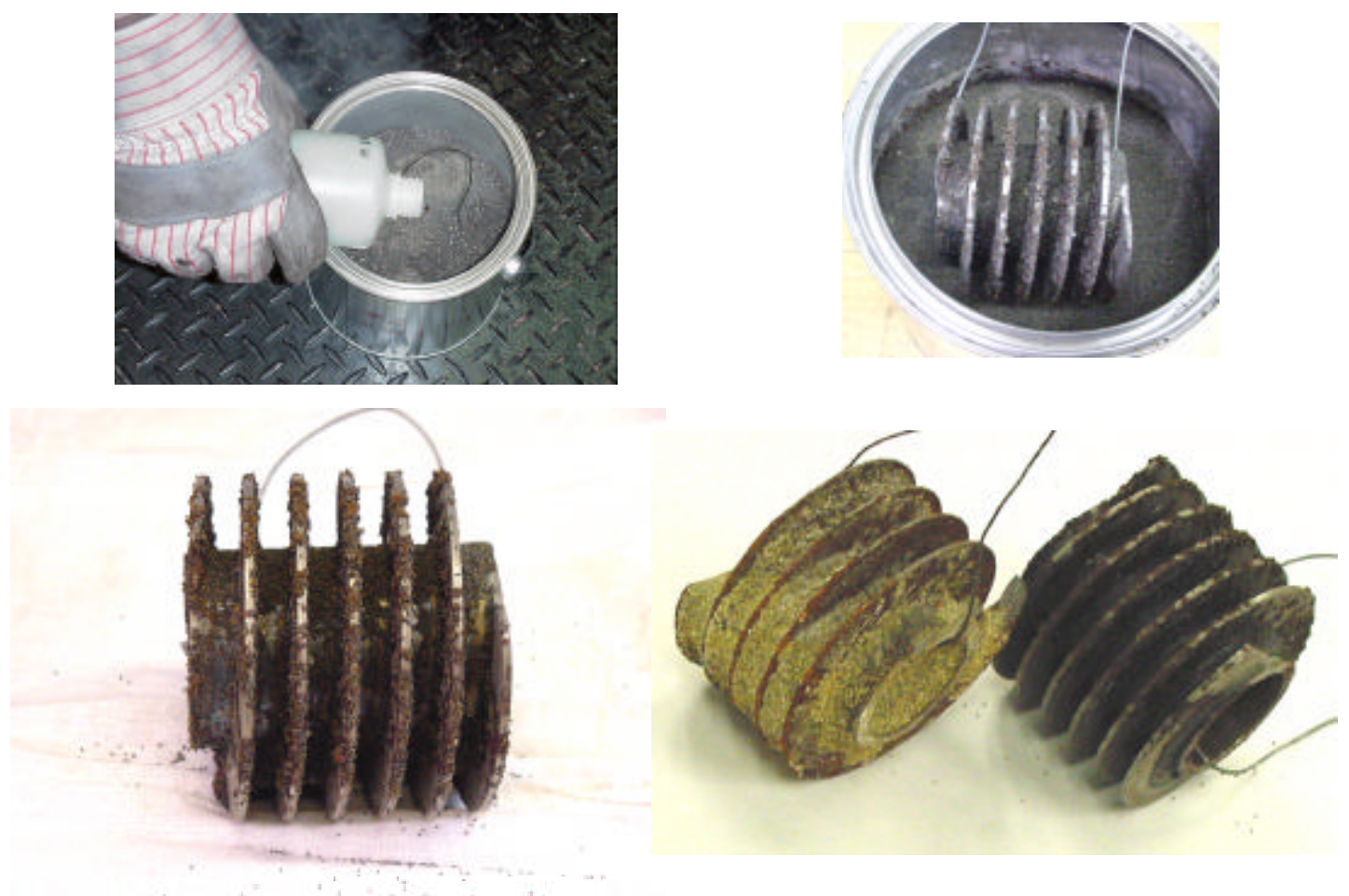

Figure 3.2-6: Tube Leak Simulation with CMB Ash

It is anticipated that the moving bed heat exchanger will have at least $90 \%$ bauxite particles passing through it and more likely greater than $95 \%$. The above tests suggest that it may not be a major problem to clean these tubes after a tube leak. The solids remained mostly free flowing, with only a few clumps of hardened solids occurring whenever local classification caused an accumulation of bed material. The tubes cleaned off down to bare metal (other than a few local deposits) after just a little mechanical rapping. It was clear though, that tube 
cleanup would be a more significant issue if the concentration of coal ash or sorbent was allowed to approach much higher levels.

\section{MTF Siphon Seal Performance Simulation}

The MTF configuration in CMB mode uses a siphon seal under the MTF combustor to seal the transport line pressure from the furnace. The available height under the combustor for developing the pressure seal was very limited. Furthermore, it was unknown how well the seal would work with a head of bauxite particles, which are both very dense and uniform sized. A series of pneumatic transport pressure drop tests were therefore conducted to confirm that the MTF siphon seal would provide sufficient sealing during CMB operation. A good pressure seal is critical to ensure high enough solid circulation rates to the moving bed heat exchanger during MTF operation.

The tests were conducted in an attrition rig with a $5 \mathrm{~cm}$ (2 in) ID vertical transport hose of 15 $\mathrm{m}(50 \mathrm{ft})$ length and a short horizontal material pickup section of $32.7 \mathrm{~m}(9 \mathrm{ft})$ length. This facility was also used for attrition testing and is described more fully in Section 3.3. A second pressure drop test series was also conducted with a different supply and discharge hopper that permitted higher solids flow rates. Pressure drops were measured in the vertical test section, in a short horizontal pickup section, and in an impact elbow. This information was used to validate our design assumptions for the MTF bauxite transport line and seal leg. The range of test conditions for the pressure drop testing is shown in Table 3.2-1.

Table 3.2-1: Test Range for Pressure Drop Tests

$\begin{array}{ccccccc} & \begin{array}{c}\text { Solids Flow } \\ \mathrm{lb} / \mathrm{hr}\end{array} & \begin{array}{c}\text { Air Flow } \\ \mathrm{lb} / \mathrm{hr}\end{array} & \begin{array}{c}\text { Air Velocity } \\ \mathrm{ft} / \mathrm{sec}\end{array} & \begin{array}{c}\text { Ws/Wa } \\ \mathrm{Ib}_{\mathrm{s}} / \mathrm{lb}_{\mathrm{a}}\end{array} & \begin{array}{c}\text { Particle Density } \\ {\mathrm{lb} / \mathrm{ft}^{3}}\end{array} & \begin{array}{c}\text { Particle } \mathrm{d}_{50} \\ \text { microns }\end{array} \\ \text { Minimum } & 120 & 120 & 22 & 0.4 & 214 & 530 \\ \text { Maximum } & 2220 & 390 & 74 & 7.0 & 224 & 780\end{array}$

Figures 3.2-7 through 3.2-9 compare the measured pressure drop with the adjusted predictions from an ALSTOM pressure drop model for the vertical, horizontal, and elbow pressure drops. The ALSTOM model was based on laboratory and field pressure drop measurements and also provided comparisons with predictions from several standard correlations. The calculated pressure drops for these tests were lower than the measured pressure drops for both the ALSTOM model and the other correlations. A correction factor was therefore developed to force the model to match the measured data and to ensure that the MTF pressure drop in the transport line was not underpredicted. 


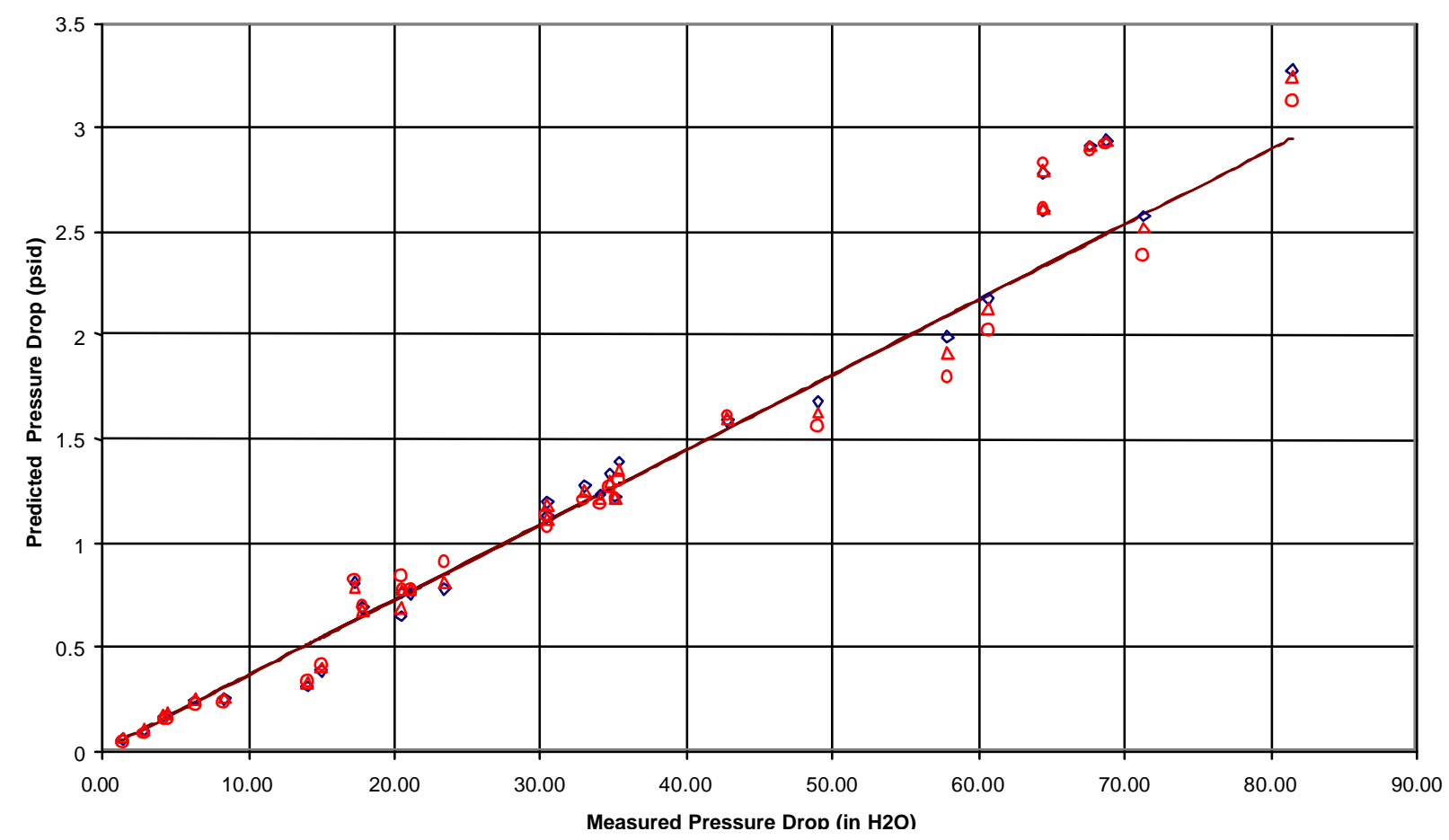

Figure 3.2-7: Pressure Drop Comparison in Vertical Run

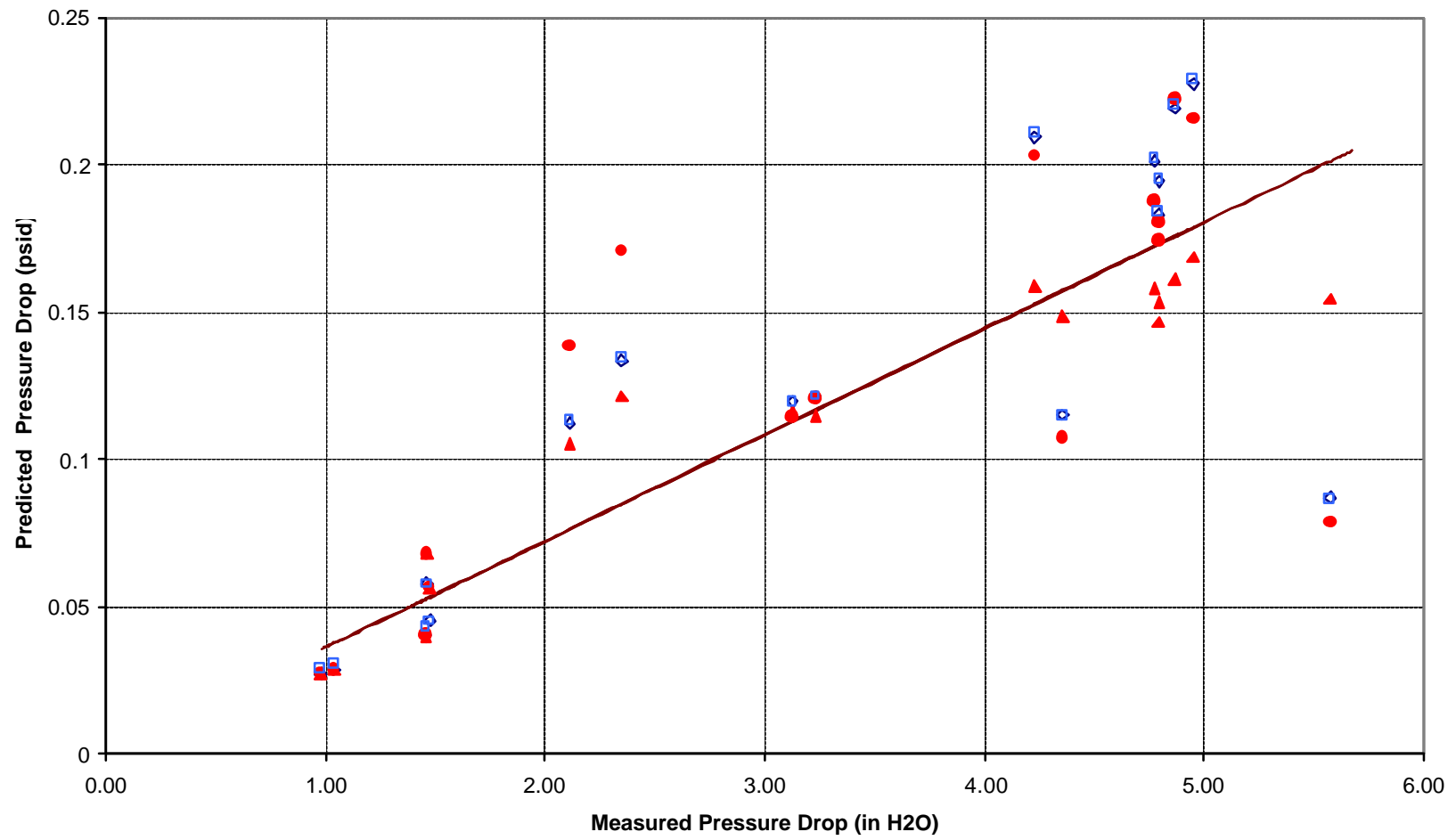

Figure 3.2-8: Pressure Drop Comparison in Horizontal Run 


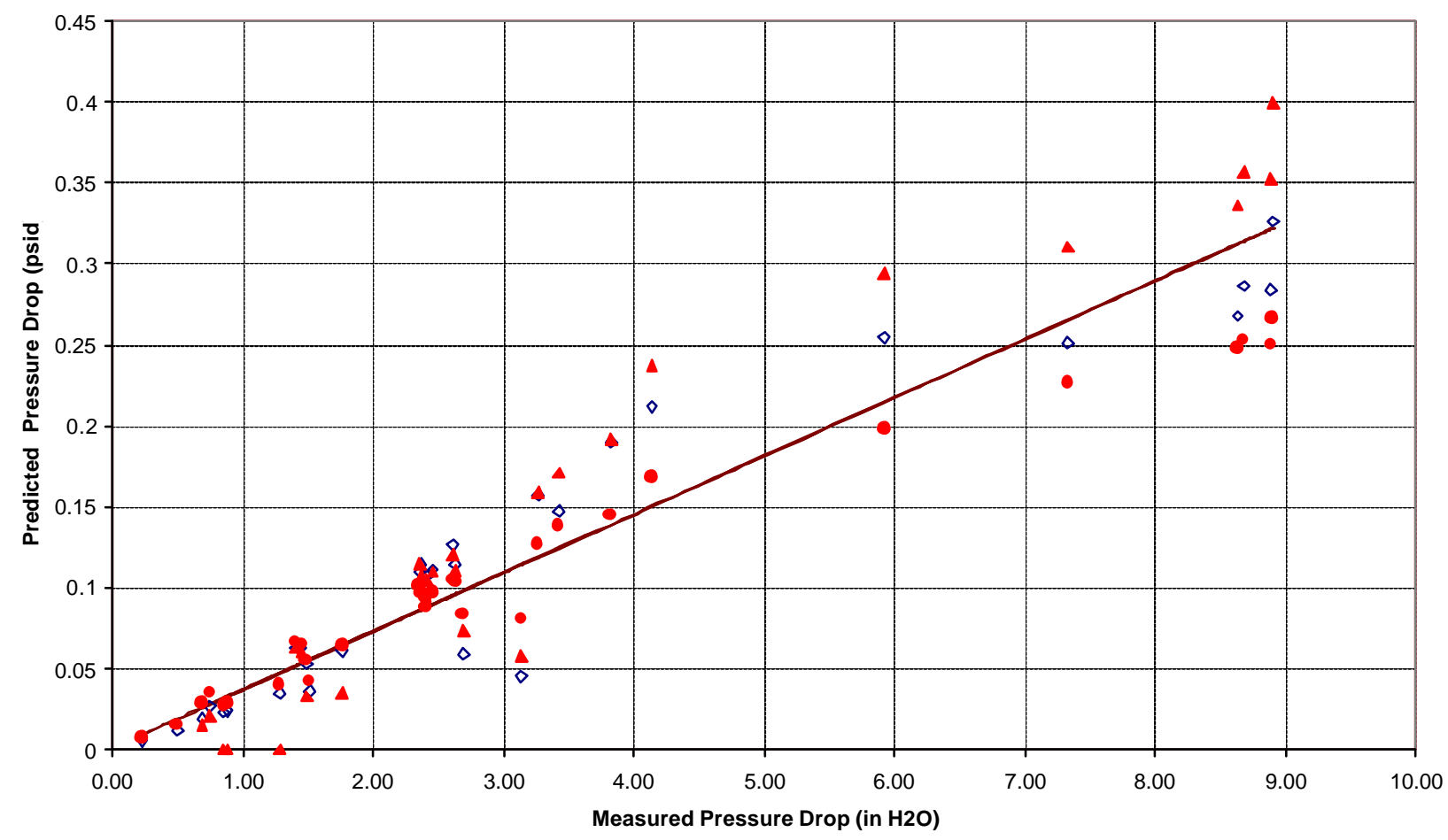

Figure 3.2-9: Pressure Drop Comparison in Impact Elbow

The corrected pressure drop predictions for the test conditions planned for the MTF gas-tosolids heat transfer tests are given in the Table 3.2-2. The calculated pressure drops ranged from 1-2 psid. The seal pot and seal leg at the bottom of the MTF combustor supplying solids to the transport pipe was capable of sealing against 3 psid back pressure. Since the pneumatic transport system pressure drop was less than the seal pressure for all test conditions, these results confirmed that the MTF seal pot design would provide sufficient sealing for the transport system to work properly. As a further precaution, a short extension to the solids discharge pipe in the bed was fabricated. This extension added the capability to operate the MTF with a deeper bed and hence provided an additional 1 psi of sealing capability.

Table 3.2-2: Transport Pressure Drop Predictions for MTF CMB Test

\begin{tabular}{|c|c|c|c|c|c|c|c|c|c|c|}
\hline $\begin{array}{r}\text { gas temp } \\
F\end{array}$ & $\begin{array}{r}\text { gas press } \\
\text { psia }\end{array}$ & $\begin{array}{l}\text { particle } \\
\text { Dia - in }\end{array}$ & $\begin{array}{r}\text { particle } \\
\text { density } \\
\text { lb/ft3 }\end{array}$ & $\begin{array}{r}\text { gas flow } \\
\# / \mathrm{hr}\end{array}$ & $\begin{array}{r}\text { solid flow } \\
\# / h r\end{array}$ & $\begin{array}{r}\text { pipe } \\
\text { diameter } \\
\text { in }\end{array}$ & $\begin{array}{r}\text { DP } \\
\text { total }\end{array}$ & $\begin{array}{r}\mathrm{DP} \\
\text { horizontal }\end{array}$ & $\begin{array}{r}\text { DP } \\
\text { vertical }\end{array}$ & $\begin{array}{r}\mathrm{DP} \\
\text { elbow }\end{array}$ \\
\hline 70 & 16.0 & 0.0276 & 224 & 4,000 & 25,000 & 8.0 & 2.11 & 0.17 & 1.77 & 0.17 \\
\hline $\begin{array}{r}70 \\
200\end{array}$ & $\begin{array}{l}16.0 \\
16.0\end{array}$ & $\begin{array}{l}0.0276 \\
0.0276\end{array}$ & $\begin{array}{l}224 \\
224\end{array}$ & $\begin{array}{l}3,000 \\
2,000\end{array}$ & $\begin{array}{l}10,000 \\
10,000\end{array}$ & $\begin{array}{l}8.0 \\
8.0\end{array}$ & $\begin{array}{l}1.19 \\
1.40\end{array}$ & $\begin{array}{l}0.06 \\
0.05\end{array}$ & $\begin{array}{l}1.08 \\
1.31\end{array}$ & $\begin{array}{l}0.05 \\
0.05\end{array}$ \\
\hline 1200 & 16.0 & 0.0276 & 224 & 1,500 & 15,000 & 8.0 & 1.12 & 0.15 & 0.82 & 0.16 \\
\hline 1600 & 16.0 & 0.0276 & 224 & 2,000 & 20,000 & 8.0 & 1.35 & 0.32 & 0.69 & 0.34 \\
\hline 2000 & 16.0 & 0.0276 & 224 & 1,500 & 15,000 & 8.0 & 1.05 & 0.23 & 0.57 & 0.25 \\
\hline
\end{tabular}




\subsection{Agglomeration}

The high combustion temperatures $\left(2000^{\circ} \mathrm{F}\right)$ in the Circulating Moving Bed (CMB) design provide the driving force for heat transfer in the moving bed heat exchanger. However, these elevated temperatures also introduce the potential for ash agglomeration problems in the fluidized bed itself. Considerable research has been focused on low-rank coals, as they are commonly associated with ash-related problems in fluidized beds. The objective of this task was therefore to review the reported research into agglomeration in fluidized beds as it relates to CMB operating conditions. Results from ALSTOM agglomeration tests conducted prior to this program were also reviewed. Based on this information, an attrition test was designed and operated to conduct long term attrition studies.

\section{Summary of Literature Review}

The inorganic material in coal particles form low-temperature melting eutectics and is transferred by collision to the surface of the inert bed particles. This material forms a coating around the bed particles and continues to grow with time. If the coating grows large enough or is sticky, then it may lead to agglomeration and eventually defluidization. The local bed operating conditions play a clear role in avoiding defluidization. The bed will remain fluidized at a given temperature (below the ash softening point) as long as the velocity is above a critical velocity. This velocity is a function of not only the particle size but also the stickiness of the particle. One method to mitigate the effects of agglomeration is by the use of alternative bed materials or additives. One of the most promising methods is the use of bauxite as the bed material. Aluminum enrichment in the ash suppresses the formation of low-temperature melting eutectics and greatly reduces the tendency for a bed to agglomerate.

A number of observations related to the CMB design can be drawn from this review. First, ash deposition on the bed media is not unusual in fluidized bed combustion. The coatings on the particles are not a major problem unless they grow excessively thick or begin to stick to other particles. Defluidization is a rapid phenomenon and clearly needs to be avoided or acted upon quickly if it does occur. Operating the CMB bed at high velocities with dense and large particles certainly helps to alleviate the potential for agglomeration by breaking up agglomerates as they form. Furthermore, the use of bauxite as the bed media helps to suppress the formation of sticky deposits on the particles that can lead to agglomeration.

\section{Agglomeration vs. Defluidization}

Agglomeration and defluidization are often used interchangeably, but they refer to separate phenomena. Agglomerates are formed when individual particles become bonded together by a matrix of low-temperature melting eutectics. They are often loosely bonded and are continually broken up by the action of the bed. Small agglomerates will remain fluidized and are not a problem, unless they grow large enough to defluidize.

Defluidization tends to be a rapid phenomena, where the bed can be well fluidized and then almost immediately be completely inactive. As the bed defluidizes, the bed material will clump together on the air distributor and block the flow of fluidizing air. Since the forces holding the individual particles together are small, the air pressure will blow rat holes or channels through the bed. The pressure drop through the bed decreases dramatically as the channels appear. This behavior is commonly used as an indicator of the onset of 
defluidization. The agglomerates at this point tend to be loosely bonded and can be easily broken apart. This accounts for the ease with which a bed that has been defluidized can be refluidized if the velocity is increased. However, the lack of mixing in a slumped bed greatly reduces the heat transfer from any burning particles in this inactive region. If allowed to continue, the local temperature rises rapidly to the initial deformation temperature and large clinker formation begins.

\section{Bed Temperature and Velocity Relationship}

Many investigators have shown a strong relationship between bed temperature, velocity, and the tendency for a bed to experience agglomeration and defluidization problems. Hydrocarbon Research was developing the H-Iron Process in 1957 for iron ore reduction by hydrogen in a fluidized bed reactor. They had frequent defluidization problems and observed that fluidization stability improved with higher velocity, lower temperature, and larger particle size. They reported a fairly sharp boundary defined by these parameters where stable fluidization can be reliably achieved. For example, if the bed was fluidized at a constant velocity and the temperature was raised, a temperature would be reached where the bed defluidized - even though the velocity was still above the theoretical minimum fluidization velocity. Lowering the temperature restored the bed to the fluidized condition if it had not been held at the higher temperature too long, or if the higher temperature had not been hot enough to melt the ash. The same pattern was observed at constant temperature by lowering and then raising the fluidizing velocity.

Jeffrey Siegell's dissertation ${ }^{1}$ on particle agglomeration showed that fluidized beds containing mixtures of agglomerating (ash) and non-agglomerating (coke) particles exhibit a tendency to defluidize at high temperature and low velocity. His research focused on agglomerating beds due to the sintering of bed material at elevated temperature. He related the fluidizing velocity when defluidization occurs to a physical property of the ash, which was termed the initial sintering temperature.

Agglomeration can occur at temperatures several hundred degrees below the ash fusion temperature (as determined by the ASTM ash fusion test). Siegel found that each material had a temperature limit at which it became sticky and began to self-adhere. If a fluidized bed was fluidized at just the minimum fluidization velocity and its temperature was raised, then it would defluidize when the bed temperature was equal to the initial sintering temperature. His research was conducted in a dilatometer, which simultaneously measured the temperature and thermal expansion of a sample. Siegel found that the temperature at which the rate of sintering in the dilatometer significantly increased corresponds closely to the temperature at which a fluidized bed at minimum fluidization would defluidize.

Siegel also conducted defluidization experiments in a six inch fluidized bed with many materials, including coal ashes. His results confirmed that as the bed temperature was increased, the fluidization velocity also had to be increased to prevent defluidization from occurring. The agglomerates that he collected just after defluidization maintained their original shapes and showed no signs of melting. He concluded that the forces holding the particles were very weak and easily broken apart. This accounted for the ease with which a bed that had been defluidized could be refluidized if the velocity was increased. 
He also analyzed the defluidization process by high-speed photography and showed that there are two competing processes occurring in an agglomerating bed. First, agglomerates are formed with up to several particles due to sintering at a temperature just below the defluidization point. These agglomerates collide with other particles and are usually broken apart as long as the bed temperature is below the high temperature defluidization limit. Once the bed is above this limit, the rate of particle agglomeration greatly exceeds that of breakup and the bed will defluidize.

Siegel proposed an agglomeration model, which stated that the tendency for a bed to defluidize increased with temperature, but decreased with velocity, particle size, and particle density. This relationship implies that the CMB design conditions (high velocity, large particles, and high particle density) all work towards minimizing agglomeration at elevated temperatures. In particular the high particle kinetic energy in the CMB bed due to its high fluidizing velocity will help to overcome the particle necking formed during initial particle contact and thus permit operation at elevated temperatures.

Siegel tested 3 different coal ashes with several size ranges each. Figure 3.3-1 shows the results from a coal ash obtained from a Consolidated Edison plant for three sizes of coal ash. The red, blue, and green trend lines show the results with the 16x20, 20x30, and 30x40 mesh coal sizes, respectively. The results clearly show an increase in bed velocity needed for fluidization as temperature increases. For example, the blue trend line shows the trend for the 20x30 mesh coal ash (which is the ash size that will be typically present in a CMB bed). The bed will fluidize uniformly at velocities above this line, but will defluidize at velocities below this line. At normal CFB bed temperature $\left(1550^{\circ} \mathrm{F}\right)$, this ash requires bed velocities in excess of $4 \mathrm{fps}$. At $\mathrm{CMB}$ conditions $\left(2000^{\circ} \mathrm{F}\right)$, the minimum bed velocity increases to about 13 fps. The defluidization velocity is clearly a function of coal type. For example, the 20x30 mesh ash from an IGT coal sample required fluidizing velocities in excess of only 6 fps to remain fluidized at a bed temperature of $2000^{\circ} \mathrm{F}$.

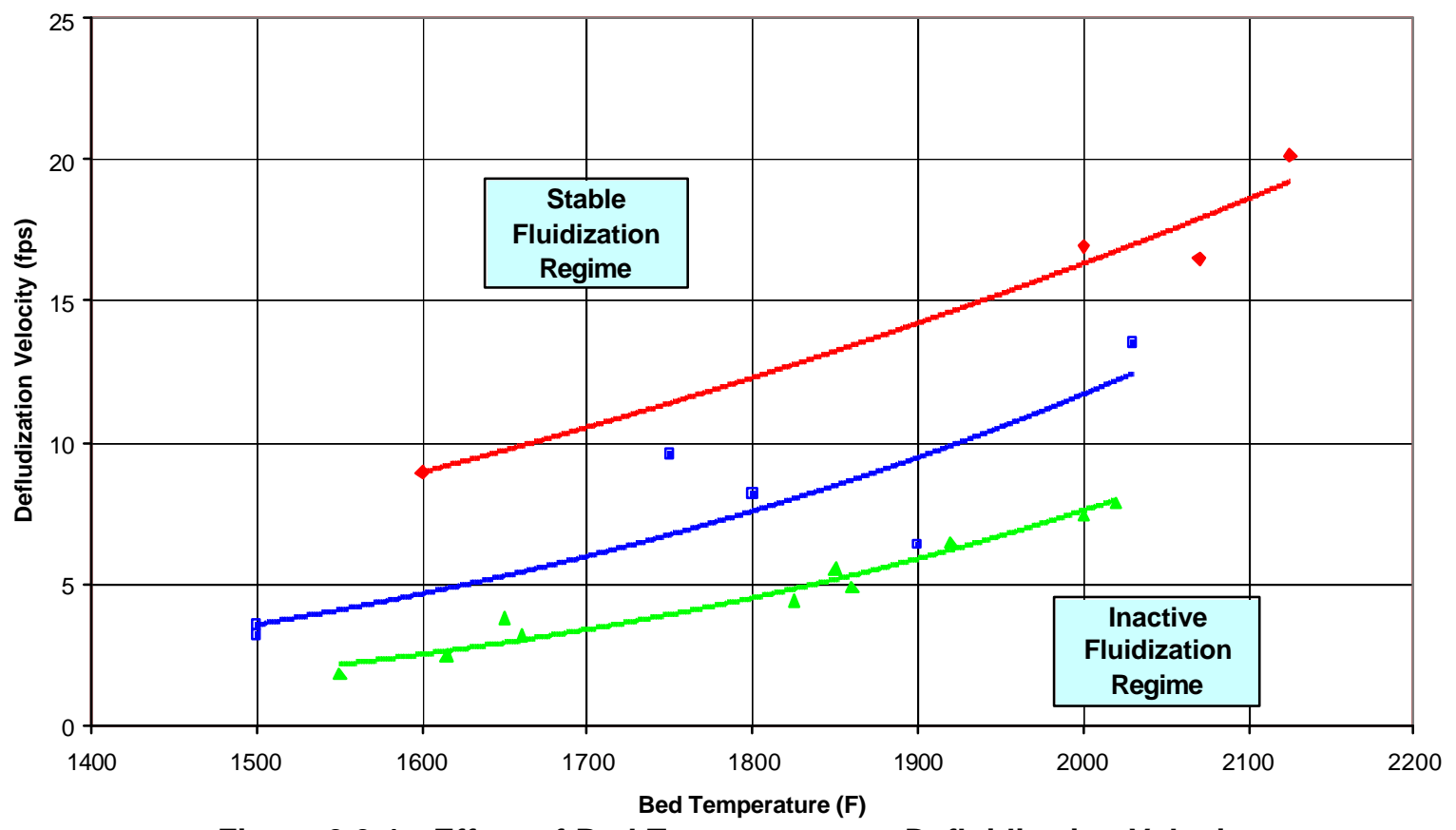

Figure 3.3-1: Effect of Bed Temperature on Defluidization Velocity 
Delvinquier $^{2}$ (1995) also studied defluidization in a low velocity fluidized bed after adding a small percentage of limestone to a sand bed. He attributed defluidization to the reaction between $\mathrm{CaO}$ and chemical compounds present as impurities on the sand surface. Figure 3.32 shows defluidization occurring at $850^{\circ} \mathrm{C}$ after the limestone addition, as evidenced by the sudden drop in the bed pressure drop (blue trend line). Delvinquier then gradually decreased the bed temperature (red trend line) over the next hour. When the bed temperature dropped to $640^{\circ} \mathrm{C}$, the bed suddenly refluidized. When he increased the temperature, the bed defluidized again as soon as the temperature hit $850^{\circ} \mathrm{C}$. These results are consistent with the results of Siegell and demonstrate the influence of temperature on the defluidization behavior.

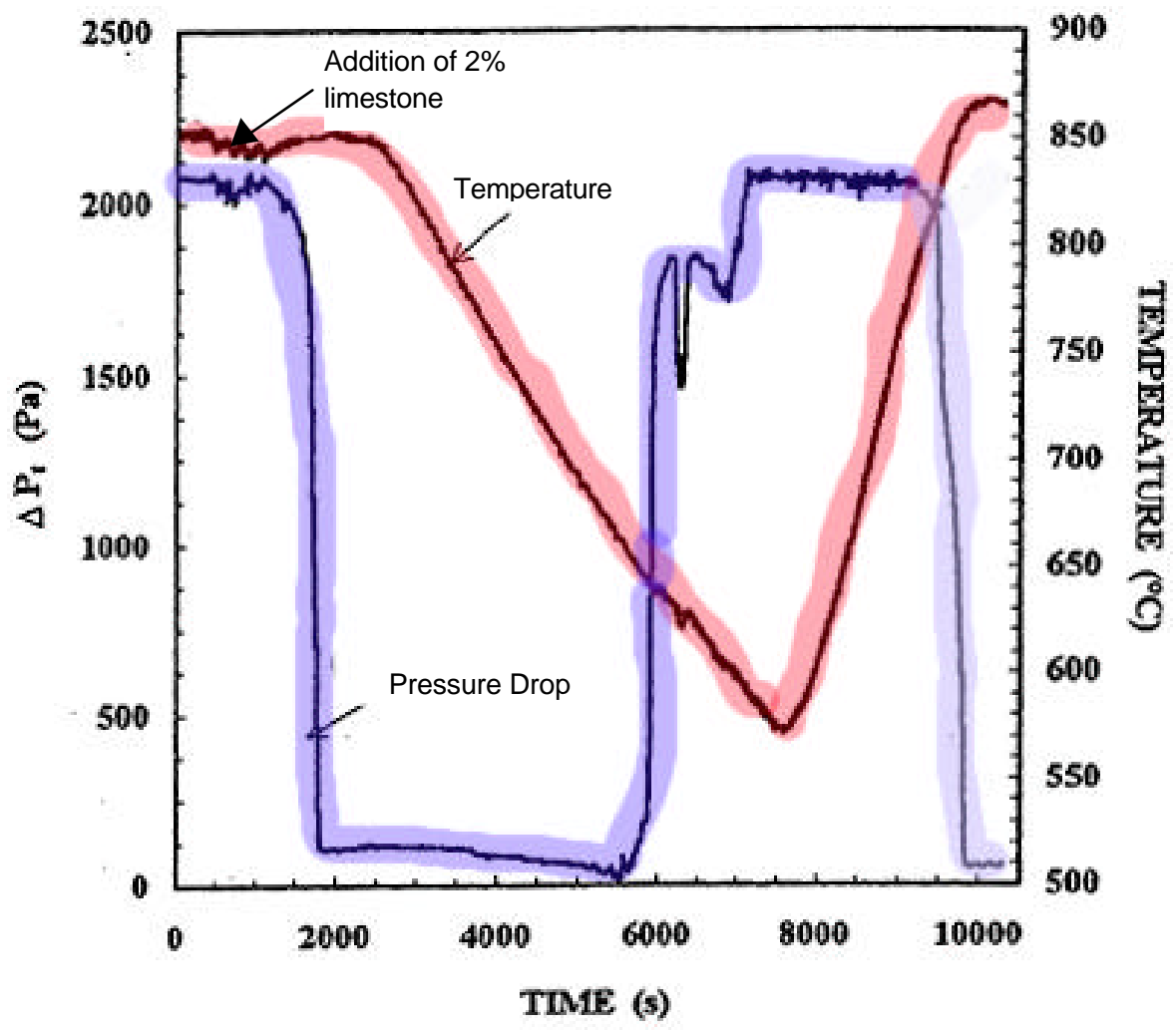

Figure 3.3-2: Effect of Bed Temperature on Defluidization

Agglomeration Mechanism

Agglomeration in a fluidized bed is a dynamic process, with small agglomerates being continually created and destroyed. When two particles come in contact with each other, they will tend to join together into a single particle. The driving force for this will be a decrease in surface area and thus surface energy. Since the bed is fluidized, it is more than likely that the particles will contact with sufficient kinetic energy to break apart and overcome the forces attempting to bond them together. However, the bed will quickly defluidize if the temperature is raised sufficiently such that the particles coming in contact will bond together with sufficient strength (due to the increased rate of sintering) to overcome their kinetic energy. If the particles remain at this high temperature they will eventually coalesce into a single dense particle of spherical shape because a sphere has the smallest surface energy for a given particle volume. ${ }^{3}$ 
There are several stages of sintering. The initial stage is caused by the occurrence of stresses from the contact of particles. The particles begin to adhere as some material transfers and early neck growth begins. The particles are easily broken apart by particle collisions at this initial stage of sintering. However, defluidization can occur if the kinetic motion of particles in the bed is insufficient to break the particles apart.

The second stage consists of densification in the bond zone area. Material is transported to this zone as the area of the bonding increases and the particle centers begin to move together. At this point, the particles cannot be easily broken apart at the boundary. The final stage is the continued and complete densification of the two particles into one.

In fluidized bed coal combustion, the initial stage of agglomeration involves the deposition of ash on the bed particle surfaces. The intermediate stage of agglomeration occurs when two or more ash-coated bed particles join together via sulfate sintering to form a composite particle. The portion of the ash coating in mutual contact with two of the original bed particles is referred to as a neck growth.

\section{FBC Agglomerate Formation}

The coal particle surface in a fluidized bed combustor can be several hundred degrees hotter than the surrounding bed particles and can approach the melting temperature of various mineral phases. This molten material migrates to the surface of the burning char particles. It then transfers to the surface of inert bed particles during collisions with the bed media. This forms a coating around the bed particle that will continue to grow in thickness with time.

Most of the ash deposition onto bed particles or cohesion between particles results from the melting or softening of aluminosilicate material from clay in the coal ash. This material flows onto the bed particles and also bridges with other particles. The presence of fluxing agents lowers the melting point of these clays and helps to initiate ash deposition and agglomeration. The iron pyrites associated with high sulfur coals is an example of an agent that fluxes with the aluminosilicates. Low-rank fuels are a particular problem as the inorganic constituents $(\mathrm{Na}, \mathrm{Ca}$, and organically bound $\mathrm{S}$ ) transform to form low-temperature melting eutectics (alkali sulfates) at fluid bed operating temperatures.

Many investigators observed the formation of a coating on the bed particles. The ash deposition on the bed material is an ongoing process and is a precursor for agglomeration and defluidization. The composition of the ash coating does not change significantly with temperature, exposure time, bed particle size, or oxygen partial pressure. However, these factors, and particularly the bed temperature, affect the rate of deposition on the coating. Furthermore, the tendency for bed particles to agglomerate increases with furnace temperature. Temperature alters the properties of the ash coating by either causing a new compound to melt and/or altering the physical properties of the ash coating (e.g. viscosity).

A physical transfer process mostly likely causes the ash coating when the bed particles collide with the coal particles. Investigators have not found any evidence that deposition of the inorganic matter on bed particles is caused by chemical reaction or by vapor condensation. The sharp boundary between bed material and ash coating is seen as 
confirmation of an absence of a chemical attack of the bed material surface. The distinct interface between coating and particle also is consistent with a lack of chemical reaction. ${ }^{4}$

The coated particles may also bond with other particles if the bed motion is not turbulent enough to break the bond between the particles. Agglomerates develop when sintering occurs between the coated bed particles as a result of a small amount of melt (eutectics) present in the solid matrix of the ash coating. At the interface between particles, a limited coalescence takes place, resulting in the formation of a bond between the coatings on the bed particles. $\mathrm{X}$-ray diffraction analysis shows that inorganic matter is distributed uniformly in the coating around the bed particles, including at the interface between bed particles. Secondary mineral reactions occur after the agglomerates have formed and tend to strengthen the agglomerates. This includes the reaction of calcium particles with the melt, with the void space between agglomerate particles being filled with recrystalized calcium sulfate.

\section{Agglomeration Mitigation}

Vuthaluru ${ }^{5}$ was studying control methodologies for mitigating ash-related problems during FBC combustion of low rank coals. His studies showed that aluminum-rich materials could be used as alternative bed materials or as additives for controlling ash deposition and agglomeration. These materials helped prevent the chemical reactions between silica (from a sand bed) and alkali species. This allowed higher proportions of solid phases to form on the surface of these bed materials. His tests were conducted in a fluidized bed reactor with an Australian low-rank coal that severely agglomerated at FBC conditions. Although his tests did not eliminate these problems, they did show a means to greatly slow down the ash deposition process.

His most promising results were obtained when he replaced the sand bed with a bed of bauxite. Tests with bauxite as the bed material showed trouble-free operation for an operating period ten times longer than with a sand bed at the same temperatures. He observed that the deposition rate on the sand was almost 4 times faster than for the bauxite. Furthermore, the coating on the sand particles was apparently sticker. The sand particles began agglomerating and eventually defluidized with a much thinner coating than was observed with the bauxite particles. Results show that the coating on both bed materials was enriched in $\mathrm{Na}$ and $\mathrm{S}$ compounds. However, the ash coating on the bauxite particles was also enriched in aluminum and had complex silicates with $\mathrm{Fe}, \mathrm{Mg}$, and $\mathrm{Ca}$. In the presence of aluminum-rich phases, the eutectics became less sticky at typical fluidized bed combustion temperatures. He stated that the key mechanism associated with agglomeration and defluidization control was the formation of these aluminum-rich mineral phases in the ash coating on bed materials. He postulated that the eutectics soaked into the pores of the bed material and did not form any distinguishable ash-coating layer. In addition, interaction with bed material resulted in the formation of the aluminum-rich phases, rendering the ash coating less sticky at FBC temperatures.

\section{Prior ALSTOM Bench Scale Results}

A series of agglomeration tests were conducted in ALSTOM's 4-inch FBC reactor with three different coals prior to the start of the CMB Proof of Concept program. The objective of these tests was to demonstrate that a range of coals could be burned in a bubbling bed of 
primarily bauxite particles at elevated temperatures without agglomeration or defluidization. These tests were run at temperatures close to $2100^{\circ} \mathrm{F}$ for up to 48 hours. The first coal tested was a West Virginia bituminous coal, which is a good quality low sulfur bituminous coal. The coal was initially burned in a bed of West Virginia coal ash and quickly formed a large number of agglomerates - some up to 0.5 inch after only 7 hours at $2000^{\circ} \mathrm{F}$. The coal was then burned in a bed of bauxite and formed only about a half dozen small pea-sized pellets after 48 hours of testing. These pellets were very friable and easily broken. In addition, a thin (about 10-20 microns) coating of ash formed around the bauxite particles. This test was the first indication that a bauxite bed may help to avoid or delay the onset of agglomeration.

Figure 3.3-3 shows a scanning electron microscope (SEM) photo of one of the small agglomerates formed while burning the West Virginia coal in the bauxite bed. It shows the presence of a thin coating around the bauxite particles and a thicker layer of material loosely bonding the particles together. This material was typical of all of the tests and was enriched with calcium aluminum silicates.

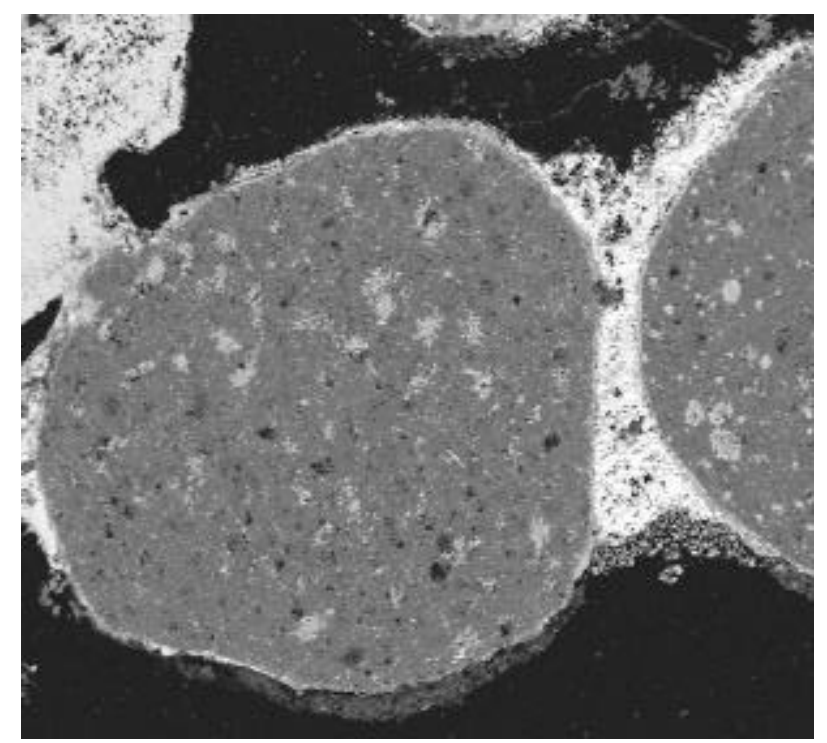

Figure 3.3-3: Bauxite Coating and Bonding During 4 Inch FBC Test

North Dakota lignite was next tested in the 4-inch reactor. This fuel has a high sodium content and is a notorious agglomerating fuel in FBC applications. This fuel was initially burned in a bed of West Virginia coal ash and quickly agglomerated at $2000^{\circ} \mathrm{F}$. The test was then repeated with a bauxite bed controlled to under $2100^{\circ} \mathrm{F}$ for 28 hours. This test resulted in the formation of many pea-sized pellets and the same ash coating seen with the Thames coal. However, the bed remained well fluidized for the duration of this test

The last fuel tested was Pittsburgh \#8 coal. This high sulfur bituminous coal has a high iron content in the ash and is a problem fuel (slagging) in certain applications. This test was run for 48 hours, with the formation of numerous small pellets and the familiar ash coating around the bauxite particles. As with the other tests, the bed remained fluidized throughout the test despite the formation of some very friable agglomerates. 


\section{Prior ALSTOM Pilot Plant Tests}

Based on these bench scale results, ALSTOM proceeded to demonstrate that the MTF could be run at elevated temperatures for extended periods of time without any agglomeration problems. These tests were also conducted prior to the start of the CMB Proof of Concept program. The MTF had not yet been modified for CMB operation, so the MTF was operated as a high temperature bubbling bed without a bauxite recirculation loop. West Virginia and Pittsburgh \#8 coals were both burned for at least 48 hours at temperatures up to $2160^{\circ} \mathrm{F}$ in a bubbling bed comprised primarily of bauxite.

The bed was more robust than we anticipated and we were able to operate with both fuels without any signs of agglomeration or defluidization at temperatures greater than $2100^{\circ} \mathrm{F}$. This was very encouraging, as the $\mathrm{CMB}$ design must be able to tolerate bed temperatures greater than the design value, either due to occasional temperature excursions or local hot spots due to fuel imbalances. However, there was a slow growth in an ash coating that surrounded the bauxite particles.

The ash accumulation observed on the bauxite surface during the MTF tests can have some long-term effects on CMB operation, particularly as they impact bed hydrodynamics and heat transfer in the combustor. The bed pressure drop will gradually increase as the ash builds up on the particles. This requires that the bed inventory be periodically drained, which will result in the loss of some bauxite. The gas-to-solids heat transfer rate is also a strong function of particle size. Larger particle sizes will have higher terminal velocities and thus shorter residence times for heat transfer. There will also be less heat transfer surface area due to fewer (but larger) particles if the solids inventory is reduced to maintain a constant bed pressure drop. This results in a reduction in heat transfer and an increase in the combustor gas outlet temperature.

The ash growth on the bauxite particle size needs to be managed to some maximum size level to maintain acceptable boiler performance. It is possible that the ash coating growth may be controlled by the CMB operation itself. The bauxite temperature history in this MTF test was not representative of a commercial CMB boiler. The bauxite particles were exposed to high bed temperatures for the full duration of this test. They experienced over 2 days of temperatures over $1095^{\circ} \mathrm{C}\left(2000^{\circ} \mathrm{F}\right)$ in both the West Virginia and Pittsburgh \#8 coal tests. However, the bauxite particles in a commercial CMB boiler only see about 8 minutes of exposure time in the bed before they pass through the moving bed heat exchanger and are then returned to the combustor. One complete circuit through the CMB could take up to 2 hours. So, the bauxite particles were actually exposed to the high temperature bed environment 15 times longer in the MTF test than the bed exposure time expected in a commercial CMB boiler. In fact, the 2-day MTF test for each coal was equivalent to 30 days of total elapsed time in a commercial CMB boiler. However, the particles in the commercial unit would also be subjected to considerable mechanical abrasion as they passed through the moving bed heat exchanger and then through the pneumatic transport line back to the top of the combustor. None of this additional abrasion was simulated in the MTF test. It was expected that at least some if not all of the particle coating would be worn off with time, which would slow down the actual coating growth rate. It was therefore decided to build an attrition test rig to determine how fast the coating would be removed through attrition. 


\section{Attrition Testing}

An attrition test rig was constructed to simulate the mechanical abrasion the particles would be subjected in a commercial CMB boiler. The CMB boiler uses a pneumatic transport system to transfer bauxite heat transfer particles from the moving bed heat exchanger (MBHE) to the top of the combustion chamber. The transport system will consist of a series of pipes having short horizontal runs from the MBHE, to a vertical pipe about 100 feet in length, to another short horizontal run, and into a disengaging cyclone. There will be two or more elbows in the system. The proposed elbows are impact tees that have desirable wear and pressure drop characteristics.

Bauxite particles moving through the pneumatic transport system will experience a series of impacts with adjacent particles, the pipe wall, impact tees, and other components. These impacts will cause some of the ash coating to be attrited from the bauxite particles. Tests were therefore conducted to measure the attrition rate during the pneumatic transport process. The tests were run long enough to give the particles the same transport line residence time that they would have had in a commercial CMB boiler over a 30 day period.

Bauxite particles drained from the bubbling bed during previous high temperature MTF tests were used for the attrition tests. The particles were sized between 16 and 30 mesh and air classified to remove particles having densities lower than bauxite.

\section{Facility Description}

The test facility used to measure attrition rates during pneumatic transport of bauxite is shown in Figure 3.3-4. The test section consisted of a horizontal 2-inch pipe at the solids inlet. A $90^{\circ}$ steel impact elbow directed the flow upwards to a 2 inch x $52 \mathrm{ft}$ long vertical hose section to a second $90^{\circ}$ impact elbow, then through a horizontal 2 inch tube to a cyclone separator. The $90^{\circ}$ impact elbows and the lower elbow contained pressure taps for pressure drop measurements. Bauxite captured by the cyclone dropped through a material hopper, down a vertical 2-inch pipe to a 4-inch plexiglas storage column. A 1-inch pipe column and pinch valve under the 4-inch column was used to control the solids flow rate and to seal the material downflow column against transport air pressure.

A venturi flow meter was mounted at the transport air inlet to measure the transport airflow rate. A material supply hopper located under the cyclone separator was empty during normal operation. A knife gate valve at the bottom of the hopper could be closed so that bauxite being transported was captured and weighed by the load cell supporting the hopper. This provided a transport rate for solids. Transport air exiting the cyclone passed through an aspirator and into a bagfilter suspended on a load cell. Attrited particles were caught in the bagfilter and weighed by a load cell. The filter media of the bag was rated to capture particles of 1 micron or greater. The load cell supporting the bagfilter provided a filter weight that could be monitored to determine the filter catch of attrited particles during the test duration. In addition a pressure cell reading of filter cake buildup on the filter walls was a further indication of filter bag loading. 


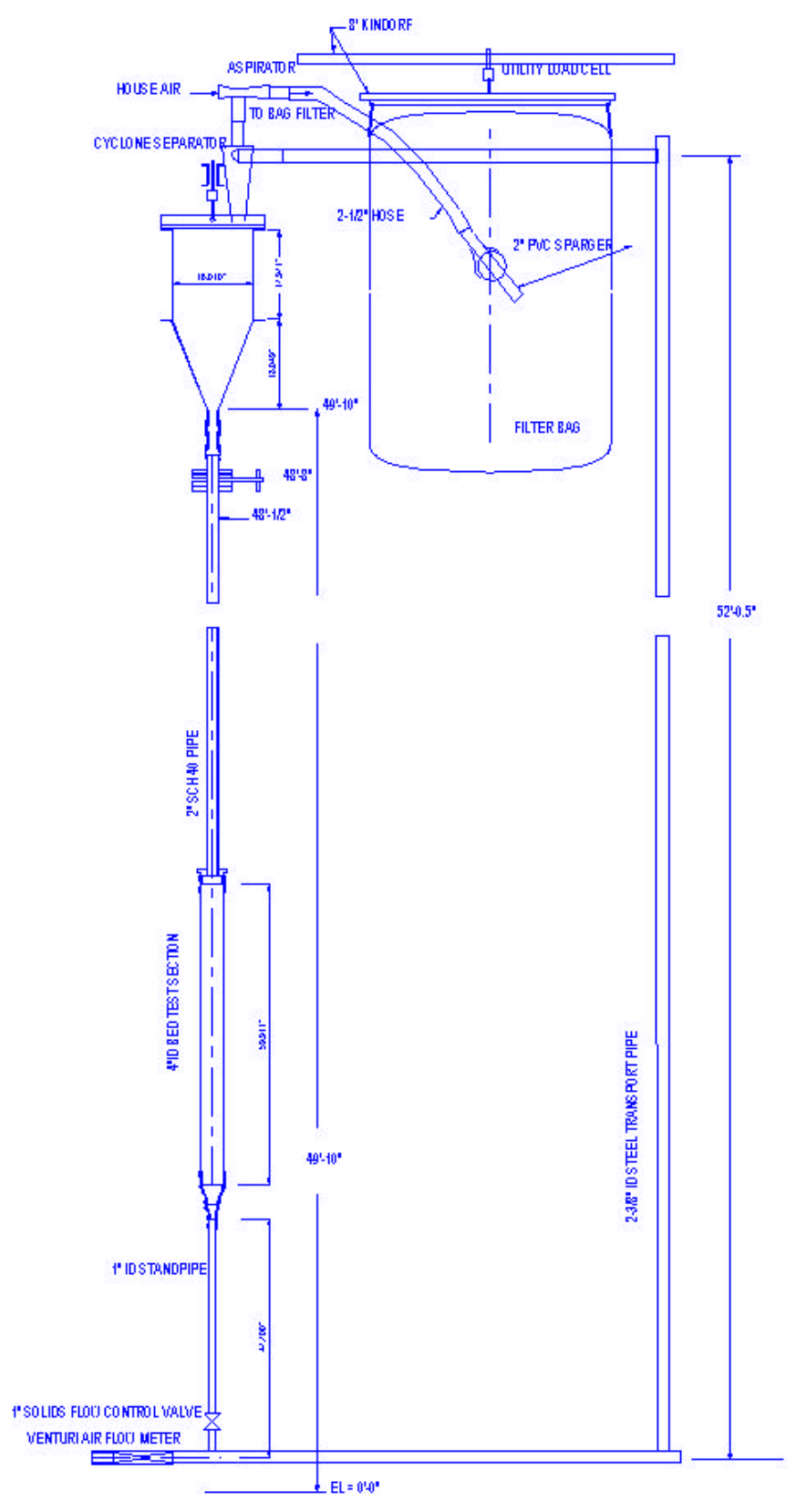

Figure 3.3-4: CMB Attrition Test Rig

The test facility was instrumented to measure and record airflow, particle supply hopper weight, filter bag weight, and several pressure drops. They were connected to a Fluke 2204A data acquisitions system that interfaced with a PC computer through a Labview data acquisition program. Data from the instruments was monitored and trends plotted on the computer screen for review of the data and setting of operating conditions. Data was recorded to a spread sheet file in the computer hard drive every 5 minutes for normal operation and every 3 seconds for those times when solids flow rates were determined by collecting solids in the supply hopper. 


\section{Test Procedure}

A preweighed charge of bauxite particles was added to the system and pneumatically transported from the bottom to the top of the loop, passed through a disengaging cyclone, and allowed to free fall to the bottom and then repeat the cycle. To do this, the airflow to the test facility was set to a desired value, the inlet air venturi removed, and a charge of bauxite aspirated into the top hopper. The venturi was reinstalled and a test was initiated by dropping the bauxite into the 4-inch storage column. Then the 1-inch pinch valve below the column was opened until a vertical test section pressure drop of desired value was obtained that was representative of that for a desired solids flow rate. The test was operated for a period of 2070 hours. Blinding of the filter by attrited material caused the flow to slowly drift. A periodic adjustment of the air supply to the aspirator brought the velocity back to the desired value.

At selected times, the 2-inch knifegate valve at the bottom of the material hopper at the top of the facility was closed without any other adjustment to the system. The material was collected in the hopper and the weight was recorded by the load cell and data acquisition system. The mass flow rate of the transported material was then calculated by comparing the hopper weight gain vs. time. When sufficient material was collected the 1-inch column pinch valve was closed, the transport pipe cleaned out by transport air, and the 2 -inch valve at the hopper bottom was opened to fill the 4-inch column. The 1-inch pinch valve was then opened and flow conditions were reset.

At the end of a test the supply hopper bottom valve was closed and all bauxite was collected in the top hopper. The test facility was shut down. The 1-inch pinch valve was disconnected at its bottom, the top hopper valve opened, and bauxite drained down through the 1-inch pinch valve into a collecting bucket. The collected bauxite was then weighed to determine the weight loss of the charge due to attrition. This weight loss served as a check on the filter bag particle weight increase. Samples of the bauxite supplied at the start of the test and after the test were taken for a mesh screen size distribution analysis.

The collecting filter bag was opened and a sample of the collected particles was taken for the first test for chemical and size distribution analysis. The filter bag sample was not taken for subsequent bauxite tests, because the bag could not be easily cleaned to remove material and to prevent cross contamination of material from one test to another.

\section{Results}

Attrition results for a typical test are given in Figures 3.3-5. The red trend line shows the attrited ash accumulation in the filter bag. The blue trend line shows the increased filter pressure drop as the ash built up on the bag. The green trend line shows the transport velocity in the test column. A review of the filter bag weight gain with operating time indicated an initial exponential gain that slowly decreased to a linear gain. This weight data was fit by regression analysis to determine the linear rate and the exponential weight. The regression results were then differentiated to determine the initial attrition weight loss and final linear attrition weight loss. This analysis assumed that some of the agglomerated material was easily attrited at the start of the transport process. Harder and more adherent material was then removed at a lower rate. 


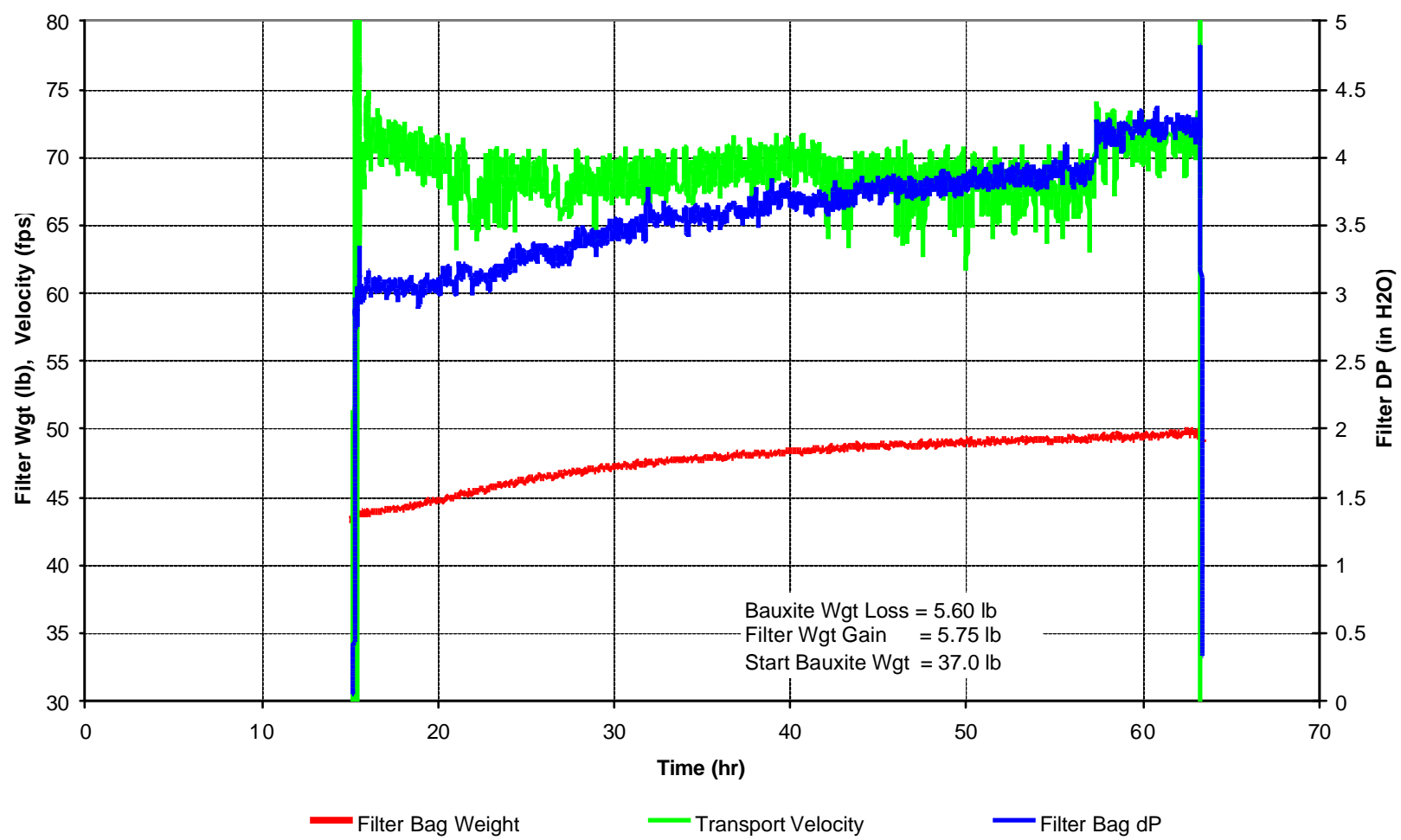

Figure 3.3-5: Filter Weight Gain from Attrition

The test data for four tests is summarized in Table 3.3-1. There were reasonable balances between the material lost from the initial bauxite fill to the bauxite collection at the end of the test and the material captured in the filter bag. The attrited particle sizes were significantly reduced compared to the initial diameter.

Table 3.3-1: Pneumatic Transport Attrition Results

\begin{tabular}{|c|c|c|c|c|c|c|c|c|c|c|c|c|c|}
\hline Test & $\begin{array}{l}\text { Start } \\
\text { Date }\end{array}$ & $\begin{array}{l}\text { Test } \\
\text { Duration } \\
\text { hr }\end{array}$ & $\begin{array}{l}\text { Average } \\
\text { Transport } \\
\text { Velocity } \\
\text { fps }\end{array}$ & $\begin{array}{l}\text { Supply } \\
\text { Material }\end{array}$ & $\begin{array}{l}\text { Particle } \\
\text { Supply } \\
\text { Weight } \\
\text { lb }\end{array}$ & $\begin{array}{l}\text { Particle } \\
\text { Weight } \\
\text { Loss } \\
\text { lb }\end{array}$ & $\begin{array}{l}\text { Transport } \\
\text { Discharge } \\
\text { Filter } \\
\text { Weight } \\
\text { Gain lb }\end{array}$ & $\begin{array}{l}\text { Supply } \\
\text { Mean } \\
\text { Particle } \\
\text { Diameter } \\
\mu\end{array}$ & $\begin{array}{l}\text { Attrited } \\
\text { Mean } \\
\text { Particle } \\
\text { Diameter } \\
\mu\end{array}$ & $\begin{array}{l}\text { Approxim } \\
\text { ate } \\
\text { Coating } \\
\text { Thickness } \\
\mu\end{array}$ & $\begin{array}{l}\text { Particle } \\
\text { Diameter } \\
\text { Weight } \\
\text { Loss } \\
\text { lb }\end{array}$ & $\begin{array}{l}\text { Initial } \\
\text { Attrition } \\
\text { Rate } \\
\% / \mathrm{hr}\end{array}$ & $\begin{array}{l}\text { Final } \\
\text { Attrition } \\
\text { Rate } \\
\% / h r\end{array}$ \\
\hline $\begin{array}{l}1 \\
2\end{array}$ & $\begin{array}{l}9 / 18 / 01 \\
9 / 24 / 01\end{array}$ & $\begin{array}{l}67 \\
21\end{array}$ & $\begin{array}{l}68.5 \\
53.7\end{array}$ & $\begin{array}{l}\text { Pitt \#8 } \\
\text { Pitt \#8 }\end{array}$ & $\begin{array}{l}45.0 \\
31.4\end{array}$ & $\begin{array}{l}6.7 \\
2.7\end{array}$ & $\begin{array}{l}7.7 \\
3.0\end{array}$ & $\begin{array}{l}780 \\
780\end{array}$ & $\begin{array}{l}700 \\
730\end{array}$ & $\begin{array}{l}35 \\
35\end{array}$ & $\begin{array}{c}11 \\
5\end{array}$ & $\begin{array}{l}0.86 \\
0.56\end{array}$ & $\begin{array}{l}0.1 \\
0.1\end{array}$ \\
\hline 3 & $9 / 26 / 01$ & 45 & 65.2 & West Virg & 37.0 & 5.6 & 5.8 & 750 & 710 & 20 & 5 & 1.45 & 0.1 \\
\hline 4 & $10 / 02 / 01$ & 62 & 68.3 & Bauxite & 42.0 & 7.3 & 6.8 & 710 & 680 & 0 & 5 & 0.02 & 0.3 \\
\hline
\end{tabular}

Figure 3.3-6 compares two bauxite particles from this test. The first particle was from the MTF high temperature test with Pittsburgh \#8 coal and had an ash coating about 60 microns thick. This material was loaded into the attrition rig at the start of the test. The second photo shows a typical bauxite particle after being recirculated through the transport line for 60 hours. The average coating thickness was 11 microns. These results show that almost $85 \%$ of the ash coating attrited off during transport. The coated bauxite from the West Virginia coal test was completely attrited down to the original bauxite surface in its attrition test. The attrition rate in all cases was dependent upon transport velocity, with higher transport velocities resulting in faster attrition rates. 

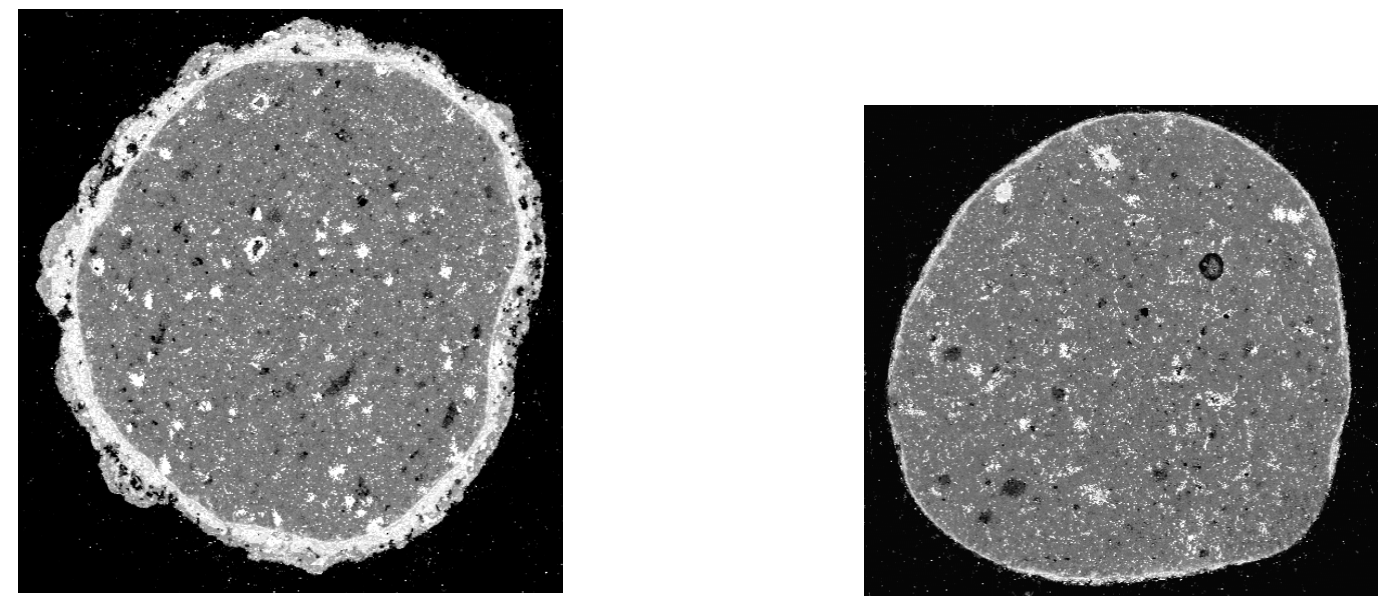

Figure 3.3-6: Effect of Attrition on Bauxite Coating

The chemical analysis of the attrited material was consistent with the coating analysis. Table 3.3-2 shows the atritted ash chemical composition for the tests that used coated bauxite from the MTF test with Pittsburgh \#8 coal. The ash composition was primarily comprised of $\mathrm{SiO}_{2}$, $\mathrm{Al}_{2} \mathrm{O}_{3}, \mathrm{Fe}_{2} \mathrm{O}_{3}$, and $\mathrm{CaO}$.

\section{Table 3.3-2: Attrited Ash Chemical Composition}

$\begin{array}{lcllc} & \text { Wt } \% & & & \\ \mathrm{SiO} 2 & 21.2 & \text { Density } & \mathrm{lb} / \mathrm{ft} 3 & 183 \\ \mathrm{Al2O} 3 & 47.1 & & & 6 \\ \mathrm{Fe} 2 \mathrm{O} 3 & 11.8 & & & \\ \mathrm{CaO} & 14.9 & \text { \% Total C } & 1.98 \\ \mathrm{MgO} & 0.4 & \text { \% Total S } & 0.02 \\ \mathrm{Na} 2 \mathrm{O} & 0.2 & & \\ \mathrm{~K} 2 \mathrm{O} & 0.1 & & \\ \mathrm{TiO} 2 & 2.7 & & \\ \mathrm{P} 2 \mathrm{O} 5 & 0.6 & & \\ \mathrm{SO} 3 & 0.0 & & \\ \mathrm{BaO} & 0.0 & & \\ \mathrm{MnO} & 0.2 & & \\ \mathrm{SrO} & 0.1 & & \end{array}$

The attrition test results show that an appreciable amount of attrition can take place in the pneumatic transport lines. This attrition may be sufficient to control the coating growth observed in the high temperature MTF tests. The amount of attrition that takes place may be different at higher transport temperatures. The MTF test campaign results discussed in Section 6.3 provide further discussion about the ash coating growth during CMB operation in the MTF. 


\subsection{Bed Mixing}

The objective of this task was to assess the lateral dispersion of fresh coal and limestone in the CMB bubbling bed and it's impact on fuel feed system design. Vertical mixing tends to be very rapid in fluidized beds because of the intense mixing promoted by the rising bubbles. Bed temperatures are normally very uniform in an axial direction. However, lateral mixing in fluidized beds is not as rapid and this can lead to temperature variations along the length of the bed if the fuel is not adequately distributed. Lateral solids mixing primarily occurs by solids spreading in the freeboard. Solids are injected into the freeboard during the eruption of exploding bubbles at the bed surface.

Good fuel dispersion is necessary to avoid local hot spots in the bed that could result in bed agglomeration or defluidization. Knowledge of the fuel dispersion is thus necessary for designing a fuel feed system that ensures uniformity of feed, minimizes bed temperature variations, and promotes good combustion and emission reduction. Design options range from a small number of sidewall feed locations similar to that of a circulating bed to a complicated arrangement of under-bed feed points. The mixing characteristics of the bubbling bed will dictate the complexity of the feed system that is required.

Bed mixing characteristics were assessed by developing an analytical prediction of the lateral dispersion and mixing within the bed. A simplified mixing model was derived that used dispersion coefficients obtained from published experimental work as the basis for the predictions. These results were then used in Task 5.1 to develop a conceptual design for a commercial fuel feed system.

The literature was reviewed for horizontal dispersion data for similar fluidized bed conditions. The most relevant data found was recently published by Werther et. al, ${ }^{1}$ who investigated the solids mixing in the lower region of a circulating fluidized bed. The lower, dense bed region for large diameter circulating beds operate at high ratios of superficial gas velocity to minimum fluidization velocity. The hydrodynamics in this region are similar to a high velocity bubble regime, not a turbulent flow regime. In the CMB, the dense bubbling bed also operates at a high value of the ratio of superficial gas velocity to the minimum fluidization velocity, $\mathrm{U}_{\mathrm{o}} / \mathrm{U}_{\mathrm{mf}}$.

Werther measured the degree of mixing by injecting a solid carbon dioxide tracer into a cold flow CFB model and then measuring the local gas concentration and temperatures. His results showed that the lateral mixing in the lower region of the CFB beds is much higher than previously observed for low velocity bubbling beds. Figure 3.4-1 shows relatively low horizontal dispersion coefficients for low velocity bubbling beds. However, the dispersion coefficient $\mathrm{D}$ for high velocity beds, such as the lower region of a CFB or a CMB, is two orders of magnitude higher, with typical values around $0.1 \mathrm{~m}^{2} / \mathrm{s}$. Assuming this applies uniformly throughout the dense bed, an estimate of the horizontal mixing around a feed point can be made. 


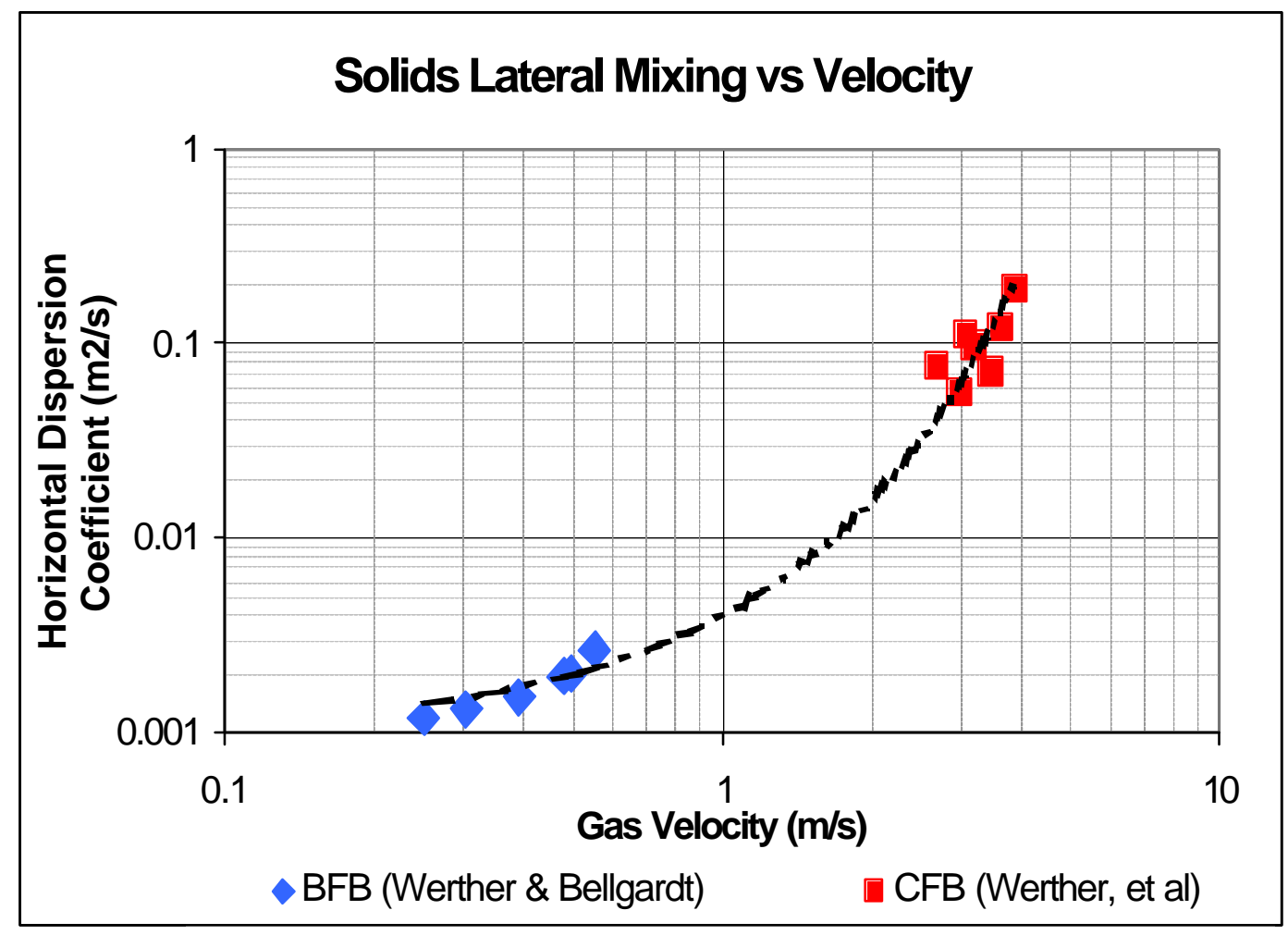

Figure 3.4-1: Impact of Bed Fluidizing Velocity on Solids Lateral Mixing

For good dispersion within a horizontal distance L of the feed point, the dimensionless number involving D, analgous to the Froude number in heat transfer, should be

$$
\frac{D t_{D B}}{L^{2}}=1 \rightarrow 3
$$

To estimate the time assume that they move in plug flow. If the depth of the dense bed is $\mathrm{H}$ and the total bed cross sectional area is $A_{c s}$, then at steady state the time the solids spend moving through the dense bed can be found as,

$$
t_{D B} \frac{\dot{m}}{A_{c s}} A_{C S}=H \rho_{S}(1-\varepsilon) A_{C S}
$$

where $\varepsilon$ is the average void fraction in the dense bed. Estimating $\varepsilon$ as $0.58, \rho_{S}$ as 3600 $\mathrm{kg} / \mathrm{m}^{3}, \mathrm{H}$ as $0.9 \mathrm{~m}$, and the downward mass flow rate as $3.5 \mathrm{~kg} / \mathrm{m}^{2} \mathrm{~s}$, $\mathrm{t}_{\mathrm{DB}}$ can be estimated as 392 seconds. Using this value of $t_{\mathrm{DB}}$ along with Werther's value of the dispersion coefficient results in a distance $\mathrm{L}$ of approximately 3.6 to $6.3 \mathrm{~m}(12-21 \mathrm{ft})$.

Based on the bed mixing model prediction, good bed mixing and correspondingly uniform bed temperatures can be achieved if the fuel feed points are no more than about 4 to 6 meters apart. This type of fuel distribution can be easily met with an overbed spreader type of feeder. The conceptual design of a CMB fuel feed system that meets these requirements is further discussed in Section 4.1. 


\subsection{In-Furnace and FDA Sulfur Capture}

The objective of this task was to evaluate the factors that impact sulfur capture in both the $\mathrm{CMB}$ combustor and in the backend Flash Dry Absorber (FDA) system. The CMB process is unique in that the system can be optimized to capture sulfur in a number of manners. One method is to use the combustor primarily as a calciner and then do most of the sulfur capture in the FDA system. This approach minimizes the formation of a sulfate shell on the sorbent particles, which should increase the sorbent reactivity and performance in the FDA. Another approach is to maximize the sulfur capture in both the furnace and the FDA system. It is possible that both approaches will be used under different operating conditions. For example, the CMB may be optimized for sulfur capture primarily in the FDA while operating at full load conditions. However, at low load conditions, the bed temperature will be reduced towards the optimum temperature window for sulfur capture (see Section 3.7 for further discussion). In this case, significant sulfur capture can take place in the combustor and the FDA can then be used for final polishing.

This section first discusses in-furnace sulfur capture, including boiler efficiency impacts, particle size effects on sorbent calcination, and temperature effects. The section then discusses sulfur capture in the FDA system.

\section{In-Furnace Sulfur Capture}

Boiler Efficiency Impact

The CMB combustor achieves sulfur capture through a combination of in-furnace sulfur capture and sulfur capture in the backend FDA system. This is similar to the method used in many CFB boilers to achieve high levels of sulfur capture. However, the distribution of sulfur capture between the combustor and FDA system can be quite different between the two systems. One area where this difference is seen is boiler efficiency.

The sulfation reaction is very exothermic. In conventional CFB boilers, most of the sulfur removal takes place within the combustor, while the FDA or comparable system is used primarily for final polishing of the gas. The sulfation energy released in the furnace heats up the combustion gases. At these high temperatures, the energy can be readily recovered. This energy is treated as a boiler efficiency credit when it is released in the combustor. Energy is also released when the sulfur is captured in the FDA. However, the gas temperature at this location is so low that any gas temperature rise due to sulfation cannot be effectively recovered. Thus, a boiler efficiency credit only occurs when the sulfur is captured in the furnace.

Figure 3.5-1 shows the effect of combustor sulfur removal on the boiler efficiency credit for two different coals. The high sulfur coal represented by the upper red line is for a $4 \%$ sulfur coal with $35 \%$ ash. The lower blue line is for a $2 \%$ sulfur coal with $12 \%$ ash. The maximum boiler efficiency credit for these coals occurs when all of the sulfur is captured in the furnace. The shaded red region shows the typical range of in-furnace sulfur capture in CFB boilers. CFBs typically capture $80 \%-95 \%$ of the sulfur in-furnace and get almost the full sulfation credit at reasonable $\mathrm{Ca} / \mathrm{S}$ mole ratios. This is because the sorbent has such a long residence time at the optimum furnace temperature for sulfur capture. 


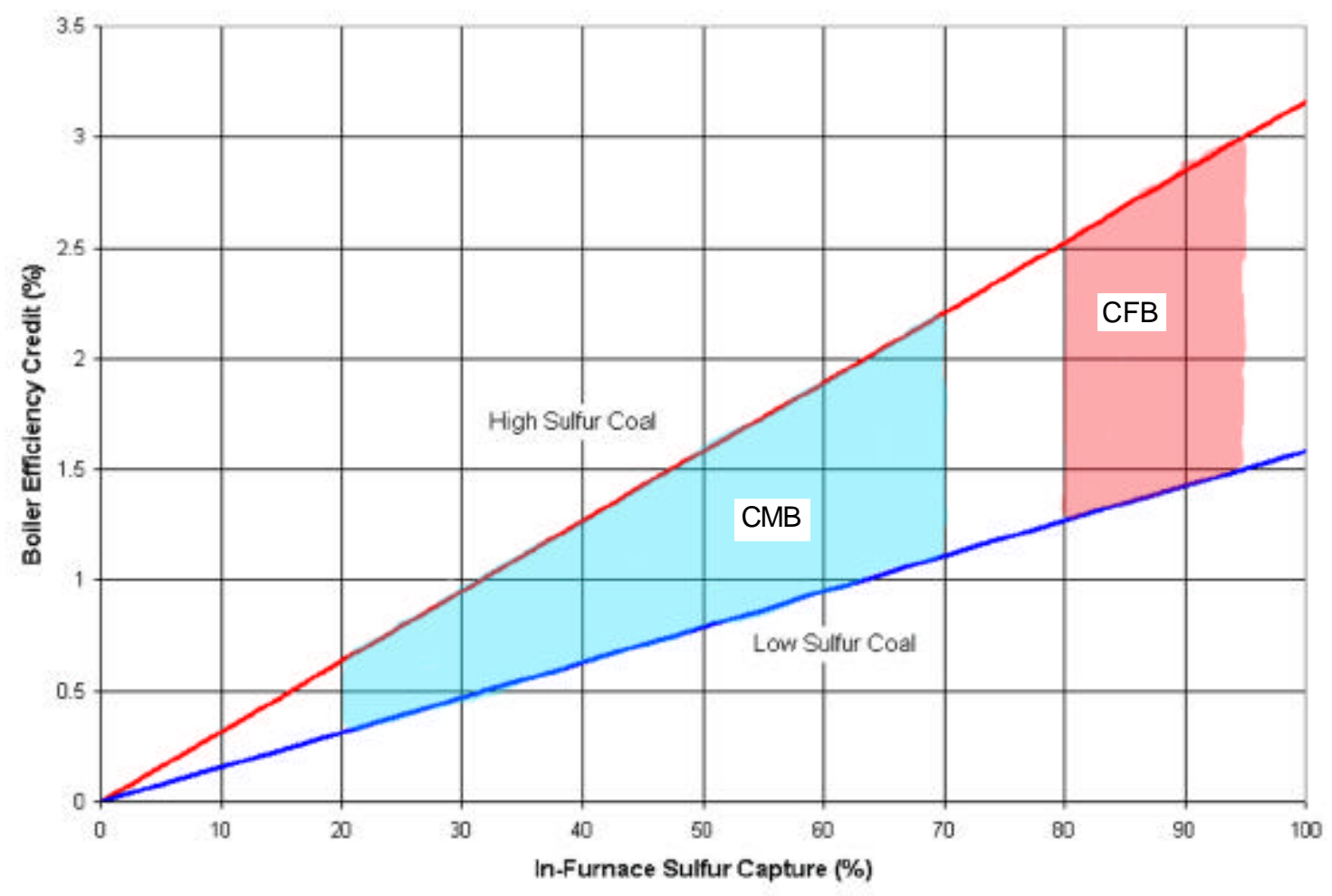

Figure 3.5-1: Effect of In-Furnace Sulfur Capture on Boiler Efficiency

The expected $\mathrm{CMB}$ in-furnace sulfur capture ranges from $20-70 \%$ and is also shown in this figure as a light blue shaded region. The CMB is designed to have most of the sulfur capture take place in the FDA system. The combustor can be operated to increase the in-furnace capture, although there may be limits to how much in-furnace capture can be achieved at reasonable $\mathrm{Ca} / \mathrm{S}$ mole ratios. This figure shows that the $\mathrm{CMB}$ boiler efficiency credit for sulfation can be between $0.1-1.2 \%$ less than a CFB for a low sulfur coal and double that for a high sulfur coal.

It also shows that the $\mathrm{CMB}$ is sensitive to coal sulfur content. With $50 \%$ in-furnace sulfur capture, a CMB firing this low sulfur coal receives half of the maximum sulfation credit, or $0.8 \%$. The sulfation credit increases to $1.6 \%$ with the high sulfur coal. For comparison, a CFB with $95 \%$ in-furnace sulfur capture receives $95 \%$ of the maximum sulfation credit or $1.5 \%$ with the low sulfur coal and $3.0 \%$ with the high sulfur coal. These results show the importance of considering the $\mathrm{CMB}$ operating conditions with respect to in-furnace sulfur capture and their impact on boiler efficiency.

\section{Calcination}

The CMB system can be operated to maximize the overall sulfur capture between both the combustor and the FDA system. One operating scenario is to maximize the sulfur capture that takes place in the FDA system. This can be achieved by feeding a fine sorbent into the combustor at a temperature where it will calcine, but not have enough time for significant sulfation to occur. In this scenario, the sorbent needs to be sized fine enough to escape through the cyclone after the first pass through the combustor. For conventional cyclones, this requires the sorbent particle size to be finer than about 30 microns. 
Figure 3.5-2 shows the extent that a limestone particle will calcine when it is injected into a CMB combustor. The red, orange, and green lines show the percent calcination for 20,30 , and 50-micron particles, respectively. The blue trend line shows the combustor temperature at each elevation. The CMB Process Model (see Section 3.8 for a description) was used to predict gas temperature profiles and residence times for a commercial CMB at full load. These profiles were input into an ALSTOM process model that calculates limestone calcination as a function of particle size, temperature, and residence time at a given temperature. The results were then integrated along the height of the combustor. The resulting curve shows the percent calcination that occurs when a limestone particle is injected at any elevation within the CMB combustor.

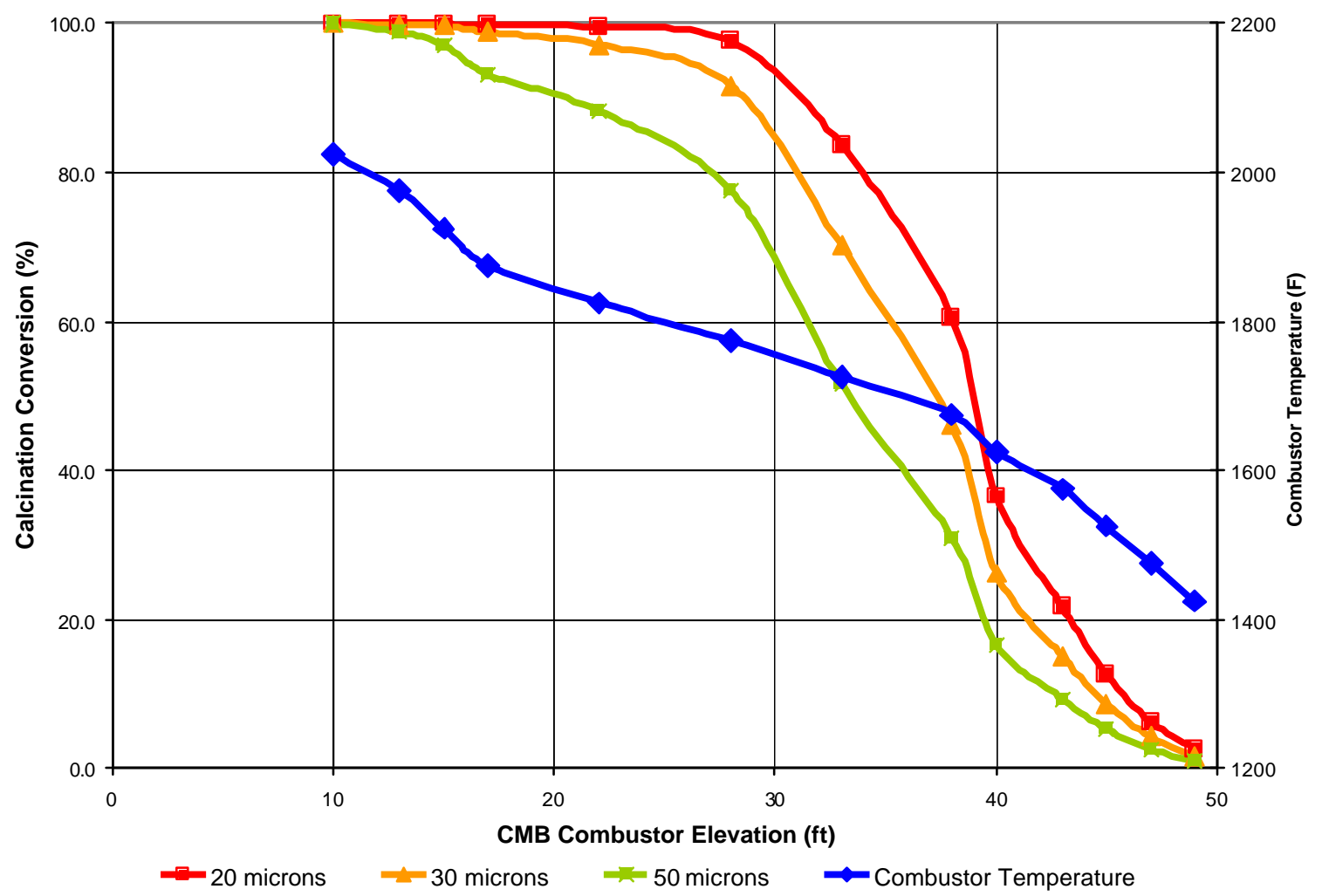

Figure 3.5-2: Effect of Particle Size and Combustor Temperature on Calcination

For example, a 30-micron particle injected at the 30 -foot elevation will only be $85 \%$ calcined after the first pass through the boiler. The same particle injected at the 20 -foot elevation will have sufficient residence time to be $98 \%$ calcined in the first pass. Any uncalcined sorbent particles that escape through the cyclone after the first pass will be unavailable for sulfur capture in the FDA system and can be treated as a loss. Since 30-micron particles may be fine enough to escape the cyclone on the first pass, they need to be injected low enough in the furnace to be fully calcined. In this case, they should be injected around the 20 -foot elevation where the gas temperature is about $1850^{\circ} \mathrm{F}$. These particles are fine enough that they will probably by fully calcined by the time they pass through the optimum temperature window for sulfur capture, which is around $1550^{\circ} \mathrm{F}-1650^{\circ} \mathrm{F}$. It is likely that some sulfur capture will take place even if the particles are only exposed for sulfur capture in the combustor in a single pass. 


\section{Combustor Temperature}

The temperature range in the $\mathrm{CMB}$ combustor can have an impact on sulfur capture in the combustor. The bed temperature can be as high as $2000^{\circ} \mathrm{F}$ at full load. Limestone can be calcined in the lower furnace without any deadburning at these temperatures. However, little sulfur capture will take place until the gas cools down towards the optimum temperature window of $1550^{\circ} \mathrm{F}$ to $1650^{\circ} \mathrm{F}$. Furthermore, it is likely that any $\mathrm{CaSO}_{4}$ exposed to the bubbling bed may release $\mathrm{SO}_{2}$ and form $\mathrm{CaO}$. Considerable research in the 1970's was focused on methods to regenerate sorbents. $\mathrm{CaSO}_{4}$ was found to decompose and release $\mathrm{SO}_{2}$ when it was exposed to temperatures above $1800^{\circ} \mathrm{F}$ and under reducing conditions. The CMB bed at full load conditions operates in conditions conducive to $\mathrm{CaSO}_{4}$ decomposition.

One consequence of this is that any cyclone recycle ash containing $\mathrm{CaSO}_{4}$ should not be recycled directly back to the bubbling bed or it will re-release any $\mathrm{SO}_{2}$ that was captured by the sorbent in its prior pass through the combustor. Instead, the recycle should be injected above the bed in more oxidizing conditions and possibly at more moderate temperatures to avoid $\mathrm{CaSO}_{4}$ decomposition.

The cyclone ash recycle can be injected into the bubbling bed if the sorbent is sized fine enough to pass through the cyclone in the first pass. In this case, there will be no $\mathrm{CaSO}_{4}$ in the recycle stream and the recycle ash can therefore be injected in the best location for carbon burnout.

\section{FDA System}

The FDA system is a dry process based on the reaction between $\mathrm{SO}_{2}$ and $\mathrm{Ca}(\mathrm{OH})_{2}$ in humid conditions. Figure 3.5-3 shows a schematic of the FDA process. In the CMB system, sorbent is calcined in the combustor, passes through the cyclone, and is collected in the FDA baghouse. The sorbent is then hydrated in the mixer and returned to the reactor duct, where the hydrated lime reacts with $\mathrm{SO}_{2}$ in the gas stream.

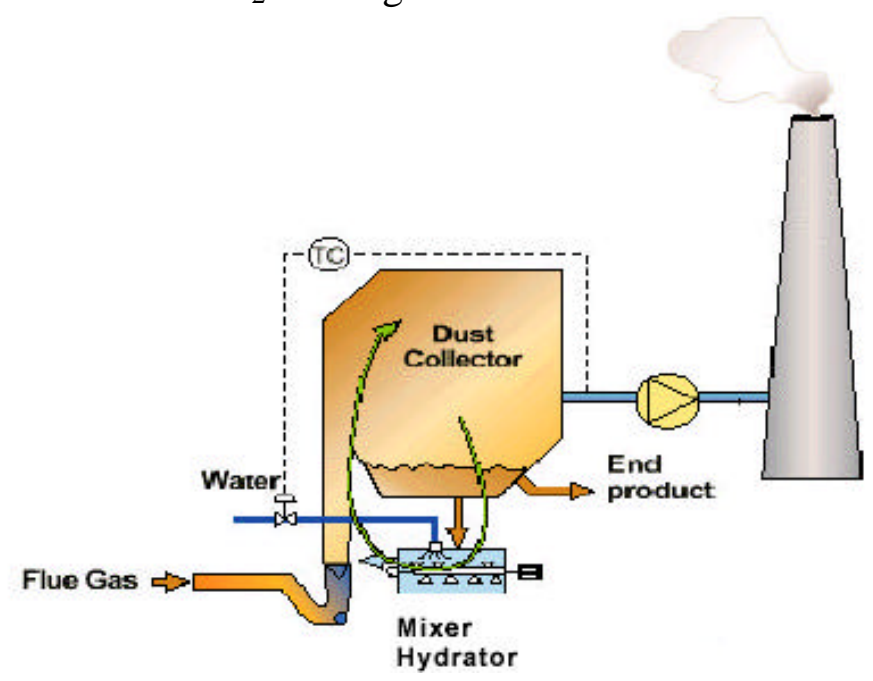

Figure 3.5-3: FDA Process Schematic

The FDA is an integral part of the CMB process and may be used as a scrubber for final gas cleanup after the combustor or as the primary device for sulfur capture. The FDA role may 
vary depending upon the CMB combustor operating conditions. Commercial FDA systems achieve high levels of sulfur capture at low $\mathrm{Ca} / \mathrm{S}$ mole ratios using hydrated lime as the sorbent. The CMB process will not use hydrated lime, but will calcine limestone directly in the combustor. The intent is to generate a sorbent in the combustor almost as reactive as the hydrated lime by injecting the sorbent in a manner to calcine the particles with little subsequent sulfation.

MTF tests were conducted in two separate campaigns with a hydrated lime sorbent to assess the maximum performance potential of the FDA system. These tests were conducted outside of the CMB Proof of Concept program, although the test matrix was adjusted to include test conditions of interest to the CMB program. The objective of these tests was to evaluate the maximum FDA performance if the sorbent generated in the combustor was very reactive and was not deactivated at all by any sulfate reactions on the particle surface. It was assumed that these results would represent an upper limit on FDA performance, as any furnace generated sorbent was unlikely to be more reactive than hydrated lime.

In both tests, the MTF was operated as a sulfur and flue gas generator. Sulfur levels were adjusted by feeding elemental sulfur into the furnace with the fuel. Commercial grade hydrated lime was then injected into the duct entering the FDA. The FDA was operated with PC flyash in the first test and with CFB ash in the second test. The FDA system performed similar to commercial FDA systems using PC flyash, with very high sulfur capture at low $\mathrm{Ca} / \mathrm{S}$ mole ratios. However, the FDA performance deteriorated when operated with the CFB flyash. The overall sulfur capture was less at a specific $\mathrm{Ca} / \mathrm{S}$ mole ratio and the performance also worsened as the FDA $\mathrm{SO}_{2}$ inlet concentration increased. These trends are illustrated in Figure 3.5-4.

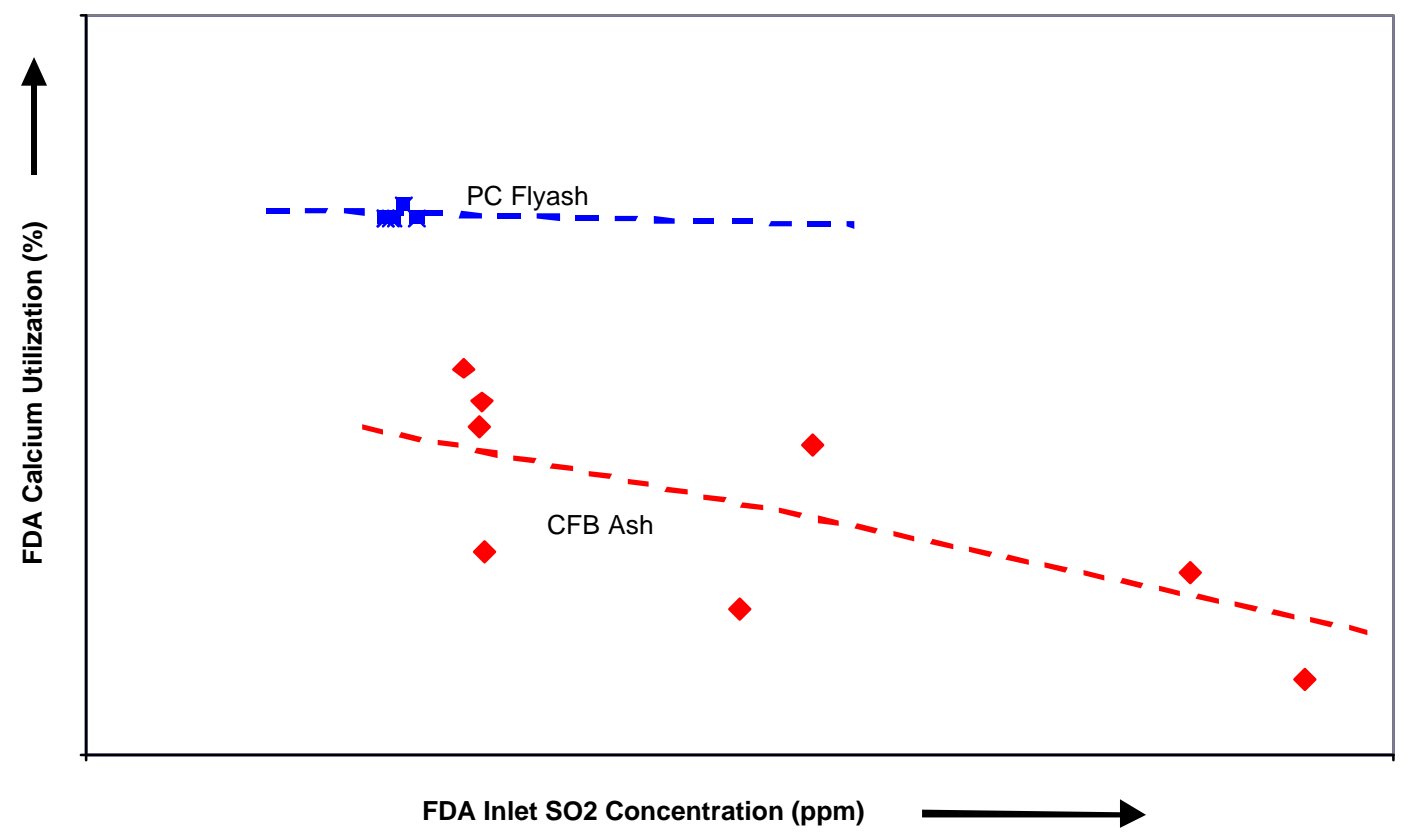

Figure 3.5-4: Effect of Ash Composition and $\mathrm{SO}_{2}$ Concentration on FDA Performance 
A number of reasons have been postulated for this performance difference. First, there may have been some mechanical distribution problems during the second test with the CFB ash. There were some problems mixing the ash leaving the FDA with water and some clumping of the particles was observed in the mixer. This may have limited water/particle contacting. Second, there are significant differences in the ash properties. PC flyash has been exposed to very high temperatures, which results in spherical or glazed particles. The CFB ash tends to have a much more porous particle structure than the PC flyash. Furthermore, the PC flyash particles are significantly finer than the CFB ash particles. The CFB particles thus have much less surface area to carry moisture. FDA operation with $\mathrm{CFB}$ ash particles may therefore require higher moisture levels to achieve the sulfur capture performance observed with PC flyash. It is also important to realize that this is pilot scale test data. Performance results from commercial CFBs with FDA systems will become available later this year. This data will provide a better indication of the relative FDA performance between CFB and PC applications and may show that the differences are less pronounced.

The CMB test program was therefore designed to address these critical issues. Tests were planned that specifically looked at the impact of particle size, moisture levels and distribution methods, and extent of particle sulfation leaving the furnace. These results will be further discussed in Section 6.6. 


\section{6 $\mathrm{NO}_{\mathrm{x}}$ and $\mathrm{N}_{2} \mathrm{O}$ Emissions}

The objective of this task was to assess CMB process parameters that will have an impact on both $\mathrm{NO}_{\mathrm{x}}$ and $\mathrm{N}_{2} \mathrm{O}$ emissions. These results were then used as guidance in developing the MTF test program objectives.

\section{Temperature}

The most obvious feature of the $\mathrm{CMB}$ design that may affect $\mathrm{NO}_{\mathrm{x}}$ emissions is the high bed temperature. Thermal $\mathrm{NO}_{\mathrm{x}}$ is formed by the oxidation of atmospheric nitrogen and its formation is highly temperature dependent. Based on the extended Zeldovich Mechanism, thermal $\mathrm{NO}_{\mathrm{x}}$ is only significant at temperatures over $2700^{\circ} \mathrm{F}$ because of the energy necessary to break the strong nitrogen triple bond. This temperature is well above the CMB operating range, so thermal $\mathrm{NO}_{\mathrm{x}}$ will not be significant for $\mathrm{CMB}$ operation.

Although thermal $\mathrm{NO}_{\mathrm{x}}$ can be discounted, there is the potential for high fuel $\mathrm{NO}_{\mathrm{x}}$ concentrations if the fuel and air are not introduced properly. High bed temperatures can reduce the concentration of $\mathrm{CO}$ and other reducing agents, which will limit the $\mathrm{NO}_{\mathrm{x}}$ destruction reactions. It is critical that the fuel be introduced into a fuel rich region and that the air is staged to minimize $\mathrm{NO}_{\mathrm{x}}$ formation. One consequence of high bed temperatures is that $\mathrm{N}_{2} \mathrm{O}$ formation should be extremely low.

Figure 3.6-1 illustrates that higher bed operating conditions do not always result in high $\mathrm{NO}_{\mathrm{x}}$ emissions. A high temperature combustion test with Pittsburgh \#8 coal was run in the MTF prior to the start of the CMB Proof of Concept program. The MTF was operated as a bubbling bed with a low cyclone ash recirculation rate. The bed was filled with bauxite and the bed and freeboard were both run at $2000^{\circ} \mathrm{F}$.

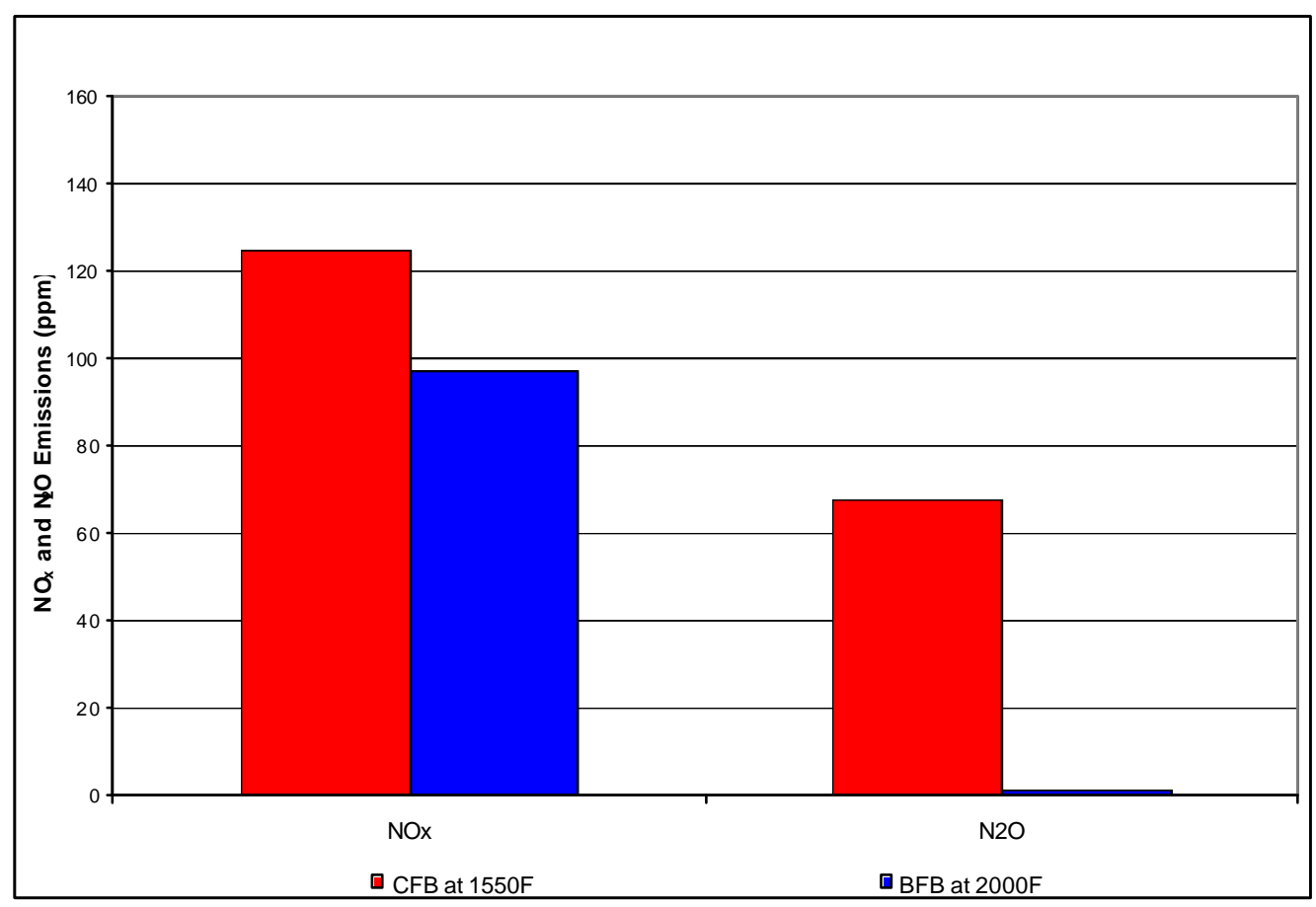

Figure 3.6-1: Effect of temperature on $\mathrm{NO}_{x}$ and $\mathrm{N}_{2} \mathrm{O}$ Emissions 
The $\mathrm{NO}_{\mathrm{x}}$ and $\mathrm{N}_{2} \mathrm{O}$ values in this figure were obtained at $20 \%$ excess air and with air staging. For comparison, $\mathrm{NO}_{\mathrm{x}}$ and $\mathrm{N}_{2} \mathrm{O}$ values are also shown from CFB operation with the same fuel and at $1550^{\circ} \mathrm{F}$ and $20 \%$ excess air. These results show that $\mathrm{NO}_{\mathrm{x}}$ values at temperatures significantly higher than $1550^{\circ} \mathrm{F}$ needn't increase with proper fuel and air management. As expected, the higher temperature practically eliminated the formation of any $\mathrm{N}_{2} \mathrm{O}$ emissions. These results were encouraging, but do not duplicate the operating conditions in a CMB combustor. The testing was not with circulating bauxite and did not match the temperature profile expected from $\mathrm{CMB}$ conditions, since the temperature remained high throughout the combustor.

\title{
Excess Air
}

$\mathrm{NO}_{\mathrm{x}}$ emissions increase with higher excess air levels. In current designs, the CMB will operate at nominally the same excess air levels as conventional CFBs. The excess air level is usually set as low as possible while maintaining acceptable carbon burnout efficiency. The $\mathrm{CMB}$ combustor has the potential to operate at lower excess air levels than conventional boiler concepts. This is because the entire heat transfer surface is located in the MBHE, which greatly minimizes the potential for tube corrosion from locally reducing conditions. The ability to operate the combustor at lower excess air levels result in significant cost savings if the boiler is designed for those conditions. The smaller gas weight reduces the size of all gas-touched equipment, including the combustor, cyclone, airheater, FDA, fans, and ductwork. The key enabler for operating the CMB at lower excess air levels will be its ability to achieve acceptable levels of carbon burnout and $\mathrm{CO}$ emissions at these conditions. The high bed temperatures will certainly help carbon burnout.

It is possible that the CMB may operate with higher excess air levels as it goes down in load. The airflow through the bubbling bed will always be maintained above a minimum velocity at all loads in order to maintain adequate fluidizing velocities. However, the CMB bauxite transport system also requires a considerable amount of air to convey the solids from the MBHE to the top of the combustor. In the current CMB design, the air will leave the solids separator and return above the bed as overfire air. This amount of air is dependent upon the required solids/air ratio and proper velocities in the transport lines. The minimum excess air level at lower loads will be set by the minimum required air flows for both adequate bed fluidization and for bauxite transport velocities.

\begin{abstract}
Air Staging
Circulating fluidized bed boilers rely on air staging to minimize $\mathrm{NO}_{\mathrm{x}}$ formation. The $\mathrm{CMB}$ boiler will also rely on deep air staging to control $\mathrm{NO}_{\mathrm{x}}$ emissions. There are some differences in the CMB technology that may influence the degree of staging.
\end{abstract}

The CMB does not have any pressure part surfaces in the combustor and therefore doesn't need to be concerned with gas-side corrosion. This permits the lower combustor to be staged deeper and over a wider region.

The impact of staging on bed fluidization needs to be considered. Deeply reducing conditions may promote the formation of low-temperature eutectics that can increase bed agglomeration 
tendencies. These tend to break up as long as the bed velocities are high enough. However, the bed velocity will decrease as air is redistributed above the bed.

\section{Bed Material}

The CMB bed material is comprised largely of bauxite, with some coal ash and sorbent particles. This composition is significantly different from CFBs, where the lower combustor bed region is a mix of coal ash and calcium compounds. This bed composition difference may have a significant impact on the formation of $\mathrm{NO}_{\mathrm{x}}$ in the bed region.

$\mathrm{NO}_{\mathrm{x}}$ emissions tend to increase in CFB boilers when limestone rates are increased. Investigators have postulated a number of reasons to explain this phenomena. They include a catalytic effect on the conversion of $\mathrm{NH}_{3}$ to $\mathrm{NO}_{x}$, reduced $\mathrm{SO}_{2}$ levels contributing to increased radicals, catalytic oxidation of $\mathrm{CO}$, and catalytic conversion of $\mathrm{HCN}$ to $\mathrm{NH}_{3}$.

Gibbs and Liu investigated the effect of bed materials on $\mathrm{NO}_{\mathrm{x}}$ and $\mathrm{N}_{2} \mathrm{O}$ formation. ${ }^{1}$ In particular they investigated the impact of adding limestone and alumina to a sand bed on $\mathrm{NO}_{\mathrm{x}}$ and $\mathrm{N}_{2} \mathrm{O}$ emissions in conventional fluidized bed combustors. Their results show that limestone addition increases the conversion of char nitrogen to $\mathrm{NO}_{\mathrm{x}}$ while also reducing the conversion to $\mathrm{N}_{2} \mathrm{O}$. The total conversion of char-nitrogen while burning an anthracite char increased increased from $64 \%$ with the sand bed to $70 \%$ after $3 \%$ limestone as added to the bed. They also ran tests where they added 5\% alumina to the bed. They found that the $\mathrm{NO}_{\mathrm{x}}$ emissions did not increase as they did with limestone addition, although they still saw the reduction in $\mathrm{N}_{2} \mathrm{O}$ emissions compared to a sand-only bed. In this case, the total char-nitrogen conversion decreased down to $56 \%$ with the addition of the alumina. They concluded that replacing a portion of the sand bed with alumina could result in decreases in both $\mathrm{NO}_{\mathrm{x}}$ and $\mathrm{N}_{2} \mathrm{O}$ emissions. The CMB will have a bed that will be largely comprised of alumina. In this case, the presence of sorbent products will be small, which should reduce the formation of $\mathrm{NO}_{\mathrm{x}}$.

The sorbent concentration in the bed may also be minimized by how the sorbent is introduced into the combustor. It is likely that most of the sulfur capture will take place in the backend FDA system. This arrangement gives some flexibility in how and where the sorbent is feed into the combustor. Fine limestone can be feed above the bed region at a temperature sufficient for calcination. If sized fine enough, the sorbent will calcine but then elutriate and pass through the cyclone where it will capture $\mathrm{SO}_{2}$ in the FDA. In this case, the sorbent will have only a short residence time in the combustor and very little calcium will accumulate in the bed where much of the $\mathrm{NO}_{\mathrm{x}}$ formation will take place. Thus, $\mathrm{NO}_{\mathrm{x}}$ emissions may be further reduced through the proper selection of sorbent feed size and injection location.

The design of the CMB cyclone ash recycle system may also have an impact on $\mathrm{NO}_{\mathrm{x}}$ formation. Recycle material may be injected above the bed to minimize the desulfurization of any calcium sulfate in the reducing environment of the bed. This arrangement also minimizes the accumulation of fine ash and sorbent from the bed and thus also helps to reduce $\mathrm{NO}_{\mathrm{x}}$ formation. 


\section{$\mathrm{NO}_{\mathrm{x}}$ Reduction Techniques}

There are several methods that can be used for reducing $\mathrm{NO}_{\mathrm{x}}$ emissions if the uncontrolled emissions from the $\mathrm{CMB}$ are too high. These methods include selective non-catalytic reduction (SNCR), selective catalytic reduction (SCR), and reburning.

\section{SNCR}

Noncatalytic reduction of $\mathrm{NO}_{\mathrm{x}}(\mathrm{SNCR})$ with ammonia or urea is most effective at a temperature of roughly $816-1094^{\circ} \mathrm{C}\left(1500-2000^{\circ} \mathrm{F}\right)$. CFB combustors operate at the lower end of this range. The additive is injected into the furnace or cyclone and $\mathrm{NO}_{\mathrm{x}}$ reduction occurs before the gas cools in the convective backpass. In a CMB combustor, the proper temperature window for SNCR reactions is located in the lower combustor region. The additive must be injected, mixed, and reacted before the gas cools to below about $816^{\circ} \mathrm{C}\left(1500^{\circ} \mathrm{F}\right)$.

The CMB Process Model (described in Section 3.8) was used to predict the gas temperature profile in the MTF for several full and part load cases. The temperature profiles are shown in Figure 3.8-2. The x-axis indicates the MTF furnace height. The cumulative gas residence times from the air distributor are also labeled on this figure. The light blue shaded region indicates the appropriate temperature range for SNCR reactions to take place. SNCR could be applied in the $\mathrm{CMB}$ combustor between the heights where the gas temperature trend lines pass through this temperature window.

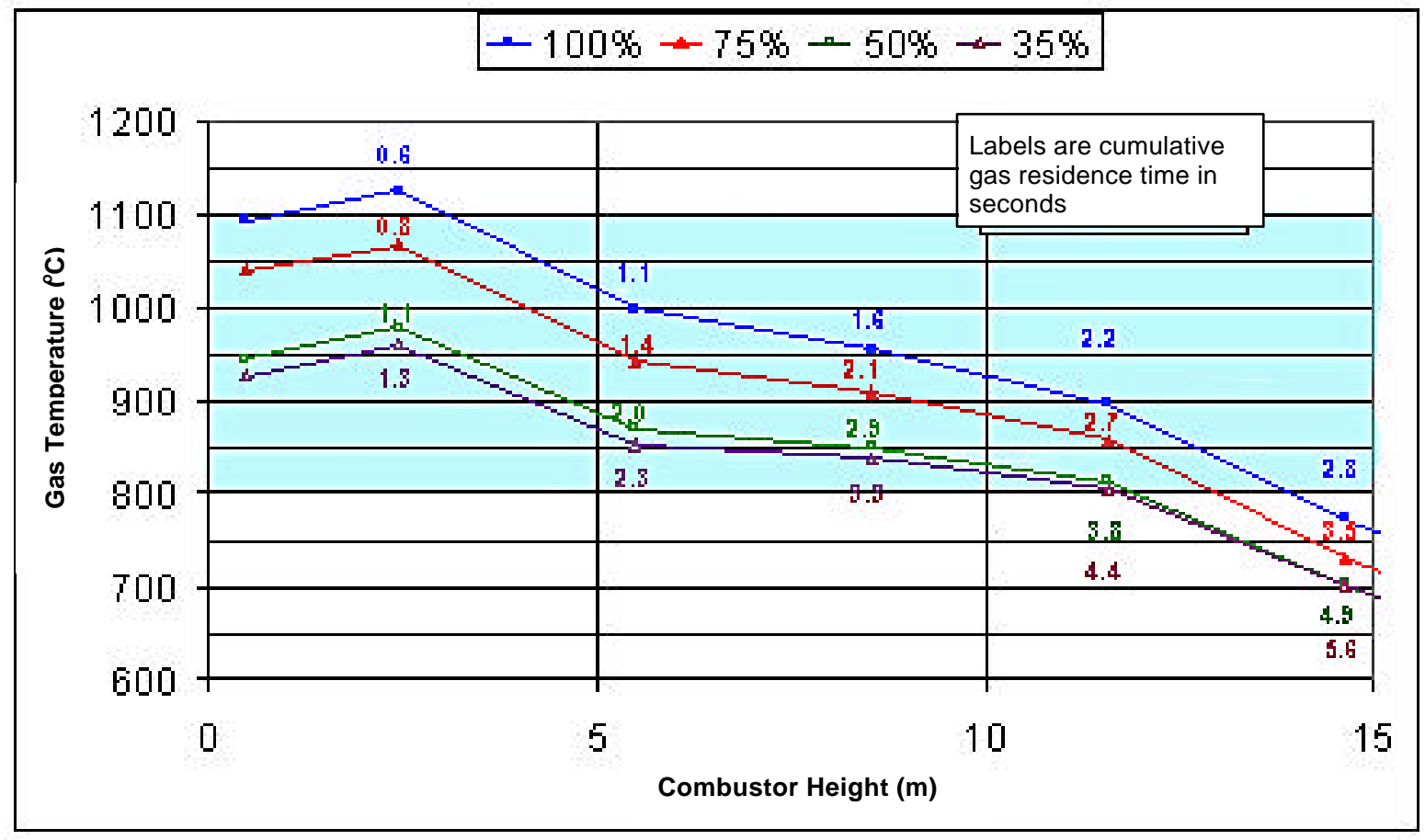

Figure 3.6-2: CMB Temperature Profiles in MTF Suitable for SNCR

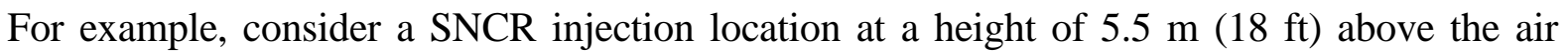
distributor. At full load, there is a gas residence time of about 1.5 seconds from this location to where the gas cools to $816^{\circ} \mathrm{C}\left(1500^{\circ} \mathrm{F}\right)$. At part loads, the temperature is lower at this injection height, but because of the reduced flow, there is still at least 1.5 seconds residence 
time above $816^{\circ} \mathrm{C}\left(1500^{\circ} \mathrm{F}\right)$ in each case. This is an indication that we can find a suitable injection location at all loads.

The injection point could also be lower in the furnace to get more time at higher temperatures. For a large combustor though, there may be the risk that the additive is consumed too quickly at higher temperatures before it mixes well. These results were used to help select the location for SNCR injection for the last test campaign in the MTF.

\section{SCR}

Selective catalytic reduction (SCR) occurs in separate backend equipment. Typical operating temperatures for base metal catalysts are between 232 and $427^{\circ} \mathrm{C}\left(450\right.$ and $\left.800^{\circ} \mathrm{F}\right)$, which matches the expected furnace outlet temperature of the CMB at all loads.

\section{Reburning}

Reburning is another technique that may reduce the $\mathrm{NO}_{\mathrm{x}}$ emissions. A benefit with this method is that it avoids any potential problems with ammonia slip. Reburning creates a high temperature, low stoichiometry zone by the injection of a fuel higher up in the furnace to reduce $\mathrm{NO}_{\mathrm{x}}$ that was produced in the lower furnace. Combustion of the fuel is then completed under oxidizing conditions 


\subsection{Operational Control}

The objective of this task was to establish a preliminary steady state load following characteristic for a circulating moving bed power plant. A conceptual $300 \mathrm{Mw} \mathrm{CMB}$ plant was used as the basis for this study. The results provided input for equipment selection and for the CMB Process Model. They were also used for an evaluation of reheat steam temperature control methodology and for an investigation of load range performance. Also evaluated were startup, a black plant scenario, and alternative methods for reheat steam temperature control.

Figure 3.7-1 shows the physical arrangement of the surfaces in the moving bed heat exchanger. Hot solids from the combustor are delivered by gravity to the top of the MBHE. The solids then pass through the finishing superheat (SHFIN), finishing reheat (RHFIN), low temperature superheat (LTSH), once-through surface (OT3), low temperature reheat (LTRH), and then the remaining once-through surface (OT2, OT1).

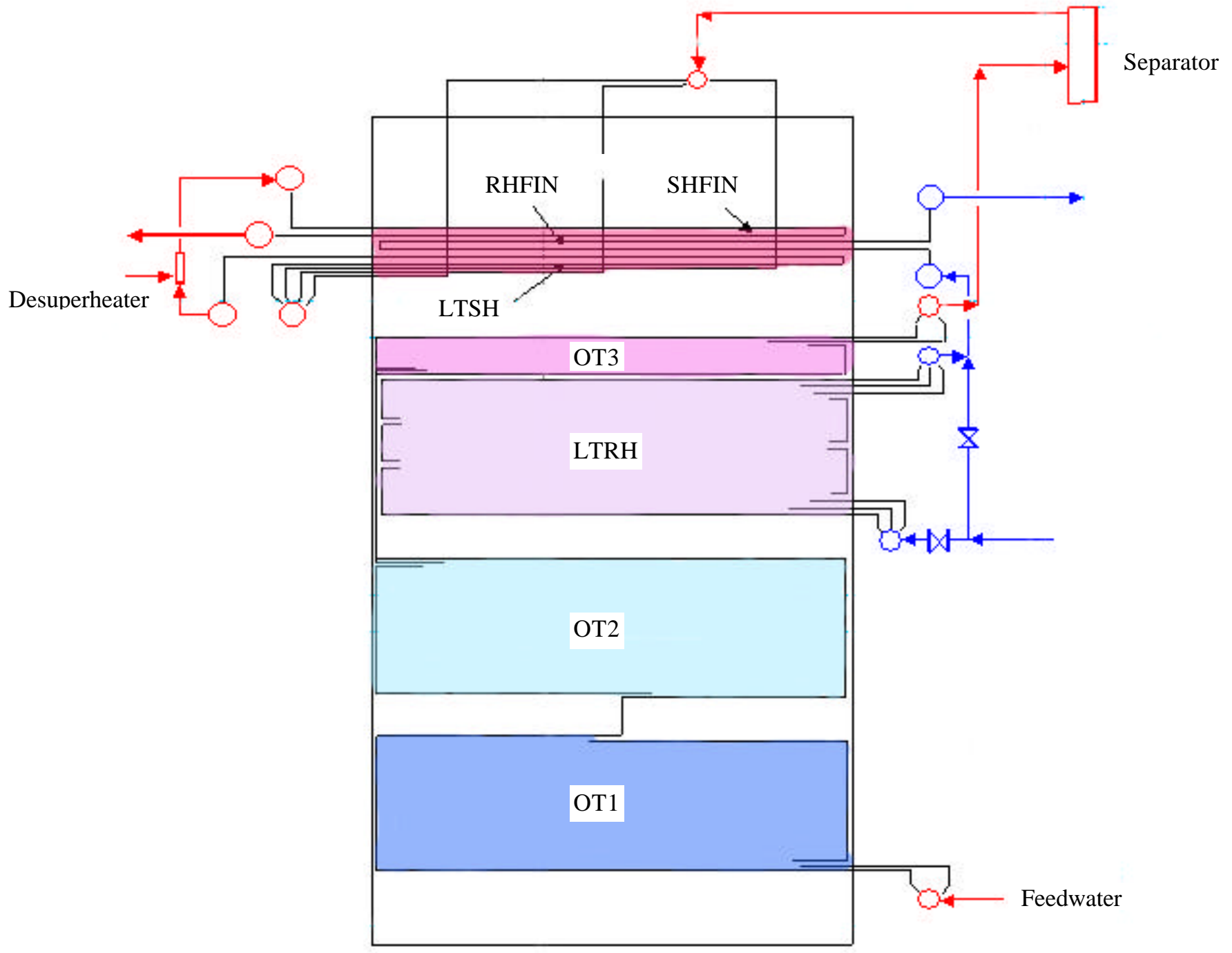

Figure 3.7.1: CMB Heat Exchanger Surface Arrangement 
The MBHE includes all of the heat absorbing surfaces and is operated to provide the heat duty requirements of the steam turbine. The combustor operating conditions are adjusted to provide the MBHE with the required bauxite flow and solids inlet temperatures necessary to meet the required steam flow conditions.

The evaluation used a once through (OT) system for the high-pressure steam over a 35 to 100 percent load range. Below 35 percent a recirculation system was used to maintain a minimum flow in the OT circuits. High-pressure steam temperature control was by feedwater to fuel ratio and by desuperheat in the recirculation range. Reheat steam temperature was controlled by bauxite inlet temperature, reheat steam bypass, and reheat desuperheat spray water.

Two analysis models were used. The CMB process model was used to determine the combustor process conditions and the moving bed heat exchanger (MBHE) inlet conditions. A separate MBHE model provided surfacing and performance of the heat exchanger sections. The models were run in unison for the following loads: 100, 75, 44, and 35 percent of steam flow. Thirty five percent load was selected as the transition load from recirculation to once through operation. Both once through and recirculation performance were calculated at 35 percent load. Overall plant predicted performance matched that of a traditional CFB.

Bauxite flow, inlet temperature, and outlet temperature are the variables that establish the heat input to the heat absorbing surfaces of the MBHE. The MBHE is totally independent of fuel characteristics. A low solids outlet temperature is desired because it reduces the gas temperature from the combustor and consequently the stack temperature. The results shown in Figure 3.7-2 indicate that the bed temperature would need to be reduced from $2000^{\circ} \mathrm{F}$ to $1700^{\circ} \mathrm{F}$ to meet steam conditions as load is reduced from $100 \%$ to $35 \%$ load, respectively. For the same load range, the bauxite solids recirculation rate would decrease by $50 \%$, as shown in Figure 3.7-3. The study concluded that using bauxite inlet temperature as a primary control and bypassing of steam around the low temperature reheat section for a trim was a viable approach.

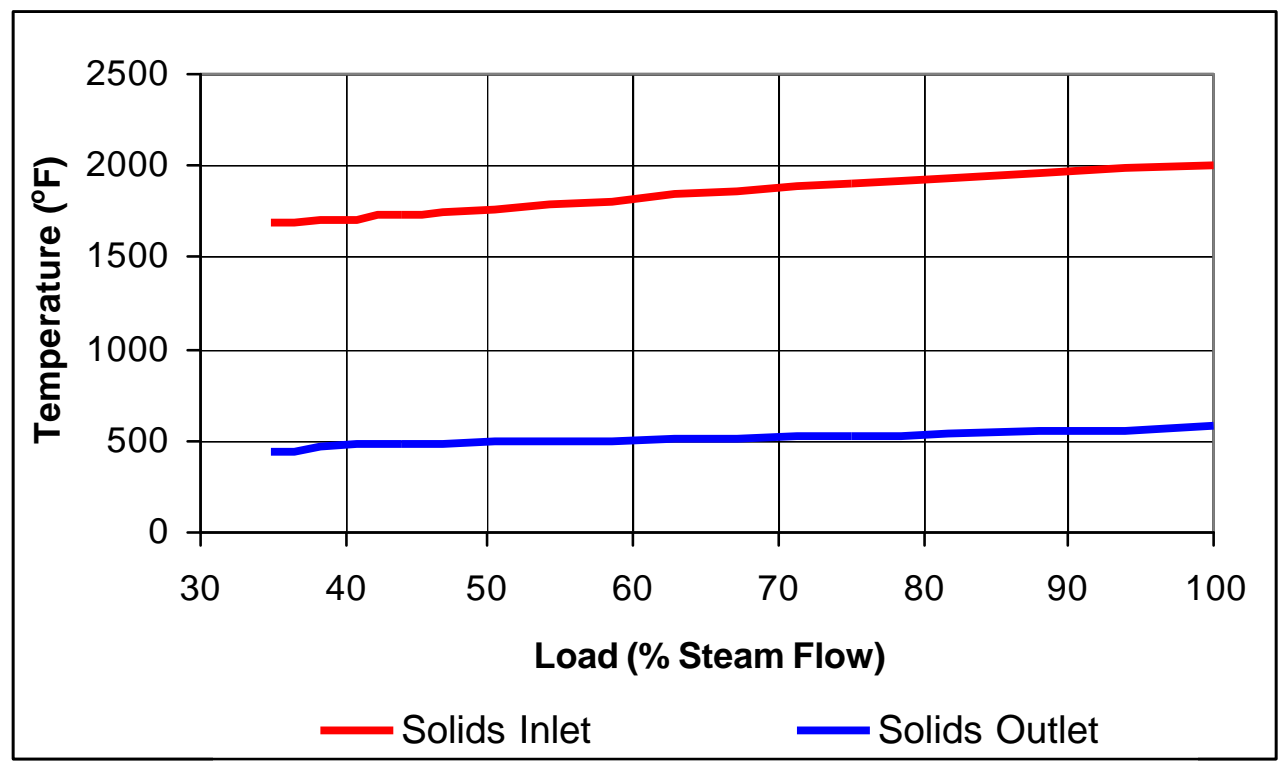

Figure 3.7-2: MBHE Solids Temperature Variation with Load 


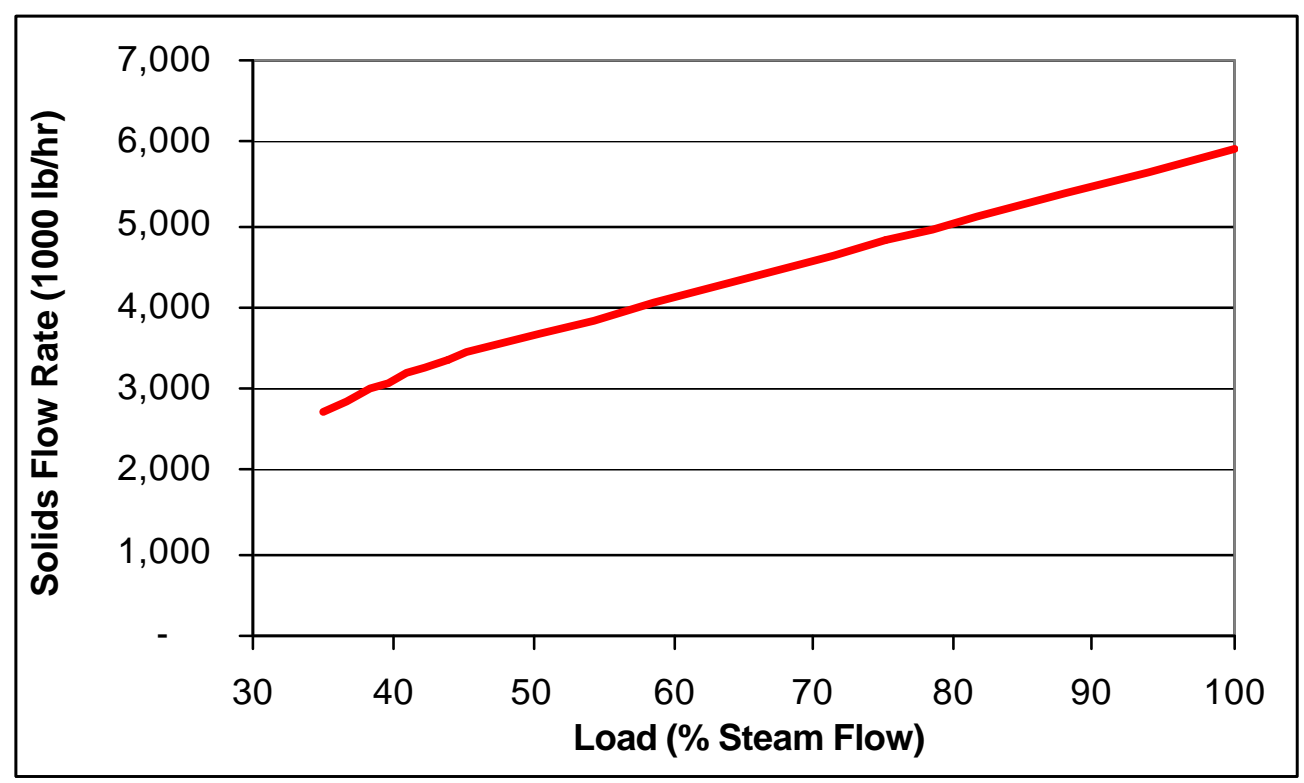

Figure 3.7-3: MBHE Solids Flow Rate with Load

During a start-up, the unit will initially be in recirculation mode and the OT section will be full of water. It is envisioned that a flow of solids will be initiated and slowly heated. The temperature will be controlled such that pressure part material guidelines downstream of the separator will be allowed to initially run dry. The solids temperature will be allowed to increase as steam production is begun and cooling becomes available. After turbine synchronization is completed, the solids will begin a preset ramp similar to the coal and gas flows.

During a black plant condition, controls will allow the unit to revert to the recirculation mode with natural circulation. The steam generated will only cool tubing downstream of the separator. Unless an automatic superheater outlet to the RH inlet bypass system is provided the reheat sections will run dry. Eventually, the recirculation system will dry out. This condition needs to be compared to that of a traditional CFB and appropriately addressed.

Some alternative techniques of reheat temperature control were also studied. The best alternate was either separate MBHE's or a MBHE with a division wall having a separate superheat duct and a reheat duct. This method would be ideal if a means of establishing two streams of bauxite with a temperature control of each section can be developed. There would be no operating penalty such as excess air, gas recirculation, or burner tilt (which raises stack temperature). 


\subsection{Process Model}

The objective of this task was to use ALSTOM Power's existing CMB Process Model to predict CMB performance in the MTF. This would help develop the planned test programs and help to anticipate process issues before the tests began. The first step was to update the existing CMB process model with the latest heat transfer correlation. The model was then modified to simulate the MTF and run through various scenarios planned for future testing.

\section{CMB Process Model Description}

The CMB Process Model is an Excel-based spreadsheet that models the overall thermal performance of a $\mathrm{CMB}$, with a focus on the combustor. The model includes complete mass and energy balances around all major sections of the CMB process, including the combustor bed, freeboard, heat exchanger, and airheater. The freeboard portion of the model is subdivided into 10 slices. They are solved iteratively to calculate the solids suspension density, heat transfer profiles, and the gas and solid temperature profiles throughout the combustor. A sample combustor temperature profile is shown in Figure 3.8-1 for a 30.5-m $(100-\mathrm{ft})$ tall CMB combustor. The blue trend line shows the combustion gas temperature as the falling bauxite cools it. In this case, the bauxite is entering the top of the combustor at $700^{\circ} \mathrm{F}$. The gases are leaving the bed at $2000^{\circ} \mathrm{F}$ and are cooled to about $750^{\circ} \mathrm{F}$ when they exit the combustor.

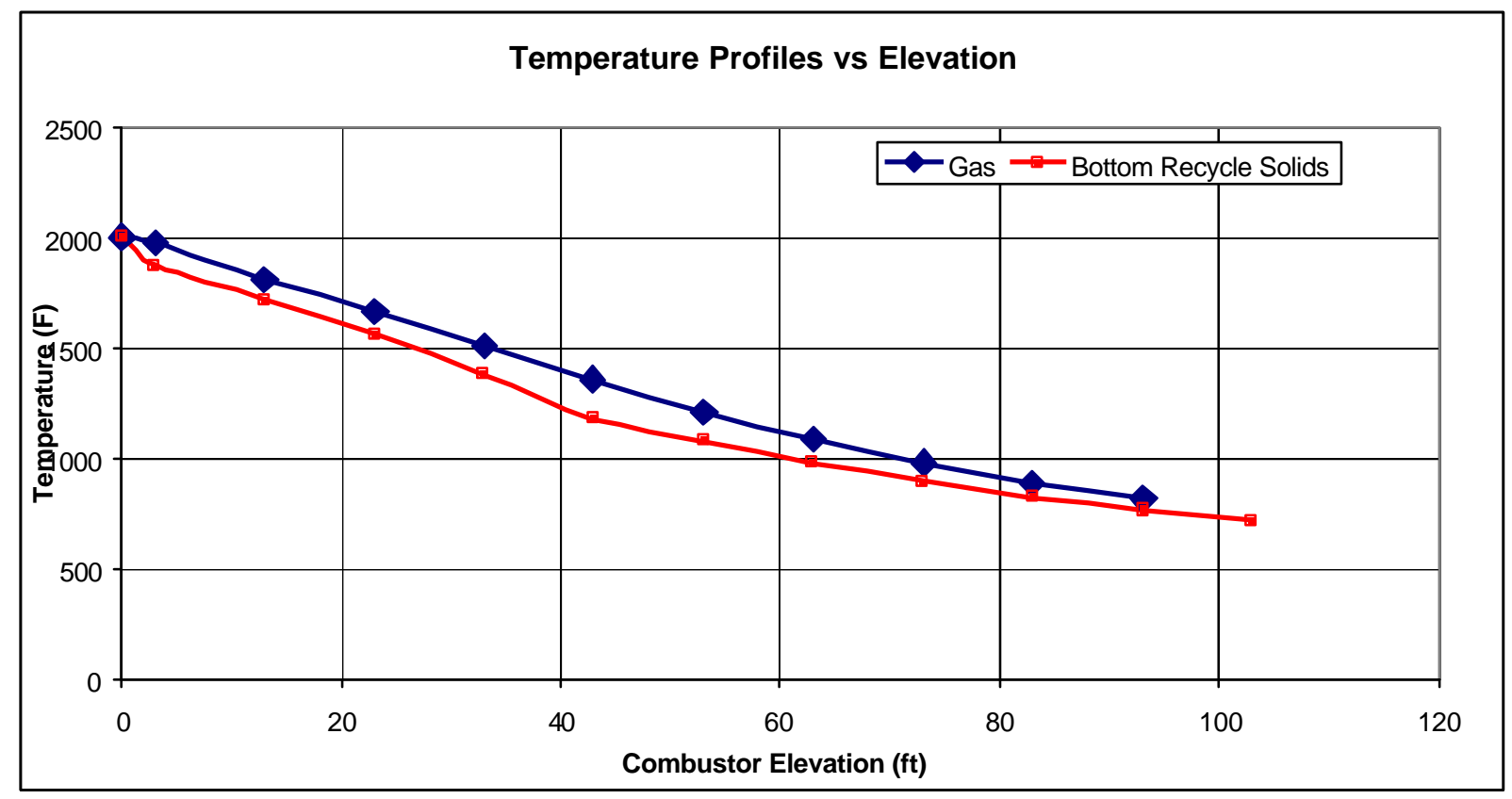

Figure 3.8-1: Process Model Temperature Predictions for 300Mw CMB 
The CMB Process Model is very flexible and can accommodate a wide range of combustor configurations and operating conditions. Figure 3.8-2 summarizes the major inputs and assumptions that are used in the freeboard portion of the process model. It also describes the primary model outputs.

\section{Model Inputs}

-Particle diameter, density

- Combustor geometry, number of slices

- Heat transfer solids inlet temperature

and flow rate

-Cyclone recycle flow rate

-Heat release profile

- Overfire air location, flow, temperature

\section{Model Assumptions}

- Gas and Solids are well mixed

-Solids are spherical particles

- Overfire air is well mixed in slice it enters

-Heat Release is uniform across bottom $X$ slices

-Tsurf = Tgas

\section{Model Outputs}

- Gas and solids temperature profiles

- Gas and solids residence time profiles

-Solids suspension density and heat transfer profiles

Figure 3.8-2: Freeboard Slice Model Inputs, Assumptions and Outputs

Figure 3.8-3 shows the calculational procedure that was used to predict the temperature profiles in the freeboard slice model. The model used two different methods to calculate the temperatures in each slice. The first method used an unsteady state heat conduction procedure. It assumed uniform particle temperatures throughout the particle core and a constant gas temperature in each slice. An unsteady state heat balance was then used to calculate the particle temperature. The model used an iterative procedure to calculate the gas and solid temperatures for each slice. The iterations continued until the calculated inlet and outlet temperatures matched the assumed gas outlet temperature used to begin the calculation.

The second procedure applied a steady state heat balance on each slice. In this case, the gas and solid temperatures leaving each slice equaled the slice mixed temperature. 


\section{Calculational Procedure}

-Assume $\mathrm{T}_{\text {gas }}$ out

-Assume average $\mathrm{T}_{\text {gas }}$ per slice

-Calculate $\mathrm{C}_{\mathrm{p}}, \mathrm{k}, ?_{\mathrm{g}}, \mu_{\mathrm{g}}$

- Calculate $\mathrm{v}_{\text {gas }}$, terminal velocity

- Calculate slip velocity, suspension density, residence time, $\mathrm{h}_{\mathrm{o}}, \mathrm{T}_{\mathrm{s}}$ -From heat balance, calculate $\mathrm{T}_{\mathrm{gas}}$ inlet for slice. Find new average $\mathrm{T}_{\text {gas }}$ and repeat until converges.

-Repeat for each slice. After last slice, compare $\mathrm{T}_{\text {gas }}$ initial to desired $\mathrm{T}_{\text {gas }}$. -If not the same, then adjust $\mathrm{T}_{\text {gas }}$ out and repeat all calculations.

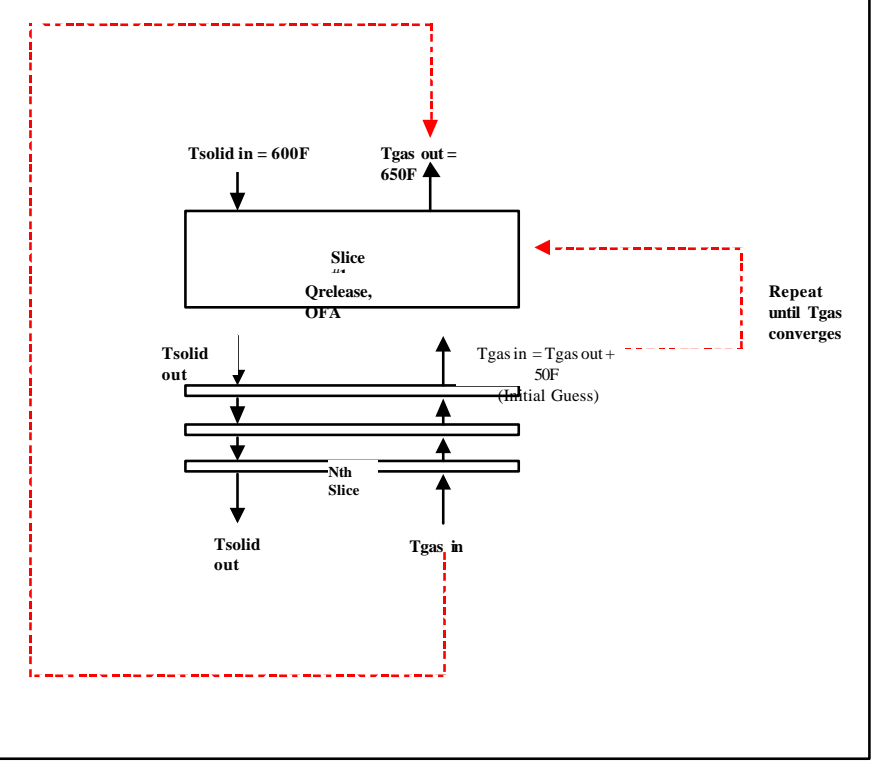

Figure 3.8-3: Freeboard Slice Model Calculational Procedure

The CMB Process Model was then modified to accommodate the MTF geometry. Changes included adding in the MTF geometry and fuel/sorbent specifications. An additional heat exchanger was added to cool the recycled bauxite to simulate the water-cooled transport line or FBHE. The model was modified to allow it to run with or without an airheater. The overall model was also overhauled, with calculations simplified and rearranged for clarity.

\section{MTF Process Model Simulations}

The revised CMB process model was then used to look at the predicted temperature profiles in the MTF for the planned CMB test campaigns. There are enough differences between the MTF and the proposed commercial designs, that matching everything was difficult. These differences are discussed below.

The MTF does not have the same height as a commercial CMB combustor, so it can not get the same degree of cooling at the same velocities. The objective was to just match the temperature profiles predicted in the lower portion of a commercial unit. The MTF was tall enough that it was expected to cool the gases sufficiently by the combustor outlet that combustion reactions will have slowed down.

At the MTF limit of $3 \mathrm{MW}_{\text {th }}(9.9 \mathrm{MBtu} / \mathrm{hr})$, the combustor plan area/heat input was larger than the commercial design. This was addressed by operating the MTF at slightly lower gas velocities (about $10 \%$ less) than expected in the commercial design. The strategy was to match the profile of gas temperature vs. gas residence time for a commercial CMB combustor rather than vs. combustor height. 
The biggest limitation was that the MTF did not initially have the moving bed heat exchanger in operation during the first two test campaigns for cooling the bauxite. A water/steamcooled transport line was installed in place of the MBHE for the initial test campaigns. This allowed the testing to focus on evaluating gas-to-solids heat transfer in the combustor without dealing with the additional complexities of operating the MBHE. However, the water-cooled transport line provided a maximum cooling duty of about $1.0 \mathrm{Mw}(3.3$ $\mathrm{MBtu} / \mathrm{hr}$ ) which is roughly half of what is required. Without sufficient cooling of the bauxite, the bauxite can't cool the flue gas enough to match the expected temperature profiles in a commercial unit. Instead, the gas will spend more time at the high temperatures.

Figure 3.8-4 shows temperature predictions from the CMB Process Model for three different combustor configurations. The time-temperature profile for the $300 \mathrm{Mw}$ commercial case is shown in the blue trend line. Also shown are two cases for the MTF, where the bauxite is cooled by either a water-cooled transport line (red trend line) or by a moving bed heat exchanger (green trend line). The water-cooled transport line did not provide the full heat extraction needed to cool the bauxite. With only 1.0 Mw (3.3 MBtu/hr) of cooling, the MTF could not achieve the same profile as the commercial case. The MBHE could remove the required $1.8 \mathrm{Mw}(6.2 \mathrm{MBtu} / \mathrm{hr})$ from the bauxite. With the moving bed heat exchanger installed, the MTF had plenty of cooling capability and could be fired at its full capacity to match expected time-temperature profiles.

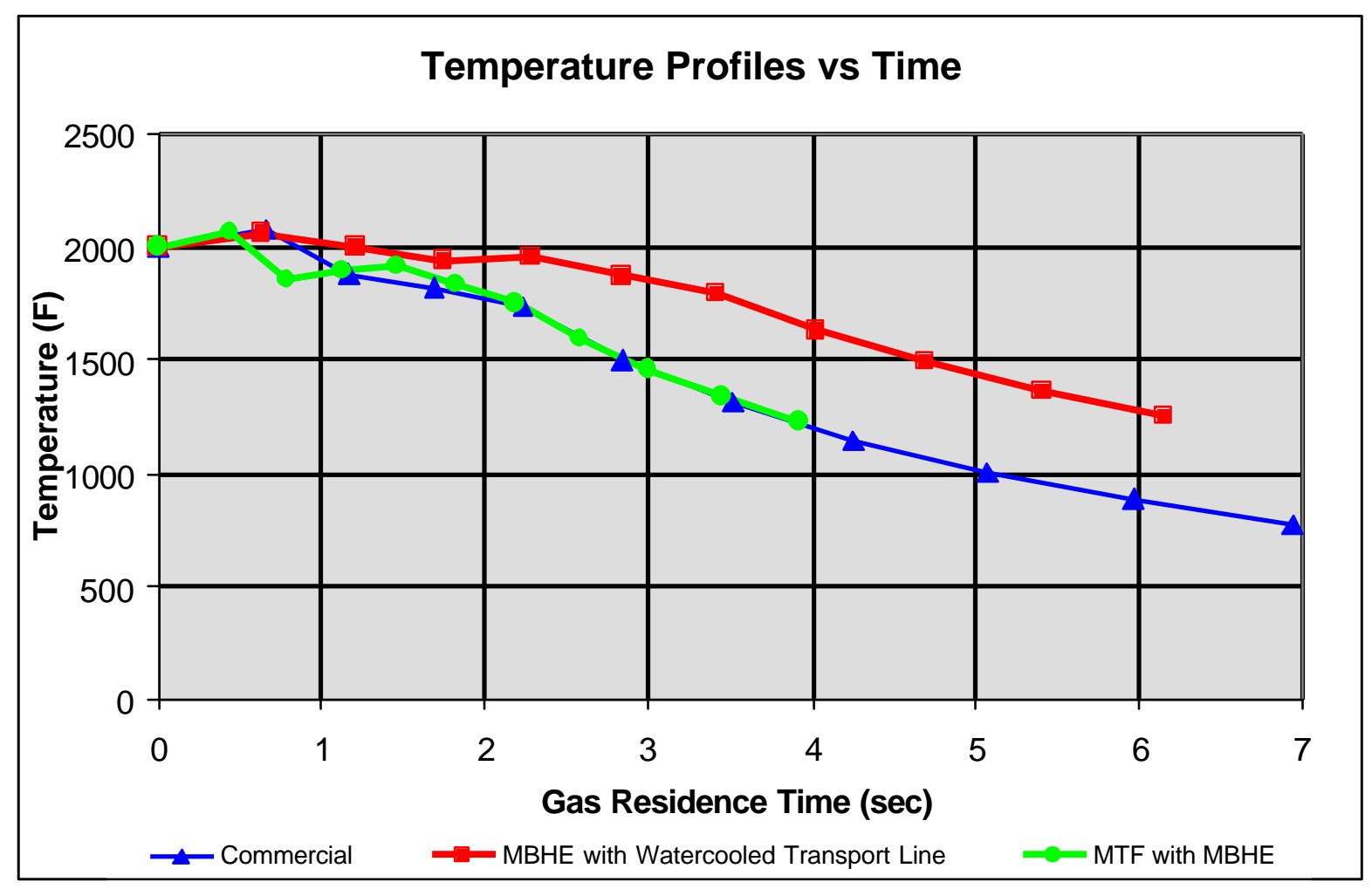

Figure 3.8-4: Gas Temperature Profile Predictions for the MTF and 300Mw CMB 


\section{Other Process Model Simulations}

The Process Model was used for several other simulations. The model predictions for the effective gas residence time in a temperature range effective for SNCR was discussed in Section 3.6. The predictions of the effect of cyclone ash recycle on combustor temperatures are discussed in Section 4.1. The process model showed that increases in recycle rate did not impact the overall bed temperature, but did increase the combustor gas outlet temperature.

The process model was also used to investigate the process impact of mixing grids in the combustor freeboard. The CMB testing in the cold flow heat transfer model and in the MTF pilot plant both used internal mixing grids as a means to improve gas/solid contacting and to improve gas-to-solids heat transfer. The process model was then used to investigate other process implications of the mixing grids or other combustor internals.

The process model was used to run a series of parametric variations to explore this situation. The base case model assumed a moderate amount of solids refluxing in the lower combustor. Increasing the overall refluxing below the grid location simulated the addition of mixing grids. Figure 3.8-5 shows the results of the base case model and a second case where the grids were installed at an elevation of $12-\mathrm{m}$ (40-ft).

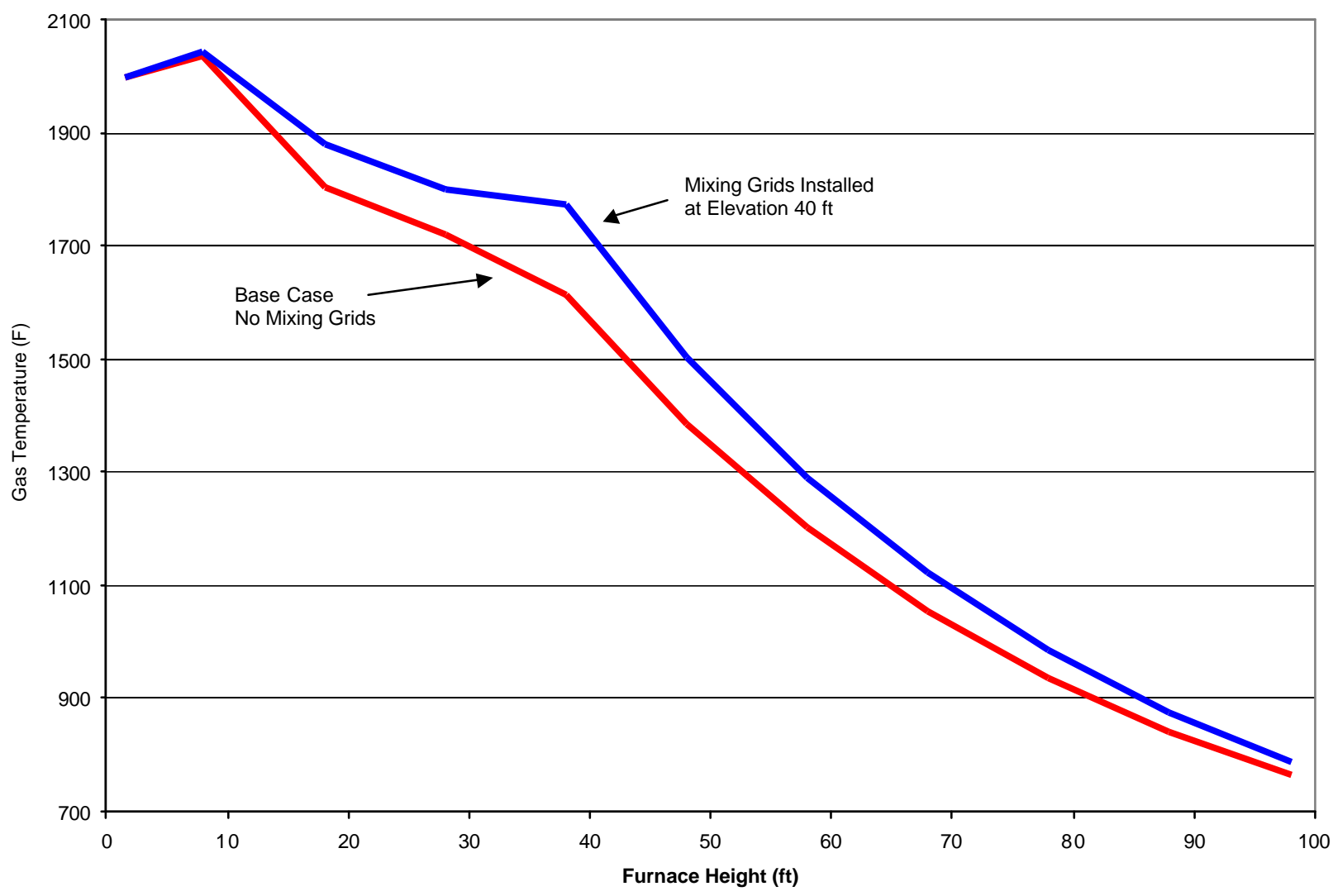

Figure 3.8-5: Effect of Solids Reflux on Gas Temperature Profile 
As expected, the higher reflux ratio below the mixing grids (see blue trend line) tended to flatten out the temperature profile in the lower combustor. This resulted in a longer residence time at higher temperatures and slightly higher gas outlet temperatures leaving the combustor. In this specific case, the gas residence time between $980-1090^{\circ} \mathrm{C}(1800-$ $2000^{\circ} \mathrm{F}$ ) increased by over $80 \%$. This could have some significant benefits for carbon burnout and $\mathrm{NO}_{\mathrm{x}}$ control if SNCR injection were used. However, this particular scenario showed little added benefit for increasing residence time within the optimum temperature window for sulfur capture. The temperature profile would vary depending on the type of mixing grid and the elevation it is located at. 


\subsection{COMPONENT DEVELOPMENT}

The objective of these tasks was to evaluate selected component systems in support of MTF testing and commercial design concepts. The focus was on determining requirements for and developing design concepts for the fuel feed system, the recycle system, and the solids inlet distributor system.

\subsection{Fuel Feed and Recycle System}

The objective of this task was to develop a conceptual design for the fuel feed and recycle system. A major requirement is that the fuel must be distributed uniformly enough that excessive temperature variations are avoided within the bubbling bed.

\section{Recycle System}

The primary focus of this task was on the fuel feed system. However, the CMB Process Model was used to assess the impact of recycle feed variations on bed temperature. The model showed that changes in recycle had little effect on bed temperature, but significantly changed the combustor gas outlet temperature.

Figure 4.1-1 illustrates how the combustor gas outlet temperature increases as the cyclone ash recycle ratio increases. The simulation assumes that the cyclone ash recycle is fed into the bubbling bed and exits at the average bed temperature. This case was run with constant bauxite feed rate and solids inlet temperature. The combustor gas outlet temperature increased by $350^{\circ} \mathrm{F}$ as the recycle ratio increased from 0 to $1 \mathrm{lb}$ solids/lb gas. The bed temperature remained constant at $2000^{\circ} \mathrm{F}$, which was set by the bauxite flow rate and solids inlet temperature.

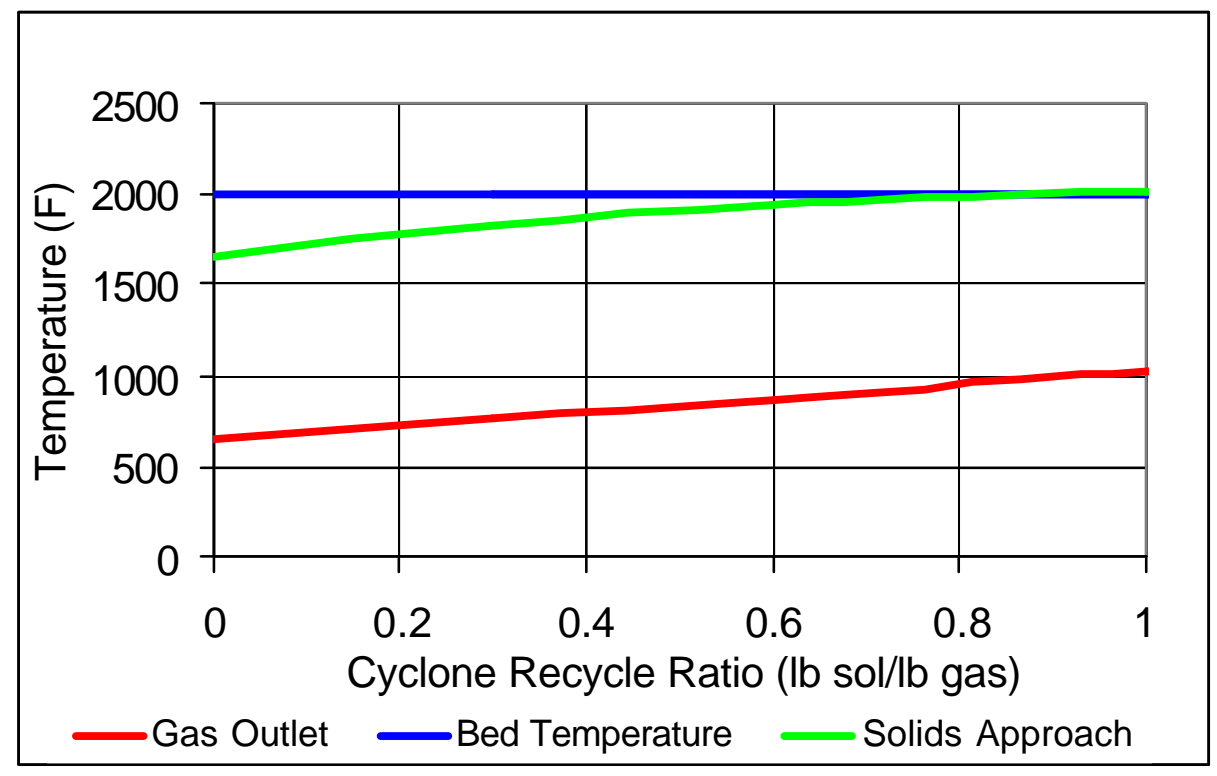

Figure 4.1-1: Effect of Cyclone Recycle Rate on Bed Temperature

Although the cyclone recycle solids were directly cooling the bed, they effectively had no impact on the bed temperature. This is because the recycle ash leaves the bed at the bed temperature and then transfers energy to the falling bauxite. The bauxite is now cooling both 
the combustion gases and the recycle ash. Since the bauxite flow is constant and the heat transfer rate hasn't significantly changed, the bauxite temperature just before it falls into the bubbling bed increases as the cyclone ash recycle rate increases. The bauxite now has less cooling impact on the bed, which offsets the cooling from the cyclone recycle stream. The net cooling effect to the bed is the same regardless of the cyclone recycle rate and the bed temperature remains constant.

Recycle distribution can still have an impact on local bed temperatures. The design of this system is dependent upon process requirements that aren't finalized. Current thinking is to inject the recycle material directly above bed. This facilitates recycle solids distribution and also keeps the bulk of the recycle ash out of the bubbling bed. This could help to mitigate any potential agglomeration effects and also minimize desulfization in the reducing regions of the bed.

\section{Fuel Feed System}

Fuel Feed System Requirements

The fuel feed system for a commercial CMB boiler with a large bed plan area must provide adequate mixing and dispersion of the coal throughout the fluidized bed. This distribution is required for effective combustion and to prevent local hot spots that would cause agglomeration of softened ash. There are a number of design considerations for feeding fuel to a fluidized bed with a large plan area. The first is how to get the fuel to various points in the bed. The second is how uniform the fuel distribution is. The third is how well the fuel mixes in the bed to avoid local hotspots.

The test results that are discussed in Section 5.3 show that the CMB bubbling bed is quite tolerant of bed temperature variations. Bed temperatures were maintained for over 6 hours at temperatures up to $160^{\circ} \mathrm{F}$ hotter than the nominal $2000^{\circ} \mathrm{F}$ operating condition. No noticeable process degradation nor agglomeration was observed during this period. This test showed that the CMB can tolerate some bed temperature variations and temporary upset conditions. The discussion in Section 3.4 also showed that lateral bed mixing at these high velocities is quite good. The fuel should be sufficiently mixed to avoid excessive bed temperature variations if the fuel feed points are spaced every $12-21$ feet.

The conceptual design effort at this point focused on an overbed spreader system to distribute the fuel above the bubbling bed. This system is much simpler and more reliable than inbed pneumatic feed systems and is capable of distributing the fuel across wide bed areas. The initial concern with this type of system was how much the falling bauxite solids would affect the solids distribution. In the $\mathrm{CMB}$, the falling solids may effect the trajectory of the thrown coal, keeping the fuel from adequately covering the surface of the bed.

\section{Impact of Falling Solids on Spreader}

A analysis was therefore conducted to look at the feasibility of using an overbed spreader feeder. The analysis used a typical feeder spreading $1 / 4$ inch topsize coal with injection velocities about 8 meters/second. It was assumed that the coal feeder was about 2 meters above the surface of the bubbling bed. In still air without any particle interactions, it was assumed that the coal would be thrown about 7.5 meters. The analysis looked at how the 
flight paths of various sized fuel particles were affected when they were subjected to a series of impacts by falling bauxite particles.

An analysis of the feeder performance using CFD was not considered to be useful since CFD codes generally are not capable of solving particle to particle interactions. However, CFD simulations were used to generate the approximate densities of the falling particles in the gas flow above the bed.

This analysis considered four different situations. For the assumed process conditions, the average bauxite concentration above the bed was about $0.85 \mathrm{~kg} / \mathrm{m}^{3}\left(0.0336 \mathrm{lb} / \mathrm{ft}^{3}\right)$. Several areas where the bauxite was falling in relatively small streams had concentrations around 8.5 $\mathrm{kg} / \mathrm{m}^{3}\left(0.336 \mathrm{lb} / \mathrm{ft}^{3}\right)$. The spaces in between these streams had practically no particle concentration. Finally, for the case with very poor bauxite distribution there was an area near the wall where the concentration of bauxite was greater than $8.5 \mathrm{~kg} / \mathrm{m}^{3}\left(0.336 \mathrm{lb} / \mathrm{ft}^{3}\right)$. This area extended for several meters on one side of the furnace. This situation would be the worst case for spreading fuel if it occured in front of a fuel spreader.

A given coal particle size swept a specific volume in its trajectory. Considering the density of the falling bauxite, the number of impacts the coal particle experienced was calculated. The collisions were assumed to be inelastic, and the bauxite was assumed to be falling downward at its terminal velocity. No effect from the gas velocity was considered.

Three different sized coal particles were used and trajectories were estimated for the following conditions:

1. No bauxite collisions

2. Bauxite collisions at the average bauxite.density

3. Collisions assuming density changes as fuel travels through high density regions and low density regions

4. Collisions through high-density regions only

The first case was a base case for comparison. The second case was probably the case that describes the average spreader performance over time as the falling bauxite pattern shifts during operation. The third case represented the approximate performance of the spreader as it tried to throw particles through the smaller areas of higher density bauxite. The fourth case was a worst case scenario.

It was expected that the fuel trajectory would fluctuate from case 1 to case 3 as the flow patterns in the furnace changed, with most of the fuel probably falling where case 2 predicts. How much fuel will follow each case was not estimated. Table 4.1-1 lists the range by condition and fuel size. 
Table 4.1-1: Effect of Particle Impact on Coal Trajectory

\begin{tabular}{lllll}
\hline Condition & 1 & 2 & 3 & 4 \\
\hline Fuel size & & & & \\
$6.35 \mathrm{~mm}(.25 \mathrm{inch})$ & $7.6 \mathrm{~m}(25 \mathrm{ft})$ & $5.2 \mathrm{~m}(17 \mathrm{ft})$ & $3.7 \mathrm{~m}(12 \mathrm{ft})$ & $2 \mathrm{~m}(6.5 \mathrm{ft})$ \\
& & & & \\
$3.81 \mathrm{~mm}(.15 \mathrm{inch})$ & $7.6 \mathrm{~m}(25 \mathrm{ft})$ & $4.3 \mathrm{~m}(14 \mathrm{ft})$ & $2.4 \mathrm{~m}(8 \mathrm{ft})$ & $<1 \mathrm{~m}$ \\
$1.27 \mathrm{~mm}(.05 \mathrm{inch})$ & $7.6 \mathrm{~m}(25 \mathrm{ft})$ & $3.7 \mathrm{~m}(12 \mathrm{ft})$ & $1.5 \mathrm{~m}(5 \mathrm{ft})$ & $<1 \mathrm{~m}$ \\
\hline
\end{tabular}

The results from this analysis are summarized below:

1. The effective range of a fuel spreader in a falling bauxite CMB is about $67 \%$ of the range in a conventional furnace.

2. The drop out pattern of the fuel on the bed is probably a lot wider than the conventional case.

3. If the bauxite is distributed badly with most of it falling in front of the spreader, then fuel will only penetrate about a meter into the furnace.

4. A system can be designed to work with the reduced range, but the falling solids distribution must be reasonable.

Figures 4.1-2 to 4.1-4 illustrate the fuel trajectories described above. Table 4.1-2 illustrates the calculation of the average impact distance.

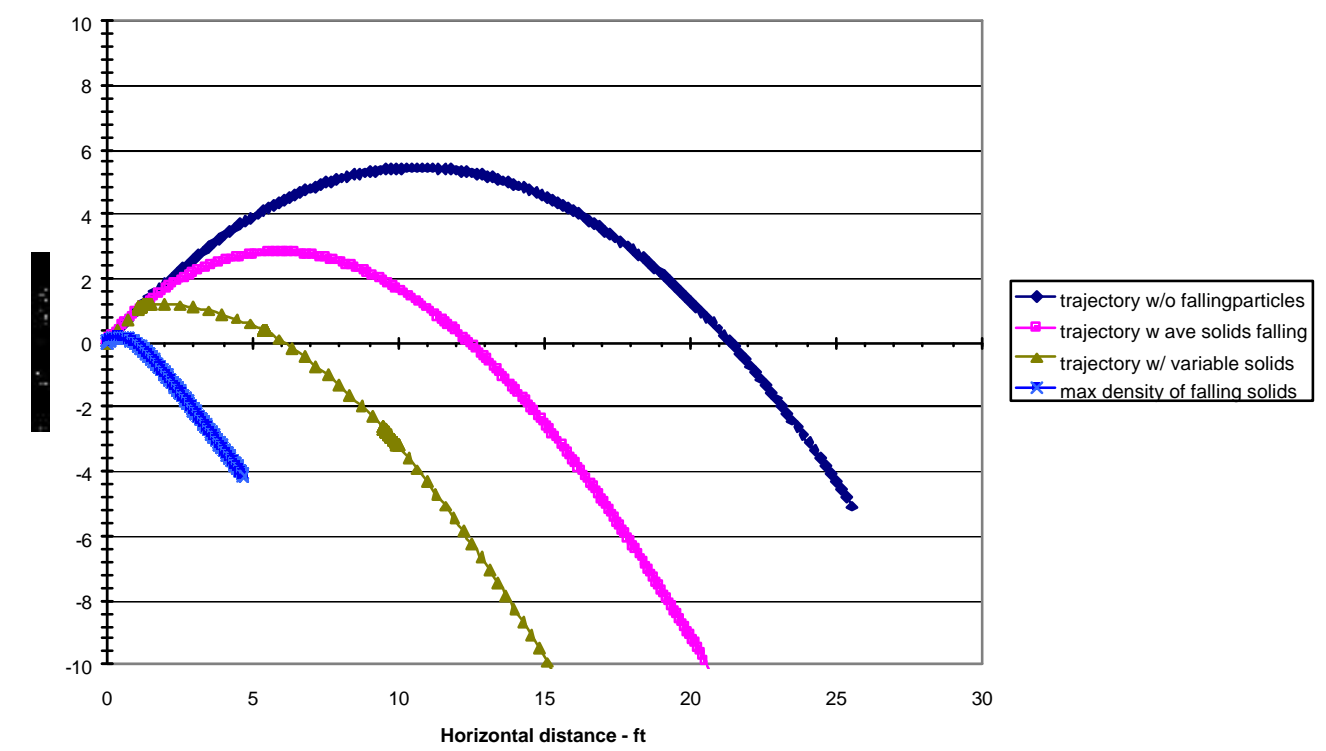

Figure 4.1-2: Trajectory of 0.25 Inch Coal Particles 


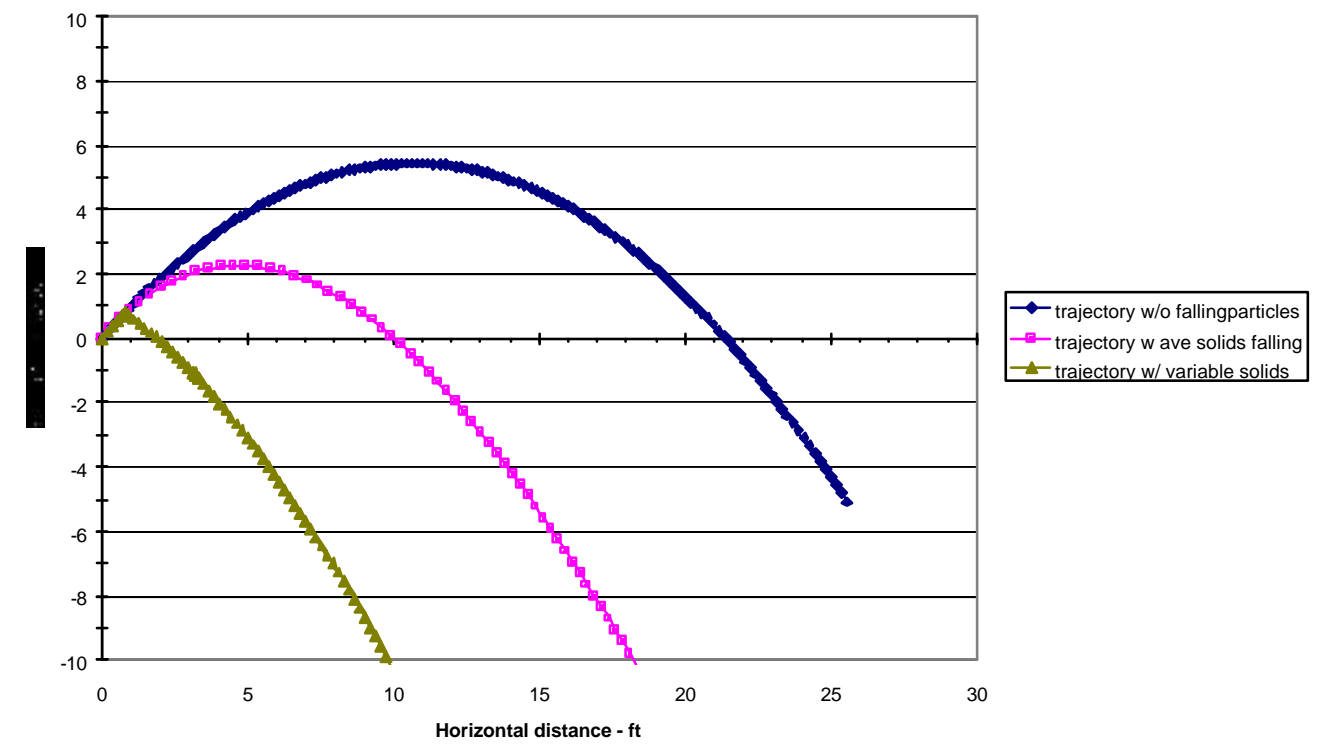

Figure 4.1-3: Trajectory of 0.15 Inch Coal Particles

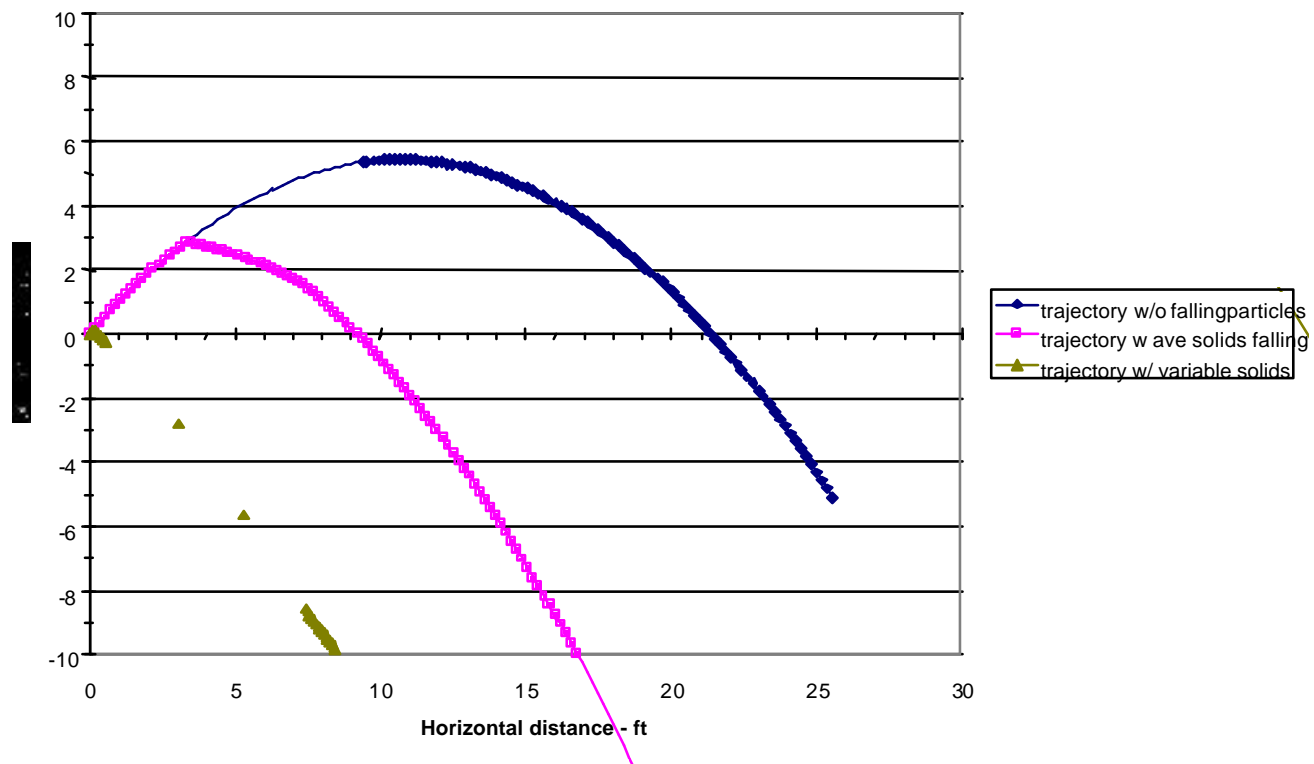

Figure 4.1-4: Trajectory of 0.05 Inch Coal Particles 
Table 4.1-2: Interaction of coal from spreader stoker with falling bauxite

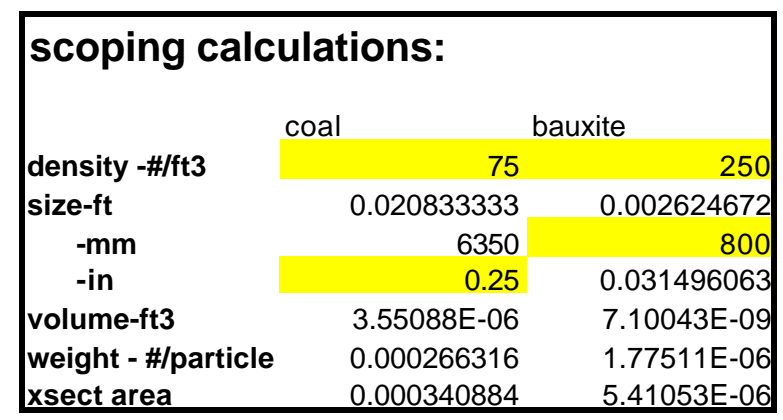

\begin{tabular}{lr}
\hline max dpm concentration & 2.405 \\
ave: & 0.03369 \\
\hline
\end{tabular}

\begin{tabular}{|c|c|c|c|c|}
\hline bauxite density - \#/ft & particles/ft3 & \# of impacts/ft & $\begin{array}{l}\text { mean dist betwee } \\
\mathrm{ft}\end{array}$ & impacts \\
\hline 10 & 5633462 & 1920.359 & 0.000521 & 0.0062 \\
\hline 1 & 563346 & 192.036 & 0.005207 & 0.0625 \\
\hline 0.1 & 56335 & 19.204 & 0.052074 & 0.6249 \\
\hline 0.01 & 5633 & 1.920 & 0.520736 & 6.2488 \\
\hline 0.001 & 563 & 0.192 & 5.207359 & 62.4883 \\
\hline 2.405 & 1354848 & 461.846 & 0.002165 & 0.0260 \\
\hline 0.03369 & 18979 & 6.470 & 0.154567 & 1.8548 \\
\hline
\end{tabular}

The above results show that fuel can be distributed by an overbed spreader through the falling bauxite, although the fuel trajectory may be somewhat reduced by particle to particle impacts. The next effort focused on looking at the application of overbed fuel spreaders to large scale $\mathrm{CMB}$ boilers.

\section{Coal Spreader Specifications}

Coal can be fed to the CMB combustion chamber by coal spreaders located just above the fluidized bed. A survey of coal spreaders was made to determine the distance coal could be spread over the bed, how uniform the distribution would be, and what resources are needed by the spreaders. Airflow requirements are significant as the air becomes part of the CMB overfire air. The coal capacity is important as it impacts the number of coal feeders required for a given boiler size.

Two types of spreader were considered in this evaluation, a pneumatic air swept and a mechanical underthrow spreader. The pneumatic air swept spreader shown in Figure 5.1-5 has no moving parts in the fuel path and is simple and inexpensive to operate. ${ }^{1}$ The spreader consists of a fuel downspout, an admission port in the combustor wall, an air inlet nozzle, and a deflector plate at the bottom of the admission port. The air swept spreader does not have a fuel metering control element. This is an extra cost item that needs to be considered for the total fuel feed system cost. 


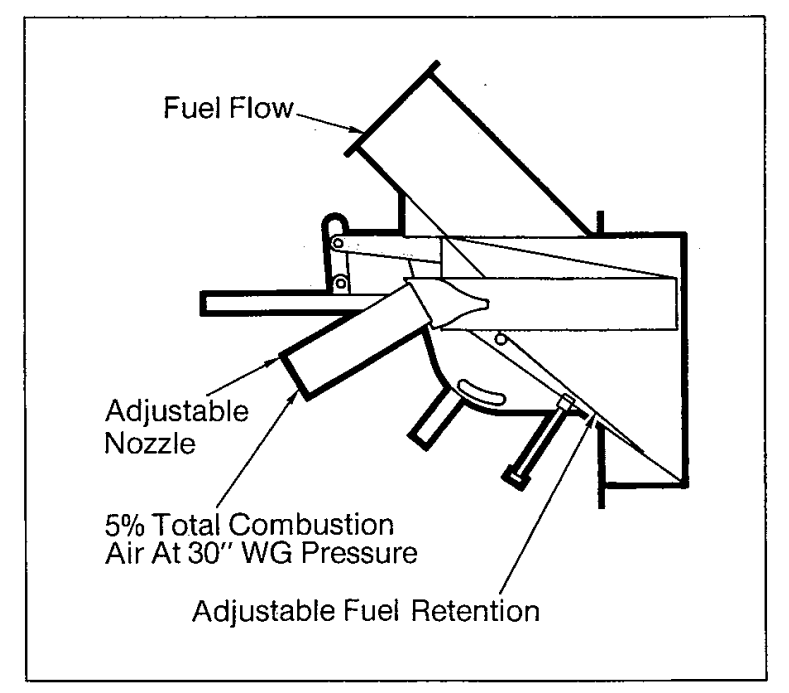

Figure 4.1-5: Pneumatic Air Swept Spreader

The mechanical spreader has an inlet chute, coal metering belt, an admission port, a rotary drum with paddles that throw the coal into the combustion chamber, and an adjustment to vary the trajectory of the coal discharge as shown in Figure 4.1-6. ${ }^{2}$ The mechanical spreader is more complicated and subject to erosion, but requires little air for operation, and may require less power.

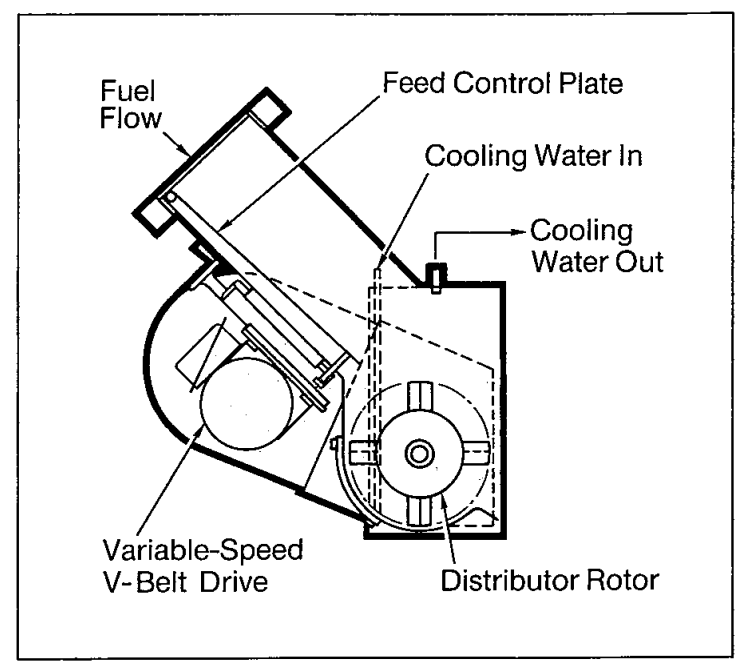

Figure 4.1-6: Mechanical Spreader

Air swept spreaders can have coal capacities as high as 36,000 $\mathrm{lb} / \mathrm{hr}$ with fuel/air ratios around 5. Mechanical spreaders have lower coal capacities, but also require significantly less air. Mechancial spreaders are available with fuel capacities up to $18,000 \mathrm{lb} / \mathrm{hr}$ with fuel/air ratios around 20.

Economics may favor designs using the pneumatic spreader, although the reduced air requirements for the mechanical spreader could be significant. Both spreaders rely on a head 
of coal upstream of the spreader to seal the coal supply from hot combustion gasses due to combustor pressure.

The fuel distribution in the combustion chamber provided by the spreader varies depending on the spreader operating characteristics. Figure 4.1-7 shows the coal distribution for a test conducted on an air swept spreader. ${ }^{3}$ Varying the air flow and deflector position in the spreader determines whether the coal is distributed near or far from the spreader outlet and also the lateral distribution from a discharge centerline. This airflow and velocity characteristic is exploited to improve the distribution. A rotary vane installed in the air supply duct provides a continually varying air velocity and a continually varying distance for coal spreading. This smoothes out the discontinuities shown in Figure 4.1-7.

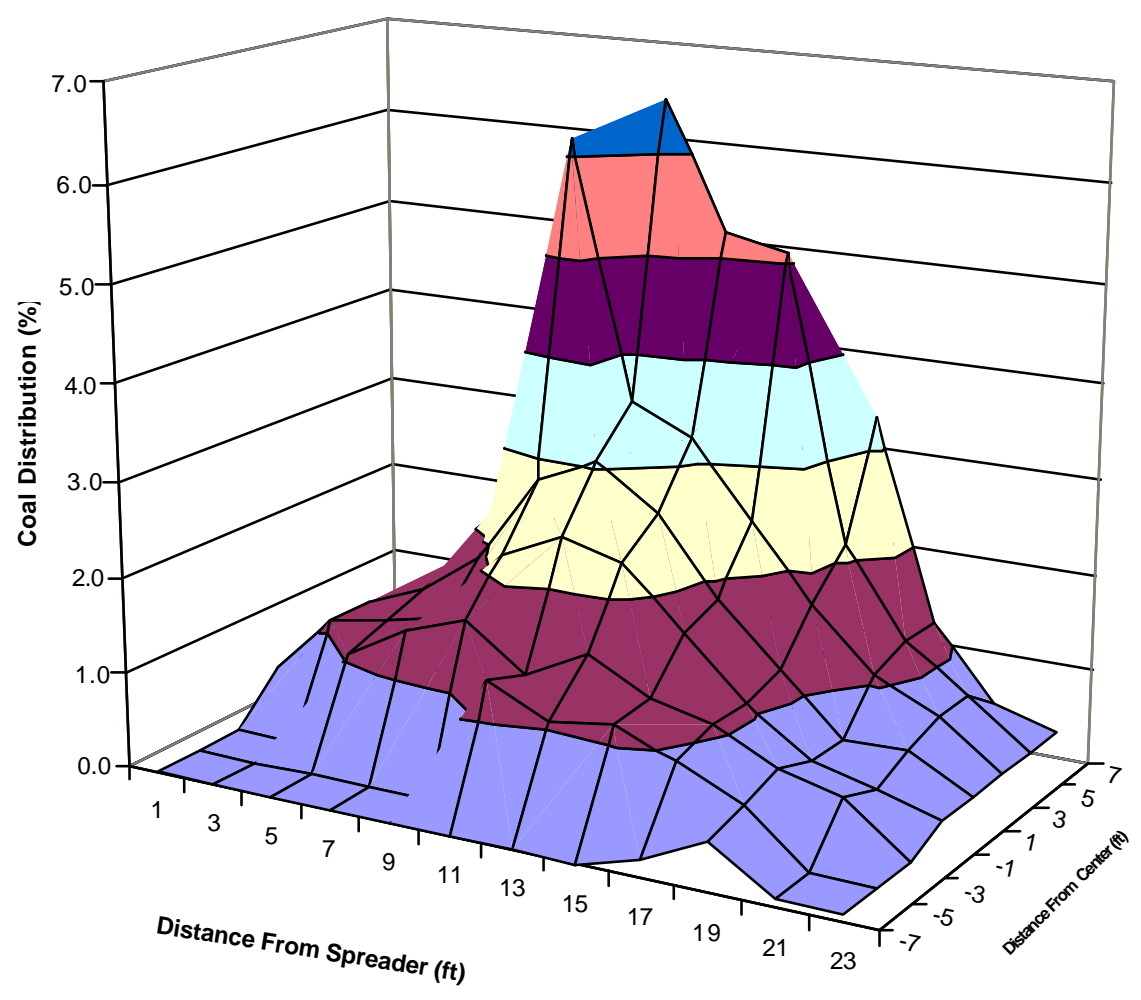

Figure 4.1-7: Air Swept Coal Spreader Distribution 
The mechanical underthrow feeders show similar coal spreading results. The mechanical spreader throw distance is a function of underthrow drum rotary speed. Using a variable speed inverter drive would provide a more uniform coal distribution. A typical coal distribution from a mechanical spreader is shown in Figure 4.1-8. ${ }^{4}$

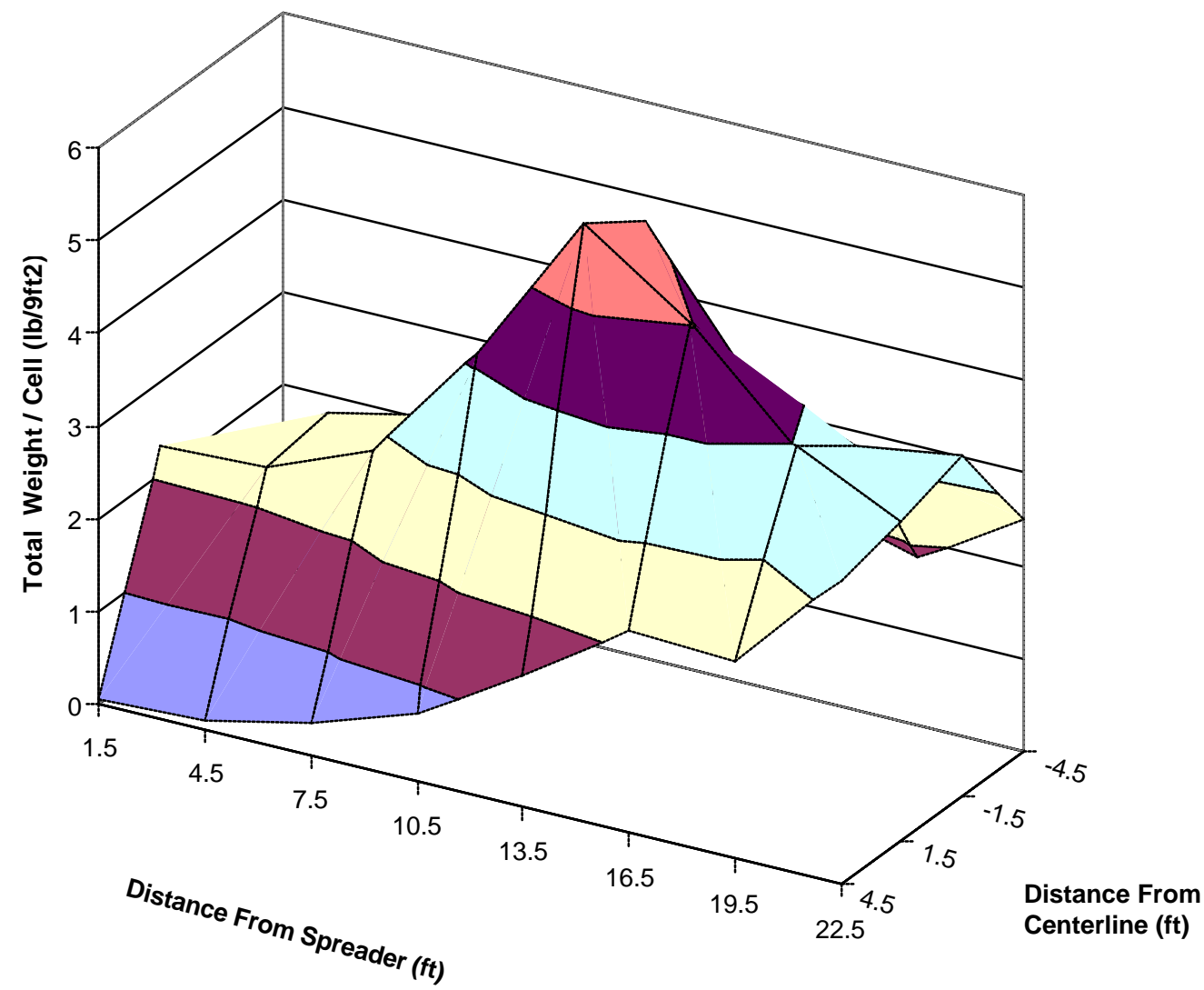

Figure 4.1-8: Mechanical Coal Spreader Distribution

These results show that both types of spreaders are capable of throwing the fuel over 20 feet, although this distance may be reduced somewhat by interactions with the falling bauxite.

\section{Commercial Design}

A conceptual fuel feed system was developed for a nominal 300 MW CMB boiler. The combustion chamber for this boiler was a 54-ft diameter circular cylinder and full load operation requires $355,000 \mathrm{lb} / \mathrm{hr}$ coal feed. The conceptual design utilized ten pneumatic air swept spreaders arranged around the perimeter of the combustor.

Figure 4.1-9 shows a plan view of the combustion chamber. The approximate coverage area of coal discharged from each spreader is shown in outline for a total of ten feeders. The red shaded area represents the coal distribution area from a single spreader. The light blue shaded area represents the additional area coverage for that one spreader due to the lateral mixing and movement of coal within the fluidized bed. This is based on the lateral mixing results from Section 3.4 that indicate that the coal will migrate horizontally $12-22$ feet from the point which it is feed. In this case, the coal particles will migrate laterally from the point 
where they land in the bed, as indicated by the red shaded region in Figure 4.1-9. The combination of the fuel distribution by the spreaders and the lateral mixing by the fluidized bed should be sufficient to distribute the fuel across the entire bed plan area.

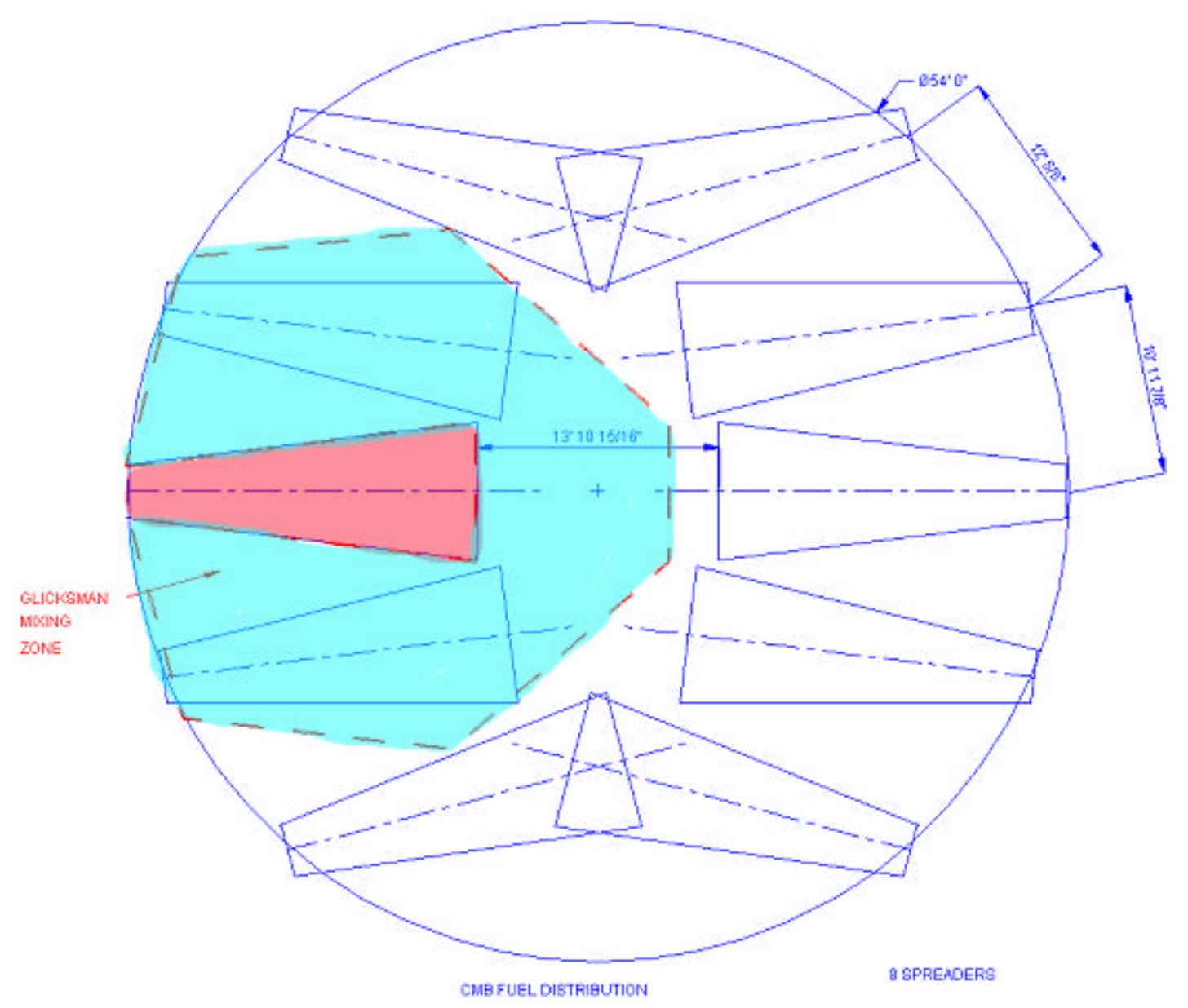

Figure 4.1-9: Coal Feed Distribution for 300 Mw CMB Boiler

These results indicate that coal can be feed to a CMB Boiler using a reasonable number of commercially available coal spreaders. Air swept spreaders are the logical choice at this time because of their large capacity and simplicity. Further testing and analysis are necessary to determine whether the airflow requirements have an unfavorable effect on combustion performance or $\mathrm{NO}_{\mathrm{x}}$ emissions. If so, then a mechanical spreader will also work. This device has significantly reduced air requirements, but will require more feeders because of its lower capacity. 


\subsection{Solids Inlet Distributor System}

The objective of this task was to assess the solids inlet distribution requirements at the top of the combustor for a commercial CMB combustion system. Distribution results were reviewed from two-dimensional bench scale tests conducted prior to this program. In addition, tests were conducted in PPL's 15-inch cold flow model and in the MTF. The results were then applied to a distribution system for a commercial CMB system.

The solids distributor is a critical component in a CMB system. Solids exit the moving bed heat exchanger, are pneumatically transported to the top of the combustor, are separated, and collected in a hopper. The solids are then feed to a solids distributor at the top of the combustor, where they are dispersed across the combustor cross-section into the rising combustion gas. The distributor must be capable of spreading the solids out uniformly without restricting the flow. The design must also be resistant to plugging from occasional oversized particles.

\section{Review of Prior Distribution Results}

PPL's Slice Model Test Facility was constructed prior to this program to evaluate methods to promote the lateral distribution of bauxite particles from a single inlet pipe source at the top of the combustor. The overall facility shown in Figure 4.2-1 is about 65 feet tall and includes the slice model plus associated material handling equipment. The slice model test section (highlighted in red) is 45 inch wide by 4 inch deep by 16 feet high. The frame of the facility was of steel with horizontal sample ports spaced every 24 inches vertically. The face of the facility was covered with $1 / 2$ inch thick plexiglas to permit viewing of the flow of the material exiting the inlet pipe as it was distributed through the slice.

A solids supply hopper connected to the top of the test section was supported on load cells. A weight vs. time record logged by the data acquisition system was used to measure the solids supply to the test section. Three inlet nozzles were available to permit solids to be admitted to the center of the model or at the side of the model. Most tests were conducted with the solids entering the side of the model to evaluate the ability to distribute solids over a longer lateral distance. A blower connected to a plenum at the bottom of the test section provided an upward flow of air through the test section. A thin plate diameter tap orifice meter at the blower inlet measured the air rise velocity. A central drain at the bottom of the test section drained solids to a collecting hopper. The bauxite flow was simulated by sized sand having a $D_{50}$ of $720 \mu$. The sand had flow characteristics similar to the bauxite, was less expensive, and was easier to work with. 


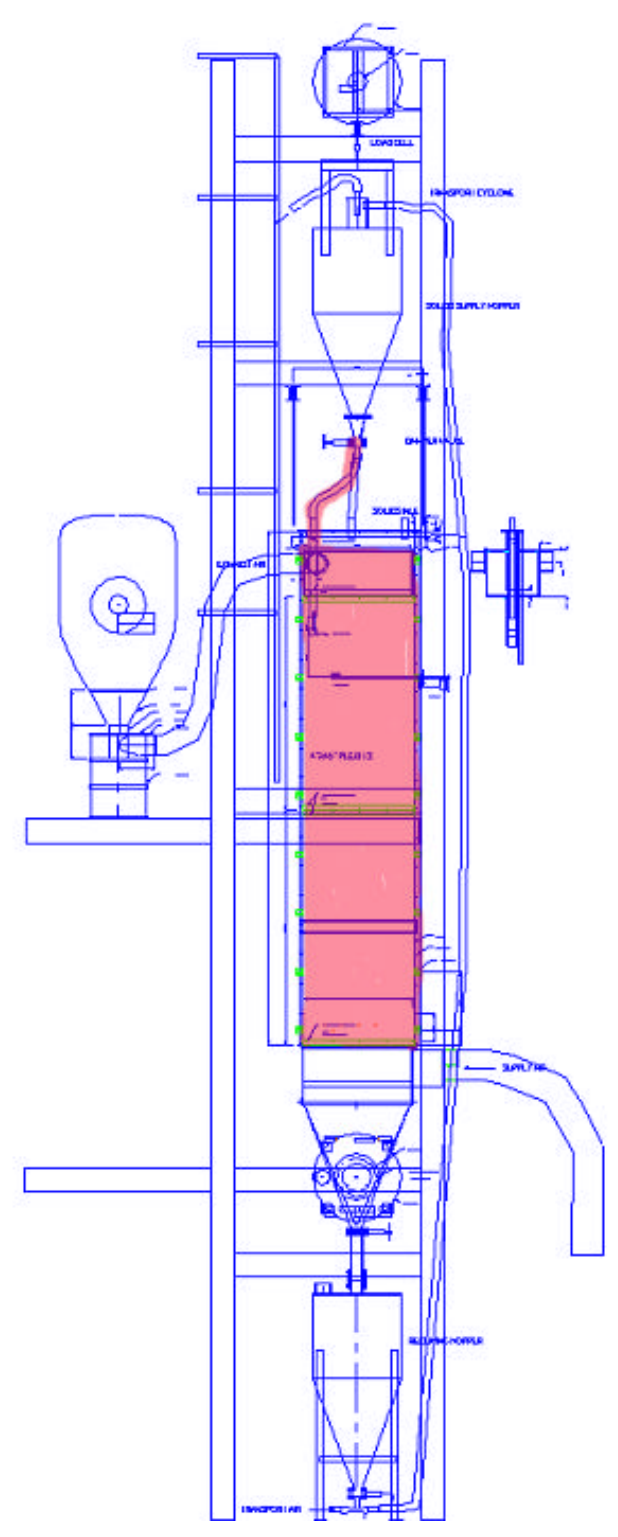

Figure 4.2-1: CMB Bauxite Inlet Distribution Slice Model Facility

The distribution of the solids in the test section was measured by an optic beam probe shown in Figure 4.2-2. The probe consisted of a light emitter and a photo diode spaced 1 inch apart. A lens mounted after the emitter provided a collimated beam. An electronic frequency meter was connected to the output of the diode and provided a 4-20ma signal proportional to the frequency of particles breaking the beam between the light source and the diode. The output signal of the frequency meter was connected to the data acquisition system and recorded every three seconds during a test. The probe could be rotated around its axis to provide a test section centerline solids frequency measurement or a wall frequency measurement. 


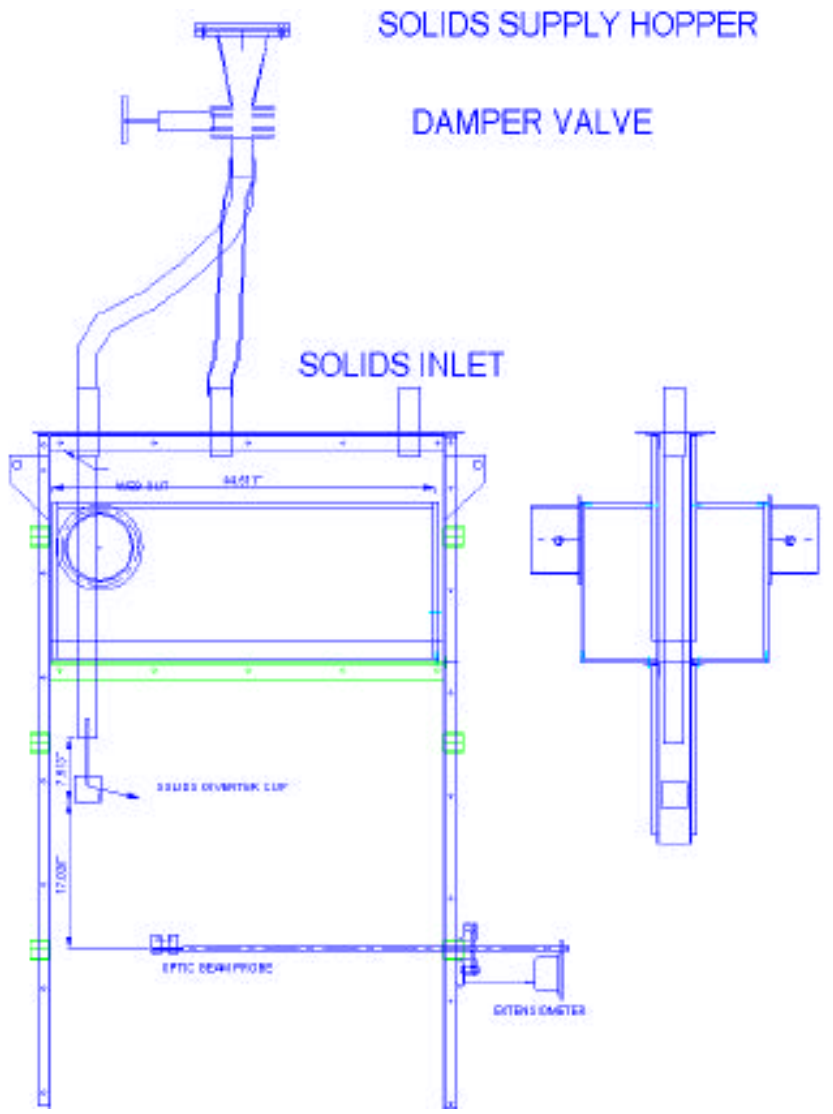

Figure 4.2-2: Bauxite Slice Model Inlet \& Measurement Detail

The lateral position of the probe within the model was determined by a string extensiometer connected to the end of the probe and the side of the model. This provided an accurate position of the probe at all times.

Data from the supply hopper load cells, air flow orifice, optic probe, and extensiometer were recorded every 3 seconds to a PC hard drive by a Labview Data acquisition program connected to a Fluke Data Recorder. The test data was copied into a master spreadsheet for analysis after the test was completed. The data was plotted vs. time and extensiometer readings were used to determine times when the probe was located at a particular location. All readings during that time were averaged for all measurements and the average readings were plotted as a function of probe position.

An $8 \mathrm{~mm}$ video camera was used to record the distribution of solids in the test section for selected tests. The visual observation of the solids distribution confirmed the optic measurements.

\section{Slice Model Test Results}

Most of the distribution tests were run with the distributor located in the extreme left side of the test model. This arrangement allowed the widest spreading of solids in a lateral direction. 
A distributor that could give a good distribution across the 45-inch width of this facility would be able to cover a $44 \mathrm{ft}^{2}$ area if scaled up in three dimensions.

The initial tests were run with solids entering the top of the test section from the inlet pipe without any distributor. The solids tended to flow straight downward without any significant dispersion as shown in Figure 4.2-3. The optic solids frequency probe shows a high frequency of particles cutting the bean under the inlet pipe, but few particles beyond a distance of 5 inches from the inlet pipe centerline.

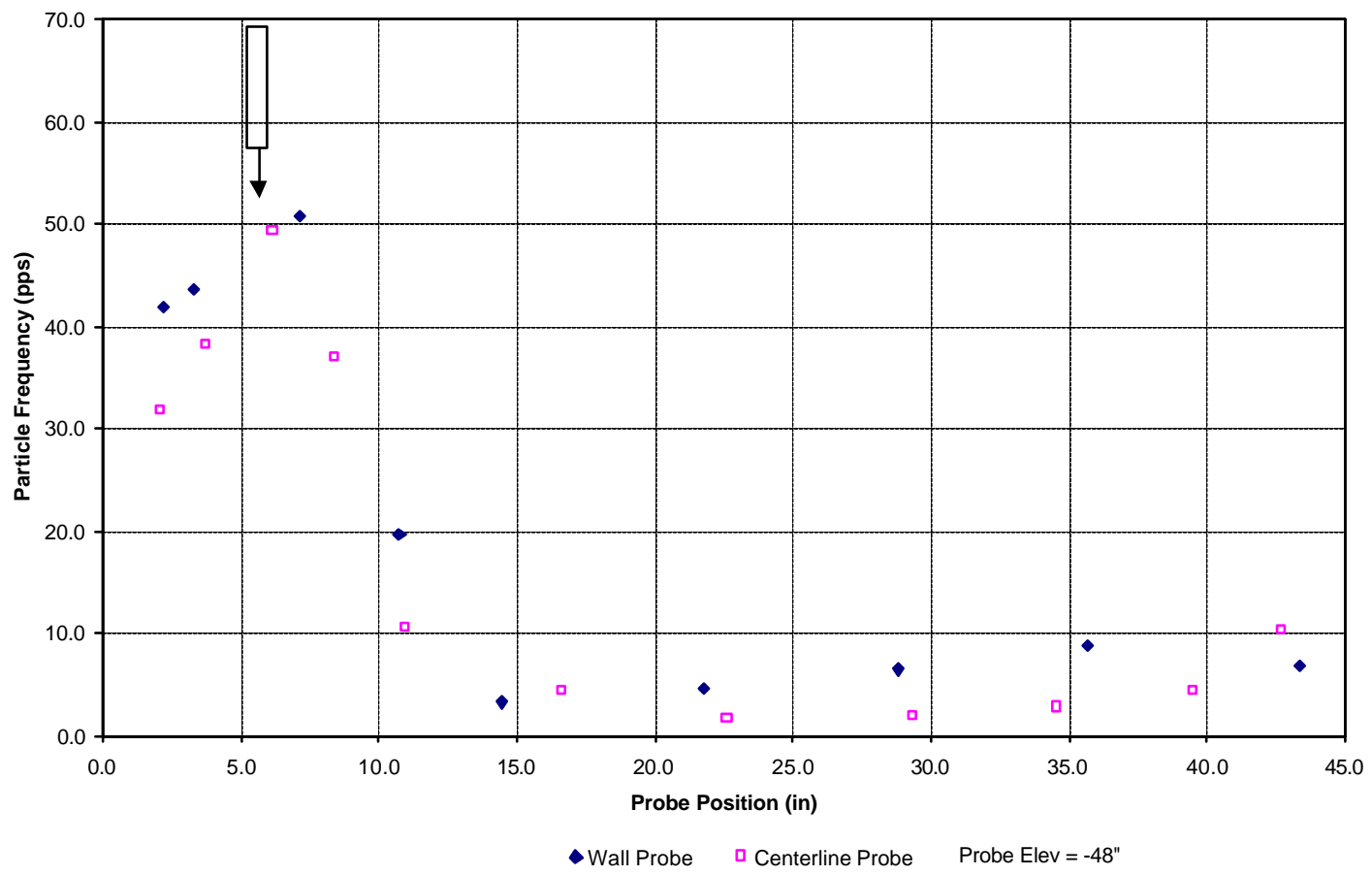

Figure 4.2-3: Effect of Straight Inlet Pipe on Solids Distribution

The solids distribution was significantly improved by adding a diverter cup with one side cut out below the solids inlet pipe. This modification forced the solids to flow out that side and caused a significant shift of solids from below the inlet pipe to the other side of the test section. Figure 4.2-4 shows typical solids distribution with the new distributor. The results showed that distribution was very good to the edge of the model. Clearly, the solids could have been distributed further than the width of this model. 


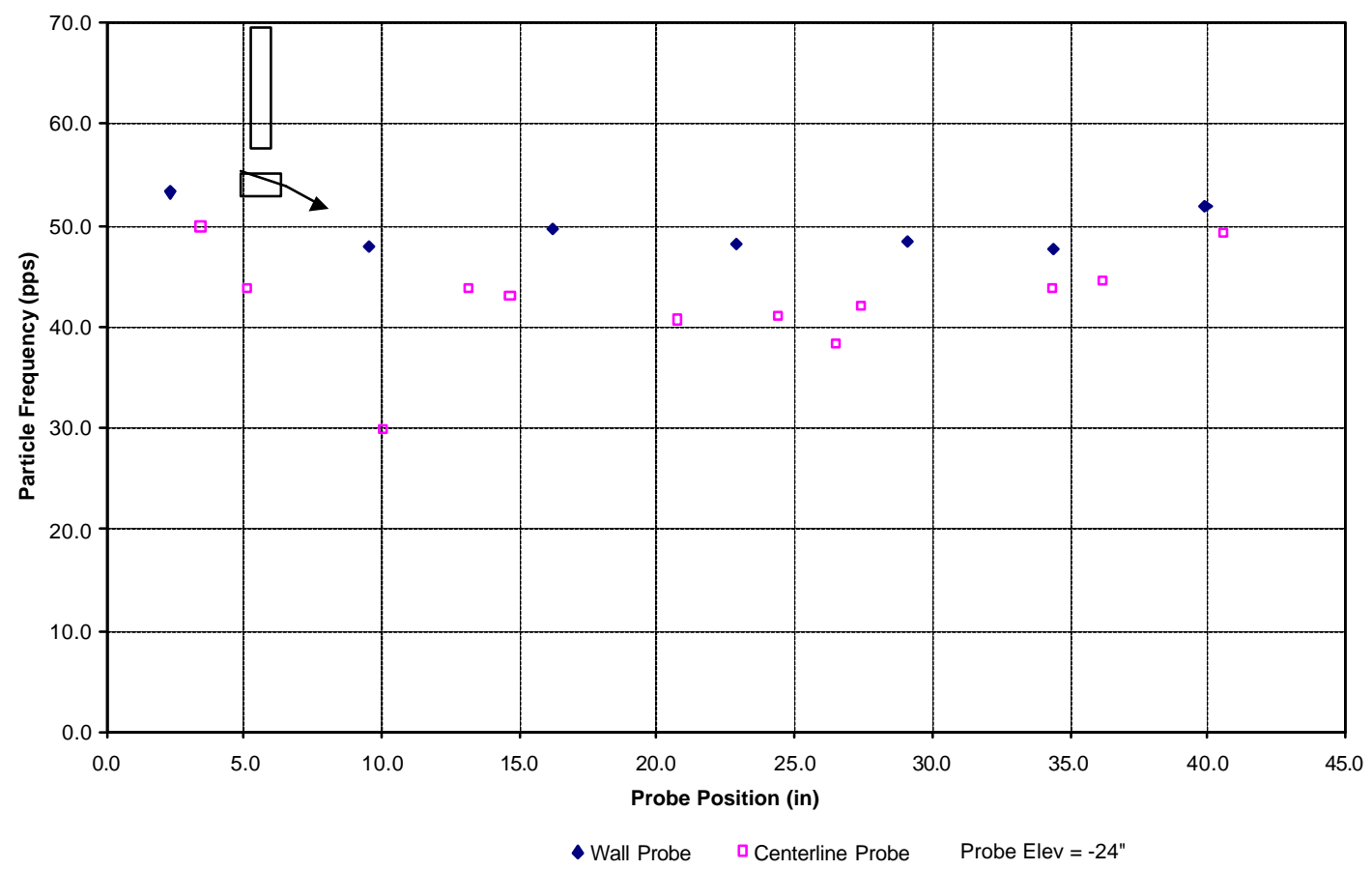

Figure 4.2-4: Effect of Diverter Cup on Solids Distribution

\section{5 inch model}

The results of the slice model were then applied to the 15-inch cold flow column, which was previously described in Section 3.1. The one dimensional distributor plate was replaced with a basket consisting of a bottom plate with eight vertical bars rising to the inlet pipe. This produced 8 radial discharge streams of solids flowing out horizontally. The streams would intersect the column walls and slide down the wall because of the small clearance between the wall and inlet pipe. Therefore a cylindrical shroud opened at the top and bottom was placed around the distributor basket to divert the stream downward away from the wall.

The 15-inch model confirmed the earlier conclusion that a distributor was needed to spread solids out. Figure 4.2-5 shows the optic probe particle frequency data when solids were introduced without any solid distributor. There was a peak in the solids frequency in the distribution representing an undispersed jet of solids passing down the model, similar to the results seen in Figure 4.2-3. 


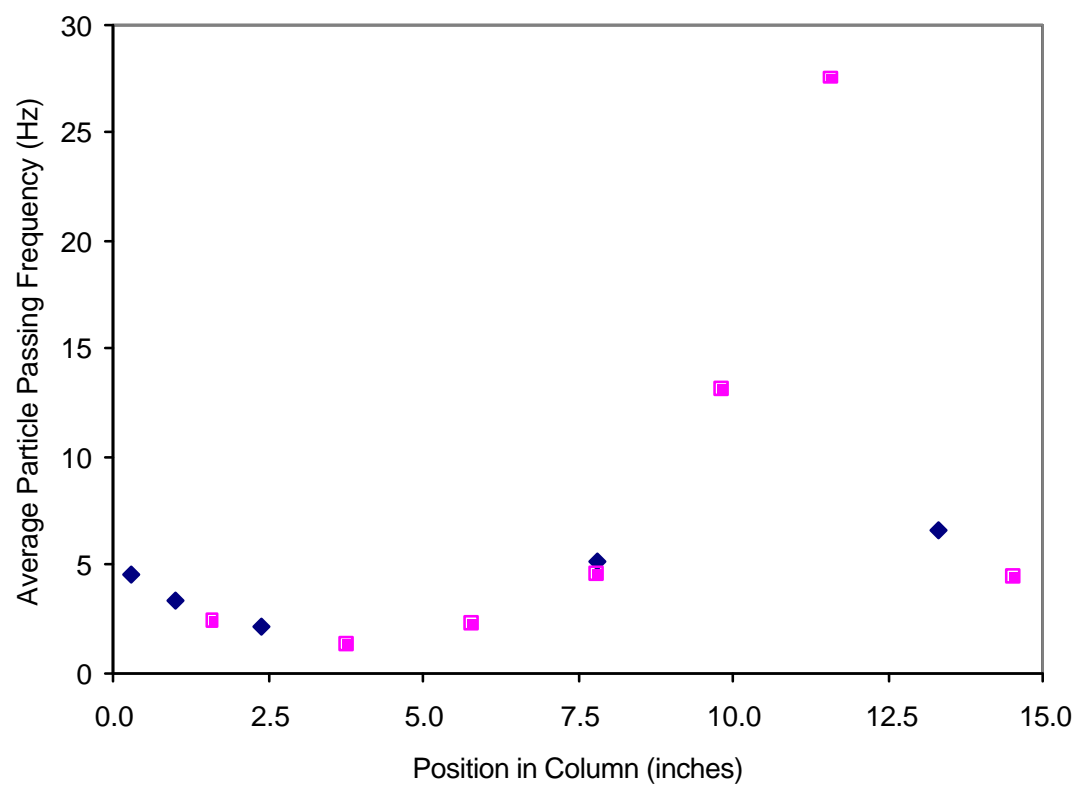

Figure 4.2-5: Solids Distribution without Distributor

The solids distributor significantly improved the solids distribution. Figure 4.2-6 shows the average particle passing frequency at the 16-foot elevation. The two different colored symbols indicate two separate sequential traverses. The results showed that the solids were distributed across the column, although there were slight peaks at the walls.

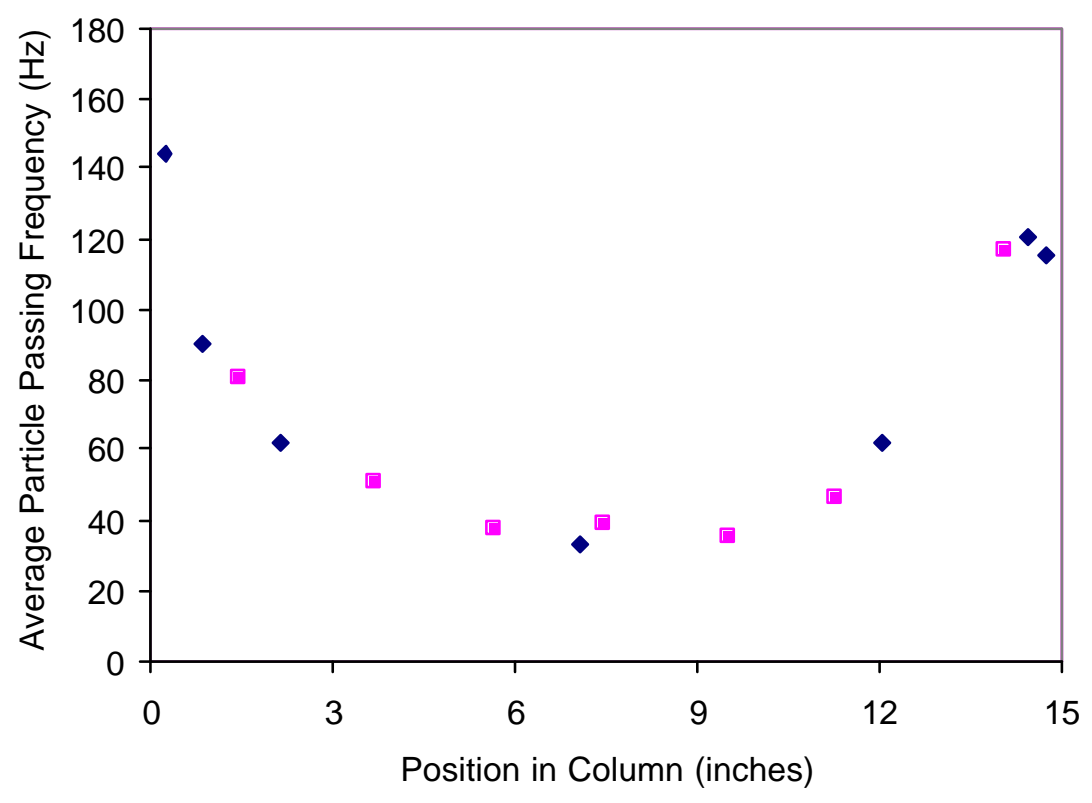

Figure 4.2-6: Solids Distribution at $16 \mathrm{ft}$ Elevation 
Figure 4.2-7 shows the average particle velocity passing through the optic probe for the same test. The solids migration velocity (defined as the particle terminal velocity minus the gas velocity) is also plotted as a horizontal line at $1.7 \mathrm{~m} / \mathrm{s}$. These results showed that the particles were falling at uniform velocity across most of the column, with somewhat higher velocities along the wall. This was expected, as the gas velocity typically was lower along the walls.

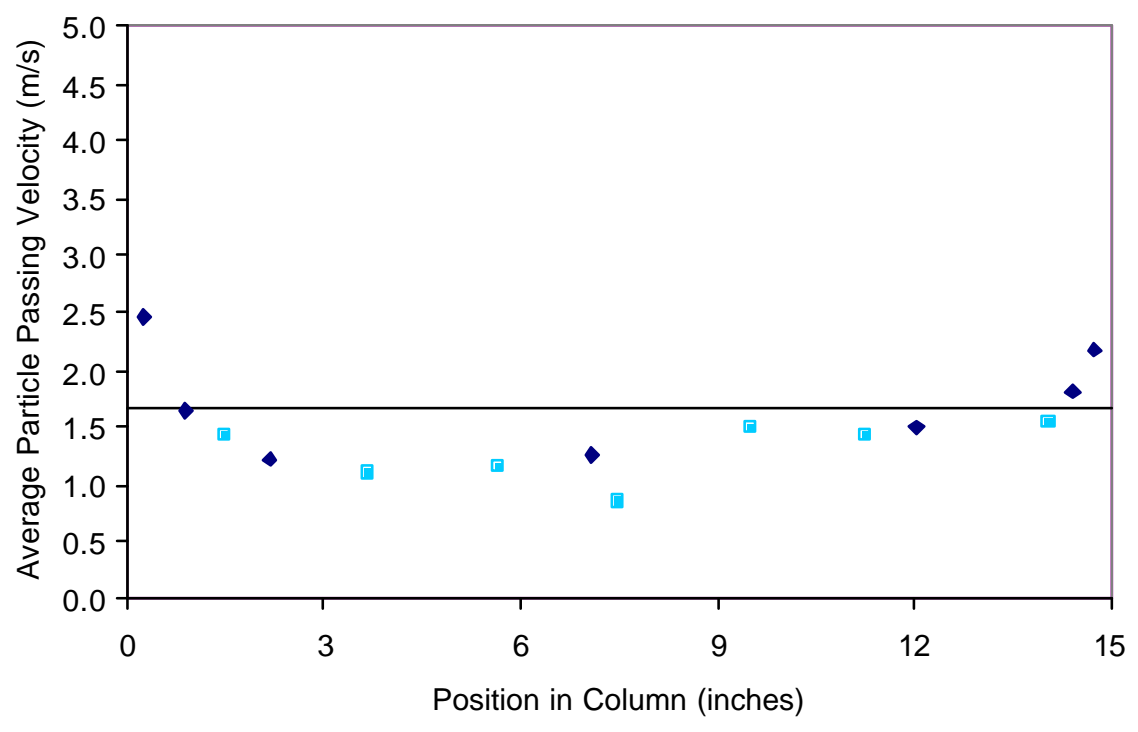

Figure 4.2-7: Solids Migration Velocity at $16 \mathrm{ft}$ Elevation

\section{MTF Results}

A similar distributor was scaled up for use in the MTF. Optic probe measurements were again measured during hot air distribution tests. The optic probe results coupled with temperature mapping and heat transfer results (discussed further in Section 6.1) indicated that the solids distributor did a good job of spreading the solids across the combustor.

The bauxite solids frequency distribution in the MTF combustor at the 40-ft elevation is shown in Figure 4.2-8. The solids distribution was reasonably uniform, with only a slight increase at one wall. The uniform distribution was further supported by the uniform temperature distributions measured across the MTF. The solids migration velocity measured by the optic probe is shown in Figure 4.2-9 for the CMB. The average solids velocity is again superimposed as a horizontal line in this figure. 


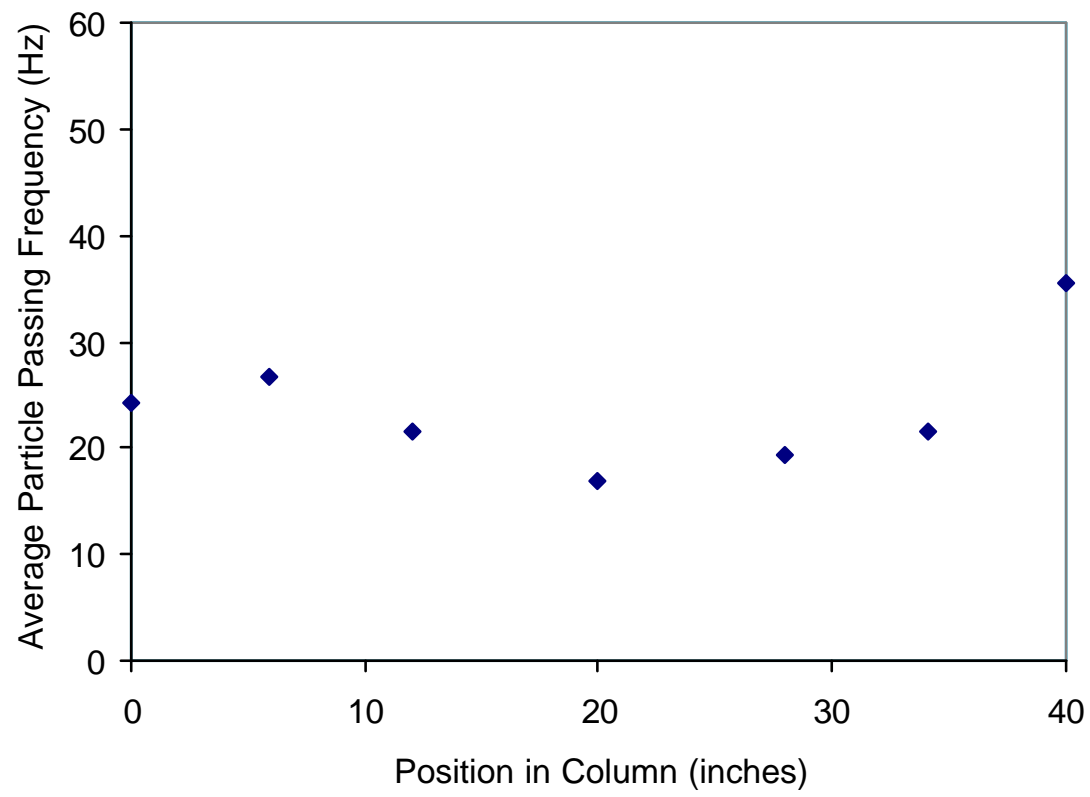

Figure 4.2-8: Solids Distribution in MTF at 40ft Elevation

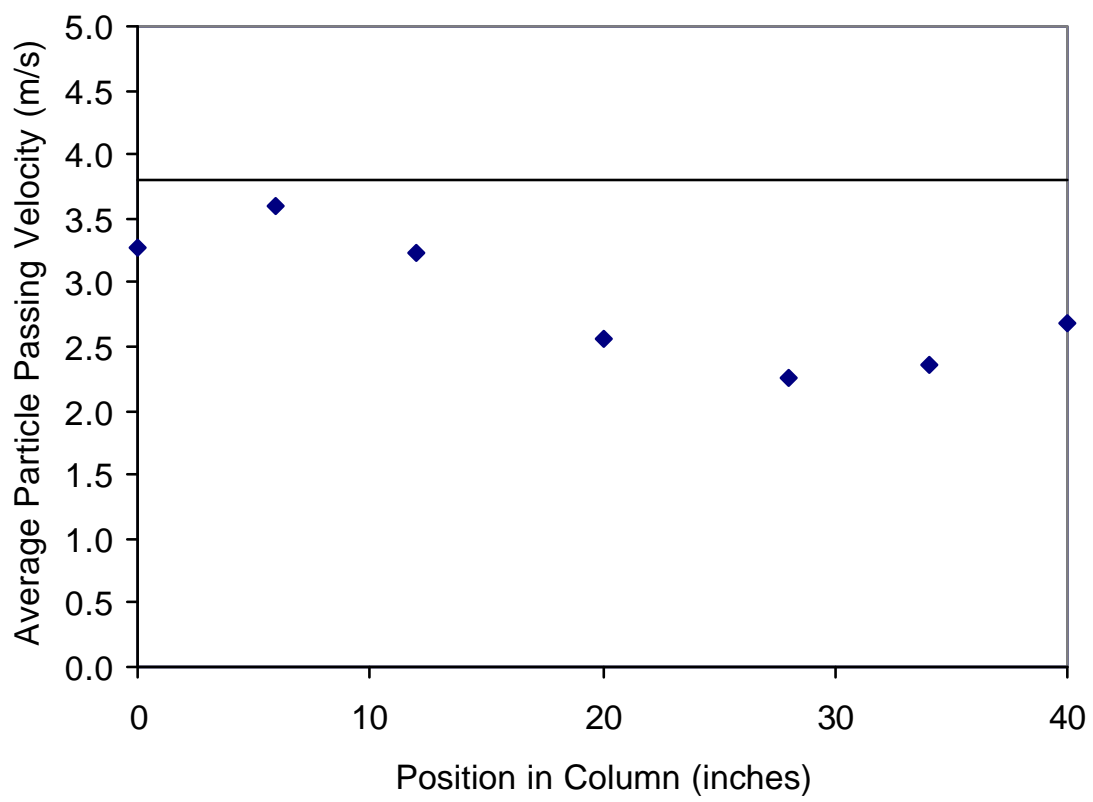

Figure 4.2-9: Solids Migration Velocity in MTF at $40 \mathrm{ft}$ Elevation

\section{Commercial Design}

The slice model demonstrated that a basket-type distributor could distribute solids uniformly at least 45 inches in one direction. Scaling this up in three dimensions would cover a circular area at least a $7.5 \mathrm{ft}$ diameter or $44 \mathrm{ft} 2$. The distributors for the 15-inch cold flow model and 
the MTF showed that this design can be scaled up in three dimensions and still provide uniform solids distribution in all directions.

A key $\mathrm{CMB}$ development effort is to continue scaling the distributor to larger scales. Figure 4.2-10 shows the conceptual distributor coverage for a $300 \mathrm{Mw}$ CMB with a 54-ft diameter cylindrical combustor chamber. This design used 7 distributors, each covering a 20 -ft diameter area. The coverage from a single distributor is shown as a red shaded area. This conceptual design requires a significant scaleup from our current experience. A more moderate scaleup would use 12 distributors, each covering a $15-\mathrm{ft}$ diameter area. This arrangement would result from a $\mathrm{CMB}$ design with 6 pneumatic transport lines conveying solids to the top of the combustor. A two way split below the collection hoppers would supply the twelve bauxite distributors. Future tests are needed to identify the maximum range that a distributor can cover. A larger cold or hot flow scale up model is the logical first step for scaling up the design of larger solids distributors.

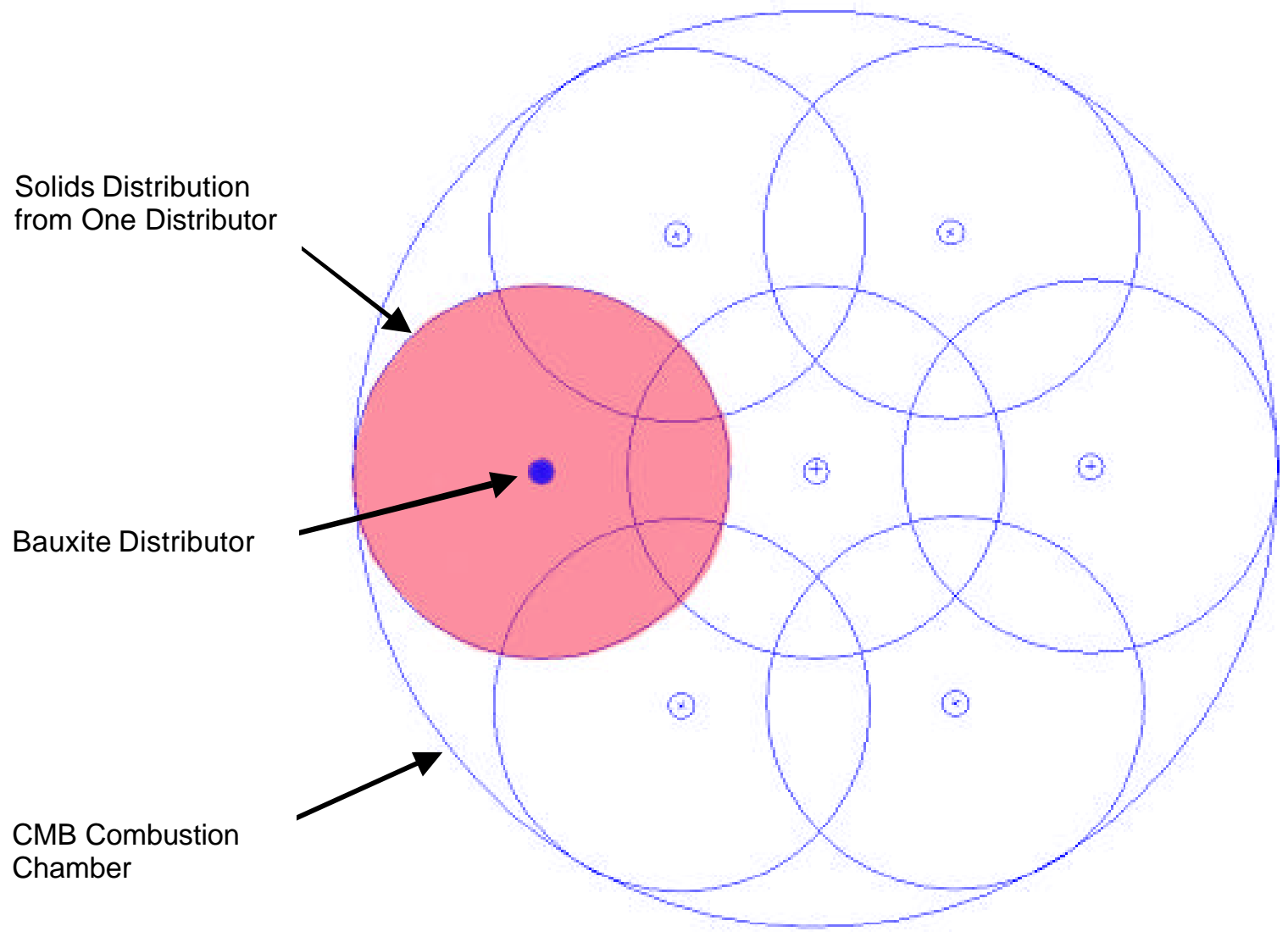

Figure 4.2-10: Bauxite Solids Distribution in 300 Mw CMB with 7 Distributors 


\subsection{MTF TEST CAMPAIGNS}

The objective of this task was to demonstrate proof of concept for the CMB module. ALSTOM Power's Multi-Use Combustion Test Facility (MTF) was modified to allow operation in a $\mathrm{CMB}$ configuration. This section describes the MTF facility, the facility modifications, and the test campaigns that were completed to evaluate the CMB concept.

\subsection{Description of ALSTOM Power Inc's. Multi-Use Combustion Test Facility}

ALSTOM Power Inc.'s "Multi-Use Combustion Test Facility" was developed by its US Power Plant Laboratories (PPL) to support the Power Generation Business's strategic development needs. This facility provides the flexibility to perform pilot testing with conventional pulverized-coal firing, fluidized bed combustion, and gasification firing conditions, thus addressing the requirements for several test facilities. The test facility is located at the US Power Plant Laboratories facilities in Windsor, CT. It has accrued approximately 4000 hours of operation on a wide variety of fuels since the initial startup in 1997 .

The MTF can be operated under atmospheric conditions at firing capacities up to $3 \mathrm{MW}_{\text {th }}(9.9$ $\mathrm{MBtu} / \mathrm{hr}$ ). The combustor has an inside diameter of $1 \mathrm{~m}$ (40 inches) and can be configured to have an overall height of more than $18 \mathrm{~m}(60 \mathrm{ft})$. It is equipped with comprehensive instrumentation and control systems and is housed in an enclosed building with supporting ancillary equipment.

The combustor design provides the flexibility to switch lower combustor sections, which permits operation under various firing regimes. When operating in pulverized coal firing modes, the facility's capabilities allow fundamental combustion and emission investigations, fuel characterizations, and assessment of fireside impacts on various aspects of boiler operation.

The MTF also allows testing with both circulating and bubbling fluidized bed conditions, as well as various other conditions being considered for advanced processes. Capabilities for testing under fluidized bed combustion modes provide detailed data on heat transfer, hydrodynamics, combustion, sulfur capture and process control.

Investigations can be conducted with test fuels including coal, oil, and gas as well as various alternative fuels such as petroleum coke and biomass. Complete solid fuel and additive handling systems, a flue gas scrubbing system, and Pilot Electrostatic Precipitator and Fabric Filter Test Facilities are also incorporated into the Multi-Use Test Facility.

The MTF facility was initially modified in this project for CMB operation with natural gas or coal firing. The hot solids pick up and transport line was installed to transport bauxite from the bottom of the combustor to the top. The solids transport line was a water-cooled pipe that allowed testing of the hot gas-to-solids heat transfer before the moving bed heat exchanger was installed. The MTF baghouse was also converted into a FDA system.

The final modification was adding a moving bed heat exchanger, which allowed the MTF to operate in a fully integrated $\mathrm{CMB}$ configuration. The moving bed heat exchanger was not located directly underneath the combustor as envisioned in a commercial unit, since this was 
not cost effective. Instead, the moving bed heat exchanger was placed next to the lower combustor and a separate pneumatic transport system carried the hot solids up to it.

Areas where the MTF modifications were made are shown in Figure 5.1-1.

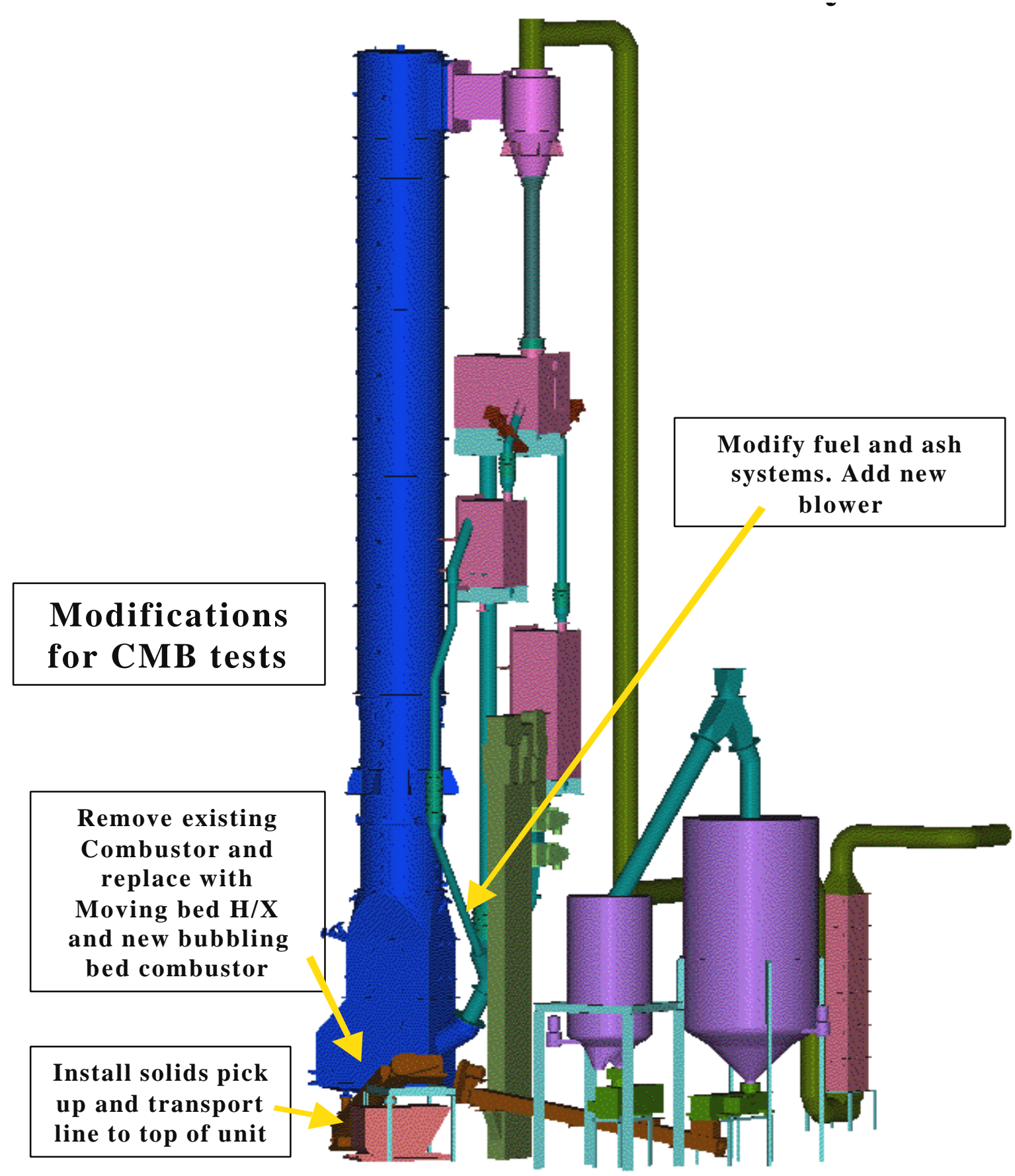

Figure 5.1-1: MTF Modifications 


\subsection{Test 1 - Hot Gas Test}

\section{Objective}

The objective of this test campaign was to evaluate gas-to-solids heat transfer under high temperature conditions and on a larger scale than in the cold flow heat transfer facility. A water-cooled bauxite recycle system was added to the MTF to simulate CMB operation. This allowed the combustor to be operated in CMB mode without the added complexity of operating a MBHE along with a second solids transport system during the initial facility operation. This modification enabled detailed gas-to-solids heat transfer tests to be conducted in the combustor, along with initial coal fired CMB tests.

\section{Combustor Modifications}

The MTF combustor was initially modified to allow measurement of the heat transfer from a rising hot gas to a cloud of falling particles. Figure 5.2-1 shows a side elevation of the MTF after the initial modifications. The light green lines show the siphon seal at the bottom of the combustor and the watercooled transport line.

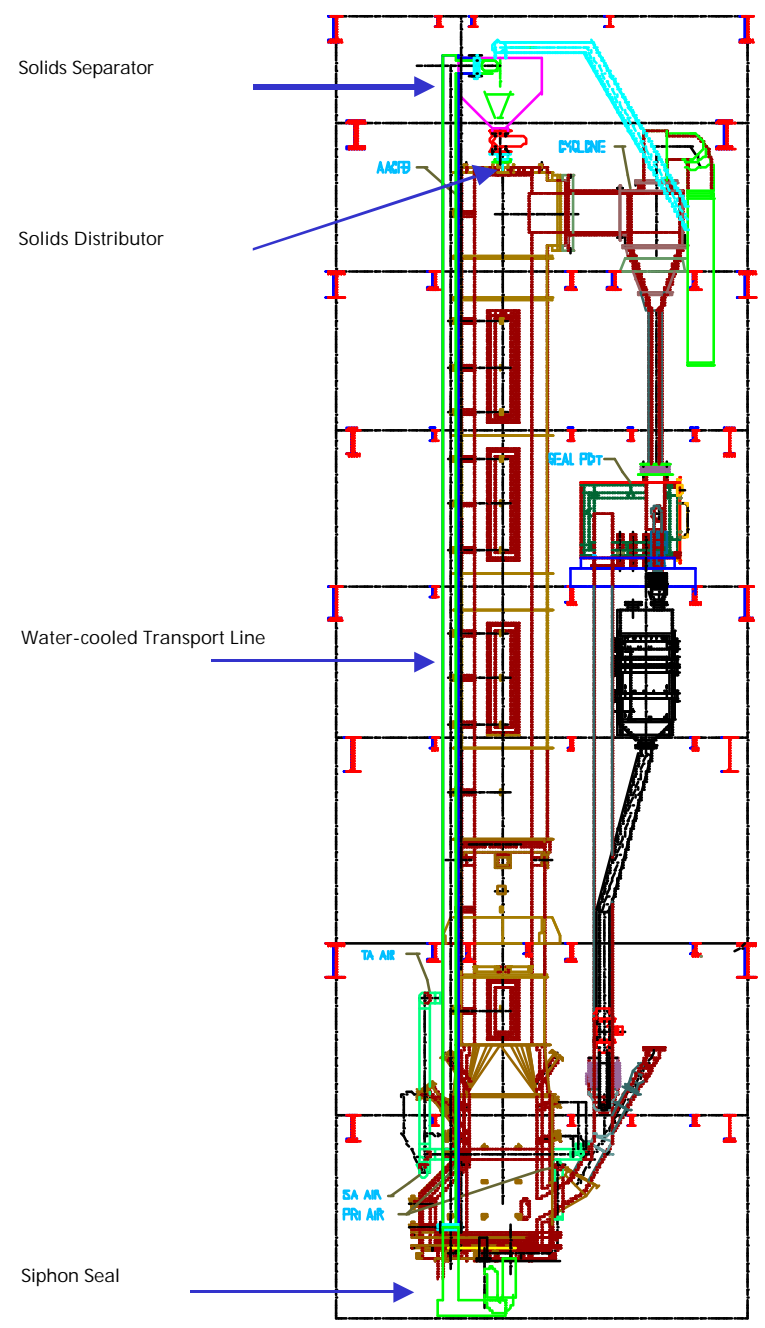

Figure 5.2-1: MTF Hot Gas Modifications 
Bauxite particles were supplied to the top of the combustor from a supply hopper mounted on top. The hopper was designed as a low efficiency cyclone or dropout hopper, as the relatively large diameter and dense bauxite particles were easy to separate from the transport air. A variable speed rotary valve controlled the flow rate from the hopper. Load cells were mounted on the bottom of the hopper to measure bauxite inventory. Figure 5.2-2 shows the bauxite separator hopper mounted on top of the combustor.

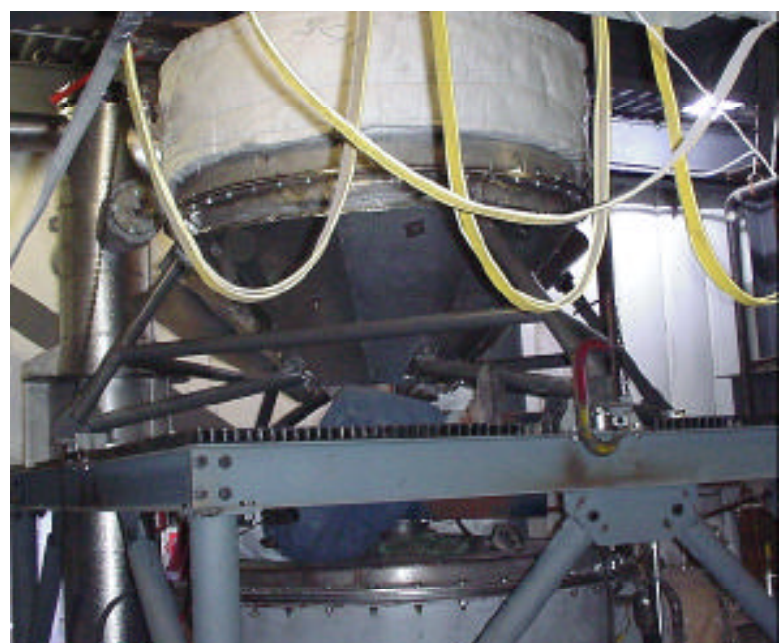

Figure 5.2-2: Bauxite Separator Being Mounted To Roof

Bauxite discharged from the hopper rotary valve fell down a 5 inch inlet pipe to a basket distributor $2.5 \mathrm{ft}$ below the bottom of the cyclone inlet duct. This provided a dispersed flow of bauxite to the rising combustor gas stream. The distributor was a scaled up version of the distributor used on the 15-inch cold flow model. The solids exited the inlet pipe through a series of vertical slots. A shroud around the slots prevented the solids from being thrown outward towards the combustor walls. Figure 5.2-3 shows the bauxite distributor being mounted to the combustor roof.

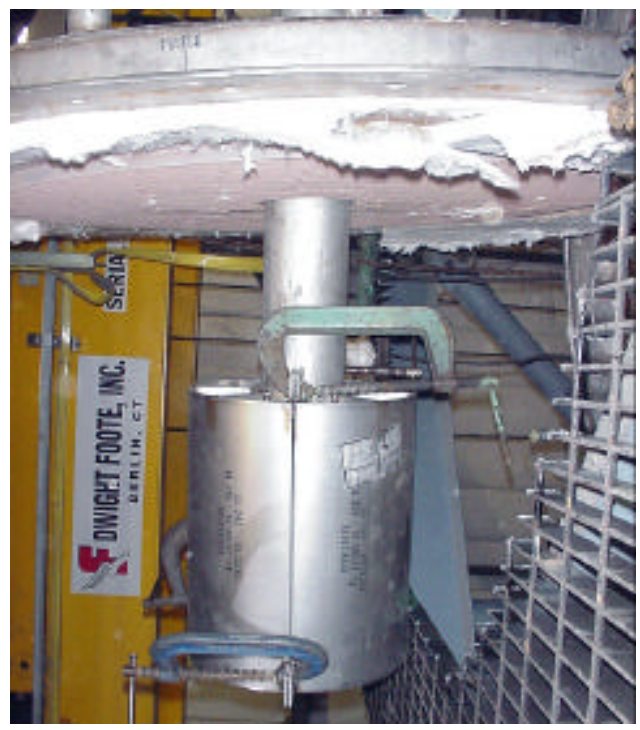

Figure 5.2-3: Bauxite Distributor Being Mounted To Roof 
The bauxite particles passed down through the rising combustion gases, cooling the gases and heating the particles. The particles fell into a fluidized bed at the bottom of the combustor. The particles exited the top of the bed through an elevated standpipe to a cooled transport pipe under the combustor. The particles were then pneumatically transported up to the supply hopper.

Particles exited the bottom of the combustor through a 6 inch overflow pipe 45 inches above the bed fluidizing nozzles. The overflow pipe was made of Rolled Alloy (RA) 253 material. Midway through the test campaign, a grizzly was mounted on top of the overflow pipe to prevent oversize particles from passing into the transport line. The grizzly was made of RA253 strips welded together with a maximum opening of $1 / 2$ inch. Figure 5.2-4 shows the overflow pipe with the grizzly mounted on top.

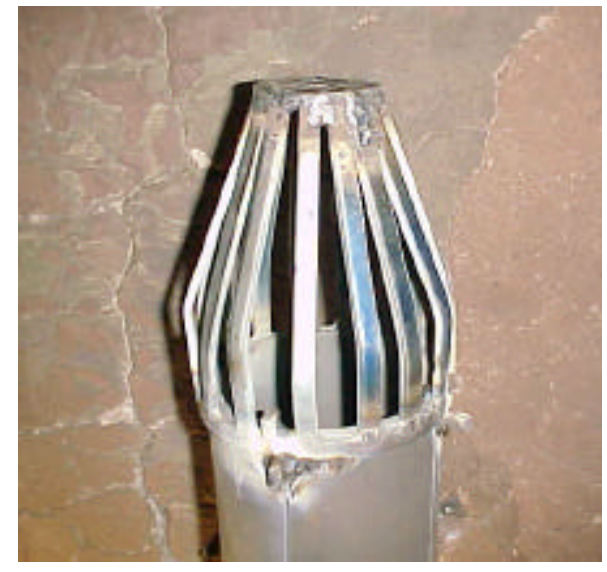

Figure 5.2-4: Downcomer Screen

The overflow pipe exited the inlet air plenum under the combustor and dropped down into a water-cooled fluidizing J-Valve or siphon seal. This section acted as a seal between the transport line pressure and the combustor. The loop seal was a very compact design because of the limited clearance below the combustor. Several air injection ports provided fluidization. Figure 5.2-5 shows the loop seal mounted below the combustor.

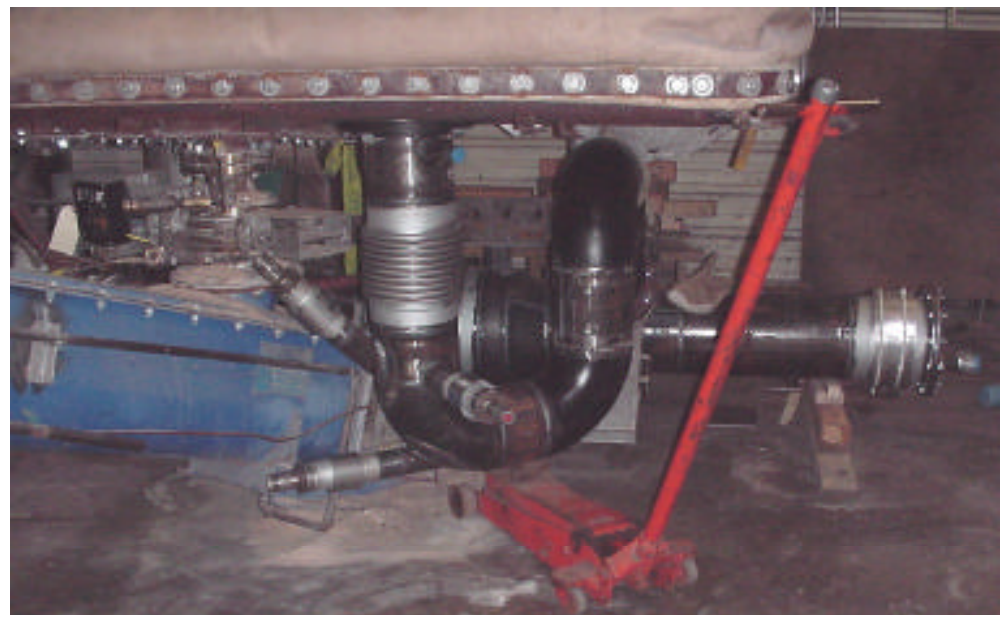

Figure 5.2-5: Loop Seal Below The MTF 
The discharge from the J-Valve entered an 8 inch water-cooled transport pipe. Solids were transported horizontally a short distance, entered an impact elbow, were transported vertically through an 8 -inch water cooled transport pipe to a top short horizontal run, and then entered the top of the supply hopper. The solids inlet to the top hopper entered at a tangential position to facilitate the removal of the bauxite particles from the transport air. Transport air exited a 6-inch nozzle at the top center of the supply hopper and was discharged downstream of the MTF baghouse. Figure 5.2-6 shows the water-cooled transport line before installation and a portion of the transport line mounted next to the combustor.
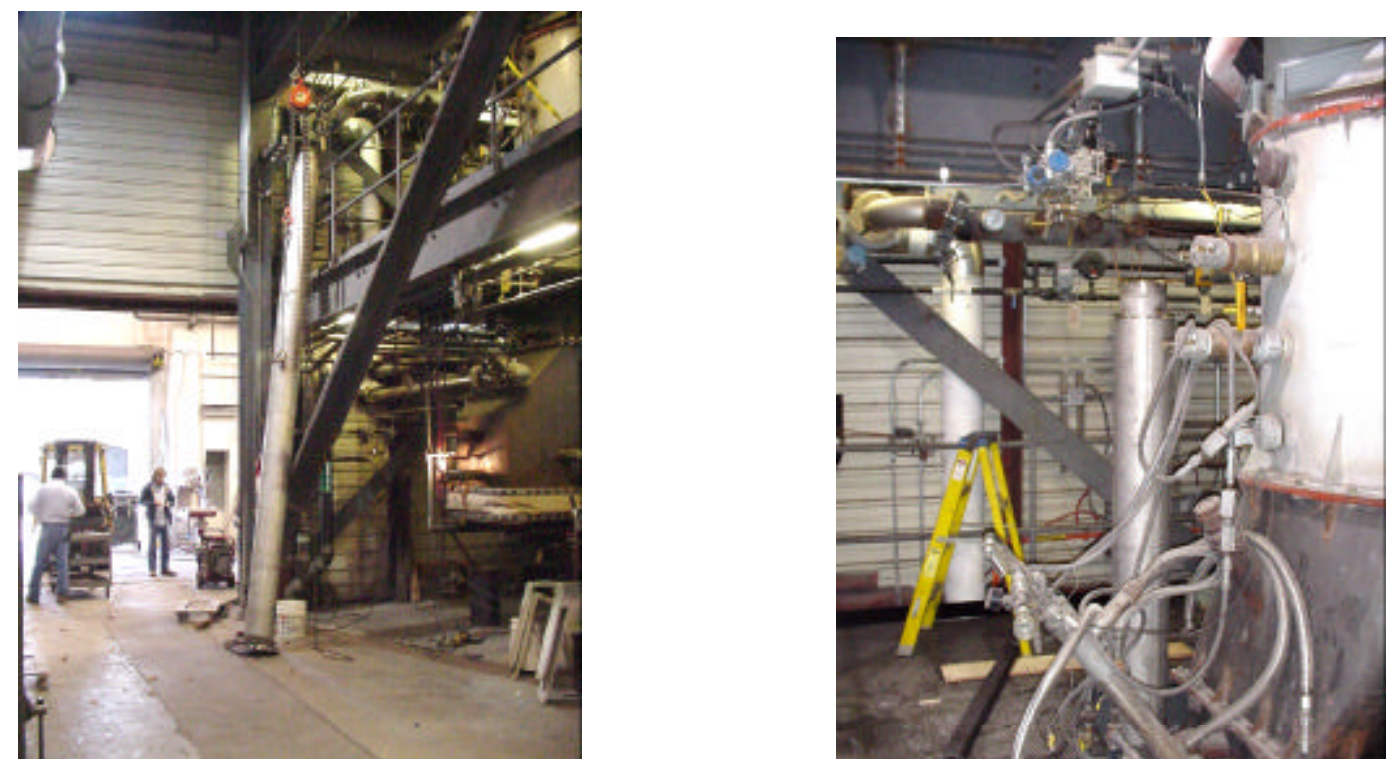

Figure 5.2-6: Water-Cooled Transport Line Installation

Two distribution grids were also added to the combustor at selected elevations to assess their impact on heat transfer and solids/gas flow distribution in the upper region of the combustor. The grids were designed with an open area of about $46 \%$, which was comparable to the open area of the grids used in the 15 inch cold flow test facility. The grids were mounted on a shaft that allowed them to be rotated in or out of position during testing.

Figure 5.2-7 shows two photos of the mixing grids. The left photo shows a mixing grid being installed in the open position. In this configuration, the grid had little influence on the falling solids. The right photo shows the upper mixing grid installed in the closed position, which helped to redistribute the falling particles. This photo also shows the lower mixing grid still oriented in the open position. 

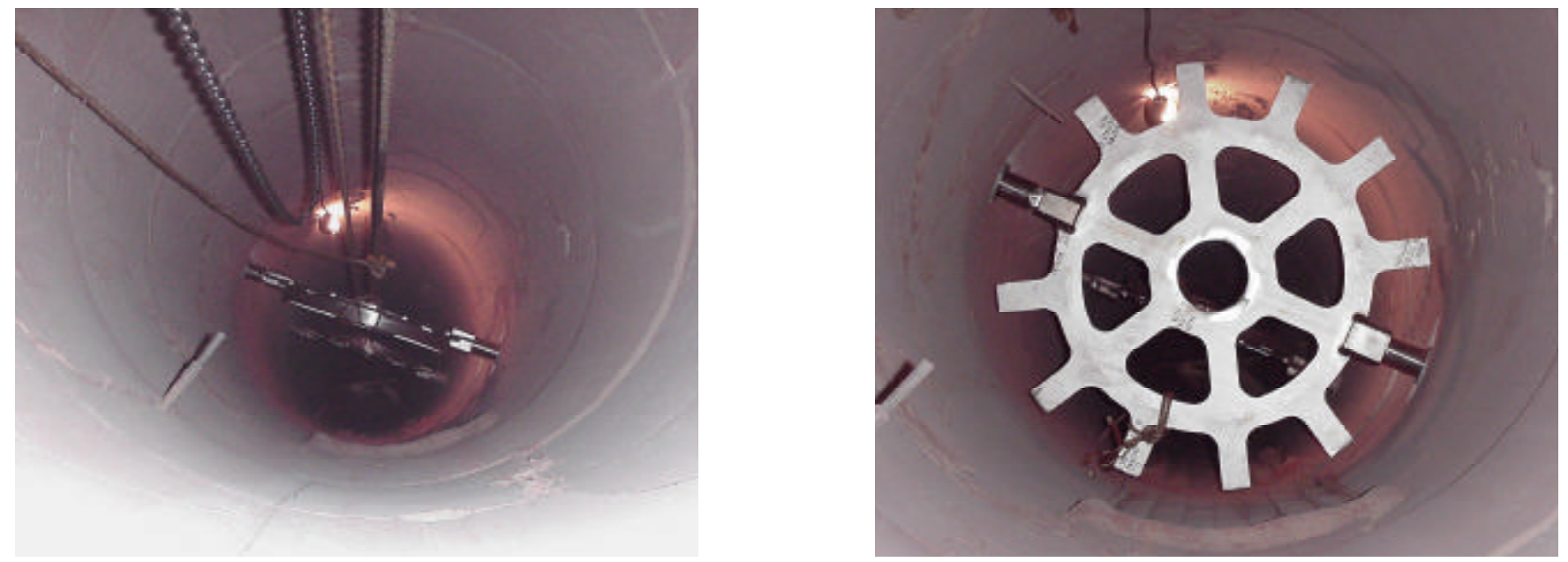

Figure 5.2-7: Mixing Grid Installation

In-bed gas spargers were added to improve bed heatup during the gas fired test. Two electric air preheaters supplied hot air. The air inlet temperature was measured by a thermocouple at each air heater flow measurement station.

The gas temperature rising in the combustor was measured by a series of thermocouple rakes. The rakes consisted of inverted angle shields that prevented falling bauxite from impacting the thermocouples. A series of thermocouples were mounted under the shields to measure the gas temperature at several radial locations. Temperature measurements were taken at the 18 , $25,30,37,47,55,58$, and 64-foot elevations. Temperature rakes with 13 thermocouples were located at the 37, 47, and 55-foot elevations. A rake with 5 thermocouples was installed at the combustor crossover duct to the cyclone at the 64-foot elevation. The remaining elevations all had three thermocouples installed. A vertical thermocouple rake located in the center of the cyclone duct measured gas temperatures exiting the combustor.

\section{Test Matrix}

Table 5.2-1 summarizes the test matrix for the first test campaign. The series began with warm air heat transfer tests and then continued with natural gas fired and coal fired heat transfer tests. 
Table 5.2-1: Test Matrix for the first MTF Campaign

\begin{tabular}{|c|c|c|c|}
\hline & & \multicolumn{2}{|c|}{ February 2002 CMB Test Matrix } \\
\hline \multicolumn{2}{|c|}{ Warm Air Tests } & Heat Transfer Tests & \\
\hline & & & \\
\hline & 1 & 700 microns w/ Grids & $\begin{array}{l}4 \text { tests over a range of gas and solid flowrates: } \\
2 \text { tests with flux and temperature probing ( } 8 \mathrm{hr}) \\
2 \text { tests without probing ( } 2 \mathrm{hr}) \\
1 \text { transition test with only one grid in place }\end{array}$ \\
\hline & 2 & 700 microns w/o Grids & $\begin{array}{l}4 \text { tests over a range of gas and solid flowrates: } \\
1 \text { tests with flux and temperature probing ( } 8 \mathrm{hr}) \\
3 \text { tests without probing }(2 \mathrm{hr})\end{array}$ \\
\hline & 3 & 530 microns w/o Grids & $\begin{array}{l}4 \text { tests over a range of gas and solid flowrates: } \\
1 \text { tests with flux and temperature probing ( } 8 \mathrm{hr}) \\
3 \text { tests without probing ( } 2 \mathrm{hr})\end{array}$ \\
\hline \multicolumn{2}{|c|}{ Gas-Fired Tests } & Heat Transfer Tests & \\
\hline & & & \\
\hline & 4 & $1750^{\circ} 530$ microns w/o Grids & 2 tests; one with temperature probing \\
\hline & 5 & $2000^{\circ} 530$ microns w/o Grids & 2 tests; one with temperature probing \\
\hline & 6 & $1750^{\circ} 700$ microns w/o Grids & 2 tests; one with temperature probing \\
\hline & 7 & $2000^{\circ} 700$ microns w/o Grids & 2 tests; one with temperature probing \\
\hline & 8 & $2000^{\circ} 700$ microns w/ Grids & $\begin{array}{l}1 \text { transition test with only one grid in place } \\
4 \text { tests; none with temperature probing }\end{array}$ \\
\hline & 9 & $1750^{\circ} 700$ microns w/ Grids & 4 tests; two with temperature probing \\
\hline \multirow{2}{*}{\multicolumn{2}{|c|}{ Coal-Fired Tests }} & (All 700 microns w/ Grids) & \\
\hline & & & \\
\hline & 10 & $1750^{\circ}$ Heat Transfer Tests & 3 tests: two with temperature probing \\
\hline & 11 & $1750^{\circ}$ Part Load Test & $50 \%$ Load test; nominal $4 \mathrm{MMBtu} / \mathrm{hr}, 50 \%$ XSA \\
\hline & 12 & $2000^{\circ}$ Heat Transfer Tests & 4 tests; none with temperature probing \\
\hline & 13 & $2000^{\circ}$ Base Case Test & $\begin{array}{l}\text { Base Case test; nominal } 6 \mathrm{MMBtu} / \mathrm{hr} \\
20 \% \text { XSA, 60\%PA } \\
\text { Steady run for FDA performance }\end{array}$ \\
\hline & 14 & $2000^{\circ}$ Combustion Parameters & $\begin{array}{l}\text { Vary combustion parameters: } \\
-15 \% \text { XSA } \\
\text { - } 50 \% \text { PA } \\
\text { - } 70 \% \text { PA } \\
\text { - high S/G ratio } \\
\text { - optimum low NOx combination }\end{array}$ \\
\hline & 15 & $2000^{\circ}$ Fine Limestone & $\begin{array}{l}\text { Switch from normal limestone grind/ feed location to } \\
\text { very fine limestone injected higher in the furnace } \\
\text { (approx } 1800^{\circ} \mathrm{F} \text { window) }\end{array}$ \\
\hline & 16 & Shutdown Test & Observe carbon burnout after end of coal feed. \\
\hline
\end{tabular}

\section{Test Procedure}

A heat balance method used to calculate the bauxite flow rate based on coolant temperature increases, coolant flow, and bauxite temperature decreases did not work as well as wanted. A thermowell at the bottom of the vertical transport section of the cooled transport pipe had a fin effect that gave readings of the cooling water temperature rather than the transported bauxite temperature. This prevented calculation of independent horizontal and vertical transport pipe flow rates. The flow rate calculation method was modified early in the test program to use fluidized bed average temperatures and gave results that were generally as expected. 
Heat flow from the hot gas to the bauxite particles was measured by the average difference of successive thermocouple rakes at different elevations in the combustor. The heat flow, bauxite inlet temperature, and bauxite specific heat was used to calculate a bauxite temperature profile in the combustor. Solids temperature traverse probes were used to confirm the bauxite temperature for selected tests, but the probe results did not match rake results as well as liked. There was a traverse thermocouple fin effect from the cooling water that affected the probe results.

An experimental dual beam optic probe was used to traverse selected elevations of the combustor during the warm air tests. This probe measured the frequency of particles passing through a laser beam. This was translated to a particle density. Also, an autocorrelation of particle passages between the upper and lower beams was used to determine particle velocity. Several traverses were taken early in the warm air test series with too short a scan time, so data for those conditions was not accurate. The final traverse had sufficiently long scan times to be considered good.

The average bauxite particle density in the combustor was calculated by the difference between calculated particle terminal velocity, gas rise velocity, bauxite mass flow rate, and the combustor flow cross sectional area. The density, mass flow, and particle diameter were used to calculate the particle surface area in the combustor. The surface area, gas side heat flow, and log mean temperature difference between gas and solids were used to calculate a particle surface heat transfer coefficient.

Operating test conditions were measured by an Advant control and data acquisition system connected to a portable PC controlled by a Labview operating system. Data was recorded every 3 minutes to the harddrive of the computer. This data was entered into a spreadsheet for preliminary analysis and calculation of an average value of selected test variables. The average values for each test were then copied to a summary spreadsheet for final data analysis. Data for the optic solids density and velocity probe was measured by a standalone PC. Data for the solids temperature probe was measured by a second standalone PC. The file date and time for these probes was synchronized with the Advant clock for data comparison.

The test files were opened by an Excel spreadsheet. This spreadsheet contained a series of charts that presented the supply hopper flow, probe data, pressure drop, air temperatures, profile temperatures, etc. as a function of test time. These charts provided an indication of the test condition stability for the duration of the test series. A review of the condition-time charts showed periods of stable operation. Average values of each measurement were calculated for those periods and stored in the top of the spreadsheet for data analysis. A similar spreadsheet was constructed for the gas fired tests, and for the coal fired tests.

\section{Operational Summary}

The first portion of the CMB test campaign (Task 4.1) began as scheduled on February 11, 2002 and continued around the clock until February $16^{\text {th }}$. The objective of this test week was to gather gas-to-solids heat transfer data from the falling bauxite particles to the warm rising air. The airheaters could preheat the combustor air supply to $1000^{\circ} \mathrm{F}$. However, the air temperature was restricted to temperatures of $250-350^{\circ} \mathrm{F}$ because of external supply system 
limits. These warm air tests formed a basis of heat transfer measurements that were not complicated by gas or coal combustion in the freeboard or by ash loading influences on gas side heat flow calculations. Fifteen tests were completed, with parametric variations in airflow rate, bauxite flow rate, bauxite particle size, and number of mixing grids. The tests included detailed probing at multiple elevations for solids loading, solids temperature, solids velocity, and gas temperature.

The second week of testing began on February $18^{\text {th }}$ and continued around the clock through the February $23^{\text {rd }}$, when the facility transitioned to coal-fired operation (Task 4.2). The objective of the second week's testing was to continue gas-to-solids heat transfer evaluation, but now using hot gases generated from natural gas firing. The gas combustion tests permitted heat transfer effects to be determined at temperatures up to $2180^{\circ} \mathrm{F}$ without the complication of ash loading on the combustion gas. Eleven tests were completed at temperatures approaching $1200^{\circ} \mathrm{C}\left(2200^{\circ} \mathrm{F}\right)$, included detailed probing at multiple elevations for gas composition, gas temperature, and solids temperature. These tests were complicated by incomplete burnout of gas in the fluid bed. The resulting gas temperature profile prevented the use of the normal log mean temperature difference (LMTD) to determine heat transfer rates. Fortunately, gas burnout was completed by the combustor midpoint and heat transfer could be assessed in the upper region of the MTF.

The first CMB coal-fired tests began in the third test week with the combustion of a West Virginia bituminous coal. An initial test condition provided three data points at similar conditions. An isokinetic ash sample was obtained at mid-elevation of the combustor as well as an ash circulation flow from a heat balance on the MTF cyclone seal pot. Additional tests were planned but a failure of the fuel feed-recycle pipe stopped the test series.

\section{Results}

The operation was remarkably smooth for the first test week, given the extent of the facility modifications. The solids circulation system worked well and all equipment worked reliably. Some problems experienced in the second week were attributed to combustor refractory spalling. The refractory was already starting to spall prior to this test campaign due to the many startups the facility previously experienced and was due for replacement. The high combustor temperatures and a rapid heatup rate during this startup probably exacerbated this problem. Some large pieces of refractory got into the bauxite downcomer (exiting the bed) and collected in the siphon seal and in the horizontal portion of the transport line. Remarkably, some large flat chunks of refractory almost four inches across were transported up to the top of the combustor and became lodged in the solids distributor, thus interfering with bauxite flow to the combustor. The unit was shutdown temporarily to remove the refractory pieces (from the bed, siphon seal, horizontal transport line, and solids distributor). Figure 5.1-8 shows some of the refractory pieces that accumulated in the solids distributor at the top of the combustor. A screen or grizzly was installed across the top of the downcomer in the fluidized bed to prevent new pieces of refractory from lodging in the recirculation system. The pilot plant then returned back in operation and ran smoothly. 


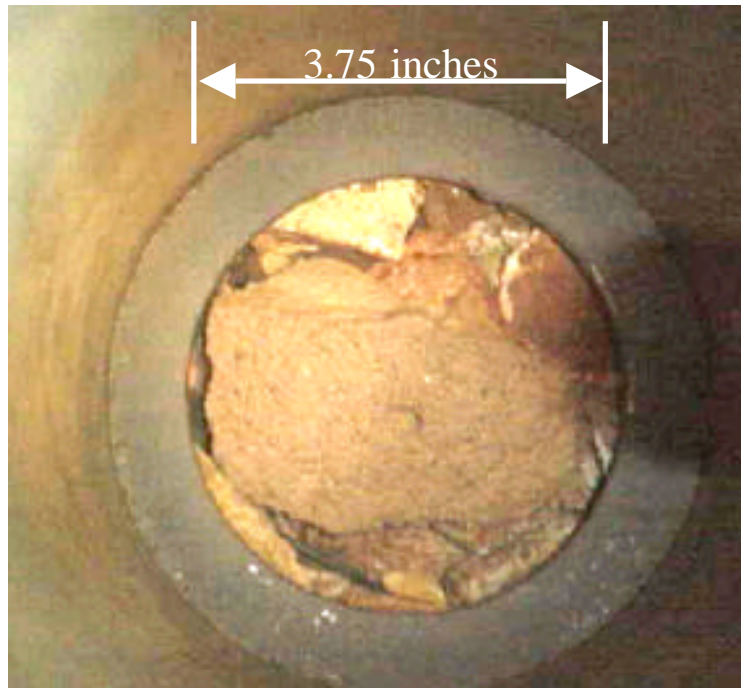

Figure 5.2-8: Refractory Accumulation In Solids Distributor

The unit transitioned to coal firing on February $23^{\text {rd }}$ and ran on coal for 15 hours before the unit had to come off line for coal feed system repairs. The unit was in full bauxite circulation mode during this period and ran very smoothly. All systems were operational, including the FDA baghouse for sulfur capture. Initial coal-fired heat transfer testing was completed at a $950^{\circ} \mathrm{C}\left(1750^{\circ} \mathrm{F}\right)$ bed temperature. However, during transition to low load test conditions, the unit had to be shutdown due to overheating and failure of the coal feed pipe. This is a problem that is not specific to $\mathrm{CMB}$, but attributed to coal feed hangup that had been experienced in the past with non-standard CFB testing. The coal is fed into the solids return leg from the main cyclone. There is the potential for the coal to stick and buildup on the hot pipe surface, particularly when feeding bituminous coal. The coal is normally flushed out of this line fast enough when we have high ash recirculation rates associated with CFB operation. However, coal hangup in the pipe was exacerbated by the low ash recirculation rates characteristic of low load operation plus by the lower ash rates associated with CMB operation. It was therefore decided to redesign and replace the coal feed system with a chain conveyor feed system.

\section{Summary of Test Campaign Results}

The test results showed that the heat transfer was as good or better than expected based on earlier heat transfer tests in ALSTOM's two cold flow models. Heat transfer was also as good or better than predicted based upon previous CFD models for similar test conditions.

Overall, the results from this testing were very encouraging with respect to both operability and thermal performance. The following list summarizes some major observations from this test campaign.

- Demonstrated that the bauxite dipleg adequately sealed the bubbling bed from the transport line back pressure. Operation showed that the available height was sufficient to seal, without any significant air blowback into the bed from the transport line.

- Demonstrated reliable transport, circulation, distribution, and control of bauxite solids. 
- Demonstrated that bauxite could be distributed into the combustor gas stream and get very good heat transfer between the gas and solids. Initial traverses indicated that the solids distribution was relatively uniform. In fact, distribution only seemed to improve marginally when the mixing grids were installed.

- Demonstrated that the pilot plant could be operated in full CMB mode with coal firing. Although the test was cut short due to coal feed system problems, 15 hours were run with full bauxite recirculation and coal firing at bed temperatures up to $980^{\circ} \mathrm{C}\left(1800^{\circ} \mathrm{F}\right)$.

- Demonstrated that the combustor gas outlet temperatures could be controlled solely by the bauxite recirculation loop. Combustion gases were cooled down from $1090^{\circ} \mathrm{C}$ $\left(2000^{\circ} \mathrm{F}\right)$ to almost $540^{\circ} \mathrm{C}\left(1000^{\circ} \mathrm{F}\right)$ through gas-to-solids heat transfer only and without the aid of any combustor heat absorption.

- There were no signs of bauxite carryover into the main cyclone crossover duct. Traces of bauxite were collected in the gas outlet duct leaving the bauxite separator. This separator was designed as a dropout hopper and had relatively low collection efficiency. We did not detect the presence of any attrited bauxite in the hopper gas outlet duct.

- There were no signs of any significant erosion in the transport lines or bauxite separator target zone.

- The FDA baghouse system was not operating long enough to achieve steady state conditions, but it was recirculating ash smoothly and was capturing $\mathrm{SO}_{2}$.

- It was learned that large pieces of refractory or rock can float to the top of the bed and get into the solids downcomer and accumulate in the transport system. This reinforced the need for a screen at the top of the downcomer and a revision of the bauxite distributor design to pass oversize material. This issue may have been minimized during longer-term coal fired operation as normal bed drain operation would have removed most of the large refractory pieces. 


\subsection{Test 2 - Coal 1 (no MBHE)}

\section{Objective}

The objective of this task was to continue evaluation of CMB process performance under coal-fired conditions. The water-cooled transport line was still used for all heat extraction. This simplified operation and allowed tests to be conducted without the added complexity of a second solids circulation loop. However, the limited cooling duty of the transport line limited testing to partial load conditions. The baghouse after the MTF was also converted into a Flash Dry Absorber (FDA) system. This modification allowed evaluation of CMB sulfur capture in both the combustor and in the FDA system.

\section{Combustor Modifications}

Coal Feed System

It was decided to redesign the MTF coal feed system to feed the coal into the combustor independent of the cyclone ash stream. The system could then be designed for proper cooling regardless of the wide range of ash circulation rates tested on the MTF. The new system was designed to have the added flexibility to inject coal directly into the bed or at elevations higher up into the combustor. The design still retained the capability to inject the coal into the solids return duct from the cyclone. The new design provided the MTF with new feeding capabilities while also minimizing the issue of coal build up in the solids return leg, which prematurely ended the first test campaign.

The new feed system was started up before the second CMB test campaign and worked very well during an MTF test campaign for a separate program. Figure 5.3-1 shows the lower portion of the MTF with the new feed system installed.

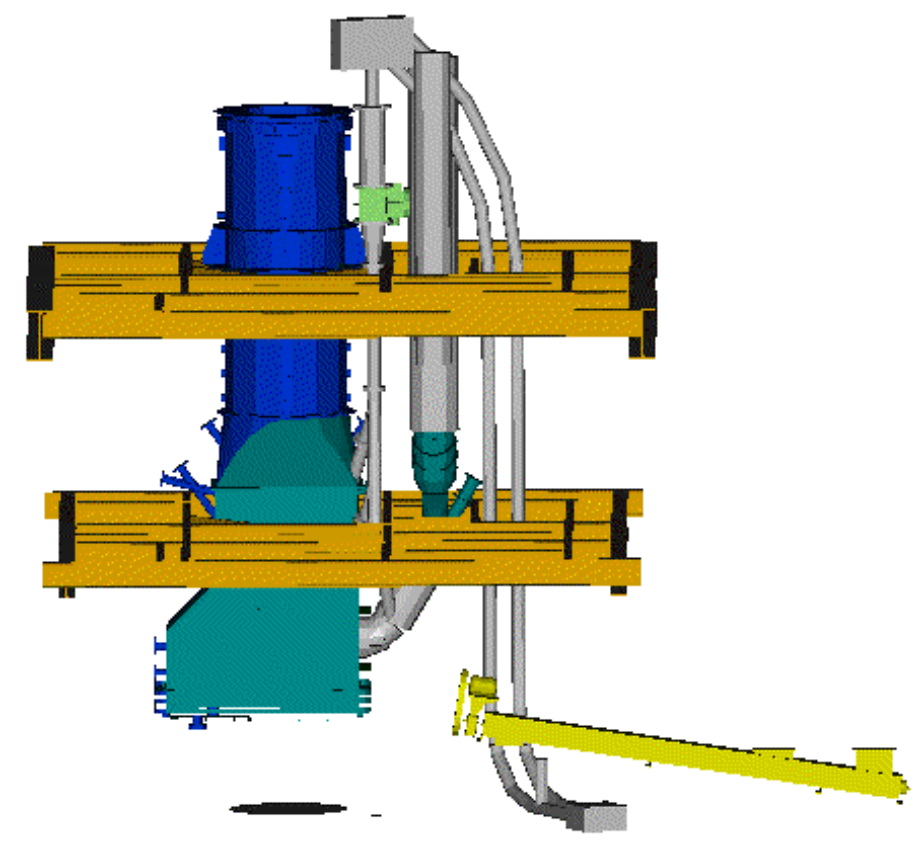

Figure 5.3-1: MTF Coal Feed System

Refractory 
The combustor refractory was replaced to prevent further spalling during the test campaign. The previous castable refractory system was replaced with a high density, high alumina brick hard face, which made the combustor more resistant to higher operating temperatures and thermal shock. A new access door was also installed at the top of the combustor during this outage. This door improved access to the upper combustor and facilitated installation of the solids distributor and the mixing grids. The replacement refractory included a 2-inch layer of insulating board, low-density castable refractory, as well as the outer layer of dense bricks.

Recycle System

The cyclone ash recycle system was modified to provide flexibility in the ash injection location. Solids were initially injected directly into the combustor, but the high bed temperatures caused any $\mathrm{CaSO}_{4}$ in the ash to decompose and release $\mathrm{SO}_{2}$. A pneumatic feed system was therefore installed to permit ash collected in the MTF cyclone to be reinjected into the combustor at one of two vertical locations. The cyclone siphon seal was partially defluidized to force all of the ash to flow into a fluid bed heat exchanger. The solids then passed through a rotary valve, which acted as an air seal between the transport system and the fluid bed heat exchanger. This system still had the capability of feeding the ash directly into the bed. In this case, the FBHE rotary valve was shut off and the siphon seal was fully fluidized. The ash then flowed into the siphon seal overflow pipe and drained into the bed.

\section{Other Modifications}

The first test campaign showed the importance of keeping oversized material out of the transport line. A new solids downcomer grizzly was installed in the bed with narrower openings. The discharge slots in the solids distributor at the top of the combustor were made wider to allow any large material that passed through the grizzly to exit out of the distributor. The limestone feed system was also modified to allow the sorbent to be pneumatically feed to different elevations in the combustor.

\section{Laser Level Indicator}

The laser level indicator that was discussed in Section 3.1 was installed on the MTF bauxite supply hopper. The system was mounted on a water-cooled standoff with a high temperature glass viewport. Purge air was directed on the bottom and top of the view port. Two pen lasers with a 110-volt power supply were oriented to have the beams intersect at the bottom of the hopper. When bauxite was added to the hopper the laser beams intersected the surface and were displaced apart proportionately to the ratio of bauxite height to total laser beam length and horizontal distance. A video camera mounted above the view port transmitted the beam displacement to a monitor in the control room. The beam displacement on the control room monitor was calibrated by loading measured amounts of bauxite into the hopper and measuring the corresponding monitor beam displacement.

Figure 5.3-2 shows more details of the laser indicator system. The left photo shows the laser indicator system mounted on top of the bauxite supply hopper. The right photo shows the video camera output during MTF operation. The two white dots from the laser indicate the displacement by the bauxite level in this hopper. This displacement corresponds to a hopper inventory of about 1600 pounds of bauxite. The white trails leading to these two dots are dust 
particles being illuminated by the laser beams. The other "shooting star" tracks are from burning coal particles that were transported to the hopper from the combustor.

The laser level indicator worked very well during the test program, although the purge air occasionally needed adjustment to keep the lens clear from dust. A similar system was installed on the MBHE bauxite supply hopper also.
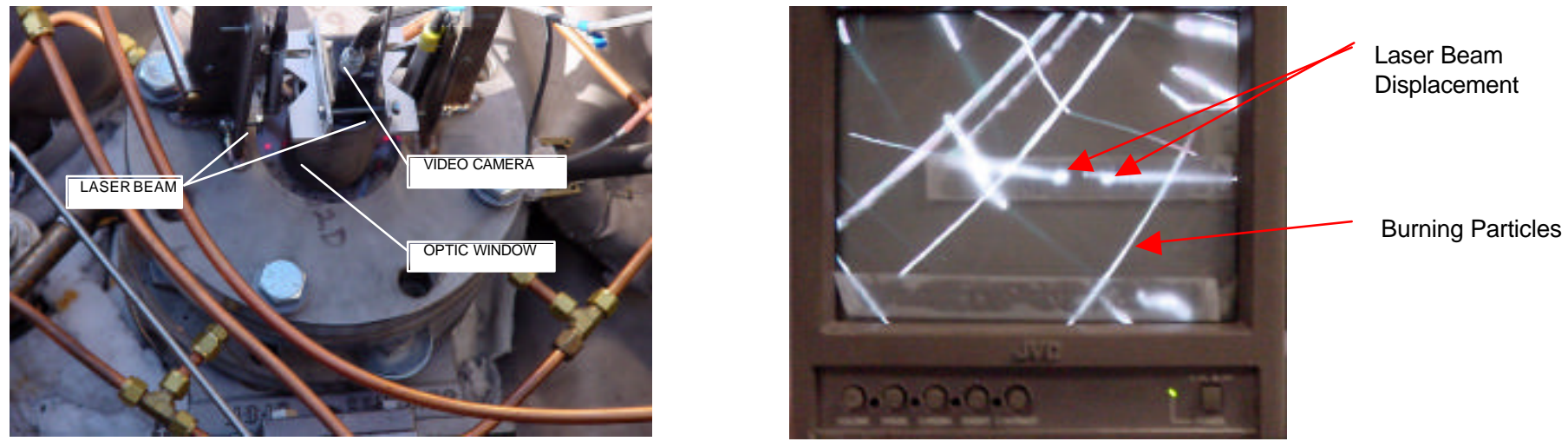

Figure 5.3-2: Laser Level Installation and Video Output

\section{FDA Modifications}

The existing MTF baghouse was converted into a FDA system prior to the first CMB test campaign. However, it wasn't operated for any significant amount of time until this second test series. The changes included modification of the existing baghouse, erection of new baghouse support steel and work platforms, and installation of the FDA mixer/hydrator. The workscope also included a new baghouse drain and conveying system, additive feed system, FDA reaction duct, modification of the flue gas ducting, and additional gas analyzers, instrumentation, and controls systems. Figure 5.3-3 shows the MTF FDA during the conversion.

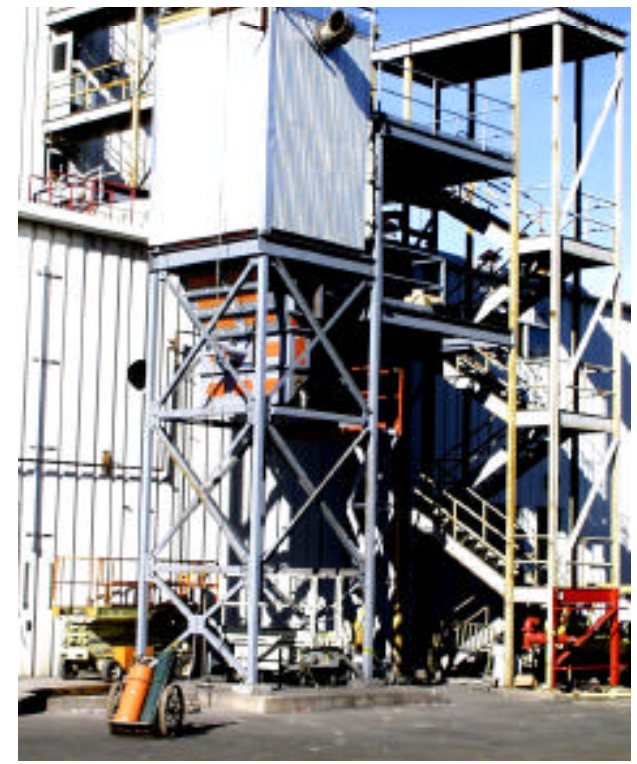

Figure 5.3-3: MTF FDA Baghouse Conversion 
Figure 5.3-4 shows the FDA additive feeder (in blue) and the FDA mixer (in red). The additive feeder is used to feed sorbents, such as hydrated lime, directly into the mixer. Ash from the baghouse hopper is combined with moisture in the FDA mixed and then injected into the reactor duct.
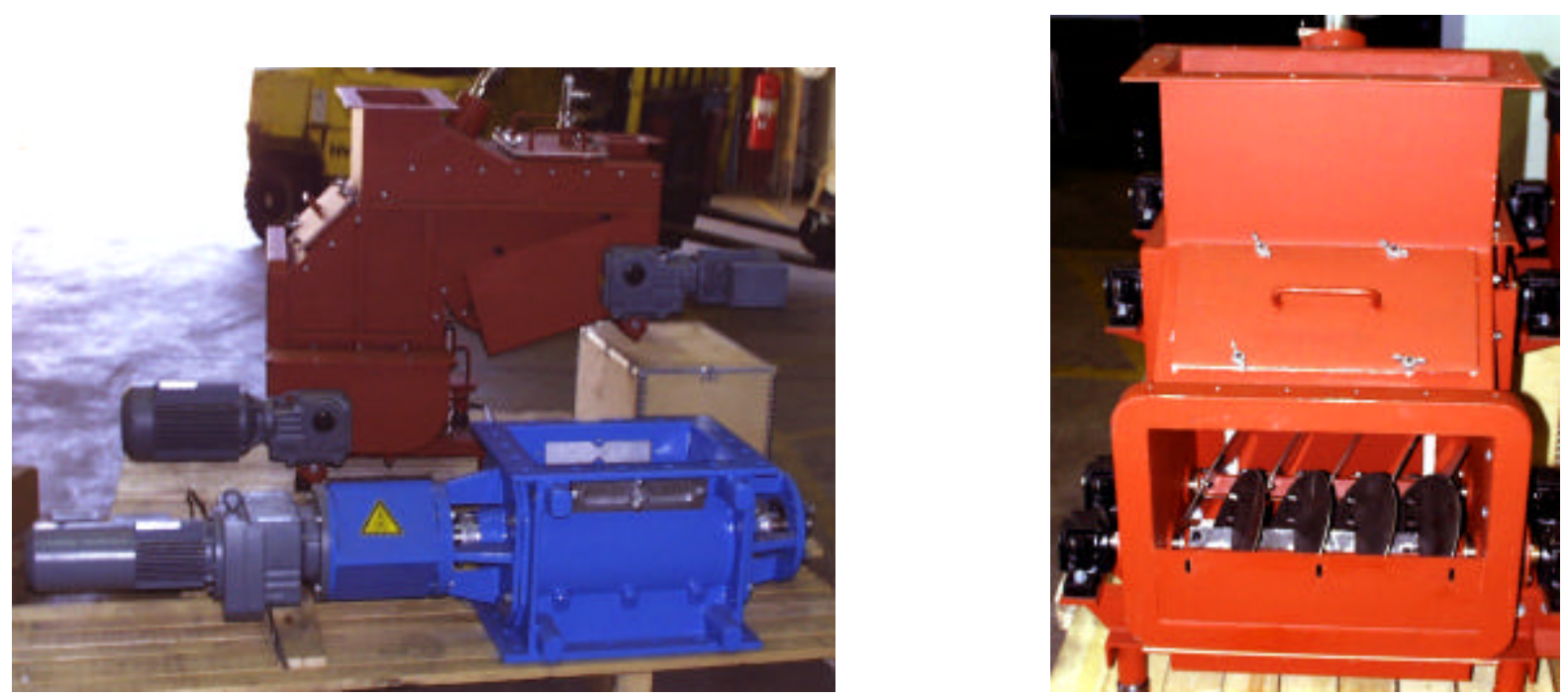

Figure 5.4-4: FDA Additive Feeder and Mixer

The FDA system was shaken down and calibrated as part of a non-CMB program. The MTF was operated on gas firing only. FDA performance was evaluated by circulating PC flyash and then CFB ash around the FDA bagfilter. Coal combustion flue gas was simulated through $\mathrm{SO}_{2}$ injection in the combustion gas. Test variables included duct humidity, $\mathrm{Ca} / \mathrm{S}$ mole ratio, FDA circulation rate, and the differential between the FDA outlet and dewpoint temperatures.

\section{Test Matrix}

Table 5.3-1 outlines the test matrix that was planned for the second test campaign. The initial tests were focused on establishing baseline performance at a partial load $\left(1800^{\circ} \mathrm{F}\right)$ and maximum load (as limited by the transport line cooling capability). Various conditions were then changed to observe their effect on combustion and emission performance, including staging, excess air, and ash recycle injection level. The balance of the tests was then focused on improving sulfur capture. A series of tests were run with various sizes and types of sorbents. Elemental sulfur was also feed into the combustor to simulate firing a high sulfur coal. 
Table 5.3-1: CMB Test Matrix \#2

\begin{tabular}{|c|c|c|}
\hline \multicolumn{3}{|c|}{ Test } \\
\hline 0 & Start up & \\
\hline 1 & Part Load Test & $\begin{array}{l}\text { nominal } 4 \mathrm{MBtu} / \mathrm{hr}, 50 \% \mathrm{XSA} \\
\text { (repeat of earlier test point) }\end{array}$ \\
\hline 2 & $\begin{array}{l}2000^{\circ} \mathrm{F} \text { Base Case } \\
\text { Test }\end{array}$ & $\begin{array}{l}20 \% \text { Excess Air, } 60 \% \text { Primary; } \\
\text { include quick gas comp probing }\end{array}$ \\
\hline 3 & Low Excess Air Test & $15 \%$ \\
\hline 4 & Low Primary Air Split & $50 \%$ \\
\hline 5 & High Primary Air Split & $80 \%$ \\
\hline 6 & $\begin{array}{l}\text { Alternate reinjection } \\
\text { locations }\end{array}$ & $\begin{array}{l}\text { pneumatically convey from FBHE - } \\
\text { test at two locations }\end{array}$ \\
\hline 7 & Best Case & $\begin{array}{l}\text { Establish best air split with best } \\
\text { reinjection location }\end{array}$ \\
\hline 8 & Probing & $\begin{array}{l}\text { at Best Case } \\
\text { - gas probing } \\
\text { - test with grids On and Off }\end{array}$ \\
\hline 9 & Vary ash S/G Ratio & \\
\hline 10 & $\begin{array}{l}\text { Pulverized Chemstone } \\
\text { injection }\end{array}$ & $\begin{array}{l}\text { Switch over to the pulverized sorbent } \\
\text { injected higher into the furnace. }\end{array}$ \\
\hline 11 & $\begin{array}{l}\text { Alternate primary air } \\
\text { split }\end{array}$ & with the pulverized limestone \\
\hline 12 & Aragonite & Switch to Aragonite \\
\hline 13 & $\begin{array}{l}\text { Alternate primary air } \\
\text { split }\end{array}$ & with Aragonite \\
\hline 14 & Sorbent X & Switch to Sorbent X \\
\hline 15 & $\begin{array}{l}\text { Normal Chemstone } \\
\text { Sorbent }\end{array}$ & Return to base sorbent. \\
\hline 16 & Added sulfur & $\begin{array}{l}\text { Add elemental sulfur feed to the } \\
\text { combustor to simulate higher sulfur. }\end{array}$ \\
\hline
\end{tabular}

\section{Operational Summary}

The test campaign began on September 13, 2002 with some initial cold flow tests to verify bauxite solids transport operation and to calibrate the new dual beam laser level indicator system. The hot testing began on September $16^{\text {th }}$ and the test program continued until September $27^{\text {th }}$. Over 20 test conditions were established during this test campaign to evaluate combustor process and heat transfer performance.

The first week of tests covered a variety of operating conditions, including

- Lower combustor temperature (from 1750 to $2000^{\circ} \mathrm{F}$ ) - to observe performance at reduced and full load conditions.

- A range of excess air and air staging splits. Because of the limited amount of cooling duty in the bauxite transport loop (the MBHE was not yet installed) the firing rate was limited to about $65 \%$ load. Since a minimum amount of airflow was required to maintain 
adequate fluidization in the fluidized bed, the amount of air staging for $\mathrm{NO}_{\mathrm{x}}$ control was limited in this test.

- Tests with and without the bauxite distribution grids in place - to observe the effect on temperature profile and mixing.

- Alternate injection location of recirculating ash. Ash captured in the cyclone was normally recirculated to the lower combustor, which is at $2000^{\circ} \mathrm{F}$. Sulfur retained in this ash as $\mathrm{CaSO}_{4}$ is likely to be re-released at this high temperature. In some tests the ash was reinjected into the mid-furnace where the temperature was more conducive to sulfur capture.

The first week was done with the same Chemstone sorbent used for several CFB tests. At $2000^{\circ} \mathrm{F}$ the sulfur capture in the furnace was naturally low and the sulfur capture in the backend FDA system was not enough to achieve acceptable overall emission targets.

In the second week other sorbents were tested in order to try to improve the overall sulfur capture.

- Aragonite, which is much more reactive than Chemstone, did give somewhat higher sulfur capture both in the furnace and the FDA.

- Pulverized Chemstone (90\% less than 9 microns) had better sulfur capture in the furnace (about 40\%) and was fine enough to mostly pass through the cyclone to the FDA. This increase in unreacted calcium allowed the FDA to achieve $100 \%$ sulfur capture.

- Pulverized Chemstone was also tested with elemental sulfur added to the furnace to simulate a high sulfur coal. The FDA was able to capture $99 \%$ of this increased sulfur load.

- A proprietary product, Sorbent X, achieved better sulfur capture in the furnace and FDA than the normal-sized Chemstone and the Aragonite. The good FDA performance, however, was likely due to residual calcium inventory from the preceding pulverized Chemstone tests.

- Chemstone with FBHE ash injection to the FDA. For the normal-sized sorbents (Chemstone, Aragonite, and Sorbent $\mathrm{X}$ ) much of the unreacted calcium was removed from the furnace in the drain from the fluid bed heat exchanger (FBHE). Towards the end of the test week, Chemstone was tested with and without injecting FBHE drain ash directly to the FDA. The FBHE ash gave a small improvement in FDA sulfur capture.

A final transient test was conducted at the end of the test campaign. A loss of coolant scenario was replicated by manually tripping the bauxite rotary valve at the top of the combustor. The control system was designed to trip the coal feed system whenever the rotary valve tripped and leave the fans running. The bed temperatures remained constant for about 10 seconds after the trip and then quickly decayed.

Tables 5.3-2 and 5.3-3 show the coal and ash analyses for the West Virginia coal. Table 5.3-4 shows the ASTM Ash Fusibility Temperatures for this coal. 
Table 5.3-2: West Virginia Coal Analysis

\begin{tabular}{|l|c|}
\hline Component & Wt \% - West Virginia Coal \\
\hline $\mathrm{C}$ & 71.7 \\
\hline $\mathrm{H}$ & 4.9 \\
\hline $\mathrm{O}$ & 5.2 \\
\hline $\mathrm{N}$ & 1.5 \\
\hline $\mathrm{S}$ & 1.3 \\
\hline Ash & 10.8 \\
\hline Moisture & 4.6 \\
\hline & \\
\hline HHV (Btu/lb) & 12,871 \\
\hline
\end{tabular}

Table 5.3-3: West Virginia Coal Ash Analysis

\begin{tabular}{|l|c|}
\hline Component & Wt \% - West Virginia Coal \\
\hline $\mathrm{SiO}_{2}$ & 51.3 \\
\hline $\mathrm{Al}_{2} \mathrm{O}_{3}$ & 22.8 \\
\hline $\mathrm{Fe}_{2} \mathrm{O}_{3}$ & 11.1 \\
\hline $\mathrm{CaO}$ & 7.0 \\
\hline $\mathrm{MgO}$ & 0.7 \\
\hline $\mathrm{Na}_{2} \mathrm{O}$ & 0.5 \\
\hline $\mathrm{K}_{2} \mathrm{O}$ & 1.8 \\
\hline $\mathrm{TiO}_{2}$ & 2.0 \\
\hline $\mathrm{P}_{2} \mathrm{O}_{5}$ & 0.5 \\
\hline $\mathrm{SO}_{3}$ & 1.5 \\
\hline $\mathrm{MnO}$ & 0.1 \\
\hline $\mathrm{BaO}$ & 0.0 \\
\hline $\mathrm{SrO}$ & 0.0 \\
\hline
\end{tabular}

Table 5.3-4: ASTM Ash Fusibility for West Virginia Coal

\begin{tabular}{|c|c|}
\hline & West Virginia Coal \\
\hline I.T & $+2700^{\circ} \mathrm{F}$ \\
\hline S.T & $+2700^{\circ} \mathrm{F}$ \\
\hline H.T & $+2700^{\circ} \mathrm{F}$ \\
\hline F.T & $+2700^{\circ} \mathrm{F}$ \\
\hline
\end{tabular}

\section{Summary of Test Campaign Results}

The test campaign began on September $13^{\text {th }}$ with some initial cold flow testing to verify bauxite solids transport operation and to calibrate the new dual beam laser level indicator system. The hot testing began on September $16^{\text {th }}$ and the test program continued until September $27^{\text {th }}$. Over 20 test conditions were established during this test campaign to 
evaluate combustor process and heat transfer performance. The following items summarize some of the key results from this test period.

- The MTF operated very smoothly in CMB mode during this period. The lower combustor was operated at $2000^{\circ} \mathrm{F}$ for most of the testing. The combustion gases were cooled to $1000^{\circ}-1400^{\circ} \mathrm{F}$ solely by gas-to-solids heat transfer from the falling bauxite particles.

- The bauxite solids circulation system worked very reliably. The solids circulation rate responded immediately to changes in the bauxite feed rotary valve speed and provided excellent control of combustor temperatures. The dual beam laser level indicator was trouble-free and was a reliable indicator of bauxite supply hopper inventory.

- The gas-to-solids heat transfer performance was similar to or slightly better than previously observed.

- Combustion performance was also very good. The combustion efficiency ranged from $98.5-99.6 \%$. The $\mathrm{CO}$ emissions for most of the testing were also low and were typically about $50 \mathrm{ppm}$ at $3 \% \mathrm{O}_{2}$.

- Excellent sulfur capture was demonstrated for the overall CMB system, including the combustor and the backend FDA system. The tests were conducted at a constant $\mathrm{Ca} / \mathrm{S}$ mole ratio of 2 . The West Virginia coal had a sulfur content of $1.3 \%$. The CMB was able to achieve virtually $100 \%$ sulfur removal with the pulverized Chemstone limestone. A $4 \%$ sulfur coal was also simulated by feeding elemental sulfur with the coal. In this case, over $99 \%$ sulfur capture was achieved at a $\mathrm{Ca} / \mathrm{S}$ mole ratio of 2 .

- Nitrogen oxide emissions were somewhat higher than typical CFB levels for this fuel, although similar to emissions from pulverized coal firing with low $\mathrm{NO}_{\mathrm{x}}$ burners. $\mathrm{NO}_{\mathrm{x}}$ emissions were clearly reduced through air staging. However, the firing rate was limited in this test since the MBHE was not installed. The bauxite was cooled only in the watercooled transport line. Since a certain amount of primary air was required for adequate fluidization, this limit on heat input restricted how deeply the air could be staged in this test. $\mathrm{NO}_{\mathrm{x}}$ emissions with full air staging were evaluated during the next test campaign with the MBHE in service. The MBHE has a larger cooling capacity than the watercooled transport line and allowed the CMB to be staged to a much greater extent.

- $\mathrm{N}_{2} \mathrm{O}$ emissions were practically eliminated for both low load and high load CMB operation.

- A transient loss of coolant test was run at the end of the test campaign. The bauxite solids rotary valve was intentionally tripped, which stopped all cooling in the combustor. The loss of coolant automatically tripped the coal feed system. After this event, there was no increase in bed temperature even though there was no cooling and residual carbon continued to burn. The bubbling bed maintained its $2000^{\circ} \mathrm{F}$ temperature for less than 20 seconds and then began to rapidly decrease. The bed carbon concentration was estimated to be well less than $0.1 \%$ carbon. 


\subsection{Test 3 - Coal 1 \& 2 (with MBHE)}

\section{Objective}

The objective of this task was to expand the evaluation of CMB process performance under coal fired conditions to include MBHE performance and a second fuel. The MBHE not only provided an opportunity to characterize solids-to-tube heat transfer, but the larger heat extraction in the MBHE allowed the MTF to be operated at higher loads. This permitted greater flexibility in running the combustor under staged conditions. The process evaluation included the effect of limestone size on FDA performance and $\mathrm{NO}_{\mathrm{x}}$ control through staging, excess air, and SNCR. A second coal was selected for this test with a very low ASTM ash fusion temperature. This fuel coupled with some very high temperature tests, allowed examination of how tolerant the bubbling bed was to temperature excursions and fuel characteristics.

\section{Modifications}

$M B H E$

The MBHE was designed to have the flexibility to meet the range of test conditions planned for the CMB test program. The heat exchanger had four tube banks, which allowed characterization of the heat transfer profile along the height of the heat exchanger. Also, the tube passes could be cooled or left uncooled to increase heat transfer test flexibility. The MBHE tube bundles and manifolding arrangement were designed to provide solids outlet temperatures in the range of $425-540^{\circ} \mathrm{C}\left(800-1000^{\circ} \mathrm{F}\right)$ for solids inlet temperatures of 650$1095^{\circ} \mathrm{C}\left(1200-2000^{\circ} \mathrm{F}\right)$ and solids flow rates of $2270-11,300 \mathrm{~kg} / \mathrm{hr}(5,000-25,000 \mathrm{lb} / \mathrm{hr})$.

The tube bundles were sectionalized to provide variable heat transfer surface areas for control of the solids outlet temperatures. Cooling water passing through selected tube bundles cooled the solids flowing through the MBHE. Changes in coolant flow had little effect on solids outlet temperatures. Increasing or decreasing the number of tube bundles in service was the main control parameter on solids temperature.

Figure 5.4-1 shows an overall view of the MBHE. The MBHE consisted of four tube bundles, each split into two sections. Each combined bundle was ten tubes wide. The bundles consisted of 2.0 inch OD tubes with circumferential fins on 0.5 -inch spacing. The tubes were T22 alloy and the fins were Armco 409 alloy. Tube spacings were offset with $\mathrm{S}_{\mathrm{T}}=3.5$ inch and $S_{\mathrm{L}}=1.875$ inch. The first two tube bundles were three tubes deep in the vertical orientation and had fins of 0.50 inch high by 0.12 inch thick. The third and fourth tube bundles were four and two tubes deep respectively and had fins of 0.625 inch high and 0.12 inch thick.

The horizontal finned length of each tube bundle pass was 32 inches. The fin tip to fin tip clearance between adjacent tubes was 1 inch in order to permit rubble of that size to pass through the bundle. The tubes were arranged in a staggered array so that bauxite passing vertically down could not bypass any region without contacting a finned surface. 


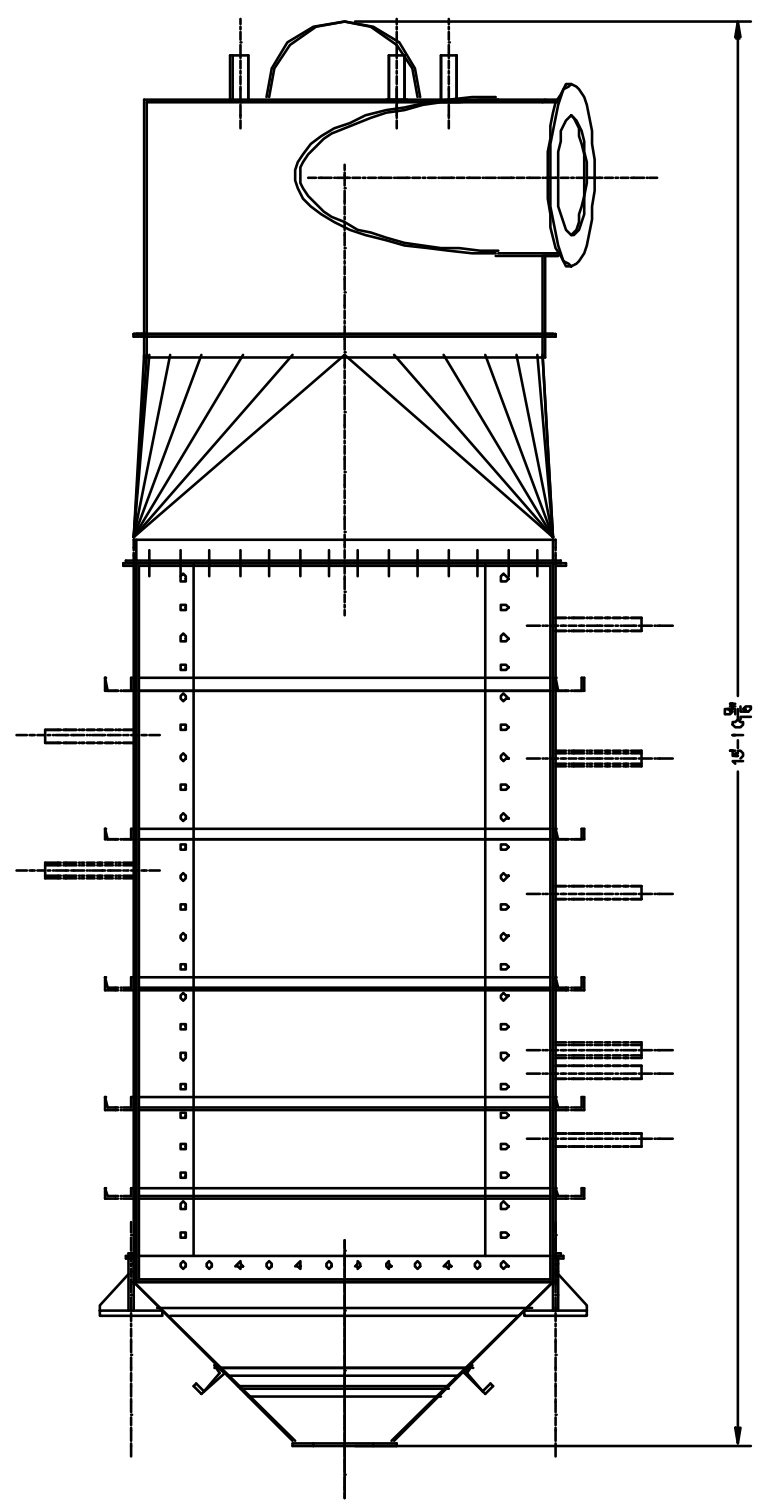

Figure 5.4-1: Overall View of the MBHE

The tube bundles were water-cooled. Cooling water was measured by a turbine meter for each bundle. The inlet temperature was measured by a Type $\mathrm{K}$ thermocouple. Each tube bundle was split into two sections. The cooling water flow was split and entered each section at the bottom. The water made 2 to 3 horizontal passes and 3 vertical passes, exited the heat exchanger, passed by outlet water thermocouples, passed vertically upward to a tee combining the water from each side, passed a second average discharge thermocouple, and exited to a drain. The two thermocouples at each side of the tube bundle indicated whether the two passes were receiving uniform heat flow from the bauxite. The combined water flow thermcouple was compared with the two individual discharge thermocuples to evaluate uniformity of cooling water on each side of the tube bundle. A cross section of the tube bundle is shown in Figure 5.4-2. 


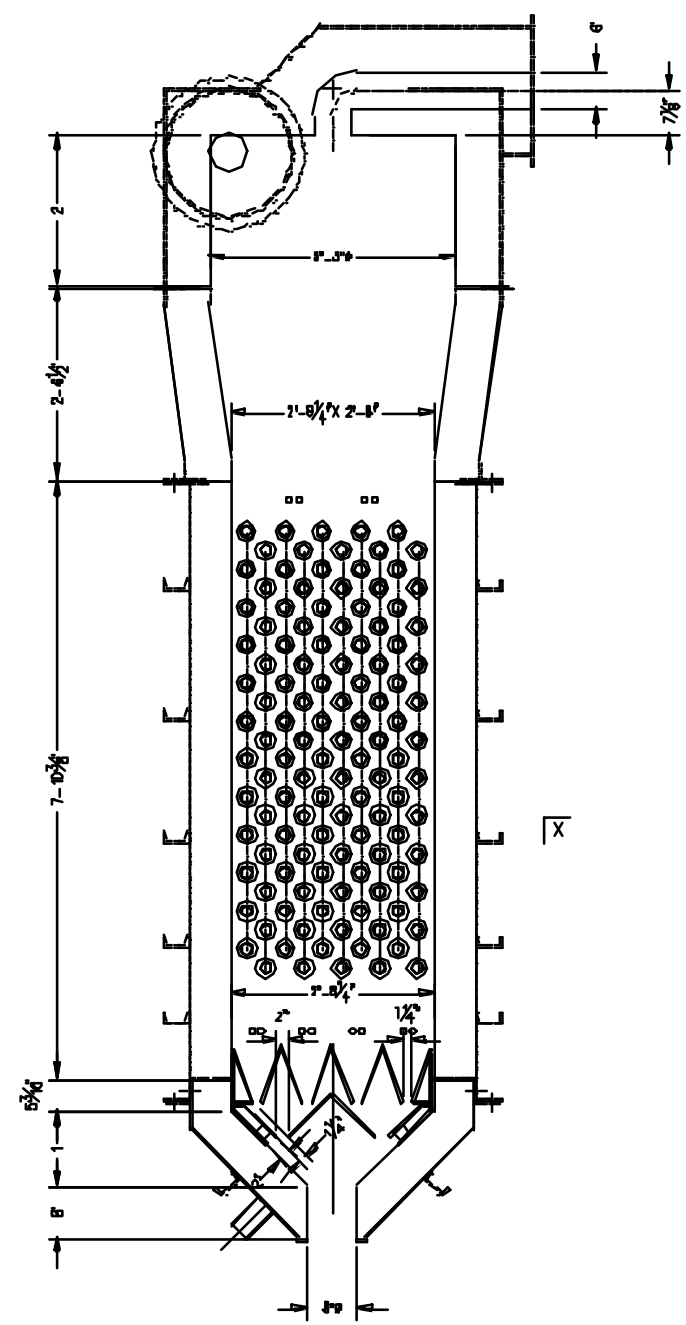

Figure 5.4-2: MBHE Cross-Sectional View

Solids were pneumatically supplied to the top of the MBHE from the MTF combustor overflow seal pot located at the bottom of the combustor. A 6 inch ID refractory lined pipe transported the bauxite from the combustor seal pot to the top of the MBHE. The pipe was lined with 4 inch of Kasolite 19L insulating refractory and a 3 inch liner of KS4 hardface refractory at the inside. A refractory lined cyclone was located at the top of the heat exchanger to separate transport air from the bauxite. A Maxon burner was installed at the inlet of the transport pipe to preheat the transport air so that the bauxite leaving the combustor would not be cooled. The burner was sized to not only preheat the transport air, but to also offset the cooling in the loop seal so the bauxite could be maintained at $2000^{\circ} \mathrm{F}$ when it reached the MBHE. The transport air exited a central port at the top of the refractorylined cyclone.

An open space between the cyclone and the solids inlet thermocouples at the top of the tube bundle acted as a surge-storage volume to accumulate mismatches between bauxite transport to the heat exchanger and from the heat exchanger. A dual-beam laser level detector at the 
top of the heat exchanger provided the facility operators with an indication of the flow balance in and out of the heat exchanger.

The MBHE heat transfer rate was determined for each bundle, using the cooling water as a heat flow medium. The inlet temperature of the coolant was measured by a common inlet header thermocouple. The outlet temperature of each split bundle was measured by a thermocouple inserted axially through the header, into the outlet of the tube to a depth of 8 inches. The average heat flow to a bundle was calculated from the average inlet-outlet temperature difference, coolant flow rate, and coolant specific heat. The solids flow rate through the heat exchanger was calculated from the solids average inlet-outlet temperature difference, MBHE tube bundle total heat flow, and solids specific heat.

Efficient operation of the MBHE required a uniform solids flow distribution through the tube bundle. A flow distribution baffle shown in Figure 5.4-3 was installed at the bottom of the MBHE for this reason. The distribution baffle consisted of a series of orifice plates, the top having sixteen 1-1/4 inch square openings, the second having four 2 inch square openings, and the bottom having an 8 inch opening. Pyramidal hoppers were used rather than perforated flat plates for the orifices to facilitate draining of the material when the MBHE was emptied. Also, pyramidal hoppers promote mass flow better than flat orifice plates. The slope of the top hopper walls was $70^{\circ}$ while the slope of the second and third hopper walls were $45^{\circ}$. The horizontal spacing of the top $70^{\circ}$ hoppers was 8 inches with a vertical height of $8-1 / 2$ inches. The lower pyramidal hopper was 30 inches square and 6-1/2 inches high. The solids flow from the first orifice plate through the second and third is in effect open channel or chute flow, which has more favorable mass flow characteristics than closed channel flow, thus permitting $45^{\circ}$ hopper slopes and lower head room requirements.
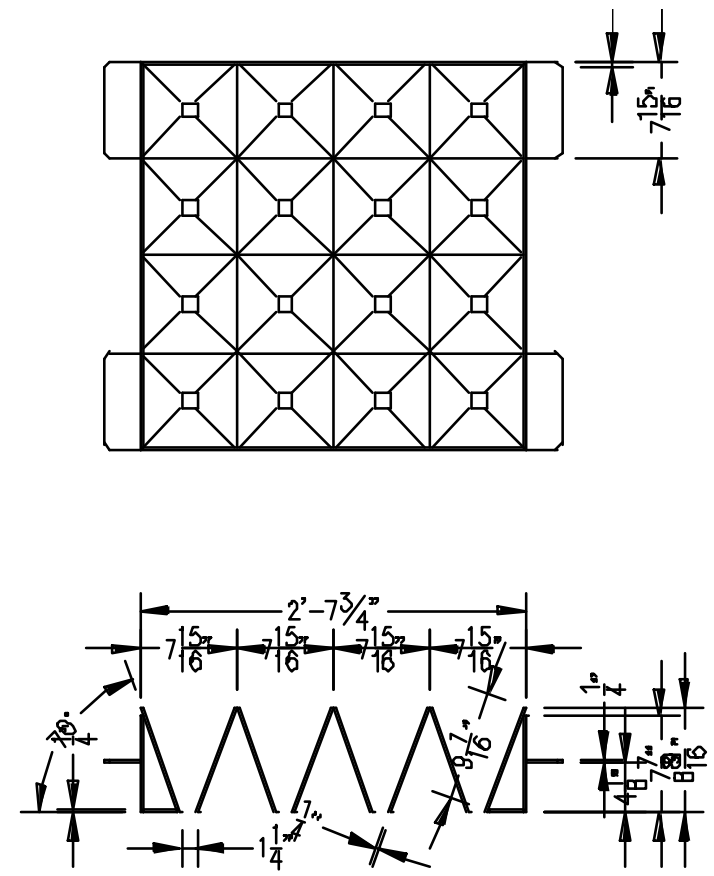

Figure 5.4-3: MBHE Flow Distribution Baffle 
Instruments were installed in the MBHE to measure its performance. The primary instruments were type $\mathrm{K}$ thermocouples to measure solids inlet and outlet temperatures and thermocouples to measure the tube bundle coolant inlet and outlet temperatures. In addition, four turbine meters were used to measure cooling water flow rates to each tube bundle. All instruments were read by a Labview data acquisition system and stored on the PPL server network for later analysis.

In order to determine the solids flow distribution through the baffle, a thermocouple grid was installed above the distribution baffle with a thermocouple above each baffle outlet. Deviations from the average temperature by individual thermocouples indicated that a higher or lower than average solids flow was passing through the particular baffle opening. Individual thermocouples were also installed in the outlet of each tube in the bundles.

An intermediate solids temperature was calculated from the average solids inlet temperature, top tube bundle heat transfer, calculated solids flow rate, and solids specific heat. This solids temperature was calculated because the spacing between top and bottom bundles was too low for an accurate solids temperature measurement by thermocouples.

Figure 5.4-4 compares a schematic of the MBHE with a photo of the heat exchanger and solids separator casing during construction.
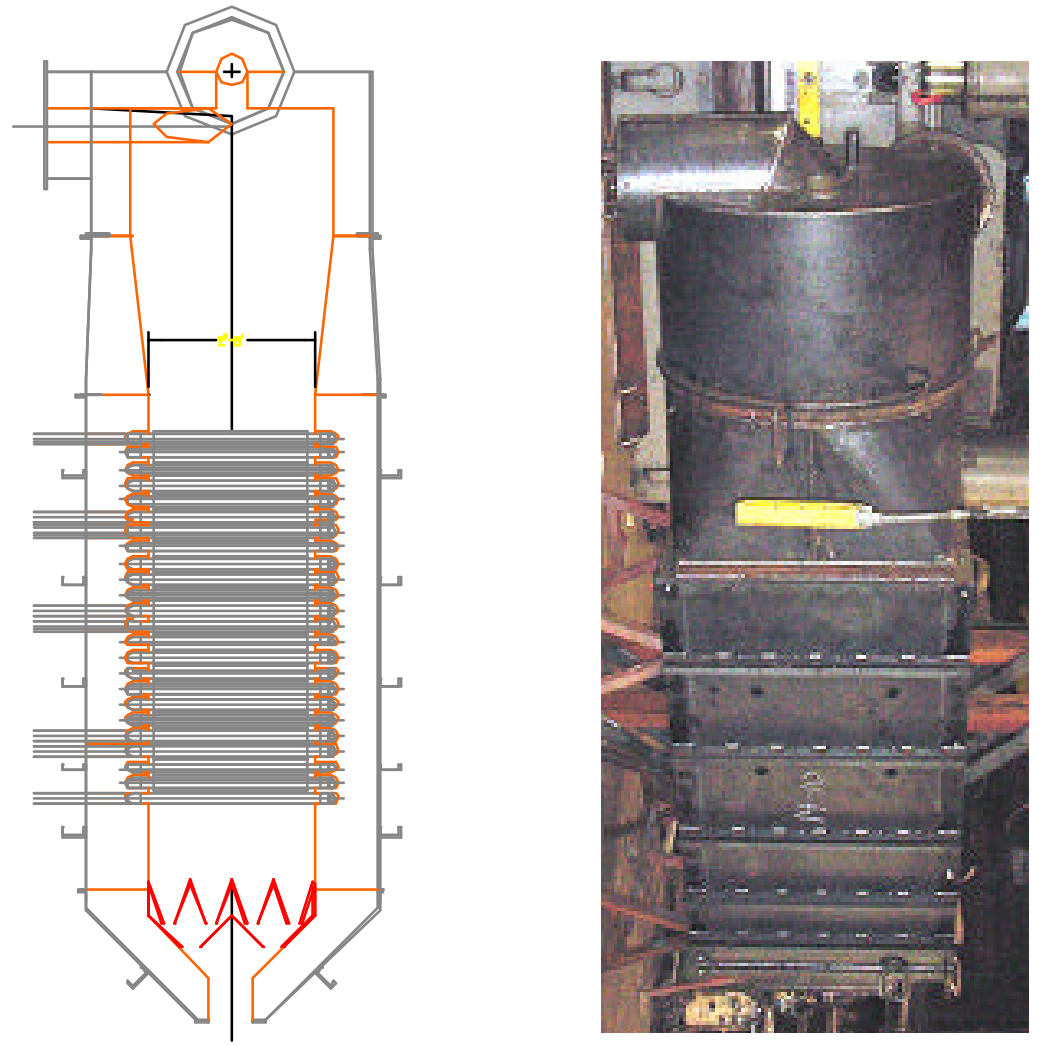

Figure 5.4-4: MBHE Schematic and Casing 
Wax refractory molds were installed on the tube ends of each tube bundle. The refractory for the heat exchanger liner was poured around the molds. The molds were then burned off during refractory curing, leaving a hole in the refractory for the tube bends to expand into. Figure 5.4-5 shows the red endcaps as they were mounted on one of the bundles. The right photo shows the bundles being installed into the heat exchanger casing in preparation for refractory pouring.
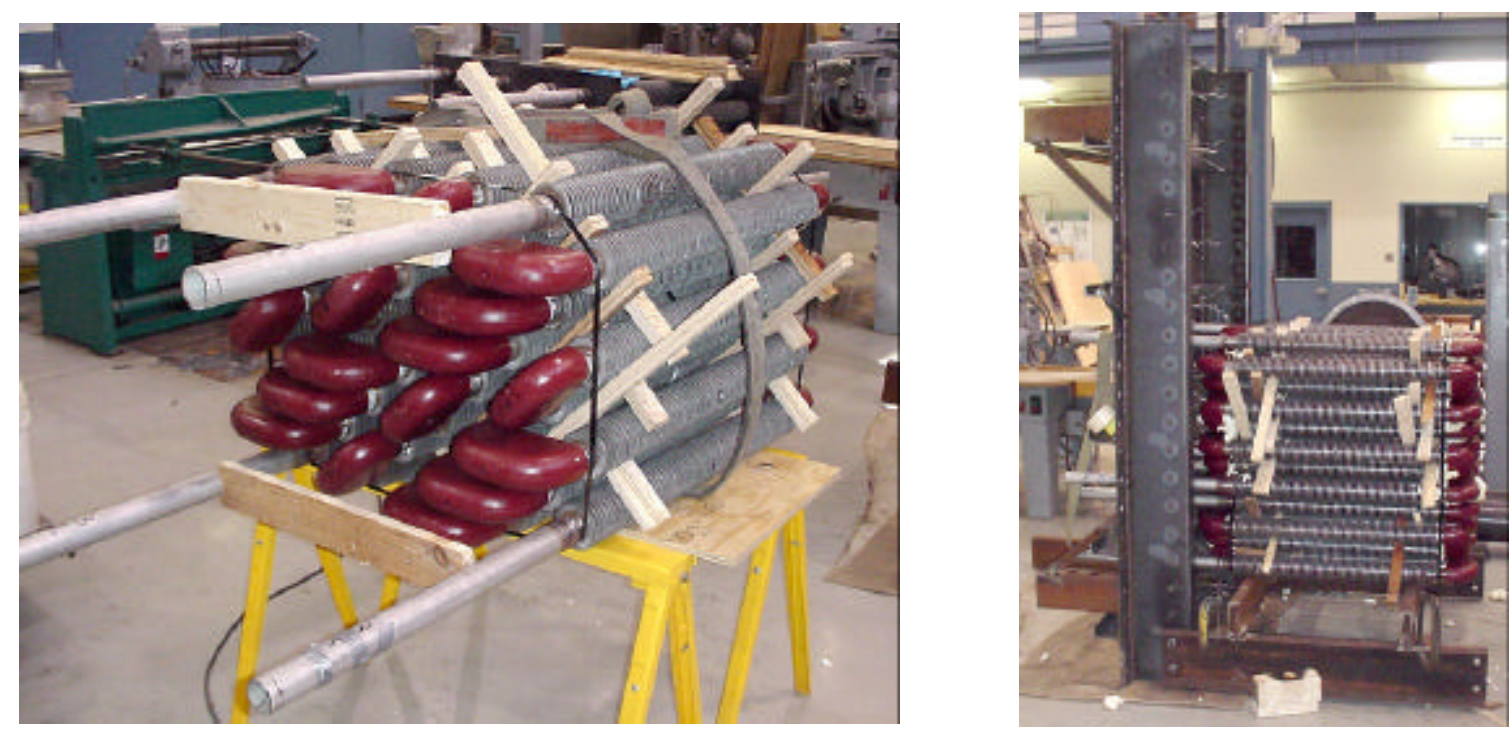

Figure 5.4-5: Wax Mold Endcaps Installed on Tube Bundles

Figure 5.4-6 shows the top of the MBHE bauxite cyclone and the hopper bottom with baffle plate. Hot solids entered the cyclone through the left refractory-lined duct opening and were separated in the cyclone. The clean hot gases exited through the top right refractory lined duct into a water-cooled duct and were then exhausted into the gas outlet duct after the FDA system.

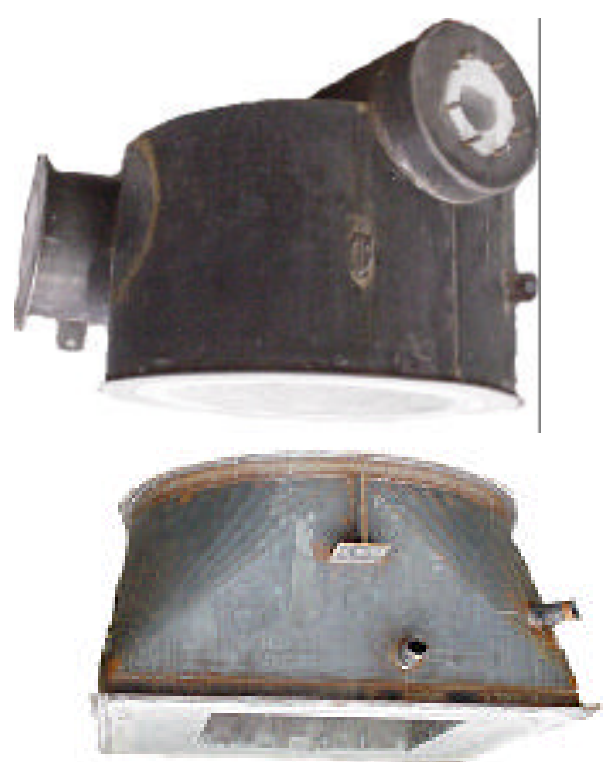

Figure 5.4-6: MBHE Cyclone and Transition Section 
Figure 5.4-7 shows the nearly assembled MBHE with tube bundle installed. The wooden spacers were used to hold the tube bundles in place while the refractory was poured. They were burned off, along with the wax molds, during the refractory cure.

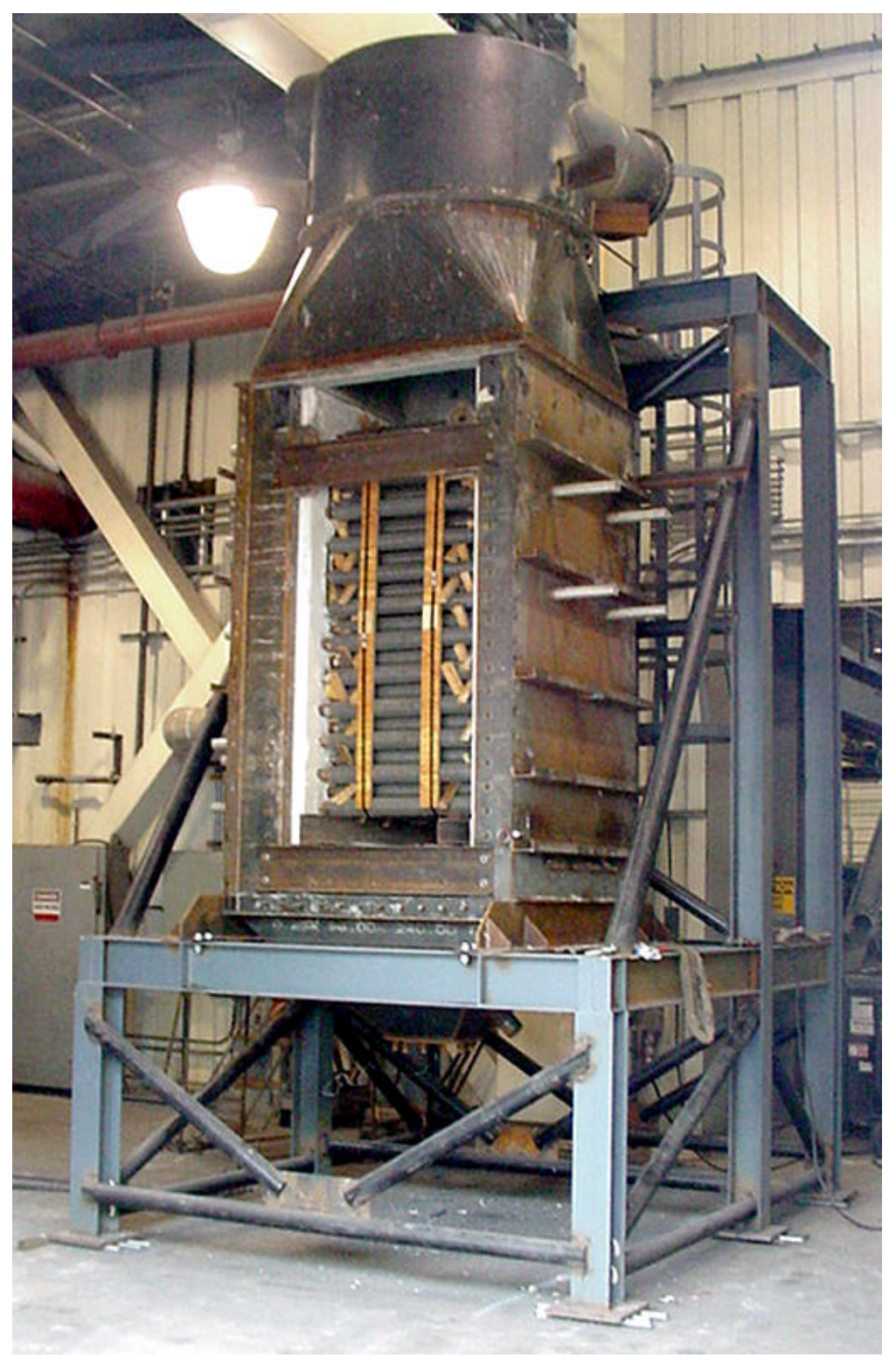

Figure 5.4-7: MBHE with Tube Bundles Installed

\section{Combustor Modifications}

A water-cooled serpentine pipe heat exchanger was installed at the outlet of the MTF main cyclone. The original flue gas cooler was not cooling the flue gas adequately before the gas reached the FDA system. The new heat exchanger cooled the gas sufficiently and added greater flexibility for FDA gas inlet temperature control. 
The open slots on the original grizzly that was mounted on the solids downcomer in the bed (see Figure 5.2-4) were too wide and allowed some oversize material to pass into the transport line. The grizzly was replaced with a newer design to prevent large rocks from getting into the MBHE. The new design was a commercially available wire basket that is used for dipping parts into hot chemical baths. The basket was made of 0.187 inch diameter wire with 3/8 inch diameter support bars. All materials were made of SS330. Figure 5.4-8 shows the new grizzly mounted on the solids downcomer.

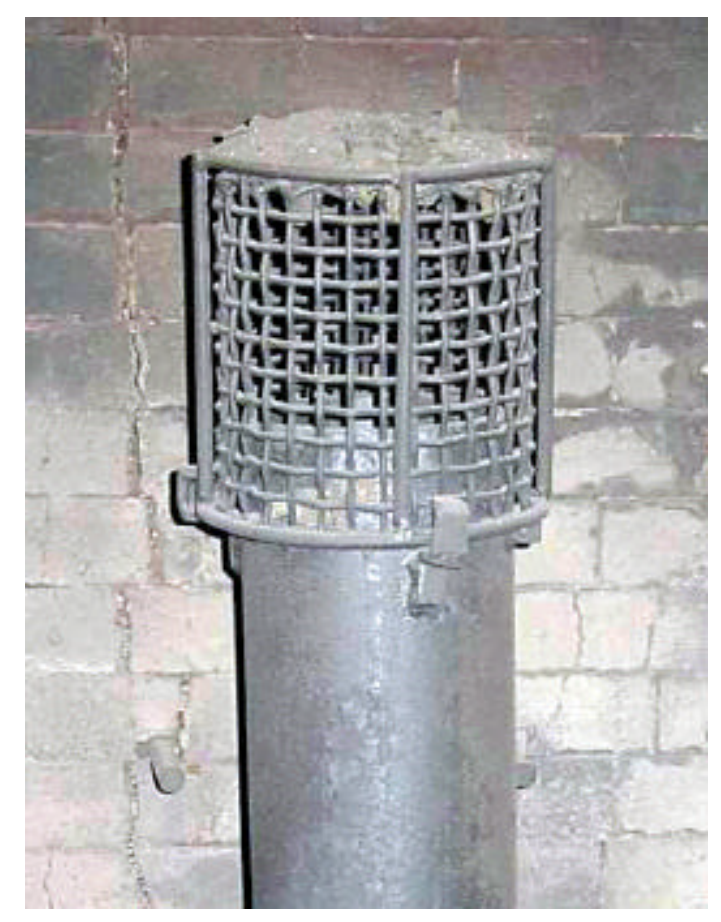

Figure 5.4-8: Wire Basket Grizzley

\section{Measurement of $\mathrm{SO}_{3}$ and $\mathrm{NH}_{3}$ slip under $\mathrm{CMB}$ conditions}

Instrumentation was also set up during this test campaign to take measurements for $\mathrm{SO}_{3}$ and $\mathrm{NH}_{3}$ in the flue gas before the FDA. The sampling systems used for the measurements are shown in Figure 5.4-9. The sample gas pretreatment system was composed of a tubular ESP at $350^{\circ} \mathrm{F}$ to precollect calcium-containing ash particles followed by a Teflon filter and a gas transport line that connects up to impinger trains. The Teflon transport line was heated to $350^{\circ} \mathrm{F}$ in order to avoid any condensation By employing a laminar ESP, the interaction between gas species and solids was minimized.

For $\mathrm{SO}_{3}$ measurement, a controlled condensation system was constructed to selectively condense out $\mathrm{SO}_{3}$ while keeping the moisture in the flue gas in vapor phase. A modified Graham condenser with a back-up medium frit was employed and maintained at $140^{\circ} \mathrm{F}$, a temperature between $\mathrm{H}_{2} \mathrm{SO}_{4}$ dew point $\left(200\right.$ to $\left.300^{\circ} \mathrm{F}\right)$ and water dew point $\left(\sim 60^{\circ} \mathrm{F}\right)$. The condenser was followed by an impinger train with various chemical solutions for redundant 
sampling purposes. The $\mathrm{SO}_{3}$ collected in the condenser was rinsed for concentration determination by barium-thorin titration.

For $\mathrm{NH}_{3}$ measurement, EPA conditional test method CTM-027 was employed. The first two impingers were filled with $0.1 \mathrm{~N} \mathrm{H}_{2} \mathrm{SO}_{4}$ solution for capture of $\mathrm{NH}_{3}$. The concentration of $\mathrm{NH}_{3}$ in the solution was later determined by ion chromatography.

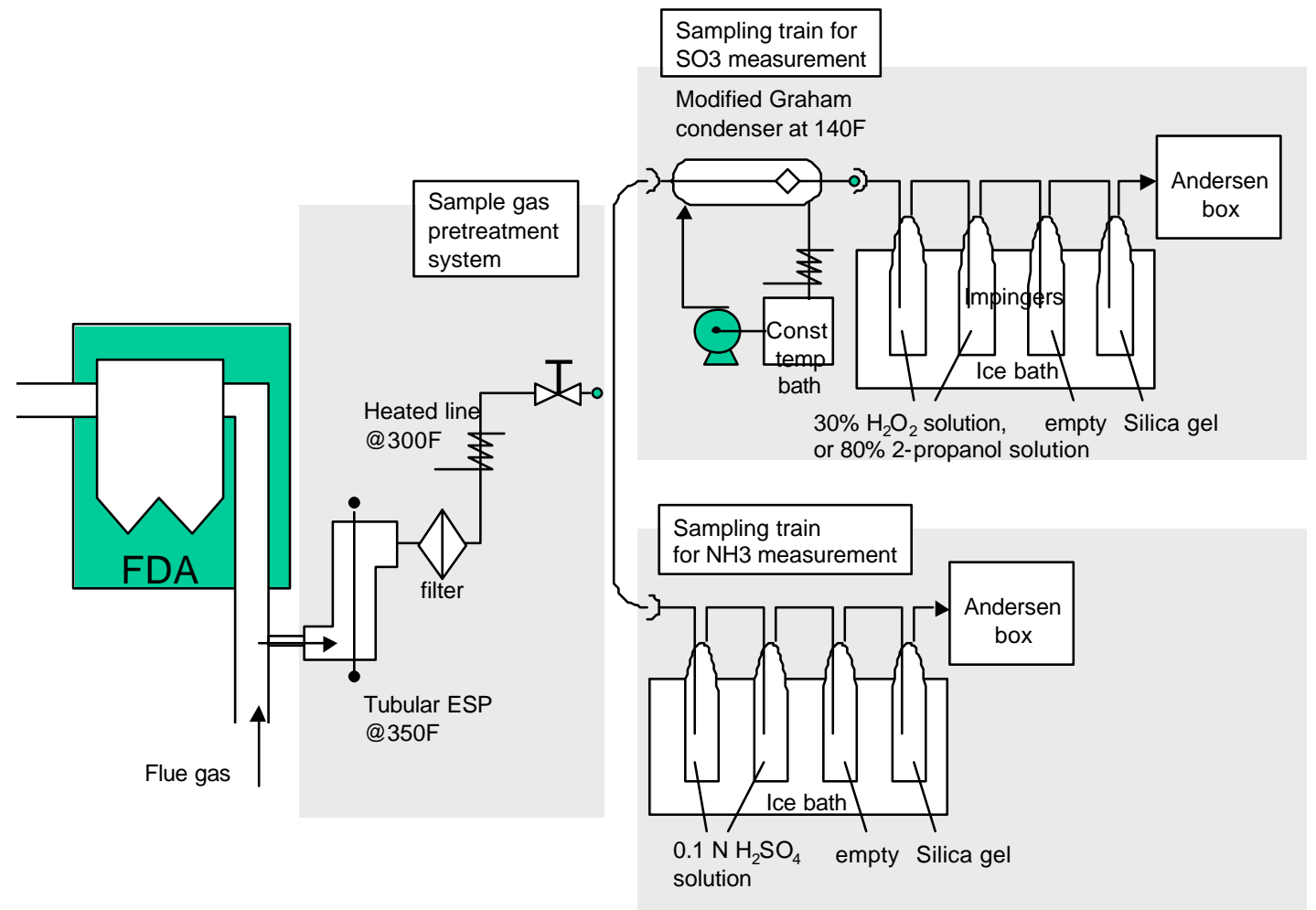

Figure 5.4-9: $\mathrm{SO}_{3} / \mathrm{NH}_{3}$ measurement system

\section{Test Matrix}

Table 5.4-1 outlines the test matrix that was planned for the third test campaign. Many of the tests had multiple objectives, as MBHE, combustor, and FDA performance could all be tested simultaneously.

The objective of the initial test series was to determine the process performance with West Virginia coal at full load conditions. The MBHE had a much higher heat extraction than the water-cooled transport line used previously and permited operation at higher load conditions. The remaining tests were then run with Pittsburgh \#8 coal. A 100 hour test was planned with this fuel to demonstrate operation with a coal with a very low ASTM ash fusion temperature. This test included two higher temperature tests to show how sensitive the bubbling bed was to temperature excursions and maldistributions. A series of load variations was planned during this test period to characterize the MBHE over a range of solids flow rates. Many parametric tests were also included to characterize the effect of staging and SNCR on $\mathrm{NO}_{\mathrm{x}}$ emissions and the effect of limestone particle size on sulfur capture. 
Table 5.4-1: CMB Test Matrix \#3

\begin{tabular}{|ll|}
\hline Test & \\
0 & Gas Startup \\
1 & High Temperature Gas Firing \\
2 & $2000^{\circ} \mathrm{F}$ in MBHX \\
3 & West Virginia Coal only \\
4 & Coal only w/ ammonia \\
5 & Base Case with Limestone \\
6 & Low Recycle Reinjection \\
7 & Deep Staging I \\
8 & Deep Staging II \\
9 & Ammonia Injection \\
10 & Ground FBHE Ash to FDA \\
11 & Pittsburgh 8 high sulfur coal \\
12 & Base conditions with medium limestone \\
13 & No reinjection \\
14 & Low Excess Air \\
15 & Load Points (for MBHE) \\
16 & Base Conditions with fine limestone \\
17 & No reinjection \\
18 & Load Points (for MBHE) \\
19 & Deep Staging I \\
20 & Deep Staging II \\
21 & Low Excess Air \\
22 & Ammonia Injection \\
23 & High Temp Test - 2100 ${ }^{\circ} \mathrm{F}$ \\
24 & High Temp Test - 2150 ${ }^{\circ} \mathrm{F}$ \\
\hline
\end{tabular}

\section{Operational Summary}

This test campaign required four separate operating periods to achieve the overall test objectives. Two forced outages were required due to failures of non-CMB related equipment. Corrective measures were also required for some of the new subsystems related to the new MBHE system.

The test campaign began on December 2, 2002. The MTF started up with the West Virginia bituminous coal and the Chemstone limestone. All systems were operational and solids were transporting smoothly between the combustor and the MBHE. The MTF was shut down two days later when hot spots developed on the Maxon burner box and in the refractory lined transport line between the combustor and the MBHE. Further inspections showed that some refractory had worn away in the burner box and that the refractory lined transport line was severely eroded. The wear was attributed to a couple of factors. First, the transport system was operated at times at velocites much higher than designed. Second, the material selection for the refractory hardface was not sufficiently abrasion resistant for this application.

It was decided that the easiest near term repair for the transport line was to insert a 5-inch 310 stainless steel pipe inside the 6-inch opening in the transport line. Refractory was then injected around the pipe. The 310 stainless steel vertical transport line had shown practically no wear after the February and September test campaigns, so this approach seemed to be an 
reasonable solution. The main downside with the pipe liner was higher predicted pressure drops due to the smaller pipe diameter. The solids temperature passing through the transport line also had to be restricted to about $1800^{\circ} \mathrm{F}$. This did not affect the bed operating conditions, but required the Maxon burner firing rate to be limited and resulted in somewhat lower solids inlet temperatures into the MBHE.

The target zone of the MBHE solids separator was also showing some wear patterns and was repaired with a better grade of refractory. The MBHE tube bundles had some debris from the worn refractory pipe that had accumulated in the lower hopper. The tubes themselves were clean. The debris was removed and the MBHE door was replaced.

The MTF restarted on December $13^{\text {th }}$ and operated until the $16^{\text {th }}$. The startup was delayed when solids would not flow out of the combustor into the transport line. Further inspection showed that the grizzly was no longer mounted on the solids downcomer in the bed and that the loop seal was plugged. After removing the combustor door, the wire basket grizzly was found completely fallen apart after only 48 hours of exposure at $2000^{\circ} \mathrm{F}$. Although the wires and support rings themselves were in excellent condition, the welds holding the interwoven wire mesh had broken. The original grizzly was therefore reinstalled on the solids downcomer with some additional support rings to reduce the size of the openings. The modified grizzly is shown in Figure 5.4-10.

Figure 5.4-10: Modified Grizzly

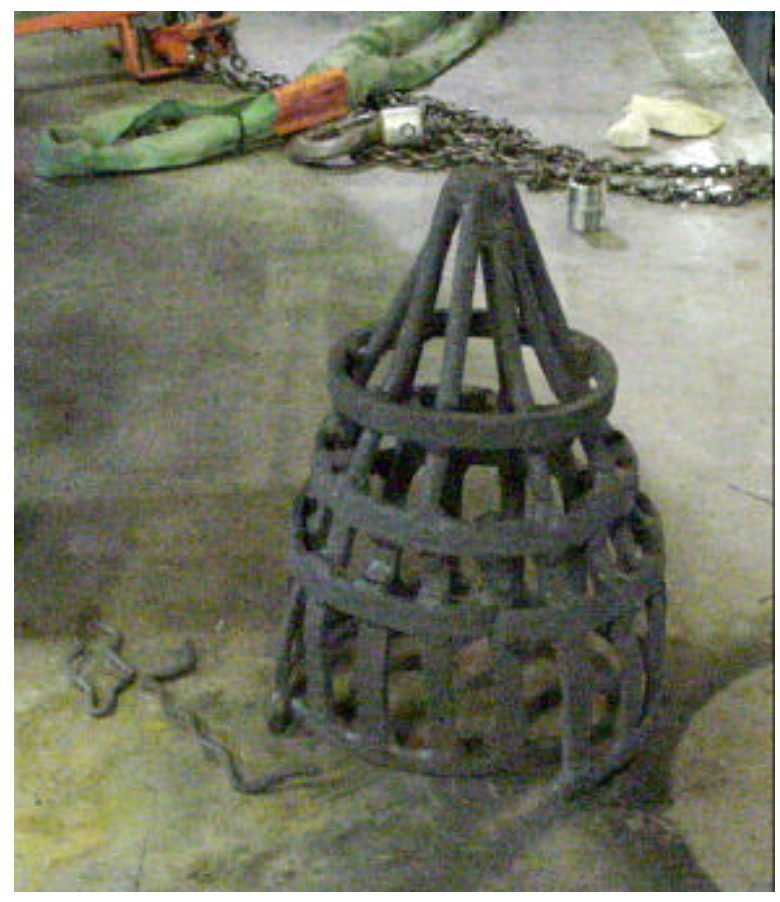

The maximum MBHE solids flow during this period was less than achieved during the first operating period. It appeared that flow was being restricted in the bottom of the MBHE. At this point, the MTF was shutdown to also repair some MTF equipment unrelated to CMB operation. 
The MBHE inspection during this outage found that some oversize material had accumulated in the bottom of the MBHE distributor and plugged about $75 \%$ of the openings. This oversized material included chucks of refractory that had spalled off of the MBHE solids separator and also large material from the combustor that probably passed through the downcomer before the grizzly was replaced.

At this point, it was decided to make several modifications prior to the next restart. The refractory in the target zone of the MBHE solids separator was removed and replaced with high density alumina bricks. Bricks were also installed at the impact tees in the transport pipe. The wear-resistant phosphate-bonded refractory that was used for repairs in this area did not perform well and was showing significant wear. A perforated plate was installed in the bottom of the MBHE just above the outlet solids distributor. The purpose of this plate was to trap any oversize material that passed through the MBHE before it could get stuck in the outlet distributor. A new grizzly was also fabricated and installed on the solids downcomer in the combustor. The grizzly was made out of a sheet of perforated rolled alloy. Figure 5.4-11 shows the final grizzly design installed on the solids downcomer.

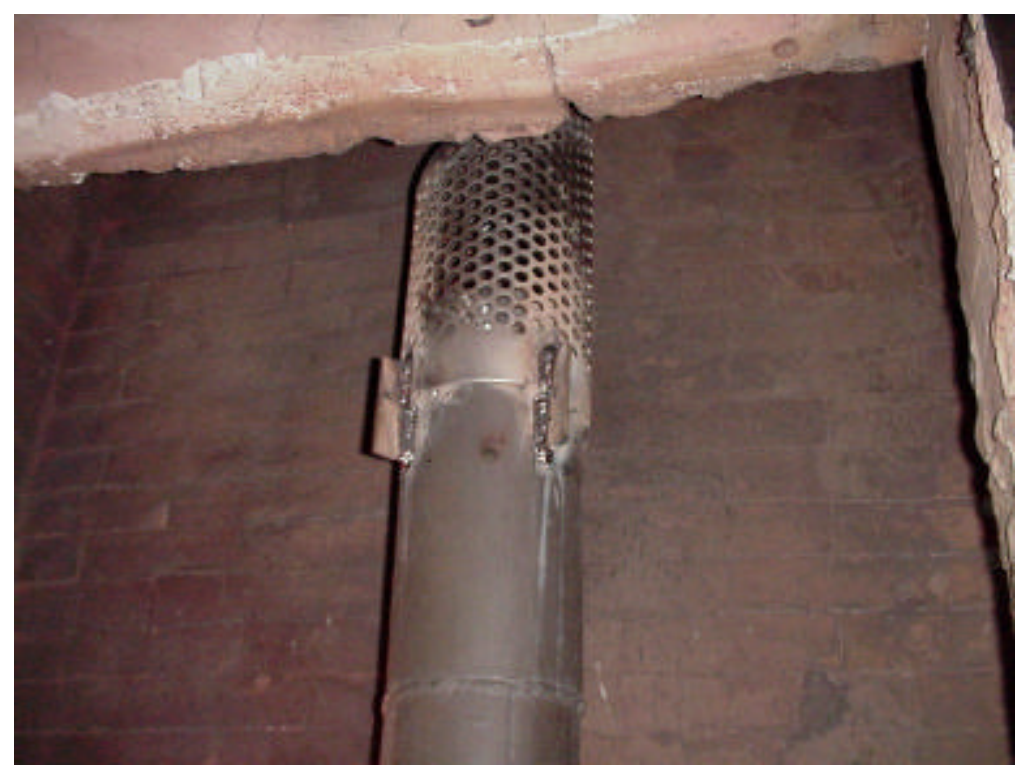

Figure 5.4-11: Perforated Grizzly Design

The third operational period began on February 2, 2003 and continued until February $4^{\text {th }}$. The unit operated much smoother, although the lower MBHE thermocouples still indicated that there was some solids flow maldistribution. The main problem during this period was an inability to build up circulation solids in the FDA baghouse. A dust loading on the baghouse outlet indicated substantial ash loss through the baghouse. The MTF was shut down and the baghouse bags were replaced during this outage. Inspection of the MBHE showed that the solids distributor was again partially plugged. It was therefore decided to increase the outlet area of the solids distributer from 1.25 inch $\times 1.25$ inch to 2 inch $\times 2$ inch. 
The final startup began on February $17^{\text {th }}$ and testing continued until February $23^{\text {rd }}$. Pittsburgh \#8 coal was fired for the duration of this test period. All systems operated smoothly. Solids circulation from the combustor to the MBHE and then up to the top of the combustor was very reliable and flow was unrestricted. All tests were completed as planned.

Tables 5.4-2 and 5.4-3 show the coal and ash analyses for the Pittsburgh \#8 coal. Table 5.4-4 shows the ASTM Ash Fusibility Temperatures for this coal.

Table 5.4-2: Pittsburgh \#8 Coal Analysis

\begin{tabular}{|l|c|}
\hline Component & Wt \% - Pittsburgh \#8 Coal \\
\hline C & 70.6 \\
\hline H & 4.8 \\
\hline O & 6.3 \\
\hline N & 1.3 \\
\hline S & 2.9 \\
\hline Ash & 7.2 \\
\hline Moisture & 6.9 \\
\hline & \\
\hline HHV (Btu/lb) & 12,764 \\
\hline
\end{tabular}

Table 5.4-3: Pittsburgh \#8 Coal Ash Analysis

\begin{tabular}{|l|c|}
\hline Component & Wt \% - Pitsburgh \#8 Coal \\
\hline $\mathrm{SiO}_{2}$ & 47.7 \\
\hline $\mathrm{Al}_{2} \mathrm{O}_{3}$ & 19.9 \\
\hline $\mathrm{Fe}_{2} \mathrm{O}_{3}$ & 22.9 \\
\hline $\mathrm{CaO}$ & 3.0 \\
\hline $\mathrm{MgO}$ & 0.7 \\
\hline $\mathrm{Na}_{2} \mathrm{O}$ & 0.6 \\
\hline $\mathrm{K}_{2} \mathrm{O}$ & 2.1 \\
\hline $\mathrm{TiO}_{2}$ & 1.0 \\
\hline $\mathrm{P}_{2} \mathrm{O}_{5}$ & 0.5 \\
\hline $\mathrm{SO}_{3}$ & 1.5 \\
\hline $\mathrm{MnO}$ & $<0.1$ \\
\hline $\mathrm{BaO}$ & $<0.0$ \\
\hline $\mathrm{SrO}$ & 0.1 \\
\hline
\end{tabular}


Table 5.4-4: ASTM Ash Fusibility for Pittsburgh \#8 Coal

\begin{tabular}{|c|c|}
\hline & Pittsburgh \#8 Coal \\
\hline I.T & $2140^{\circ} \mathrm{F}$ \\
\hline S.T & $2185^{\circ} \mathrm{F}$ \\
\hline H.T & $2240^{\circ} \mathrm{F}$ \\
\hline F.T & $2290^{\circ} \mathrm{F}$ \\
\hline
\end{tabular}

\section{Summary of Test Campaign Results}

Three moving bed heat transfer test points were obtained during the first test sequence in December 2002 during natural gas firing. The purpose of these tests was to operate the CMB combustor bed at temperatures up to $2200^{\circ} \mathrm{F}$ to provide high bauxite temperatures to the inlet of the MBHE. Gas was used as the fuel rather than coal to eliminate the possibility of agglomeration of coal ash on the bauxite particles. However, limitations of the bauxite transport air inlet burner casing did not permit the desired $2000^{\circ} \mathrm{F}$ inlet temperature conditions at the MBHE inlet.

Additional moving bed heat transfer data was gathered during the subsequent test periods with much higher solids flow rates. Once the system was shaken down, the bauxite transport system was very reliable. In fact, there was not a single instance of interruptions in solids transport during the last test period in either the transport to or from the MBHE.

All other subsystems also worked reliably during the final test period. All test conditons were obtained, included six hours of operation at bed temperatures as high as $2160^{\circ} \mathrm{F}$. The following items summarize some of the key results from this test period.

- The MBHE heat transfer rate was considerably better than previous results obtained in a prior test program with an in-line tube bundle. The improvement was attributed to the staggered tube bundle arrangement.

- The MBHE heat transfer rate deteriorated when the solids flow distribution was disrupted in the MBHE. This illustrated the importance of maintaining a uniform solids flow distribution throughout the MBHE.

- All mechancial systems, including both solids transport systems and the FDA system, worked without any problems or pluggages in the last test sequence after the system was finally shaken down.

- The combustion performance was very good with both coals. The combustion efficiency ranged from $98.4 \%$ to $99 \%$ for the Pittsburgh \#8 coal.

- $\mathrm{NO}_{\mathrm{x}}$ emissions were reduced to $88 \mathrm{ppm}$ through air staging. The results also demonstrated that $\mathrm{NO}_{\mathrm{x}}$ emissions could be further reduced with SNCR.

- The sulfur capture was $96 \%$ at a $\mathrm{Ca} / \mathrm{S}$ mole ratio of 2 while using a fine commercial grind of Marblewhite limestone.

- The combustor ran for 110 hours at $2000^{\circ} \mathrm{F}$ and 6 hours at higher temperatures up to $2160^{\circ} \mathrm{F}$ with Pittsburgh \#8 coal with no signs of agglomeration. 


\subsection{CMB Heat Exchanger Materials Test Probe}

\section{Objective}

The CMB heat exchanger relies on high temperature finned surface to extract heat from hot solids. The extended surface will operate at a temperature higher than conventional boiler materials at a given steam temperature. The purpose of this test probe was to provide a preliminary assessment of alloy performance in the CMB heat exchanger environment. After exposure to high temperature conditions, the material samples would be removed for inspection and evidence of oxidation, erosion, and corrosion

\section{Probe Description}

The materials test probe exposed multiple samples of seven different alloys to the high temperature environment in the top of the MBHE. The probe was air-cooled to a controlled temperature of $1,350{ }^{\circ} \mathrm{F}\left(732{ }^{\circ} \mathrm{C}\right)$. This temperature was chosen to be representative of the maximum fin tip temperature during MBHE operation. A view of the assembled probe is presented in Figure 5.5-1. The probe was mounted about 18 inches above the top tube bundle. The probe entered from the middle of the west heat exchanger wall and was oriented in a west-to-east direction.

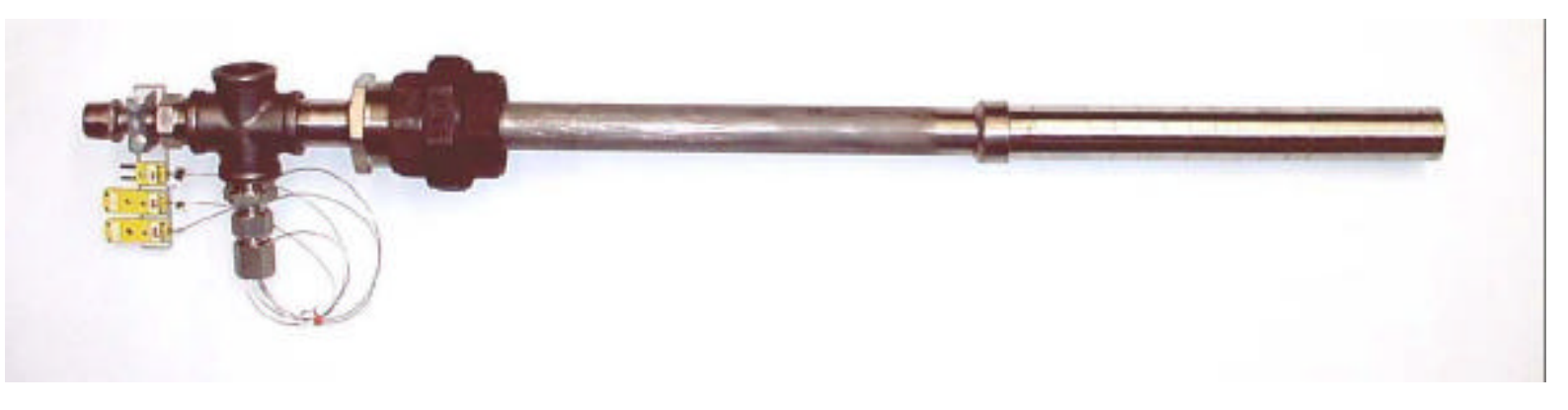

Figure 5.5-1: Assembled Materials Test Probe

The probe used a selection of materials that are candidates for MBHE tube or fin materials. The material samples included two austentic stainless steels (SS310 and 316), one ferritic stainless steel (SS410), three inconel alloys (IN800, 802, 617) and one pure nickel sample (Ni). Figure 5.5-2 shows the material selections and their location on the probe. Each material sample is color coded in this figure so its placement can be observed on the probe.
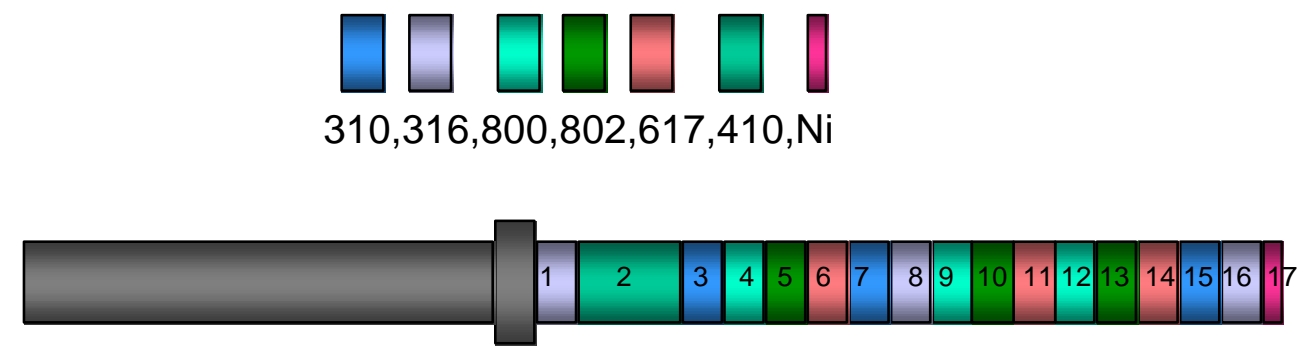

Figure 5.5-2: Material Selection and Location 


\section{Results}

The materials test probe was exposed to high temperatures in the CMB heat exchanger during three operational periods. The time/temperature history and the probe temperature setpoint is shown in Figure 5.5-3. This temperature history is a composite of three exposure periods and not a continuous run. This figure shows that the corrosion sample was exposed to the desired $1350^{\circ} \mathrm{F}$ temperature for only a small portion of its total exposure time.

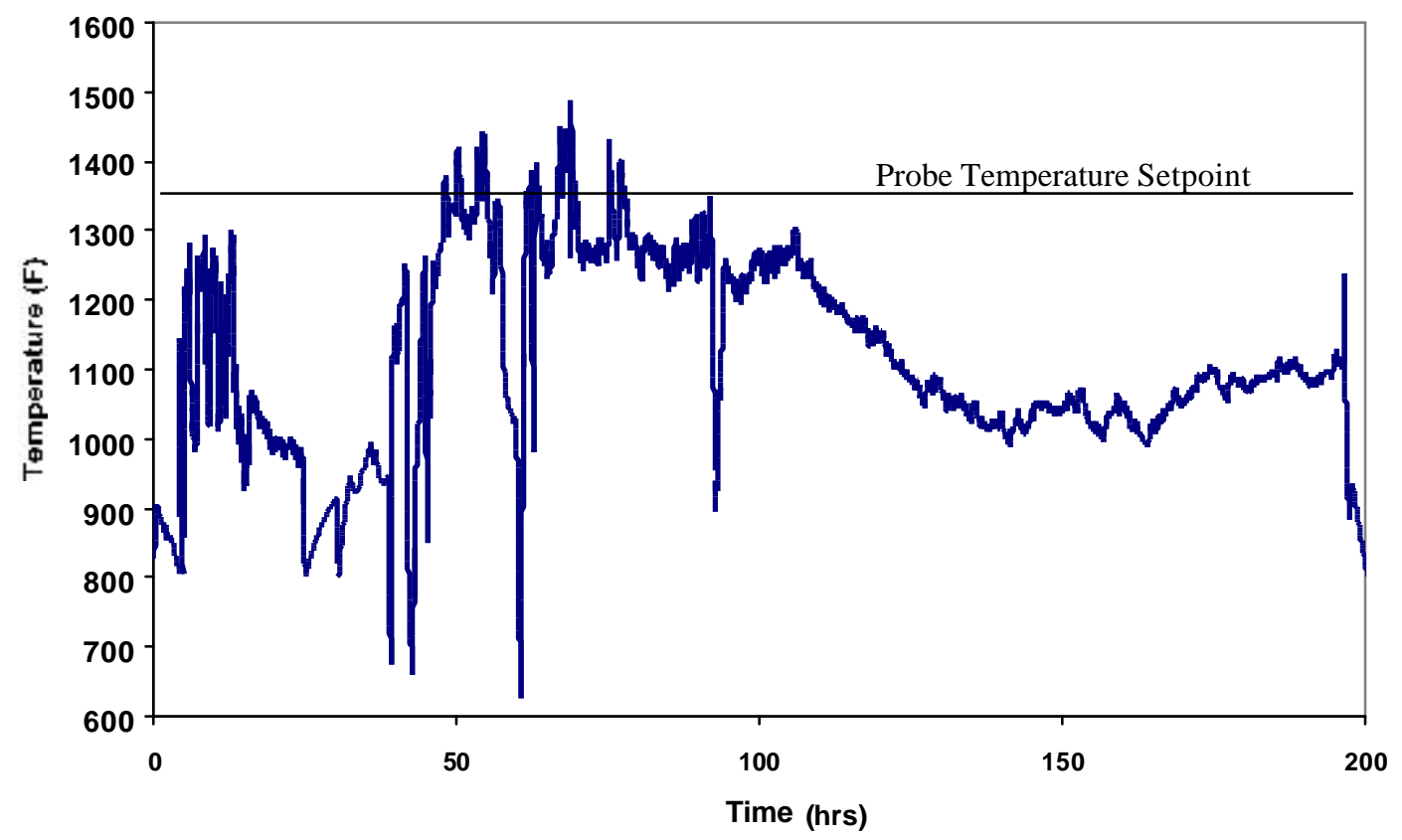

Figure 5.5-3: Materials Probe Temperature Exposure History

As will be discussed in Section 6.2, the solids flow distribution was not uniform through the MBHE. The materials probe was apparently located in a region of slow moving or stagnant solids and was not always exposed to the full solids temperature entering the MBHE. Since the temperature in this region was often less than $1350^{\circ} \mathrm{F}$, the probe temperature controller was unable to maintain the probe temperature at the proper conditions. Figure 5.5-4 shows a plan view of the MBHE, with the location of the four solids inlet thermocouples and the materials probe.

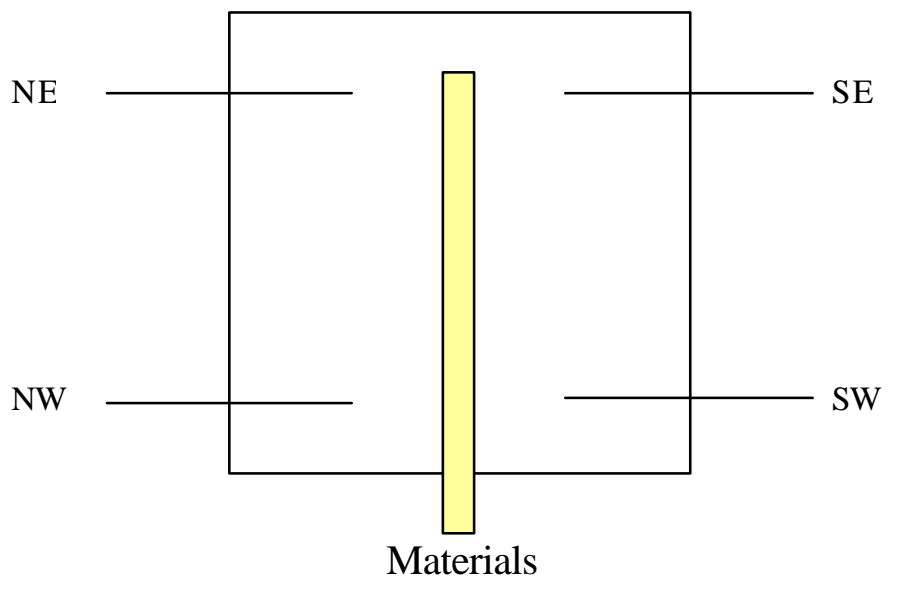

Figure 5.5-4: Plan View of MBHE 
Figure 5.5-5 shows the MBHE solids inlet temperature profile during the three tests periods that the MBHE was in operation. This figure shows that the solids distribution deteriorated after day three, with the solids on the south side being considerably cooler than the north side. This is indicative of a lack of solids flow on the south side. The probe location shown in Figure 5.4-4 shows that the probe was located in the middle region right between the high and low temperature regions.

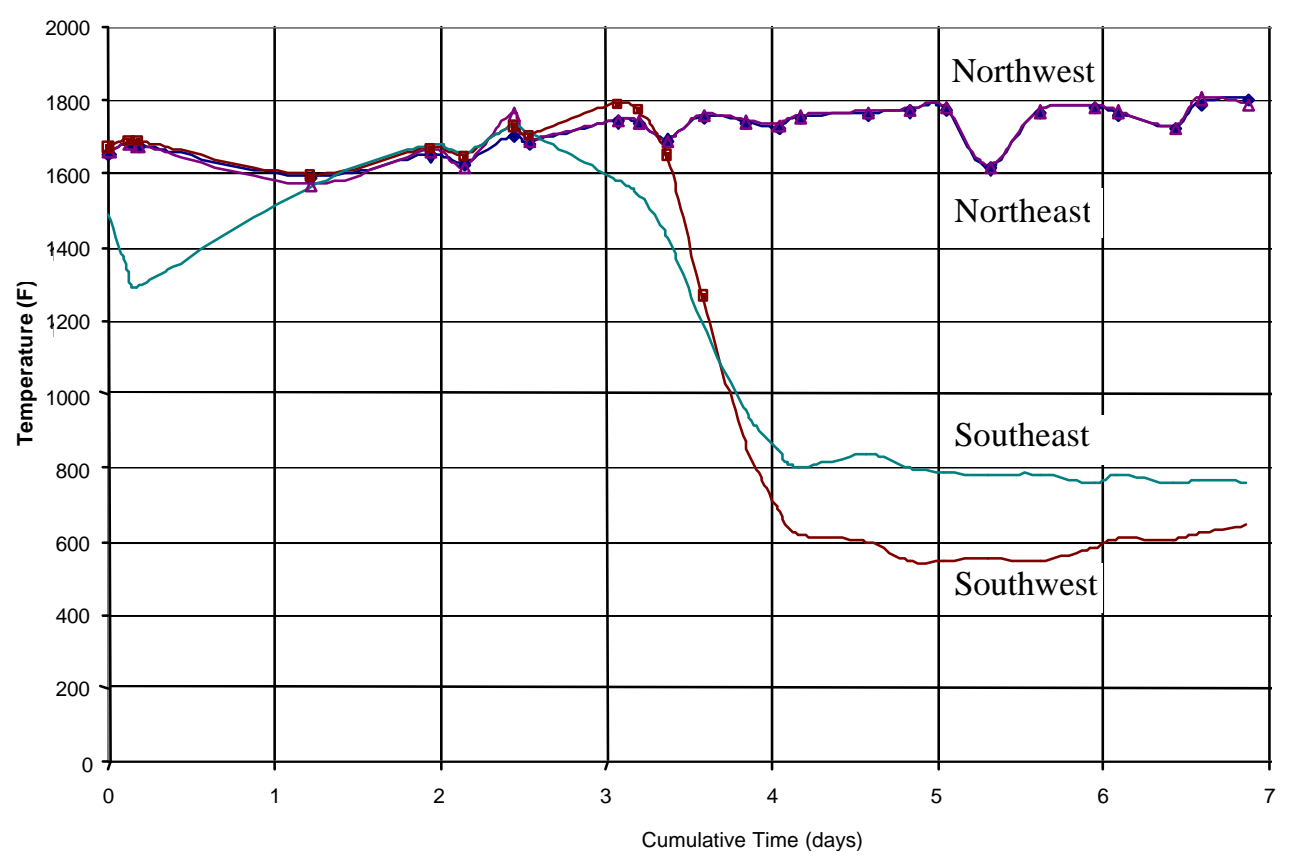

Figure 5.5-5: MBHE Solids Inlet Temperature History

Based on the limited exposure time, it was decided not to take the materials probe apart at this time for metallurgical examination. The probe has been placed into storage and will be reinserted into the MBHE for the next MTF test campaign to allow it to accumulate additional operating time at the proper exposure temperatures. The probe will then be removed for complete examination and analysis. 


\subsection{DATA ANALYSIS}

The objective of this task was to review and analyze the results of the three MTF test campaigns. The analysis covered the areas of heat transfer, combustion performance, emissions, transport system performance, and transient response to a loss of coolant.

\subsection{Gas-to-Solids Heat Transfer}

A major objective of the CMB Proof of Concept tests in the MTF was to evaluate gas-tosolids heat transfer. In fact, the objective of the first test campaign in February 2002 was to evaluate gas-to-solids heat transfer and mixing. Tests were conducted with warm air, natural gas firing, and then coal firing The warm air and natural gas fired tests simplified the gas-tosolids heat transfer analysis by eliminating the effects of ash properties on heat transfer.

\section{February 2002 Results}

Figure 6.1-1 shows an example of some of the data that was collected during the natural gasfired portion of this test program. The top six trend lines (red, orange, yellow, green, light blue, blue) show the gas temperatures measured at the centerline of the combustor at elevations from $5.5 \mathrm{~m}(18 \mathrm{ft})$ to the combustor outlet $(19.5 \mathrm{~m} / 64 \mathrm{ft})$. The bottom orange trend line shows the solids inlet temperature as they were introduced into the top of the combustor. This figure illustrates how effectively the gas was cooled by the falling solids as the gas rose through the combustor. Parametric variations were made with gas flow rates, solids flow rates, gas inlet temperature, and particle size. Some internal mixing grids were also tested to observe their impact on the degree of gas/solid mixing and heat transfer.

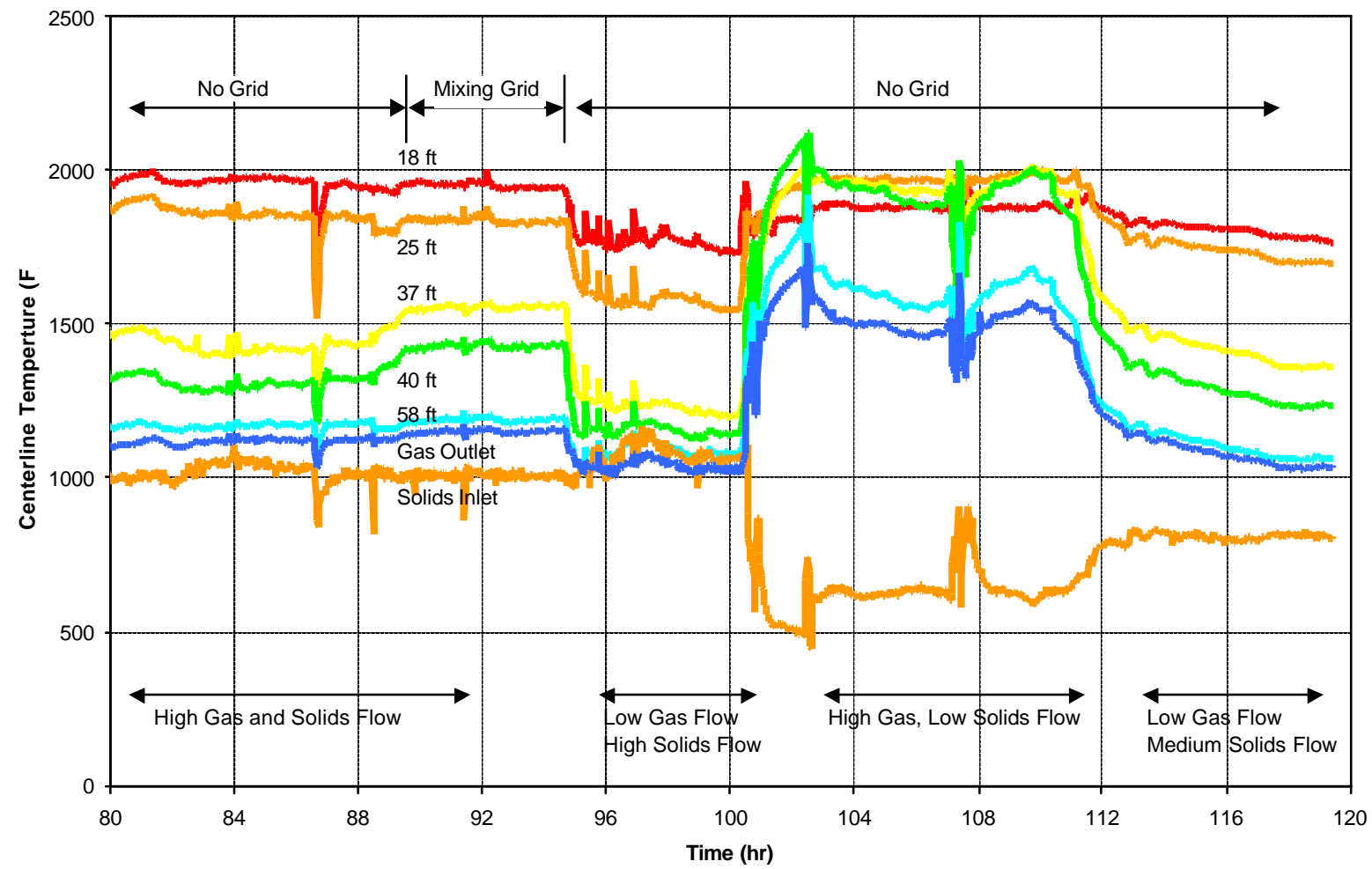

Figure 6.1-1: Combustor Temperature Profiles During Natural Gas-Fired Tests 
The temperature measurements showed that the gas and solids flow distribution was relatively uniform throughout the combustor. Thermocouple rakes installed in the combustor indicated that a relatively uniform gas profile existed at each elevation. Traverse probes used to measure the radial temperature variation of the gas and solids indicated uniform distributions. The gas temperature distribution also indicated that the solids distributor at the top of the combustor worked well.

The distribution of solids raining down in the combustor was indirectly evaluated by the gas temperature distribution. Uneven solids distribution would cause uneven gas temperature distributions. Thermocouple rakes were installed at selected elevations to measure the gas temperature distribution. A typical radial gas temperature distribution taken in an east-west orientation is shown in Figure 6.1-2 for a test condition on February 21, 2002.

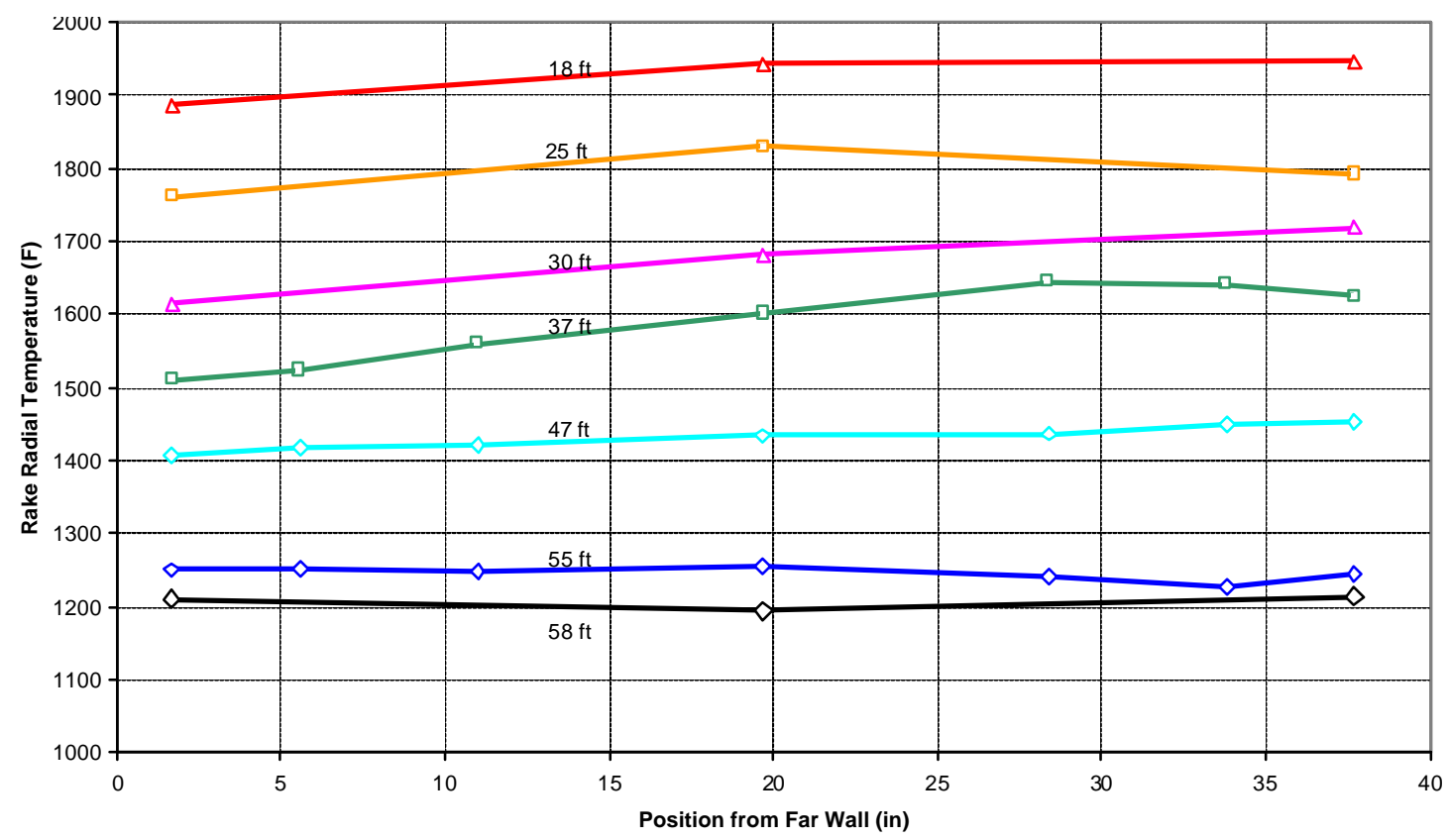

Figure 6.1-2: Combustor Radial Temperature Profile

The axial distribution of centerline temperatures for each rake is shown in Figure 6.1-3 for the same time period. This test was for a 1.8:1 solids-to-gas loading that caused the gas temperature to have a steeper gradient than the solids. The red trend line shows the measured gas temperature along the combustor centerline. The blue trend line represents the calculated solids temperature at each elevation based on the heat transferred from the gas. The initial peak in the gas temperature was due to the burnout of the natural gas in the lower combustor. The profile indicates that all combustion took place before the $25 \mathrm{ft}$ elevation. Any change in solids temperature beyond this point was attributed to heat transfer from the hot gases to the cooler solids. 


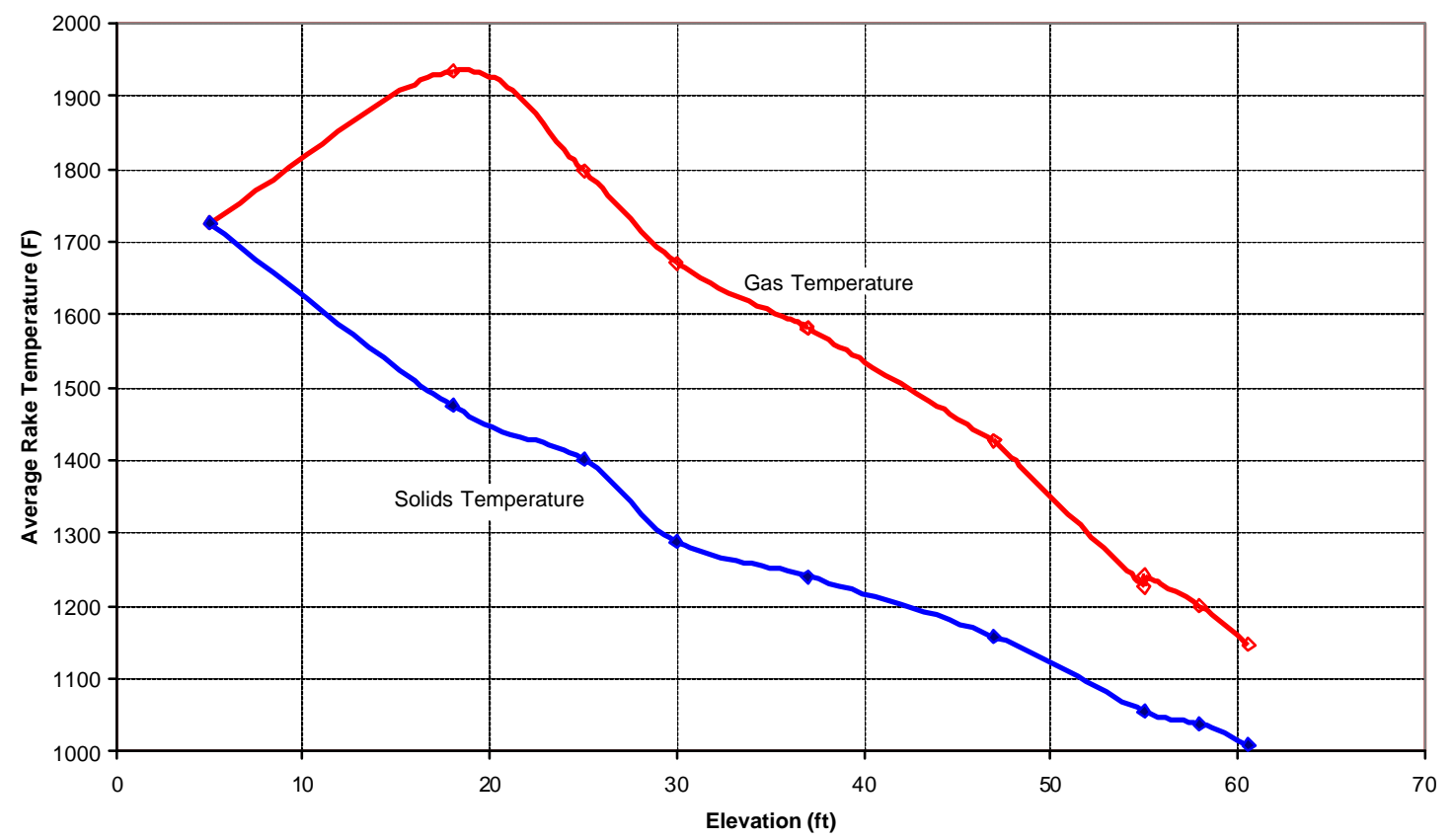

Figure 6.1-3: Combustor Axial Temperature Profile

\section{September 2002 and February 2003 Results}

The September 2002 test campaign was primarily focused on CMB combustion and emission characterization. The February 2003 test campaign was focused on moving bed heat transfer, agglomeration, and emission performance. Heat transfer to the bauxite raining down the combustor was of secondary importance during this test campaign. Nevertheless, valuable heat transfer data was gathered in parallel with all of the other test activities. Included in the combustion tests was introduction of the cyclone ash recycle at different elevations, different fuel and ash conditions, bauxite agglomeration effects, and different staging of the secondary air introduction. These variables influenced the gas temperature profile in the combustor and the subsequent heat transfer along the combustor length.

The September test series had a water-cooled dipleg below the main cyclone that was used to determine cyclone ash recycle ash flow by a cooling water heat balance. The February test series had an uncooled dipleg and the recirculated ash flow had to be determined by isokinetic samples from the cyclone inlet duct. The initial three tests had gas firing in the combustor and no ash recirculation. Results of these tests matched the performance of earlier gas fired tests.

Figure 6.1-4 shows a typical combustor temperature profile for a test in February 2003. The top and bottom red trend lines are the average bed and combustor outlet gas temperatures, respectively. The bottom tan line is the bauxite temperature at the top of the combustor. The other trend lines represent the gas temperature as the gas rose up the combustor and was cooled by the falling bauxite. 


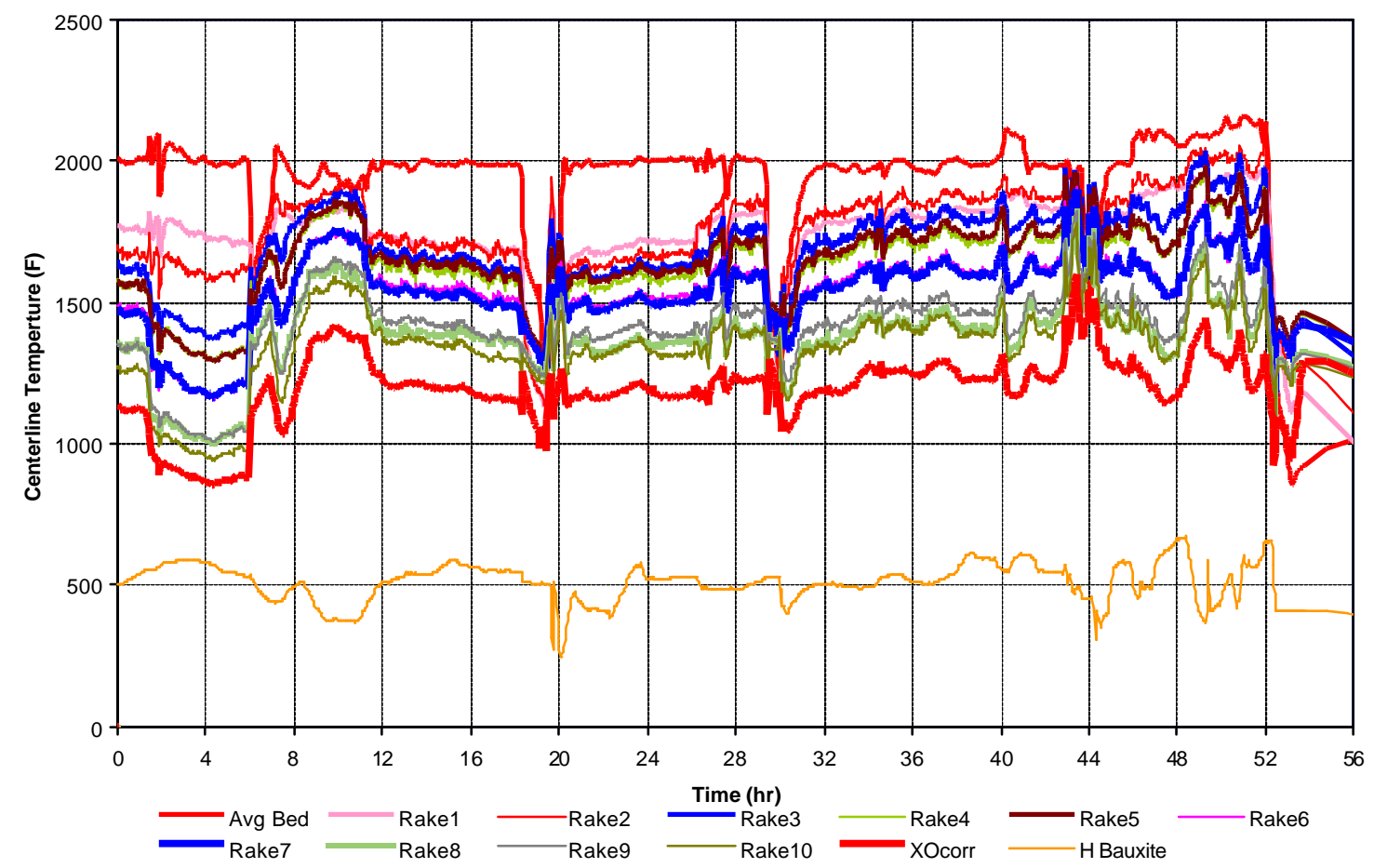

Figure 6.1-4: Combustor Temperature Profile in February 2003 Test

The effect of gas flow rate on the total heat transferred from the gas to the falling solids is shown in Figure 6.1-5. This figure shows that the heat flow increased with gas velocity as expected. The solid orange and red triangles include the results from the warm air and natural gas fired tests, respectively. The trend line represents a best fit through this data only. The open red triangles includes some additional gas-fired operation in December. The remaining data points are all from coal-fired operation. The black triangles, green diamonds, and blue circles were from the coal-fired tests in February 2002, September 2002, and February 2003, respectively.

The coal points in this figure are consistently higher than the gas and warm air trend line. The main difference between these tests and the previous tests was the presence of ash particles entrained in the gas stream during the coal-fired tests. The highest points in this figure were from the February 2003 test series, which had the highest cyclone ash recycle rate. 


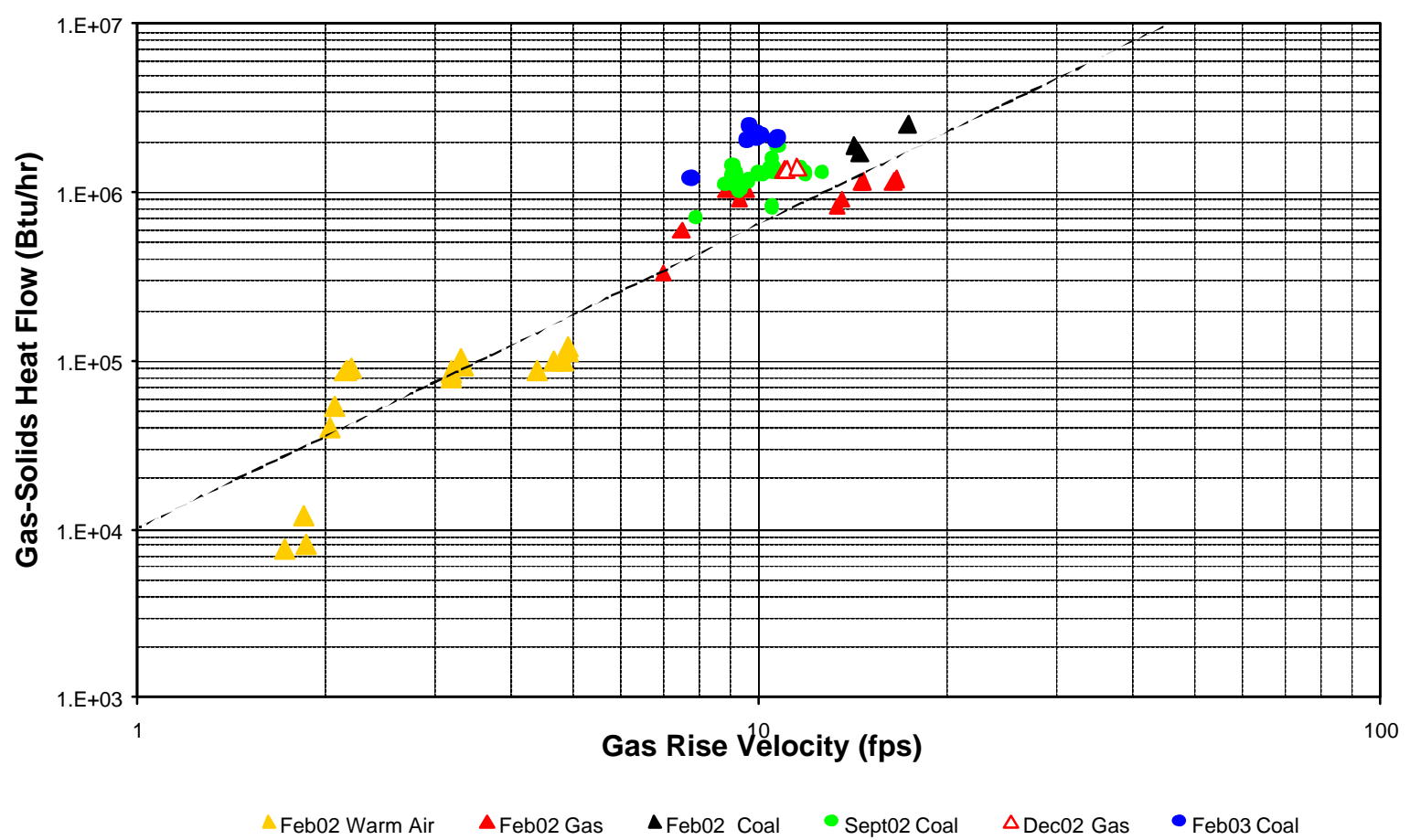

Figure 6.1-5: Heat Flow vs. Gas Velocity

Figure 6.1-6 shows another combustor temperature profile from the September test series. The gas temperatures, particularly in the upper combustor, were slowly increasing over most of this test period.

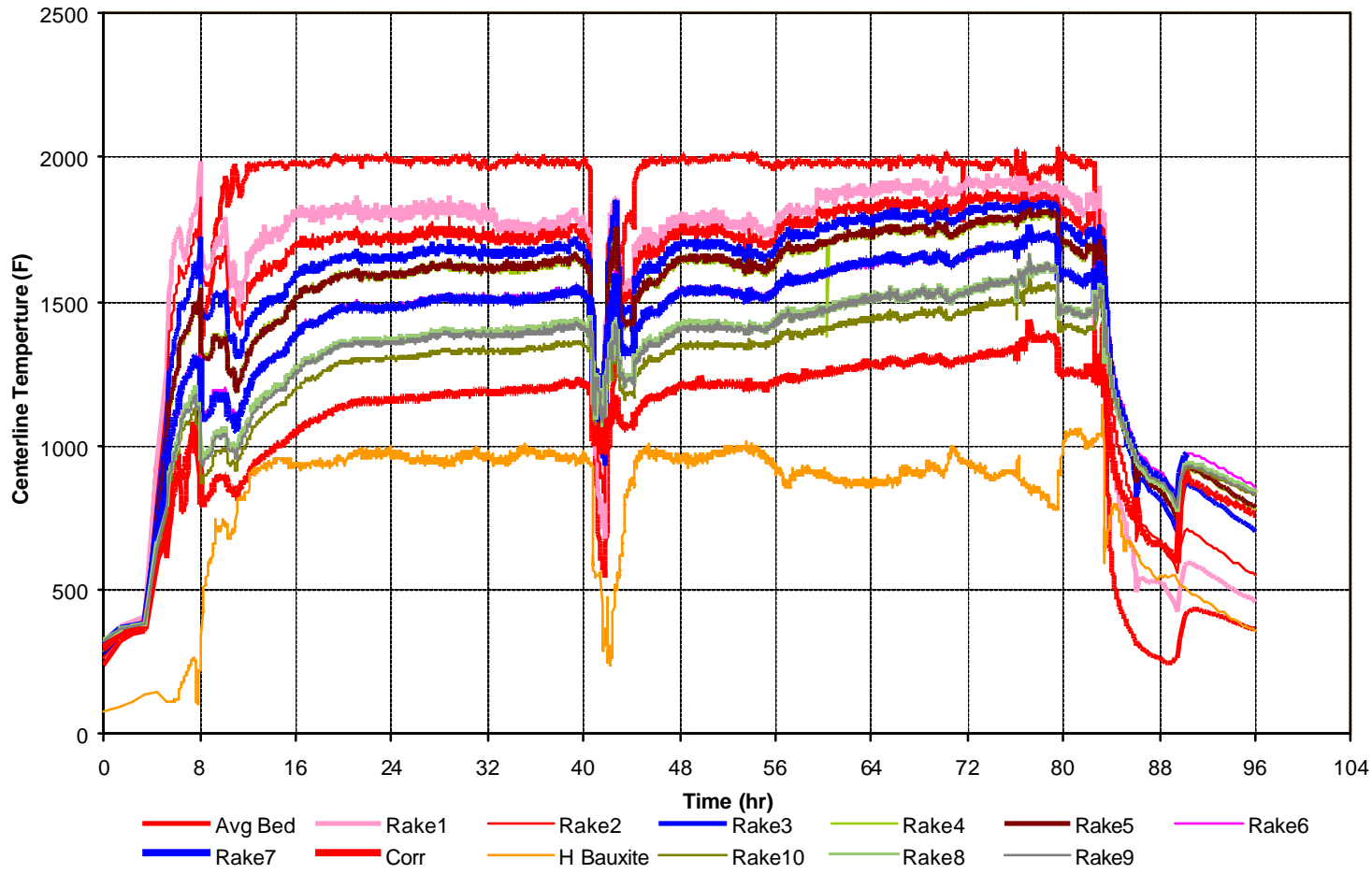

Figure 6.1-6: Combustor Temperature Profile With Increasing Recycle Solids Rate 
Figure 6.1-7 shows some additional trend lines from this same test period. The total gas flow (blue) was constant during most of this test. The bauxite flow (black) was also held constant for the first half of the test period and was then reduced. However, the cyclone ash recycle rate (red) was increasing throughout the test period and was only stable for a short period between hours 48 to 54. Notice in Figure 6.1-6 that this time period was the only time when all of the combustor gas temperature trend lines were constant. The recycle ash mass flow was a significant amount of mass flow compared to the gas mass flow. This was an important consideration, since the bauxite solids had to recover the energy from both the rising combustion gases and recycle ash solids. These figures show the importance of accounting for the recycle ash solids when assessing gas-to-solids heat transfer.

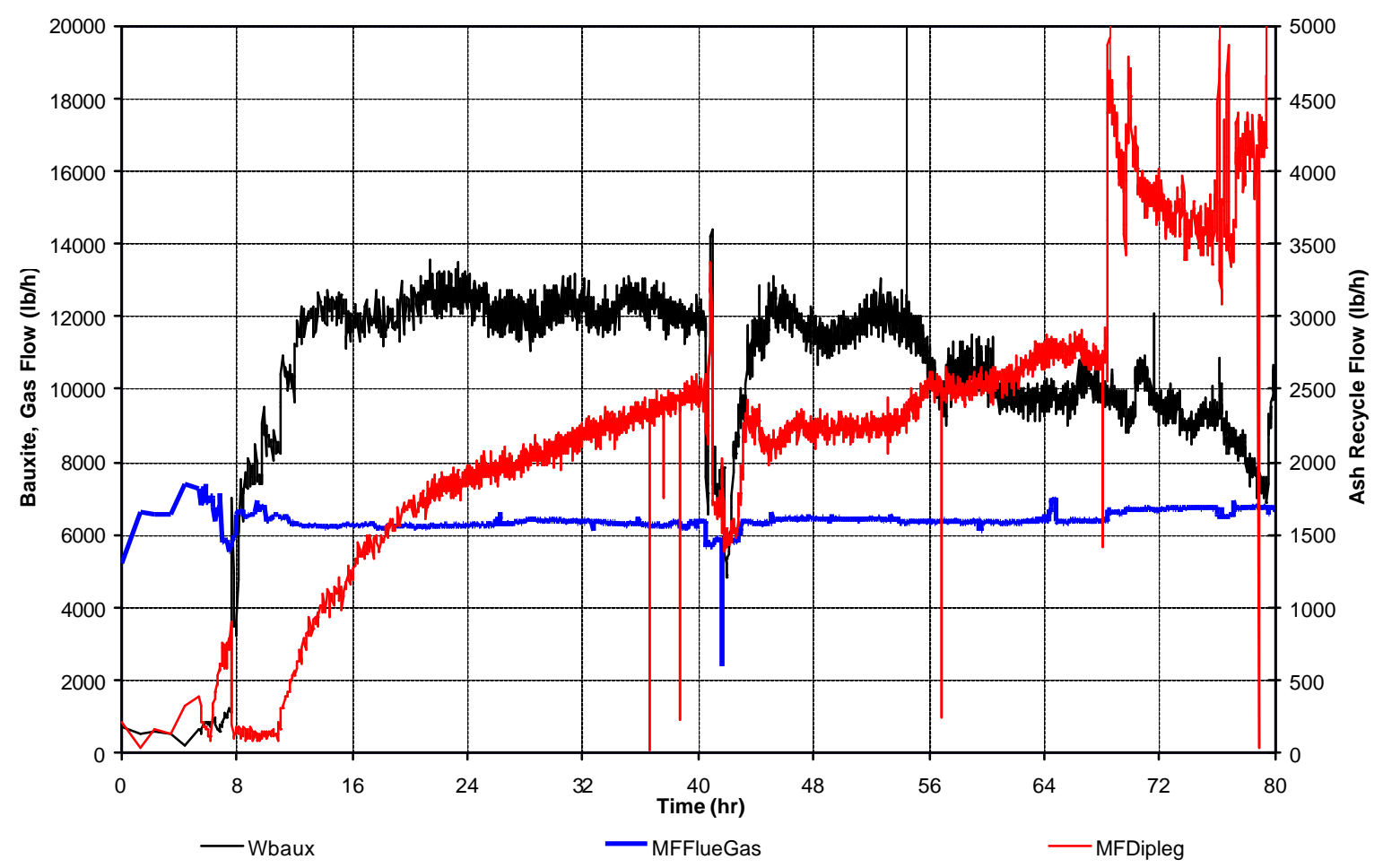

Figure 6.1-7: Cyclone Ash Recycle Flow Rate During September Test

\section{Mixing Grids}

A set of tests was run during the warm air tests in February 2002 to determine the effect of the mixing grids on the solids distribution and heat transfer. The test was initially conducted with two mixing grids in place and then the test was repeated with the mixing grids removed. The solids flow was measured with a solids extraction sampling probe at several radial locations. The mixing grids reduced the radial variation of the solids extraction sample weights. However, there was no noticeable change in the combustor gas temperature profiles with or without the mixing grids. These results showed that the solids distribution was already fairly uniform throughout the MTF combustor and mixing grids were not necessary at the MTF scale. 


\section{Gas-to-Solids Heat Transfer Coefficients}

The heat transfer coefficient between the gas and bauxite particle surface was calculated from the total heat flow from the gas to the solids $(\mathrm{Q})$, the surface area of the solid particles in the combustor $\left(\mathrm{A}_{\mathrm{p}}\right)$, and the Log Mean Temperature Difference between particles and gas. The heat transfer coefficient was determined from the equation:

$\mathrm{h}=\mathrm{Q} / \mathrm{A}_{\mathrm{p}} / \mathrm{LMTD}$

where:

$\mathrm{h}=$ gas-to-solid heat transfer coefficient

$\mathrm{Q}=$ heat transfer from gas to particles

$\mathrm{A}_{\mathrm{p}}=$ particle surface area

$\mathrm{LMTD}=\log$ mean temperature difference (based on bulk gas temperatures)

The heat flow Q was calculated by energy balance that considered the heat given up by the gas and also accounted for any system heat losses. The surface area $A_{0}$ was determined by calculating the solids terminal velocity and then subtracting the average gas rise velocity to obtain the solids migration velocity. The solids flow rate, combustor cross-sectional flow area, and the migration velocity was then used to calculate a solids cloud density. This density was then used to calculate the surface area of the solids in the combustor:

A particle radiation heat transfer coefficient was also calculated for the coal fired tests because of the appreciable amount of ash particles traveling upward with the gas. These particles emitted radiation to the bauxite particles. A radiation heat transfer coefficient was calculated for radiation with an emissivity of 0.4 applied to the bauxite. This radiation heat transfer coefficient was then subtracted from the total heat transfer coefficient for the coalfired tests, leaving the convective heat transfer coefficient.

The convective surface heat transfer coefficient is usually expressed in a dimensionless Nusselt number which in turn is expressed as a function of Reynolds Number:

$\mathrm{Nu}=\mathrm{h} * \mathrm{D}_{\mathrm{p}} / \mathrm{k}$

where:

$\mathrm{Nu}=$ Nusselt number

$\mathrm{h}=$ Surface Convective Heat Transfer Coefficient $(\mathrm{Btu} / \mathrm{hr} / \mathrm{ft} 2 / \mathrm{F})$

$\mathrm{D}_{\mathrm{p}}=$ Particle Diameter (ft)

$\mathrm{k}=$ Thermal Conductivity of Gas $(\mathrm{Btu} / \mathrm{hr} / \mathrm{ft} / \mathrm{F})$

The Nusselt Number is related to the particle velocity as a function of the dimensionless Reynolds number. For this application the Reynolds Number was based on the particle migration velocity down the combustor. The recycle ash flow had a clear effect on heat transfer and was therefore treated as a pseudo gas stream in the Reynolds Number. The heat transfer results from the MTF test campaigns are summarized in Figure 6.1-8 as a 
dimensionless Nusselt Number vs. Solids Migration Reynolds Number. The theoretical heat transfer coefficient for a single spherical particle falling through a gas stream is also represented in this figure as a dashed blue line.

This figure shows that the single particle correlation did not fit the data very well, particularly at low migration Reynolds Numbers or high gas velocities. The single particle correlation assumes that the particles fall freely in the gas with a relative velocity between the gas and particle equal to the particle terminal velocity. Changes in gas velocity should not affect the relative velocity or the heat transfer coefficient. However, the data indicated a reduction in heat transfer coefficient with increasing gas velocity and decreasing migration velocity. As the migration velocity decreased, the particle density increased because of reduced velocity and at a fixed mass flow. This density increase caused more interactions between particles. Particles in close proximity had a tendency to follow in each other's wake due to a drag reduction phenomena. Particles following a lead particle were exposed to gas cooled by the lead particle, and therefore did not have the full gas-particle temperature difference available to the lead particle. This accounted for the reduction in the Nusselt Number at high gas velocities or at low migration Reynolds Number.

At very low gas velocities, the downward velocity of the particles relative to the ground (i.e. $\mathrm{V}_{\text {term }}$ minus $\mathrm{V}_{\text {gas }}$ ) was close to the terminal velocity. There was little solids holdup and not many particle interactions. For these cases, the observed solid-to-gas heat transfer coefficient was close to the theoretical value prediction.

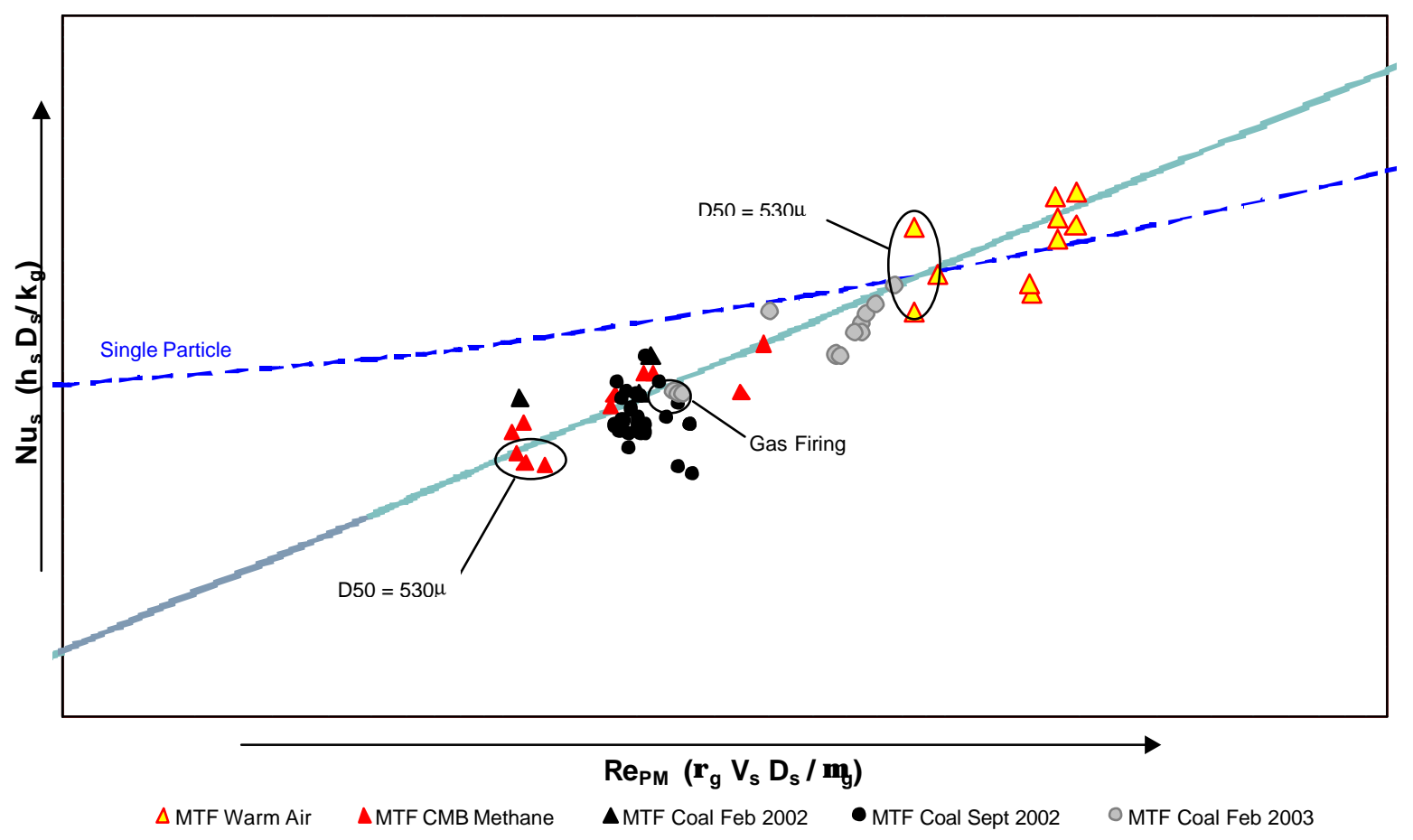

Figure 6.1-8: Nusselt Number vs. Reynolds Number

Figure 6.1-8 also shows a few test points that were conducted with a finer size of bauxite. The average bauxite size was 530 microns for these tests compared with the typical 700- 
micron size bauxite used for most of the tests. This was not a wide enough variation in size to see a noticeable performance difference during the tests. The total heat flow during these tests was unchanged between the two sizes of bauxite. The bauxite flow rate was maintained constant. The smaller bauxite particle size for the same mass flow resulted in a higher total solids surface area. The heat transfer coefficient therefore had to be less since the total heat transfer remained the same. Figure 6.1-8 shows that the test points with the finer bauxite particles fall within the bulk of the test results. 


\subsection{Moving Bed Heat Transfer}

A major objective of the final CMB test campaign was to evaluate solids-to-tube heat transfer coefficients in the moving bed heat exchanger. A preliminary heat transfer model was developed prior to this program based on moving bed heat exchanger tests with an in-line tube bundle and with fluidized bed ash material as the heat transfer media. The MBHE design was refined in this test campaign with a staggered tube array and used bauxite as the heat transfer media. The heat exchanger was tested over several operating periods, with solids inlet temperatures to the heat exchanger ranging from $1620^{\circ} \mathrm{F}-1800^{\circ} \mathrm{F}$. The solids flow rates ranged from 5,200 to $19,300 \mathrm{lb} / \mathrm{hr}$ during these periods.

\section{Results}

The test series were conducted with the data acquisition system recording data every 3 minutes. The test data was imported into a preliminary analysis spreadsheet and plotted in a series of charts of solids temperatures, solids flow rates, heat flow, and coolant temperatures to determine periods of steady state operation. Once the steady state conditions were determined, average values of each instrument measurement were calculated for a period of 30 minutes or ten measurement readings. Figure 6.2-1 shows a typical set of solids temperatures in the MBHE starting on February 19, 2003. The four highest trend lines represent the 4 temperatures at the top of the MBHE (TE1017-TE1020). The remaining 16 trend lines are the solids temperature measurements located just above each of the 16 solid outlet distributor openings at the bottom of the MBHE.

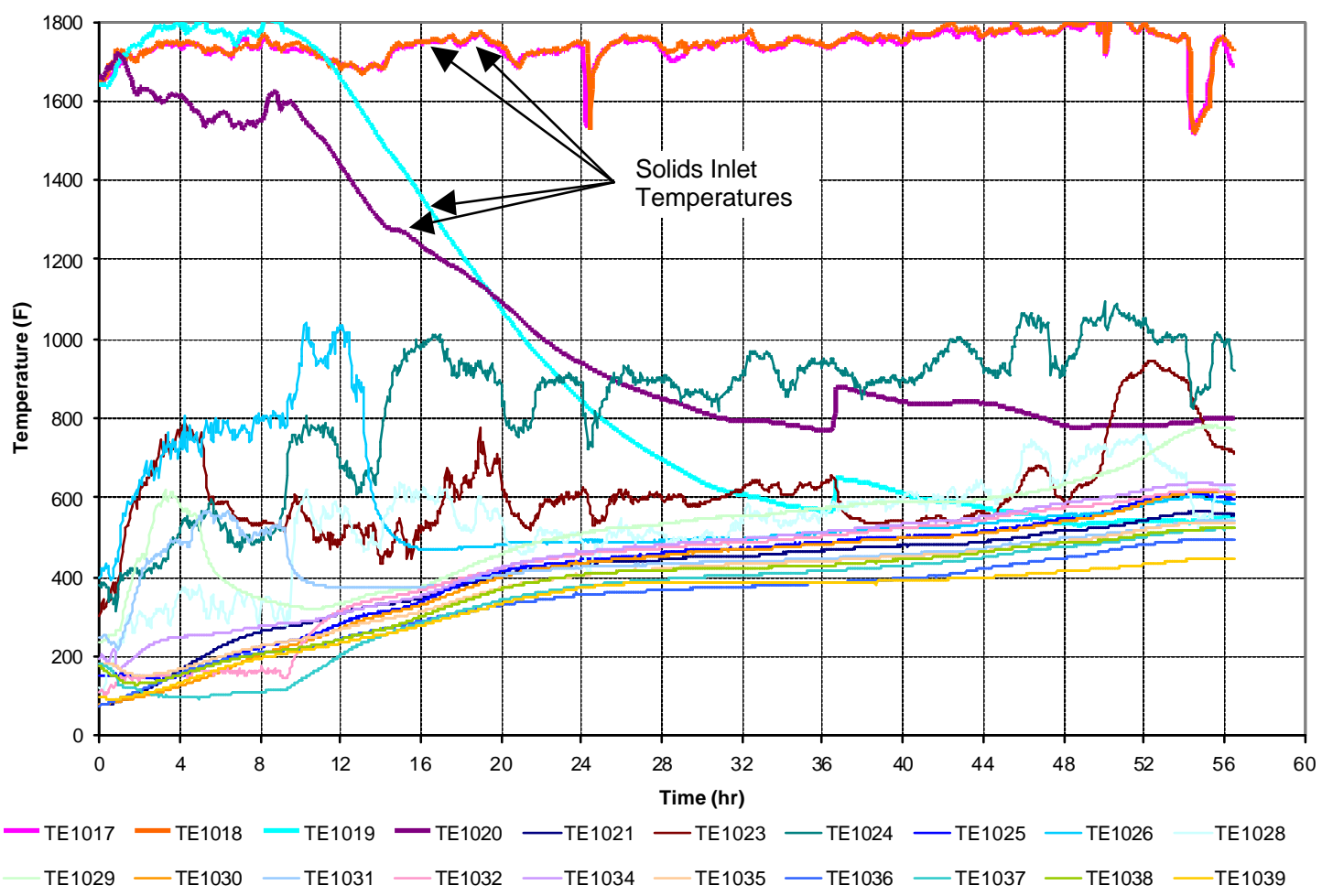

Figure 6.2-1: MBHE Solids Temperatures for Typical Test Condition

Figure 6.2-1 also shows an example of solids maldistribution in the MBHE. This was indicated by the dropoff in the solids inlet temperature after 10 hours of operation. A description of the different thermocouples shown in this figure is provided in Table 6.2-1. 
Table 6.2-1: Identification of MBHE Thermocouples

$\begin{array}{llc}\text { Tag \# } & \text { Description } & \text { Units } \\ & & \text { " H2O guage } \\ \text { PT4475 } & \text { MBHX Top Pressure } & { }^{\circ} \mathrm{F} \\ \text { TE1072 } & \text { MBHX Gas Outlet Temperature } & { }^{\circ} \mathrm{F} \\ \text { TE1017 } & \text { Top TC 1 (NW) } & { }^{\circ} \mathrm{F} \\ \text { TE1018 } & \text { Top TC 2 (NE) } & { }^{\circ} \mathrm{F} \\ \text { TE1019 } & \text { Top TC 3 (SW) } & { }^{\circ} \mathrm{F} \\ \text { TE1020 } & \text { Top TC 4 (SE) } & { }^{\circ} \mathrm{F} \\ \text { TE1021 } & \text { Bottom TC 1,1 (NW) } & { }^{\circ} \mathrm{F} \\ \text { TE1023 } & \text { Bottom TC 1,2 } & { }^{\circ} \mathrm{F} \\ \text { TE1024 } & \text { Bottom TC 1,3 } & { }^{\circ} \mathrm{F} \\ \text { TE1025 } & \text { Bottom TC 1,4 (NE) } & { }^{\circ} \mathrm{F} \\ \text { TE1026 } & \text { Bottom TC 2,1 } & { }^{\circ} \mathrm{F} \\ \text { TE1028 } & \text { Bottom TC 2,2 } & { }^{\circ} \mathrm{F} \\ \text { TE1029 } & \text { Bottom TC 2,3 } & { }^{\circ} \mathrm{F} \\ \text { TE1030 } & \text { Bottom TC 2,4 } & { }^{\circ} \mathrm{F} \\ \text { TE1031 } & \text { Bottom TC 3,1 } & { }^{\circ} \mathrm{F} \\ \text { TE1032 } & \text { Bottom TC 3,2 } & { }^{\circ} \mathrm{F} \\ \text { TE1034 } & \text { Bottom TC 3,3 } & { }^{\circ} \mathrm{F} \\ \text { TE1035 } & \text { Bottom TC 3,4 } & { }^{\circ} \mathrm{F} \\ \text { TE1036 } & \text { Bottom TC 4,1 (SW) } & { }^{\circ} \mathrm{F} \\ \text { TE1037 } & \text { Bottom TC 4,2 } & { }^{\circ} \mathrm{F} \\ \text { TE1038 } & \text { Bottom TC 4,3 } & { }^{\circ} \mathrm{F} \\ \text { TE1039 } & \text { Bottom TC 4.4 (SE) }\end{array}$

The solids-to-surface heat transfer rate was quite encouraging during the MBHE test program, although the results were affected by blockages in the lower MBHE that caused non-uniform solids flow patterns. Figure 6.2-2 shows the solids inlet temperature measurements at the top of the MBHE. The timeline for this figure (and for the following figures) is based on cumulative days of operation and includes all days the MBHE was in service over several test periods.

This figure shows that the MBHE solids inlet temperature never got above $1800^{\circ} \mathrm{F}$ even though the bed was operating at or above $2000^{\circ} \mathrm{F}$. The water-cooled siphon seal below the combustor absorbed a significant amount of heat from the bauxite particles, which cooled them well below the bed temperature. The Maxon natural gas burner was intended to make up for this heat loss by preheating the transport air in the bauxite transport line. Unfortunately, refractory problems with the burner box casing limited preheating the transport air to about $1800^{\circ} \mathrm{F}$.

Figure 6.2-2 also shows that nonuniform solids distribution through the MBHE affected the solids inlet temperatures. This issue became very pronounced after the outlet size area of the lower solids distribution grid was increased (about day 3 in Figure 6.2-2). This modification was made just before the third operational period to prevent blockage of the MBHE outlet hoppers by refractory pieces that had spalled off from the MBHE cyclone. The flow maldistribution stemmed from blockage on the south outlet side of the MBHE and extended all the way up to the top of the MBHE. Note that the tan box in this figure shows the orientation of the four thermocouples at the MBHE solids inlet. 


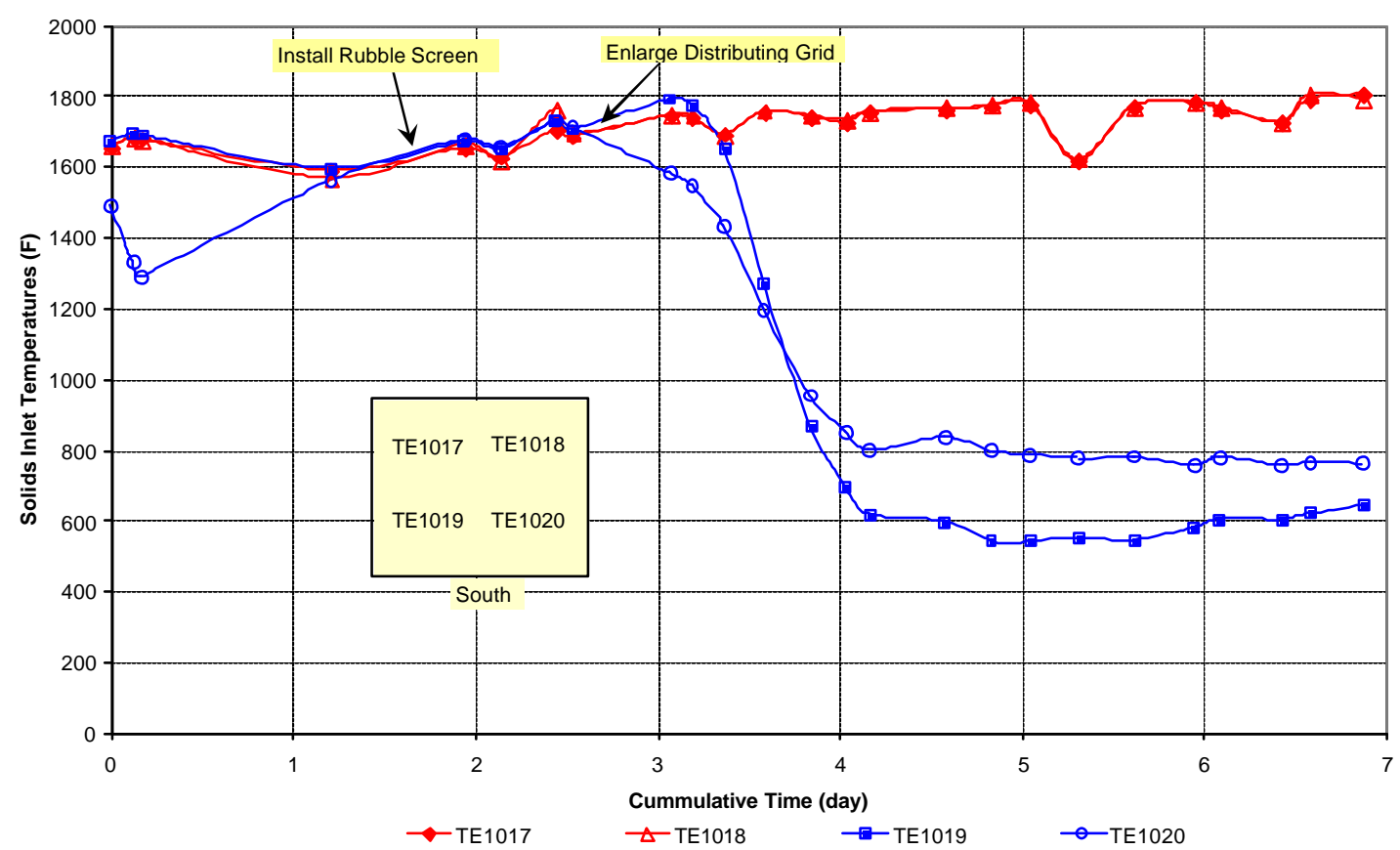

Figure 6.2-2: MBHE Solids Inlet Temperatures

Figure 6.2-3 shows the same trends for the MBHE solids outlet thermocouples over the duration of the test campaign. The tan box shows the orientation for some of the thermocouples at the MBHE solids outlet. The temperature measurements on the south side of the MBHE tended to be lower than average and very unresponsive, indicative of being in a slow or non-moving region of solids. The highest temperature measurements were on the north side and center where most of the solids flow was occurring.

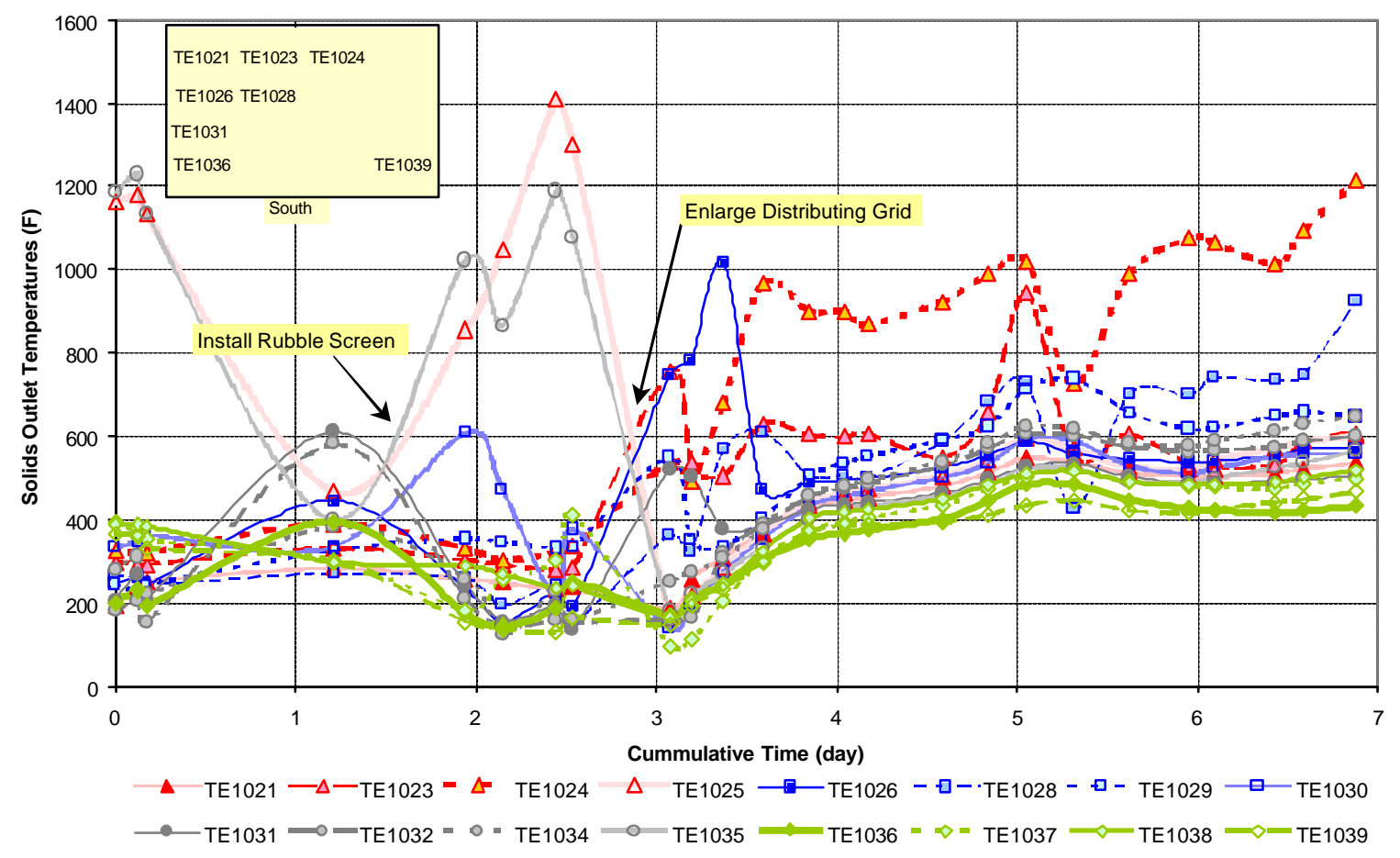

Figure 6.2-3: MBHE Solids Outlet Temperatures 
Figure 6.2-4 shows the MBHE cooling water outlet temperatures for the top two bundles over the test period. The water entered at the bottom center of each bundle and exited at the top of the bundle on both the west and east sides. In the initial operating period, the bottom east side of the MBHE was plugged with refractory rubble from the refractory-lined transport line. The cooling water outlet temperatures for the top two bundles were much hotter on the west side (TE1081 and TE1079) during the first two days of operation than on the east side. This was because the solids were preferentially flowing through the MBHE along the west side. The rubble screen was installed above the MBHE outlet distributor at this point to prevent this pluggage. The trends show that the solids flow was still biased on one side for periods of time during the remaining operation.

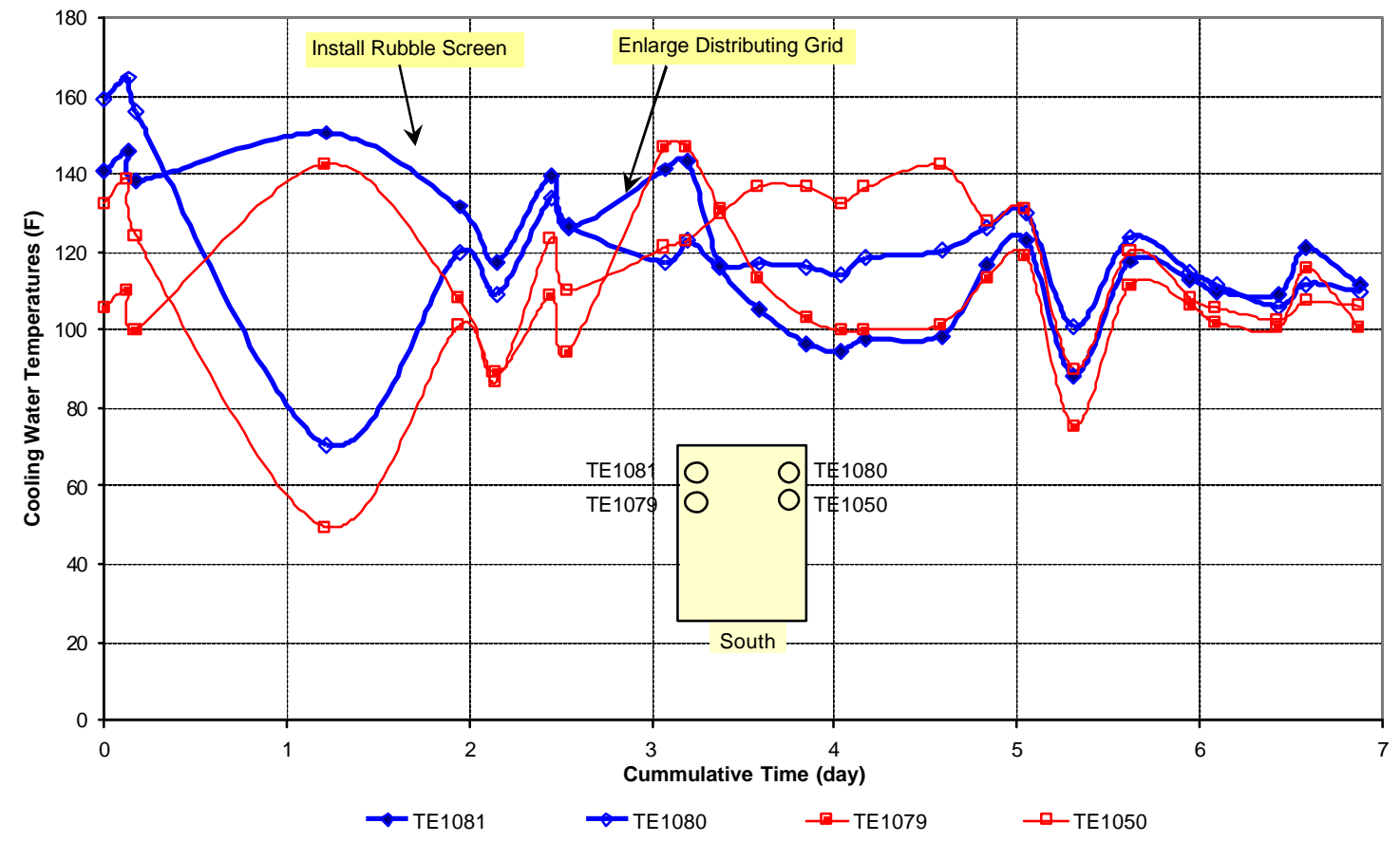

Figure 6.2-4: MBHE Cooling Water Outlet Temperatures

\section{Heat Transfer Results}

ALSTOM Power's MBHE design spreadsheets that were developed through a previous program were used to design the MBHE for the MTF modifications. Derivatives of the same spreadsheets were also used to calculate predicted solids side heat transfer coefficients for the bundles at each MTF test condition. This gave a predicted heat flow for the tube bundles that could be compared with the measured bundle heat flow. The measured solids inlet temperatures, coolant inlet temperatures, solids flow rate, and coolant flow rates were input as fixed values for these calculations. The solids side heat transfer coefficients were iterated until the solids temperature difference, solids heat flow, and the surface heat transfer heat flow matched the measured data.

Figure 6.2-5 compares the ratio of the measured vs. the predicted heat flow for the top three MBHE tube bundles over the duration of the test period. The measured heat flows for the top tube bundle averaged $60 \%$ higher than predicted for the initial MBHE operation. After the bottom of the distributing grid was enlarged, the performance started at the $60 \%$ 
improvement value but then started to slowly deteriorate. This same trend is shown by the solids inlet temperatures in Figure 6.2-2. The heat transfer performance for the lower tube bundles was not as good as the top bundle. The second bundle had an initial 20\% higher rate than predicted (after the distributing grid was enlarged) and the bottom bundle matched the predicted rate.

The top tube bundle always had higher heat transfer performance than the lower bundles. This phenomena was also observed in tube bundle test results by Jörg Niegsch ${ }^{1}$ However, the magnitude of the difference between bundles for this test was probably caused by maldistribution of the solids flowing through the distributing grid at the bottom of the heat exchanger. The bauxite was free flowing, but rubble in the grid caused flow interruptions in individual grid locations. The solids flow tended to redistribute at higher elevations in the heat exchanger. The angle of friction for $700 \mu$ bauxite is $55^{\circ}$. Bauxite flows uniformly above this angle. This means that tube bundles located 45 inches above the grid should have relatively uniform flow. Those below will not and will have a degraded heat transfer performance as shown in Figure 6.2-5. Note that even with non-uniform flow conditions, the measured heat flow for the top tube bundle was the same or better than predicted by the design spreadsheet. This is a good indication that the staggered tube arrangement made a significant improvement to the solids to tube heat transfer as compared to the prior results with an in-line tube array.

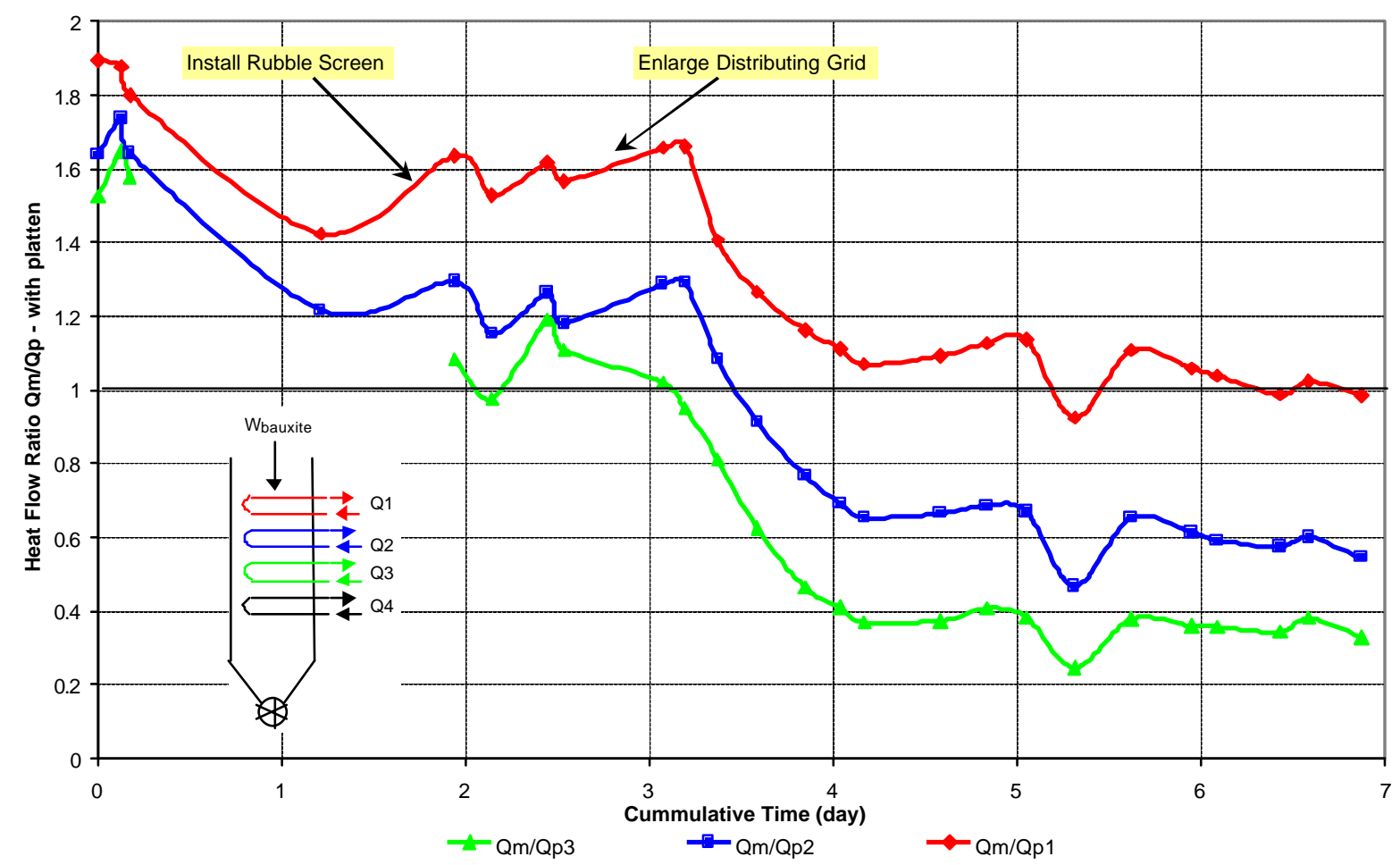

Figure 6.2-5: MBHE Measured vs Predicted Heat Flow

The surface heat transfer coefficients on the fin and tube were iteratively calculated until the measured heat flow of the cooling water matched the surface heat flow based on input data. The results of the fin surface to bauxite heat transfer coefficient are shown in Figure 6.2-6 for 
the top tube bundle. The coefficients are normalized as a bare tube equivalent heat transfer coefficient. This is the coefficient that a bare tube needs to achieve the same heat transfer as a spiral finned tube of the same length. The coefficients were quite high until the solids maldistribution became more pronounced.

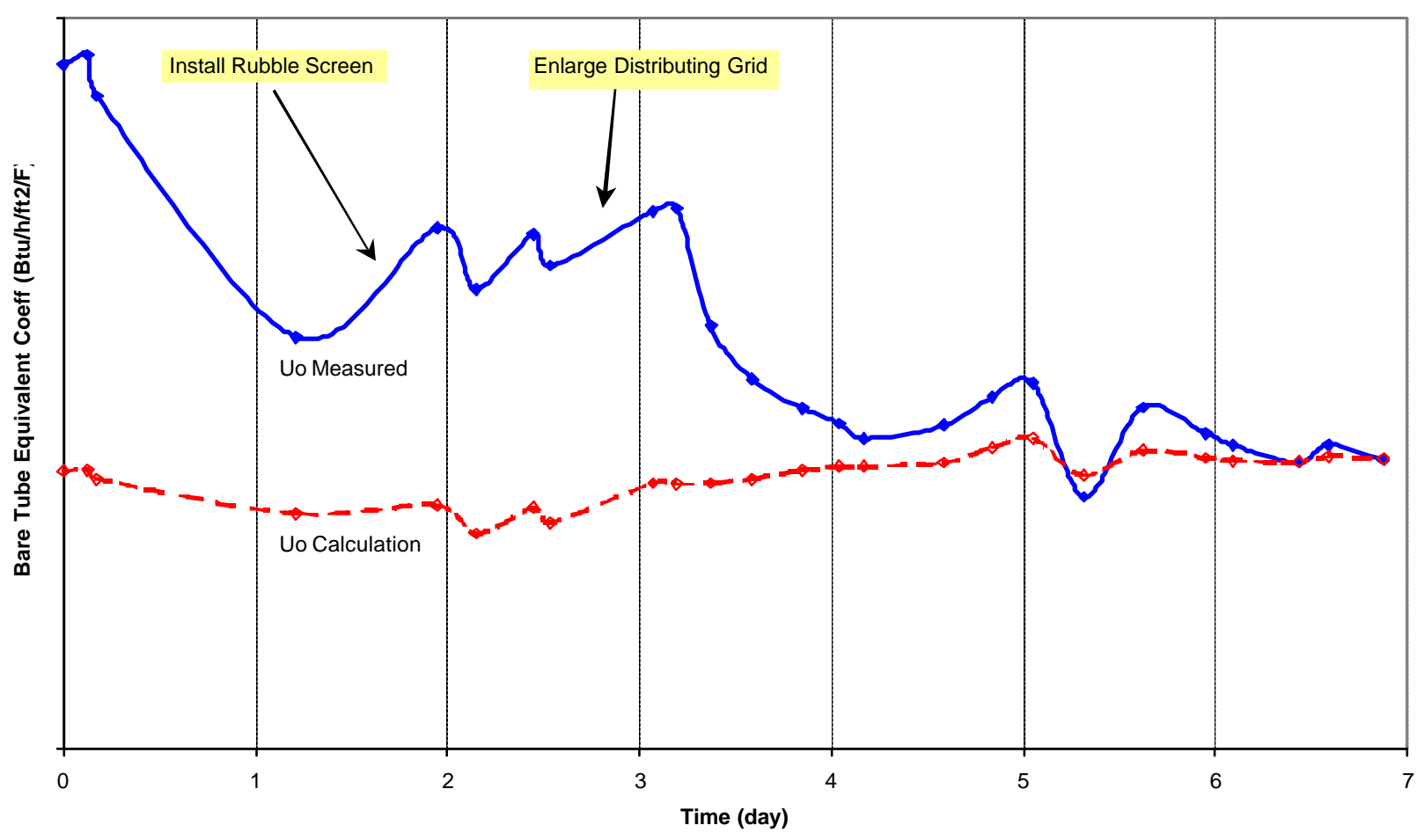

Figure 6.2-6: MBHE Bare Tube Heat Transfer Coefficient - Top Bundle

The bauxite flow distribution within the heat exchanger was not very uniform during some of the operation. Examination of Figures 6.2-5 and 6.2-6 show deteriorated heat flow at day 1.2 and starting at day 3.2. The left and right section outlet coolant temperatures in Figure 6.2-4 shows a significant temperature difference and resulting heat pickup difference in the top bundle. Correspondingly, the solids inlet temperatures shown in Figure 6.2-2 show that the south half of the MBHE had reduced flows at day 3.2. This is also reflected in the top bundle heat flows in Figures 6.2-5 and 6.2-6. Maldistribution of the solids flow indicated by temperatures is reflected in decreased heat flows. The deterioration was also more significant in the lower bundles than the upper bundle as shown in Figure 6.2-5.

Figure 6.2-7 shows the decline in the fin surface heat transfer coefficient for the top tube bundle during three different test periods. The coefficients were highest during the initial test period (red data points) until the MBHE plugged up with refractory rubble. The blue data points show that the heat transfer coefficient was reduced after the perforated screen was added to the bottom of the MBHE to prevent pluggage from any rubble. Finally, the coefficients declined even further in the third operating period (green data points) after the openings in the MBHE outlet distributor were enlarged. The last two modifications actually made the solids flow through the MBHE less uniform than before the changes were made. Note that the tube fins were practically clear of any rocks lodged in the tube fins. The 
deterioration in the heat transfer coefficients was clearly due to solids flow maldistribution and not a physical plugging of the tube bundle fins.

Figure 6.2-7 also shows that the heat transfer coefficient increased with solids flow rate through the MBHE. The rate of increase was higher than observed from the previous test program. It was not clear if the heat transfer coefficients were a stronger function of solids flow rate with the staggered tube bundles than they were with the inline tubes. It was also possible that the solids flow through the MBHE was somewhat more uniform at high solids

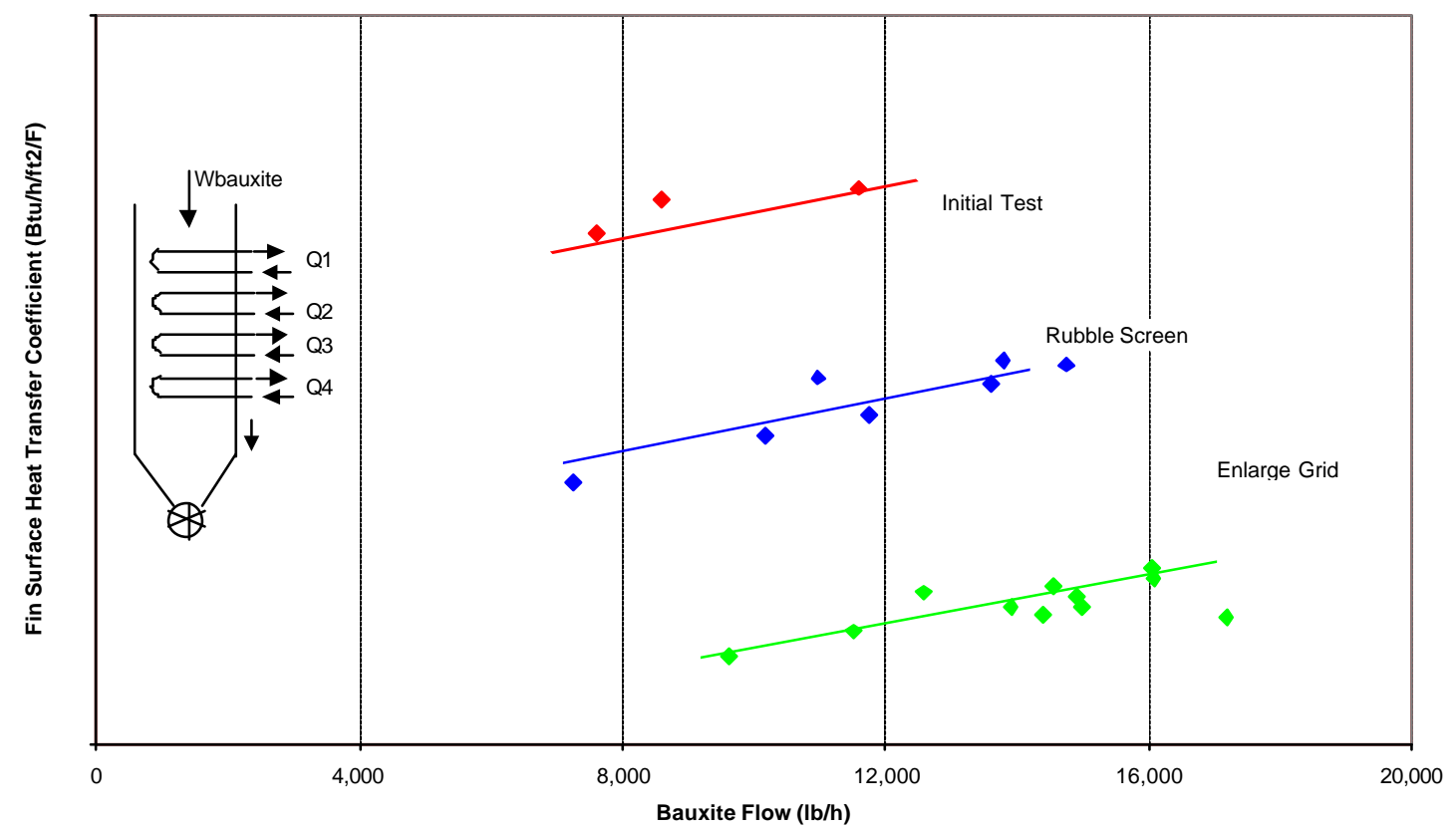

flow rates.

Figure 6.2-7: Effect of Solids Flow on Heat Transfer Coefficients

The solids inlet temperature was only varied over a limited range because of limitations on the burner box casing refractory. Radiation effects were not significant during this test series compared with other variables. The heat transfer coefficients were therefore calculated under the assumption that radiation heat transfer was not a contributing factor. If radiation were significant, the influence at $2000^{\circ} \mathrm{F}$ would be $50 \%$ greater than at $1800^{\circ} \mathrm{F}$.

\section{Summary}

The MBHE test results showed that the performance of the staggered pitch tube bundles exceeded the performance of the previous inline tube bundles by up to $60 \%$. It is possible that the tube bundle performance could have been even higher than observed since the tube bundle showed signs of significant solids flow maldistribution even when the best heat transfer rates were obtained. One promising result was that the tube bundle fins were largely rock-free, with only a few instances of rocks lodged in the fins.

The staggered tube bundle performance can now be predicted by using a significantly reduced allowance for surface shading as compared to the inline tube bundle prediction model. The shading factor accounts for reduced local heat transfer rates in those tube areas where a platen of solids forms between adjacent vertical tubes. The predictive model 
currently does not include any radiation effect, as equipment limitations prevented operation with a high enough solids inlet temperature to evaluate this effect.

It is clear that future work must focus on improving solids flow distribution through the MBHE. The results demonstrated that maldistribution of the solids flow through the tube bundle has a significant influence on performance. The results showed that the solids flow distribution baffle at the bottom of the MBHE provided an acceptable distribution during initial operation and at fixed flows. However, the distribution baffle was susceptible to pluggage by rubble from the refractory liner of the transport system and heat exchanger walls. Enlarging the baffle to pass rubble resulted in poor distribution and reduced heat transfer performance.

The distribution baffle at the bottom of the MBHE needs to be replaced with an improved design. One possible improvement would be to use an active distributing grid. This design would replace the current hopper arrangement with a single layer of small hoppers, each having a pneumatically actuated seal pot at the bottom. A pneumatic control system would sequentially activate hoppers in a logic sequence to ensure uniform flow through the grid and MBHE. Additional cold flow tests are required to refine this concept before it can be implemented. 


\subsection{Agglomeration}

One objective of the CMB test campaigns was to determine the effect of the high bed temperatures on ash agglomeration and ash buildup on the bauxite particles. Bed samples were collected at frequent intervals during the tests to monitor the growth of ash deposits on the bauxite particles. The objective of the last test campaign was to specifically look at the effect of coal properties on ash agglomeration. For this test, Pittsburgh \#8 bituminous coal was selected because it has a very low ash fusion temperature and is known as a bad slagging fuel in certain applications. Selected samples were then sent for scanning electron microscope (SEM) analysis in order to monitor the buildup of ash coating on the bauxite particles.

Agglomeration effects were studied in the second and third MTF test campaigns. The second test campaign (September 2002) was run with a West Virginia bituminous coal for about 150 hours of operation at $2000^{\circ} \mathrm{F}$. The third campaign (February 2003) with Pittsburgh \#8 coal included 110 hours at $2000^{\circ} \mathrm{F}$ or above, with a maximum temperature of $2160^{\circ} \mathrm{F}$. Figure $6.3-1$ summarizes the bed temperature history for the duration of the test campaign with Pittsburgh \#8 coal. The occasional temperature drops (especially after the $70^{\text {th }}$ hour of operation) were caused by momentary fuel disruptions due to wet coal hanging up in the feeder. For comparison, the light blue band in this figure indicates the normal operating temperature range in a conventional CFB boiler.

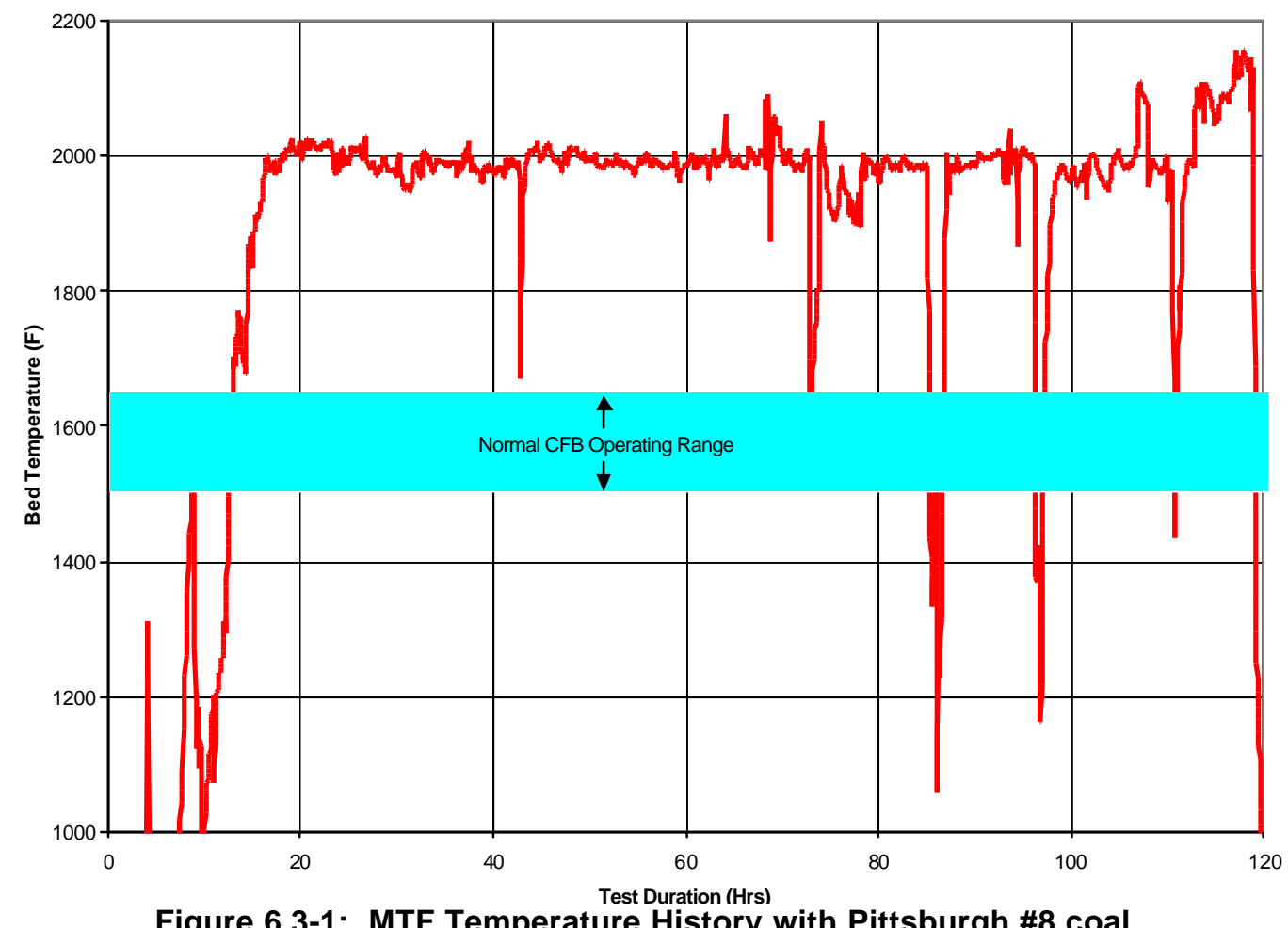

Figure 6.3-1: MTF Temperature History with Pittsburgh \#8 coal

Since there were no signs of any agglomerate formation and the ash coating on the bauxite was not growing rapidly, it was decided to increase the bed temperature during the Pittsburgh \#8 coal tests to see how sensitive the bed conditions were to temperature variations. The temperature was increased to $2100^{\circ} \mathrm{F}$ and held there for 4 hours. It was then further increased to $2160^{\circ} \mathrm{F}$ and held there for an additional 2 hours. No agglomerates were observed as the bed material was drained out of the combustor. 
The local bed ash composition may play a key role in the ash coating growth rate observed on the bauxite particles. The CMB system is designed to operate with a bed that is primarily bauxite. The bed material was not classified during these tests, which allowed rocks and coal ash to build up in the bed and increased the presence of ash constituents that contribute to agglomeration and ash coating growth. The MTF bed drain system was temporarily unavailable, so we could have had an accumulation of rocks and ash in the system. In a prior test with Pittsburgh \#8, we found that the bed composition had changed over a 50 hour test from $100 \%$ bauxite to about $75 \%$ bauxite. A commercial CMB boiler requires a more continuous classification system to maintain a bauxite concentration close to $95 \%$.

A scanning electron microscope was used to analyze polished cross-sections of coated bauxite particles which had been embedded in an epoxy resin. The SEM was a JOEL 840A electron probe microanalyzer with Thermo-NORAN's Vantage microanalysis system. Energy dispersive spectroscopy (EDS) provided quantitative elemental analysis of the coatings, which in turn identified the elements used in the elemental X-ray mapping of several coated samples. Using the Vantage's digital imaging capabilities, backscattered electron images were generated to contrast the coatings from the bauxite substrate. Thickness measurements were made from the coating images using the software's generated measuring capabilities. Thickness measurements were taken at many different locations for each particle, with at least 5 different particles measured for each sample. All of the thickness measurements were then averaged for a composite thickness for that time period.

\section{Ash Coating Growth - West Virginia Coal}

The ash buildup on the bauxite particles was quite varied during the September 2002 test with the West Virginia bituminous coal. Figure 6.3-2 shows the increase in the coating thickness surrounding the bauxite particles over the duration of this test. Also included in blue (data points and trend line) are the results from a previous MTF campaign with the same fuel.

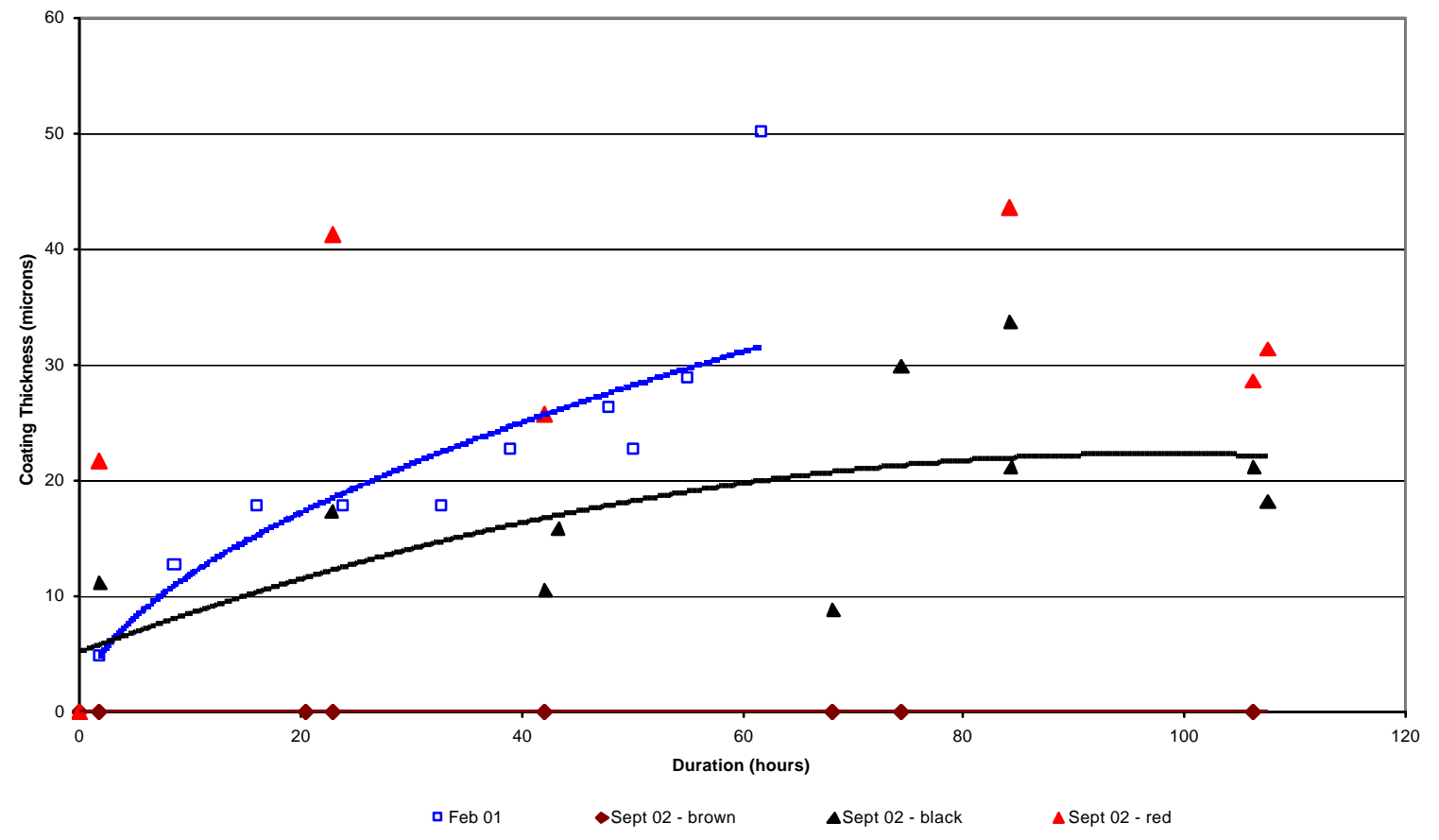

Figure 6.3-2: Bauxite Coating Thickness with West Virginia Coal 
The first thing noticed during this test was that some of the bauxite particles behaved differently than others. The particles seemed to be divided into three distinct groups. The furnace was initially loaded with bauxite that was obtained before this program. This bauxite visually looked black. After running out of this material, we then used some newer bauxite from the same supplier. Although it was the same material, it visually had more of a brownish color. A third group of bauxite particles had a reddish cast to them. These were particles that had been exposed to the bed and had developed a coating that gave them some color.

As shown in Figure 6.3-2, the brownish particles had virtually no coating develop on them over the entire duration of the test campaign. The black particles developed a coating up to around 20 microns. The reddish particles, which were not very abundant, had coatings between 30-40 microns.

Table 6.3-1 shows an EDS analysis of the original brown (divided into light and dark) and the black bauxite particles. The composition for all of the particles was very similar, with about $80 \% \mathrm{Al}_{2} \mathrm{O}_{3}, 7 \%$ each of $\mathrm{SiO}_{2}$ and $\mathrm{Fe}_{2} \mathrm{O}_{3}$, and $4 \% \mathrm{TiO}_{2}$. There were no obvious differences to account for the unusual coating growth behaviors between these different bauxite particles.

Table 6.3-1: EDS Analysis of Bauxite Particles

\begin{tabular}{|c|c|c|c|}
\hline \multirow{2}{*}{$\begin{array}{l}\text { Compound } \\
\text { Formula }\end{array}$} & \multicolumn{3}{|c|}{ Compound Wt.\% (Ave) } \\
\hline & Light Brown & Dark Brown & Black \\
\hline$\overline{\mathrm{Al} 2 \mathrm{O} 3}$ & 80.46 & 777.62 & 80.78 \\
\hline $\mathrm{SiO} 2$ & 7.62 & 8.07 & 7.46 \\
\hline $\mathrm{TiO} 2$ & 3.85 & 4.45 & 3.58 \\
\hline $\mathrm{Fe} 2 \mathrm{O} 3$ & 7.09 & 8.58 & 7.37 \\
\hline $\mathrm{MnO}$ & 0.31 & 0.44 & 0.00 \\
\hline $\mathrm{ZrO} 2$ & 0.67 & 0.85 & 0.67 \\
\hline $\mathrm{CaO}$ & 0.00 & 0.00 & 0.13 \\
\hline
\end{tabular}

In order to compare the coating growth data from this campaign with the earlier MTF test program, the operating hours need to be compared on the same basis. The earlier test program was run as a $2000^{\circ} \mathrm{F}$ bubbling bed with no bauxite recirculation. The bauxite particles therefore were exposed to the high temperature bed conditions for the full duration of the test. The September 2002 CMB test did have a bauxite recirculation loop. Since it took some time for the bauxite particles to pass through the solids separation hopper on top of the combustor, only a portion of the particle residence time was at the full bed temperature. Figure 6.3-3 normalizes the particle's residence time for the September 2002 test as time spent at the full $2000^{\circ} \mathrm{F}$ bed temperature.

The coating growth rate was expected to be slower for these tests compared to the earlier tests due to the mechanical abrasion and friction the particles experience in the transport loop. The earlier test was run as a bubbling bed only and the particles were therefore not subjected to any attrition in the transport system. However, these results are difficult to compare with the earlier results because of the different characteristics of the three different colored bauxites. The brown bauxite clearly had dramatically less coating growth, the black had about the same or slightly less, and the reddish particles had more coating. 


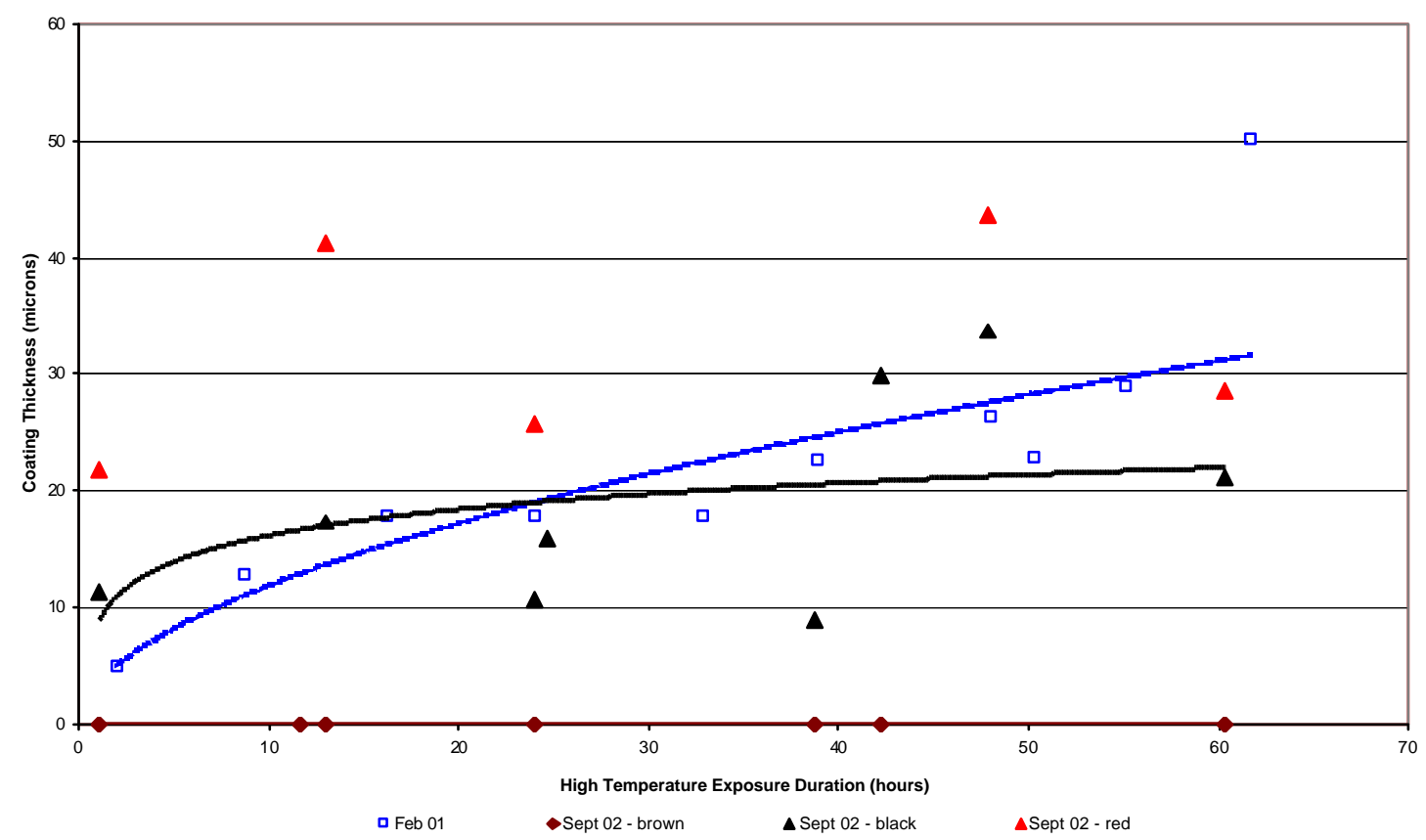

Figure 6.3-3: Bauxite Coating Thickness vs Exposure Time (West Virginia Coal)

Figure 6.3-4 restates the coating growth rate as a $\%$ volume increase in particle size per hour, with the duration normalized as actual high temperature exposure time. There was considerable scatter in the results for the three different types of bauxite. However, the coating growth rate was the same or in many cases less than the growth rate observed in the earlier testing without a transport system. The difference was at least partially attributed to attrition in the transport line wearing down the coating.

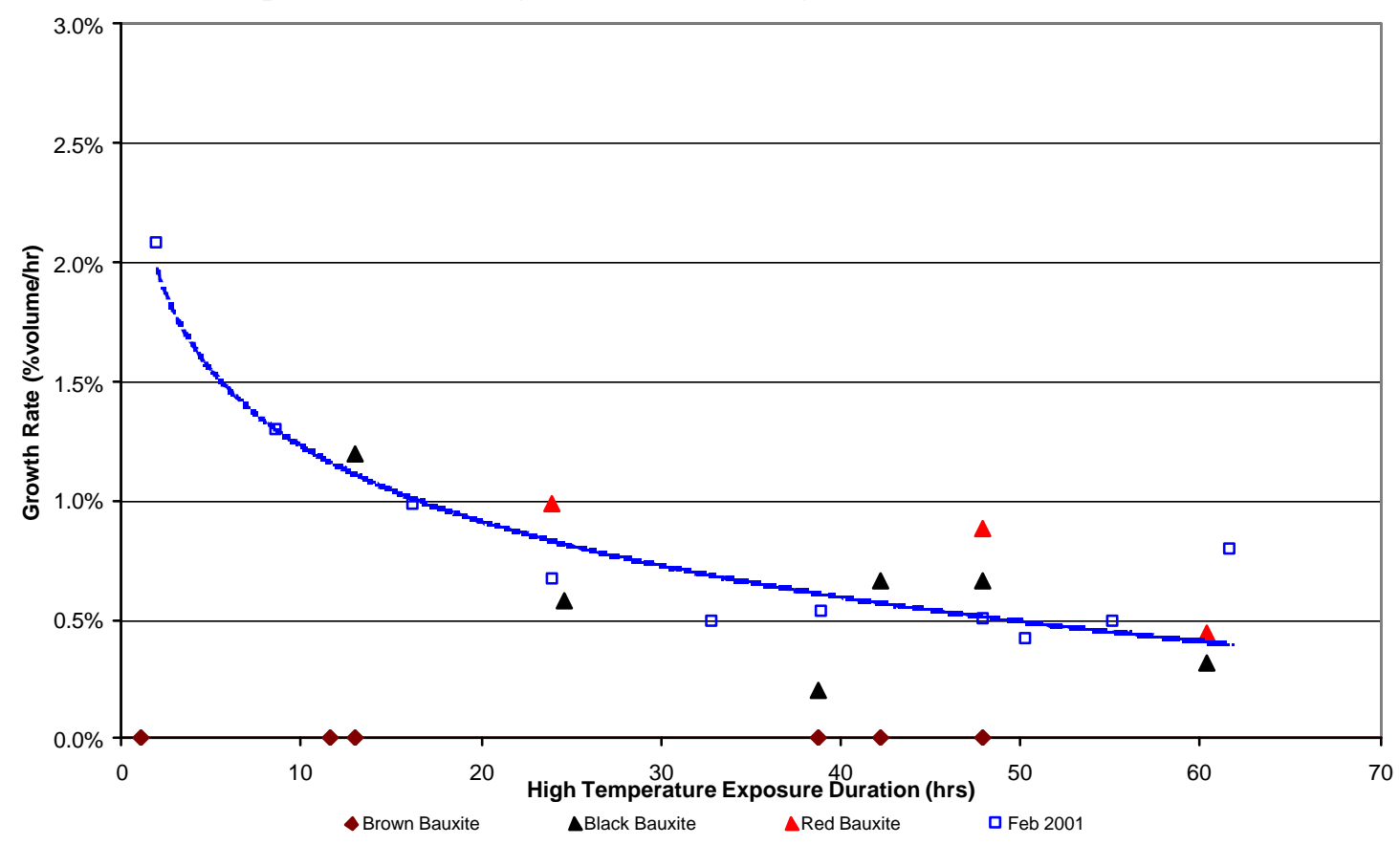

Figure 6.3-4: Coating Growth Rate vs Exposure Time (West Virginia Coal) 
Figure 6.3-5 shows SEM photos at four levels of magnification of a coated bauxite particle after 42 hours of operation while burning the West Virginia coal. This particle was one of the "red" bauxite coated particles, which showed the thickest coating of the three types previously mentioned. The red boxes in this figure show the area that is magnified in the next photo.

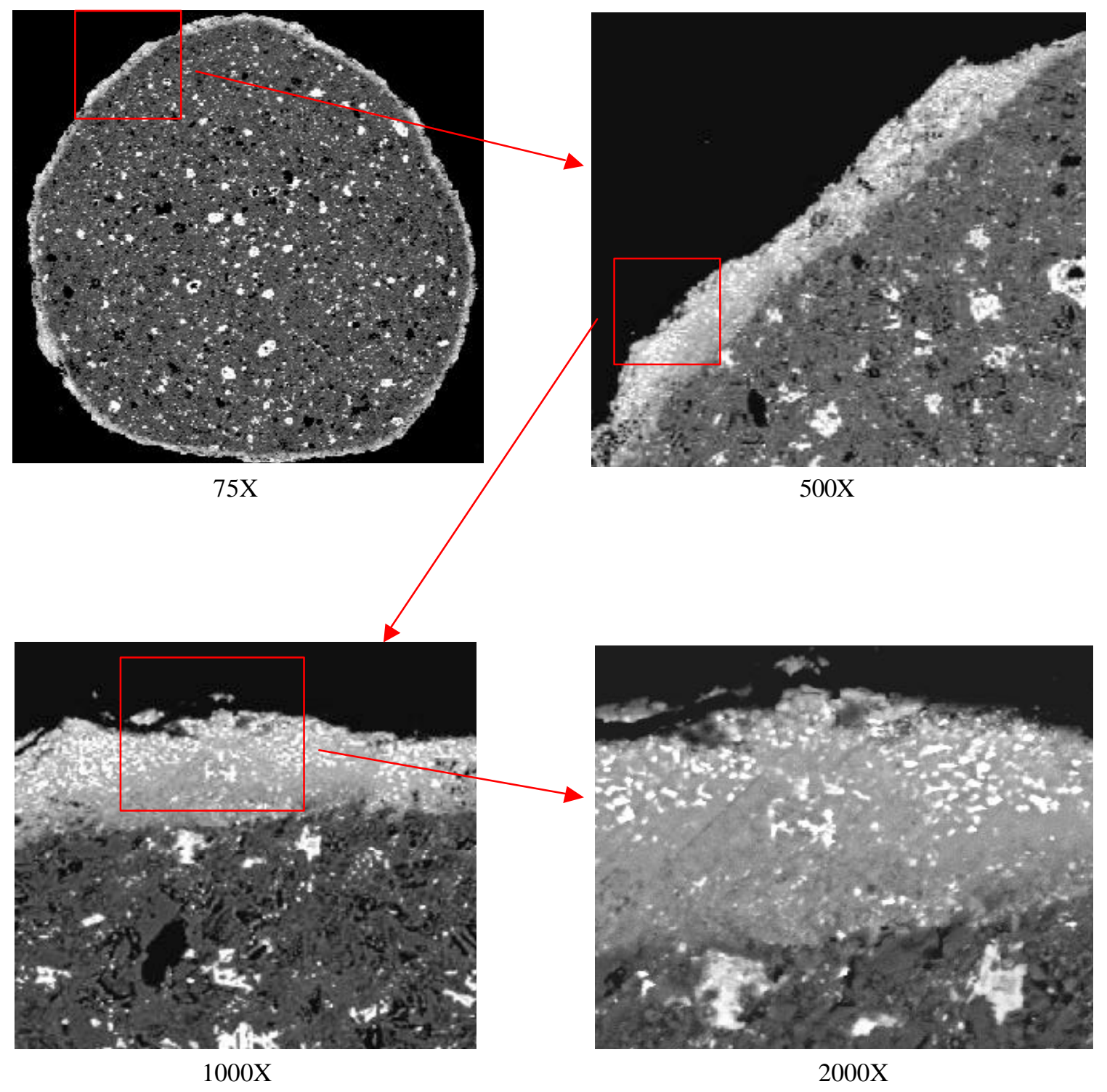

Figure 6.3-5: SEM Photos after 42 Hrs Exposure (West Virginia Coal) 
Figure 6.3-6 shows an EDS elemental mapping of several different regions in this coating. The coating was primarily a mixture of calcium, aluminum, silica, and iron oxides in varying proportions. There were only minor percentages of other compounds, including $\mathrm{MgO}$ and $\mathrm{Na}_{2} \mathrm{O}$. There was virtually no sulfur present in the coating. This could be significant, as the University of North Dakota had observed that sulfate bonding was a key mechanism in the second stage of agglomeration, where particles begin to stick together. With the high CMB bed temperatures, it was unlikely that much sulfation was taking place.

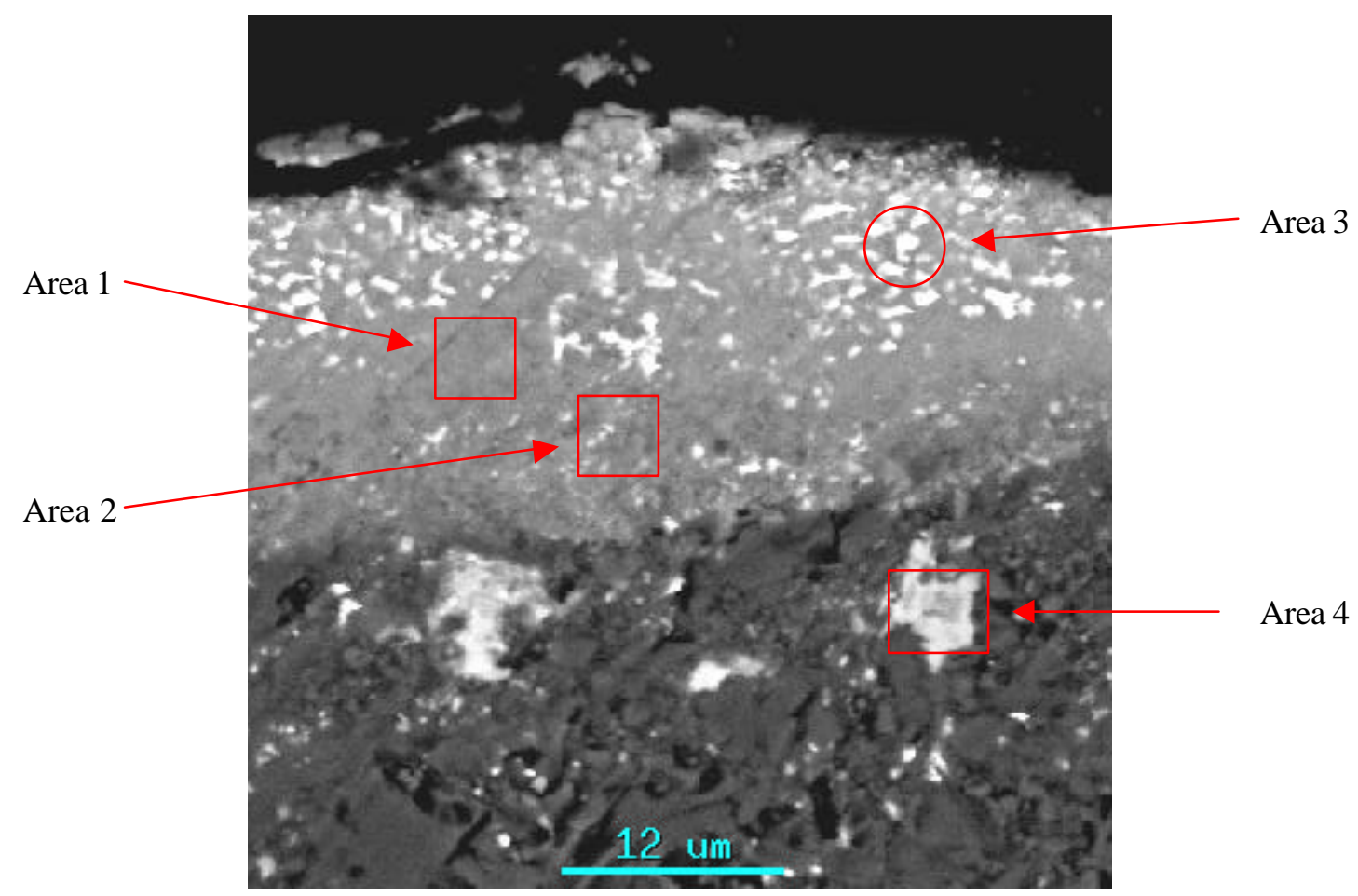

\begin{tabular}{|c|cccc|}
\hline Compound & \multicolumn{4}{|c|}{ Compound Wt \% } \\
\hline Formula & Area 1 & Area 2 & Area 3 & Area 4 \\
\hline \hline $\mathrm{SiO2}$ & 24.67 & 20.15 & 11.47 & 0.45 \\
$\mathrm{Al} 2 \mathrm{O} 3$ & 25.53 & 28.92 & 11.84 & 31.95 \\
$\mathrm{Fe} 2 \mathrm{O} 3$ & 8.17 & 10.12 & 54.20 & 38.97 \\
$\mathrm{CaO}$ & 40.95 & 37.76 & 18.20 & 0.28 \\
$\mathrm{MgO}$ & 0.68 & & 0.81 & 0.33 \\
$\mathrm{TiO} 2$ & & 2.17 & 0.84 & 24.91 \\
$\mathrm{P} 2 \mathrm{O} 5$ & & 0.88 & & \\
$\mathrm{Cr} 2 \mathrm{O} 3$ & & & 0.55 & \\
$\mathrm{MnO}$ & & & 0.69 & 2.42 \\
$\mathrm{NiO}$ & & & 1.41 & \\
$\mathrm{ZrO2}$ & & & & 0.70 \\
\hline
\end{tabular}

Figure 6.3-6: EDS Elemental Mapping of Bauxite Particle after 42 Hrs Exposure 
The X-ray mapping shown in Figure 6.3-7 shows the distribution of oxygen, aluminum, silica, calcium, iron, and titanium throughout the coating of the same particle. Calcium and silica were both distributed uniformly throughout the coating.

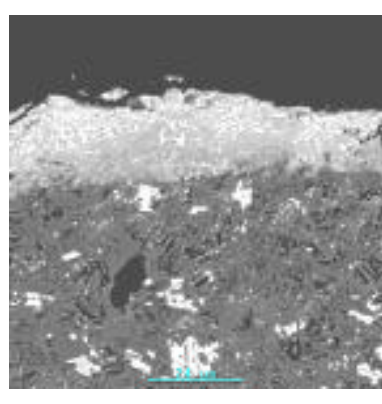

Backscatter Image $1000 X$

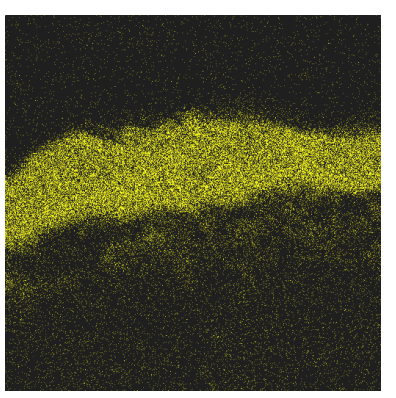

Ca_k $\alpha$

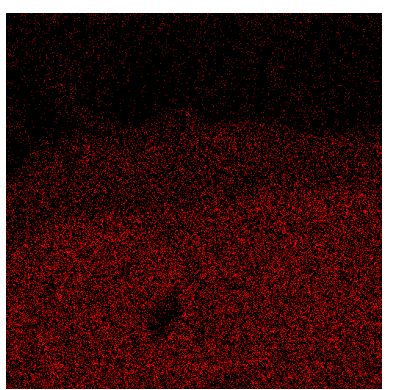

O_k $\alpha$

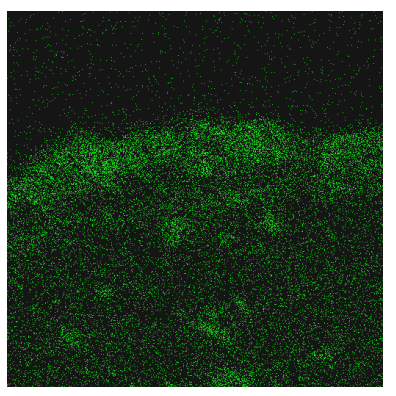

Fe_k $\alpha$

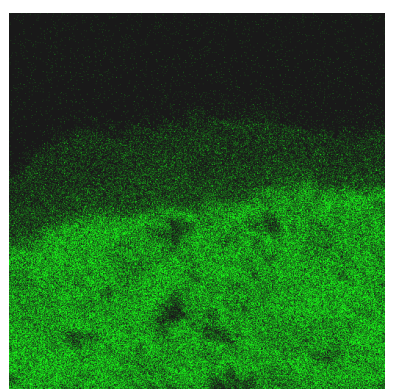

$1000 X$

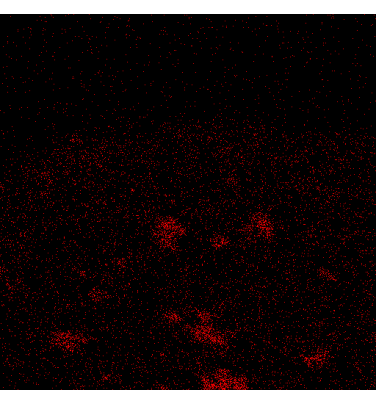

Ti_k $\alpha$

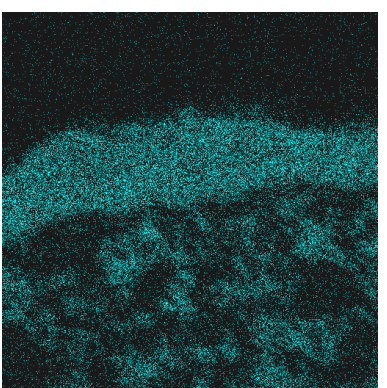

Si_k $\alpha$ $1000 X$

Figure 6.3-7: X-Ray Mapping of Bauxite Coating after 42 Hrs Exposure

\section{Ash Coating Growth - Pittsburgh \#8 Coal}

The ash buildup on the bauxite particles during the Pittsburgh \#8 coal tests was not as varied as the results observed with the West Virginia coal during the September 2002. This test campaign included about 110 hours of operation with the MBHE in service and bed temperature of $2000^{\circ} \mathrm{F}$ or higher. The test also included six hours of operation at temperatures between $2100^{\circ} \mathrm{F}$ and $2160^{\circ} \mathrm{F}$.

The bauxite used in this test was left over from previous CMB operation with the West Virginia coal and already had some coating on the particles. Figure 6.3-8 shows the increase in the ash coating thickness surrounding the bauxite particles over the duration of the test. Also included in blue (both data points and trend line) are the results from a previous MTF campaign with the same fuel. The previous test campaign also had periods of operation at temperatures above $2100^{\circ} \mathrm{F}$. Figure 6.3-8 also identifies the ash coating thickness data from the high temperature tests for each test campaign. 


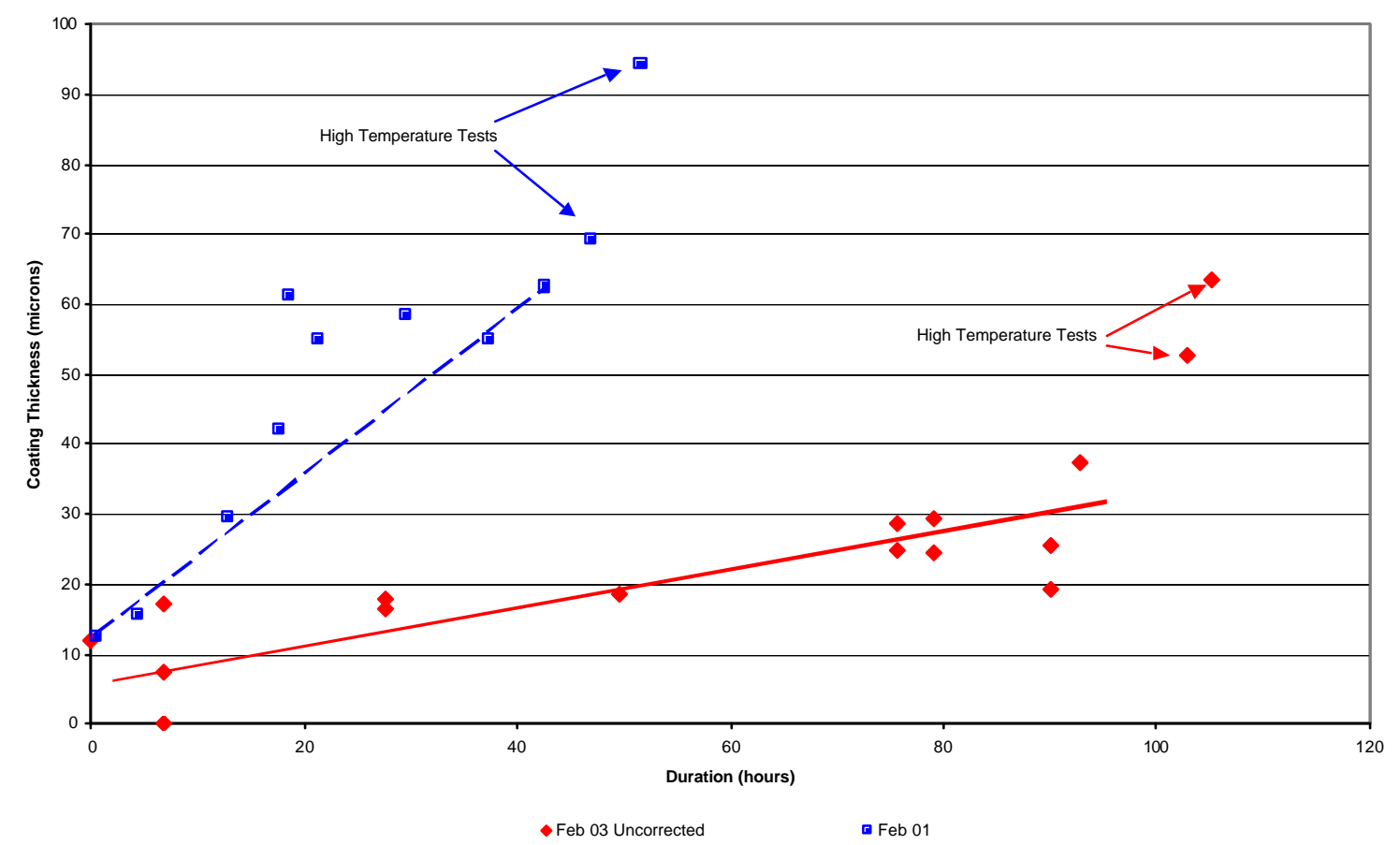

Figure 6.3-8: Bauxite Coating Thickness with Pittsburgh \#8 Coal

The results showed a gradual increase in the coating with time and then a step change in the coating thickness when the temperature was increased up to $2100^{\circ} \mathrm{F}$ and then $2160^{\circ} \mathrm{F}$ over a six hour duration. Although the coating growth rate increased with the higher bed temperatures, there were no signs of agglomerates in the bed and the bed remained well fluidized. These results indicate that the CMB fluidized bed is quite robust and can tolerate temporary temperature excursions or temperature maldistributions.

As discussed before, these test results needed to be normalized to the actual time exposed to bed temperature to be consistent with the results from the earlier MTF test campaign. Since the bauxite particles spent a long time passing through the MBHE, the actual solids exposure time to high temperature conditions was considerably less than the total residence time. During these tests, the bauxite particles were exposed to the high temperature bed for about 12 minutes every hour. The particles spent the balance of the time passing through the transport system, the MBHE, and the solids separation hopper on top of the combustor. The ash coating thickness results can be further corrected to account for the initial coating that was on the particles prior to beginning the test with the Pittsburgh \#8 coal.

Figure 6.3-9 shows the operating hours for the Pittsburgh \#8 coal test (as red data points) normalized as time spent at the full $2000^{\circ} \mathrm{F}$ bed temperature. The dashed red line further normalizes the coating growth trend line to a 0 micron thickness at the start of the test. As before, the earlier test results are shown as the blue data points and trend line. These results showed that the coating continued to grow as it was exposed to the high temperature conditions in the bed. However, the coating thickness for a given exposure time was quite less than the results observed in the previous test that did not have a bauxite circulation loop. 
This difference was attributed to the mechanical abrasion and attrition the particles were subjected to as they passed through the MBHE and the transport systems.

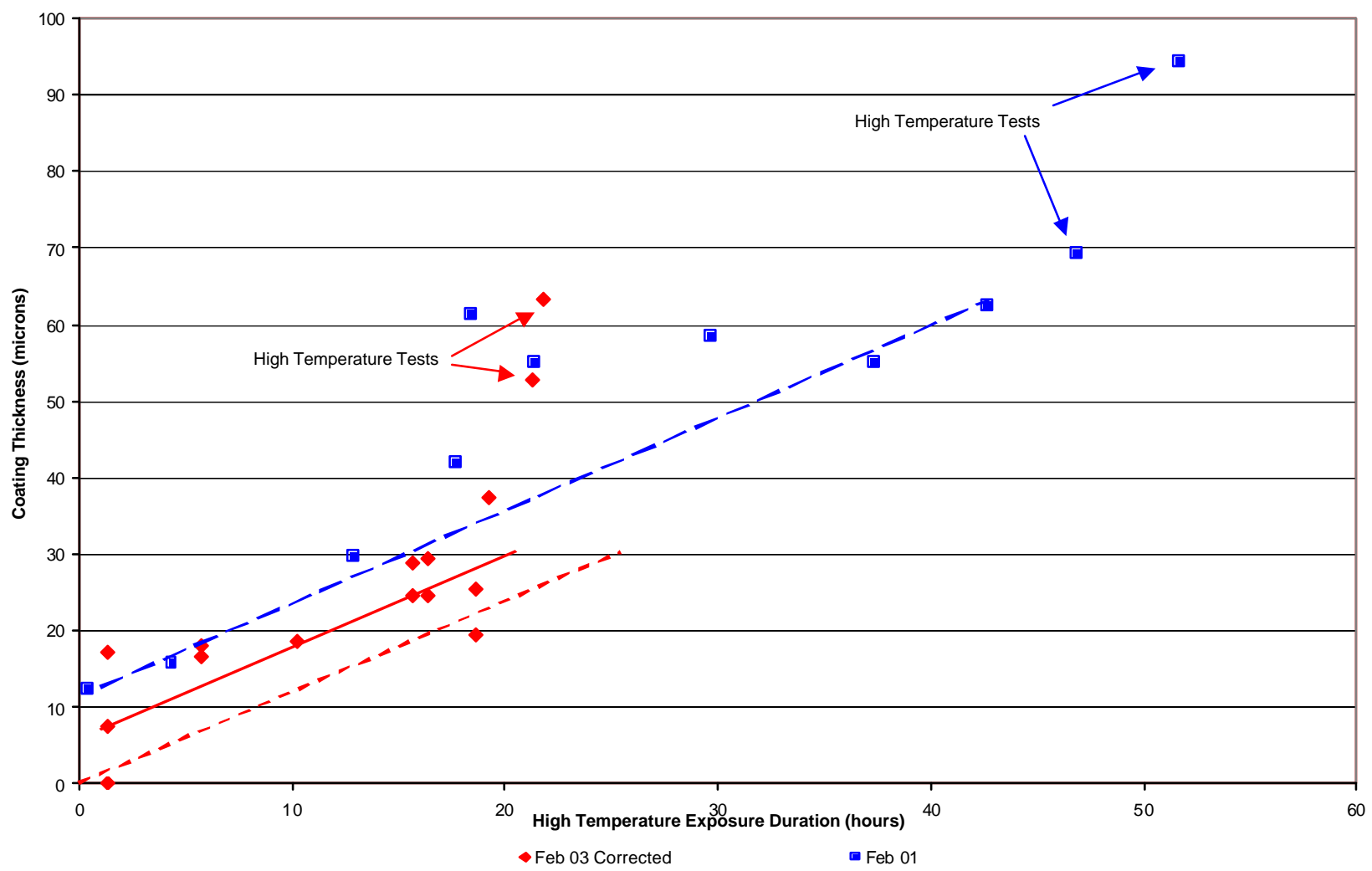

Figure 6.3-9: Bauxite Coating Thickness vs Exposure Time (Pittsburgh \#8 Coal)

Figure 6.3-10 presents the ash coating growth rate with the Pittsburgh \#8 coal as a \% volume increase in particle size per hour, with the duration normalized as actual high temperature exposure time. The thickness data for the February 2003 test includes the initial coating thickness from prior operation. Normalizing the data to remove this thickness would further shift the growth curve downward. The two test points at temperatures about $2100^{\circ} \mathrm{F}$ for each test series were not included in this figure so the trends could be more clearly seen. 


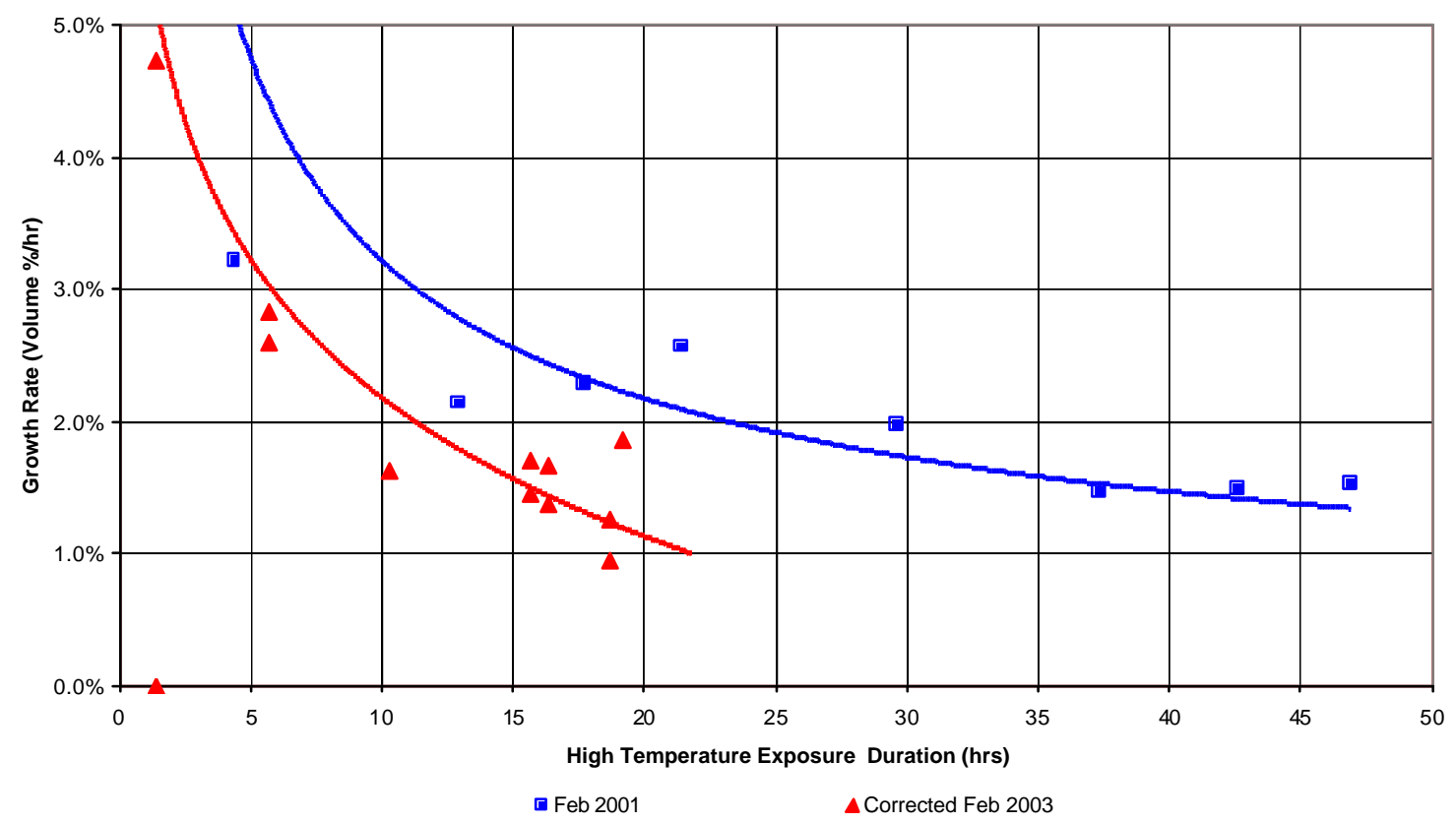

Figure 6.3-10: Coating Growth Rate vs Exposure Time (Pittsburgh \#8 Coal)

The results in this figure clearly showed that the coating growth rate was slower in the February 2003 campaign when the MBHE and bauxite transport system were in operation. The attrition in the recirculation loop removed some of the coating and slowed although not eliminated the buildup of ash on the particle surface. Although the growth rate was slowing, the MTF was not run long enough to determine if the particle ash coating would eventually reach a steady state level, where any further growth was offset by attrition. There was some evidence from prior work that some of the coating was spalling off when the coating became thick. Further operation is needed to look at the long-term effects of coating growth and its effect on CMB operation.

The effect of the two different coals on the coating growth rate is shown in Figure 6.3-11. The ash coating growth rate from the Pittsburgh \#8 coal tests in February 2003 are shown as the green data points and trend line. The ash coating growth rate from the West Virginia coal tests in September 2002 are shown as the brown, black, and red data points, representing the three different colored bauxite samples that behaved quite differently. A trend line is also shown for the black colored bauxite.

Despite the scatter with the West Virginia coal results, it's apparent that the ash coating layer grew more rapidly on the bauxite particles during the Pittsburgh \#8 coal fired tests. This was not surprising, as the ASTM Initial Softening Temperature (see Table 5.4-4) was only $2140^{\circ} \mathrm{F}$ for this ash, compared to over $2700^{\circ} \mathrm{F}$ for the West Virginia bituminous coal ash. At one point in this test, the average bed temperature was even above the Initial Softening Temperature for the Pittsburgh \#8 coal ash. Furthermore, the actual temperatures at the burning coal particle surface could be several hundred degrees hotter than the bed temperature and thus well above the ash softening temperature for this coal ash. This coal also has a high iron content in the ash and is a high sulfur coal, both factors that increase its propensity to slag. 


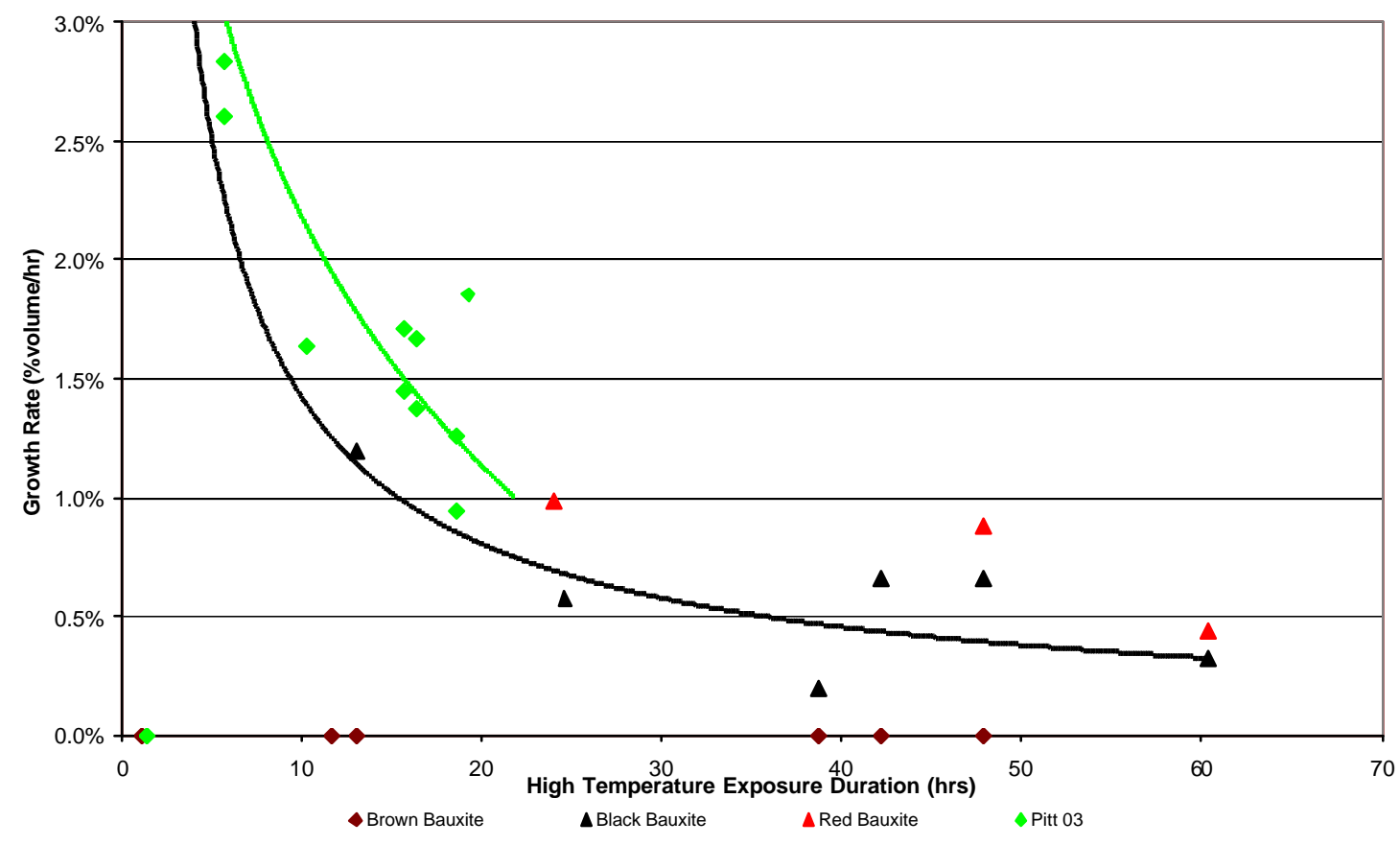

Figure 6.3-11: Coating Growth Rate for West Virginia \& Pittsburgh \#8 Coal

Figure 6.3-12 shows the growth of the ash coating thickness for six different bauxite particles at various exposure times during the Pittsburgh \#8 test. The first four particles were from the normal $\mathrm{CMB}$ operation with a $2000^{\circ} \mathrm{F}$ bed temperature. The last two particles were taken during the $2100^{\circ} \mathrm{F}$ and $2160^{\circ} \mathrm{F}$ test periods, respectively. These photos show a slow increase in the coating thickness with exposure time and then a rapid increase in thickness when the bed temperature was increased above $2100^{\circ} \mathrm{F}$. Note the unusual white banding that began in the fourth photo at 93 hours exposure and then continued in the subsequent samples. It was not clear what caused this unusual pattern. The MTF was running quite smoothly during most of this operation. However, there was a brief 30-minute shutdown about 10 hours before this sample was taken when the bed was slumped. Particles were in intimate contact with each other and there was no airflow between the particles. These conditions may have contributed to the unusual deposition on the particle surface. 


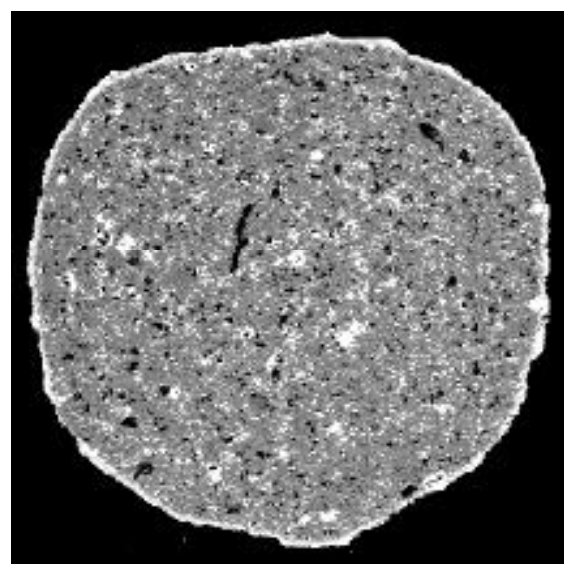

28 hours

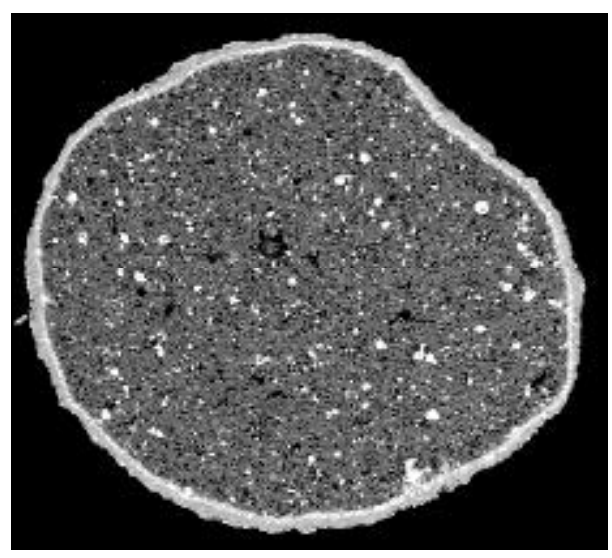

76 hours

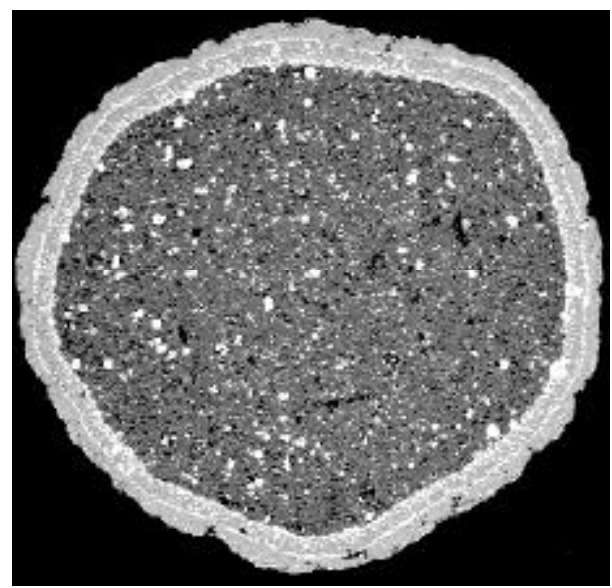

103 hours - 2 hrs @ 2100F

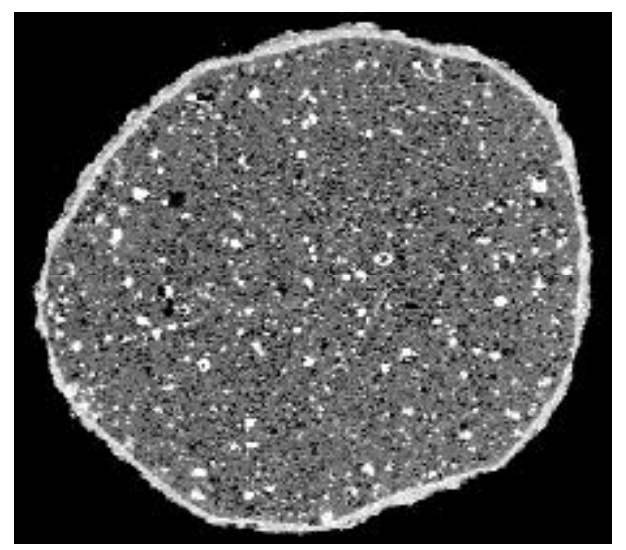

48 hours

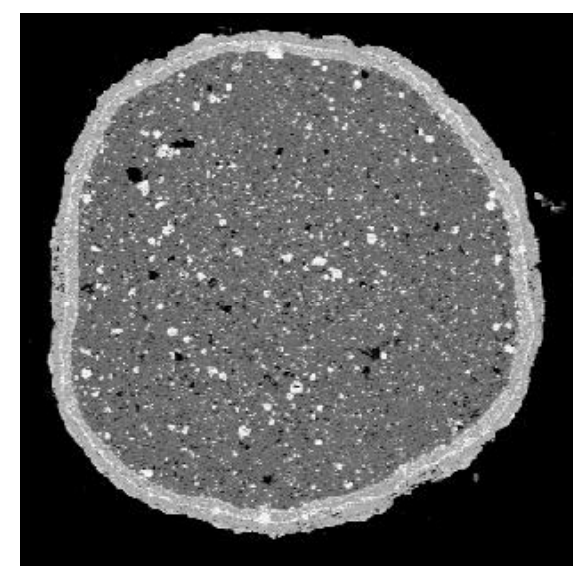

93 hours

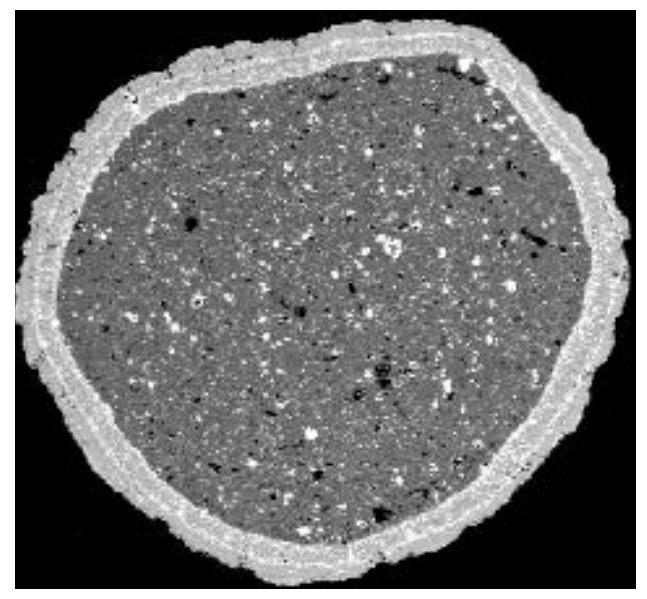

105 hrs - 2 hrs @ 2150F

Figure 6.3-12: Coating Growth on Bauxite Particles with Pittsburgh \#8 Coal 
Figure 6.3-13 shows SEM photos at three different magnifications of a coated bauxite particle after 93 hours of operation while burning the Pittsburgh \#8 coal. The red boxes indicate the areas that are magnified in the next photo. This particle was the first sample where the white banding was noticed in the coating.

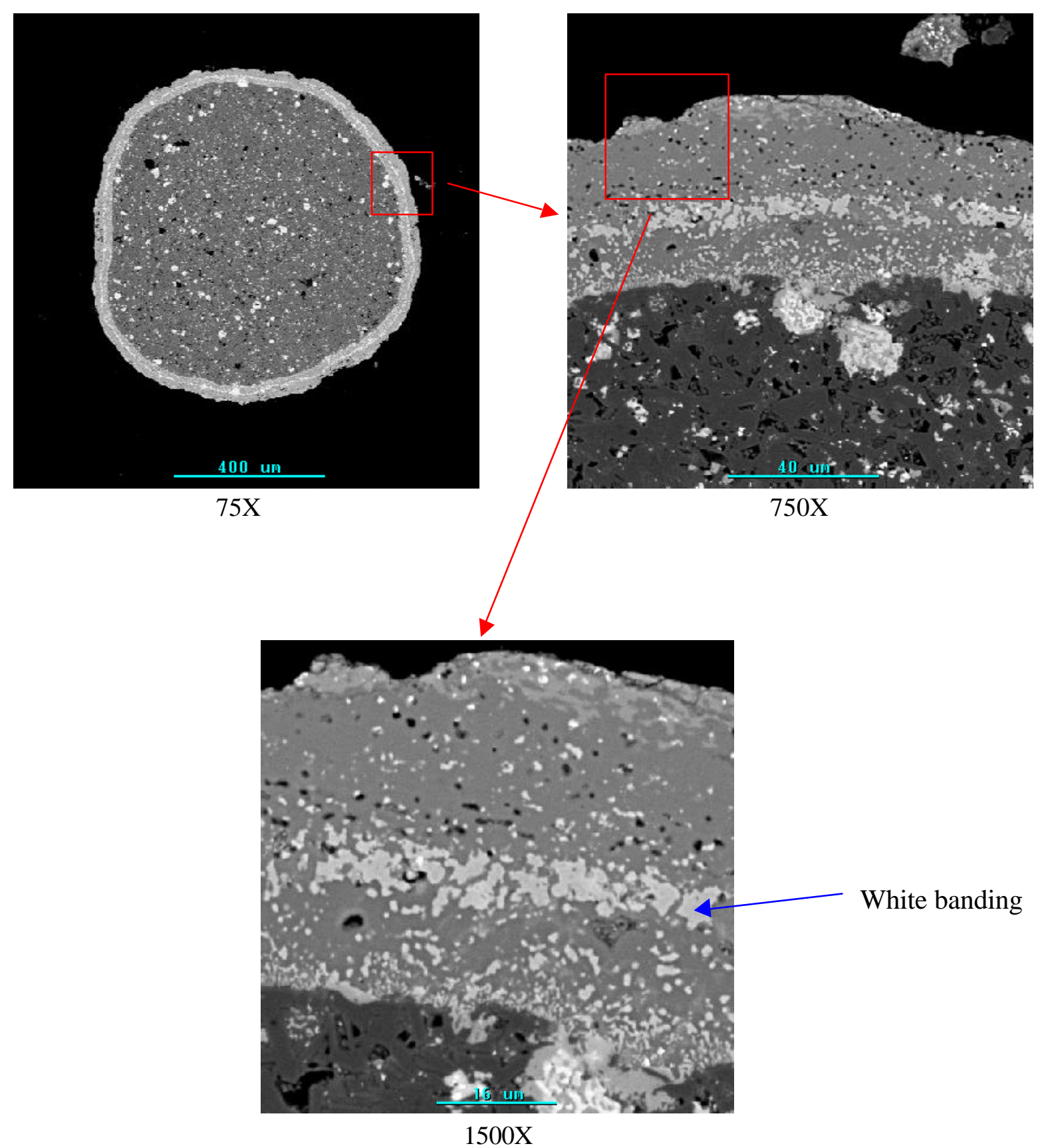

Figure 6.3-13: SEM Photos after 93 Hrs Exposure (Pittsburgh \#8 Coal) 
Figure 6.3-14 shows an EDS elemental mapping of seven different regions in this coating. The coating was again primarily a mixture of calcium, aluminum, silica, and iron oxides in varying proportions. Two areas also showed a high concentration of $\mathrm{TiO}_{2}$. The white banding that was discussed earlier is identified in this figure as Area 4. This area showed very high concentrations of both iron oxide and aluminum oxide. Silica oxide and calcium oxide both had unusually low concentrations in this area, despite being abundant in most other areas in this sample and the sample in Figure 6.3-6. Areas 6 and 7, which are near the bauxite particle surface, are the only other areas with similar ash compositions.

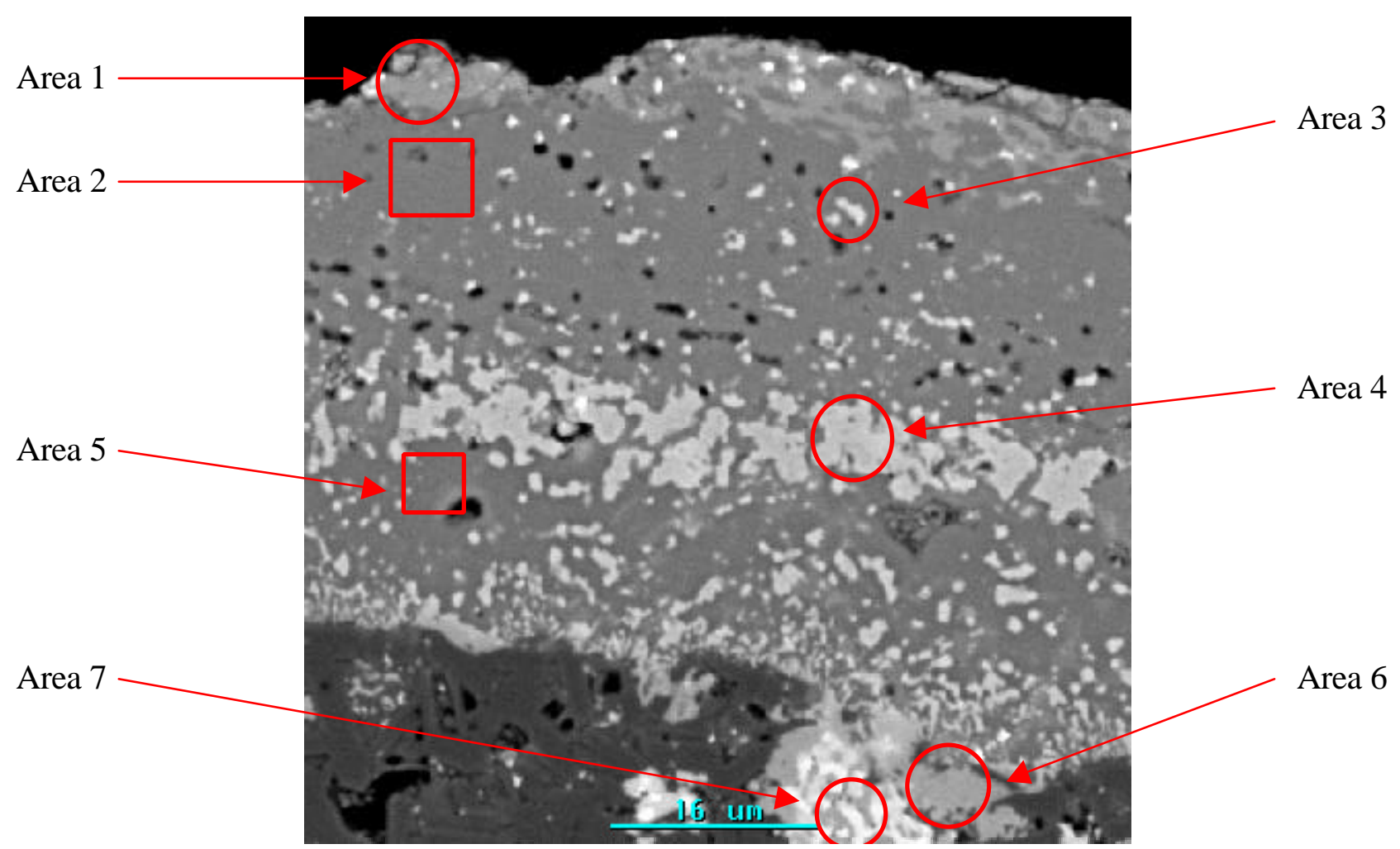

\begin{tabular}{|c|c|c|c|c|c|c|c|}
\hline Compound & \multicolumn{7}{|c|}{ Compound Wt \% } \\
\hline Formula & Area 1 & Area 2 & Area 3 & Area 4 & Area 5 & Area 6 & Area 7 \\
\hline $\mathrm{SiO} 2$ & 31.11 & 22.03 & 8.46 & 0.36 & 4.36 & 0.97 & 0.43 \\
\hline Al2O3 & 1.52 & 32.40 & 13.34 & 33.82 & 55.39 & 52.44 & 12.12 \\
\hline $\mathrm{Fe} 2 \mathrm{O} 3$ & 2.68 & 3.57 & 6.68 & 45.72 & 3.19 & 41.72 & 43.70 \\
\hline $\mathrm{CaO}$ & 62.31 & 41.46 & 39.79 & 6.71 & 36.86 & 1.31 & 0.44 \\
\hline $\mathrm{MgO}$ & & & & 3.41 & & & \\
\hline $\mathrm{TiO} 2$ & & 0.56 & 28.06 & 6.69 & 0.19 & 1.38 & 39.71 \\
\hline P2O5 & 2.38 & & & & & & \\
\hline $\mathrm{Cr} 2 \mathrm{O} 3$ & & & 0.64 & 0.71 & & & \\
\hline $\mathrm{MnO}$ & & & & 2.26 & & 2.15 & 3.04 \\
\hline $\mathrm{ZrO3}$ & & & 3.03 & & & & \\
\hline $\mathrm{Nb2O} 5$ & & & & 0.31 & & & 0.55 \\
\hline
\end{tabular}

Figure 6.3-14: EDS Elemental Mapping of Bauxite Particle after 93 Hrs Exposure 
The X-ray mapping shown in Figure 6.3-15 shows the distribution of oxygen, aluminum, silica, calcium, iron, and titanium throughout the coating of the same particle. This figure clearly shows the enrichment of iron in the area of white banding and along the particle surface. It also shows that the calcium is distributed throughout the coating everywhere except in the white banding region.

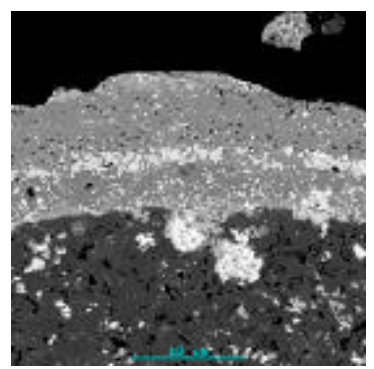

Backscatter Image $\quad \mathbf{7 5 0 X}$

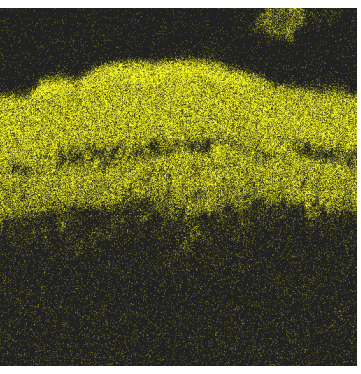

Ca_k $\alpha$

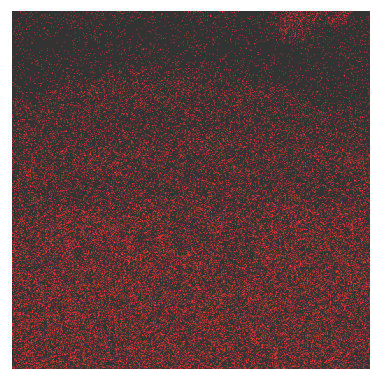

O_k $\alpha$

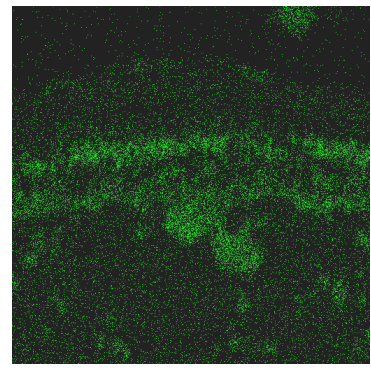

Fe_k $\alpha$

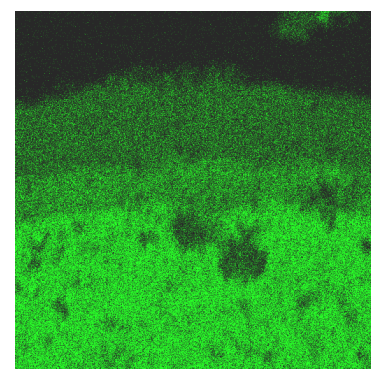

750X

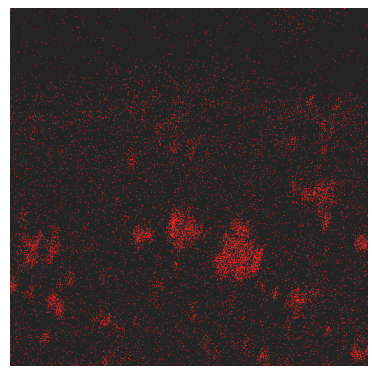

Ti_k $\alpha$

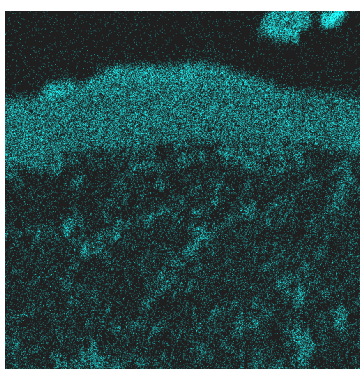

Si_k $\alpha$

Figure 6.3-15: X-Ray Mapping of Bauxite Coating after 93 Hrs Exposure

\section{Implications for CMB Operation}

\section{Growth Rates}

The results just presented show that an ash coating grows on the bauxite surface as the particle is exposed to the high bed temperature. The coating is established very quickly and then grows at a slower rate, as evidenced by the declining growth rate curves in Figures 6.34, 6.3-10, and 6.3-11. In all cases, the operating hours were normalized to an actual high temperature exposure time to compare data between different MTF test campaigns.

However, the bauxite particles in a commercial CMB boiler only have about 8 minutes of exposure time in the bed before they pass through the moving bed heat exchanger and are then returned to the combustor. One complete circuit through the CMB solids circulation loop takes 2 hours. Thus, the total operating time is 15 times longer than the normalized bed exposure time discussed in the previous section.

The coating growth rate was previously defined as the volumetric growth rate of the particle. The growth rate observed for the particles during the West Virginia coal test was about $0.3 \%$ particle volume per hour exposure, based on the black bauxite particles after 60 hours of hot exposure time (or 100 hours of total operating time). Note that the growth rate was initially 
very high and was steadily declining with time. Furthermore, the black bauxite particles had a much higher growth rate than the brown bauxite particles, which showed practically no coating growth. It is reasonable to expect that the long term growth rate could be considerably less than the $0.3 \%$ rate. For discussion purposes, we will consider the $0.3 \% / \mathrm{hr}$ rate as an upper growth rate and will assume that the lower growth rate is one third that rate, or $0.1 \% / \mathrm{hr}$.

For a commercial CMB boiler, these rates would be 15 times lower if expressed on an elapsed time basis. In this case, the upper and lower growth rates are $0.02 \%$ and $0.007 \%$ particle volume per hour elapsed time.

Based on these growth rates, we can infer some implications for CMB operation, particularly as they impact bed hydrodynamics and heat transfer in the moving bed and combustor. Figure 6.3-16 shows the minimum fluidizing velocity $\left(\mathrm{U}_{\mathrm{mf}}\right)$ and terminal velocity $\left(\mathrm{U}_{\text {term }}\right)$ for various bauxite particle sizes. Assume that the CMB bed operates at $12 \mathrm{ft} / \mathrm{sec}$ (during turndown conditions) and that we want the bed superficial velocity to be at least 4 times greater than $U_{\mathrm{mf}}$ to ensure good fluidization. This requires a maximum $\mathrm{U}_{\mathrm{mf}}$ of $3 \mathrm{ft} / \mathrm{sec}$ and correspondingly, a maximum bed particle size of 1300 microns.

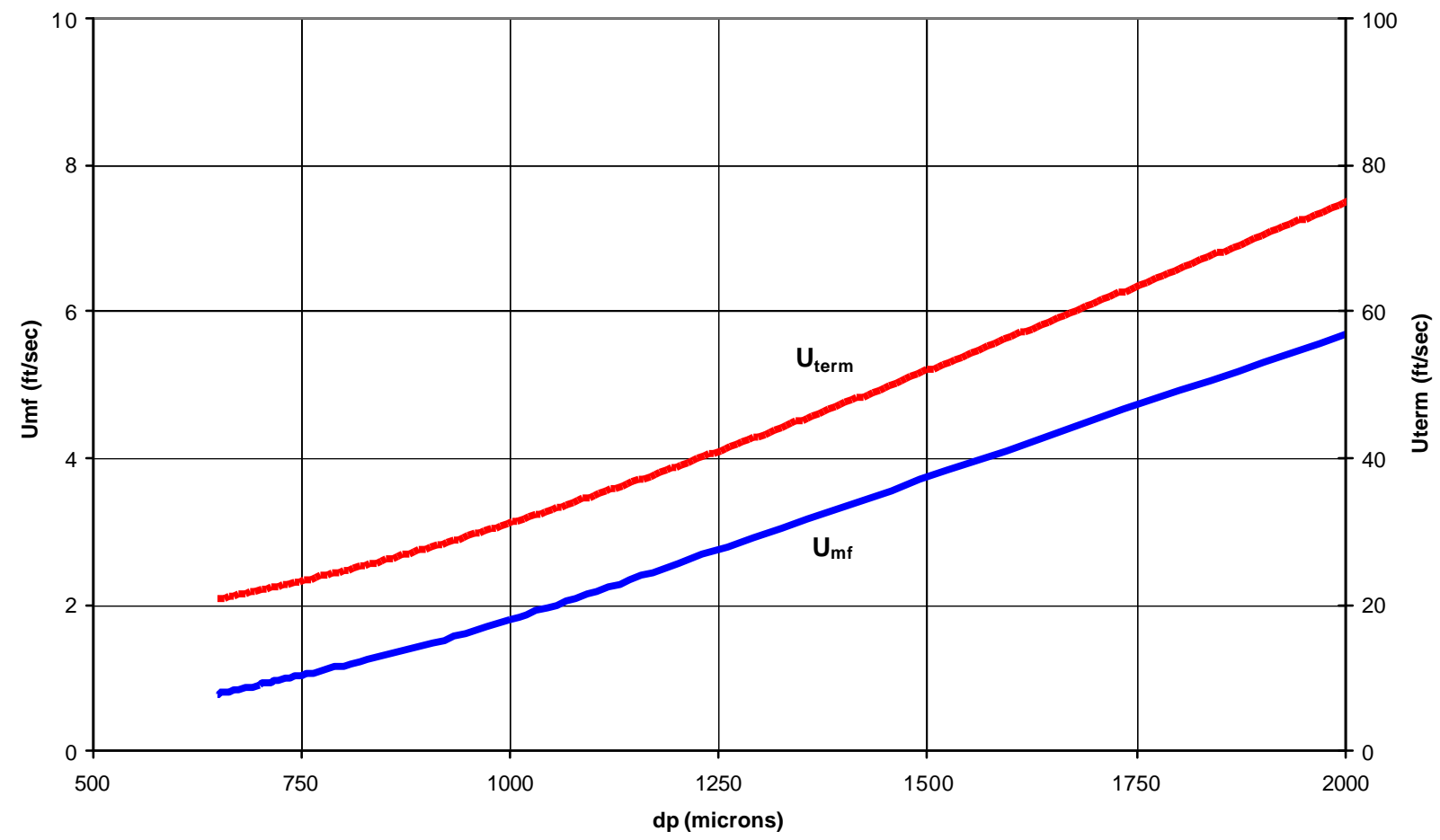

Figure 6.3-16: Minimum Fluidization and Terminal Velocities for Bauxite

Figure 6.3-17 shows the total time necessary for a bauxite particle to grow to a given size in a CMB boiler based on the particle growth rates observed in the MTF tests and corrected to total elapsed time. It would take between 3 to 10 years for the bauxite particles to grow to a maximum size of 1300 microns while firing West Virginia coal, based on the upper and lower growth rates, respectively. Based on this, the hydrodynamic impact of particle growth on bed fluidization is not a significant problem. 


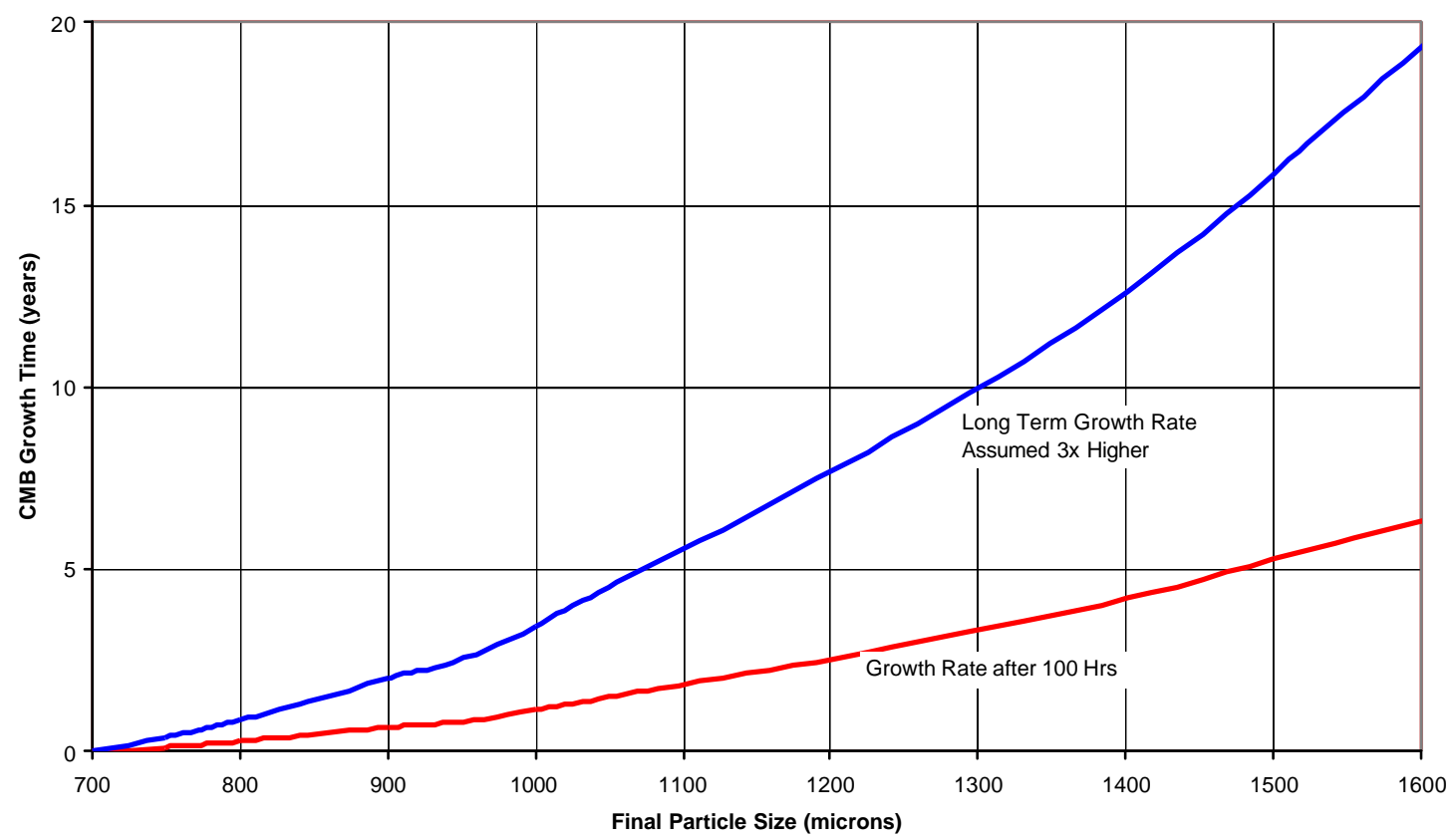

Figure 6.3-17: Exposure Time Required for Final Particle Size

\section{Moving Bed Heat Transfer}

The particle size growth should also have only a minor impact on moving bed heat transfer performance. Cold flow moving bed heat transfer tests conducted prior to this program showed only a slight decrease in the heat transfer coefficient when the bed particle size was increased by $40 \%$. This was equivalent to a bed particle growing from 700 to 1000 microns. Based on Figure 6.3-17, the particle growth time from 700 to 1000 microns is much quicker, taking between 1 and 3 years while firing West Virginia coal, respectively. Circulating the bauxite at a higher rate would offset this reduction in heat transfer coefficient. This would increase the heat transfer coefficient slightly but also increase the log mean temperature. For the $\mathrm{CMB}$ design case, increasing the bauxite recirculation rate less than $2 \%$ would offset the reduction in heat transfer due to particle size growth.

\section{Solids-to-Gas Heat Transfer}

The effect on the gas-to-solids heat transfer in the combustor may be more significant. The larger particle size has a higher terminal velocity and thus a shorter residence time for heat transfer. There will also be less heat transfer surface area due to fewer (but larger) particles if the solids inventory is also reduced to maintain a constant bed pressure drop. Figure 6.3-16 shows that the terminal velocity increases from $23 \mathrm{ft} / \mathrm{sec}$ to $33 \mathrm{ft} / \mathrm{sec}$ as the particle diameter grows from 700 to 1000 microns. This results in a reduction in heat transfer to the particles and a corresponding increase in the gas outlet temperature if process conditions aren't adjusted.

\section{Bed Pressure Drop}

The ash coating growth will also have an impact on bed pressure drop and thus solids management. The coating increases the weight of the bauxite particles and will gradually increase the bed pressure drop if the total solids inventory is not controlled. The bed inventory will increase by $3 \%$ to $9 \%$ over a month's operation if the total inventory of bauxite remains unchanged. This is based on the lower and upper growth rates while firing 
the West Virginia coal, respectively, and assuming an ash coating density of $160 \mathrm{lb} / \mathrm{ft}^{3}$. Some bed inventory will thus need to be removed on a regular basis to control the bed pressure drop.

\section{Solids Management}

The bauxite particle size will need to be managed to some maximum size level to maintain acceptable boiler performance. There are several ways of controlling particle size, such as through attrition, growth rate control, or solids replenishment. These methods are briefly discussed below.

There is considerable mechanical abrasion on these particles as they circulate through the moving bed heat exchanger and transport lines. It was hoped that this alone would be sufficient to control the particle growth rate. The cold flow attrition testing discussed in Section 3.3 showed that the coating could be completely attrited away during cold transport conditions. The hot MTF tests also showed a reduction in the coating growth rate compared to previous tests without a bauxite recirculation system. However, there was still a gradual increase in the coating with exposure time despite the attrition. This rate may slow down or stop if a steady state condition is reached between growth and attrition rates. Longer term testing is needed to evaluate this further.

It may also be possible to modify the local bed operating conditions to slow down the coating growth rate. One possibility is to minimize the presence of $\mathrm{CaO}$ in the bed, which can act as a fluxing agent. Grinding the limestone fine and injecting it above the bed may reduce the coating growth rate, while at the same time improving the quality of the lime for FDA performance.

The circulating solids size can also be managed by continuously removing some of the coarser material and replacing it with fresh material. This includes the removal of some bauxite along with the ash. The bauxite inventory that is removed will eventually need to be replenished. One cost-savings option is to sell the used bauxite to an oil company. Fresh bauxite particles are pumped into oil wells for enhanced oil recovery. One oil company currently purchases 100,000 tons/yr of bauxite for this application. The 4000 tons from a 3000Mw CMB could easily be consumed by one of these companies and may be attractive to them at a somewhat reduced price. The physical properties of the coated bauxite should still be very similar to what the oil companies pump into their wells, as spherocity, durability, and sizing are their primary criteria.

Another option is to consider the use of alternate circulating materials if the rate of replenishment is too high. There has not been any evidence of agglomerates forming as the bauxite coating gets thicker. As discussed in Section 3.3, there is evidence that the presence of alumina (such as in bauxite) minimizes the rate of ash deposition in bubbling beds. However, at some point the coating will be sufficiently thick that it shields the bed from any benefit of the aluminia in the bauxite. If the bed still operates reliably without agglomeration, then that would be evidence that a less expensive bed media could also work in this environment. The CMB could be initially started up with a bauxite bed, but then allowed to gradually turn over and build its own bed out of properly sized ash particles. Dolomite is an example of a relatively low-cost material that is frequently cited for its ability to minimize the formation of low-temperature melting eutectics. 


\subsection{Combustion Performance}

One objective of the MTF test campaigns was to assess the critical operating parameters that affect $\mathrm{CMB}$ combustion performance. The $\mathrm{CMB}$ process is quite different from $\mathrm{CFB}$ combustors. Although bed temperature is several hundred degrees hotter than CFBs, the combustor temperature is not isothermal as in CFBs. The CMB combustor temperature profile decreases with combustor height and the actual gas residence time at temperatures above $1500^{\circ} \mathrm{F}$ is less than a CFB. Furthermore, the ash recirculation rate from the main cyclone is very low compared with a CFB.

\section{Combustion Efficiency}

Combustion performance is often characterized by the combustion efficiency or the carbon heat loss. The combustion efficiency is defined by

$$
\eta_{\text {comb }}=100-\left[\left(\mathrm{C}_{\text {Drain }}+\mathrm{C}_{\text {Flyash }}+\mathrm{C}_{\mathrm{FBHE}}+\mathrm{C}_{\text {Hopper }}\right) * 14086+\mathrm{CO} * 4347\right] /\left(\mathrm{W}_{\mathrm{Coal}} * \mathrm{HHV}\right) * 100
$$

where

$\mathrm{C}_{\text {Drain }} \quad=$ carbon loss in bed drain $(\mathrm{lb} / \mathrm{hr})$

$\mathrm{C}_{\text {Flyash }} \quad=$ carbon loss in flyash $(\mathrm{lb} / \mathrm{hr})$

$\mathrm{C}_{\mathrm{FBHE}}=$ carbon loss in FBHE drain $(\mathrm{lb} / \mathrm{hr})$

$\mathrm{C}_{\text {Hopper }}=$ carbon loss in bauxite separation hoppers $(\mathrm{lb} / \mathrm{hr})$

$\mathrm{CO}=$ carbon monoxide in flue gas $(\mathrm{lb} / \mathrm{hr})$

$\mathrm{W}_{\text {Coal }} \quad=$ coal feed rate $(\mathrm{lb} / \mathrm{hr})$

HHV = coal higher heating value $(\mathrm{Btu} / \mathrm{lb})$

The major loss that needs to be considered in the combustion efficiency calculation is the flyash carbon loss. This loss was found by measuring the flyash rate and carbon concentration through a high-volume, isokinetic sampling technique at the combustor cyclone discharge.

The same high-volume sampling technique was used to determine the carbon loss at the discharge of the bauxite separation hoppers above both the MBHE and combustor. Some carbon loss was detected from both of the bauxite separation hoppers. However, in a commercial $\mathrm{CMB}$, the transport air containing this carbon will be reinjected into the $\mathrm{CMB}$ combustor as overfire air. Thus, this carbon is returned back to the combustor and has a further opportunity to burn out in the combustor.

The remaining losses were not very significant. There was no bed drain from the CMB bubbling bed during this operation. Since the bed carbon concentration was well less than $0.1 \%$, any loss in a bed drain stream would have been negligible anyway. Similarly, there was rarely any solids removal from the cyclone ash collection system. Most of this ash was reinjected through the FBHE and the carbon heat loss in this stream was $0.1-0.2 \%$. Finally, the carbon monoxide typically represented only about $0.1 \%$ heat loss. 


\section{Carbon Heat Loss}

Since the primary heat loss is through the carbon in the flyash, it is easier to spot trends by evaluating the carbon heat loss $\left(\mathrm{C}_{\text {loss }}\right)$. This is expressed as a percentage of the coal heat input through the equation

$$
\mathrm{C}_{\text {loss }}=\left(\mathrm{C}_{\text {Drain }}+\mathrm{C}_{\mathrm{Flyash}}+\mathrm{C}_{\mathrm{FBHE}}+\mathrm{C}_{\text {Hopper }}\right) * 14086 /\left(\mathrm{W}_{\text {Coal }} * \mathrm{HHV}\right) * 100
$$

\section{Results - West Virginia Bituminous Coal}

The West Virginia bituminous coal was fired during the September 2002 test campaign. Results from these tests are summarized in Table 6.4-1 The table also includes selected operating parameters, including bed temperature, combustor outlet temperature, and oxygen content in the flue gas.

Table 6.4-1: Combustion Performance with West Virginia Bituminous Coal

\begin{tabular}{|c|c|c|c|c|c|c|c|c|}
\hline Sample Time & $\begin{array}{l}\text { Unburned } \\
\text { Carbon in } \\
\text { Flyash (\%) }\end{array}$ & $\begin{array}{l}\text { Flyash } \\
\text { flow } \\
\text { lb/hr }\end{array}$ & $\begin{array}{l}\text { carbon } \\
\text { loss } \\
\text { lb/hr }\end{array}$ & $\begin{array}{l}\text { Coal } \\
\text { Flow, } \\
\underline{\text { lb/hr }}\end{array}$ & $\begin{array}{l}\text { Carbon } \\
\text { Heat } \\
\text { Loss }(\%) \\
\end{array}$ & $\begin{array}{c}\text { Bed } \\
\text { Temp } \\
{ }^{\circ} \underline{F}\end{array}$ & $\begin{array}{l}\text { Furnace } \\
\text { Outlet } \\
\text { Temp, }{ }^{\circ} \mathrm{F} \\
\end{array}$ & $\begin{array}{l}O_{2}, \\
\% \text { dry } \\
\end{array}$ \\
\hline$\overline{9 / 17 / 02 ~ 10: 44}$ & 24.49 & 22 & 5.4 & 350 & 1.78 & $1 \overline{750}$ & 1050 & 10.5 \\
\hline 9/18/02 08:45 & 14.17 & 7 & 1.0 & 501 & 0.22 & 1995 & 1295 & 5.8 \\
\hline $9 / 18 / 0211: 15$ & 19.58 & 12 & 2.3 & 500 & 0.52 & 2020 & 1300 & 5.0 \\
\hline $9 / 18 / 0216: 38$ & 17.66 & 19 & 3.4 & 530 & 0.74 & 2000 & 1360 & 4.8 \\
\hline 9/18/02 19:45 & 14.54 & 12 & 1.7 & 562 & 0.35 & 2000 & 1440 & 3.6 \\
\hline $9 / 19 / 0204: 17$ & 18.07 & 22 & 4.0 & 535 & 0.85 & 2005 & 1360 & 5.7 \\
\hline 9/19/02 09:25 & 22.10 & 10 & 2.3 & 495 & 0.53 & 2080 & 1275 & 5.2 \\
\hline $9 / 19 / 0214: 10$ & 17.42 & 32 & 5.5 & 528 & 1.20 & 2000 & 1350 & 5.2 \\
\hline 9/19/02 19:20 & 18.55 & 18 & 3.2 & 528 & 0.71 & 2020 & 1350 & 5.1 \\
\hline 9/20/02 00:00 & 20.45 & 15 & 3.1 & 510 & 0.69 & 2050 & 1330 & 8.3 \\
\hline 9/20/02 10:30 & 11.63 & 46 & 5.3 & 533 & 1.14 & 1980 & 1360 & 5.5 \\
\hline $9 / 20 / 02 \quad 14: 15$ & 13.79 & 37 & 5.1 & 450 & 1.30 & 1900 & 1320 & 6.2 \\
\hline 9/20/02 17:48 & 18.43 & 19 & 3.5 & 460 & 0.88 & 1800 & 1295 & 6.3 \\
\hline 9/20/02 20:48 & 16.91 & 20 & 3.4 & 460 & 0.85 & 2000 & 1240 & 6.4 \\
\hline $9 / 21 / 0203: 16$ & 9.20 & 36 & 3.3 & 550 & 0.69 & 2000 & 1495 & 4.7 \\
\hline 9/24/02 19:20 & 19.75 & 19 & 3.7 & 520 & 0.82 & 2000 & 1220 & 5.0 \\
\hline 9/25/02 04:00 & 11.67 & 36 & 4.2 & 510 & 0.96 & 1995 & 1280 & 5.3 \\
\hline 9/25/02 07:45 & 10.92 & 35 & 3.8 & 510 & 0.85 & 2000 & 1285 & 5.2 \\
\hline 9/25/02 13:45 & 12.18 & 47 & 5.7 & 510 & 1.29 & 1995 & 1305 & 4.5 \\
\hline $9 / 26 / 0200: 50$ & 7.75 & 33 & 2.6 & 495 & 0.60 & 2000 & 1300 & 4.0 \\
\hline 9/26/02 04:15 & 7.71 & 54 & 4.2 & 495 & 0.97 & 2010 & 1305 & 4.5 \\
\hline $9 / 26 / 02 \quad 10: 15$ & 12.23 & 25 & 3.0 & 496 & 0.70 & 1995 & 1340 & 4.5 \\
\hline $9 / 26 / 02 \quad 14: 38$ & 8.57 & 30 & 2.6 & 495 & 0.60 & 1990 & 1375 & 4.2 \\
\hline $9 / 26 / 02 \quad 19: 30$ & 8.11 & 23 & 1.9 & 495 & 0.43 & 1995 & 1400 & 4.3 \\
\hline
\end{tabular}

The tests included variations in many parameters, including bed temperature, excess air, load, cyclone ash recirculation, and mixing. The tests did not show any strong variations with any of these parameters. Apart from the first sample, which was taken at part load with low bed temperatures, the carbon heat loss was in the range of 0.3 to $1.3 \%$ of the coal higher heating value. Figure 6.4-1 shows the variation in the carbon heat loss during this test campaign. 


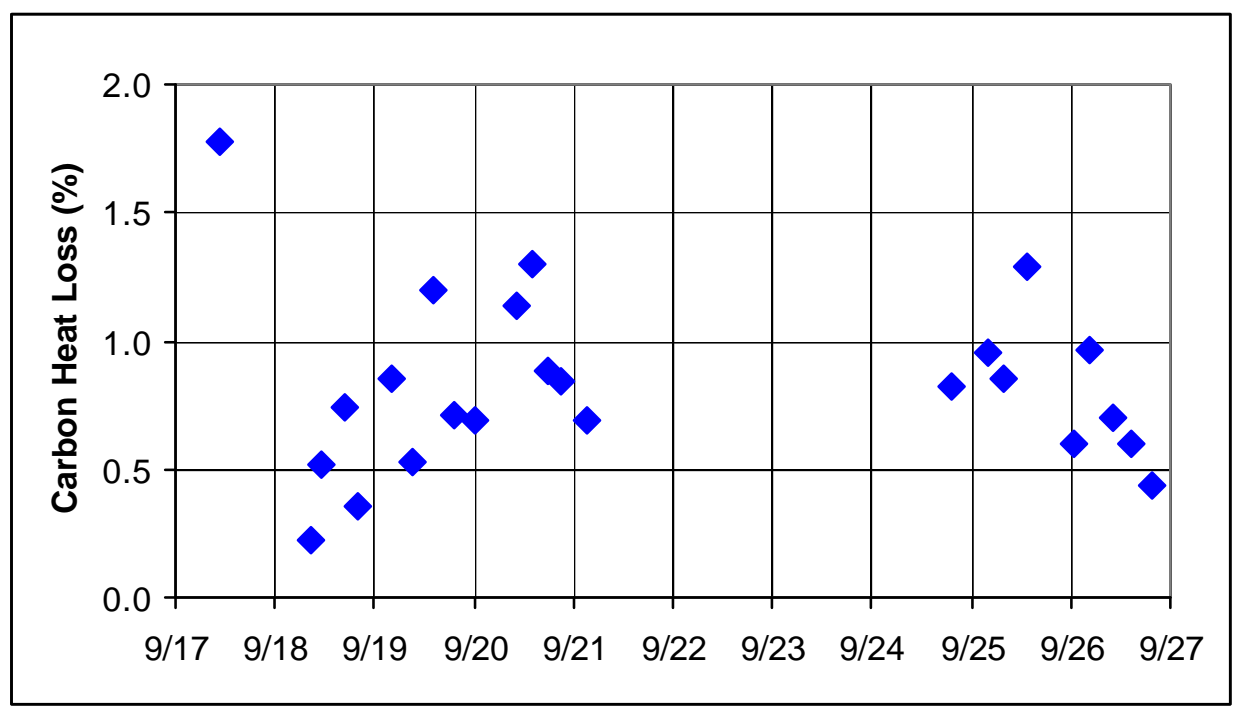

Figure 6.4-1: Carbon Heat Loss With West Virginia Coal

The oxygen concentration leaving the boiler varied from $3.6 \%$ to $8.3 \%$ on a dry basis, except for the one low load / low temperature test where it was 10.5\%. Figure 6.4-2 shows that carbon loss was not a strong function of the oxygen concentration, although the carbon heat loss was expected to increase if the oxygen was decreased much below the minimum test conditions in this figure.

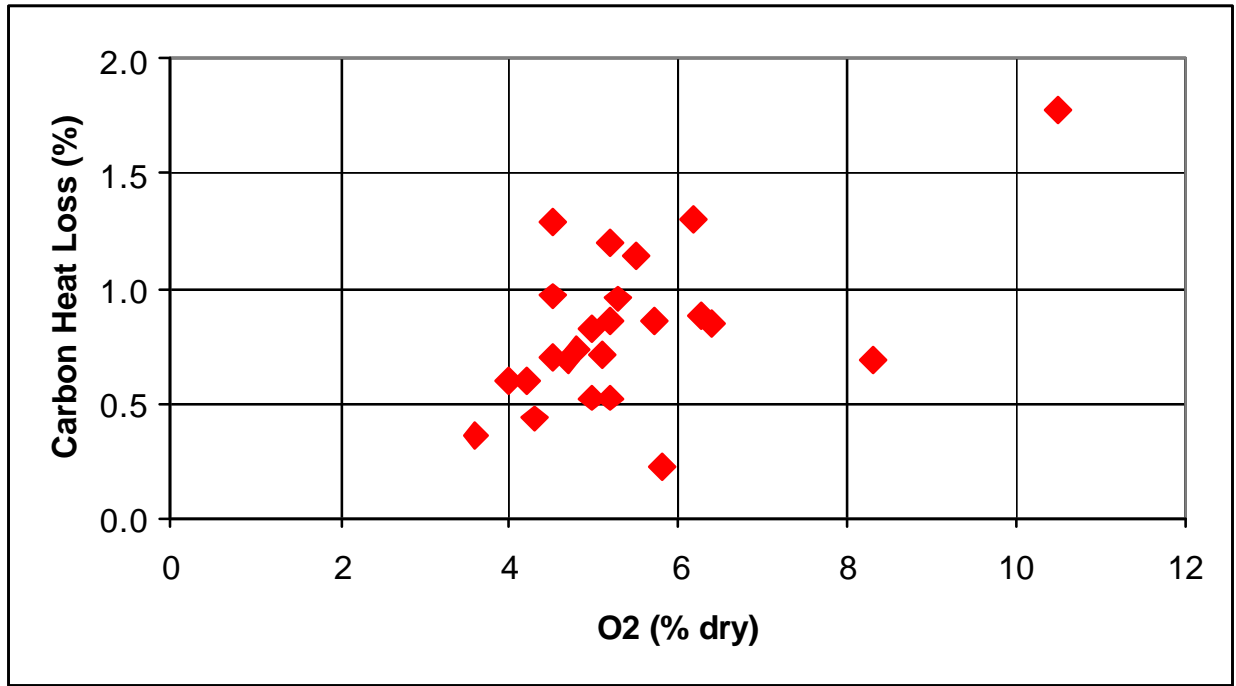

Figure 6.4-2: Effect of Oxygen on Carbon Heat Loss - West Virginia Coal

A short series of four tests was also run to look at the effect of mixing grids on the combustor performance. Two tests each were run with mxing grids in both the on and off position. There were some minor variations in test conditions, but generally the primary change was the position of the mixing dampers. As Figure 6.4-3 shows, the mixing dampers did not have any noticeable effect on the carbon heat loss. 


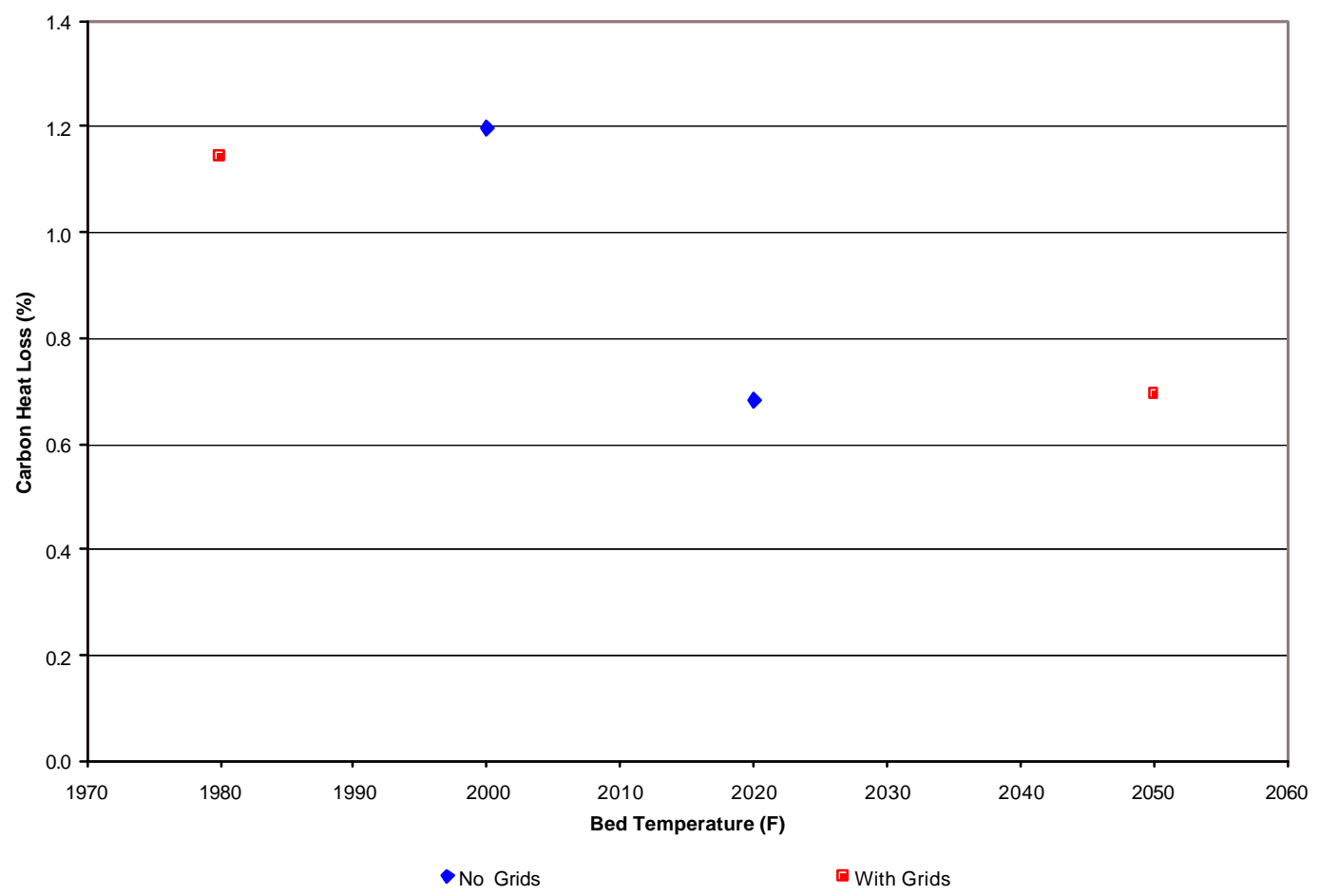

Figure 6.4-3: Effect of Mixing Grids on Carbon Heat Loss

Figure 6.4-4 shows the effect of bed temperature on the carbon loss. This figure shows little temperature effect under normal $\mathrm{CMB}$ operating conditions. The carbon loss increased significantly during the low load / lowest temperature test condition but not during the $1800^{\circ} \mathrm{F}$ and the $1900^{\circ} \mathrm{F}$ test condition.

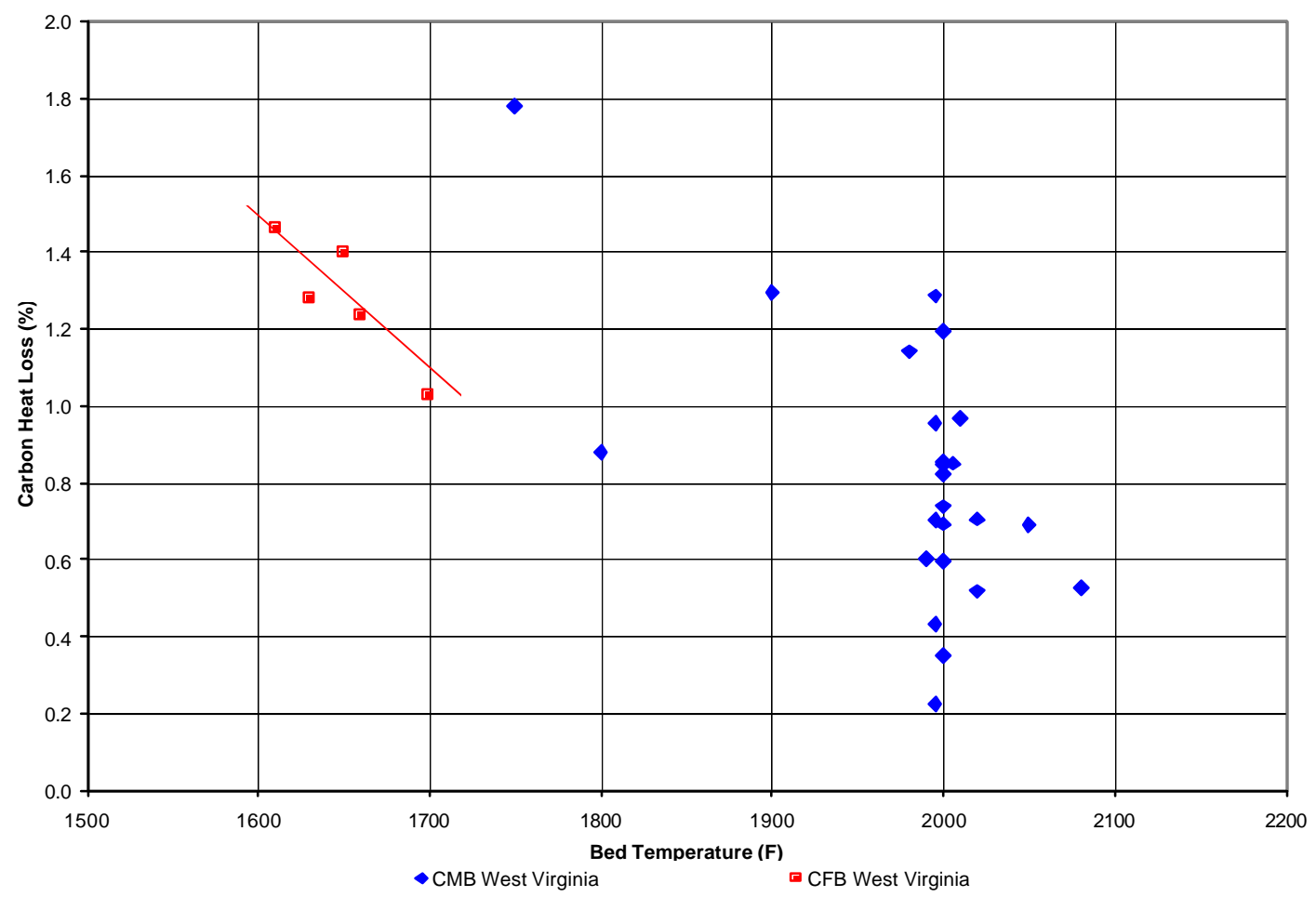

Figure 6.4-4: Carbon Loss vs Bed Temperature - West Virginia Coal 
Comparison with CFB Conditions

Figure 6.4-4 also shows the carbon heat loss from a recent CFB test campaign in the MTF using the same West Virginia bituminous coal. During CFB operating conditions, there was a trend to lower heat loss with higher combustor temperature. These results show that the CMB carbon heat loss was at least as good and frequently better than the CFB carbon heat loss results.

\section{Results - Pittsburgh \#8 Bituminous Coal}

Pittsburgh \#8 bituminous coal was fired during the February 2003 test campaign. Results from these tests are summarized in Table 6.4-2 The table also includes selected operating parameters, including bed temperature, combustor outlet temperature, and overfire air elevation level, and oxygen content in the flue gas. The table also includes the carbon loss in the two bauxite separation hopper gas outlet streams. As discussed before, this carbon will be reinjected into the combustor along with the overfire air in a commercial CMB and are therefore not considered as a carbon loss.

Table 6.4-2: Combustion Performance with Pittsburgh \#8 Bituminous Coal

\begin{tabular}{|c|c|c|c|c|c|c|c|c|c|}
\hline Sample Time & $\begin{array}{l}\text { Unburned } \\
\text { Carbon in } \\
\text { Flyash \% }\end{array}$ & $\begin{array}{l}\text { Flyash } \\
\text { flow } \\
\text { lb/hr }\end{array}$ & $\begin{array}{l}\text { carbon } \\
\text { loss } \\
\text { lb/hr }\end{array}$ & $\begin{array}{l}\text { Coal } \\
\text { Flow } \\
\text { lb/hr }\end{array}$ & $\begin{array}{l}\text { Carbon } \\
\text { Heat } \\
\text { Loss \% }\end{array}$ & $\begin{array}{l}\text { Bed } \\
\text { Temp } \\
{ }^{\circ} \text { F }\end{array}$ & $\begin{array}{l}\text { Outlet } \\
\text { Temp } \\
{ }^{\circ} \mathrm{F}\end{array}$ & $\begin{array}{l}\text { OFA } \\
\text { Elev } \\
f t\end{array}$ & $\begin{array}{l}\mathrm{O}_{2}, \\
\% \text { dry }\end{array}$ \\
\hline
\end{tabular}

\section{Cyclone Outlet Samples}

\begin{tabular}{|c|c|c|c|c|c|c|c|c|c|}
\hline A $2 / 19 / 03$ 05:40 & 15.4 & 53 & 8.2 & 725 & 1.28 & 2000 & 1180 & 12 & 5.5 \\
\hline B 2/19/03 10:45 & 14.3 & 44 & 6.2 & 725 & 0.98 & 1990 & 1235 & 22 & 4.8 \\
\hline C 2/19/03 16:00 & 13.4 & 60 & 8.1 & 725 & 1.27 & 1995 & 1255 & 22 & 4.7 \\
\hline D 2/20/03 06:00 & 11.6 & 57 & 6.6 & 680 & 1.10 & 2000 & 1260 & 12 & 4.5 \\
\hline E 2/20/03 13:15 & 13.6 & 41 & 5.5 & 680 & 0.92 & 1990 & 1230 & 12 & 4.4 \\
\hline F 2/20/03 19:53 & 11.2 & 81 & 9.0 & 715 & 1.43 & 1995 & 1250 & 12 & 2.4 \\
\hline G 2/20/03 22:25 & 9.3 & 72 & 6.7 & 715 & 1.06 & 1995 & 1220 & 22 & 3.2 \\
\hline H 2/21/03 04:50 & 7.1 & 55 & 3.9 & 550 & 0.81 & 1990 & 925 & 12 & 6.6 \\
\hline I $\quad 2 / 21 / 0308: 55$ & 6.2 & 95 & 5.9 & 675 & 0.99 & 1920 & 1350 & 12 & 3.7 \\
\hline J $\quad 2 / 21 / 03 \quad 14: 20$ & 7.2 & 99 & 7.1 & 675 & 1.19 & 1990 & 1265 & 12 & 3.8 \\
\hline K 2/22/03 00:05 & 8.3 & 83 & 6.9 & 680 & 1.15 & 2010 & 1230 & 12 & 3.4 \\
\hline L 2/22/03 05:20 & 4.1 & 104 & 4.2 & 680 & 0.70 & 2005 & 1290 & 12 & 3.6 \\
\hline M 2/22/03 12:45 & 4.4 & 138 & 6.0 & 670 & 1.02 & 1980 & 1330 & 12 & 3.7 \\
\hline N 2/22/03 15:44 & 5.6 & 68 & 3.9 & 670 & 0.65 & 2000 & 1290 & 12 & 3.8 \\
\hline O 2/22/03 22:48 & 4.4 & 56 & 2.5 & 650 & 0.43 & 2095 & 1300 & 12 & 3.9 \\
\hline P 2/23/03 02:00 & 3.8 & 39 & 1.5 & 650 & 0.26 & 2100 & 1410 & 12 & 3.6 \\
\hline
\end{tabular}

MBHE Transport Gas Outlet

\begin{tabular}{|c|c|c|c|c|c|c|c|c|}
\hline Q 2/20/03 04:00 & 10.61 & 14 & 1.4 & 680 & 0.24 & 1995 & 1265 & 12 \\
\hline R 2/22/03 18:20 & 8.52 & 15 & 1.2 & 650 & 0.22 & 1990 & 1290 & 12 \\
\hline
\end{tabular}

Bauxite Hopper Transport Gas Outlet

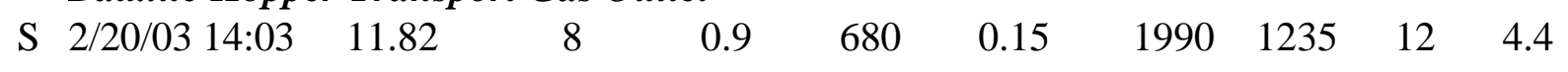


Figure 6.4-5 shows the Carbon Heat Loss for the cyclone outlet samples (A-P in Table 6.4-2. In general, the carbon heat loss varied from 0.9 to $1.2 \%$ of the coal higher heating value during normal CMB operation. The effect of some of the primary operating parameters on combustion performance is also discussed below.

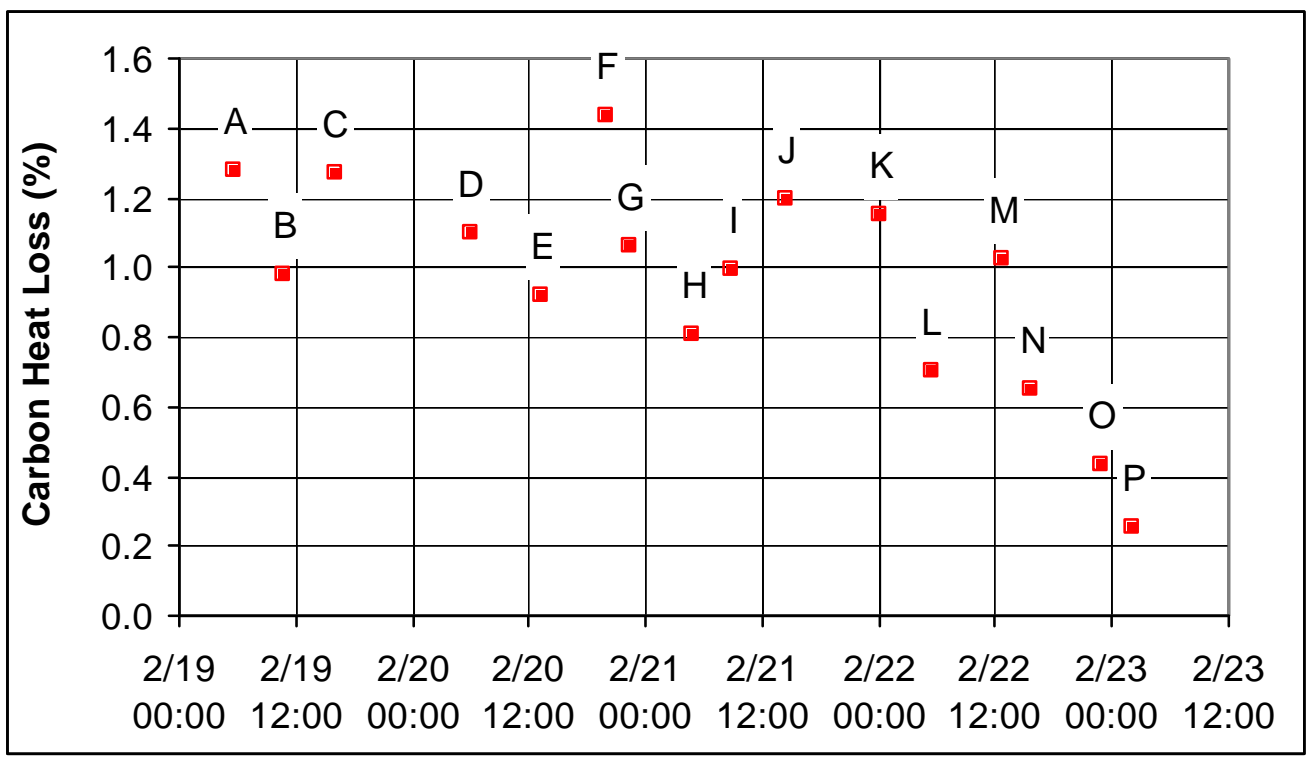

Figure 6.4-5: Combustion Performance With Pittsburgh \#8 Coal

\section{Excess Air}

The oxygen content during the early samples (A - E) was about 1 percentage point higher than the later samples (I - P). There was no apparent effect of higher levels of oxygen on carbon loss when comparing these samples.

Flyash samples $\mathrm{F}$ and $\mathrm{G}$ were taken during low excess air testing. The oxygen content of the flue gas averaged about 3\%, dry during the test. But as shown in Table 6.4-2, sample F was taken during a period of even lower excess air when the oxygen was only $2.4 \%$. In this case, the carbon heat loss of $1.43 \%$ was higher than the normal range. The heat loss indicated by sample $\mathrm{G}$ at $3.2 \%$ oxygen was in line with the others.

Following the low excess air test, we ran at part load with high excess air. During this test, the lower combustor temperature remained near $2000^{\circ} \mathrm{F}$ and the furnace outlet temperature dropped to below $950^{\circ} \mathrm{F}$. The flyash sample from this test (Sample H) had a low carbon heat loss $(0.81 \%)$.

\section{Ash Circulation}

During the low-load, high excess air test $(\mathrm{H})$, there was little or no recirculation of solids from the cyclone back to the furnace. This condition was achieved by isolating the fluid bed heat exchanger and by slumping the outlet end of the sealpot below the cyclone. It was possible that there was a small amount of circulation through the sealpot during the test, but if so, it was greatly reduced. 
This condition simulated $\mathrm{CMB}$ operation with no ash cyclone, which would be a cheaper commercial design. In a CFB system, the cyclone retains unburned carbon and unreacted calcium in the combustor and allows high solids inventory in the furnace for uniform temperature profile and good heat transfer to the waterwalls. In the CMB system, a high ash inventory is not desired. Most of the sulfur capture takes place in the backend FDA system, so retaining the unutilized calcium may be less important.

The main concern about a design with no cyclone is the unburned carbon loss. The carbon heat loss from this test at low load with little or no recirculation was slightly better than the loss during full load operation and with ash recirculation. Unfortunately, this condition was not repeated at full load conditions. At times either the FBHE was isolated or the sealpot outlet was slumped, but not both together.

\section{Air Staging Elevation}

The carbon heat loss was not affected by the level of overfire air injection. The injection port was varied from the 12 foot to 22 foot elevation.

\section{Bed Temperature}

For most of the tests, the bed temperature was maintained at $2000^{\circ} \mathrm{F}$. Flyash Sample I was taken during an unsteady period when the bed temperature was about $1920^{\circ} \mathrm{F}$ and the furnace outlet temperature was up to about $1350^{\circ} \mathrm{F}$. There was no obvious change to unburned carbon. However, the high temperature test at the end of this test campaign clearly caused a reduction in the unburned carbon heat loss (Samples $\mathrm{O}$ and P). This effect is shown in Figure 6.4-6.

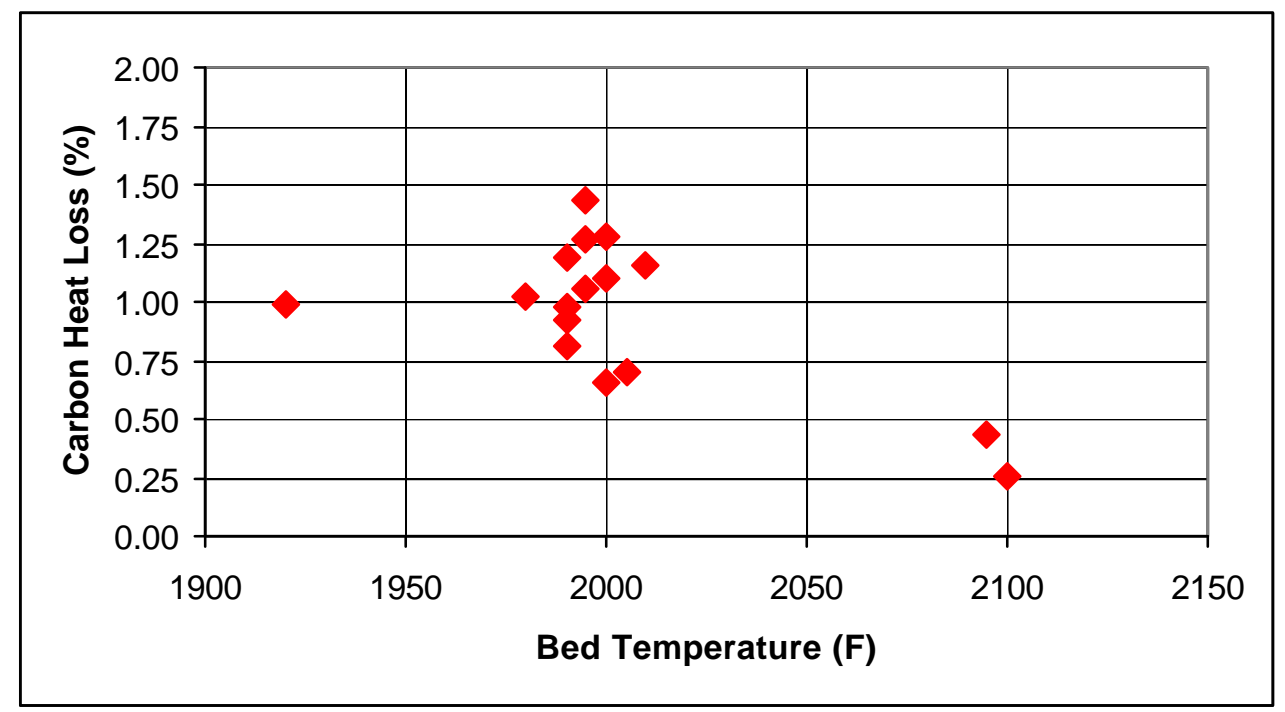

Figure 6.4-6: Effect of Bed Temperature on Carbon Loss - Pittsburgh \#8 Coal

\section{Losses from Bauxite Transfer}

In the MTF tests, hot bauxite was pneumatically transported from the bottom of the furnace to the top of the circulating moving bed heat exchanger. The cooled bauxite was then pneumatically transported from the MBHE outlet to the top of the furnace. In each case, a cyclone separated the bauxite from the transport air. Ash and unburned carbon circulated 
along with the bauxite and some was lost through each of the disengaging cyclones. Very little bauxite was lost.

Table 6.4-2 shows the carbon loss results of three samples taken from the cyclone outlets. The carbon heat loss from the two streams was about $0.4 \%$. In the base-case commercial $\mathrm{CMB}$ design, the hot bauxite will be fed by gravity to the heat exchanger section. Only the cooled bauxite will need to be pneumatically transported to the top of the furnace. The amount of transport air is large enough that it will be returned to the furnace as combustion air. Thus any unburned carbon (and unutilized calcium) in this air will be returned to the combustor.

\section{Total Heat Losses}

The preceding discussion focused on the heat loss due to carbon in the flyash, which was the major combustion inefficiency. There were a few other smaller sources of unburned carbon losses that have also been briefly mentiioned:

- unburned carbon loss in other bed drain streams

- unburned carbon loss from bauxite transport lines

- $\quad$ heating value of carbon monoxide $(\mathrm{CO})$ in the flue gas.

\section{Bed Drain}

The only other drain stream in the MTF tests was from the fluid bed heat exchanger (FBHE). For long-term commercial operation, there would also need to be some drain from the lower furnace to remove coarse material. This was not needed for these tests. The bed carbon concentration is very low and should be an insignificant loss. The loss of cooling transient test described in Section 6.8 showed that the bed carbon concentration was considerably less than $0.1 \%$.

The carbon heat loss in the FBHE drain can be estimated from the drain rate and the carbon content in the ash stream. The amount of FBHE drain material was calculated by a system mass balance (total ash generated - measured flyash). The carbon content in two FBHE drain samples was 0.4 and 0.8 wt.\%. To estimate the percent heat loss from this unburned carbon, we estimate a conservative $1.0 \%$ unburned carbon in the FBHE drain and calculate the drain rate from the mass balance. The heat loss range was:

- 0.10 to $0.17 \%$ of coal higher heating value for the West Virginia bituminous coal in September 2002

- 0.10 to $0.25 \%$ of coal higher heating value for the Pittsburgh \#8 bituminous coal in February 2003

\section{Transport Losses}

As discussed earlier, the carbon heat loss from the bauxite transport lines was about $0.4 \%$ of the coal heat input. In a commercial system, this ash will be returned to the combustor, giving another chance for the carbon to burn out. 
Carbon Monoxide Loss

For either of the bituminous fuels burned in the MTF tests, a CO emission of $100 \mathrm{ppm}$ (dry at $3 \% \mathrm{O}_{2}$ ) corresponds to about $0.082 \mathrm{lb} \mathrm{CO} / \mathrm{MBtu}$ fired. Since the heating value of $\mathrm{CO}$ is $4,347 \mathrm{Btu} / \mathrm{lb}$, the heat loss is $0.036 \%$ heat loss per $100 \mathrm{ppm}$ CO.

During the West Virginia coal tests in September 2002, the CO emissions were typically under $100 \mathrm{ppm}$ at normal conditions (with generally high $\mathrm{O}_{2}$ ).

During the Pittsburgh \#8 bituminous tests in February 2003, the CO emissions generally ranged from 150 to $400 \mathrm{ppm}$. This makes a heat loss of 0.05 to $0.14 \%$ of the coal heating value.

Combustion Efficiency

Based on the above losses, the overall combustion efficiency can be estimated for each fuel. The combustion efficiency during the West Virginia coal tests ranged from 98.5 to $99.6 \%$. The combustion efficiency during the Pittsburgh \#8 coal tests ranged from 98.4 to $99 \%$.

\section{Comparison with CFB Conditions}

Pittsburgh \#8 bituminous coal has now been burned in the MTF under both CMB and CFB operating conditions, although the fuel analysis was different during these different test series. Table 6.4-3 shows typical analyses of the fuel using during the CMB tests and an earlier, high-ash, high-sulfur Pitt\#8 fuel from a CFB test.

Table 6.4-3: Pittsburgh \#8 Coal Analysis During CMB and CFB Test Campaigns

\begin{tabular}{|l|l|l|}
\hline & $\begin{array}{l}\text { Feb 03 } \\
\text { CMB }\end{array}$ & $\begin{array}{l}\text { Dec 00 } \\
\text { CFB }\end{array}$ \\
\hline Carbon & 70.6 & 64.8 \\
\hline Hydrogen & 4.8 & 4.1 \\
\hline Oxygen & 6.3 & 6.1 \\
\hline Nitrogen & 1.3 & 1.2 \\
\hline Sulfur & 2.9 & 4.3 \\
\hline Ash & 7.2 & 14.8 \\
\hline Moisture & 6.9 & 4.7 \\
\hline HHV & 12764 & 11939 \\
\hline
\end{tabular}

The earlier CFB test had about $3 \%$ carbon heat loss with $1600^{\circ} \mathrm{F}$ furnace temperature compared to about $1 \%$ carbon heat loss in these CMB tests at $2000^{\circ} \mathrm{F}$. Some of this difference may be due to fuel differences. However, as with the West Virginia coal, the CMB combustion performance is at least as good or better than CFB performance during full load operations. 
6.5 $\mathrm{NO}_{\mathrm{x}}, \mathrm{N}_{2} \mathrm{O}$, and $\mathrm{CO}$ Emissions

An objective of the MTF test campaigns was to assess the environmental performance of the CMB process with respect $\mathrm{NO}_{\mathrm{x}}, \mathrm{N}_{2} \mathrm{O}$, and $\mathrm{CO}$. $\mathrm{CMB}$ combustor temperature profiles are significantly different from conventional CFBs, with higher bed temperatures and a declining temperature profile up the combustor. The temperatures are not high enough to generate any thermal $\mathrm{NO}_{\mathrm{x}}$, but are high enough to prevent the formation of $\mathrm{N}_{2} \mathrm{O}$. Tests were conducted with two different coals and with various degrees of air staging. Ammonia injection was also used during one test sequence to evaluate its impact on $\mathrm{NO}_{\mathrm{x}}$ reduction.

\section{Environmental Performance with West Virginia Coal}

Table 6.5-1 summarizes the emissions during a test sequence on September 18, 2002 where the airflow was varied to control $\mathrm{NO}_{\mathrm{x}}$. The baseline test conditions showed $\mathrm{NO}_{\mathrm{x}}, \mathrm{N}_{2} \mathrm{O}$, and $\mathrm{CO}$ at $270 \mathrm{ppm}$, about $150 \mathrm{ppm}$, and $0 \mathrm{ppm} @ 3 \% 02$, respectively. The primary air to the bed was then reduced, which lowered the $\mathrm{NO}_{\mathrm{x}}$ to $240 \mathrm{ppm}$ and the $\mathrm{CO}$ to $90 \mathrm{ppm}$. The total excess air was finally lowered in two stages, which reduced the $\mathrm{NO}_{\mathrm{x}}$ to $190 \mathrm{ppm}$ and the $\mathrm{CO}$ to $70 \mathrm{ppm}$. $\mathrm{N}_{2} \mathrm{O}$ emissions remained close to $0 \mathrm{ppm}$ for all test conditions. Figure 6.5-1 shows the trend lines for these emissions during this test sequence.

Table 6.5-1: Emissions with West Virginia Coal

\begin{tabular}{|c|c|c|c|c|}
\hline Test Condition & Time & $\begin{array}{l}\text { Oxygen (wet / } \\
\text { dry) }\end{array}$ & $\begin{array}{l}N O_{\mathrm{x}} @ 3 \% \mathrm{O}_{2} \\
(\mathrm{ppm})\end{array}$ & $\begin{array}{l}C O @ 3 \% C \\
(p p m)\end{array}$ \\
\hline Base Case at $2000^{\circ} \mathrm{F}$ & $07: 30-09: 30$ & $3.5 / 5.1$ & 270 & $200-100$ \\
\hline Low Primary Air & $10: 00-14: 00$ & $3.5 / 5.1$ & $230-250$ & $100-80$ \\
\hline Low Excess Air & $16: 00-17: 00$ & $3.2 / 4.8$ & 220 & 80 \\
\hline Lower Excess Air & $18: 00-20: 00$ & $2.4 / 3.5$ & 190 & 70 \\
\hline
\end{tabular}

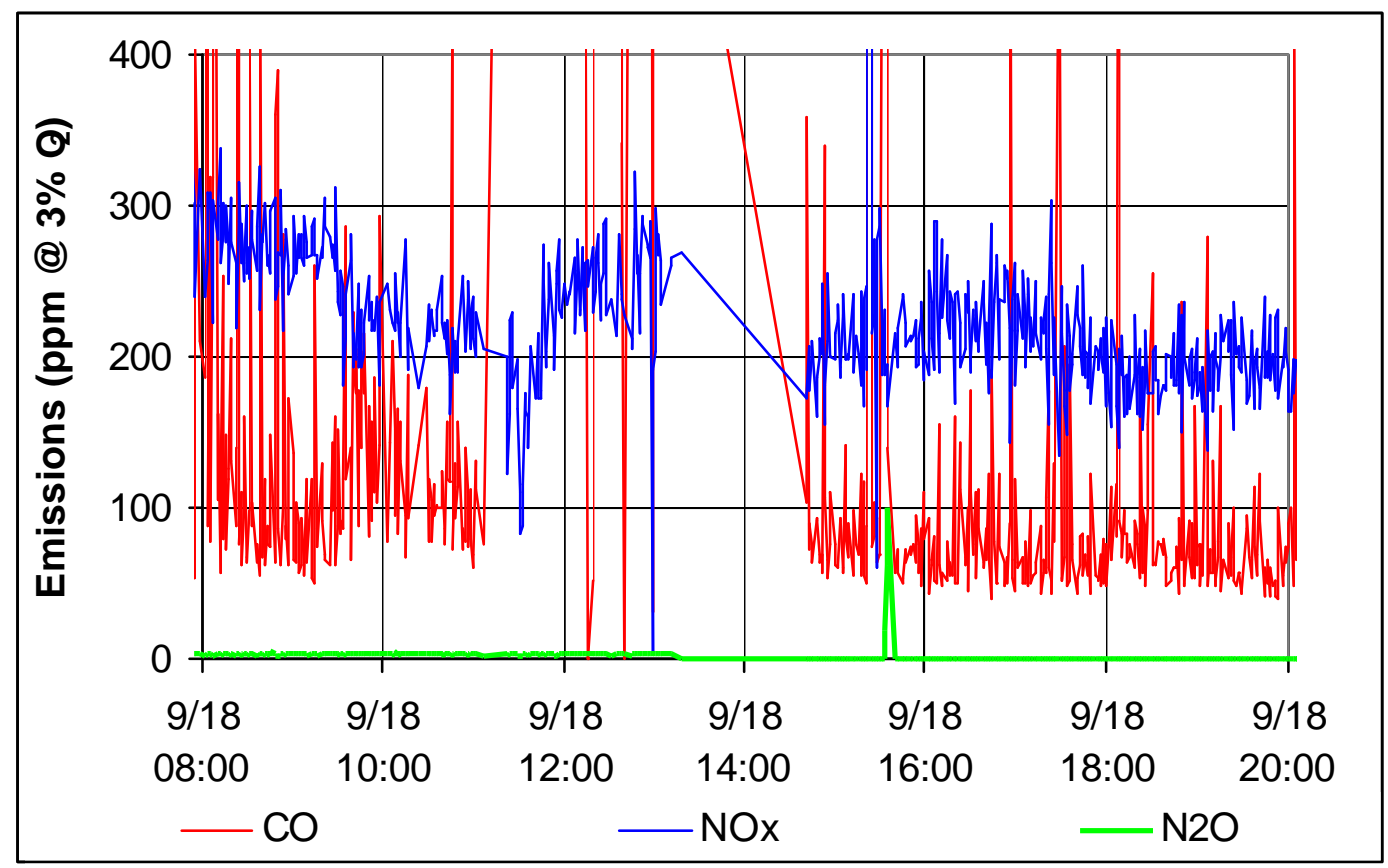

Figure 6.5-1: Emissions With West Virginia Coal 
These results showed that $\mathrm{NO}_{\mathrm{x}}$ emissions could be reduced by controlling the degree of air staging and excess air levels. Unfortunately, the depth of air staging was limited during this test series. The MBHE was not yet in service and the water-cooled transport line did not provide sufficient cooling to run the combustor at full load conditions. The primary air could not be reduced too much because we wanted to ensure adequate fluidization. Subsequent tests when operating with the MBHE at higher loads provided greater flexibility for staging.

The CO emissions decreased during this test sequence, which seemed contrary to expectations. Due to the changes in air splits, the inventory of circulating solids was increasing and therefore the temperature at the top of the furnace was increasing. $\mathrm{CO}$ emissions were very sensitive to the combustor outlet gas temperature.

$\mathrm{N}_{2} \mathrm{O}$ emissions are not currently regulated but are of interest as a greenhouse and ozonedepleting gas. $\mathrm{N}_{2} \mathrm{O}$ emissions are strongly dependent on combustion temperature. In a pulverized coal fired furnace, the emission levels are very low- just a few ppm. In CFB combustors at about $1600^{\circ} \mathrm{F}, \mathrm{N}_{2} \mathrm{O}$ emissions can be up to $100 \mathrm{ppm}$. The $\mathrm{N}_{2} \mathrm{O}$ emissions in the $\mathrm{CMB}$ were always less than $5 \mathrm{ppm}$ due to the high temperature in the lower furnace.

Other parameters were varied during the course of testing that could affect emissions. These included mixing grids, cyclone ash recycle rates, and recycle injection location. These are described in the next sections.

\section{Mixing Grids}

The bauxite mixing grids were moved into position during one test to assess its impact on performance. The only obvious impact of the mixing grids was that the furnace outlet gas temperature decreased by $20^{\circ} \mathrm{F}$, indicative of better mixing. Moving the grids back out of position caused the gas temperature to increase again by $20^{\circ} \mathrm{F}$. There was no apparent impact on $\mathrm{NO}_{\mathrm{x}}$ or $\mathrm{CO}$ emissions due to the grid position.

Cyclone Ash Recycle Rate

When circulating ash was allowed to accumulate, the upper furnace pressure drop increased. Along with the increased circulation through the cyclone, the internal refluxing in the combustor increased. This caused the combustor temperature profile to flatten out, resulting in increased combustor gas outlet temperatures. There was no apparent effect on the $\mathrm{NO}_{\mathrm{x}}$ emissions with increasing ash recycle, but the CO levels decreased due to the higher temperature in the upper furnace.

\section{Cyclone Ash Recycle Injection Level}

The furnace temperature profile was also affected by the location of the recycle return. When the recycle location was switched from the lower combustor to about 10 feet higher, the temperatures along the furnace height were lower for the same $2000^{\circ} \mathrm{F}$ bed temperature. When the injection location was moved another five feet higher, the temperatures in the upper furnace dropped further while the temperature of the bed increased to $2100^{\circ} \mathrm{F}$. The primary effect was that $\mathrm{CO}$ emissions increased from 50 to $150 \mathrm{ppm}$ after the recycle injection location was raised due to the lower combustor outlet gas temperature. $\mathrm{NO}_{\mathrm{x}}$ emissions also dropped from about $270 \mathrm{ppm}$ to $150 \mathrm{ppm}$ with the higher recycle injection. 
This reduction could have been because most of the calcium oxide in the recycle stream was now being injected well above the bed. This minimized the catalytic effect calcium oxide has on $\mathrm{NO}_{\mathrm{x}}$ formation. The combustor temperature profile during these changes is shown in Figure 6.5-2.

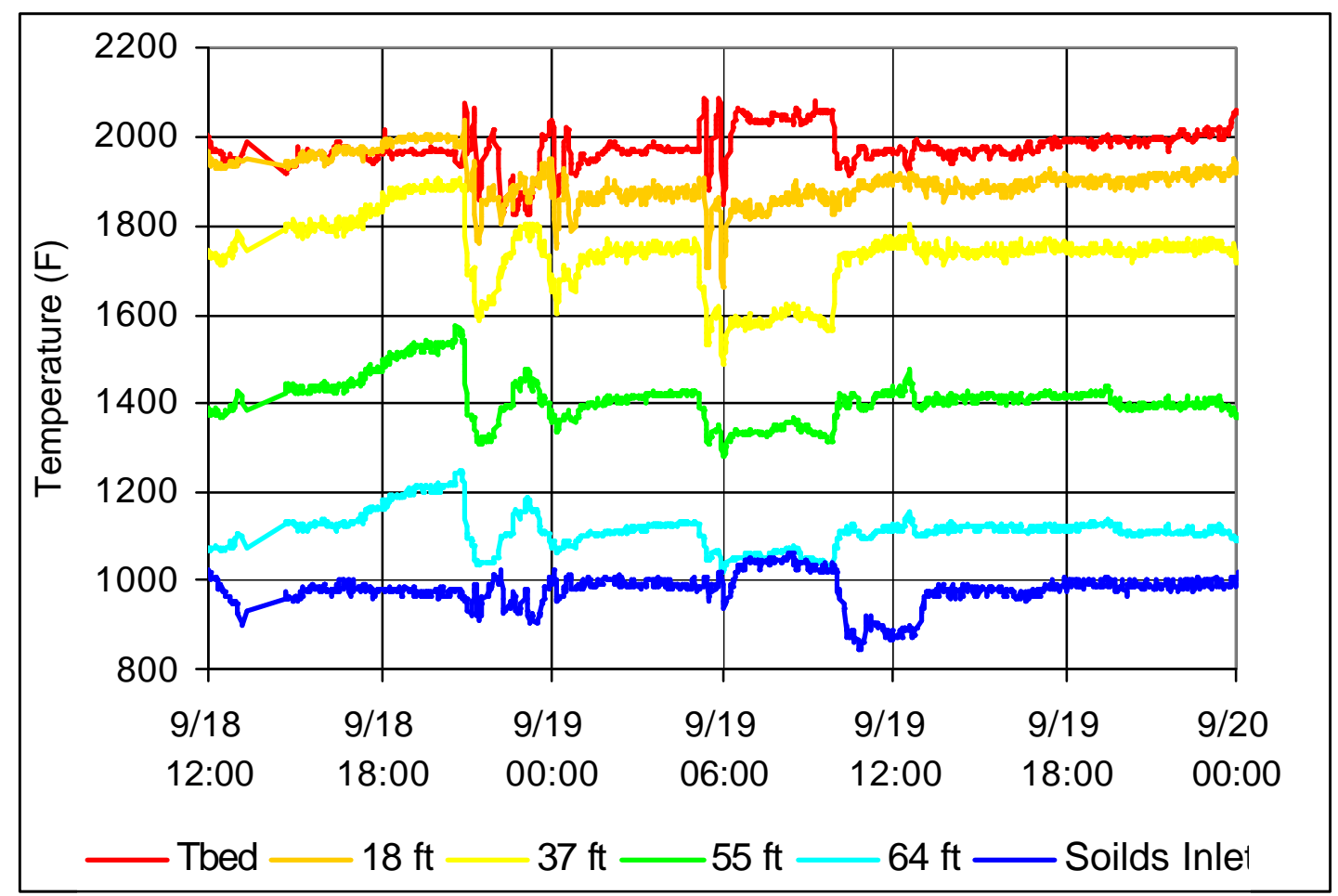

Figure 6.5-2: Combustor Temperature Profile During Recycle Location Variations

The first switch to the 10-foot location occurred at 21:00 on 9/18/02. The cool recycle solids which were being returned to the lower combustor were helping to control the bed temperature to $2000^{\circ} \mathrm{F}$. Moving this reinjection from the bed upset the bed temperature. When the bed temperature was reestablished at $2000^{\circ} \mathrm{F}$, the temperatures in the upper furnace were lower due to these reinjected solids. From 05:00 to 10:00 on 9/19/02, the ash reinjection was moved to the higher location. This also upset the heat balance in the bed. The bed temperature eventually stabilized at $2100^{\circ} \mathrm{F}$. The temperatures above the new reinjection point cooled further. The thermocouple at elevation 18 -ft was now below the reinjection point and its temperature did not decrease. At 10:00, the recycle injection point was returned to the 10-foot location and the temperature profile was similar to that seen earlier.

\section{Environmental Performance with Pittsburgh \#8 Coal}

The $\mathrm{NO}_{\mathrm{x}}$ and $\mathrm{CO}$ emissions during the February 2003 tests with Pittsburgh \#8 coal are summarized in Table 6.5-2. The table also includes details on how the emissions responded during changes in the furnace operating conditions. The $\mathrm{N}_{2} \mathrm{O}$ analyzer was not in service during these tests. $\mathrm{N}_{2} \mathrm{O}$ emissions were expected to remain close to $0 \mathrm{ppm}$ with this coal also. The following sections describe results of a series of tests with ammonia injection and airflow variations to control $\mathrm{NO}_{\mathrm{x}}$ emissions. 
Table 6.5-2: Emissions with Pittsburgh \#8 Coal

\begin{tabular}{|c|c|c|c|c|c|c|c|c|c|c|}
\hline Test & $\begin{array}{c}\text { \%Primary } \\
\text { Air }\end{array}$ & $\begin{array}{c}\% \mathrm{O}_{2}, \\
\text { dry }\end{array}$ & $\begin{array}{c}\text { Overfire } \\
\text { Air Level }\end{array}$ & $\begin{array}{c}\mathrm{NH}_{3} \\
\text { Level }\end{array}$ & $\mathrm{Ca} / \mathrm{S}^{(1)}$ & Bed Temp & $\begin{array}{c}\mathrm{NH}_{3} \text { Level } \\
\text { Temp }^{(2)}\end{array}$ & $\begin{array}{c}\text { Furnace } \\
\text { Outlet Temp }\end{array}$ & $\mathrm{NO}_{\mathbf{x}}{ }^{(3)}$ & $\mathrm{CO}^{(3)}$ \\
\hline \multicolumn{11}{|c|}{ I. Ammonia Injection on Elevation $22(2 / 4)$} \\
\hline A $14: 00-15: 00$ & 47 & 6.7 & 12 & -- & $\mathrm{C2}$ & 2000 & -- & 1100 & 350 & 120 \\
\hline B $16: 00-16: 55$ & 47 & 6.7 & 12 & 22 & $\mathrm{C} 2$ & 2000 & $1700-1750$ & 1080 & 200 & $300-500$ \\
\hline \multicolumn{11}{|c|}{ II. Changing Overfire Air (2/19) } \\
\hline A $05: 00-08: 00$ & 50 & 5.2 & 12 & -- & E2 & 2010 & -- & 1170 & 240 & 150 \\
\hline B $08: 30-11: 10$ & 50 & 4.8 & 22 & -- & $\mathrm{E2}$ & 1990 & -- & 1250 & 175 & $300-400$ \\
\hline C $11: 10-11: 45$ & 50 & 4.8 & 12 & -- & E2 & 1980 & -- & 1270 & 250 & 300 \\
\hline D $11: 45-13: 30$ & 42 & 4.5 & 12 & -- & $\mathrm{E2}$ & 1970 & -- & 1300 & 210 & 150 \\
\hline E $13: 30-16: 30$ & 42 & 4.5 & 22 & -- & $\mathrm{E2}$ & 2000 & -- & 1250 & 115 & 270 \\
\hline \multicolumn{11}{|c|}{ III. Ammonia Injection on Elevation $12(2 / 19)$} \\
\hline A $16: 50-17: 45$ & 42 & 4.6 & 22 & 12 & E2 & 1990 & $1800-1900$ & 1260 & 120 & 250 \\
\hline B $18: 00-18: 50$ & 42 & 4.6 & 12 & 12 & $\mathrm{E} 2$ & $2000-2030$ & $1800-1900$ & 1280 & 180 & $140-300_{+}$ \\
\hline \multicolumn{11}{|c|}{ IV. Ammonia Iniection on Eleyation $22(2 / 19)$} \\
\hline A $19: 15-22: 50$ & 42 & 4.6 & 12 & 22 & E2 & 1980 & $1700-1800$ & 1300 & 140 & 200 \\
\hline B $23: 00-00: 00$ & 44 & 4.6 & 12 & -- & E2 & 1990 & -- & 1260 & 185 & 175 \\
\hline \multicolumn{11}{|c|}{ V. Excess Air and Staqing (2/20) } \\
\hline A $14: 30-17: 30$ & 45 & 4.2 & 12 & -- & $\mathrm{E} 4$ & 1990 & -- & 1230 & 160 & 150 \\
\hline B $17: 30-20: 15$ & 45 & 3 & 12 & -- & E4 & 2000 & -- & $1220-1260$ & 125 & $200-400$ \\
\hline C $20: 15-22: 30$ & 45 & 3 & 22 & -- & $\mathrm{M} 2$ & 2000 & -- & 1210 & 88 & $300-400$ \\
\hline D $22: 30-23: 30$ & 45 & 3.2 & 22 & 22 & $\mathrm{M} 2$ & 1990 & $1700-1800$ & 1200 & 80 & 300 \\
\hline \multicolumn{11}{|c|}{ VI. Part Load (2/21) } \\
\hline A $\quad 04: 00-06: 00$ & 51 & 6.7 & 12 & -- & $\mathrm{M} 2$ & 2000 & -- & 930 & 280 & 600 \\
\hline & & & & & & & & & & \\
\hline
\end{tabular}

(1) $\mathrm{C} 2$ - Chemstone at Ca/S of 2:1; E2, E4 - Ecocal limestone at Ca/S of 2:1 and 4:1, respectively; M2 - Marblewhite limestone at Ca/S of 2:1

(2) Temperature at or near the ammonia injection location according to thermocouple rakes

(3) $\mathrm{NO}_{\mathrm{x}}$ and $\mathrm{CO}$ emissions are ppm by volume, dry, at $3 \% \mathrm{O}_{2}$ 


\section{Ammonia Injection}

Injection on Elevation $22 \mathrm{ft}$

A 30\% solution of aqueous ammonia was injected into the furnace on several occasions to assess its effect on reducing $\mathrm{NO}_{\mathrm{x}}$ emissions. The ammonia was introduced at a 2:1 molar ratio. The first test was on February 4, 2003 while we were still firing West Virginia coal. The excess air was high with about $6.5 \% \mathrm{O}_{2}$. Prior to injecting ammonia the $\mathrm{NO}_{\mathrm{x}}$ was about $350 \mathrm{ppm}$. When we injected ammonia as a single stream into the furnace at Elevation 22 feet, the $\mathrm{NO}_{\mathrm{x}}$ was reduced by over $40 \%$ to about $200 \mathrm{ppm}$. The $\mathrm{CO}$ emissions increased with the ammonia injection in this case.

Injection on Elevation $12 \mathrm{ft}$

Ammonia injection was tested again on February $19^{\text {th }}$ while burning Pittsburgh \#8 coal. The first tests were with ammonia injection at the 12 foot elevation and the overfire air introduced at the 22 foot elevation (Test III-A in Table 6.5-2). There was no noticeable change in $\mathrm{NO}_{\mathrm{x}}$ emissions. The injector penetration depth into the furnace was also varied with no noticeable effect.

When the OFA was moved back to Elevation 12 feet (Test III-B), the $\mathrm{NO}_{\mathrm{x}}$ increased as expected. The $\mathrm{NO}_{\mathrm{x}}$ level of $180 \mathrm{ppm}$ was lower than the comparable earlier cases with no ammonia, but similar to the no-ammonia case after these tests, so it was unclear whether there was an effect of the ammonia at this condition.

Injection on Elevation $22 \mathrm{ft}$

The ammonia injection system was moved up to elevation 22 feet while the OFA remained at the 12 foot elevation. This test condition (Test IV-A) resulted in over a $20 \%$ decrease in $\mathrm{NO}_{\mathrm{x}}$ emissions from 180 to $140 \mathrm{ppm}$. When the ammonia injection was stopped, the $\mathrm{NO}_{\mathrm{x}}$ returned to about $185 \mathrm{ppm}$.

\section{Ammonia Slip}

The $\mathrm{NH}_{3}$ concentration in the flue gas was measured during the $\mathrm{NH}_{3}$ injection tests on February $19^{\text {th }}$ upstream of the FDA system. The $\mathrm{NH}_{3}$ concentration was practically zero (not detectable).

Effect of Overfire Air Variations

At the beginning of the late February test, the amount and location of the overfire air (OFA) was varied between elevation 12 and 22 feet. The results showed that moving the overfire air from the throat of the combustor on Elevation 12 feet up to Elevation 22 feet caused a reduction in the $\mathrm{NO}_{\mathrm{x}}$ emissions (compare Test II-B with II-A \& II-C and Test II$\mathrm{E}$ with II-D). The impact on $\mathrm{CO}$ emissions was less clear. It appeared that the higher OFA location resulted in higher $\mathrm{CO}$ emissions.

\section{Excess Air and Air Staging Variations}

Test Series V in Table 6.5-2 shows the effect of excess air and staging. At the beginning of this test series, the limestone feed was doubled to a $\mathrm{Ca} / \mathrm{S}$ mole ratio of $4: 1$. Going from Test V-A to V-B the excess air was decreased through an increase in the coal flow. This 
change reduced the $\mathrm{O}_{2}$ from $4.2 \%$ to about $3 \%$. The $\mathrm{NO}_{\mathrm{x}}$ emissions dropped from 165 ppm to $125 \mathrm{ppm}$. The CO increased from $125 \mathrm{ppm}$ to $200-400 \mathrm{ppm}$.

In Test V-C, the overfire air was moved from Elevation 12 feet up to Elevation 22 feet. At the same time, the Ecocal 5050 limestone inventory was exhausted so the limestone feedstock was switched to the finer Marblewhite 325 sorbent. The limestone feed rate was reduced back down to the base $\mathrm{Ca} / \mathrm{S}$ of $2: 1$. These changes resulted in a further drop in $\mathrm{NO}_{\mathrm{x}}$ to about $88 \mathrm{ppm}$. The $\mathrm{CO}$ also increased somewhat. In Test V-D ammonia was injected into the furnace at Elevation 22 feet. This resulted in a small reduction in $\mathrm{NO}_{\mathrm{x}}$ to about $80 \mathrm{ppm}$.

\section{Load Variation}

The coal flow was reduced to $77 \%$ MCR in Test VI-A. The secondary air was reduced somewhat, but the excess air was increased $\left(6.7 \%\right.$ dry $\left.\mathrm{O}_{2}\right)$. The lower bed stayed at $2000^{\circ} \mathrm{F}$ while the furnace outlet temperature dropped from $1200-1300^{\circ} \mathrm{F}$ down to about $930^{\circ} \mathrm{F}$. As a result of the decreased outlet temperature, the $\mathrm{CO}$ emissions increased to about $600 \mathrm{ppm}$. The $\mathrm{NO}_{\mathrm{x}}$ emissions were quite high (about $280 \mathrm{ppm}$ ), presumably as a result of the high oxygen concentration. The NOx emissions were also high in the early test I-A that had the same high $\mathrm{O}_{2}$.

\section{Emission Comparison with CFB Conditions}

\section{West Virginia Coal}

The MTF pilot plant has tested the West Virginia and Pittsburgh \#8 coals under both CMB and CFB operating conditions. Table 6.5-3 lists some results from other MTF test campaigns that were conducted under CFB conditions using the same West Virginia bituminous coal which was burned in the September test. In general the CFB CO emissions were lower than observed in the CMB tests. $\mathrm{CO}$ is apparently generated in the $\mathrm{CMB}$ in the upper furnace where the gas temperatures are quite low. The $\mathrm{NO}_{\mathrm{x}}$ emissions at $\mathrm{CFB}$ conditions were also generally lower than seen in the CMB tests, other than the 2003 CFB results which were at high temperatures for CFB and at high excess air.

Table 6.5-3: CFB Emissions with West Virginia Coal

\begin{tabular}{|c|c|c|c|c|}
\hline $\begin{array}{c}\text { MTF } \\
\text { Test }\end{array}$ & $\begin{array}{c}\text { Lower } \\
\text { Furnace } \\
\text { Temp, }{ }^{\circ} \mathrm{F}\end{array}$ & $\begin{array}{c}\text { Stack } \\
\mathrm{O}_{2}, \% \\
\text { dry }\end{array}$ & $\begin{array}{c}\mathrm{CO}, \mathrm{ppm} \\
\text { dry @ 3\% } \\
\mathrm{O}_{2}\end{array}$ & $\begin{array}{c}\mathrm{NO}_{\mathrm{x}}, \mathrm{ppm} \\
\text { dry @ 3\% } \mathrm{O}_{2}\end{array}$ \\
\hline $\mathrm{A}(1998)$ & 1550 & $3.5-5.5$ & $50-80$ & $35-55$ \\
\hline $\mathrm{B}(1999)$ & 1560 & $4-5$ & $80-120$ & $60-80$ \\
\hline $\mathrm{B}(1999)$ & 1585 & $5-6$ & $70-100$ & $60-80$ \\
\hline $\mathrm{C}(2003)$ & 1600 & $\sim 7$ & $30-40$ & $150-200$ \\
\hline $\mathrm{C}(2003)$ & 1660 & $\sim 7$ & $20-30$ & $200-280$ \\
\hline
\end{tabular}

Pittsburgh \#8 Coal

A Pittsburgh \#8 bituminous coal was tested in the MTF in 1999, although the fuel analysis was somewhat different from the fuel tested during CMB operation (see Table 6.4-2). Table 6.5-4 summarizes typical CFB emissions with Pittsburgh \#8 coal. 
Table 6.5-4: CFB Emissions with Pittsburgh \#8 Coal

\begin{tabular}{|l|l|l|l|l|l|}
\hline $\mathbf{T E 1 1 3}$ & $\mathbf{T E 1 3 1}$ & $\boldsymbol{O}_{2}$ & $\boldsymbol{C O}$ & $\mathbf{N O}_{\boldsymbol{x}}$ & $\mathbf{N}_{2} \boldsymbol{O}$ \\
\hline $\begin{array}{l}\text { lower bed } \\
\text { top of } \\
\text { furnace }\end{array}$ & $\%$, dry & $\begin{array}{l}\text { ppm } \\
\text { dry, 3\% }\end{array}$ & $\begin{array}{l}\text { ppm } \\
\text { dry, 3\% }\end{array}$ & $\begin{array}{l}\text { ppm } \\
\text { dry, 3\% }\end{array}$ \\
\hline 1600 & 1625 & 2.9 & 35 & 95 & 80 \\
\hline 1605 & 1630 & 2.9 & 32 & 95 & 75 \\
\hline 1605 & 1625 & 3.1 & 32 & 100 & 75 \\
\hline
\end{tabular}

The results again show that $\mathrm{CO}$ emissions during $\mathrm{CFB}$ operation were much lower than in the CMB tests. The $\mathrm{NO}_{\mathrm{x}}$ emissions were comparable to the lowest achieved CMB levels without ammonia. The $\mathrm{N}_{2} \mathrm{O}$ levels in this $\mathrm{CFB}$ test were typical for $1600^{\circ} \mathrm{F}$. We did not analyze for $\mathrm{N}_{2} \mathrm{O}$ in the Pittsburgh \#8 CMB tests, but we expect they would be similar to the single-digit levels we saw with the West Virginia bituminous.

\section{Summary}

The $\mathrm{NO}_{\mathrm{x}}$ emissions were reduced to $100 \mathrm{ppm}$ or below without the addition of ammonia by low excess air and deeper staging. The lowest $\mathrm{NO}_{\mathrm{x}}$ emission achieved without ammonia addition was $88 \mathrm{ppm}$, which was equivalent to $0.11 \mathrm{lb} \mathrm{NO}_{\mathrm{x}} / \mathrm{MBtu}$. Note that pilot plant test facilities inherently have better mixing in the combustor than commercial units due to their smaller size. As a result, pilot plants typically have lower $\mathrm{SO}_{2}$ and $\mathrm{CO}$ emissions and higher $\mathrm{NO}_{\mathrm{x}}$ levels than large scale units. $\mathrm{N}_{2} \mathrm{O}$ emissions were always at very low levels for all conditions tested. Unfortunately, the lowest $\mathrm{CO}$ emissions were also achieved with less staging and high excess air. $\mathrm{CO}$ emissions also increased as the temperature in the upper furnace decreased. This will be a concern in a taller commercial unit where the outlet temperatures will be still lower.

Aqueous ammonia had little impact on $\mathrm{NO}_{\mathrm{x}}$ emissions when it was injected at Elevation 12 feet, regardless of the overfire air injection location. $\mathrm{NO}_{\mathrm{x}}$ reductions of 25 to $40 \%$ were achieved when the ammonia was injected at Elevation 22 feet. Not surprisingly, the reduction was greatest when the initial $\mathrm{NO}_{\mathrm{x}}$ concentration was highest. It is not known whether the difference in ammonia performance at different levels was due to the oxidation conditions (more reducing when injected lower) or to different temperatures (the lower injection point was at a higher temperature). 


\subsection{Sulfur Capture}

Another objective of the MTF test campaigns was to assess the sulfur capture performance of the CMB system in both the combustor and in the backend FDA system. The combustor was intended to primarily calcine the sorbent, which would then be used in the FDA system for sulfur capture. Significant sulfur capture was not expected in the combustor due to the very high temperatures in the lower combustor. However, the sorbent does pass through a temperature window where sulfur capture can take place.

The FDA is basically a modern version of spray drying technology. One of the main controlling process parameters is the humidity in the system, which is controlled by the water amount added to the FDA mixer. Commercially, a FDA system is normally operated at a relative humidity around $50 \%$. Higher humidities were also tested in this program to assess its effect on sulfur capture.

The FDA is operated with a very large solids inventory that takes a long time to replace and to get to steady state conditions. Due to the available pilot plant test time, many tests were conducted for shorter durations with the objective to find trends rather than running longer terms to establish actual steady state values.

\section{Limestones Tested in the MTF}

During the September 2002 and the February 2003 test campaigns, four limestones were evaluated at six different sizes in the MTF CMB tests. The initial tests were conducted with the low sulfur West Virginia coal and the February tests were run with the Pittsburgh \#8 coal. The limestones tested are briefly described below:

- Chemstone is a limestone from Virginia and is rather unreactive for sulfur capture in CFB combustors.

- Aragonite is from the Atlantic seabed and is known to be very reactive in CFB combustors.

- Sorbent $\mathrm{X}$ is a proprietary, commercial product that was produced by the manufacturer specifically for this high temperature test.

- Eco-Cal 5050 and Marblewhite 325 (from Specialty Minerals) are two sizes of North Adams limestone from western Massachusetts.

The size distributions for these sorbents are shown in Figure 6.6-1. The size distributions of the Chemstone and Aragonite are typical sieve results from earlier MTF tests. These distributions are at the coarse end of typical feed sizes for commercial CFB combustors. Sorbent $\mathrm{X}$ was finer than the Chemstone and Aragonite. The pulverized Chemstone size distribution was measured by CILAS laser technique. The Marblewhite 325 and Eco-Cal 5050 distributions are Sedigraph results from the supplier.

The size distribution of the three finest sorbents was selected to vary the amount of calcium that passed through the cyclone and was carried over to the FDA system 


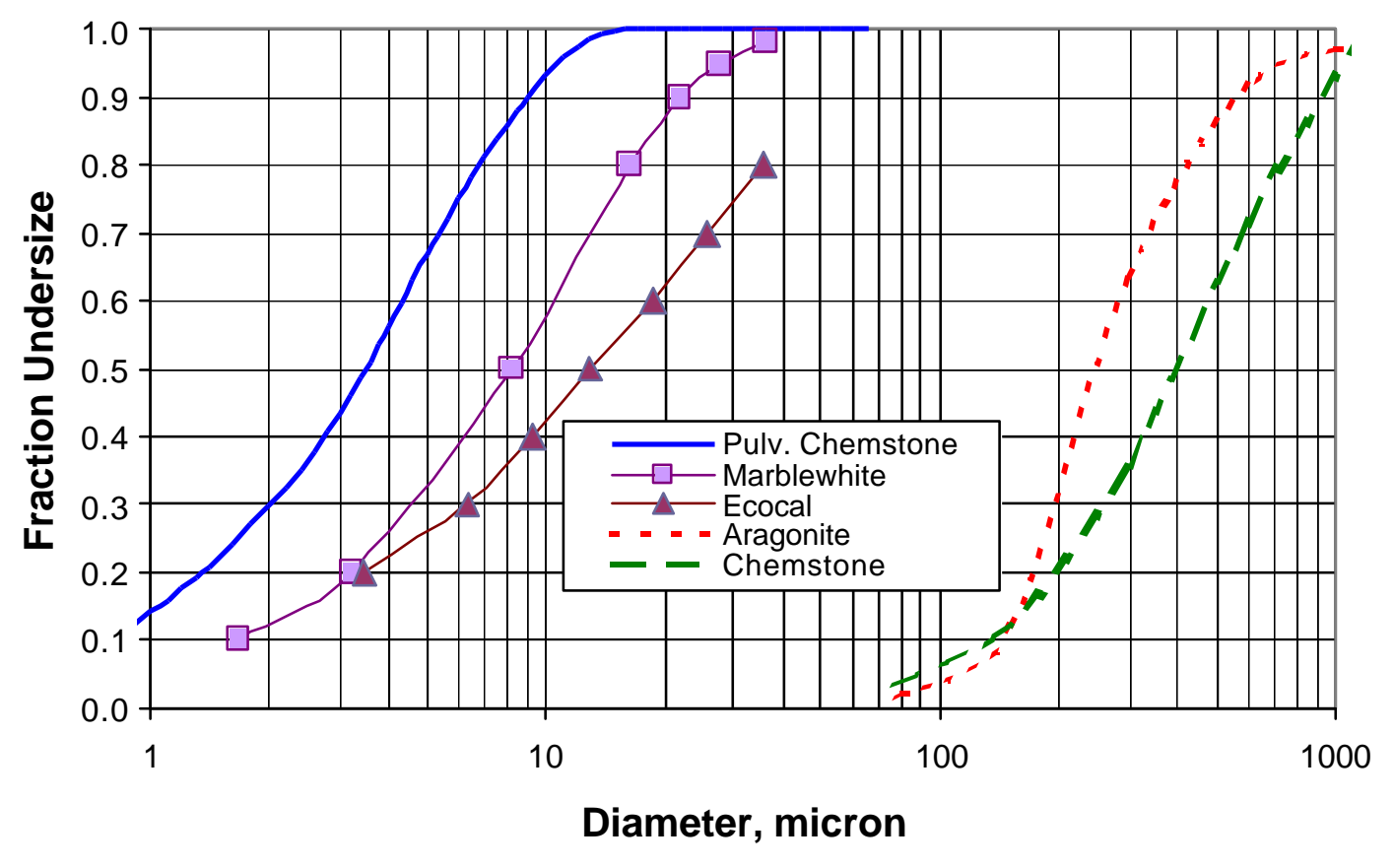

Figure 6.6-1: Limestone Size Distributions

\section{Carryover of the Calcium to the Backend FDA}

Isokinetic samples were taken of the flyash leaving the furnace cyclone throughout the MTF tests. The flyash flow rate was then determined from the amount of sample collected over the sample duration. Past results showed that this calculated flyash flow rate matches reasonably well with the flow rate determined by other methods, including mass balance on the furnace, long-term solids collection in the baghouse, or other isokinetic sampling methods (i.e. EPA Method 5). Nevertheless, the results were considered here mainly for approximate values.

Several of these flyash samples were analyzed for calcium and sulfur. The amount of calcium (total and unreacted) that was carried over to the FDA was calculated from these analyses and from the calculated flyash flow rates. Figures 6.6-2 and 6.6-3 show these results expressed as the fraction of total unreacted calcium (i.e. $\mathrm{CaO}$ based on sulfur capture in the furnace) which was carried over to the FDA system.

Note that these figures only show the amount of calcium carried over from the furnace to the backend FDA system. They do not show the actual amount of calcium present in the baghouse, since these tests were short compared to the solids residence time in the baghouse. 


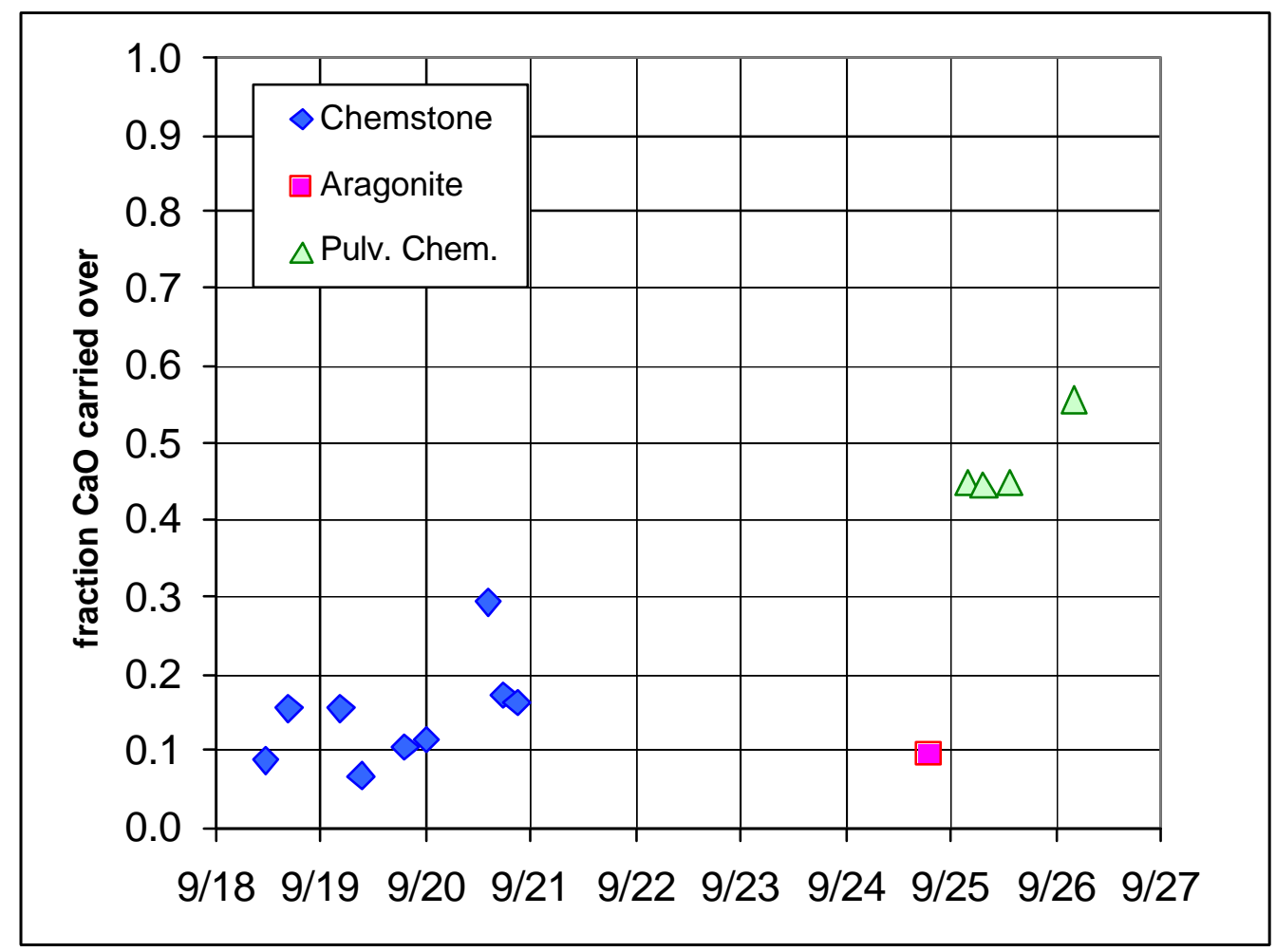

Figure 6.6-2: CaO Fraction Carried Over to FDA - West Virginia Coal

The trends shown in Figures 6.6-2 clearly show that very little of the coarse Chemstone and Aragonite sorbent was carried over to the backpass. Flyash samples taken while feeding Sorbent $\mathrm{X}$ were not analyzed for calcium, although it was expected to again show that little calcium was being carried over to the FDA. It was only after switching to the pulverized Chemstone that the amount of calcium caryover to the FDA increased significantly. Similarly in the February 2003 test campaign, the calcium carryover shown in Figure 6.6-3 increased significantly when switching from the Eco-Cal 5050 to the finer Marblewhite 325 sorbent.

It was somewhat surprising that the actual calcium carryover fraction was higher for the Marblewhite 325 limestone than for the very fine pulverized Chemstone. This may be due to differences in the absolute accuracy of the flyash flowrate measurements between the two test periods. Or perhaps there was some agglomeration of the very fine pulverized Chemstone which increased its capture in the cyclone.

The sulfur capture for in-furnace, FDA, and combined furnace/FDA are summarized in Table 6.6-1. The coarse sorbents (i.e., typical of CFB size distributions) were tested in September 2002. The fine (or pulverized) sorbents were tested in September 2002 and in February 2003. The performance of the sorbents is discussed below. 


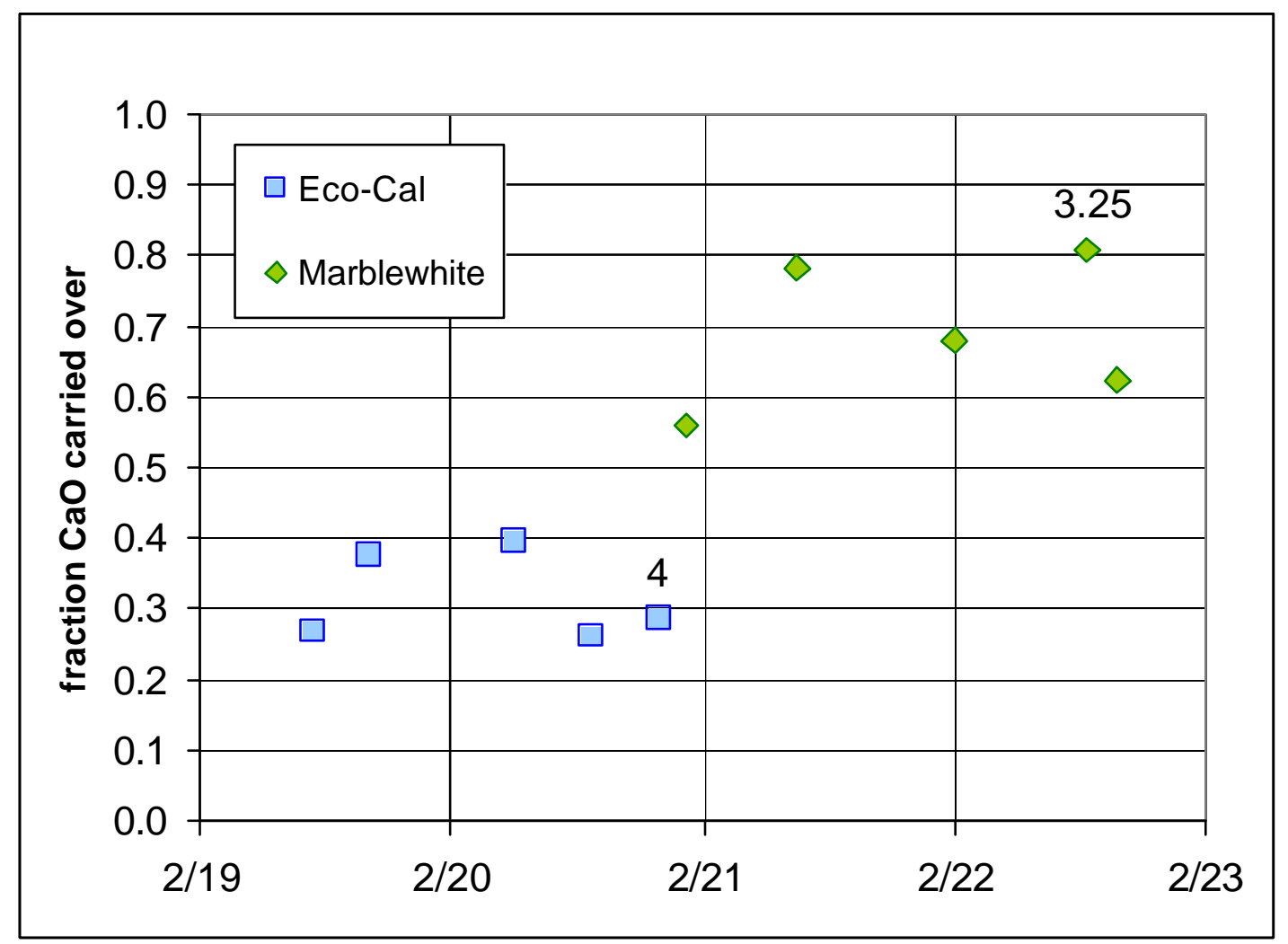

Figure 6.6-3: CaO Fraction Carried Over to FDA - Pittsburgh \#8 Coal

\section{Performance of Coarse Limestone Feedstocks}

All test conditions were run with the West Virginia coal and a $\mathrm{Ca} / \mathrm{S}$ mole ratio of 2:1. The in-furnace sulfur capture with the coarse Chemstone, Aragonite, and Sorbent $\mathrm{X}$ varied from 4 to $26 \%$. The FDA sulfur capture in the first tests ranged from $29-45 \%$ with the coarse Chemstone and Aragonite. Higher sulfur capture was obtained in the FDA by the end of the test week: $76 \%$ with Sorbent $\mathrm{X}$ and 55 - 61\% with coarse Chemstone. However, these results were achieved immediately after running with the pulverized Chemstone sorbent for nearly a day, so the improved FDA sulfur capture was likely due to a higher calcium content in the FDA. Discounting the last tests, the overall CMB/FDA sulfur capture ranged from 31 to $56 \%$.

The overall CMB/FDA sulfur capture was obviously too low with the coarse sorbents, but was not unexpected. Consider a normal application of FDA to a CFB system with a calcium-to-sulfur mole ratio of 2:1 fed to the furnace. The sulfur capture in the furnace depends on many factors, but assume $90 \%$ capture as a typical value. The calcium is therefore $45 \%$ utilized in the furnace $(90 \% / 2)$. Assume that half of the unreacted calcium is in the flyash that goes to the FDA system. The other half of the unreacted calcium is in the bed ash drain. The $\mathrm{Ca} / \mathrm{S}$ mole ratio of the unreacted calcium in the flyash to the uncaptured $\mathrm{SO}_{2}$ in the flue gas is 5.5:1. This ratio is sufficient in CFB 
applications for the FDA to do a good job of polishing the flue gas to high sulfur removals (95\% total sulfur capture or better).

Now consider the FDA after the CMB, again with a calcium-to-sulfur ratio of 2:1 fed to the combustor. Due to the higher temperature in the CMB combustor, the in-furnace sulfur capture is much lower - say $25 \%$. The calcium is now $12.5 \%$ utilized in the furnace. Again assume that $50 \%$ of the unreacted calcium is carried over to the FDA. Now the mole ratio of unreacted calcium in the flyash to uncaptured $\mathrm{SO}_{2}$ in the fluegas is 1.2:1. Under normal FDA operating conditions, this is not enough to achieve a high total sulfur capture.

There are several approaches to achieving the necessary total sulfur capture levels needed for meeting CMB performance targets:

- increase the sulfur capture in the furnace

- increase the amount of unreacted calcium reaching the FDA

- improve the performance of the FDA by operating at higher humidity

Using a finer size sorbent in the combustor did achieve a greater in-furnace sulfur capture and also let more of the calcium escape in the flyash to the FDA system. This approach is discussed in the following section, along with tests at higher humidities in the FDA.

With the coarse Chemstone sorbent, an attempt was made to increase the amount of unreacted calcium reaching the FDA by injecting FBHE ash directly to the FDA. The FBHE drain contained nearly all of the unreacted calcium that was not in the flyash. At the end of the test week, a short baseline test run with coarse Chemstone got about 55\% sulfur capture in the FDA. This high value was probably due to the high calcium in the FDA from the earlier pulverized Chemstone tests. When the FBHE ash was initially injected into the FDA, there appeared to be an increase to about $61 \%$ sulfur capture in the FDA. The tests were short and neither of these values had steadied out, but there was some improvement due to the addition of FBHE ash.

Since the FBHE ash was much coarser than flyash, some of the FBHE ash collected in September was pulverized and used for injection to the FDA in the February 2003 tests. These results are also discussed in the following section.

\section{Performance With Fine Limestone Feedstocks}

The first test series with pulverized limestone was with the Chemstone sorbent while firing the low sulfur West Virginia coal. This sorbent was ground fine enough to ensure that most of it would pass through the cyclone on the first pass. The limestone was fed pneumatically into the furnace at a $\mathrm{Ca} / \mathrm{S}$ mole ratio of $2: 1$ and at a location above the bed. The sulfur capture performance with this sorbent was dramatically improved. The infurnace capture improved to $40 \%$ while the FDA and the overall sulfur capture increased up to $100 \%$. 
Table 6.6-1: CMB Combustor and FDA Sulfur Capture

\begin{tabular}{|c|c|c|c|c|c|c|c|c|c|}
\hline Sorbent & Fuel & $\begin{array}{c}\text { CMB SO2 uncon- } \\
\text { trolled }^{*}[\mathrm{ppm}]\end{array}$ & $\begin{array}{c}\mathrm{Ca} / \mathrm{S} \text { to the } \\
\mathrm{CMB}\end{array}$ & $\begin{array}{c}\text { Relative hu- } \\
\text { midity [\%] }\end{array}$ & $\begin{array}{c}\text { FDA SO2 } \\
\text { inlet }^{*}[\mathrm{ppm}]\end{array}$ & $\begin{array}{c}\text { FDA SO2 } \\
\text { outlet }^{*}[\mathrm{ppm}]\end{array}$ & $\begin{array}{c}\text { Furnace } \mathrm{SO}_{2} \\
\text { Capture [\%] }\end{array}$ & $\begin{array}{c}\text { FDA SO2 } \\
\text { capture [\%] }\end{array}$ & $\begin{array}{l}\text { Total } \mathrm{CMB} / \mathrm{FDA} \\
\mathrm{SO}_{2} \text { capture [\%] }\end{array}$ \\
\hline \multicolumn{10}{|l|}{ September 2002} \\
\hline Chemstone coarse & Low S & 1050 & 2 & 61 & 1010 & 720 & 4 & 29 & 31 \\
\hline Chemstone coarse & Low S & 1050 & 2 & 71 & 940 & 620 & 10 & 34 & 41 \\
\hline Aragonite & Low S & 1050 & 2 & 64 & 840 & 460 & 20 & 45 & 56 \\
\hline Pulverized Chemstone & Low S & 1050 & 2 & 59 & 640 & 0 & 39 & 100 & 100 \\
\hline Pulverized Chemstone & Low S+elemental S & 3200 & 2 & 62 & 1970 & 50 & 38 & 97 & 98 \\
\hline Pulverized Chemstone & Low S+elemental S & 3200 & 2 & 51 & 1930 & 290 & 40 & 85 & 91 \\
\hline Pulverized Chemstone & Low S+elemental S & 3200 & 2 & 73 & 1850 & 24 & 42 & 99 & 99 \\
\hline Sorbent X & Low S & 1050 & 2 & 58 & 780 & 185 & 26 & 76 & 82 \\
\hline Chemstone Coarse ${ }^{* *}$ & Low S & 1050 & $\underline{2}$ & 62 & 860 & 390 & 18 & 55 & 63 \\
\hline Chemstone coarse+FBHE ash & Low S & 1050 & 2 & 60 & 840 & 330 & 20 & 61 & 69 \\
\hline \multicolumn{10}{|l|}{ February 2003} \\
\hline Eco-Cal 5050 & High S & 2400 & 2 & 56 & 1920 & 1140 & 20 & 41 & 53 \\
\hline Eco-Cal 5050+FBHE Ash & High S & 2400 & 2 & 52 & 2020 & 1020 & 16 & 50 & 58 \\
\hline Eco-Cal 5050 & High S & 2400 & 4 & 56 & 1550 & 950 & 35 & 38.7 & 60 \\
\hline Marblewhite 325 & High S & 2400 & 2 & 51 & 1750 & 1020 & 27 & 42 & 58 \\
\hline Marblewhite 325 & High S & 2400 & 2 & 75 & 1900 & 620 & 21 & 67 & 74 \\
\hline Marblewhite 325 & High S & 2400 & 3.25 & 81 & 1475 & 0 & 39 & 100 & 100 \\
\hline Marblewhite 325 & High S & 2400 & 2 & 81 & 1960 & 295 & 18 & 85 & 88 \\
\hline Marblewhite 325 & High S & 2400 & 2 & 85 & 1860 & 100 & 23 & 95 & 96 \\
\hline
\end{tabular}

* All SO 2 are ppm by volume, dry, normalized to $3 \% \mathrm{O}_{2}$

** Short term baseline before injection of FBHE ash 
Three additional tests were run to simulate firing a high sulfur fuel by adding elemental sulfur with the fuel. The calculated uncontrolled $\mathrm{SO}_{2}$ was 3,200 ppm (equivalent to a $4 \%$ sulfur coal) and the tests were run at three different relative humidities. The results again showed that up to $99 \%$ overall sulfur capture could be achieved even at high $\mathrm{SO}_{2}$ inlet conditions. The baghouse ash was not sticky and was very free flowing, even at the highest humidity levels. Figure 6.6-4 shows the effect of humidity on the sulfur removal in the FDA. This figure demonstrates the importance and effect of the humidity on FDA sulfur capture.

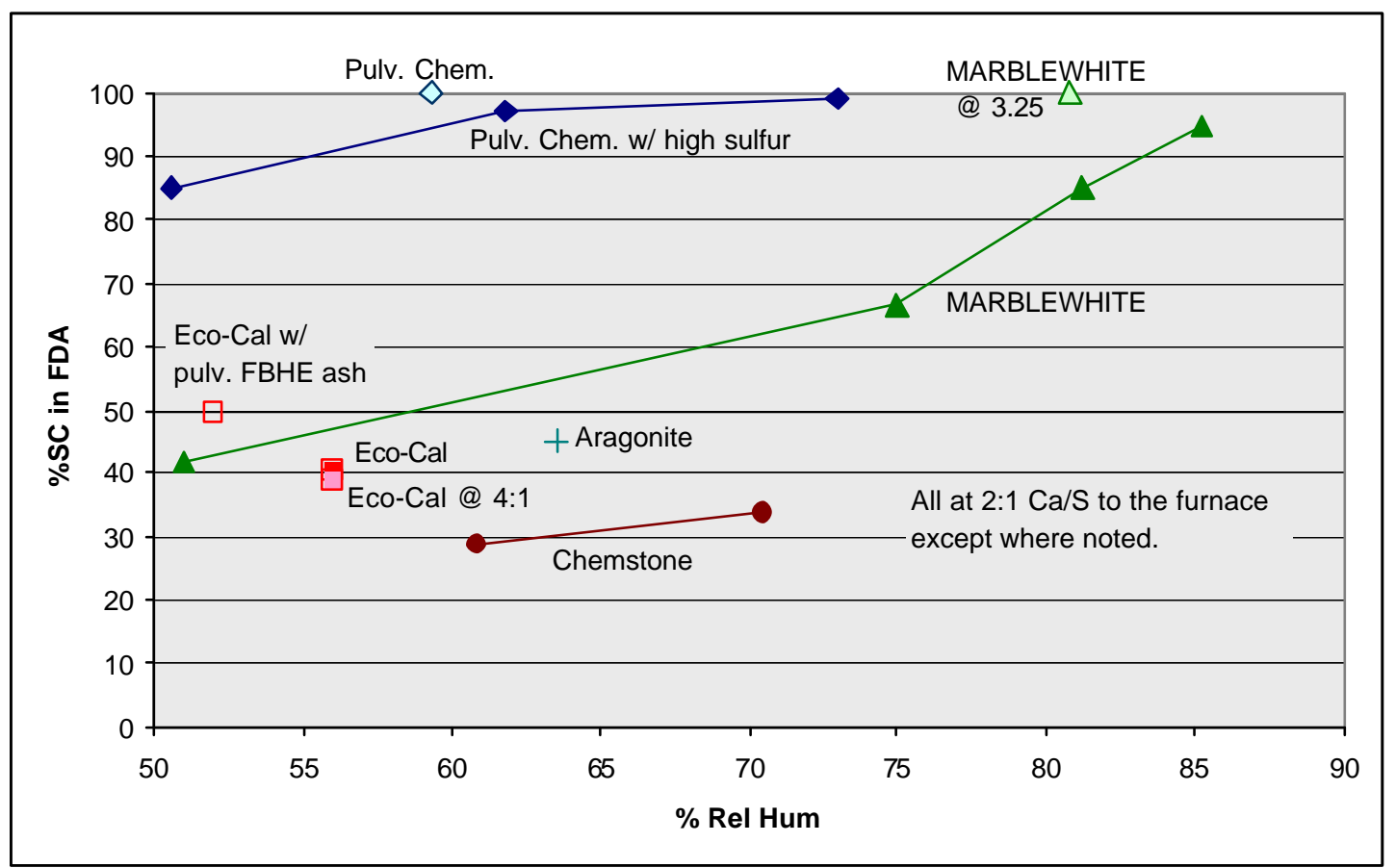

Figure 6.6-4: Effect of Humidity on FDA Sulfur Capture

Since the cost of sorbent preparation increases for finer sizes, in February two coarser sorbents were tested that would be more economical to use. The objective of these tests was to determine how fine the limestone needed to be to ensure that most of the sorbent passed through the cyclone and reached the FDA system. These tests were performed at a $\mathrm{Ca} / \mathrm{S}$ mole ratio of 2:1 while firing the high sulfur Pittsburgh \#8 coal. The sorbents were fed directly with the coal instead of by pneumatic feed.

The Eco-Cal 5050 was the coarser of these two sorbents. The in-furnace sulfur capture was $20 \%$, the FDA sulfur capture was about $40 \%$, and the total sulfur capture reached $60 \%$. As described shown in Figure 6.6-3, some of the Eco-Cal 5050 sorbent fed to the boiler did not reach the FDA for further utilization in the FDA system. To make up for this loss of alkalinity, pulverized FBHE ash from the September test was added to the FDA during one Eco-Cal 5050 test. The rate of injection was controlled to match the expected rate of FBHE drain that would be generated at steady state. The FDA sulfur capture increased slightly to $50 \%$. Again, the addition of FBHE ash material had an effect on the FDA performance. 
In the final test with Eco-Cal 5050, the $\mathrm{Ca} / \mathrm{S}$ mole ratio was increased to 4 . The objective of this test was to directly increase the carryover of lime to the backend. The in-furnace sulfur capture increased up to $35 \%$, but FDA sulfur removal remained unchanged at $39 \%$.

The tests with the finer Marblewhite 325 limestone gave improved performance overall. The in-furnace sulfur capture increased up to 27\%, although the FDA sulfur capture remained about $40 \%$ at the base humidity of $55 \%$. The FDA relative humidity was then increased to $75 \%$. The FDA performance immediately responded and FDA sulfur capture increased to $67 \%$. At this point the $\mathrm{Ca} / \mathrm{S}$ mole ratio was increased to $3.25: 1$ to increase the amount of calcium reaching the FDA. The combustor sulfur capture then increased to $39 \%$ and the FDA sulfur capture went up to $100 \%$.

The $\mathrm{Ca} / \mathrm{S}$ mole ratio was then reduced to $2: 1$ for the last two tests while still maintaining a high humidity. The FDA sulfur capture dropped to $85 \%$, with an overall sulfur capture of $88 \%$. In the final test, the FDA internal recycle rate was increased to maximize the FDA performance. The humidity also increased in the last test (from 81 to $85 \%$ ), but the increase in FDA sulfur capture to $95 \%$ occurred immediately upon the increase in circulation rate, showing how important a high recycle rate is when operating at high humidities.

At low FDA recycle rates, the solids in the mixer could have become too moist and agglomerated. This would reduce the dispersion of the solids when they were introduced into the flue gas and thus diminish system performance. At high recycle rates, the moisture content of the solids was kept at more manageable levels, resulting in improved solids properties.

As Figure 6.6-4 shows, the pulverized Chemstone had better sulfur capture in the FDA than the less fine Eco-Cal 5050 and Marblewhite 325. This was probably due to the finer particle size, but it must be noted that there was a difference in the sorbent feed systems. The pulverized Chemstone was pneumatically injected above the lower bubbling bed. The EcoCal and Marblewhite were mixed and fed with the coal into the $2000^{\circ} \mathrm{F}$ bed. It is possible that the close contact with the coal in the latter cases led to some calcium-ash interaction and deactivation of the sorbent. This possibility needs to be investigated.

\section{Other Calcium Losses}

Two other factors may have reduced the calcium utilization in the MTF tests. As discussed in Section 6.4, some of the bed ash was entrained in the bauxite recirculation loop and escaped in the gas outlet from the bauxite separation hoppers. This gas stream was diverted to the gas ducting after the FDA system. High volume samples on these gas outlet ducts showed that 6$8 \%$ of the total calcium feed was lost in this gas stream and thus did not contribute to sulfur capture. In a commercial CMB design, this gas stream would be returned to the combustor and the calcium could still be utilized. Thus, the effective $\mathrm{Ca} / \mathrm{S}$ mole ratio feed to the system was reduced by 0.1 to 0.2 after these losses are accounted for.

Another loss that needs to be considered is calcination loss. The pulverized Chemstone sorbent was pneumatically injected into the furnace at a location where the gas temperature was between 1800 and $2000^{\circ} \mathrm{F}$. There should have been sufficient residence time for the fine 
limestone particles to be fully calcined. As was previously shown in Figure 3.5-2, a 20 micron sorbent particle injected into the MTF at $1800^{\circ} \mathrm{F}$ has enough residence time to be fully calcined. The Chemstone sorbent was considerably finer than 20 microns. However, two flyash samples during the fine Chemstone tests showed that 16 to $20 \%$ of the calcium was either uncalcined or had partially recarbonated. This represents a reduction in the effective $\mathrm{Ca} / \mathrm{S}$ mole ratio of up to 0.4 if all of the sorbent passed through the cyclone and reached the FDA system. The calcination loss was attributed to the limestone pneumatic feed system. The sorbent was injected at high velocity into the combustor. The injection air probably jetted across the combustor and turned up the combustor wall. The fine limestone was entrained in this high velocity air stream and was carried up the combustor. This reduced the particle residence time in the high temperature region for both calcination and sulfation. A revised limestone injection system should reduce this problem.

\section{FDA Operation at High Humidities}

MTF experience (under CFB conditions) has shown that ashes originating from different coals and combustor operating conditions behave differently during FDA operation at high humidity. Each ash absorbs different amounts of water at the same humidity. Some ashes can retain a higher moisture content and still have good handling properties in the FDA. Other ashes are problematic even at lower moisture contents. The FDA ash properties observed during the CMB tests were much better than was expected. This allowed the tests to be conducted at higher humidity levels than normally possible during CFB operations. It is possible that the high bed temperature in the $\mathrm{CMB}$ combustor generates an ash with excellent FDA properties. For these two fuels, the CMB ash absorbed more water without creating operational difficulties. Thus, it was possible to operate safely at very high humidities with these ashes, which resulted in excellent sulfur capture performance in the FDA system.

\section{$\mathrm{SO}_{3}$ Emissions}

$\mathrm{SO}_{3}$ emissions are one of the major contributors to condensable particulate matter, a precursor of ambient PM2.5. Flue gas experiences rapid cooling, dilution, and mixing as it exits the stack. This results in gas-to-particle conversion of the condensable matter, coagulation, and chemical reactions. This eventually results in the formation of fine aerosol particles that significantly contribute to ambient PM2.5 levels.

In coal-fired boilers, the emission level of $\mathrm{SO}_{3}$ is affected by SNCR control as $\mathrm{NH}_{3}$ is injected downstream of the furnace. $\mathrm{SO}_{3}$ reacts with $\mathrm{NH}_{3}$ in the flue gas to form $\left(\mathrm{NH}_{4}\right)_{2} \mathrm{SO}_{4}$ (solid phase) and $\mathrm{NH}_{4} \mathrm{HSO}_{4}$ (liquid phase). Some of the $\left(\mathrm{NH}_{4}\right)_{2} \mathrm{SO}_{4}$ deposits on the surfaces of air preheaters creating air preheater pluggage and corrosion problems. Some of the $\left(\mathrm{NH}_{4}\right)_{2} \mathrm{SO}_{4}$ also forms submicron aerosol particles that escape through stacks and cause visibility problems.

During the February test campaign, the $\mathrm{SO}_{3}$ and $\mathrm{NH}_{3}$ levels were measured upstream of the FDA using the method described in Section 5.4. The $\mathrm{SO}_{3}$ measured (normalized to $3 \% \mathrm{O}_{2}$ ) was $2 \mathrm{ppm}$ and $4 \mathrm{ppm}$, without and with ammonia injection into the furnace, respectively. Under CFB conditions, the $\mathrm{SO}_{3}$ has been measured about $0.5 \mathrm{ppm}$ without ammonia injection. The impact of these levels on particulate emissions and on air heater fouling is unknown. The $\mathrm{SO}_{3}$ concentration was not measured after the FDA system, but is expected to 
be significantly less. As mentioned in Section 6.5 , the $\mathrm{NH}_{3}$ concentration in the flue gas measured during $\mathrm{NH}_{3}$ injection testing was practically zero.

\section{Summary}

The following items summarize the key findings from this evaluation:

- The coarse sorbents (typical CFB size distributions) had low in-furnace sulfur capture and modest sulfur removal in the FDA.

- The fine sorbents gave higher in-furnace sulfur capture. More importantly, they were able to achieve up to $100 \%$ sulfur capture in the FDA at higher humidities.

- Increasing the calcium feed to the FDA by adding FBHE bed drain (unsized or pulverized) caused an increase in the FDA sulfur capture.

- The flyash generated in the CMB combustor is well-suited for high humidities in the FDA. A high internal ash recirculation rate in the FDA will improve the performance at high humidity.

- The sorbent feed design needs to be further investigated. How and where the sorbent is fed may affect calcination, recarbonation, and/or deactivation of the sorbent.

- Based on limited testing, it appears that the $\mathrm{SO}_{3}$ emissions are slightly higher than under CFB conditions. The impact is not known.

- The sulfur emission targets can be achieved. The optimum (most economic) sorbent selection and system design must consider capital and operating costs, such as feed system design, sorbent preparation costs, and water consumption. 


\subsection{Transport Line Pressure Drop}

The CMB solids circulation system transports high rates of relatively coarse and dense particles from the bottom of the MBHE to the top of the combustor. These transport conditions are outside of the normal operating ranges encountered in conventional power plants. Section 3.2 described transport pressure drop tests that were conducted in a PPL cold flow test facility to predict pressure drops in the MTF transport line. The ALSTOM pressure drop model for horizontal and vertical transport was then modified to match the measured results. This section describes the pressure drop results observed during the MTF testing in September 2002 and February 2003.

\section{Facility Description}

The pneumatic transport system for the September 2002 tests used 8-inch ID water-cooled piping with short horizontal runs and a relatively long vertical run. The system included two impact tees for elbows. The water-cooled transport pipe was used to cool the bauxite, transport it back to the top of the combustor, and measure bauxite flow by a heat balance.

The pneumatic transport system for the December 2002, February 2003 tests started as a 6inch ID refractory lined pipe. The refractory eroded significantly after several days of operation and ended the initial test series. The transport pipe was then lined with an A310 steel pipe of 5-inch ID for the remainder of the tests. No significant erosion was detected in the steel pipe. The location of the moving bed heat exchanger required 3 impact tee elbows. Also, an additional transport pipe was used to transport bauxite from the moving bed heat exchanger to the top of the combustor. Heated air was supplied to transport the bauxite in order to minimize heat loss.

\section{Solids to Gas Ratios}

The CMB solids circulation system requires a significant amount of transport air to convey the circulating solids back to the top of the combustor. This quantity of air is too large to vent and therefore must be returned to the combustor as overfire air. It is therefore important to minimize the total quantity of transport air to keep the OFA at manageable levels. The CMB design assumes a minimum Solids to Gas (S/G) ratio of 10:1.

Figure 6.7-1 shows the solids to gas ratios that were achieved in the transport lines during the MTF test campaigns. The red data points were from operation with the 8-inch water-cooled transport line and with the 5-inch stainless steel liner. The blue data points were from operation with the refractory lined pipe. The results show that the transport line pressure drop increased as the $S / G$ ratio increased. Most encouraging, $S / G$ ratios over 14:1 were achieved at reasonable pressure drops. The combustor seal leg was capable of sealing against a 3 psid back pressure, so the transport system had the ability to operate at even higher S/G ratios if necessary.

The three blue data points show that the pressure drop through the refractory lined transport line was much higher at a given S/G ratio than through the steel-line pipes. The refractory lined pipe was very rough, especially after it became eroded. This accounted for the very high pressure drops. 


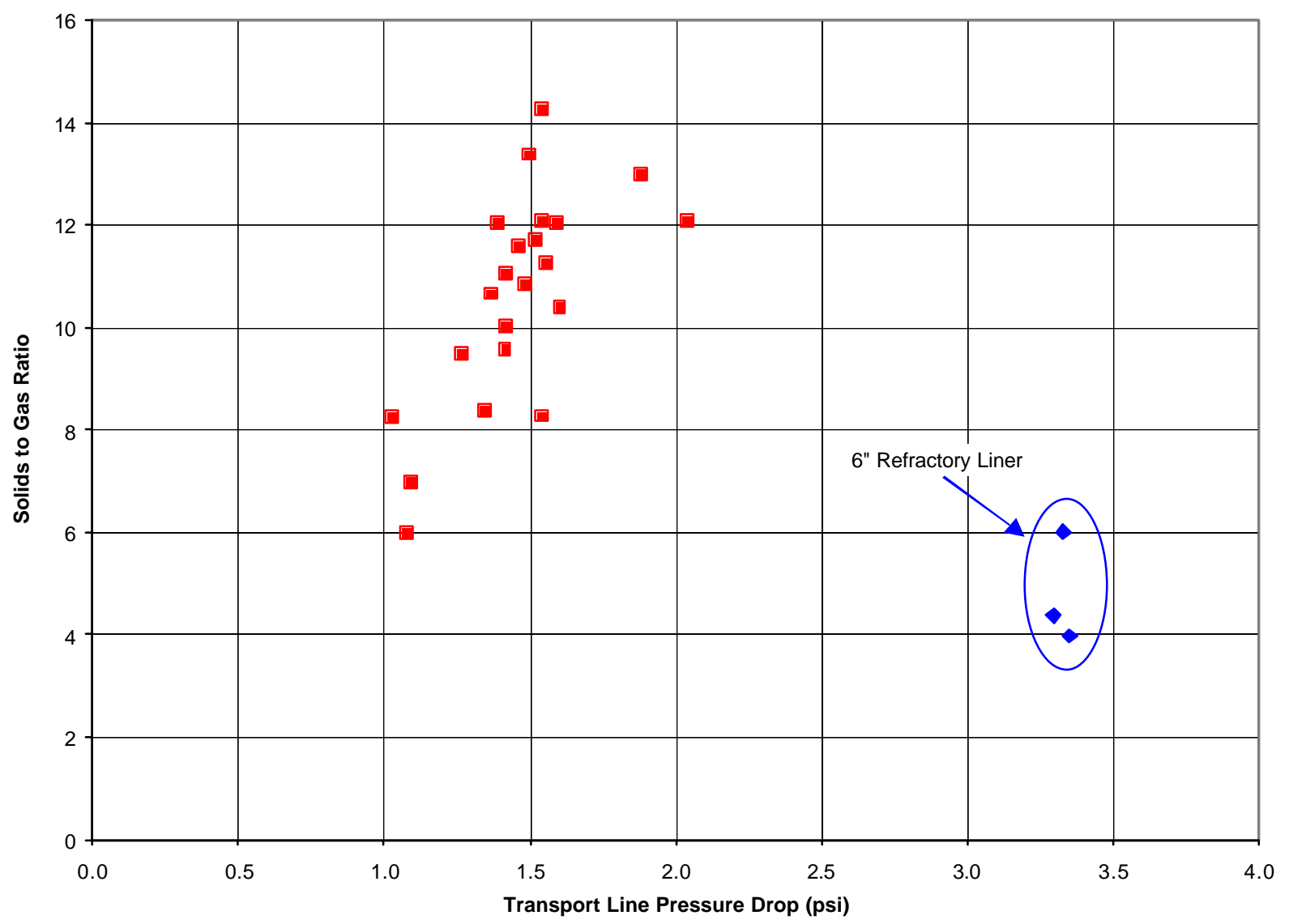

Figure 6.7-1: Effect of Solids to Gas Ratio on Pressure Drop

\section{Pressure Drop Correlation}

The modified ALSTOM pressure drop correlation was used to predict the total pressure drop through the entire transport system for test conditions in the September 2002 and February 2003 test campaigns. The predicted results are compared with the measured results in Figure 6.7-2. The dashed green line is the agreement line.

The average ratio of measured divided by predicted pressure drops for the ALSTOM total pressure drop prediction was 0.99 for the September tests and 0.98 for the February tests. These results show that the ALSTOM pressure drop correlation can be used successfully to predict pressure drops in transport systems operating with the high solids loading and with dense particles as expected during CMB operation. 


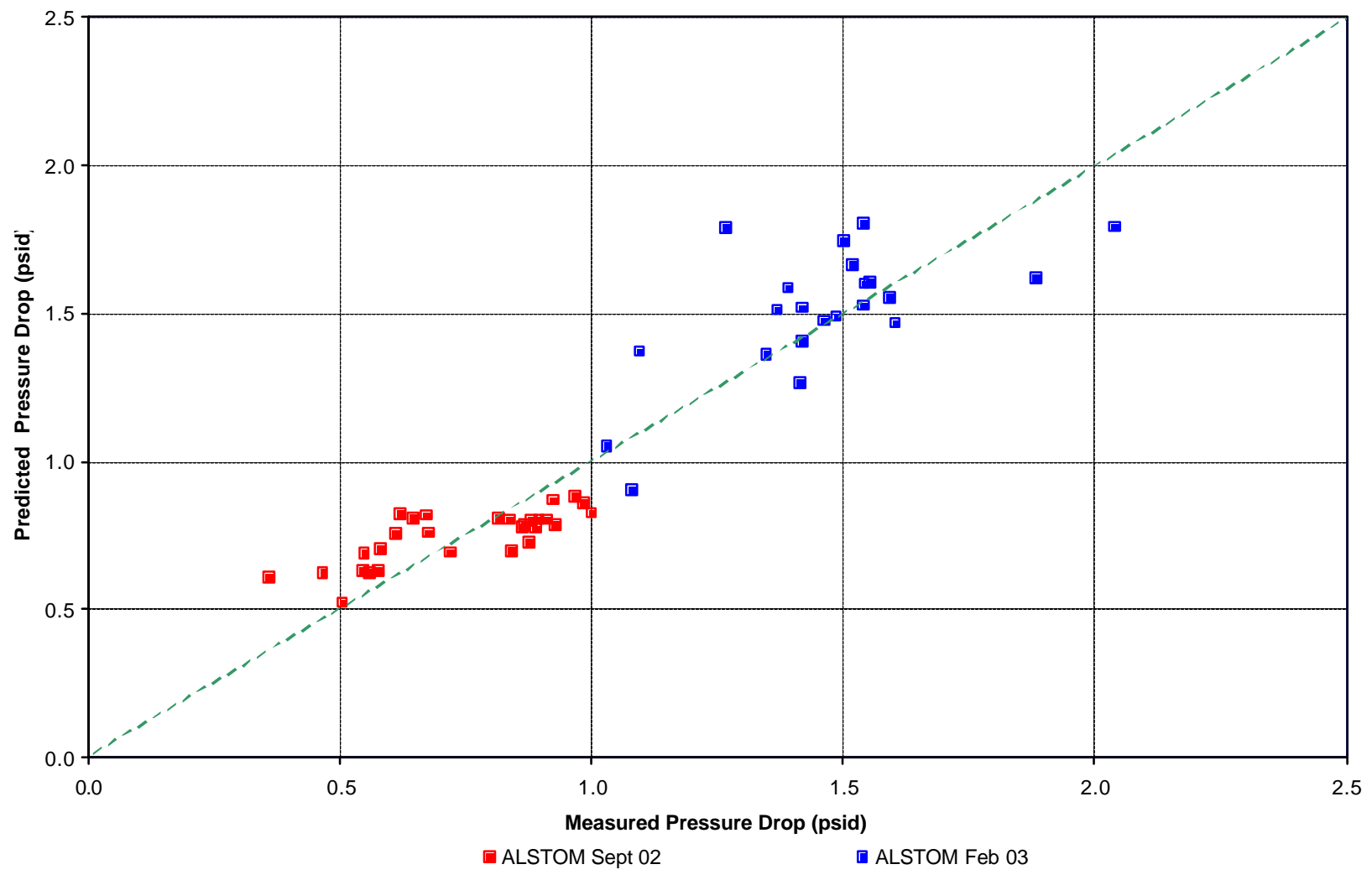

Figure 6.7-2: Total Pressure Drop Comparison 


\subsection{Transient Response - Loss of Coolant}

The MTF had a new coal conveyor feed system installed over the summer of 2002. The system operated well during the September CMB test. However, the control system was not set up properly for the new system, which resulted in a transient condition where the bed temperature quickly exceeded normal operating temperatures.

On September 21, 2002, the MTF experienced a voltage surge through the main power lines that tripped the motor drive on the bauxite rotary valve on top of the combuster. Since the bauxite was used to control combustor temperatures, this trip represented a complete loss of coolant flow to the combustor. The control system was designed to automatically trip the coal feeder whenever the bed temperature reached $2100^{\circ} \mathrm{F}$ just for situations like this.

Unfortunately, the control system tripped the coal gravimetric feeder but not the new coal conveyor. The conveyor continued to feed residual coal already within the conveyor until it was empty. The conveyor coal inventory at this time was equivalent to an additional 5 minutes of full load coal feed after the coal feeder had tripped. Figure 6.8-1 shows that this condition quickly led to a runaway bed temperature. The bauxite rotary valve tripped at 0901 hour and the coal feeder subsequently tripped at 0903 hour after the bed temperature reached $2100^{\circ} \mathrm{F}$. The bed temperature continued to rise another 4 minutes after the feeder tripped due to coal emptying out of the coal conveyor. The bed reached temperatures over $2300^{\circ} \mathrm{F}$ before the conveyor was completely empty. Coal feed was reestablished about 10 minutes later. However, the bed response was sluggish after this excursion and we eventually had to shut down the combustor to remove agglomerates that had formed in the bed during this temperature excursion.

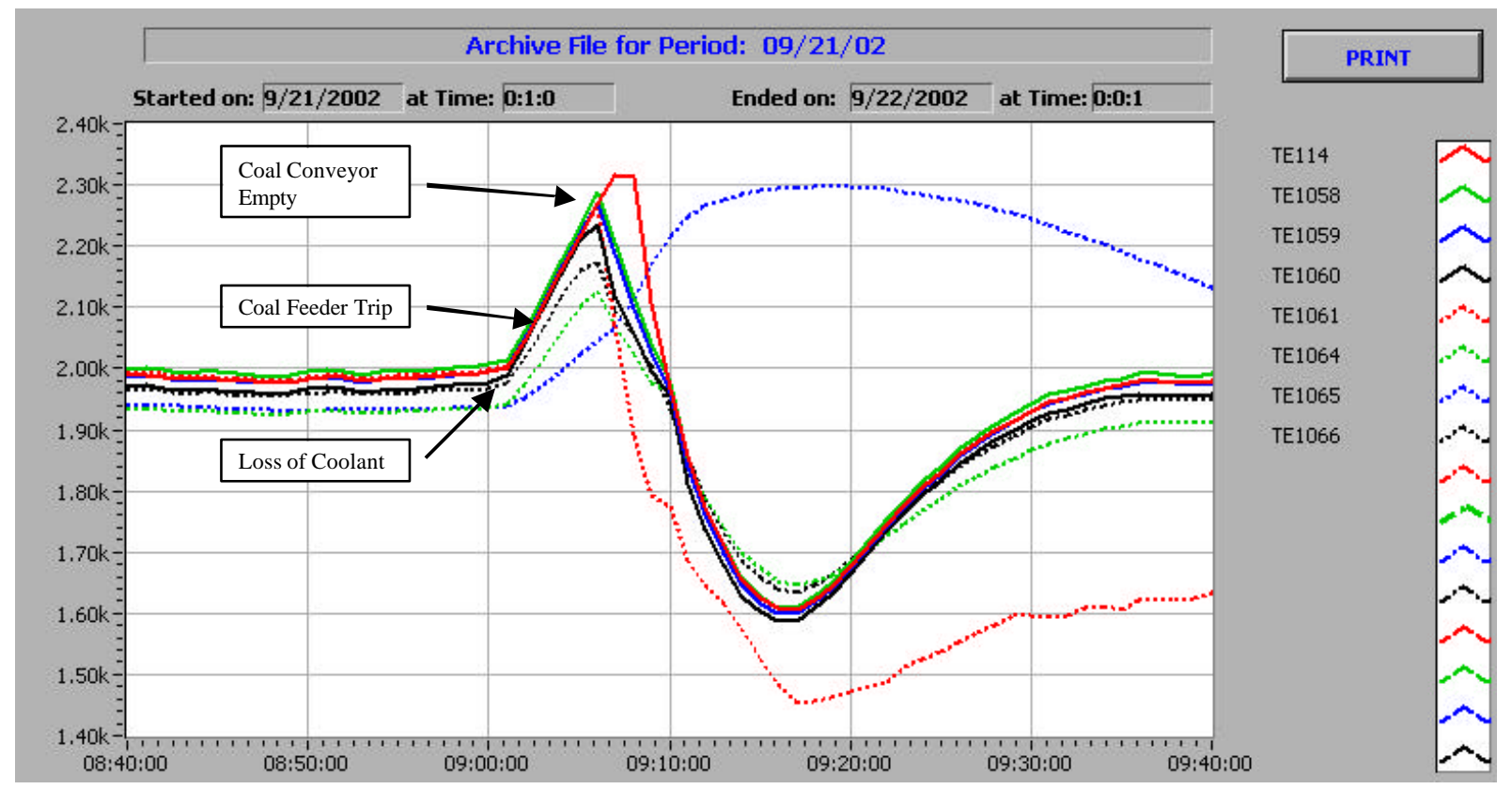

Figure 6.8-1: Bed Temperature Excursion After Loss of Coolant

The motor drives were then replaced with more tolerant drives that never again tripped due to voltage surges. The control system was also changed to trip both the coal feeder and coal conveyor after a trip on the bauxite rotary valve. 
A loss of coolant transient test was then run at the end of the September test campaign on September $27^{\text {th }}$. The objective of this test was to prove that the new control system logic worked properly and that the bed temperature would not run away after a loss of coolant. Data was recorded every second during this test and displayed as trend lines on a monitor.

The bauxite solids rotary valve was intentionally tripped at the start of the test, which stopped all cooling in the combustor. The loss of coolant automatically tripped the entire coal feed system. Figure 6.8-2 shows the recorded trend lines for the coal feed rate and for 3 bed temperature measurements. The time lapse between each hash mark on the time line is 30 seconds. After the bauxite rotary valve was tripped, there was no increase in bed temperature even though there was no cooling and residual carbon continued to burn. The bubbling bed maintained its $2000^{\circ} \mathrm{F}$ temperature for about 20 seconds and then began to rapidly decrease.

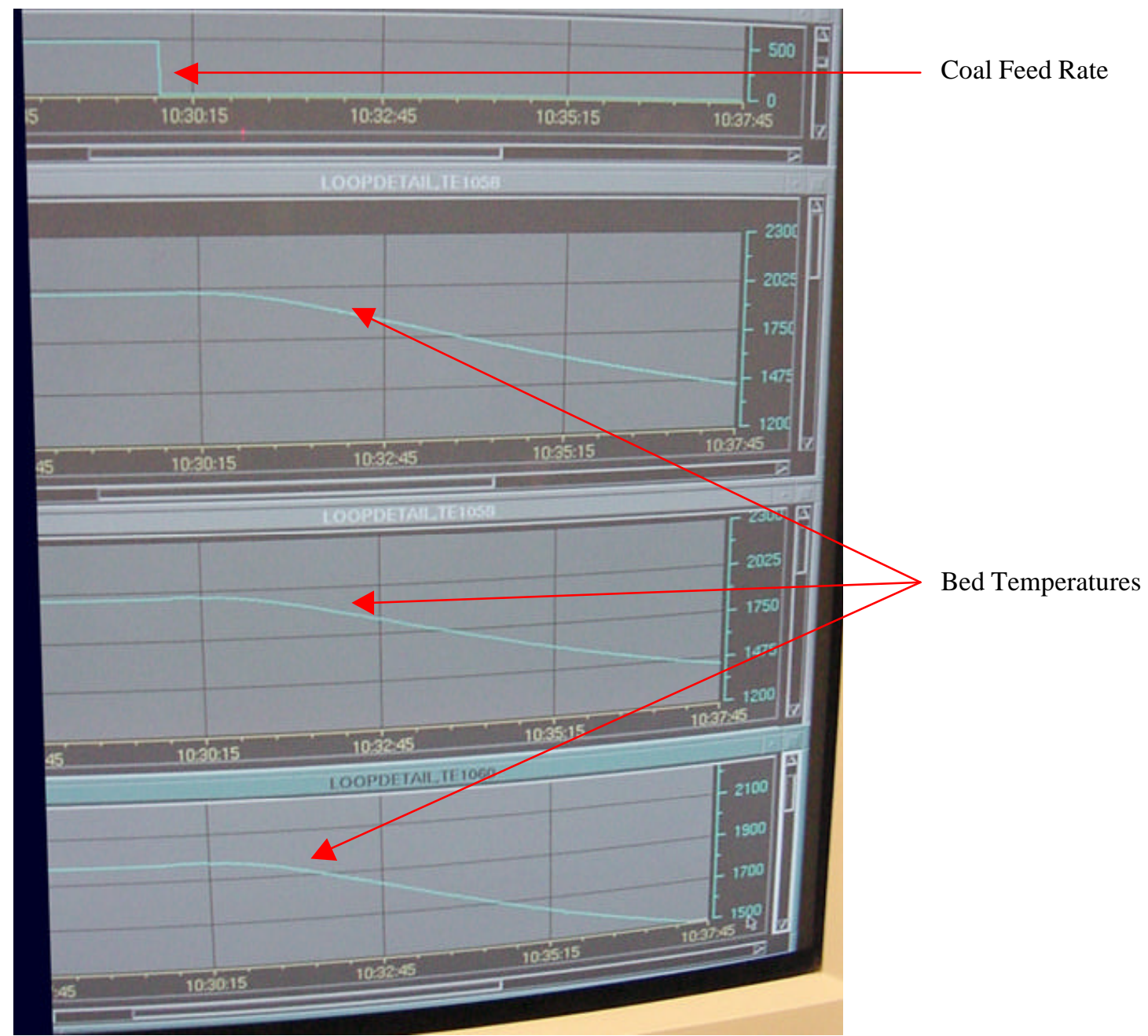

Figure 6.8-2: Bed Temperature Response During Loss of Coolant Test

Figure 6.8-3 shows the measured oxygen concentration leaving the combustor during this loss of coolant test. The time scales for the coal and oxygen trend lines are slightly offset, 
although the time lapse between each hash mark is still 30 seconds for both plots. The dotted black line identifies the start of the loss of coolant test for each plot.

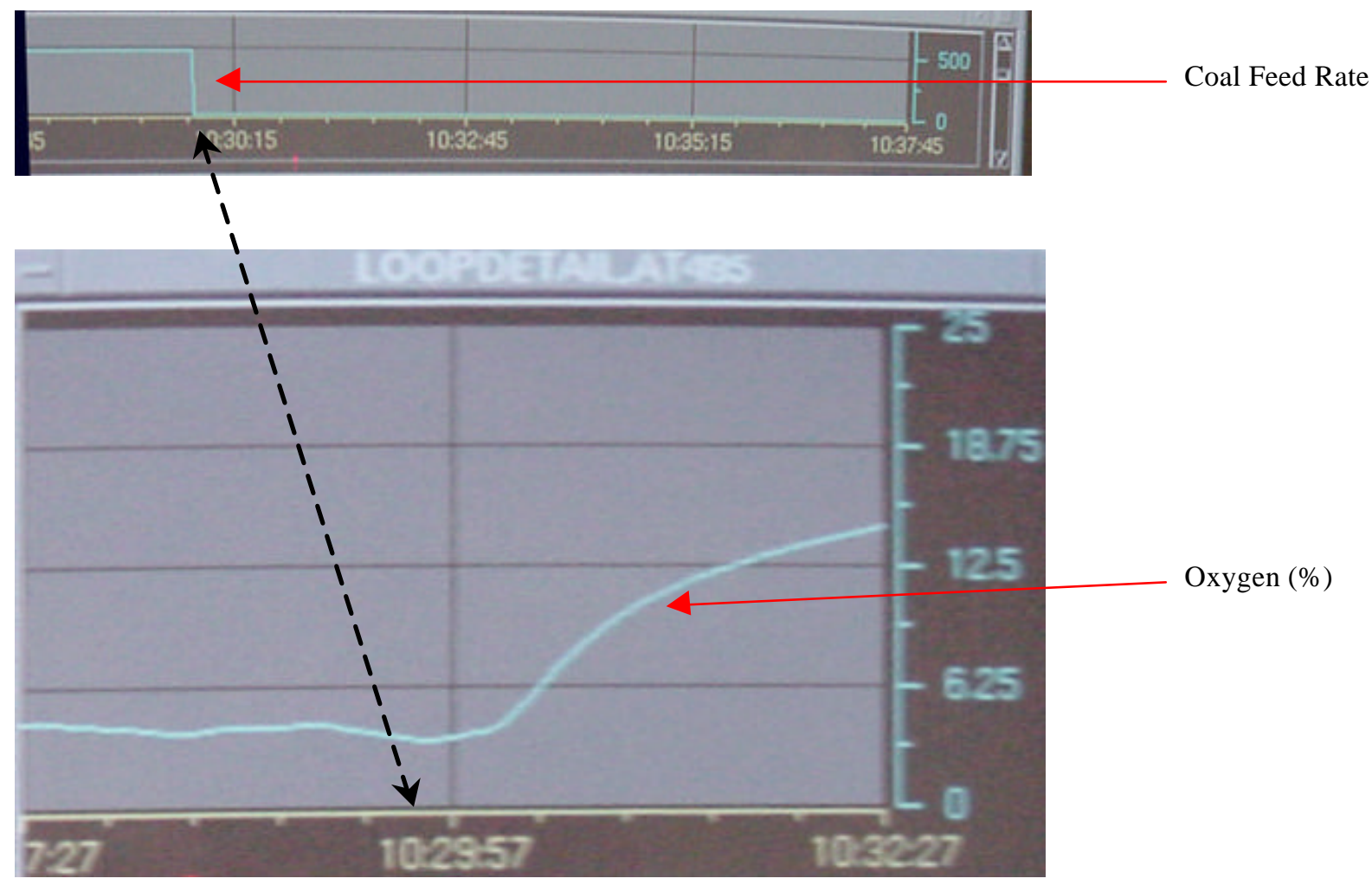

Figure 6.8-3: Oxygen Concentration During Loss of Coolant Test

As seen with the bed temperatures, the oxygen concentration began to rise very soon after the coal feeder trip as the carbon in the bed was quickly consumed. An energy balance was made around the bed to determine the bed carbon concentration necessary to maintain the bed temperature for a 20 -second period. This analysis showed that the bed carbon concentration before the fuel trip was less than $0.03 \%$. This concentration was diluted by the high concentration of bauxite in the bed, which was probably about $75 \%$ during this test. The bed carbon concentration without the bauxite dilution was $0.1 \%$.

Figure 6.8-4 shows the effect of bed temperature on the bed carbon concentration while burning bituminous coals. This figure uses the CMB undiluted carbon concentration of $0.1 \%$. It shows a typical $\mathrm{CFB} / \mathrm{BFB}$ bed carbon concentration of $0.4 \%$. The low bed temperature data used in this trend was based on public domain data. ${ }^{1}$ As expected, these results show that the bed carbon concentration decreased as the bed temperature increased. 


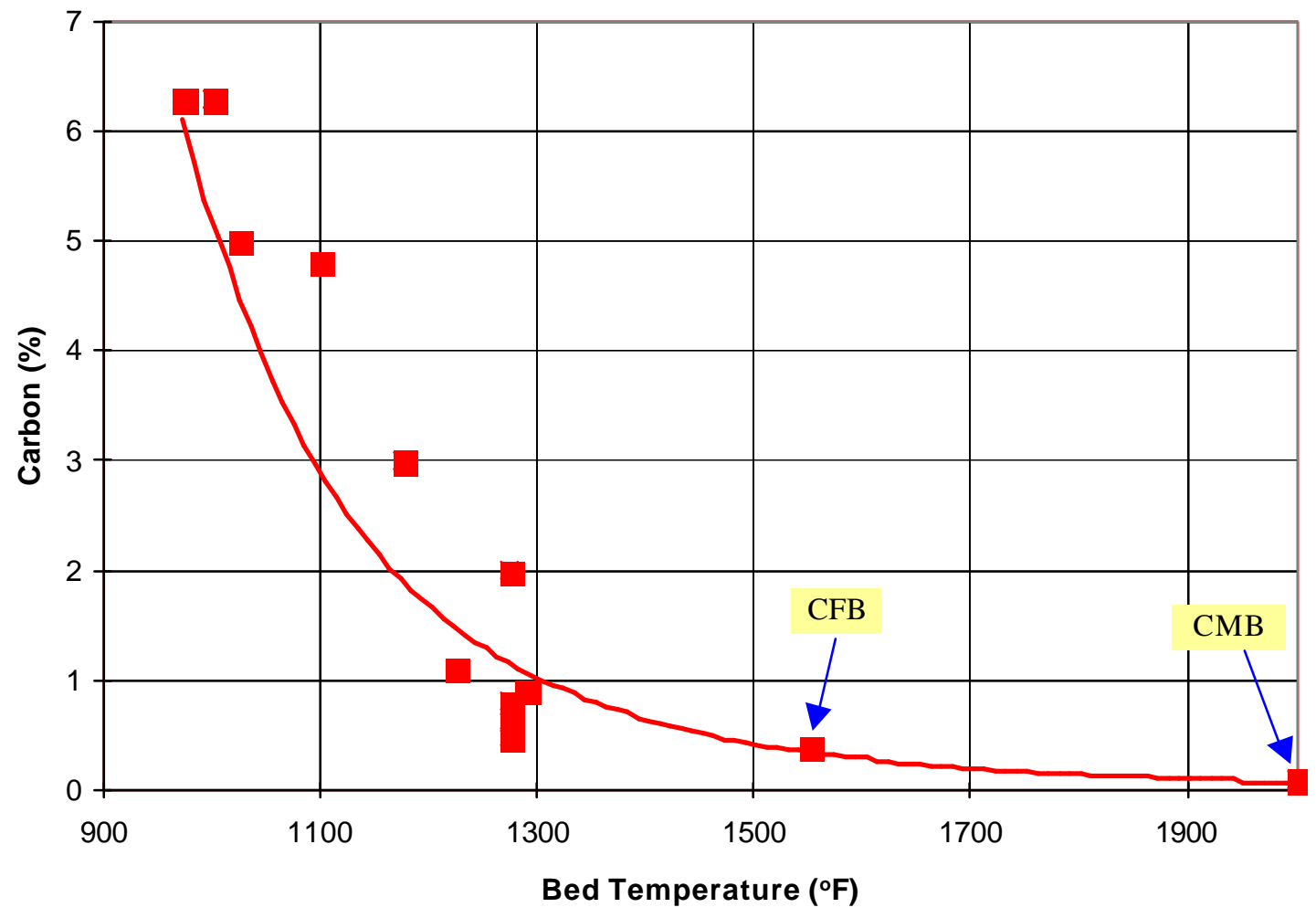

Figure 6.8-4: Effect of Temperature on Bed Carbon Concentration 


\subsection{COMMERCIALIZATION}

ALSTOM Power is committed to the continued development and commercialization of the CMB combustion system. The CMB Proof of Concept program has demonstrated the CMB concept and has shown some very promising results. The program results have also shown that there are still some significant technical uncertainties that need to be resolved before we can confidently scale up the technology for a successful demonstration plant design.

\section{Continued Development Work}

ALSTOM is planning to continue its CMB development activities and then proceed into a larger scale demonstration of the technology. The next phase of development will focus on three primary areas:

- scaleup of gas-to-solids heat transfer

- high temperature finned surface design

- mechanical and process design

The first development area is to improve our predictive capability for scaling up gas-to-solids heat transfer to larger commercial size combustors. This effort will include heat transfer tests in a larger scale facility, combined with refinement of CFD modeling techniques to be used as a scaling tool.

The second area is to develop extended surfaces that can survive in the high temperature regions of the moving bed heat exchanger. These high temperature designs will enable costeffective high temperature Rankine cycle designs using CMB technology. The improved extended surface design will then be demonstrated in the MTF MBHE.

The third area is to consider alternate $\mathrm{CMB}$ design arrangements and process improvements before selecting a design concept for the CMB Demonstration Plant. This effort will consider a number of mechanical and process design alternatives and then complete the detailed design and testing necessary to prepare for the demonstration plant design.

\section{Demonstration and Commercialization}

Figure 7.1-1 shows ALSTOM Power's roadmap for commercialization of CMB technology. Following the development activities just described, ALSTOM will proceed with a larger scale CMB demonstration plant. After a successful demonstration, ALSTOM will begin offering commercial $\mathrm{CMB}$ plants for both greenfield and retrofit steam plants. More advanced CMB plants will then be offered, including high temperature Rankine cycles and chemical looping gasification and combustion plants that build off the CMB process. 


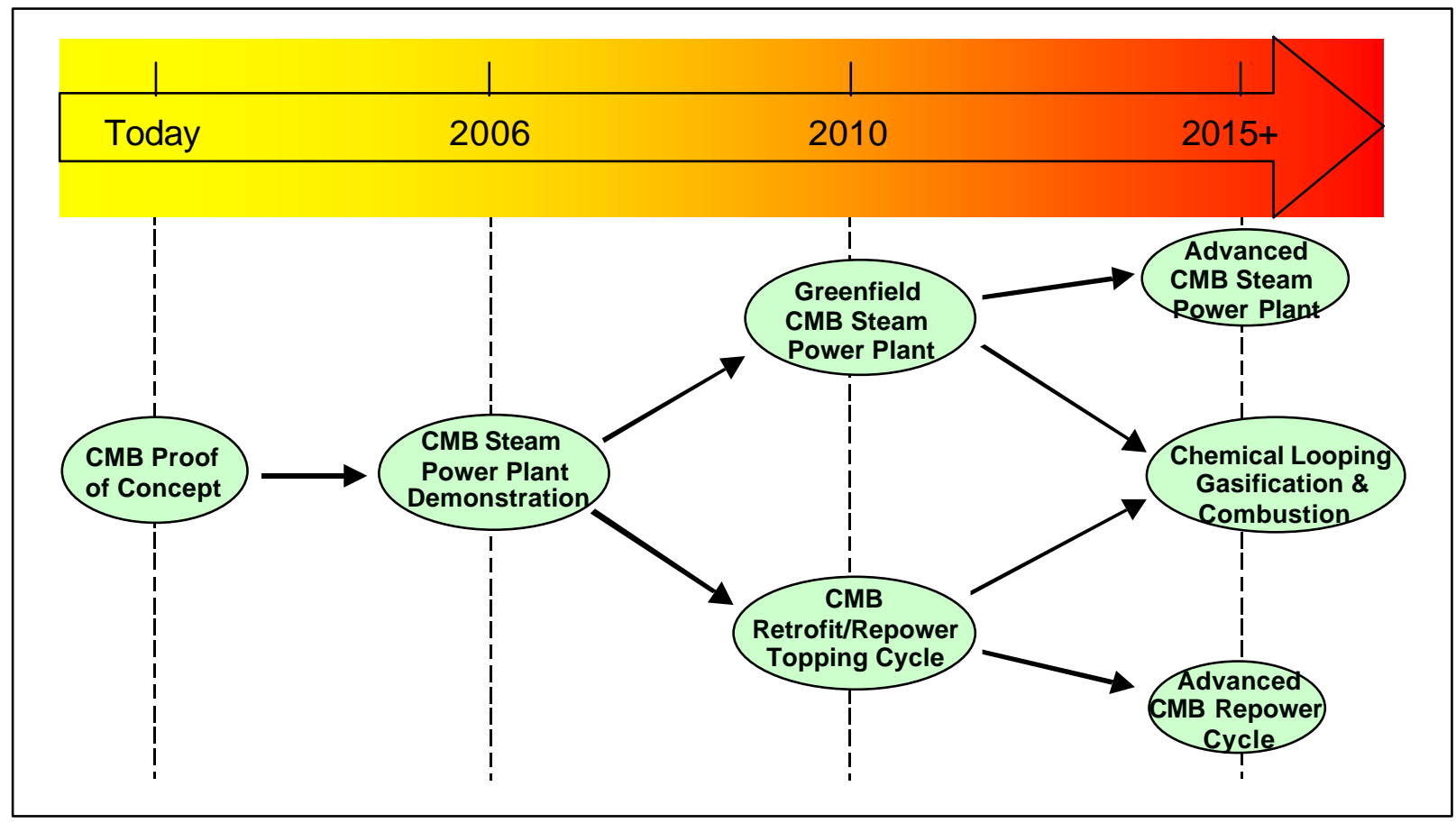

Figure 7.1-1: CMB Commercialization Roadmap 


\subsection{CONCLUSIONS AND RECOMMENDATIONS}

\subsection{Conclusions}

The objective of the CMB Proof of Concept project was to identify the technical, design, and performance challenges that need to be met to make a commercial CMB system. The project objectives were achieved through a series of experiments that were conducted in ALSTOM Power's Multi-use Test Facility. Overall project results confirmed high heat transfer rates in the combustor and MBHE. Combustion performance was very good and bed ash agglomeration was controllable. Emissions were close to state of the art levels and can be further optimized to meet the DOE's Advanced Combustion Systems targets. Mechanical systems worked well and no technical obstacles were identified to impede continued CMB development. The following section summarizes the progress that was made against the specific project objectives that were set by ALSTOM Power, in concert with the U.S. DOE, for the CMB Proof of Concept project.

- Objective: Modify the Multi-Use Test Facility to allow evaluation of process and equipment performance under $\mathrm{CMB}$ conditions of commercial interest

- Achievement: The MTF was modified in several phases. A water-cooled bauxite transport system was initially installed to allow gas-to-solids heat transfer tests to be conducted in the MTF combustion chamber. The baghouse was then converted into a FDA system to enable sulfur capture evaluation in both in-furnace and in the backend FDA system. Finally, a moving bed heat exchanger was installed to enable solids-to-tube heat transfer evaluation. All of the subsystems worked well after shake down. The MTF was then able to operate as a fully integrated CMB system. Three test campaigns were completed in the MTF with three different fuels, including natural gas and two bituminous coals, providing a wealth of performance data. All mechanical systems, including both solids transport systems and the FDA system, operated without problems or pluggages in the last test sequence.

- Objective: Evaluate gas-to-solids heat transfer and mixing in the upper furnace

- Achievement: Results confirm that combustion gases can be effectively cooled in the combustor solely by heat transfer to a stream of falling particles. Over 20 gas-to-solids heat transfer tests were conducted in the first test campaign with warm air, natural gas firing, and coal firing. Parametric variations were made in airflow rate, bauxite flow rate, bauxite particle size, and number of combustion chamber mixing grids. The results showed that the gas and solids flow distribution was relatively uniform throughout the combustor and that mixing grids were not necessary at the MTF scale.

As expected, the Nusselt Number was generally lower than predicted for single particles due to particle-to-particle interactions. Particles in close proximity had a tendency to follow in each other's wake due to a drag reduction phenomena. Particles following a lead particle were exposed to gas cooled by the lead particle, and therefore did not have 
the full gas-particle temperature difference available to the lead particle. A multi-particle model developed from earlier warm air tests gave a good fit to the whole range of MTF data.

- Objective: Evaluate factors to control ash agglomeration in the bubbling bed

- Achievement: Results indicate that bed ash agglomeration is controllable over the range of commercial temperatures. Two bituminous coals were fired for over 270 hours of operation at $2000^{\circ} \mathrm{F}$ or above. The Pittsburgh \#8 coal, which had a very low ASTM ash fusion temperature, was fired for an additional 6 hours at elevated temperatures as high as $2160^{\circ} \mathrm{F}$. No agglomerates were formed in the bed and the bed remained well fluidized throughout the operation. These results indicate that the CMB fluidized bed is quite robust and can tolerate temporary temperature excursions or temperature maldistributions.

The bauxite particles did develop an ash coating on its surface that slowly accumulated during operation. The ash coating was primarily a mixture of calcium, aluminum, silica, and iron oxides in varying proportions. The coating rate was retarded by the mechanical abrasion and attrition as the particles passed through the transport system. Although the growth rate was slowing, test duration was not long enough to conclude if the particle ash coating would eventually reach a steady state level, where any further growth was offset by attrition. There was some evidence from prior work that some of the coating would spall off when the coating became thicker.

If not controlled, the ash buildup on the particle surface can have a significant impact on gas-to-solids heat transfer and bed pressure drop. The larger particle size will increase the combustor gas outlet temperature due to the reduced particle surface area at a given solids circulation rate. Furthermore, bed inventory will need to be controlled to maintain a constant bed pressure drop as the ash coating increases. The bauxite particle size will thus need to be managed to some maximum size level to maintain proper boiler performance. Particle size can be controlled through several techniques, including attrition, modifying local bed conditions to reduce the coating growth rate, and solids replenishment.

- Objective: Evaluate solids-to-tube heat transfer and solids distribution in the moving bed heat exchanger

- Achievement: Results confirm that high solids-to-tube heat transfer rates are attainable in the MBHE. The solids-to-tube heat transfer was $60 \%$ higher than predicted from earlier ALSTOM test results with an inline tube design. This improvement was attributed to the use of a staggered pitch tube bundle design. The results also showed the importance of maintaining uniform solids flow through the heat exchanger. Blockages in the lower MBHE caused non-uniform solids flow patterns that significantly reduced the heat transfer rate. The heat transfer rate for the upper tube bundle was as good or better than that predicted from the inline bundle even with the non-uniform solids distribution. 
The top tube bundle always had a higher heat transfer coefficient than the lower bundles. This was attributed to the maldistribution of solids flowing through the distributing grid at the bottom of the heat exchanger. The heat transfer coefficient tended to increase with solids flow rate through the MBHE. Finally, the tube bundle fins were largely unplugged, with only a few instances of rocks lodged in the fins.

- Objective: Evaluate $\mathrm{CMB}$ process performance, including carbon burnout, sulfur capture in the furnace and in the backend FDA system, and other gaseous emissions, including $\mathrm{CO}, \mathrm{NO}_{\mathrm{x}}$, and $\mathrm{N}_{2} \mathrm{O}$

- Achievement: Results indicate good combustion performance and gaseous emissions that could be controlled to current state-of-the-art CFB levels and can be further optimized to meet the DOE Advanced Combustion System targets. Tests were conducted with two different coals, four different sorbents with six different size distributions, and with ammonia injection.

The combustion performance was as good as or better than CFB performance with the same coals. The combustion efficiency for the two coals ranged from 98.4 to $99.6 \%$. One test condition was run at reduced load without any ash recycle from the cyclone. The combustion performance during this test was slightly better than the performance at full load with ash recycle. Further work needs to done to assess this condition as operation without a cyclone represents a considerable cost savings for a commercial CMB boiler.

$\mathrm{NO}_{\mathrm{x}}$ emissions were reduced to below $100 \mathrm{ppm}$ without the addition of ammonia by low excess air and deeper staging. $\mathrm{NO}_{\mathrm{x}}$ emissions with Pittsburgh \#8 coal were comparable to MTF performance during CFB operation. $\mathrm{NO}_{\mathrm{x}}$ levels were as low as $88 \mathrm{ppm}$ or $0.11 \mathrm{lb}$ $\mathrm{NO}_{\mathrm{x}} / \mathrm{Mbtu}$ without ammonia injection. $\mathrm{NO}_{\mathrm{x}}$ emissions were higher with the West Virginia coal than during CFB operation. However, the air staging was limited during these tests because of limitations with the water-cooled transport line during this test campaign. $\mathrm{NO}_{\mathrm{x}}$ reductions of up to $40 \%$ were achieved when aqueous ammonia was injected. The reduction level was affected by the injection location and the local temperature and oxidizing conditions. No ammonia slip was detected during this testing.

$\mathrm{N}_{2} \mathrm{O}$ emissions were extremely low during all tests because of the high temperatures in the lower furnace. Emissions were always less than $5 \mathrm{ppm}$, which is considerably less than during $\mathrm{CFB}$ operation.

$\mathrm{CO}$ emissions were generally higher than observed during $\mathrm{CFB}$ operation. $\mathrm{CO}$ is apparently generated in the upper furnace where the gas temperatures are low. Emissions tended to increase as the temperature in the upper furnace decreased. $\mathrm{CO}$ emissions typically ranged from 150 to 300 ppm during these tests.

The coarse sorbents (typical CFB size distributions) had low in-furnace sulfur capture and modest sulfur removal in the FDA. The FDA performance was affected by the limited amount of unreacted calcium that reached the FDA. The fine sorbents - especially at higher humidities - gave higher in-furnace sulfur capture. The in-furnace capture 
improved to $40 \%$ while the FDA and the overall sulfur capture increased up to $100 \%$ at a $\mathrm{Ca} / \mathrm{S}$ mole ratio of $2: 1$. The project goal of $98 \%$ sulfur capture over a combined $\mathrm{CMB} / \mathrm{FDA}$ system is clearly attainable with fine sorbent sizes.

The flyash generated in the $\mathrm{CMB}$ combustor is well-suited for operation with high humidities in the FDA. The ash was able to retain a very high moisture content and still have good handling properties in the FDA. A high internal ash recirculation rate in the FDA will improve the performance at high humidity.

- Objective: Develop a preliminary conceptual design for a demonstration plant

- Achievement: This task was deferred to a follow-on CMB development program. However, many key inputs for a demonstration plant design were developed during the course of this program. Design correlations were developed for predicting gas-to-solids heat transfer, solids-to-tube heat transfer, and pressure drop in the solids transport systems. Concepts were developed for the fuel feed system and the solids inlet distributor. Process design criteria, including combustion and environmental performance, were assessed for two bituminous coals.

\subsection{Recommendations}

The following recommendations are made for further CMB development:

1. Gas-to-solids heat transfer testing showed that the solids distribution and heat transfer performance are quite good at the MTF scale. However, CFD models require a better representation of the physical phenomena occurring in the combustor, particularly the particle-to-particle interactions, before they can be used as a reliable tool for scale up predictions. Grid dynamics need to be better understood also. A larger scale test loop is needed to properly calibrate the CFD model so it can be used for scale up. The test loop should be large enough to model a full scale solids distributor and several other critical components at significant scale.

2. The MBHE demonstrated that very good solids-to-tube heat transfer can be achieved with a properly designed bundle. It is clear that future work must focus on improving the solids flow distribution through the MBHE. The results demonstrated that maldistribution of the solids flow through the tube bundle has a significant influence on performance. An improved design needs to be developed to replace the distribution baffle at the bottom of the MBHE to ensure uniform solids flow.

3. Additional work is needed on the extended surface tube design in the MBHE. A design review is needed to keep material stresses to acceptable levels, thus enabling its use in the high temperature tube bundle of an ultra-supercritical boiler.

4. Additional process optimization is required to meet the performance targets for the DOE's and CURC's advanced plants. Additional work is needed to reduce $\mathrm{NO}_{\mathrm{x}}$ emissions, including more aggressive air staging and SNCR injection. CO emissions need to be better understood and a strategy developed for reducing $\mathrm{CO}$ as furnace outlet temperatures are lowered. The CMB sulfur capture performance will be able to meet the 
emissions targets. The impact of sorbent feed design on calcination, recarbonation, and deactivation of the sorbent needs to be further investigated. 


\subsection{REFERENCES}

3.1-1 An Experimental and Numerical Study of Flow and Convective Heat Transfer in a Freely Falling Curtain of Particles, Hruby et.al., Transactions of the ASME, V110, p 172, June, 1988

3.1-2 Simplified Scaling Procedures, Leon Glicksman et. al., Powder Technology, 1993, p 177-199

3.2-1 Schuttgutbewegung und Wärmeubergang im Wanderebett, Jörg Niegsch, University of Dortmund, 1993

3.3-1 Defluidization Phenomena in Fluidized Beds of Sticky Particles at High Temperatures, Jeffery Siegell, City University of New York, 1976

3.3-2 Defluidization at High Temperature in Fluidized Bed of Sand by Addition of Calcium Carbonate, Delvinquier, et.al., Cherchar, 1995

3.3-3 Thermally-induced Agglomeration in Fluidized Beds, Peter C. Compo, City University of New York, 1989

3.3-4 The Role of Inorganic Matter in Coal in the Formation of Agglomerates in Circulating Fluid Bed Boilers, A. R. Manzoori and P. K. Agarwal, University of Adelaide, 1992

3.3-5 Fate of Inorganic Constituents During Fluidized Bed Combustion of Low-Rank Coals: Effect of Temperature on Ash Characteristics, H. B. Vuthaluru, et.al., University of Adelaide

3.4-1 Solids Mixing In The Bottom Zone Of A Circulating Fluidized Bed, Philipp Schlichthaerle and Joachim Werther, 2001, Powder Technology, Volume 120, pg 21-33

3.6-1 The Influence of Limestone and Alumina on NOx and N2O Emissions From Char Combustion in a Fluidized Bed Combustor, Bernard M. Gibbs and Hao Liu, Proceedings of the $15^{\text {th }}$ International Conference on Fluidized Bed Combustion, Georgia, May 1999

4.1-1 Combustion Fossil Power, Joseph Singer editor, Combustion Engineering, 1991, pg 12-20

4.1-2 Combustion Fossil Power, Joseph Singer editor, Combustion Engineering, 1991, pg 12-20

4.1-3 ALSTOM Power Internal Report, 1993

4.1-4 ALSTOM Power Internal Report, 1993

6.2-1 Schuttgutbewegung und Wärmeubergang im Wanderebett, Jörg Niegsch, University of Dortmund, 1993

6.8-1 Method of Fly Ash Beneficiation and Apparatus for Same, Joe Cochran and Prank Kirkconnell, U.S. Patent 5,399,194, Electric Power Research Institute, March 21, 1995 


\subsection{ACRONYMS AND ABBREVIATIONS}

$\begin{array}{ll}\text { ASTM } & \text { American Society for Testing and Materials } \\ \text { BFB } & \text { Bubbling Fluidized Bed } \\ \text { CFB } & \text { Circulating Fluidized Bed } \\ \text { CFD } & \text { Computational Fluid Dynamics } \\ \text { CMB } & \text { Circulating Moving Bed } \\ \text { CURC } & \text { Coal Utilization Research Council } \\ \text { DOE } & \text { Department of Energy } \\ \text { EDS } & \text { Energy Dispersive Spectroscopy } \\ \text { FBC } & \text { Fluidized Bed Combustion } \\ \text { FBHE } & \text { Fluid Bed Heat Exchanger } \\ \text { FDA } & \text { Flash Dry Absorber } \\ \text { FEA } & \text { Finite Element Analysis } \\ \text { HHV } & \text { Higher Heating Value } \\ \text { LMTD } & \text { Log Mean Temperature Difference } \\ \text { LTRH } & \text { Low Temperature Reheater } \\ \text { MBHE } & \text { Moving Bed Heat Exchanger } \\ \text { MIT } & \text { Massachusetts Institute of Technology } \\ \text { MTF } & \text { Multi-Use Test Facility } \\ \text { NETL } & \text { National Energy Technology Laboratory } \\ \text { OT } & \text { Once Through } \\ \text { PC } & \text { Pulverized Coal } \\ \text { PPL } & \text { Power Plant Laboratories } \\ \text { RA } & \text { Rolled Alloy } \\ \text { RHFIN } & \text { Finishing Reheat } \\ \text { RMS } & \text { Root Mean Square } \\ \text { SCR } & \text { Selective Catalytic Reduction } \\ \text { SEM } & \text { Scanning Electron Microscope } \\ \text { SHFIN } & \text { Finishing Superheat } \\ \text { SNCR } & \text { Selective Non-Catalytic Reduction } \\ \text { S?G } & \text { Solids to Gas Ratio } \\ \text { Umf } & \text { Minimum Fluidization Velocity } \\ \text { Uterm } & \text { Terminal Velocity } \\ & \end{array}$

